UNIVERSIDADE DE SÃO PAULO

ESCOLA DE ENGENHARIA DE SÃO CARLOS

DEPARTAMENTO DE ENGENHARIA DE ESTRUTURAS

DANIEL BOMFIM ROCHA DOS SANTOS

\title{
Modelagem numérica de lajes mistas de aço e concreto em situação de incêndio
}





\title{
Modelagem numérica de lajes mistas de aço e concreto em situação de incêndio
}

\author{
Dissertação apresentada à Escola de \\ Engenharia de São Carlos da Universidade \\ de São Paulo, como parte dos requisitos \\ para a obtenção do título de Mestre em \\ Engenharia de Estruturas. \\ Área de concentração: Estruturas metálicas \\ Orientador: Prof. Dr. Jorge Munaiar Neto \\ VERSÃO CORRIGIDA \\ A versão original encontra-se na Escola de Engenharia de São Carlos
}

São Carlos

2014 
AUTORIZO A REPRODUÇÃO TOTAL OU PARCIAL DESTE TRABALHO, POR QUALQUER MEIO CONVENCIONAL OU ELETRÔNICO, PARA FINS DE ESTUDO E PESQUISA, DESDE QUE CITADA A FONTE.

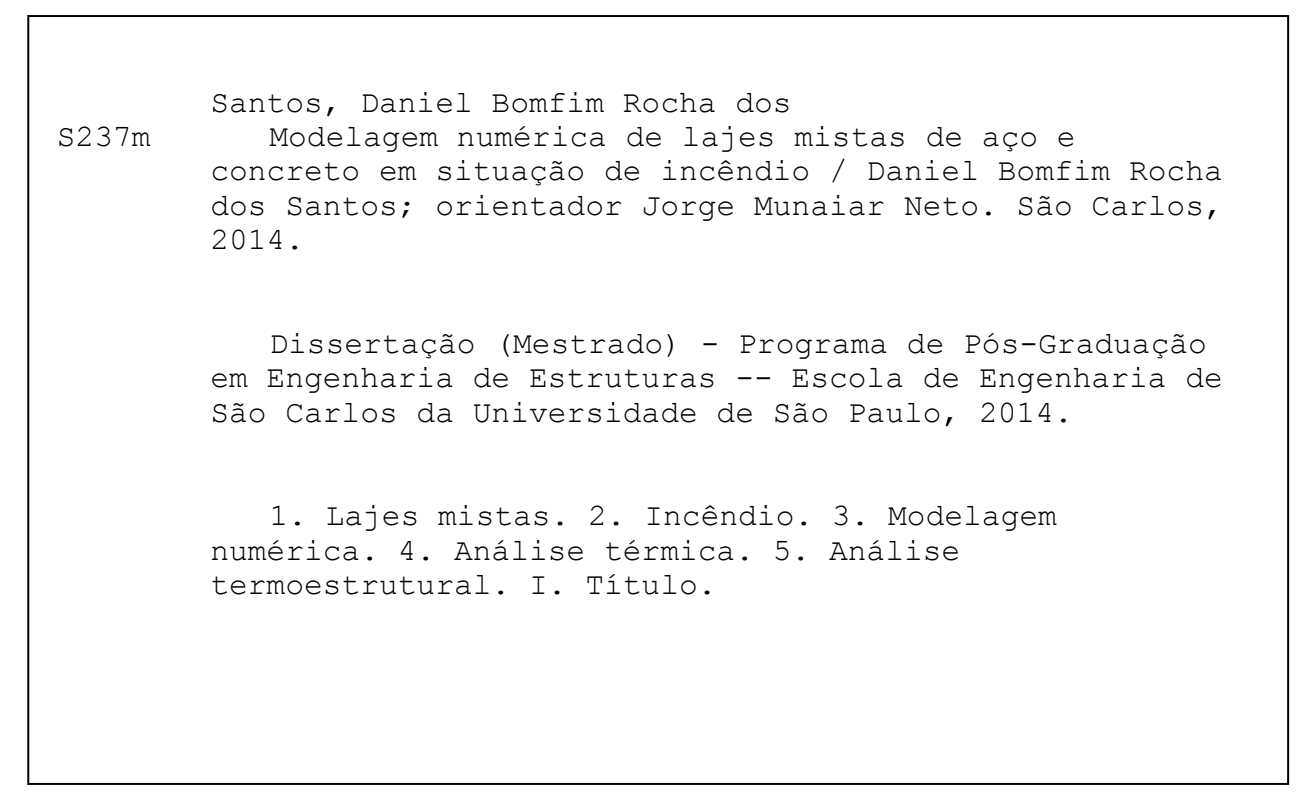




\section{FOLHA DE JULGAMENTO}

Candidato: Engenheiro DANIEL BOMFIM ROCHA DOS SANTOS.

Título da dissertação: "Modelagem numérica de lajes mistas de aço e concreto em situação de incêndio".

Data da defesa: 12/05/2014

\section{Comissão Julgadora:}

Prof. Associado Jorge Munaiar Neto (Orientador)

(Escola de Engenharia de São Carlos/EESC)

Dr. Gustavo Monteiro de Barros Chodraui

(Codeme Engenharia S.A)

Profa. Dra. Silvana De Nardin

(Universidade Federal de São Carlos/UFSCar)

\section{Resultado:}
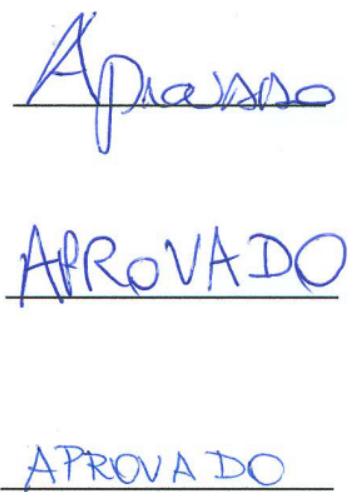

Coordenadora do Programa de Pós-Graduação em Engenharia Civil (Engenharia de Estruturas):

Profa. Associada Ana Lucia Homce de Cresce El Debs

Presidente da Comissão de Pós-Graduação:

Prof. Titular Denis Vinicius Coury 

Aos meus pais Manoel e Creusa, minhas irmãs Maria Cleides, Maria Lucilene, Roseneide, Noeli e Inaiá e meu irmão Marcelo. 

Primeiramente, agradeço a Deus pelo dom da vida, conhecimento e por ter me guiado nos momentos mais difíceis.

À Tácila, pelo amor, carinho, compreensão, amizade e incentivo, estando sempre ao meu lado, mesmo nos momentos mais difíceis.

Aos meus pais, Manoel e Creusa pela confiança e incentivo, minhas irmãs Maria Cleides, Maria Lucilene, Roseneide, Noeli e Inaiá e meu irmão Marcelo pelo forte incentivo e auxílio desde a minha preparação para o vestibular.

A todos os amigos de graduação e do Departamento de Engenharia de Estruturas da Escola de Engenharia de São Carlos, especialmente a Diôgo, Érica Kimura, Fernando, Hugo, João Marinho, Mateus, Rafael Niño e Fábio Rocha pela grande ajuda e suporte na utilização do pacote computacional TNO DIANA.

A todos meus amigos de trabalho, especialmente aos engenheiros Davi, Rafael Eclache e Emerson pela minha recepção em Belo Horizonte.

Aos professores Silvana da UFSCar e Armando da Unicamp pelas contribuições no exame de qualificação.

Ao meu orientador, Jorge Munaiar Neto, pelo apoio, paciência e orientação.

Aos demais professores e funcionários do Departamento de Engenharia de Estruturas, pelo conhecimento e ajuda em todas as etapas do mestrado.

À FAPESP - Fundação de Amparo à pesquisa do Estado de São Paulo e ao CNPq Conselho Nacional de Pesquisa e Desenvolvimento Científico, pelo apoio financeiro para realização desta pesquisa.

Ao Departamento de Engenharia de Estruturas da Escola de Engenharia de São Carlos pelo suporte proporcionado no desenvolvimento do presente trabalho.

A todos os professores que fizeram parte de minha formação acadêmica, desde o primário até o mestrado, pela formação intelectual e profissional. 

SANTOS, D. B. R. Modelagem numérica de lajes mistas de aço e concreto em situação de incêndio. 2014. 243p. Dissertação (mestrado) - Departamento de Engenharia de Estruturas, Escola de Engenharia de São Carlos, Universidade de São Paulo, São Carlos, 2014.

As lajes mistas de aço e concreto consistem de um sistema estrutural formado por fôrmas de aço (chapas perfiladas) permanentes sobre a qual é lançado o concreto armado. Após a cura do concreto, esses elementos trabalham conjuntamente, garantindo o comportamento misto. Esse tipo de sistema é amplamente utilizado na construção civil brasileira, por propiciar diversas vantagens, como a não utilização de fôrmas de madeiras e escoras. Com a finalidade de avaliar o comportamento térmico, estrutural e termoestrutural acoplado desse tipo de sistema, foram desenvolvidos modelos numéricos em elementos finitos no pacote computacional TNO DIANA em duas etapas distintas. Na primeira etapa é feita uma análise térmica bidimensional, cujos campos térmicos na seção transversal da laje são calibrados por meio de resultados experimentais disponíveis na literatura, avaliando os principais parâmetros que influenciam na distribuição de temperatura na laje, como a emissividade resultante e a resistência térmica na interface aço/concreto. Nessa etapa também se desenvolve um pósprocessador em Visual Basic 11.0 capaz de ler os campos térmicos gerados pelo DIANA e calcular o momento fletor plástico resistente em função do tempo de exposição ao fogo. Esses resultados são comparados com aqueles calculados de acordo o modelo de cálculo da ABNT NBR 14323:2013. A segunda etapa consiste no desenvolvimento de modelos numéricos tridimensionais para se avaliar o comportamento termoestrutural acoplado de lajes mistas simplesmente apoiadas. Nessa etapa, primeiramente se faz a validação e calibração dos modelos numéricos à temperatura ambiente, avaliando fatores como a simetria dos modelos e a resistência ao cisalhamento longitudinal na interface entre a fôrma de aço e o concreto. Posteriormente, se realiza a validação do modelo numérico em temperatura elevada por meio de resultados experimentais disponíveis na literatura, considerando os efeitos dos gradientes térmicos na degradação das propriedades mecânicas e na expansão térmica do aço e concreto. Após a calibração do modelo numérico tridimensional em temperatura ambiente e elevada, se realizam análises paramétricas considerando a influência da armadura positiva, da espessura fôrma de aço, da resistência à compressão do concreto, da altura da laje e do vão entre apoios, por meio da curva de incêndio padrão. Os resultados obtidos dos modelos numéricos tridimensionais são comparados com aqueles obtidos pelo método do momento fletor plástico, calculados por meio dos resultados dos modelos térmicos, e de acordo o modelo de cálculo da ABNT NBR 14323:2013.

Palavras Chaves: Lajes mistas, incêndio, modelagem numérica, análise térmica, análise termoestrutural. 



\section{ABSTRACT}

SANTOS, D. B. R. Numerical modelling of steel-concrete composite slabs in fire. 2014. 243p. Thesis (master) - Departamento de Engenharia de Estruturas, Escola de Engenharia de São Carlos, Universidade de São Paulo, São Carlos, 2014.

Steel-concrete composite slabs consist on a structural system comprising of permanent steel sheeting on which reinforced concrete is cast. After the cure of concrete, these elements work in conjunction, ensuring the composite behavior. This structural system is widely used in Brazilian civil construction, especially for providing several advantages, such as no use of formwork and post shores. In order to assess thermal, structural and staggered flow-stress behavior of this structural system, finite elements numerical models were developed in software TNO DIANA in two distinct steps. In the first step a two-dimensional thermal analysis is carried out, whose thermal fields in the slab cross section are calibrated by experimental results available in the literature, evaluating the main parameters that affect the temperature distribution in the slab, as the resulting emissivity and thermal resistance in the steel/concrete interaction. In this stage is also developed a post-processor in Visual Basic 11.0, which is able to read the thermal fields generated by DIANA and calculate the plastic bending moment capacity versus fire exposure time. These results are compared with those calculated according to the ABNT NBR 14323:2013 calculation model. The second step consists in the development of three-dimensional numerical models to evaluate the staggered heat-flow behavior of simply supported composite slabs. In this step, first is done the calibration and validation of the numerical models at ambient temperature, assessing factors such as the symmetry of the models and the longitudinal shear resistance between steel sheeting and the concrete. Later, numerical models are validated in fire through experimental results available in the literature, considering the effects of thermal gradients in the degradation of the mechanical properties and thermal expansion of steel and concrete. After validation of the three-dimensional numerical models at ambient and elevated temperature, parametric analysis are performed considering the influence of sagging reinforcement, the thickness of steel sheeting, compressive strength of the concrete, the slab height and the span between supports, through standard fire curve. The bending resistance of tri-dimensional numerical models is compared with that obtained by the plastic theory, calculated through the results of two-dimensional thermal models, and according to ABNT NBR 14323:2013 calculation model.

Keywords: Composite slabs, fire, numerical modeling, thermal analysis, flow-stress analysis. 



\section{Sumário}

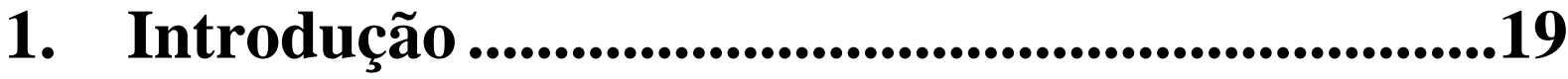

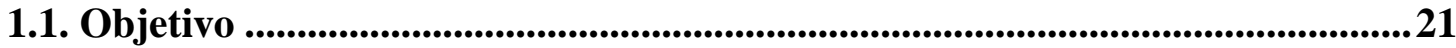

1.2. Justificativa ....................................................................................................................... 22

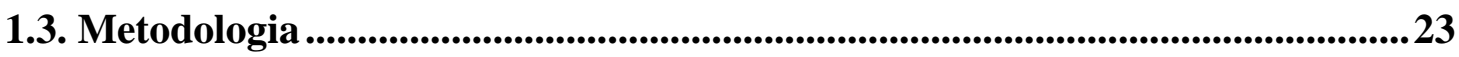

1.4. Organização do trabalho................................................................................25

\section{As ações térmicas e as lajes mistas de aço e}

\section{concreto....................................................................27}

2.1. Alguns incêndios históricos .................................................................................227

2.2. Curvas de incêndio ............................................................................................31

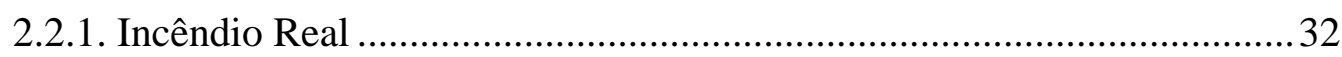

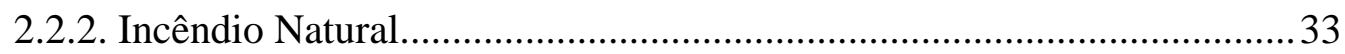

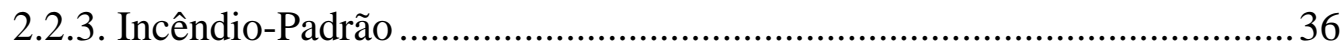

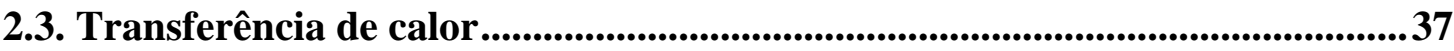

2.4. Propriedades dos materiais de interesse ........................................................39

2.5. As formas de aço do Brasil..........................................................................................39

2.6. Comportamento estrutural .............................................................................................. 40

2.6.1. Fase de construção ......................................................................... 40

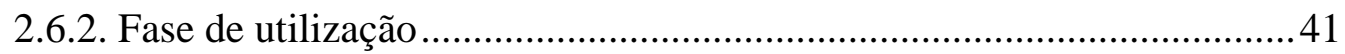

2.6.3. Critérios de resistência ao fogo ............................................................ 42

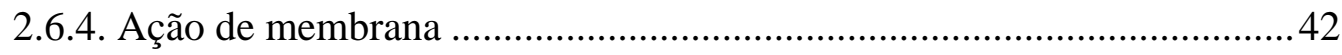

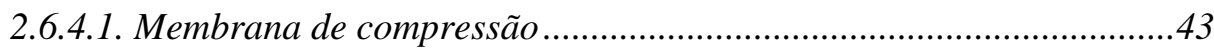

2.6.4.2. Membrana de tração........................................................................43

2.7. Considerações sobre o projeto à temperatura ambiente....................................44

2.7.1. Verificação da fôrma de aço ................................................................ 45

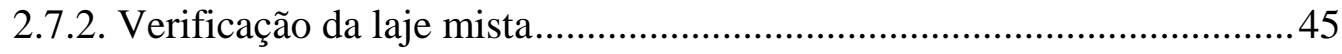

2.8. Dimensionamento em situação de incêndio ...........................................................46

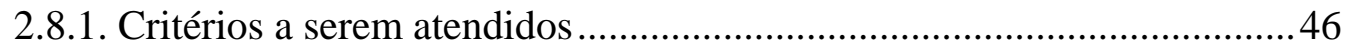

2.8.2. Momento fletor positivo resistente de cálculo - $\boldsymbol{M} \boldsymbol{f} \boldsymbol{i}, \boldsymbol{R d}+\ldots \ldots \ldots \ldots \ldots . . . . .47$

2.8.3. Momento fletor negativo resistente de cálculo - $\boldsymbol{M} \boldsymbol{f} \boldsymbol{i}, \boldsymbol{R d}-\ldots \ldots \ldots \ldots \ldots . . .51$

2.9. Pesquisas sobre o tema ....................................................................................5

2.9.1. Comentários sobre ensaios em lajes mistas .........................................54

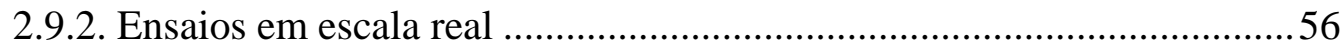

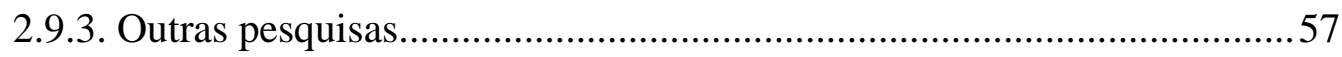

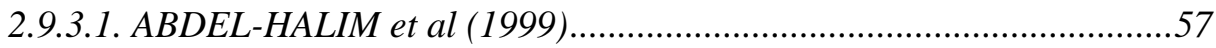

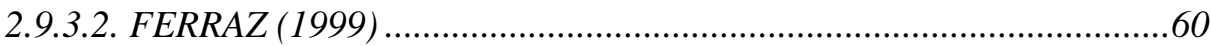




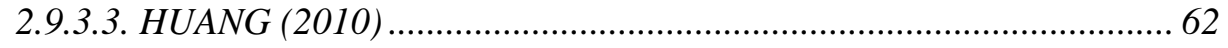

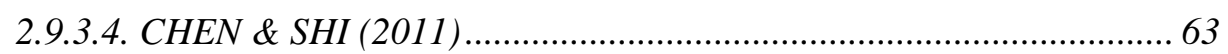

2.9.3.5. GUO \& BAILEY (2011) .................................................................. 66

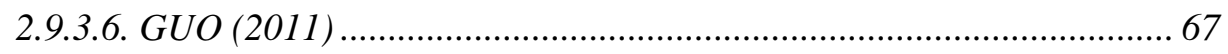

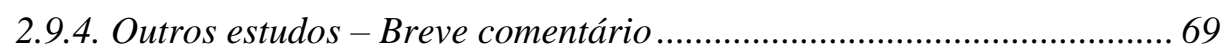

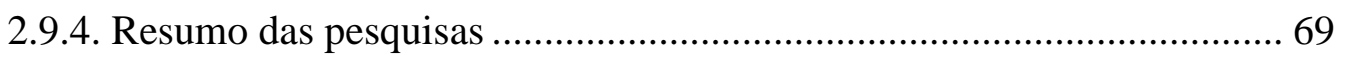

\section{Aspectos referentes à estratégia de modelagem numérica .......................................................................71 71}

3.1. Introdução.......................................................................................................................................... 71

3.2. Sobre o código computacional TNO DIANA ................................................ 72

3.3. Definição do modelo térmico no DIANA ......................................................... 73

3.3.1. Considerações com relação à etapa de Pré-processamento ..................... 73

3.3.1.1. Definição da geometria................................................................... 74

3.3.1.2. Definição dos elementos finitos ......................................................... 74

3.3.1.3. Definição dos carregamentos térmicos.............................................. 75

3.3.1.4. Condições de contorno e definição dos materiais .............................. 75

3.3.2. Considerações com relação à etapa de Processamento .......................... 76

3.3.3. Considerações com relação à etapa de Pós-processamento ................... 77

3.3.4. Pré-processamento e processamento em arquivo de lotes...................... 78

3.4. Definição do modelo termoestrutural no DIANA .......................................... 79

3.4.1. Pré-processamento do modelo.............................................................. 80

3.4.1.1. Definição da geometria ..................................................................... 80

3.4.1.2. Elementos finitos utilizados .............................................................. 81

3.4.1.3. Carregamentos considerados na análise ………………….............. 82

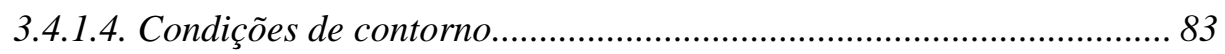

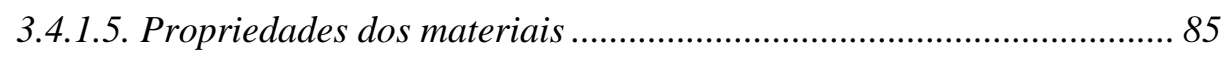

3.4.2. Quanto ao Processamento ................................................................ 89

3.4.3. Quanto ao Pós-processamento............................................................ 90

3.5. Outras considerações sobre o modelo termoestrutural ................................... 91

3.5.1. Energia de fratura do concreto ............................................................ 91

3.5.2. Largura de banda da fissura................................................................ 91

3.5.3. Módulo de elasticidade do concreto em temperaturas elevadas............. 92

3.5.4. O modelo constitutivo parabólico para o concreto comprimido ............ 93

3.5.5. O modelo constitutivo exponencial para o concreto tracionado ............ 95

3.5.6. Coeficiente de expansão térmica ............................................................. 96

\section{Análises térmicas - Considerações e} procedimentos adotados ................................99

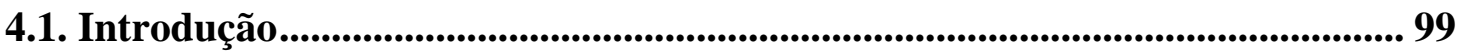


4.2. Influência da malha de elementos finitos.......................................................99

4.3. Validação dos modelos térmicos...............................................................102

4.3.1. Análise da influência da resistência térmica na interface ..................... 102

4.3.2. Análise da influência da condutividade térmica do concreto ............... 106

4.3.3. Análise da influência da umidade do concreto .................................... 108

4.3.4. Outros resultados experimentais - Análises complementares .............. 109

4.3.4.1. Temperatura da fôrma de aço .........................................................109

4.3.4.2. Temperatura do concreto .............................................................111

4.4. Comparações da proposta de estratégia de modelagem numérica com prescrições normativas...................................................................................................... 113

4.4.1. Com relação à temperatura na fôrma de aço......................................... 114

4.4.2. Com relação à temperatura na armadura ............................................ 115

4.4.3. Determinação do Momento fletor resistente......................................... 118

4.4.3.1. Momento fletor resistente devido à fôrma de aço................................118

4.4.3.2. Momento fletor resistente devido à armadura positiva .....................119

4.5. Posição da armadura positiva.........................................................................121

\section{Análises estruturais e termoestruturais:} resultados e discussões .......................................125

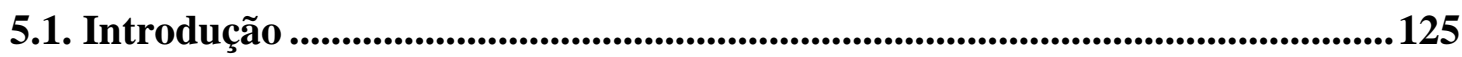

5.2. Validação do modelo numérico à temperatura ambiente .................................. 126

5.2.1. Modelo numérico de laje mista com interação completa...................... 126

5.2.2. Modelo numérico com elementos de interface .................................... 129

5.2.2.1. Interface com rigidez linear ............................................................130

5.2.2.2. Interface considerando bond-slip .................................................132

5.2.3. Influência da chapa de apoio.................................................................. 133

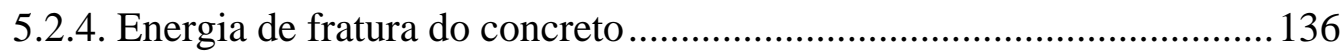

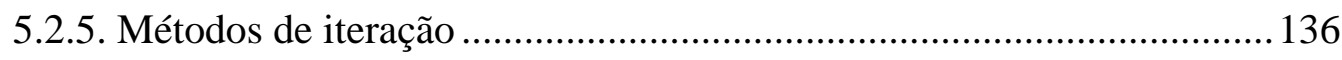

5.3. Validação do modelo termoestrutural .......................................................... 138

5.3.1. Comparação com resultados experimentais........................................ 139

5.3.2. Campos térmicos na laje .................................................................. 142

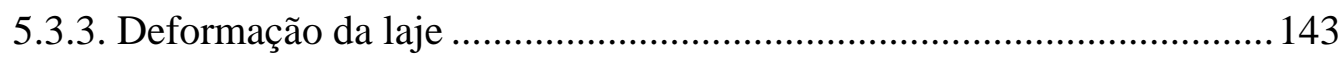

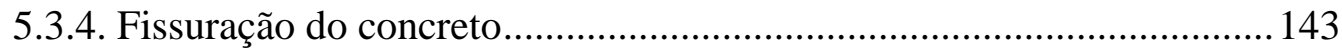

5.3.5. Tensões na fôrma de aço.................................................................... 146

5.4. Resultados e discussões adicionais dos modelos numéricos .............................. 147

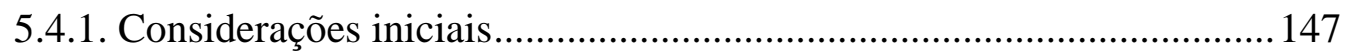

5.4.2. Critério para cálculo do tempo resistente............................................ 149

5.4.3 Resultados de interesse com base em análise paramétrica ................... 149

5.4.3.1. Análise com base no fator de carga ..................................................149 
5.4.3.2. Influência da armadura positiva e espessura da fôrma de aço ....... 154

5.4.3.3. Influência da altura total da laje e do vão entre apoios ................... 155

5.4.3.4. Influência da resistência característica do concreto ........................ 158

5.4.3.5. Resumo dos resultados................................................................. 159

\section{Conclusão e sugestões para trabalhos futuros 161}

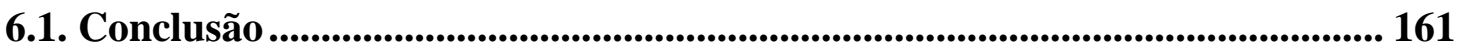

6.2. Sugestões para trabalhos futuros.............................................................................. 165

Referências Bibliográficas .......................................... 167

AnexoS.............................................................................. 173

Anexo A - Os processos de transferência de calor ..................................................... 175

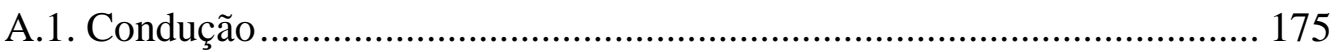

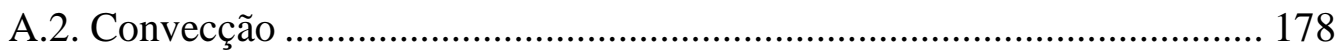

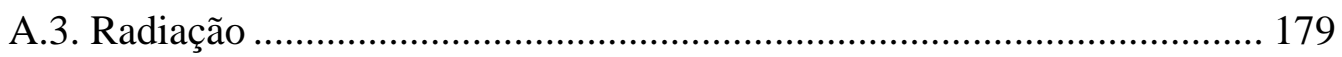

Anexo B - Propriedades térmicas e mecânicas dos materiais................................. 181

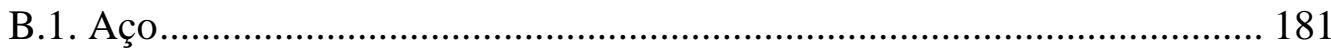

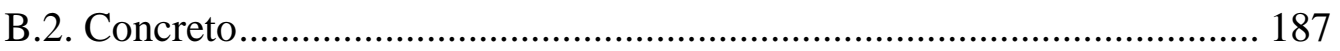

Apêndices 1..............................................................193

Apêndice A - Comandos do iDIANA e processamento em arquivos de lotes .... 195

Apêndice B - Arquivo Batch para análise térmica ................................................... 200

Apêndice $\mathbf{C}$ - Arquivos de propriedades térmica dos materiais e de processamento ........................................................................................................... 204

Apêndice D - Procedimento para cálculo do momento fletor plástico ................. 206

Apêndice E - Subrotinas computacionais para cálculo do momento fletor plástico

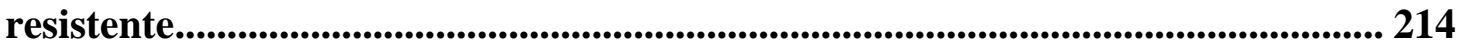

Apêndice F - Arquivo Batch para análise termoestrutural.................................... 222

Apêndice $\mathbf{G}$ - Arquivo de propriedade termoestrutural do aço .............................. 229

Apêndice $\mathbf{H}$ - Arquivo de propriedade termoestrutural do concreto ................... 231

Apêndice I - Arquivo de processamento do modelo termoestrutural................... 233

Apêndice $\mathbf{J}$ - Resultados adicionais de validação do modelo térmico .................... 235

Apêndice K - Resultados adicionais do modelo térmico ......................................... 238

Apêndice L - Gráficos para análise do posicionamento da armadura na laje... 240 


\section{CAPÍTULO 1}

\section{Introdução}

Inicialmente, pode-se definir o incêndio como "fogo" não controlado que, segundo WANG (2002), se não houver formas eficazes de controle esse mesmo fogo pode trazer consequências devastadoras.

O incêndio sempre esteve presente ao longo da história provocando grandes acidentes, inclusive em contexto estrutural. Porém, a preocupação em projetar estruturas resistentes ao fogo é bastante recente, tendo em vista que, segundo MARTINS (2000), somente a partir de 1995 algumas universidades brasileiras começaram a desenvolver estudos e pesquisas sobre o assunto, fato que possibilitou a elaboração de normas brasileiras sobre o dimensionamento de estruturas, dentre elas, a ABNT NBR 14323:2013 voltada às estruturas de aço e mistas de aço e concreto em situação de incêndio, intitulada "Projeto de estruturas de aço e de estruturas mistas de aço e concreto de edifícios em situação de incêndio".

Segundo REGOBELLO (2007), as normas que atualmente contemplam esse assunto abordam a análise do elemento estrutural isolado e, portanto, conduzem, de modo geral, a projetos antieconômicos de pouca flexibilidade. Para tanto, uma melhor compreensão do comportamento do incêndio e seu impacto nas estruturas ainda se faz importante para permitir criar métodos que tornem o projeto de estruturas em situação de incêndio mais seguro e econômico. Esses métodos devem ser comprovados com a realização de ensaios experimentais.

No contexto experimental, os ensaios para previsão do comportamento de estruturas em situação de incêndio também são realizados, geralmente, em elementos isolados, e tem dado grande contribuição nessa área, porém demandam elevados investimentos financeiros e humanos. Desse modo, são utilizados pacotes computacionais, baseados nos métodos dos elementos finitos para prever o comportamento estrutural.

Sabe-se que a elevação de temperatura do meio reduz rapidamente as propriedades mecânicas do aço, do concreto, da madeira ou de qualquer outro material, sendo que no caso do aço tal efeito fica ainda mais evidente devido à sua elevada condutividade térmica (que faz com que ele absorva e transmita calor mais rapidamente). Desta forma, até pouco tempo atrás se acreditava que o aço sempre precisaria de material de proteção para resistir às ações térmicas (WANG, 2002). Segundo BUCHANAN (2002), estruturas metálicas podem resistir 
aos efeitos de um incêndio brando, sendo que testes em escala real mostraram que edificações bem projetadas não entraram em colapso, mesmo quando alguns dos seus principais elementos estruturais estavam sem material de proteção ao fogo.

Atualmente, os principais métodos de revestimento contra fogo para estruturas de aço são: materiais projetados, placa de gesso acartonado, tinta intumescente, entre outros. Entretanto, é importante ressaltar que o custo com revestimento convencional contra fogo pode chegar até a $30 \%$ do preço do aço, ressaltando-se que em algumas estruturas esta proteção é desnecessária, podendo conduzir a economia considerável (LAWSON, 2001).

Vale destacar também que o uso de elementos de concreto em conjunto com elementos de aço dispostos adequadamente na seção transversal e trabalhando de forma conjunta dá origem às denominadas Estruturas Mistas de Aço e Concreto, as quais, em meados do século XIX, surgiram como elementos mistos a serem utilizados primeiramente devido à proteção ao fogo e à corrosão que o concreto confere ao aço (RAMOS, 2010). Hoje, as estruturas mistas de aço e concreto têm grande importância e reconhecimento, pois constituem um sistema estrutural que aproveita as vantagens de ambos os materiais e, ao mesmo tempo, minimiza as suas desvantagens (ROCHA, 2012). Nesse contexto, enquadramse as lajes mistas de aço e concreto, que consistem de uma fôrma de aço incorporada ao concreto, geralmente com armaduras de distribuição (tela) na parte superior da laje. Se necessário também devem ser previstas armaduras positivas (Figura 1.1).

Essas lajes geralmente são apoiadas em vigas de aço, as quais quando trabalhando de maneira conjunta, formam um sistema do tipo viga mista de aço e concreto. Na Figura 1.1 é apresentada a laje mista considerando dois tipos possíveis de fôrma de aço: com nervura trapezoidal e reentrante. No Brasil, atualmente se encontra disponível no mercado somente a fôrma de aço com nervura trapezoidal.
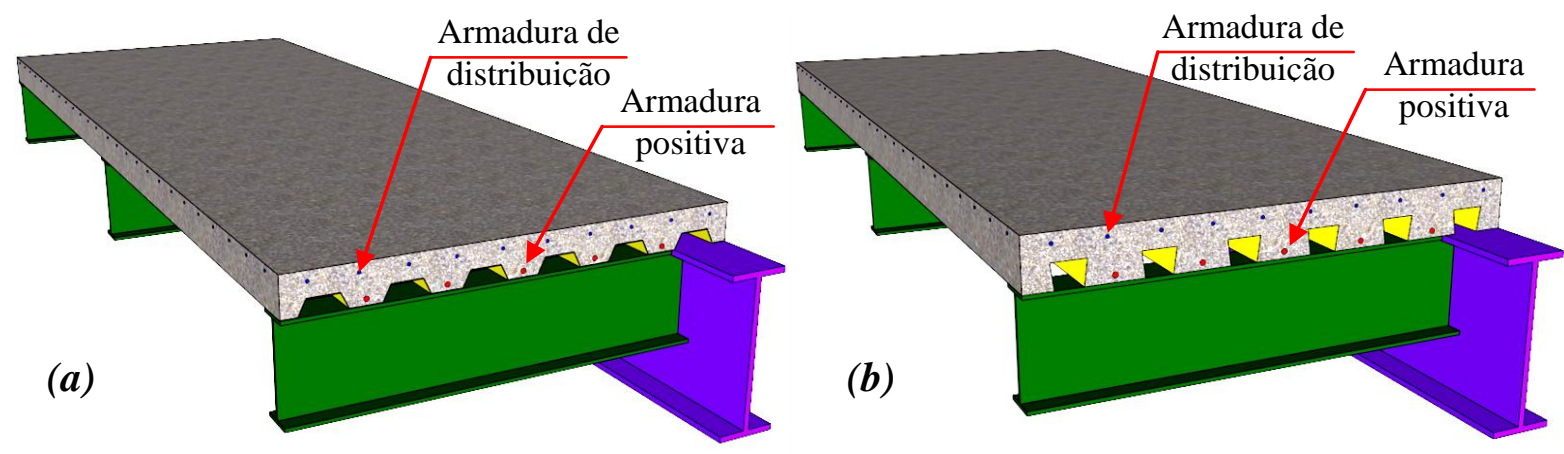

Figura 1.1 - Lajes mistas com (a) nervura trapezoidal e $(b)$ reentrante

Os primeiros sistemas de laje mista de aço e concreto surgiram no final da década de 1930 para uso em edifícios altos, trazendo considerável redução da carga permanente e apresentando-se como substituto do sistema tradicional de lajes de concreto armado (CRISINEL \& O'LEARY, 1996). Na Europa, as lajes mistas de aço e concreto só apareceram no final da década de 1950. Nesses primeiros sistemas a aderência entre a fôrma de aço e o concreto se dava unicamente por atrito, exceto para os casos onde se tinha elevados carregamentos. 
Para que esse sistema funcione conjuntamente é necessário que se tenha aderência suficiente entre ambos os elementos para resistir ao cisalhamento da interface entre fôrma de aço e o concreto. Na laje mista é possível destacar três tipos de aderência: química, por atrito e mecânica, além da ancoragem de extremidade, conforme pode ser observado na Figura 1.2, cujas naturezas são descritas a seguir (SSETDA, 2005):

-Química: é muito frágil e incerta, por isso não deve ser considerada em projetos;

-Por atrito: não é capaz de transferir elevados esforços de cisalhamento (Figura 1.2a). No caso das fôrmas reentrantes o confinamento do concreto aumenta o atrito na interface;

-Mecânica: ocorre devido às mossas na superfície da fôrma de aço (Figura 1.2b);

-Ancoragem de extremidade: feita através da soldagem de "stud-bolts", cantoneiras ou amassamento da fôrma de aço (Figura 1.2c). Utilizada para resistir às elevadas tensões de cisalhamento longitudinal próximo aos apoios.

(a)

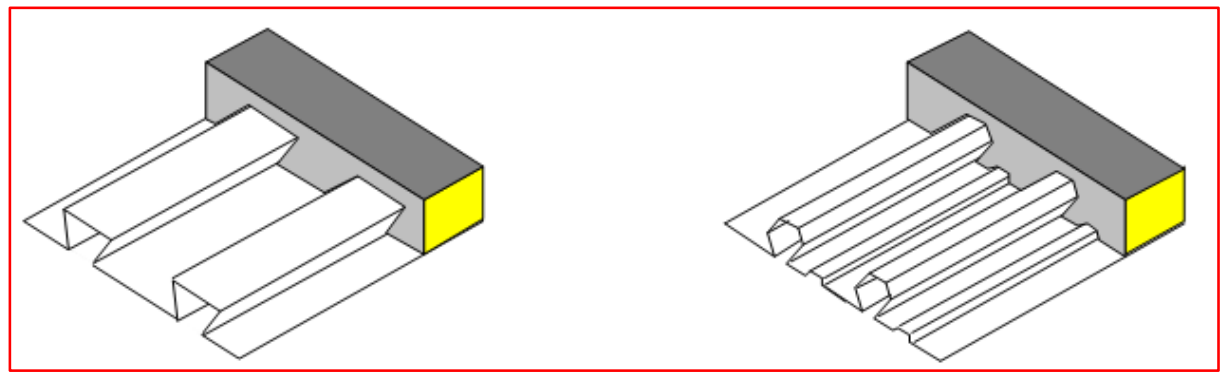

(b)

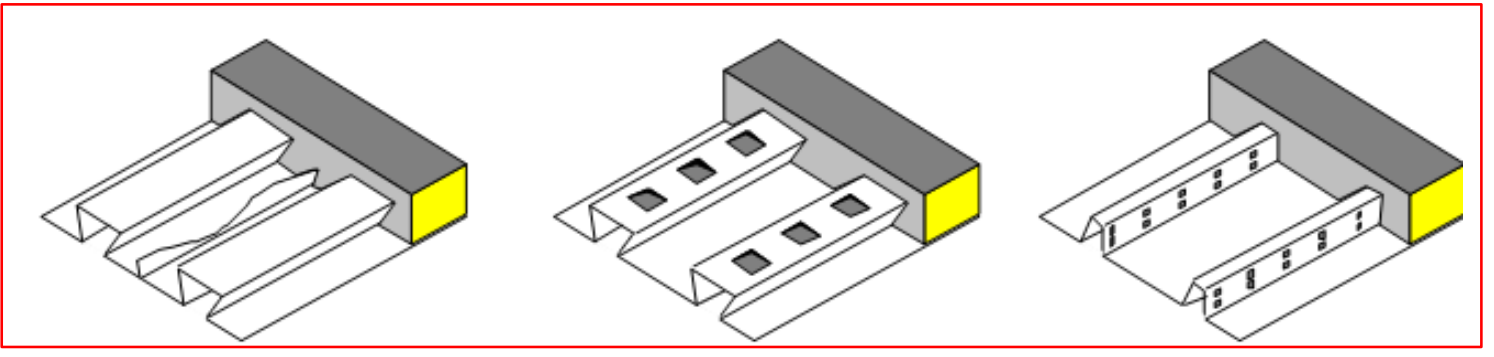

(c)
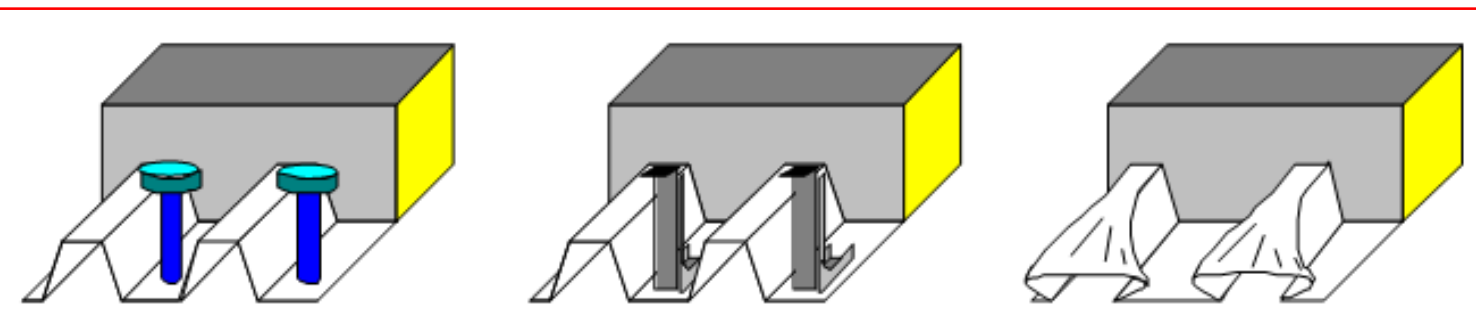

Figura 1.2 - Mecanismos de aderência entre a fôrma de aço e o concreto: (a) Aderência por atrito, $(b)$ Aderência mecânica e $(c)$ Ancoragem de extremidade (SSEDTA, 2005)

\subsection{Objetivo}

O objetivo principal deste trabalho é desenvolver modelos numéricos, via código computacional TNO DIANA, que permitam representar satisfatoriamente o comportamento 
estrutural, térmico e termoestrutural de lajes mistas de aço e concreto em situação de incêndio. Para tanto, como objetivos específicos, podem-se citar:

- Propor estratégias de modelagem numérica para lajes mistas de aço e concreto com nervuras trapezoidais em situação de incêndio;

- Verificar a eficiência do código computacional TNO DIANA em relação ao estudo das lajes mistas em situação de incêndio, uma vez que este está em crescente uso no Departamento de Engenharia de Estruturas da EESC/USP;

- Obter a distribuição de temperatura na seção transversal da laje mista utilizando a curva Temperatura x Tempo com base no incêndio-padrão proposto pela ISO 834 - 1999;

- Analisar, a partir das informações do modelo numérico, a influência da emissividade do aço e a resistência térmica e mecânica na interface entre a fôrma de aço e o concreto na capacidade resistente de lajes mistas em situação de incêndio;

- Desenvolver um pós-processador capaz de ler os campos térmicos do modelo térmico desenvolvido no DIANA e, com base nesses dados, calcular o momento fletor plástico resistente.

- Comparar a capacidade resistente do sistema obtida do modelo térmico com as prescrições da ABNT NBR 14323:2013 e com o modelo termoestrutural tridimensional.

- Fazer análises paramétricas considerando a influência da armadura positiva, da espessura da fôrma de aço, da resistência à compressão do concreto, da altura e do vão entre apoios da laje mista.

\subsection{Justificativa}

A análise de laje mista de aço e concreto em situação de incêndio ainda está pouco difundida no Departamento de Engenharia de Estruturas da Escola de Engenharia de São Carlos. Dentro desse contexto, se destaca que em ALVA (2000) se aborda, de forma sucinta, o processo de dimensionamento desse tipo de sistema, porém foi realizada somente uma revisão bibliográfica sobre o processo de dimensionamento, não sendo realizada nenhuma análise numérica ou experimental.

O processo de dimensionamento de lajes mistas em situação de incêndio segundo a ABNT NBR 14323:2013 para a resistência ao momento fletor positivo (correspondendo ao momento de plastificação da seção) é feito considerando uma distribuição de temperatura na laje por meio de uma altura efetiva. Essa mesma norma também apresenta um equacionamento para obtenção da temperatura na armadura positiva, de modo a obter sua correspondente resistência ao escoamento. 
A ABNT NBR 14323:2013 mantem a mesma filosofia da versão anterior (ano de 1999), porém com equações de dimensionamento baseadas no EUROCODE 4 Part 1-2 (EN 1994-1-2:2005), podendo considerar a contribuição da fôrma de aço na resistência de lajes mistas em situação de incêndio.

A realização de ensaios de estruturas em situação de incêndio pode ser entendida como solução para o estudo do comportamento das lajes mistas em situação de incêndio, porém, é sempre bastante trabalhosa além de demandar elevados recursos financeiros. Desta forma a análise numérica, com base no método dos elementos finitos, se torna um recurso atraente para a previsão do comportamento e da capacidade resistente de estruturas em situação de incêndio, entretanto essa análise deve ser acompanhada de resultados experimentais para validação dos modelos numéricos.

Como as lajes mistas são constituídas em grande parte por concreto, optou-se por utilizar o pacote computacional TNO DIANA, uma vez que este possui modelos constitutivos avançados para o concreto, sendo possível também a realização de análises térmica e termoestrutural acopladas.

\subsection{Metodologia}

O presente trabalho propõe um estudo numérico sobre o comportamento estrutural de sistemas de lajes mistas de aço e concreto em situação de incêndio através do método dos elementos finitos. Essa análise será feita no pacote computacional DIANA em duas etapas:

a-) A primeira etapa consistirá da obtenção dos campos térmicos na seção da laje, baseada em análises bidimensionais. O modelo numérico será calibrado e comparado com resultados disponíveis em ABDEL-HALIM et al. (1999) e GUO \& BAILEY (2011). Esta etapa inicial visa construir curvas "Temperatura vs. Tempo" para a fôrma de aço e ao longo da altura da laje mista, utilizando a curva de aquecimento com base no incêndio-padrão, e comparando com as prescrições da ABNT NBR 14323:2013.

No pacote computacional DIANA os tipos de elementos finitos utilizados serão aqueles denominados Q4HT para a superfície de aço e concreto, IL4HT para a interface entre a fôrma de aço e o concreto e B2HT para simular o efeito da transferência de calor entre o meio e a estrutura. No Capítulo 4 serão vistas mais informações a respeito desses elementos.

b-) A segunda etapa do trabalho consiste em realizar análises do tipo termoestrutural, em que serão consideradas as não linearidades do material e geométrica, o processo de fissuração e a resistência na interface entre a fôrma de aço e o concreto. Nessa etapa primeiramente será realizada uma modelagem numérica à temperatura ambiente, visando calibrar os modelos com base nos dados experimentais obtidos por FERRAZ (1999). Posteriormente, será realizada a modelagem numérica considerando a variação de temperatura, com base nos resultados obtidos por meio dos modelos analisados à temperatura ambiente, porém, considerando a 
inclusão da variação das propriedades físicas e térmicas dos materiais com a temperatura, conforme será visto no Capítulo 2. Nesses modelos, os resultados numéricos serão validados utilizando-se os resultados experimentais disponíveis em GUO \& BAILEY (2011), adotando a estratégia numérica apresentada em ROCHA (2012) e GUO (2011).

Para este tipo de análise, o modelo numérico no DIANA é composto por dois domínios: análise de fluxo térmico e análise estrutural. Esses domínios serão sobrepostos de modo que os resultados da análise térmica sejam transferidos para a análise estrutural, simulando o efeito de um elemento estrutural com carregamento constante juntamente com o aumento da temperatura do meio, como geralmente é realizado em ensaios laboratoriais.

Dessa forma, o modelo numérico no DIANA deve ser primeiramente composto de elementos de fluxo, de modo a efetuar a análise de fluxo térmico. Posteriormente o modelo passa a efetuar a análise estrutural, onde os elementos de fluxo são convertidos em elementos estruturais. Mas essa conversão somente é possível através de alguns tipos de elementos finitos, conforme pode ser observado na Tabela 1.1 .

Tabela 1.1 - Elementos finitos correspondentes para análises termoestruturais

\begin{tabular}{lc|cccc}
\hline \multirow{2}{*}{ Flow-stress domain } & \multicolumn{3}{c}{ Conversion to flow analysis } \\
\cline { 3 - 6 } & & heat & concen. & \multicolumn{2}{c}{ groundwater } \\
\hline \multirow{2}{*}{ pl. stress } & CT12M & T3HT & T3HT & T3GW & T3HT \\
& CQ16M & Q4HT & Q4HT & Q4GW & Q4HT \\
\hline \multirow{4}{*}{ pl. strain } & CT12E & T3HT & T3HT & T3GW & T3HT \\
& CQ16E & Q4HT & Q4HT & Q4GW & Q4HT \\
& CQ20E & Q4HT & Q4HT & Q4GW & Q4HT \\
& CQ22E & Q4HT & Q4HT & Q4GW & Q4HT \\
\hline \multirow{4}{*}{ axisymm. } & CT12A & T3AHT & T3AHT & T3AGW & T3AHT \\
& CQ16A & Q4AHT & Q4AHT & Q4AGW & Q4AHT \\
& CQ20A & Q4AHT & Q4AHT & Q4AGW & Q4AHT \\
& CQ22A & Q4AHT & Q4AHT & Q4AGW & Q4AHT \\
\hline \multirow{5}{*}{ solid } & CTE30 & TE4HT & TE4HT & TE4GW & TE4HT \\
& CTP45 & TP6HT & TP6HT & TP6GW & TP6HT \\
& CHX60 & HX8HT & HX8HT & HX8GW & HX8HT \\
& CHX64 & HX8HT & HX8HT & HX8GW & HX8HT \\
\hline \multirow{5}{*}{ interface } & N4IF & IPT2H & IPT2H & - & IPT2H \\
& N6IF & IPT2H & IPT2H & - & IPT2H \\
& CL12I & IL4HT & IL4HT & - & IL4HT \\
& CT36I & IT6HT & IT6HT & - & IT6HT \\
& CQ48I & IQ8HT & IQ8HT & - & IQ8HT \\
\hline
\end{tabular}

Fonte: DIANA - Users manual - Analysis Procedures, 2005

Serão utilizados para a modelagem do concreto e da fôrma de aço os elementos finitos sólidos HX8HT e CHX60 para a análise térmica e estrutural, respectivamente. Para a modelagem da interface entre a fôrma de aço e o concreto, serão utilizados os elementos IQ8HT e CQ48I. Observar que, de acordo a Tabela 1.1, esses elementos são correspondentes para análises térmicas e termoestruturais acopladas. 
Para a modelagem dos efeitos de transferência de calor do meio para a estrutura será utilizado o elemento finito quadrilateral de contorno BQ4HT. No Capítulo 03 serão vistas mais informações a respeito dos elementos supracitados.

\subsection{Organização do trabalho}

No capítulo 1 é feita uma breve abordagem do tema a ser estudado, apresentado os principais objetivos, justificativa do trabalho e a metodologia utilizada na construção dos modelos numéricos.

No capítulo 2 são apresentados brevemente alguns casos de acidentes históricos ocorridos no contexto mundial e nacional, buscando identificar e entender suas principais causas e consequências. Também é feita uma apresentação das curvas de incêndio e uma breve introdução aos processos de transferência de calor, cujo entendimento é fundamental para a modelagem numérica. Por fim, se faz uma revisão bibliográfica sobre as lajes mistas de aço e concreto, apresentado de forma sucinta o comportamento estrutural desse tipo de sistema e algumas considerações sobre o projeto em temperatura ambiente e em situação de incêndio bem como algumas pesquisas realizadas sobre o tema.

No capítulo 3 são expostos os principais aspectos da modelagem numérica, referentes ao código computacional TNO DIANA e a definição do modelo térmico e termoestrutural. Também são apresentadas as considerações sobre os modelos constitutivos para o aço e o concreto, devido às particularidades do DIANA.

No capítulo 4 são apresentados os resultados e considerações referentes ao comportamento térmico de lajes mistas de aço e concreto em situação de incêndio por meio de modelos térmicos bidimensionais desenvolvidos no pacote computacional TNO DIANA 9.4.4. Inicialmente se faz a validação dos modelos térmicos e posteriormente uma comparação dos resultados numéricos com os resultados calculados de acordo a ABNT NBR 14323:2013.

No capítulo 5 são apresentados os resultados e análises dos modelos estruturais (à temperatura ambiente) e termoestruturais (em temperaturas elevadas). Este capítulo está divido em basicamente três etapas: validação e análises do modelo estrutural, validação e análises do modelo termoestrutural e resultados e discussões dos modelos numéricos. Nesta última etapa se faz uma comparação do modelo de cálculo da ABNT NBR 14323:2013 com os resultados dos modelos termoestruturais e do modelo térmico.

Por fim, no capítulo 6, são apresentadas as principais conclusões do trabalho bem como sugestões para trabalhos futuros.

Também são apresentados neste trabalho anexos contendo uma introdução aos processos de transferência de calor e as propriedades dos materiais e apêndices sobre 
aspectos adicionais da modelagem numérica realizada no DIANA e resultados dos modelos térmicos não apresentados no capítulo 4. 


\section{CAPÍTULO 2}

\section{As ações térmicas e as lajes mistas de aço e concreto}

\subsection{Alguns incêndios históricos}

Casos de incêndios sempre existiram ao longo da história e com consequências desastrosas. O primeiro a se ter notícia foi o Grande Incêndio ocorrido na cidade de Roma no ano de 64 d.C., conforme ilustrado na Figura 2.1. Há muitas controvérsias sobre quem o teria provocado, mas a hipótese mais aceita pelos historiadores é que o incêndio teria iniciado em volta do Circo Máximo, no centro comercial de Roma, e se espalhou rapidamente por toda a cidade em razão da existência de habitações de madeira naquela época.

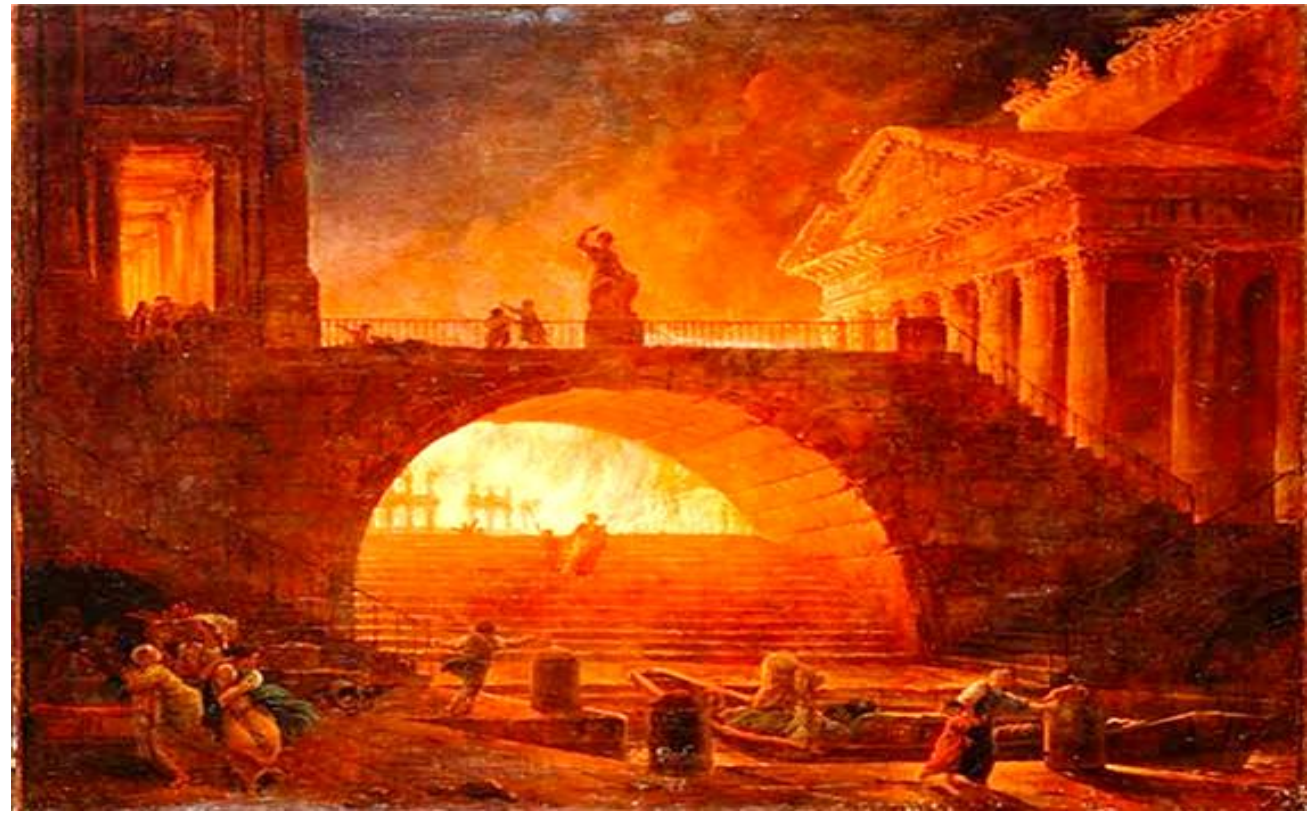

Figura 2.1 - Ilustração do Grande Incêndio de Roma. Fonte: http://pt.wikipedia.org/wiki/Grande_inc\%C3\%AAndio_de_Roma

Apesar de os incêndios serem registrados desde a antiguidade, as primeiras exigências de proteção contra incêndio surgiram por volta de 1666, com a ocorrência de um grande incêndio na cidade de Londres (KIRCHHOF, 2004). Porém, este tema só começou a ser 
realmente estudado em meados do século 19 e início do século 20. O Grande Incêndio de Londres iniciou em uma padaria na manhã do dia 2 de setembro de 1666 e rapidamente se espalhou por toda cidade, deixando mais de 100 mil desabrigados ${ }^{1}$. A Figura 2.2 apresenta o detalhe de um quadro da época ilustrando o referido incêndio. No ano de 1863 destaca-se o incêndio ocorrido durante uma festa religiosa na Igreja da Companhia de Jesus (Figura 2.3), em Santiago no Chile, deixando mais de 1800 pessoas mortas ${ }^{2}$. O incêndio foi provocado pela falha em uma luminária que funcionava a base de gás hidrogênio e parafina.

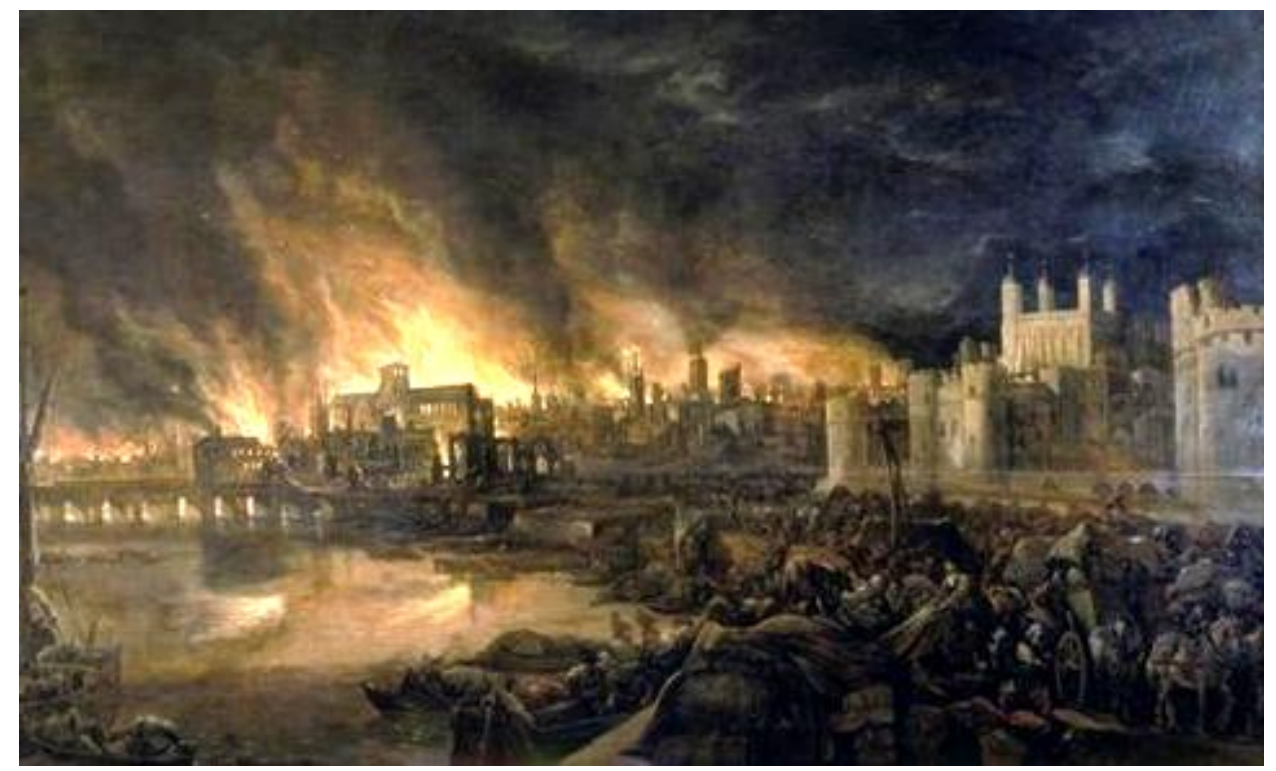

Figura 2.2 - Ilustração do Grande Incêndio de Londres. Fonte: http://operamundi.uol.com.br/conteudo/noticias/6114/conteudo+opera.shtml

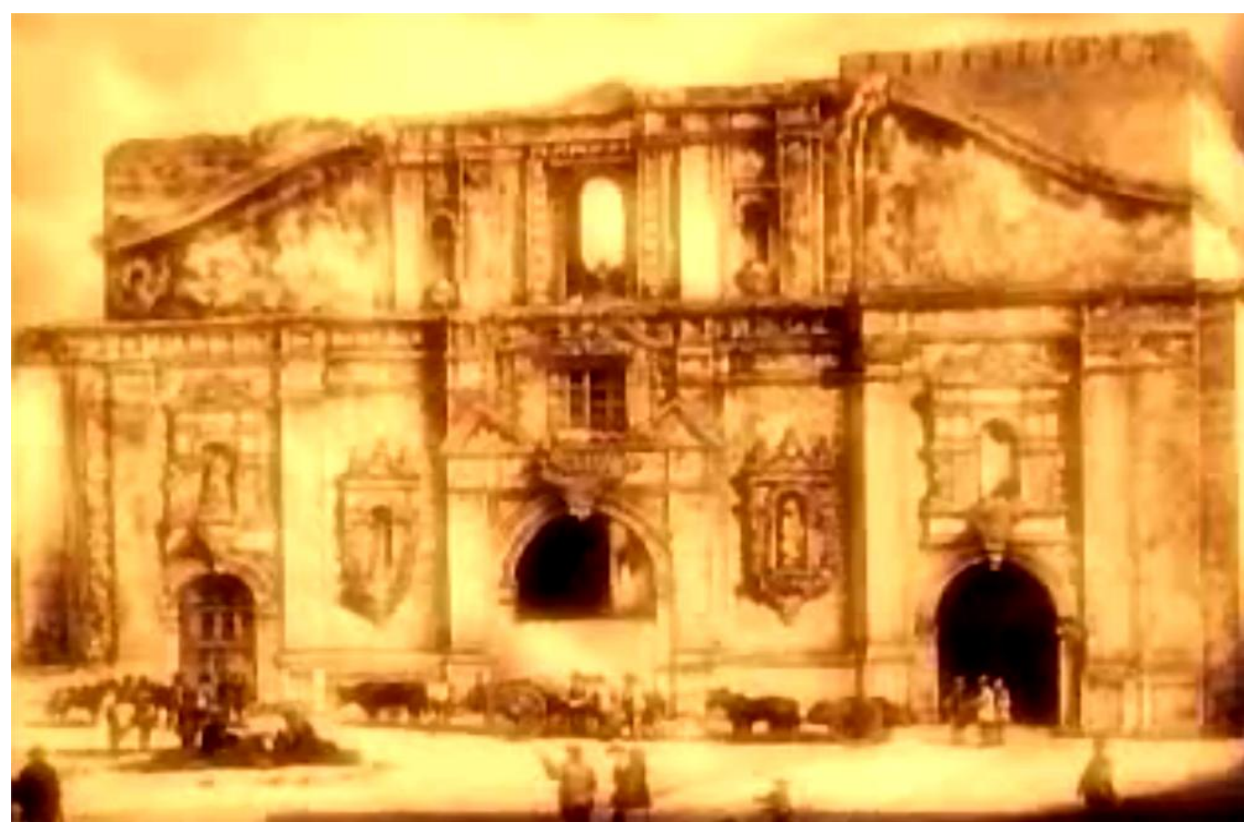

Figura 2.3 - Ilustração do incêndio na Companhia de Jesus, Santiago, Chile. Fonte: http://www.educarchile.cl/Portal.Base/Web/VerContenido.aspx?ID=137540

\footnotetext{
${ }^{1}$ Fonte: http://operamundi.uol.com.br/conteudo/noticias/6114/conteudo+opera.shtml

${ }^{2}$ Fonte: http://www.nuestro.cl/comunidad/aportes/iglesia_compania2.htm 
Também no século 19, no dia 10 de outubro de 1871, ocorreu o Grande Incêndio de Chicago, USA, ilustrado na Figura 2.4. Atualmente, a versão mais aceita é que esse incêndio se iniciou em um estábulo de uma fazenda, e rapidamente se espalhou por toda a cidade por meio de faíscas que eram conduzidas pelo vento. O incêndio teve duração de dois dias, resultando em 300 mortos, 100 mil desabrigados e 200 milhões de dólares de prejuízo ${ }^{3}$. As casas feitas de madeira facilitaram a propagação do incêndio.

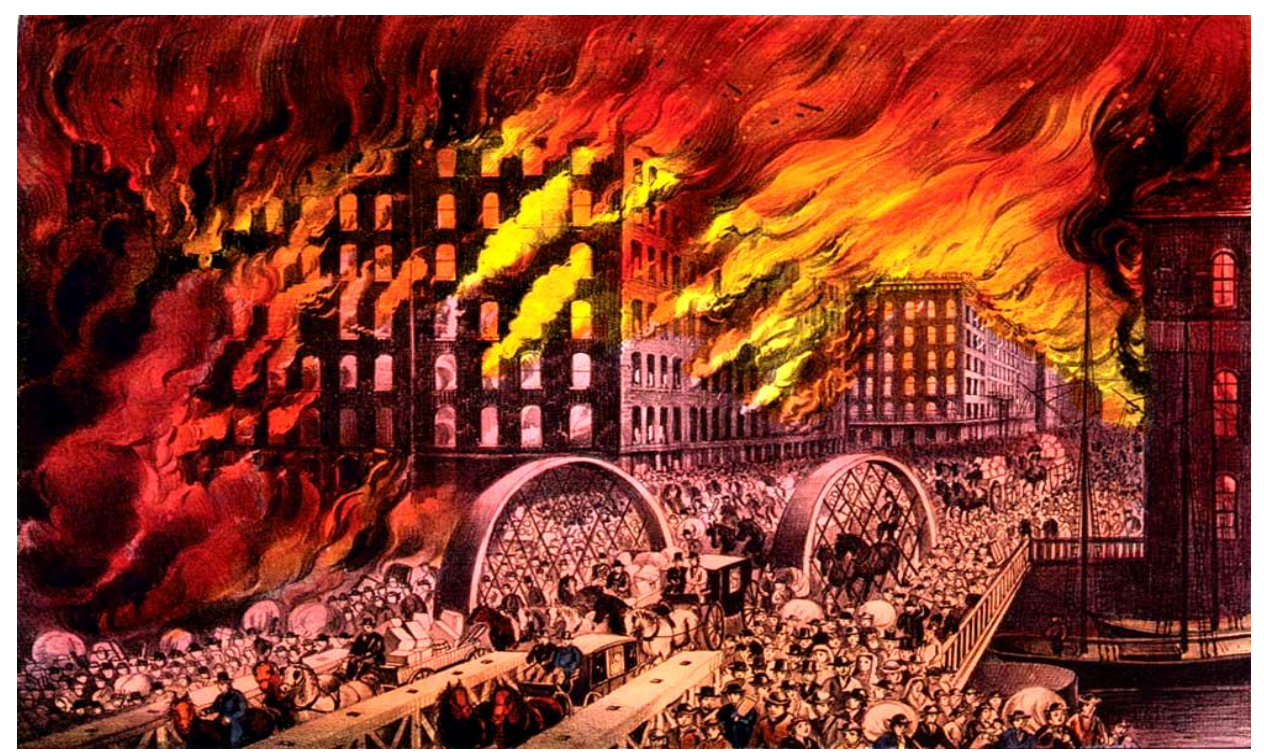

Figura 2.4 - Ilustração do Grande Incêndio de Chicago, USA. Fonte: http://cienciahoje.uol.com.br/colunas/em-tempo/a-cidade-arde

Com base no exposto, é possível perceber que esses grandes incêndios tiveram sua origem em um único foco, porém se espalharam por uma grande área, trazendo consequências desastrosas, pois na época ainda não se tinha preocupação com a segurança contra incêndios.

Com relação ao âmbito nacional, três incêndios merecem destaque, ocorridos nos edifícios ANDRAUS (São Paulo), JOELMA (São Paulo) e ANDORINHAS (Rio de Janeiro). Segundo REGOBELLO (2007) foram estes que impulsionaram a sociedade na busca por soluções para a prevenção de incêndios e minimização dos seus danos. Com relação ao incêndio no edifício ANDRAUS em 1972, ilustrado na Figura 2.5, foram registradas 16 mortes, e segundo as informações apresentadas em KIMURA (2009) foi constatado que não havia nenhum tipo de sistema de segurança, tais como chuveiros automáticos, sinalização de saídas de emergência e alarmes de detecção automática, aspecto que dificultou a desocupação desse edifício.

O incêndio no Edifício JOELMA (atual Edifício Praça da Bandeira) foi semelhante ao caso do Edifício ANDRAUS, porém, neste caso os helicópteros de resgate não podiam pousar sobre sua cobertura devido ao telhado formado por placas de amianto. O saldo da tragédia foi de 179 mortos e 300 feridos $^{4}$.

\footnotetext{
${ }^{3}$ Fonte: http://www.dw-world.de/dw/article/0,,294889,00.html

${ }^{4}$ Fonte: http://www.alemdaimaginacao.com/Noticias/Os\%20Misterios\%20do\%20Joelma.html
} 


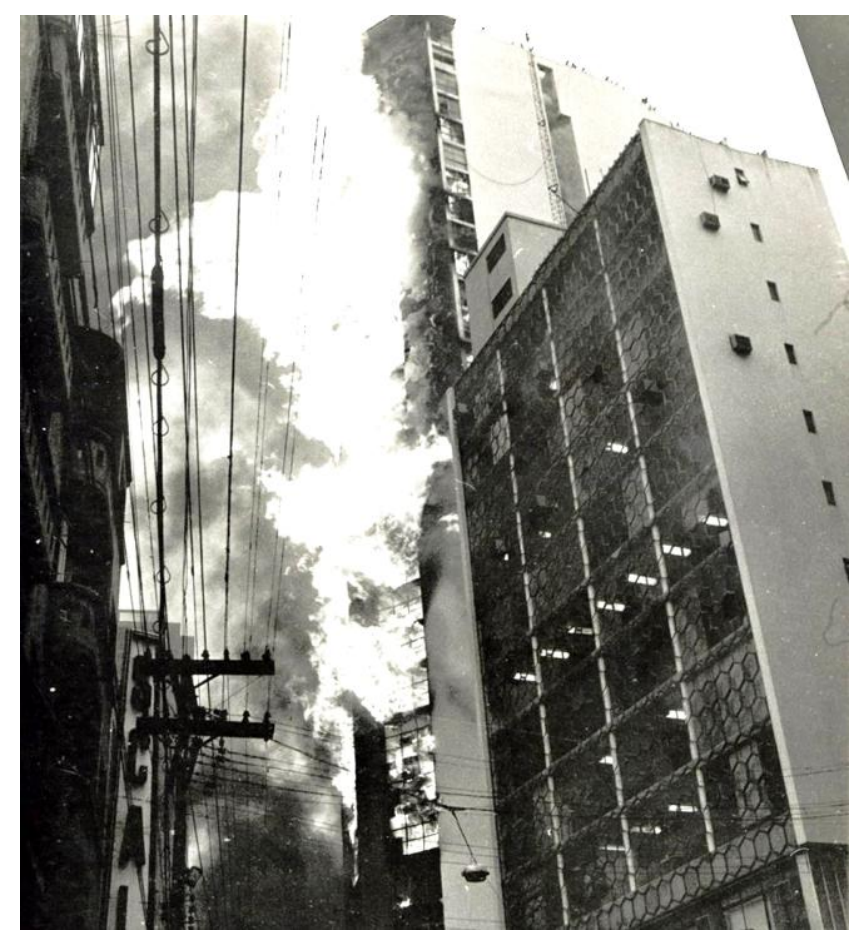

Figura 2.5 - Incêndio no Edifício Andraus, SP em 1972. Fonte: http://www.pilotopolicial.com.br/ospioneiros-do-salvamento-\%E2\% 80\% 93-o-incendio-do-edificio-andraus/

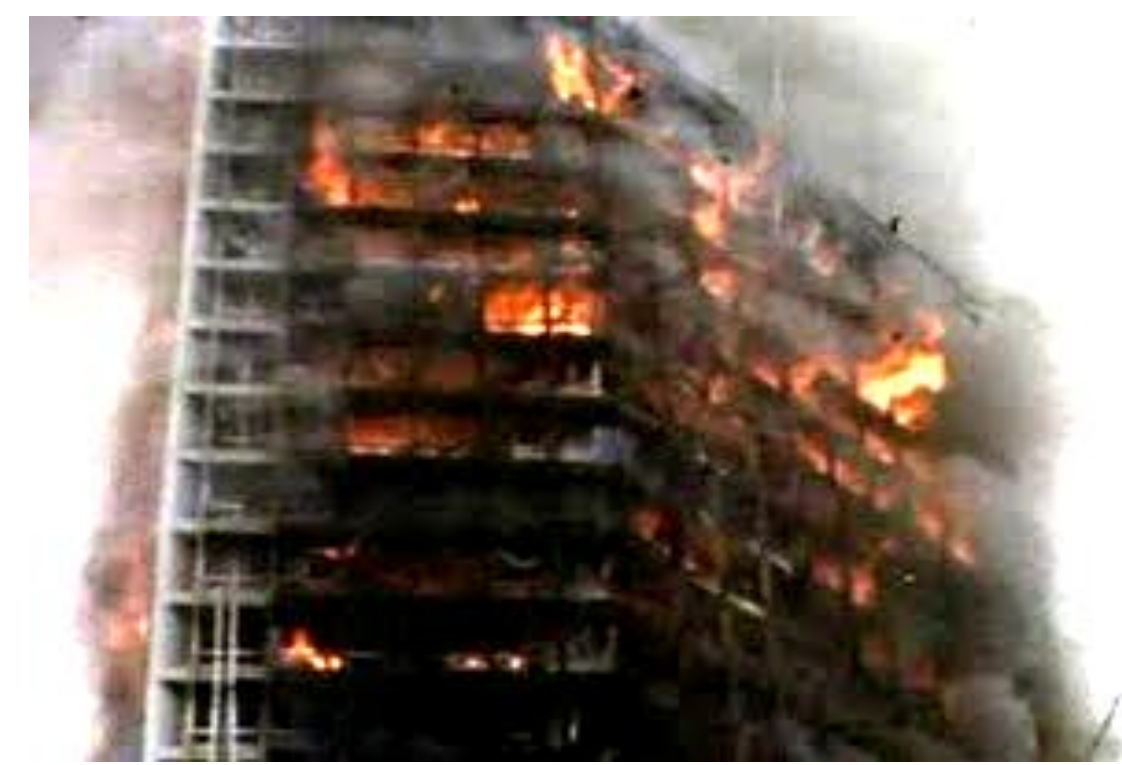

Figura 2.6 - Incêndio no Edifício Joelma, SP em 1974. Fonte: http://www.cinepipocacult.com.br/2011/12/joelma-23-andar.html

Outro incêndio que merece destaque foi o ocorrido no Edifício ANDORINHAS, localizado no centro comercial do Rio de Janeiro. Nesse incêndio, apresentado na Figura 2.7, foram registrados cerca de 50 feridos e confirmadas 21 mortes $^{5}$. A falta de água e a dificuldade de acesso ao prédio foram as principais dificuldades dos bombeiros para controlar as chamas.

\footnotetext{
${ }^{5}$ Fonte: http://www.jblog.com.br/hojenahistoria.php?itemid=7096 


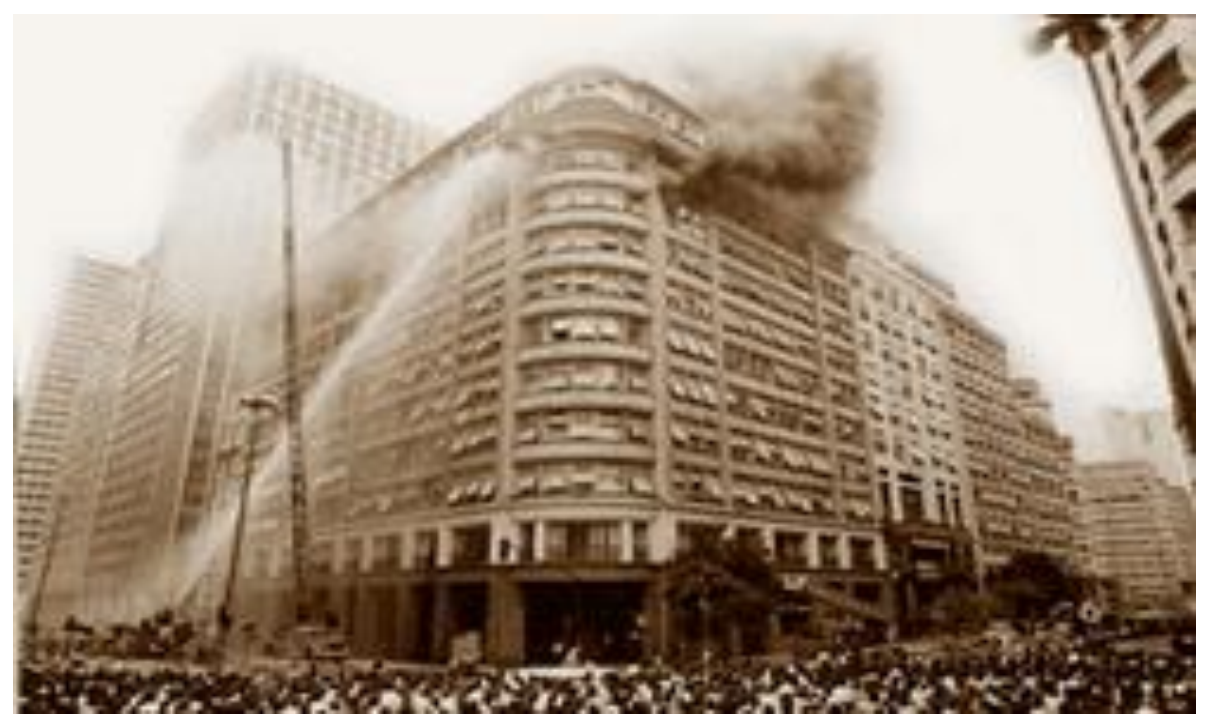

Figura 2.7 - Incêndio no Edifício Andorinhas, RJ em 1986. Fonte: http://www.jblog.com.br/hojenahistoria.php?itemid=7096

Para os três edifícios apresentados anteriormente, segundo a perícia técnica realizada na época, a causa dos incêndios estava relacionada a problemas elétricos, no caso, sobrecarga ou curto-circuito. Tais incidentes impulsionaram a criação, em tempo recorde, de um decreto sobre proteção contra incêndio e, a partir daí, outras regulamentações foram criadas, sendo basicamente adaptações de legislações estrangeiras (FERREIRA; CORREIA e AZEVEDO, 2006 apud ROCHA, 2012).

Nos anos seguintes foram desenvolvidas as primeiras normas brasileiras sobre segurança de incêndio, com destaque para a ABNT NBR 5672, intitulada Exigências particulares das obras de concreto armado e protendido em relação à resistência ao fogo, a qual foi cancelada em 2001, pois apresentava prescrições que inviabilizavam economicamente a execução de obras de concreto (REGOBELLO, 2007).

Mais recentemente, na madrugada do dia 27 de janeiro de 2013, ocorreu um incêndio em uma discoteca na cidade de Santa Maria no estado do Rio Grande do Sul. O saldo da tragédia foi de 242 mortos (Fonte: http://noticias.uol.com.br), sendo a principal causa a inalação da fumaça tóxica. Segundo o relatório do CREA-RS (2013) as causas fundamentais para a ocorrência do incêndio foi a combinação do uso de material de revestimento acústico inflamável associado à realização de show com componentes pirotécnicos. Segundo esse mesmo relatório, o grande número de vítimas foi influenciado pela dificuldade de desocupação, deficiências nas saídas de emergência e excesso da lotação máxima permitida.

\subsection{Curvas de incêndio}

Segundo SILVA (2001) a principal característica de um incêndio, no que concerne ao estudo das estruturas, é a curva que fornece a temperatura dos gases em função do tempo de incêndio, visto que a partir dessa curva é possível calcular a máxima temperatura atingida 
pelas peças estruturais e sua correspondente resistência mecânica quando exposta a elevadas temperaturas. Essas curvas estão divididas segundo três tipos de incêndios, no caso, real, natural e padrão, os quais serão apresentados a seguir.

\subsubsection{Incêndio Real}

Para que um incêndio seja deflagrado são necessários três fatores: fonte de calor, comburente (oxigênio) e material combustível. Deste modo o comportamento da curva "Temperatura vs. Tempo" para um incêndio real depende basicamente da quantidade de comburente e da carga de incêndio disponíveis.

Pode-se distinguir três fases distintas numa curva de incêndio real: ignição, fase de aquecimento e fase de resfriamento, conforme apresentado na Figura 2.8. Segundo SILVA (2001) a fase de ignição apresenta baixas temperaturas, sem riscos à estrutura, e caso a edificação possua medidas de proteção contra incêndio, tais como detectores de calor e fumaça, chuveiros automáticos, brigada de incêndio, etc., eficientes para extinguir o fogo, nenhuma verificação adicional da estrutura será necessária.

O instante de aumento brusco da temperatura é conhecido como "flashover" ou inflamação generalizada e ocorre quando a superfície de toda carga de incêndio presente no ambiente entra em ignição (SILVA, 2001). Já a fase de resfriamento inicia após a extinção de toda carga de incêndio presente no ambiente.

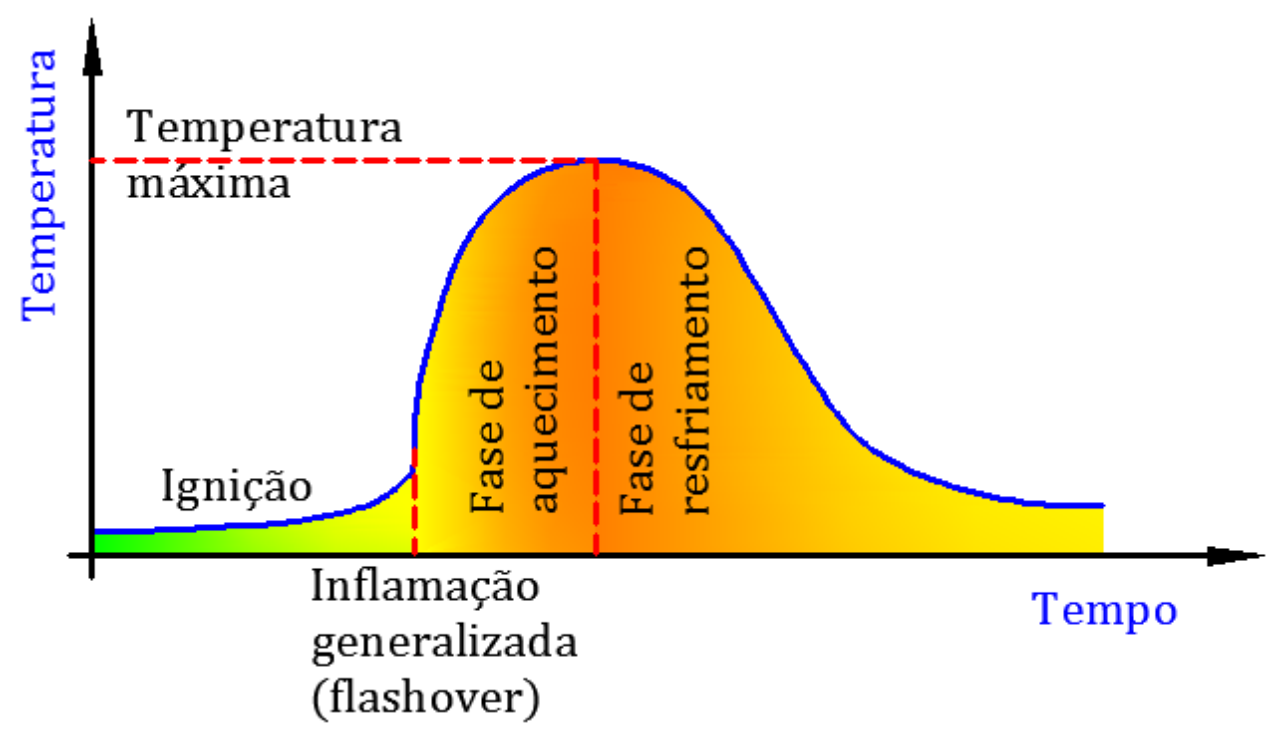

Figura 2.8 - Curva temperatura-tempo de um incêndio real (Modificado de SILVA, 2001)

De acordo com o exposto em KIMURA (2009), apesar de representativa, a curva de um incêndio real é de difícil determinação, pois há vários parâmetros associados, como a disposição das aberturas, quantidade de cargas combustíveis, fator de ventilação, que são de grande variabilidade a depender do tipo de edificação. Desta forma a representação de um incêndio acaba sendo simplificada na forma de uma curva de Temperatura $\mathrm{x}$ Tempo por meio dos modelos de incêndio natural e incêndio padrão. 


\subsubsection{Incêndio Natural}

No modelo de incêndio natural desconsidera-se a fase de ignição do incêndio real e a fase de resfriamento é simplificada por uma reta, conforme Figura 2.9. Portanto pode-se dizer que o modelo de incêndio natural corresponde a uma simplificação do modelo de incêndio real.

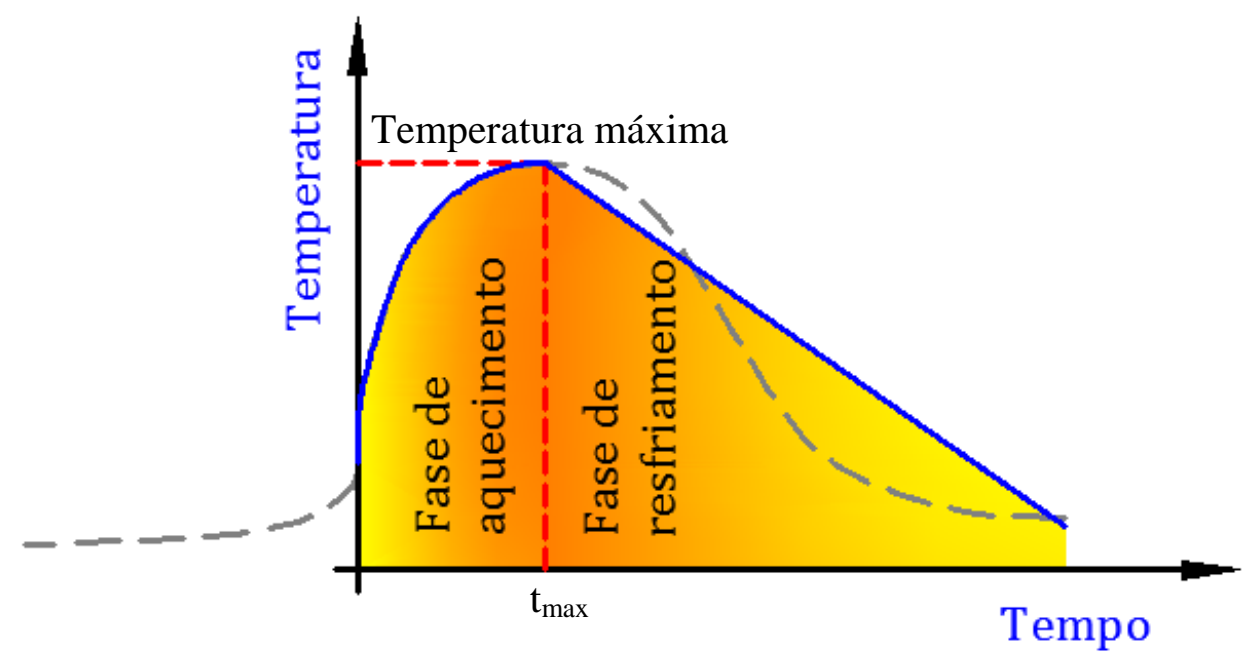

Figura 2.9 - Curva temperatura-tempo de um incêndio natural (Modificado de SILVA, 2001)

Segundo SILVA (2001), denomina-se incêndio natural a situação para a qual se admite que a temperatura dos gases respeite as curvas temperatura-tempo construídas a partir de ensaios (ou modelos matemáticos aferidos a ensaios) de incêndios que simulam a real situação de um compartimento em chamas. Os resultados desses ensaios demonstram que as curvas temperatura-tempo de um incêndio natural compartimentado dependem de três parâmetros: Carga de incêndio, Grau de ventilação e Características térmicas do material de vedação.

O EUROCODE 1 Part 1-2 apresenta, como proposta para modelos de incêndio natural, aqueles denominados por modelo avançado e modelo simplificado. No modelo avançado deve-se levar em conta as propriedades dos gases e a troca de massa e energia. Esse modelo exige que a simulação seja realizada utilizando códigos computacionais específicos de dinâmica dos fluidos, que fornece a evolução da temperatura no compartimento em função do tempo e do espaço.

No modelo simplificado o comportamento da curva Temperatura vs. Tempo é determinado por meio de curvas parametrizadas, apresentadas no Anexo A do EUROCODE 1 Part 1-2 e só pode ser utilizado quando o compartimento em questão possuir menos de $500 \mathrm{~m}^{2}$ de área de piso, sem aberturas no teto e altura máxima de $4 \mathrm{~m}$. A obtenção e construção dessa curva se baseia na Equação 2.1.

$$
\theta_{g}=20+1325\left(1-0,324 e^{-0,2 t^{*}}-0,204 e^{-1,7 t^{*}}-0,472 e^{-19 t^{*}}\right)
$$


Na Equação 2.1, valem:

$\theta_{g}$ é a temperatura dos gases no compartimento em chamas em ${ }^{\circ} \mathrm{C}$;

$t^{*}=t . \Gamma$, sendo t o tempo em horas;

O parâmetro $\Gamma$ adimensional é chamado de fator de correção do tempo e é dependente do fator de abertura (O) e da absorção térmica (b) do compartimento, dado pela Equação 2.3.

$$
\Gamma=\frac{(O / b)^{2}}{(0,04 / 1160)^{2}}
$$

Na Equação 2.3, valem:

$b=\sqrt{\rho c \lambda}\left[\mathrm{J} / \mathrm{m}^{2} \mathrm{~s}^{1 / 2} \mathrm{~K}\right]$, limitado no intervalo de $100 \leq \mathrm{b} \leq 2200 ;$

$O=A_{v} \sqrt{h_{e q}} / A_{t}\left[m^{1 / 2}\right]$, limitado no intervalo $0,02 \leq \mathrm{O} \leq 0,20 ;$

Onde:

$\rho\left[\mathrm{kg} / \mathrm{m}^{3}\right]$ - Densidade do material de vedação do compartimento;

$c[\mathrm{~J} / \mathrm{kgK}]$ - Calor específico do material de vedação do compartimento;

$\lambda[W / m K]$ - Condutividade Térmica do material de vedação do compartimento;

$A_{v}\left[m^{2}\right]$ - Área total de aberturas verticais nas paredes;

$h_{e q}[m]$ - Média ponderada das alturas das aberturas nas paredes;

$A_{t}\left[m^{2}\right]$ - Área total do compartimento (paredes, teto e piso, incluindo as aberturas).

O EUROCODE 1 Part 1-2 também apresenta formulações para o cálculo da absorção térmica (b) nos casos em que o material de vedação é composto por camadas de diferentes materiais e nos casos em que se deseja considerar diferentes valores de " $b$ " para as paredes, teto e piso. O tempo em que ocorre a temperatura máxima $\left(\mathrm{t}_{\max }\right)$ é dado pela Equação 2.6.

$$
t_{\max }=\max \left[0,2 \cdot 10^{-3} \cdot q_{t, d} / O ; t_{\text {lim }}\right]
$$

Na Equação 2.6, valem:

$q_{t, d}$ é o valor de projeto da densidade da carga de incêndio relacionada à toda área da superfície $A_{t}$ do compartimento, sendo que $q_{t, d}=q_{f, d} . A_{f} / A_{t}\left[\mathrm{MJ} / \mathrm{m}^{2}\right]$. Obedecendo aos limites: $50 \leq q_{t, d} \leq 1000\left[\mathrm{MJ} / \mathrm{m}^{2}\right]$. 
$q_{f, d}$ é o valor de projeto da densidade da carga de incêndio relacionada com a área do piso, tomado do anexo E desta mesma norma.

$t_{\text {lim }}$ é o tempo limite para o incêndio, e possui os valores de 25,20 ou 15 minutos se o incêndio possuir baixa, média ou alta taxa crescimento. A taxa de crescimento do incêndio depende do tipo de ocupação e é apresentada na Tabela E.5 do anexo E do EUROCODE 1 Part 1-2.

Se o tempo máximo adotado for o tempo limite, deve se alterar o cálculo do fator de correção do tempo $(\Gamma)$ para o uso na Equação 2.1, onde t $^{*}$ passa a ser:

$$
\begin{aligned}
& t^{*}=t . \Gamma_{\lim } \\
& \Gamma_{\lim }=\frac{\left(O_{\lim } / b\right)^{2}}{(0,04 / 1160)^{2}} \\
& O_{\text {lim }}=0,1 \cdot 10^{-3} \cdot q_{t, d} / t_{\text {lim }}
\end{aligned}
$$

Se $\mathrm{O}>0,04 m^{1 / 2}$ e $\mathrm{q}_{\mathrm{t}, \mathrm{d}}<75 \mathrm{MJ} / \mathrm{m}^{2}$ e $\mathrm{b}<1160 \mathrm{~J} / \mathrm{m}^{2} \mathrm{~s}^{1 / 2} K$ então o valor de $\Gamma_{\text {lim }}$ apresentado pela Equação 2.8 deverá ser multiplicado por um fator " $k$ " dado por:

$$
k=1+\left(\frac{O-0,04}{0,04}\right)\left(\frac{q_{t, d}-75}{75}\right)\left(\frac{1160-b}{1160}\right)
$$

Estabelecido o ponto limite da curva, o trecho descendente é aproximado por uma reta, que deve obedecer ao seguinte equacionamento:

$$
\begin{array}{lcc}
\theta_{g}=\theta_{\text {max }}-625\left(t^{*}-t_{\text {max }}^{*} \cdot x\right) & \text { para } & t_{\text {max }}^{*} \leq 0,5 \\
\theta_{g}=\theta_{\text {max }}-250\left(3-t_{\text {max }}^{*}\right)\left(t^{*}-t_{\text {max }}^{*} \cdot x\right) & \text { para } & 0,5 \leq t_{\text {max }}^{*} \leq 2 \\
\theta_{g}=\theta_{\text {max }}-250\left(t^{*}-t_{\text {max }}^{*} \cdot x\right) & \text { para } & t_{\text {max }}^{*} \geq 2
\end{array}
$$

Onde,

$$
\begin{array}{ll}
x=1,0 & \text { se } t_{\text {max }}>t_{\text {lim }} \\
x=t_{\text {lim }} \frac{\Gamma}{t_{\text {max }}^{*}} & \text { se } t_{\text {max }}=t_{\text {lim }}
\end{array}
$$




\subsubsection{Incêndio-Padrão}

Uma curva típica para um incêndio-padrão é apresentada na Figura 2.10. A característica principal dessa curva é a de possuir apenas um ramo ascendente, admitindo, portanto, que a temperatura dos gases seja sempre crescente com o tempo e, além disso, independente das características do ambiente e da carga de incêndio (SILVA, 2001).

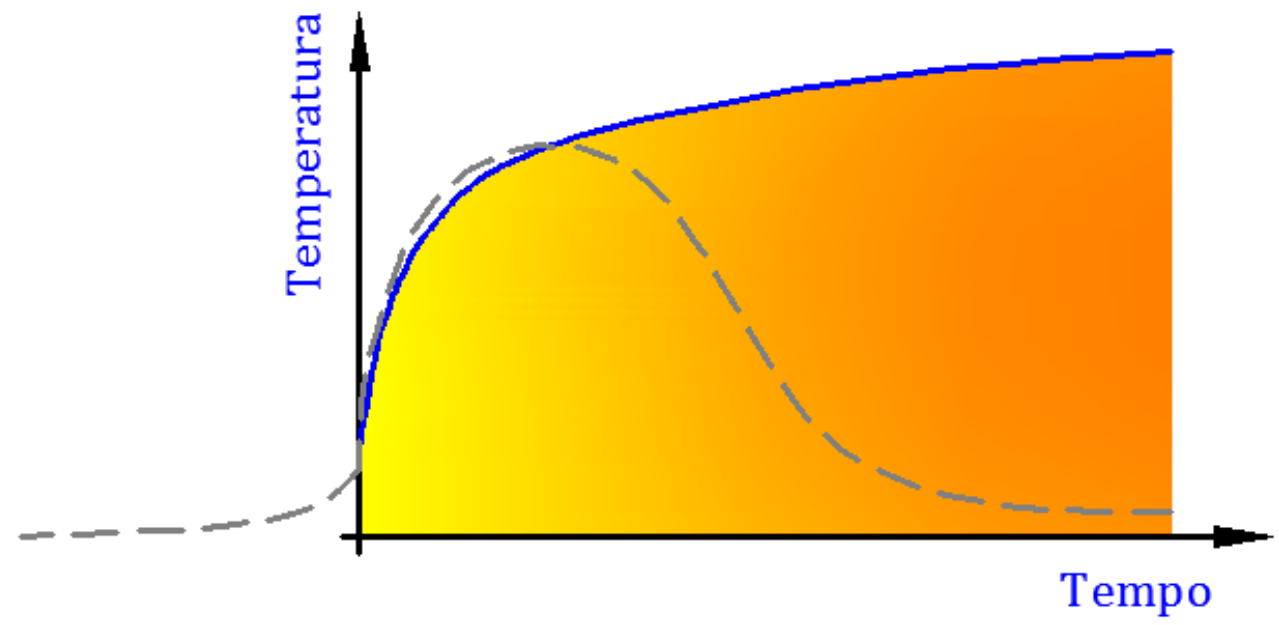

Figura 2.10 - Curva temperatura-tempo de um incêndio padrão (Modificado de SILVA, 2001)

O EUROCODE 1 Part 1-2 apresenta três curvas para um incêndio-padrão, são elas:

a) Curva temperatura-tempo padrão: Aplica-se aos ambientes cuja carga combustível é formada principalmente por materiais celulósicos. Esta é a curva padrão ISO 834 (1999) que também é usada pela ABNT NBR 14432:2001, apresentada na forma da Equação 2.12, em que $\theta_{g}$ é a temperatura do ambiente em chamas $\left(\mathrm{em}^{\circ} \mathrm{C}\right)$ e $t$ é o tempo de exposição ao incêndio em minutos.

$$
\theta_{g}=20+345 \log (8 t+1)
$$

b) Curva para incêndios externos: A temperatura dos gases próximos aos elementos estruturais é dada pela Equação 2.13.

$$
\theta_{g}=660\left(1-0,687 e^{-0,32 t}-0,313 e^{-3,8 t}\right)+20
$$

c) Curva de hidrocarbonetos: Aplica-se aos ambientes em que o material combustível é formado principalmente por hidrocarbonetos. A temperatura dos gases é dada pela Equação 2.14 .

$$
\theta_{g}=1080\left(1-0,325 e^{-0,167 t}-0,675 e^{-2,5 t}\right)+20
$$

Outra curva muito citada pela bibliografia se refere àquela proposta pela ASTM E 119. Essa curva não tem um equacionamento próprio. Seu comportamento é definido por um número discreto de pontos, conforme mostra a Tabela 2.1, e na forma gráfica conforme apresentada na Figura 2.11. 
Tabela 2.1 - Pontos discretos da curva Temperatura vs. Tempo recomendados pela ASTM E 119

\begin{tabular}{c|c|c|c}
\hline \multicolumn{4}{|c}{ Pontos discretos da curva da ASTM E 119 } \\
\hline Tempo $(\mathbf{m i n})$ & Temperatura $\left({ }^{\mathbf{0}} \mathbf{C}\right)$ & Tempo $(\mathbf{m i n})$ & Temperatura $\left({ }^{\mathbf{0}} \mathbf{C}\right)$ \\
\hline 0 & 20 & 55 & 916 \\
\hline 5 & 538 & 60 & 927 \\
\hline 10 & 704 & 65 & 937 \\
\hline 15 & 760 & 70 & 946 \\
\hline 20 & 795 & 75 & 955 \\
\hline 25 & 821 & 80 & 963 \\
\hline 30 & 843 & 85 & 971 \\
\hline 35 & 862 & 90 & 978 \\
\hline 40 & 878 & 120 & 1010 \\
\hline 45 & 892 & 240 & 1093 \\
\hline 50 & 905 & 480 & 1260 \\
\hline
\end{tabular}

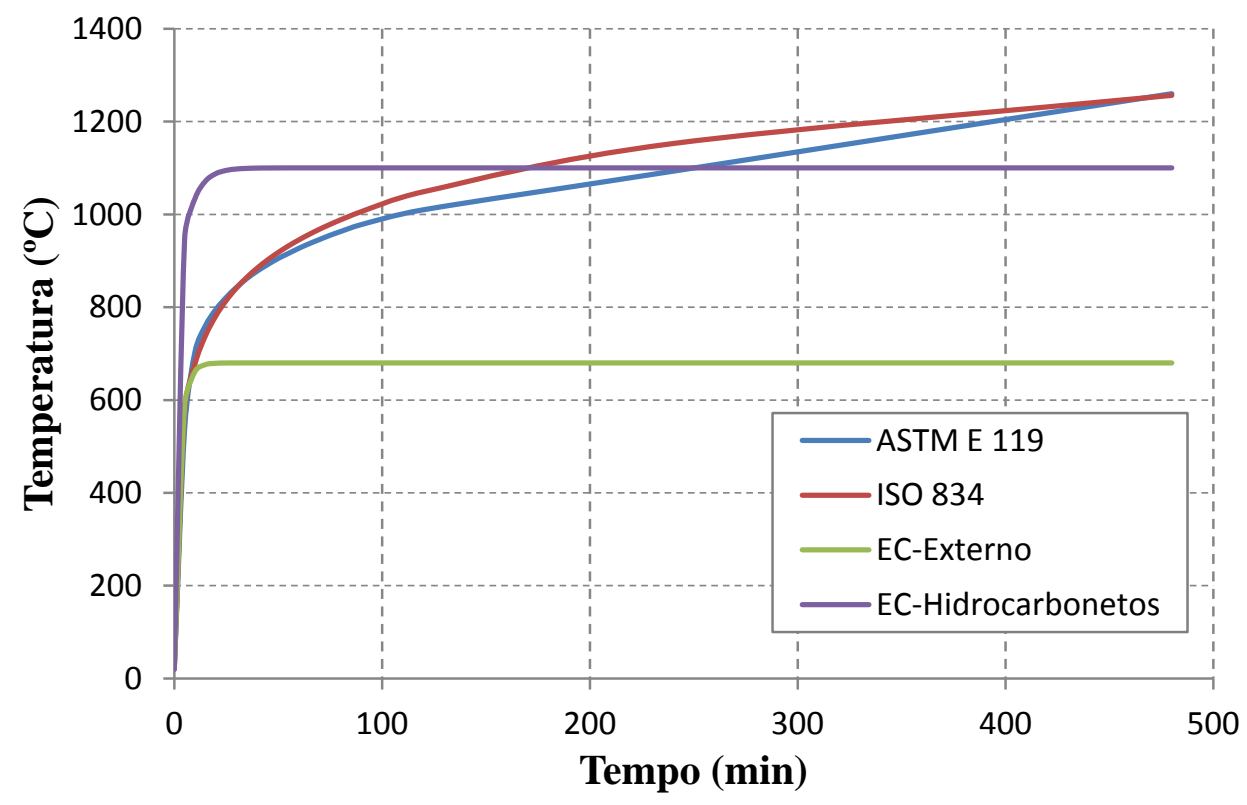

Figura 2.11 - Principais curvas de incêndio padrão

A temperatura dos gases, representada matematicamente pelas curvas de incêndio, permite a obtenção dos campos térmicos em elementos de interesse por meio dos processos conhecidos como transferências de calor.

\subsection{Transferência de calor}

Existem três mecanismos básicos de transferência de calor: condução, convecção $e$ radiação. $\mathrm{O}$ entendimento desses mecanismos tem grande importância quando se deseja 
modelar uma estrutura em situação de incêndio. Segundo WANG (2002) a solução analítica para problema de transferência de calor só é possível nos casos mais simples. Desse modo, em aplicações de segurança contra incêndio, problemas de transferência de calor são resolvidos experimental ou numericamente. Como os experimentos são caros e aplicados a situações específicas, a análise numérica é largamente utilizada.

A condução é o processo de transferência de calor de regiões com maior energia cinética molecular para regiões de menor energia por meio de colisões moleculares, sem movimento macroscópico de matéria. O fluxo de calor ao longo da espessura do material por condução é expresso segundo a lei de Fourier, apresentada na Equação 2.15, em que $\lambda$ $\left(\mathrm{W} / \mathrm{m}^{\circ} \mathrm{C}\right)$ é a condutividade térmica do material e $d T$ é a diferença de temperatura ao longo da espessura infinitesimal $d x$.

$$
\dot{Q}=-\lambda \frac{d T}{d x}
$$

A convecção é a transferência de calor que ocorre na interface de um fluido e uma superfície sólida, devida ao movimento desse fluido (WANG, 2002). Assim, para que haja a troca de calor por convecção, é necessário que o fluido aquecido esteja em contato com o sólido. De modo geral o fluxo de calor por convecção é proporcional à diferença de temperatura dos gases aquecidos $\left(T_{g}\right)$ e a temperatura na superfície do elemento $\left(T_{m}\right)$, dado pela Equação 2.16, em que $\alpha_{c}$ é o coeficiente de transferência de calor por convecção. Segundo o EUROCODE 1 Part 1-2 (2002), pode-se utilizar os valores dos coeficientes de transferência de calor por convecção na superfície em contato com o fogo e na face oposta iguais a $25 \mathrm{~W} / \mathrm{m}^{2 \circ} \mathrm{C}$ e $9 \mathrm{~W} / \mathrm{m}^{2 \circ} \mathrm{C}$ respectivamente.

$$
\dot{Q}=\alpha_{c}\left(T_{g}-T_{m}\right)
$$

A radiação é a transferência de calor devido às ondas eletromagnéticas que podem ser absorvidas, transmitidas ou refletidas em uma superfície. Segundo WANG (2002) a quantidade de radiação de cada uma dessas parcelas depende da temperatura, do comprimento de onda eletromagnética e das propriedades do corpo atingido pela radiação. Utilizando a lei de Kirchhoff, é possível demonstrar que o fluxo de calor por radiação é dado pela Equação 2.17 .

$$
\dot{Q}=\varepsilon_{r} \sigma\left(T_{1}^{4}-T_{2}^{4}\right)
$$

Na Equação 2.17, $T_{1}$ e $T_{2}$ são as temperaturas das superfícies 1 e 2 respectivamente, $\varepsilon_{r}$ a emissividade resultante entre os gases aquecidos e a superfície considerada e $\sigma$ a constante de Stefan-Boltzmann (igual a 5,67.10 ${ }^{-8} \mathrm{~W} / \mathrm{m}^{2} \mathrm{~K}^{4}$ ). Segundo o EUROCODE (prEN 1991-12:2002) e a ABNT NBR 14323:2013 pode-se adotar o valor da emissividade resultante igual a 0,70 .

No Anexo A são apresentados mais detalhes sobre os processos de transferência de calor. 


\subsection{Propriedades dos materiais de interesse}

O entendimento da variação das propriedades térmicas (condutividade térmica, calor específico e alongamento térmico) e mecânicas (resistência e módulo de elasticidade), em função da temperatura do concreto e do aço, tem grande importância na análise de estruturas em situação de incêndio.

É importante ressaltar que as propriedades térmicas e mecânicas descritas nas normas brasileiras só são aplicáveis para os tipos de aço descritos na ABNT NBR 8800:2008 e na ABNT NBR 14762:2010. O mesmo vale para o concreto, onde só poderá ser aplicada a norma ABNT NBR 15200:2012 se os cálculos estruturais estiverem de acordo com a ABNT NBR 6118:2003, para concreto armado.

As propriedades físicas do aço (fôrma de aço e armadura) e do concreto, segundo as normas brasileiras e europeias, utilizadas neste trabalho estão apresentadas no Anexo B, sendo que para o concreto foram adotadas as propriedades referentes ao caso com densidade normal.

\subsection{As formas de aço do Brasil}

Atualmente, a utilização das lajes com fôrma de aço incorporada é uma alternativa atraente, pois permite a racionalização do processo construtivo e, por isso, são empregadas com sucesso em edifícios de aço, de concreto armado e em pontes, apresentando vantagens construtivas, estruturais e econômicas. Dentre as vantagens advindas do uso de lajes com fôrma de aço incorporada citam-se as mais relevantes (DE NARDIN et al., 2005):

- A fôrma de aço substitui as armaduras positivas, gerando economia de tempo, material e mão de obra, pois os serviços de corte, dobramento e montagem das armaduras são eliminados ou reduzidos;

- Elimina a utilização de fôrmas de madeira, que constituem uma parcela significativa do custo total de uma estrutura de concreto;

- Reduz sensivelmente a necessidade de escoramentos tornando o canteiro de obras mais organizado, reduzindo o tempo gasto com montagem/desmontagem dos escoramentos e retirada de fôrma;

- A fôrma de aço pode servir de plataforma de trabalho nos andares superiores e proteção aos operários em serviço nos andares inferiores;

- As fôrmas de aço são leves, de fácil manuseio e instalação;

- O uso de fôrmas de aço facilita a execução das diversas instalações e a fixação de forros falsos. 
No Brasil, as empresas METFORM e PERFILOR produzem esse tipo de sistema, nas linhas Steel deck e Polydeck, respectivamente, ambas compreendendo formas de aço trapezoidal. Na linha Steel deck são produzidos dois tipos de fôrmas de aço: MF-50 e MF-75' com espessuras iguais a $0,80 \mathrm{~mm}, 0,95 \mathrm{~mm}$ e $1,25 \mathrm{~mm}$. Na linha Polydeck também são produzidas fôrmas nas mesmas espessuras. As dimensões dessas fôrmas são apresentadas nas Figuras 2.12 a 2.14, e suas aplicações dependem das necessidades de projeto.

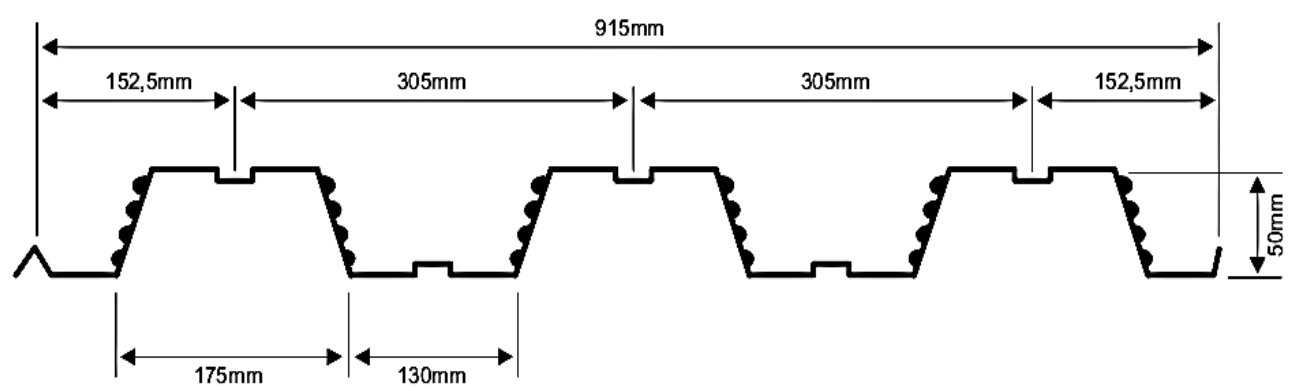

Figura 2.12 - Seção transversal do Steel deck MF-50

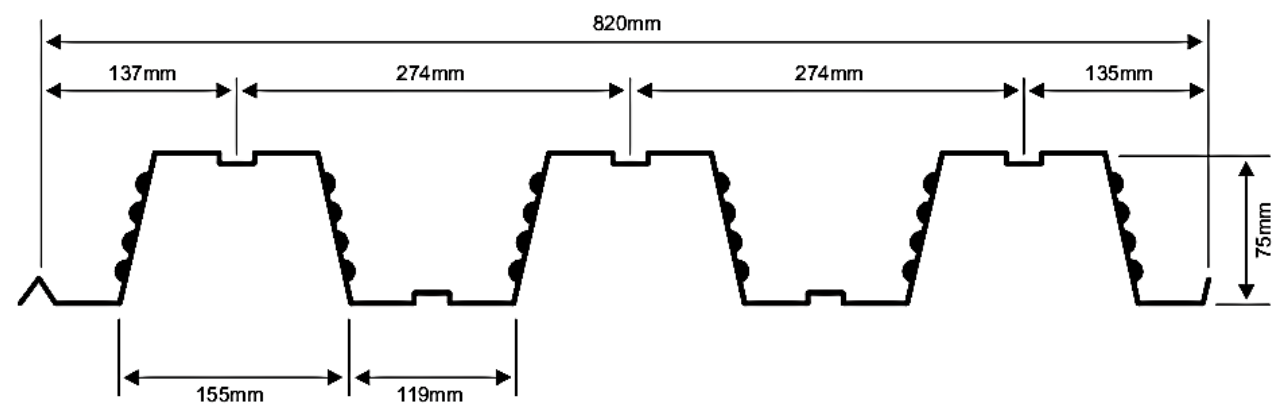

Figura 2.13 - Seção transversal do Steel deck MF-75

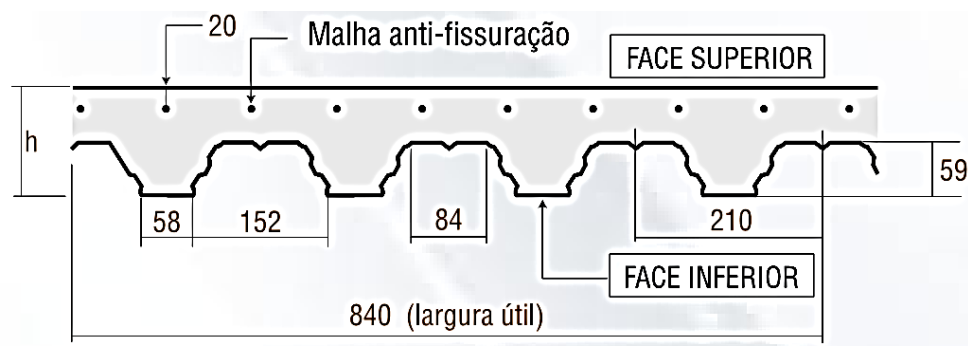

Figura 2.14 - Seção transversal da fôrma de aço Polydeck

\subsection{Comportamento estrutural}

\subsubsection{Fase de construção}

Durante a construção a fôrma de aço é responsável por resistir aos carregamentos externos, funcionando como uma viga (laje trabalhando somente na direção das nervuras). Nessa fase, a fôrma de aço está sujeita aos esforços de flexão e cortante. Por ter espessura muito fina, essa fôrma está sujeita a instabilidade local em resposta às tensões de compressão e de cisalhamento, reduzindo sua capacidade resistente.

\footnotetext{
${ }^{6}$ A numeração no final da nomenclatura refere-se à altura da fôrma 40
} 


\subsubsection{Fase de utilização}

Após a cura, o concreto passa a trabalhar conjuntamente com a fôrma de aço, que pode substituir total ou parcialmente as armaduras positivas, porém não tem o benefício de estar totalmente imersa no concreto como nas armaduras tradicionais (CRISINEL; O'LEARY, 1996). Por outro lado, tem-se a vantagem de melhorar o isolamento térmico e a estanqueidade da laje, para fins de incêndio, bem como não ter o problema de fendilhamento do concreto.

Segundo CRISINEL e O’LEARY (1996), nas condições normais de carregamento, a laje mista se comporta como uma viga fissurada com flexão na direção longitudinal. $\mathrm{O}$ comportamento do gráfico "Carga vs. Deslocamento", conforme Figura 2.15, obtido com base em resultados de ensaios com controle de deslocamento, é apresentado a seguir e depende das condições de aderência na interface aço-concreto:

- Para baixos carregamentos, o concreto ainda não apresenta fissuras e a interação açoconcreto é total, deste modo a relação Carga vs. Deformação é linear;

- Com o aumento do carregamento o concreto começa a fissurar sob tração, reduzindo a rigidez da estrutura e resultando em maiores deslocamentos;

- Com carregamentos superiores aos de projeto, pode resultar em escorregamentos na interface do aço com o concreto, devido à ruptura por cisalhamento longitudinal;

- O modo de ruptura da laje mista depende tanto do tipo de fôrma de aço quanto da geometria e do vão da laje, resultando em ruptura frágil ou dúctil.

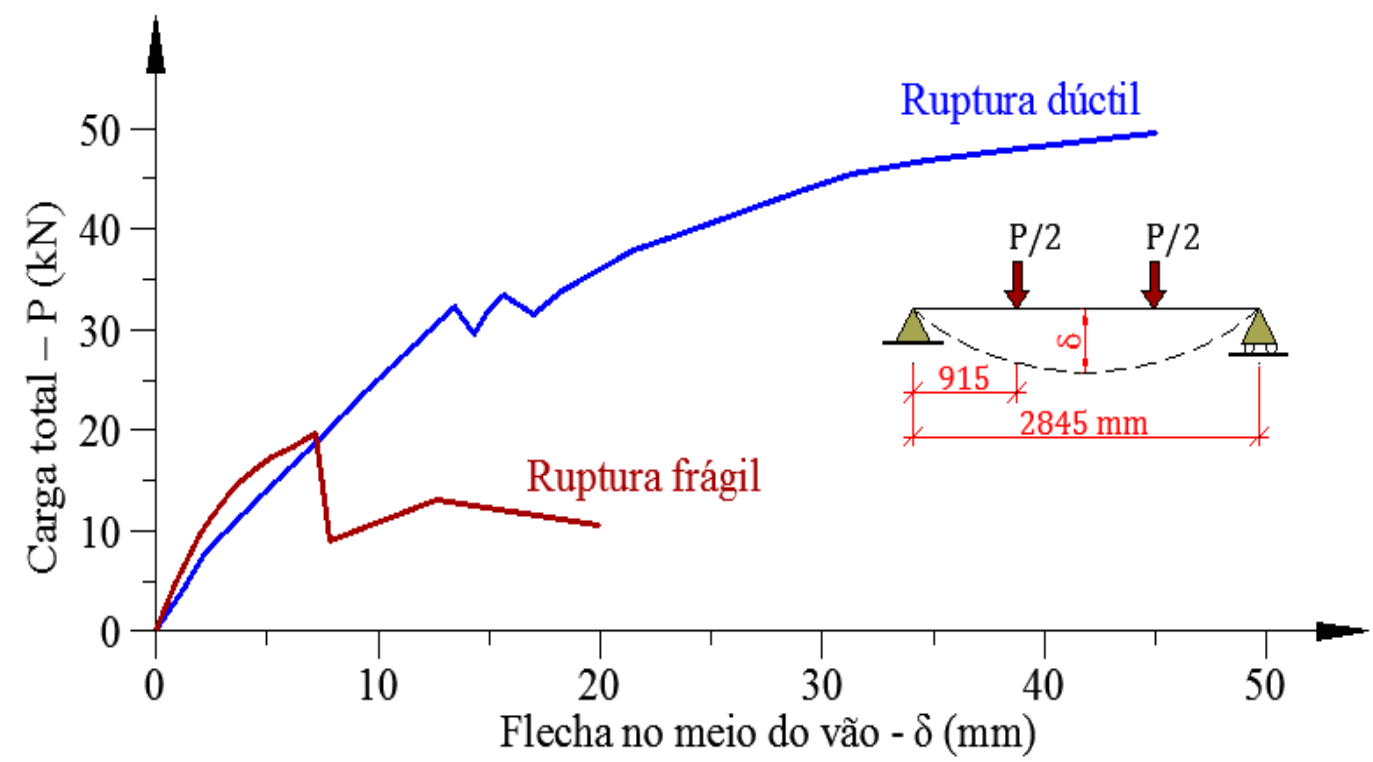

Figura 2.15 - Dois modos típicos de ruptura de laje mista (Modificado de CRISINEL; O’LEARY, 1996)

Na ruptura frágil a carga rapidamente decai no instante em que há o escorregamento relativo na interface da fôrma de aço e do concreto. O cisalhamento passa a ser resistido por 
atrito e aderência mecânica. Com o aumento da deformação na laje tem-se um pequeno aumento na carga, porém, não supera o pico de carga anterior. Na ruptura dúctil a aderência mecânica é capaz de transferir a força cortante até a ruptura, que ocorre por flexão ou por cisalhamento longitudinal, permitindo maiores deslocamentos.

\subsubsection{Critérios de resistência ao fogo}

Em situação de incêndio, a laje mista com a função de compartimentação deve assumir três critérios de resistência ao fogo: estabilidade, isolamento e estanqueidade, conforme pode ser observado na Figura 2.16. Estabilidade é capacidade da estrutura em resistir aos carregamentos. Isolamento ${ }^{7}$ refere-se à capacidade de impedir que a face da estrutura não exposta ao fogo atinja temperatura muito elevada. Estanqueidade ${ }^{8}$ é a capacidade de impedir a penetração de chamas através da estrutura. Segundo WANG (2002), para estruturas de aço ou mista de aço e concreto, o critério de estabilidade é o mais crítico.
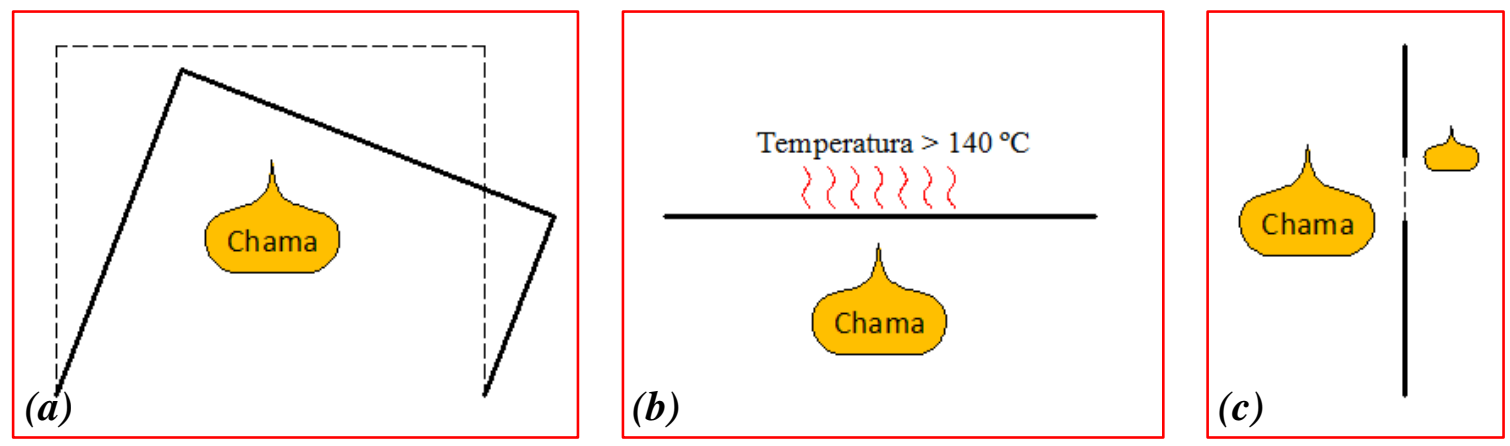

Figura 2.16 - Critérios de resistência ao fogo: (a) Estabilidade, $(b)$ Isolamento e (c) Estanqueidade (Modificado de WANG, 2002)

\subsubsection{Ação de membrana}

A ação de membrana é um comportamento geometricamente não linear, i.e., um efeito de segunda ordem, cuja natureza depende das vinculações de apoio sobre o contorno do compartimento coberto pela laje, e da restrição à movimentação horizontal imposta pelos apoios e/ou pelas estruturas adjacentes (ALLAM et al., 2000 apud COSTA, 2008). Podem-se definir dois tipos de membrana: de compressão e de tração.

\footnotetext{
${ }^{7}$ A ABNT NBR 14432:2001 define o isolamento como a capacidade de um elemento construtivo de impedir a ocorrência, na face que não está exposta ao incêndio, de incrementos de temperatura maiores que $140^{\circ} \mathrm{C}$ na média dos pontos de medida ou maiores que $180^{\circ} \mathrm{C}$ em qualquer ponto de medida.

${ }^{8}$ A ABNT NBR 14432:2001 define a estanqueidade como a capacidade de um elemento construtivo de impedir a ocorrência de rachaduras ou aberturas, através das quais podem passar chamas e gases quentes capazes de ignizar um chumaço de algodão.

42
} 


\subsubsection{Membrana de compressão}

A ação da membrana de compressão ocorre quando o carregamento aplicado está localizado na parte superior da laje, considerando ainda os apoios na parte inferior e que o deslocamento vertical não exceda a altura da laje, produzindo um efeito de arco, conforme pode ser observado na Figura 2.17.

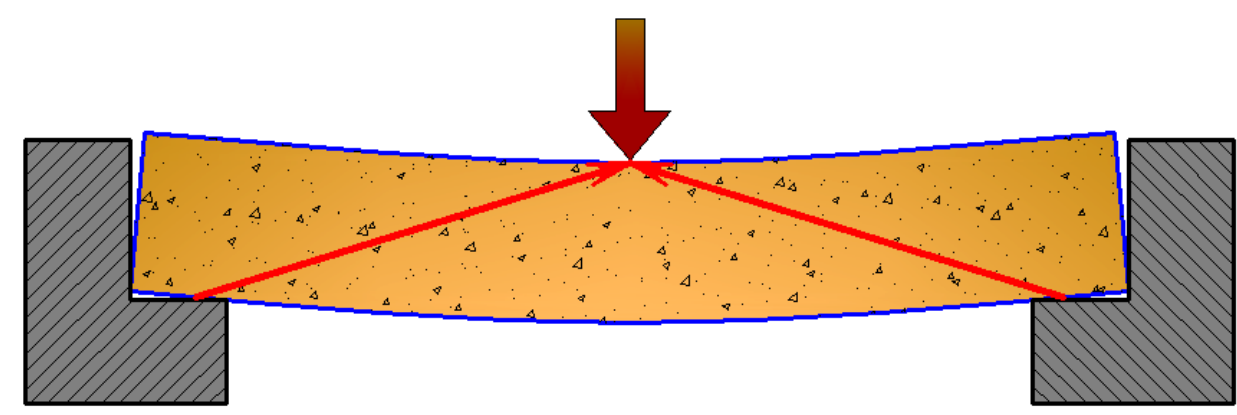

Figura 2.17 - Ação da membrana de compressão (Modificado de WANG, 2002)

O deslocamento vertical permitido da laje é aproximadamente $1 / 2$ da sua altura, de modo que para a ação da membrana de compressão ser um mecanismo viável a laje deve ser muito alta (WANG, 2002). Além do mais, se faz necessário que os apoios externos possuam elevada rigidez lateral para suportar a força de compressão da laje.

\subsubsection{Membrana de tração}

A ação da membrana de tração inicia quando o deslocamento vertical da laje ultrapassa a sua altura, instante em que a membrana de compressão transforma-se em membrana de tração, causando uma mudança na configuração de estabilidade (efeito conhecido como "snap-through"). Com grandes flechas, a parte central da laje fica tracionada formando um anel de compressão ao redor, conforme pode ser observado pela Figura 2.18.

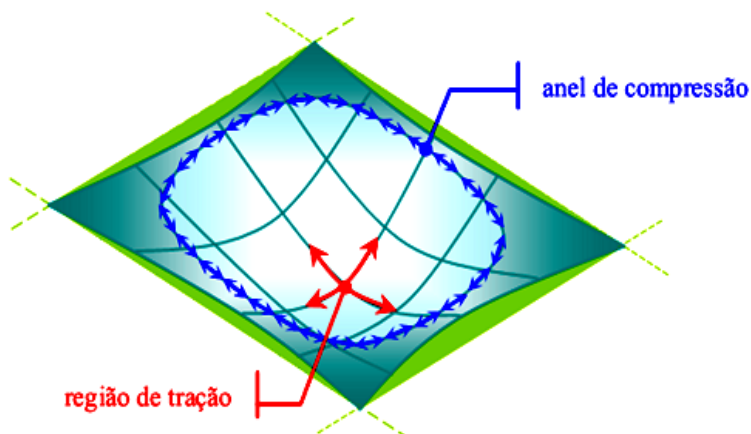

(a) Laje sem restrição axial

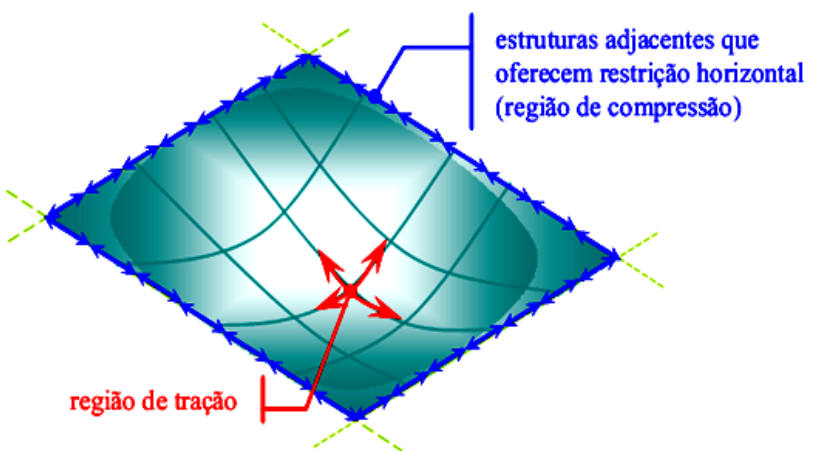

(b) Laje com restrição axial

Figura 2.18 - Ação da membrana de tração em lajes (COSTA, 2008) 
A tração no centro da laje é resistida pelas armaduras de distribuição, geralmente utilizada em lajes mistas para controlar a retração do concreto. A resistência da zona de tração depende das condições de restrição axial da laje. Para uma laje sem restrição axial (Figura 2.18.a) as forças de tração nas barras são resistidas pelo anel de compressão, enquanto que para a laje com restrição axial (Figura 2.18.b) essas forças são resistidas pelas estruturas vizinhas (laje contínua). A Figura 2.19 ilustra o comportamento Carga vs. Deslocamento para laje com e sem restrição axial, onde é possível observar que para deslocamentos superiores à aproximadamente a metade da altura da laje $(\mathrm{h} / 2)$, se tem o início do efeito de membrana.

Para que ocorra a zona de tração é necessário que haja grandes deformações da laje. Segundo WANG (2005), a resistência da zona de tração pode ser bem superior à resistência à flexão da laje. Este fato tem atraído a atenção de muitos pesquisadores, principalmente em se tratando de lajes mistas em situação de incêndio, onde não se tem a verificação do estado limite de serviço.

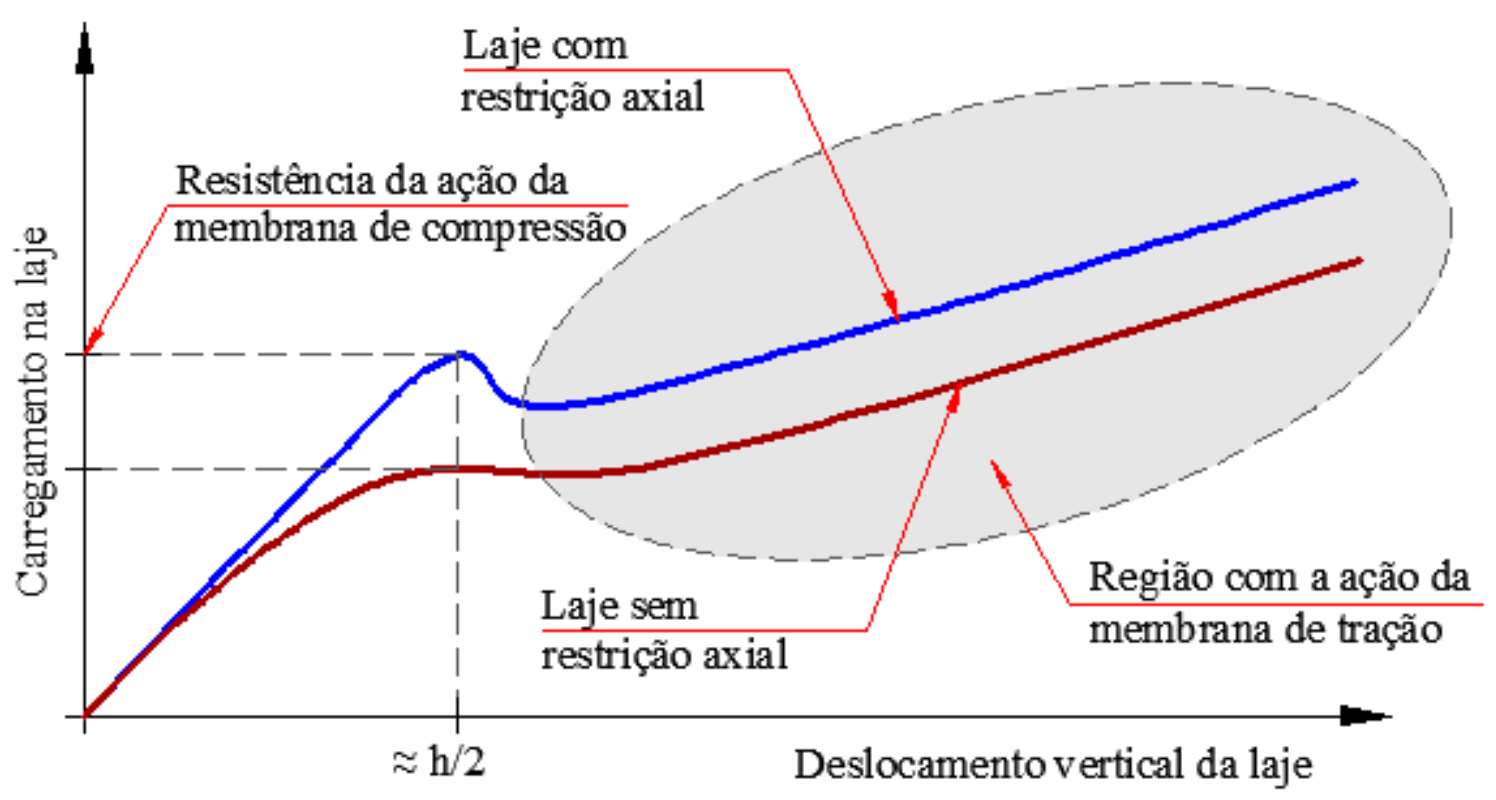

Figura 2.19 - Comportamento Carga vs. Deslocamento para laje com e sem restrição axial (Modificado de WANG, 2002)

\subsection{Considerações sobre o projeto à temperatura ambiente}

No âmbito nacional o dimensionamento de lajes mistas à temperatura ambiente deve estar de acordo a ABNT NBR 8800:2008, que teve como base o EUROCODE 4 Part 1-1 (EN 1994-1-1:2004) e envolve duas fases distintas: a verificação da fôrma de aço durante a construção e da laje mista após a cura do concreto. Para os dois casos é necessário verificar os estados limites de serviço (ELS) e os estados limites últimos (ELU). Por possuir nervuras em apenas uma direção, a rigidez à flexão na direção perpendicular às nervuras é bem menor que 
a rigidez na direção longitudinal. Deste modo, para o dimensionamento de lajes mistas, geralmente faz-se a simplificação que há flexão em apenas uma direção.

\subsubsection{Verificação da fôrma de aço}

Por se tratar de elemento de aço formado a frio, o dimensionamento da fôrma de aço deve ser feito de acordo a ABNT NBR 14762:2010. Os seguintes carregamentos são previstos pela ABNT NBR 8800:2008:

- Pesos próprios da fôrma de aço, do concreto fresco e da armadura;

- Sobrecarga de construção;

- Efeito de empoçamento 9 .

Para o estado limite de serviço, a deformação do aço deve estar dentro do limite permitido, considerando o efeito dos escoramentos (se houver). Para os ELU, de acordo a ABNT NBR 8800:2008 deve ser utilizada a análise elástica para verificação da fôrma de aço.

\subsubsection{Verificação da laje mista}

A verificação da laje mista deve estar de acordo com o Anexo Q da ABNT NBR 8800:2008. Os seguintes carregamentos devem ser considerados:

- Peso próprio da laje mista;

- Camada de acabamento;

- Cargas acidentais e permanentes.

Segundo CRISINEL e O'LEARY (1996), a análise do sistema de lajes mistas pode ser: elástica-linear, elástica-linear com redistribuição de momento, plástica (rótula plástica) e avançada (levando em consideração a não linearidade do material e o escorregamento na interface aço/concreto). Para o ELU, deve-se verificar a resistência de cálculo para as seguintes solicitações:

- Flexão: o momento resistente pode ser calculado de acordo a teoria plástica (formação de rótulas plásticas);

- Cisalhamento vertical: ocorre nas regiões próximas aos apoios;

- Cisalhamento longitudinal: baseado na interação total ou parcial entre a fôrma de aço e concreto;

- Punção: provocada por cargas concentradas na laje.

Segundo a ABNT NBR 8800:2008, para o ELS deve ser feita a verificação da fissuração do concreto (sobre os apoios) e deslocamento vertical. Também deve ser prevista a utilização de armadura para combater os efeitos de retração na parte superior da laje (armadura de distribuição). Outras verificações a serem realizadas são o escorregamento nas

\footnotetext{
${ }^{9} \mathrm{O}$ efeito de empoçamento refere-se às deformações da fôrma de aço durante a construção, que causa um aumento no consumo de concreto e, consequentemente, um aumento do peso próprio.
} 
extremidades das lajes externas e as vibrações (induzidas por equipamentos ou movimentos de pessoas). A ABNT NBR 8800:2008 não permite o escorregamento na interface aço/concreto (interação completa).

\subsection{Dimensionamento em situação de incêndio}

Diferente do dimensionamento à temperatura ambiente, o dimensionamento em situação de incêndio não envolve a verificação para o estado limite de serviço, e tal fato permite a estrutura apresentar grandes deformações. Para a estrutura, o importante é apresentar capacidade resistente suficiente para permitir desocupação da edificação e o trabalho do corpo de bombeiros, sem que seja atingido o colapso da mesma.

O procedimento de cálculo apresentado no que segue tem como base o Anexo $\mathrm{C}$ da ABNT NBR 14323:2013, a qual possui as mesmas formulações do EUROCODE 4 Part 1-2 (EN 1994-1-2:2005).

\subsubsection{Critérios a serem atendidos}

O critério de estanqueidade pode ser considerado satisfeito apenas pela presença da fôrma de aço. O critério de isolamento térmico é atendido se a espessura efetiva da laje, $h_{e f}$, calculada de acordo a Equação 2.18, for maior ou igual ao valor dado pela Tabela 2.2, em função do tempo requerido de resistência ao fogo (TRRF). O TRRF pode ser entendido como um tempo mínimo que um elemento estrutural deve resistir a uma ação térmica padronizada (curva de incêndio padrão) e não indica o verdadeiro tempo de colapso da estrutura, uma vez que na prática essa está sujeita a um incêndio natural.

Tabela 2.2 - Espessura efetiva mínima da laje em função do TRRF

\begin{tabular}{c|c}
\hline TRRF (min) & Espessura efetiva mínima, $\boldsymbol{h}_{\text {ef }}(\mathbf{m m})$ \\
\hline 30 & 60 \\
\hline 60 & 80 \\
\hline 90 & 100 \\
\hline$h_{e f}=h_{1}+\frac{h_{2}}{2} \frac{l_{1}+l_{2}}{l_{1}+l_{3}}$ & para $\frac{h_{2}}{h_{1}} \leq 1,5$ e $h_{1}>40 \mathrm{~mm}$ \\
$h_{e f}=h_{1}\left(1+0,75 \frac{l_{1}+l_{2}}{l_{1}+l_{3}}\right)$ & para $\frac{h_{2}}{h_{1}}>1,5$ e $h_{1}>40 \mathrm{~mm}$
\end{tabular}

Se $l_{3}>2 l_{1}$ a espessura efetiva pode ser tomada igual a $h_{1}$.

Onde as dimensões $h_{1}, h_{2}, l_{1}, l_{2}$ e $l_{3}$ são definidas na Figura 2.20. 


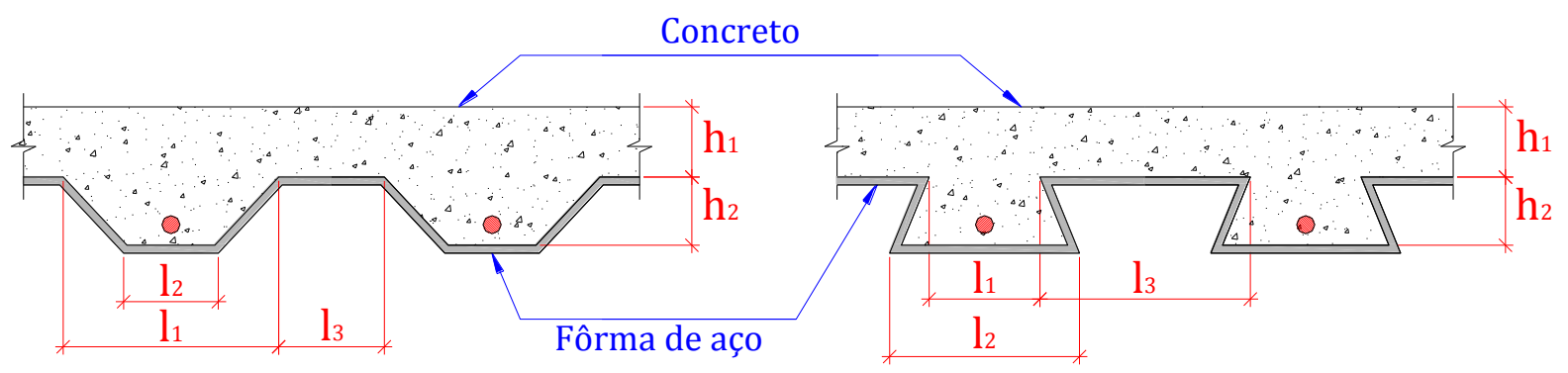

Figura 2.20 - Dimensões da seção transversal da laje

Para verificação da capacidade resistente é preciso atender aos critérios apresentados na Tabela 2.3, referentes aos modos de colapso da estrutura, que dependem da existência ou não de armaduras positiva ou negativa no interior do concreto acima da fôrma de aço.

Tabela 2.3 - Modos de colapso e condição a ser atendida pelas lajes

\begin{tabular}{|c|c|c|c|}
\hline \multicolumn{3}{|c|}{ Sistema estático e modo de colapso ${ }^{\text {a) }}$} & $\begin{array}{l}\text { Condição } \\
\text { necessária }\end{array}$ \\
\hline $\begin{array}{l}\text { Laje sem armadura } \\
\text { negativa (colapso por } \\
\text { rótula plástica sob } \\
\text { momento positivo na } \\
\text { seção central) }\end{array}$ & & $\begin{array}{l}(0) \\
M_{f i, R d}^{+}\end{array}$ & $M_{f i, R d}^{+} \geq q_{f i, d} \frac{L^{2}}{8}$ \\
\hline $\begin{array}{c}\text { Laje com armadura } \\
\text { negativa apenas em } \\
\text { um apoio e armadura } \\
\text { positiva }\end{array}$ & & $\begin{array}{c}(0) \\
M_{f i, R d}^{+}\end{array}$ & $\begin{array}{l}M_{f i, R d}^{+}+0,45 M_{f i, R d}^{-} \\
\geq q_{f i, d} \frac{L^{2}}{8}\end{array}$ \\
\hline $\begin{array}{l}\text { Laje com armaduras } \\
\text { negativas nos dois } \\
\text { apoios e armadura } \\
\text { positiva }\end{array}$ & $\begin{array}{l}(-2) \\
M_{f i, R d}^{-}\end{array}$ & $\begin{array}{l}(\infty) \\
M_{f i, R d}^{+}\end{array}$ & $\begin{array}{l}M_{f i, R d}^{+}+M_{f i, R d}^{-} \\
\geq q_{f i, d} \frac{L^{2}}{8}\end{array}$ \\
\hline $\begin{array}{l}\text { Lajes com armaduras } \\
\text { negativas nos dois } \\
\text { apoios e sem } \\
\text { armadura positiva }\end{array}$ & $\begin{array}{l}(2) \\
M_{f i, R d}^{-}\end{array}$ & $M_{f i, R d}^{+}=0$ & $M_{f i, R d}^{-} \geq q_{f i, d} \frac{L^{2}}{8}$ \\
\hline
\end{tabular}

Para as equações apresentadas na Tabela $2.3, q_{f i, d}$ é a carga uniformemente distribuída de cálculo, considerando a largura de influência usada no cálculo do momento resistente, $L$ é o vão da laje (distância entre duas vigas de apoio da laje) e $M_{f i, R d}^{+}$e $M_{f i, R d}^{-}$são respectivamente os momentos fletores positivos e negativos resistentes, calculados de acordo os itens subsequentes.

\subsubsection{Momento fletor positivo resistente de cálculo $-M_{f i, R d}^{+}$}

O momento fletor positivo resistente de cálculo corresponde ao momento de plastificação, obtido com base no diagrama de tensões na seção da laje. De acordo a ABNT 
NBR 14323:2013 a variação de temperatura na laje pode ser obtida por meio da Tabela 2.7 e Figura 2.24 apresentadas no item subsequente e a força de tração na armadura deve levar em conta a redução da resistência ao escoamento com a temperatura.

O primeiro passo para o cálculo do momento fletor resistente é localizar a posição da linha neutra plástica (LNP). Considerando uma fatia de laje, conforme apresentado na Figura 2.21, tem-se que a posição da LNP, se esta estiver localizada na laje de concreto, é dada por:

$$
y_{p}=\frac{F_{s s}+F_{s}+F_{s i}+f_{a y, t} A_{w}}{0,85 f_{c k, \theta}\left(l_{1}+l_{3}\right)}
$$

Para a Equação 2.19, valem:

$F_{S S}:$ Força de tração na mesa superior da fôrma de aço *

$F_{S}$ : Força de tração na barra longitudinal tracionada*

$F_{s i}$ : Força de tração na mesa inferior da fôrma de aço *

$f_{a y, t}$ : Resistência ao escoamento da alma da fôrma de aço *

$f_{c k, \theta}$ : Resistência à compressão do concreto em temperatura elevada

$A_{w}$ : Área da alma da fôrma de aço, tomada igual a $2 t \sqrt{h_{2}^{2}+\left(\frac{l_{1}-l_{2}}{2}\right)^{2}}$, sendo $t$ a espessura da fôrma de aço.

(*) Considerando a redução da resistência com o aumento de temperatura

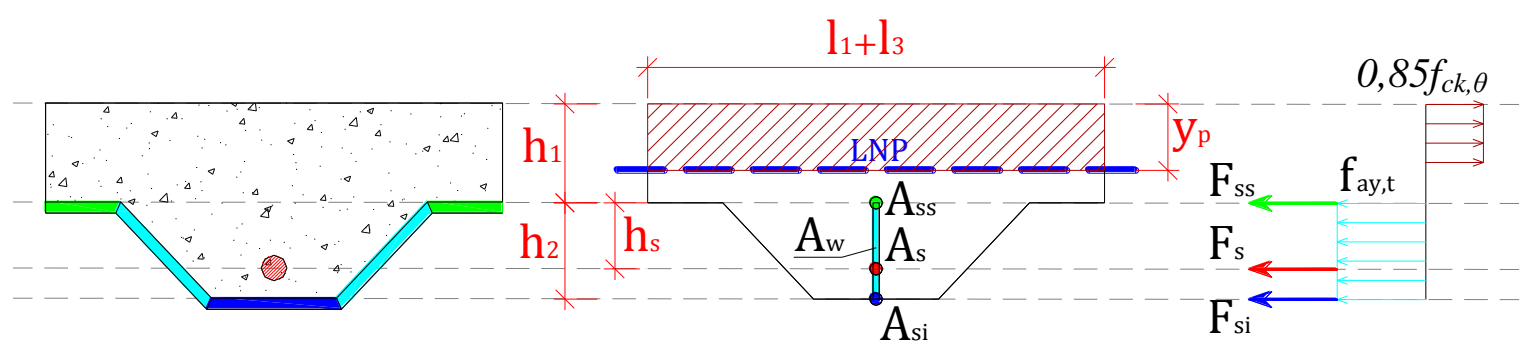

Figura 2.21 - Determinação da LNP

Para cálculo da força de tração nas barras é necessário o conhecimento de sua respectiva temperatura, que é dada pela Equação 2.20, em que z é um fator que indica a posição da armadura, dado pela Equação 2.21.

$$
\begin{gathered}
\theta_{s}=c_{0}+c_{1}\left(\frac{u_{f 3}}{h_{2}}\right)+c_{2} z+c_{3} \frac{A}{L_{r}}+c_{4} \alpha+c_{5} \frac{1}{l_{3}} \\
\frac{1}{z}=\frac{1}{\sqrt{u_{f 1}}}+\frac{1}{\sqrt{u_{f 2}}}+\frac{1}{\sqrt{u_{f 3}}}
\end{gathered}
$$

Para as Equações 2.20 e 2.21, valem:

- $u_{f 1}, u_{f 2}$ e $u_{f 3}$ as menores distâncias, em milímetros, do eixo da barra em relação á fôrma de aço, como especificado na Figura 2.22. 
- $A / L_{r}$ é a relação entre a área da seção transversal de concreto dentro da nervura e a superfície da nervura, dado pela Equação 2.22.

$$
\frac{A}{L_{r}}=\frac{h_{2}\left(\frac{l_{1}+l_{2}}{2}\right)}{l_{2}+2 \sqrt{h_{2}^{2}+\left(\frac{l_{1}+l_{2}}{2}\right)^{2}}}
$$

- $\alpha$ é o ângulo entre a alma da fôrma e o eixo horizontal, em graus, dado pela Equação 2.23.

$$
\alpha=\arctan \left(\frac{2 h_{2}}{l_{1}-l_{2}}\right)
$$

- $c_{0}, c_{1}, c_{2}, c_{3}, c_{4}$ e $c_{5}$ são coeficientes dados na Tabela 2.4 em função do TRRF e do tipo de concreto.

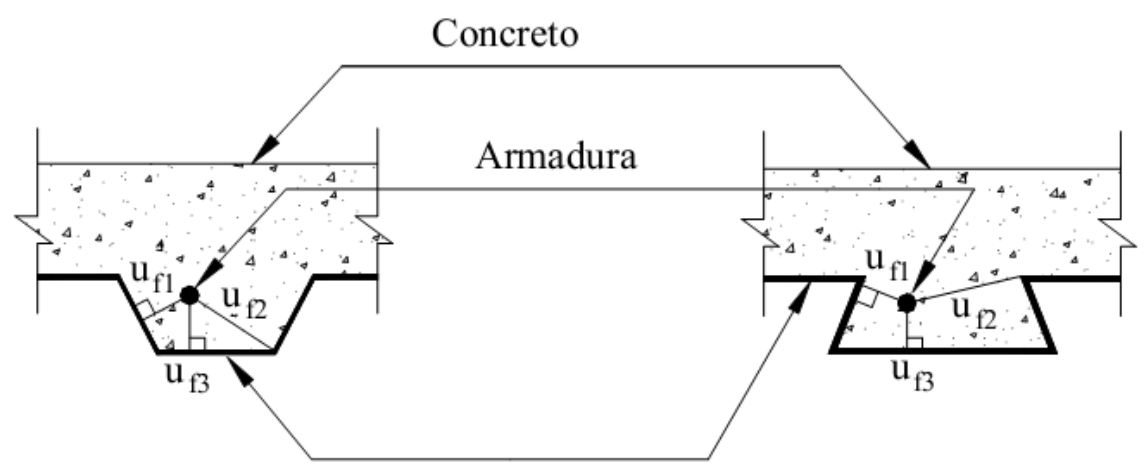

Fôrma de aço

Figura 2.22 - Posição geométrica da armadura

Tabela 2.4 - Coeficientes $c_{0}, c_{1}, c_{2}, c_{3}, c_{4}$ e $c_{5}$ para determinação da temperatura na armadura

\begin{tabular}{c|c|c|c|c|c|c|c}
\hline $\begin{array}{c}\text { Tipo de } \\
\text { concreto }\end{array}$ & $\begin{array}{c}\text { TRRF } \\
(\mathbf{m i n})\end{array}$ & $\boldsymbol{c}_{\mathbf{0}}\left({ }^{\circ} \mathrm{C}\right)$ & $\boldsymbol{c}_{\mathbf{1}}\left({ }^{\circ} \mathrm{C}\right)$ & $\begin{array}{c}\boldsymbol{c}_{\mathbf{2}} \\
\left({ }^{\circ} \mathbf{C} . \mathbf{m m}^{\mathbf{0} 5}\right)\end{array}$ & $\begin{array}{c}\boldsymbol{c}_{\mathbf{3}} \\
\left({ }^{\circ} \mathrm{C} . \mathbf{m m}\right)\end{array}$ & $\boldsymbol{c}_{\mathbf{4}}\left({ }^{\circ} \mathrm{C} /{ }^{\circ}\right)$ & $\begin{array}{c}\boldsymbol{c}_{\mathbf{5}} \\
\left({ }^{\circ} \mathrm{C} . \mathbf{m m}\right)\end{array}$ \\
\hline \multirow{2}{*}{$\begin{array}{c}\text { Densidade } \\
\text { normal }\end{array}$} & 60 & 1191 & -250 & -240 & $-5,01$ & 1,04 & -925 \\
\cline { 2 - 8 } & 90 & 1342 & -256 & -235 & $-5,30$ & 1,39 & -1267 \\
\cline { 2 - 8 } & 120 & 1387 & -238 & -227 & $-4,79$ & 1,68 & -1326 \\
\hline \multirow{3}{*}{$\begin{array}{c}\text { Baixa } \\
\text { densidade }\end{array}$} & 30 & 809 & -135 & -243 & $-0,70$ & 0,48 & -315 \\
\cline { 2 - 8 } & 90 & 1336 & -242 & -292 & $-6,11$ & 1,63 & -900 \\
\cline { 2 - 8 } & 120 & 1381 & -240 & -269 & $-5,46$ & 2,24 & -918 \\
\hline
\end{tabular}

Caso se opte por considerar a resistência da fôrma de aço no dimensionamento, há a necessidade do conhecimento da temperatura de cada componente da fôrma (mesa inferior, alma e mesa superior) que pode ser obtida pela Equação 2.24, em que $\phi$ é o fator de configuração (ou fator de vista) da mesa superior da fôrma, dado pela Equação 2.25. 


$$
\begin{aligned}
& \theta_{s}=b_{0}+b_{1} \frac{1}{l_{3}}+b_{2} \frac{A}{L_{r}}+b_{3} \phi+b_{4} \phi^{2} \\
& \phi=\frac{\sqrt{h_{2}^{2}+\left(l_{3}+\frac{l_{1}-l_{2}}{2}\right)^{2}}-\sqrt{h_{2}^{2}+\left(\frac{l_{1}-l_{2}}{2}\right)^{2}}}{l_{3}}
\end{aligned}
$$

$b_{0}, b_{1}, b_{2} b_{3}$ e $b_{4}$ são coeficientes dados na Tabela 2.5 para cada componente da fôrma em função do TRRF e do tipo de concreto.

\begin{tabular}{|c|c|c|c|c|c|c|c|}
\hline $\begin{array}{l}\text { Tipo de } \\
\text { concreto }\end{array}$ & $\begin{array}{c}\text { TRRF } \\
(\mathbf{m i n})\end{array}$ & $\begin{array}{c}\text { Partes da } \\
\text { fôrma de } \\
\text { aço }\end{array}$ & $b_{0}\left({ }^{\circ} \mathrm{C}\right)$ & $b_{1}\left({ }^{\circ} \mathrm{C} . \mathrm{mm}\right)$ & $b_{2}\left({ }^{\circ} \mathrm{C} . \mathrm{mm}\right)$ & $b_{3}\left({ }^{\circ} \mathrm{C}\right)$ & $b_{4}\left({ }^{\circ} \mathrm{C}\right)$ \\
\hline \multirow{9}{*}{$\begin{array}{c}\text { Densidade } \\
\text { normal }\end{array}$} & \multirow{3}{*}{60} & $\begin{array}{c}\text { Mesa } \\
\text { inferior }\end{array}$ & 951 & -1197 & $-2,32$ & 86,4 & $-150,7$ \\
\hline & & Alma & 661 & -833 & $-2,96$ & 537,7 & $-351,9$ \\
\hline & & $\begin{array}{c}\text { Mesa } \\
\text { superior }\end{array}$ & 340 & -3269 & $-2,62$ & 1148,4 & $-679,8$ \\
\hline & \multirow{3}{*}{90} & $\begin{array}{c}\text { Mesa } \\
\text { inferior }\end{array}$ & 1018 & -839 & $-1,55$ & 65,1 & $-108,1$ \\
\hline & & Alma & 816 & -959 & $-2,21$ & 464,9 & $-340,2$ \\
\hline & & $\begin{array}{c}\text { Mesa } \\
\text { superior }\end{array}$ & 618 & -2786 & $-1,79$ & 767,9 & $-472,0$ \\
\hline & \multirow{3}{*}{120} & $\begin{array}{l}\text { Mesa } \\
\text { inferior }\end{array}$ & 1063 & -679 & $-1,13$ & 46,7 & $-82,8$ \\
\hline & & Alma & 925 & -949 & $-1,82$ & 344,2 & $-267,4$ \\
\hline & & $\begin{array}{c}\text { Mesa } \\
\text { superior }\end{array}$ & 770 & -2460 & $-1,67$ & 592,6 & $-379,0$ \\
\hline \multirow{12}{*}{$\begin{array}{c}\text { Baixa } \\
\text { densidade }\end{array}$} & \multirow{3}{*}{30} & $\begin{array}{c}\text { Mesa } \\
\text { inferior }\end{array}$ & 800 & -1326 & $-2,65$ & 114,5 & $-181,2$ \\
\hline & & Alma & 483 & -286 & $-2,26$ & 439,6 & $-244,0$ \\
\hline & & $\begin{array}{c}\text { Mesa } \\
\text { superior }\end{array}$ & 331 & -2284 & $-1,54$ & 488,8 & $-131,7$ \\
\hline & \multirow{3}{*}{60} & $\begin{array}{l}\text { Mesa } \\
\text { inferior }\end{array}$ & 955 & -622 & $-1,32$ & 47,7 & $-81,1$ \\
\hline & & Alma & 761 & -558 & $-1,67$ & 426,5 & $-303,0$ \\
\hline & & $\begin{array}{c}\text { Mesa } \\
\text { superior }\end{array}$ & 607 & -2261 & $-1,02$ & 664,5 & $-410,0$ \\
\hline & \multirow{3}{*}{90} & $\begin{array}{l}\text { Mesa } \\
\text { inferior }\end{array}$ & 1019 & -478 & $-0,91$ & 32,7 & $-60,8$ \\
\hline & & Alma & 906 & -654 & $-1,36$ & 287,8 & $-230,3$ \\
\hline & & $\begin{array}{c}\text { Mesa } \\
\text { superior }\end{array}$ & 789 & -1847 & $-0,99$ & 469,5 & $-313,0$ \\
\hline & \multirow{3}{*}{120} & $\begin{array}{c}\text { Mesa } \\
\text { inferior }\end{array}$ & 1062 & -399 & $-0,65$ & 19,8 & $-43,7$ \\
\hline & & Alma & 989 & -629 & $-1,07$ & 186,1 & $-152,6$ \\
\hline & & $\begin{array}{c}\text { Mesa } \\
\text { superior }\end{array}$ & 903 & -1561 & $-0,92$ & 305,2 & $-197,2$ \\
\hline
\end{tabular}

Tabela 2.5 - Coeficientes $b_{0}, b_{1}, b_{2} b_{3}$ e $b_{4}$ para determinação da temperatura nas partes da fôrma de 
O momento fletor positivo resistente de cálculo é dado pelo somatório do produto de cada força resistente (Figura 2.21) pela sua distância em relação à LNP, dado pela Equação 2.26 (para a LNP localizada na laje de concreto, conforme Figura 2.21):

$$
\begin{gathered}
M_{f i, R d}^{+}=0,85 f_{c k}\left(l_{1}+l_{3}\right) \frac{y_{p}^{2}}{2}+F_{s s}\left(h_{1}-y_{p}\right)+F_{s}\left(h_{1}-y_{p}+h_{s}\right) \\
+F_{s i}\left(h_{1}-y_{p}+h_{2}\right)+f_{a, y t} A_{w}\left(h_{1}-y_{p}+\frac{h_{2}}{2}\right)
\end{gathered}
$$

De acordo a ABNT NBR 14323:2013 o tempo requerido de resistência ao fogo (TRRF) das lajes mistas de aço e concreto pode ser considerado no mínimo igual a 30 minutos, desde que seja atendido o critério de isolamento térmico, dado em 2.8.1.

\subsubsection{Momento fletor negativo resistente de cálculo $-M_{f i, R d}^{-}$}

O momento fletor negativo resistente de cálculo também corresponde ao momento de plastificação, obtido pelo diagrama de tensões na seção da laje, pelo método da seção transversal reduzida.

Nesse método despreza-se a parte da seção com temperatura superior à temperatura limite, dada pela Equação 2.27. A resistência da parte restante pode ser tomada igual à temperatura ambiente.

$$
\theta_{\text {lim }}=d_{0}+d_{1} N_{s}+d_{2} \frac{A}{L_{r}}+d_{3} \phi+d_{4} \frac{1}{l_{3}}
$$

- $N_{S}$ é a força axial resistente da armadura negativa tomada à temperatura ambiente;

- $d_{0}, d_{1}, d d_{3}$ e $d_{4}$ são coeficientes dados na Tabela 2.6 em função do TRRF e do tipo de concreto.

Tabela 2.6 - Coeficientes $d_{0}, d_{1}, d d_{3}$ e $d_{4}$ para determinação da temperatura-limite

\begin{tabular}{c|c|c|c|c|c|c}
\hline $\begin{array}{c}\text { Tipo de } \\
\text { concreto }\end{array}$ & $\begin{array}{c}\text { TRRF } \\
(\mathbf{m i n})\end{array}$ & $\boldsymbol{d}_{\mathbf{0}}\left({ }^{\circ} \mathrm{C}\right)$ & $\boldsymbol{d}_{\mathbf{1}}\left({ }^{\circ} \mathrm{C} . \boldsymbol{N}\right)$ & $\boldsymbol{d}_{\mathbf{2}}\left({ }^{\circ} \mathrm{C} . \mathbf{m m}\right)$ & $\boldsymbol{d}_{\mathbf{3}}\left({ }^{\circ} \mathrm{C}\right)$ & $\boldsymbol{d}_{\mathbf{4}}\left({ }^{\circ} \mathrm{C} . \mathbf{m m}\right)$ \\
\hline \multirow{2}{*}{$\begin{array}{c}\text { Densidade } \\
\text { normal }\end{array}$} & 60 & 867 & $-0,00019$ & $-8,75$ & -123 & -1378 \\
\cline { 2 - 7 } & 90 & 1055 & $-0,00022$ & $-9,91$ & -154 & -1990 \\
\cline { 2 - 7 } & 120 & 1144 & $-0,00022$ & $-9,71$ & -166 & -2155 \\
\hline \multirow{3}{*}{$\begin{array}{c}\text { Baixa } \\
\text { densidade }\end{array}$} & 30 & 524 & $-0,00016$ & $-3,43$ & -80 & -392 \\
\cline { 2 - 7 } & 90 & 1030 & $-0,00026$ & $-10,95$ & -181 & -1834 \\
\cline { 2 - 7 } & 120 & 1159 & $-0,00025$ & $-10,88$ & -208 & -2233 \\
\hline
\end{tabular}


A isoterma para a temperatura-limite pode ser determinada com base em quatro pontos característicos, conforme mostrado na Figura 2.23, cujas coordenadas são dadas pelas expressões:

$$
\begin{aligned}
& x_{1}=0 \\
& y_{1}=\frac{1}{\left(\frac{1}{z}-\frac{4}{\sqrt{l_{1}+l_{3}}}\right)^{2}} \\
& x_{2}=\frac{l_{2}}{2}+y_{1} \frac{\cos \alpha-1}{\operatorname{sen} \alpha} \\
& y_{2}=y_{1} \\
& x_{3}=\frac{l_{1}}{2}-\frac{b}{\operatorname{sen} \alpha} \\
& y_{3}=h_{2} \\
& x_{4}=\frac{l_{1}+l_{3}}{2} \\
& y_{4}=h_{2}+b
\end{aligned}
$$

Para o conjunto de equações 2.28 , valem:

$b=\frac{l_{1}}{2} \operatorname{sen} \alpha\left(1-\frac{\sqrt{a^{2}-4 a+c}}{a}\right)$

$a=l_{1} \operatorname{sen} \alpha\left(\frac{1}{z}-\frac{1}{\sqrt{h_{2}}}\right)^{2}$

$c= \begin{cases}-8(1+\sqrt{1+a}), & \text { para } a \geq 8 \\ 8(1+\sqrt{1+a}), & \text { para } a<8\end{cases}$

O parâmetro $z$ é calculado de acordo a Equação 2.20 fazendo-se $\theta_{s}=\theta_{\text {lim }} \mathrm{e}^{u_{f 3}} / h_{h_{2}}=0,75$.

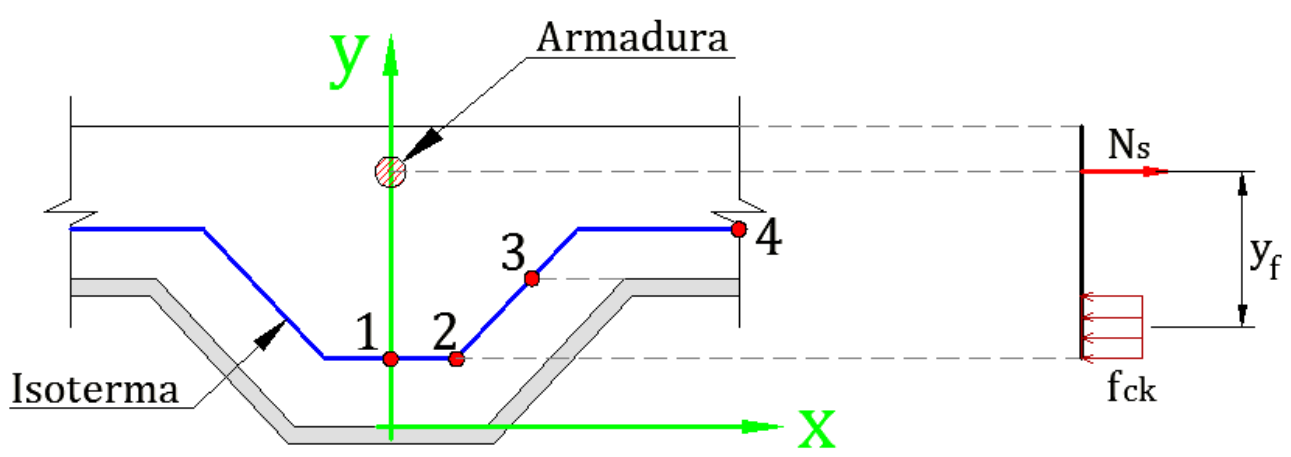

Figura 2.23 - Esquema para a isoterma da temperatura limite 
Determinando a isoterma da temperatura limite, calcula-se a posição da LNP e determina-se o momento fletor negativo resistente de cálculo.

Caso $y_{1}>h_{2}$ despreza-se o concreto dentro das nervuras. A laje deve então ser calculada com espessura uniforme, igual à espessura do concreto acima da fôrma de aço. Neste caso a variação de temperatura no concreto pode ser obtida em função do tempo requerido de resistência ao fogo (TRRF), dividindo a altura da laje no máximo em 14 fatias, de acordo a Tabela 2.7 e a Figura 2.24, para concreto de densidade normal.

Tabela 2.7 - Variação de temperatura na altura da laje para concreto de densidade normal

\begin{tabular}{|c|c|c|c|c|c|}
\hline \multirow{2}{*}{ Fatia $\mathbf{j}$} & \multirow{2}{*}{$\begin{array}{c}\text { Altura y } \\
(\mathrm{mm})\end{array}$} & \multicolumn{4}{|c|}{ Temperatura $\theta_{\mathrm{c}}\left({ }^{\circ} \mathrm{C}\right)$ para o TRRF (min) } \\
\hline & & 30 & 60 & 90 & 120 \\
\hline 1 & 0 a 5 & 535 & 705 & - & - \\
\hline 2 & 5 a 10 & 470 & 642 & 738 & - \\
\hline 3 & 10 a 15 & 415 & 581 & 681 & 754 \\
\hline 4 & 15 a 20 & 350 & 525 & 627 & 697 \\
\hline 5 & 20 a 25 & 300 & 469 & 571 & 642 \\
\hline 6 & 25 a 30 & 250 & 421 & 519 & 591 \\
\hline 7 & 30 a 35 & 210 & 374 & 473 & 542 \\
\hline 8 & 35 a 40 & 180 & 327 & 428 & 493 \\
\hline 9 & 40 a 45 & 160 & 289 & 387 & 454 \\
\hline 10 & 45 a 50 & 140 & 250 & 345 & 415 \\
\hline 11 & 50 a 55 & 125 & 200 & 294 & 369 \\
\hline 12 & 55 a 60 & 110 & 175 & 271 & 342 \\
\hline 13 & 60 a 80 & 80 & 140 & 220 & 270 \\
\hline 14 & $\geq 80$ & 60 & 100 & 160 & 210 \\
\hline
\end{tabular}

Para concretos de baixa densidade os valores da Tabela 2.7 podem ser reduzidos em $10 \%$.

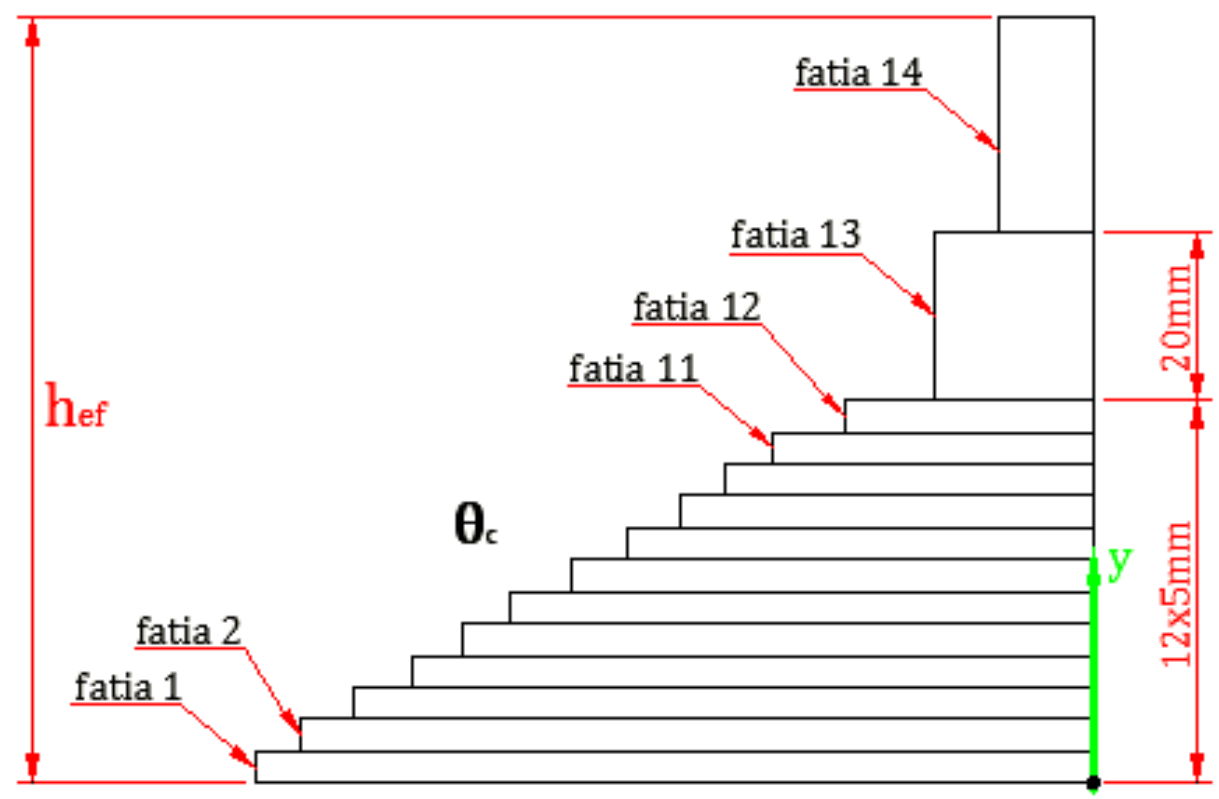

Figura 2.24 - Esquema da variação de temperatura na laje 
A resistência à compressão de cada fatia de concreto é dada pelos fatores de redução apresentados no Anexo B, de acordo sua respectiva temperatura conforme a Tabela 2.7. Com os valores dessas resistências determina-se a posição da LNP e calcula-se o momento fletor negativo resistente de cálculo.

\subsection{Pesquisas sobre o tema}

O principal objetivo deste item é coletar informações sobre ensaios em lajes mistas, tanto à temperatura ambiente quanto em temperaturas elevadas, visando principalmente calibrar adequadamente os modelos numéricos que serão aqui propostos e estabelecer aspectos conclusivos para que sejam usados e comparados com os resultados numéricos a sem obtidos.

\subsubsection{Comentários sobre ensaios em lajes mistas}

Os ensaios de estruturas em situação de incêndio podem ser conduzidos de duas maneiras: em regime transiente ou em regime estacionário. Nos ensaios em regime transiente, primeiro se aplica o carregamento na estrutura até um determinado valor, permanecendo constante durante o ensaio. Em seguida, a estrutura é submetida a um aumento de temperatura, até que algum critério de ruptura seja alcançado. Nos ensaios em regime estacionário é feito o contrário, primeiro se eleva a temperatura da estrutura até um valor estacionário e, em seguida, se aplica incrementos de carregamentos até a estrutura atingir o colapso. Se o comportamento estrutural é independente da taxa de aquecimento ou do histórico de carregamento, ambos os métodos dão o mesmo resultado (WANG, 2002). O ensaio em regime transiente é mais utilizado, pois melhor representa a situação real de uma estrutura.

Os ensaios em elementos estruturais isolados são realizados em fornos. Para o aumento da temperatura dos gases dentro do forno se utiliza, geralmente, a curva Temperatura vs. Tempo referente ao incêndio-padrão. Dimensões típicas para esses fornos são de $4 \mathrm{~m}$ na horizontal e $3 \mathrm{~m}$ na vertical. Na Figura 2.25 é apresentado o forno adquirido pelo Departamento de Engenharia de Estrutura da EESC/USP com dimensões internas de 4,0m x $3,0 \mathrm{~m} \times 1,5 \mathrm{~m}$ de altura, totalmente automatizado e movido a gás natural, que possibilita a realização de ensaios em elementos estruturais como lajes e vigas, com dimensões reais. Este forno faz parte do Projeto Temático intitulado "Segurança das Estruturas em Situação de Incêndio", financiado pela Fapesp. 


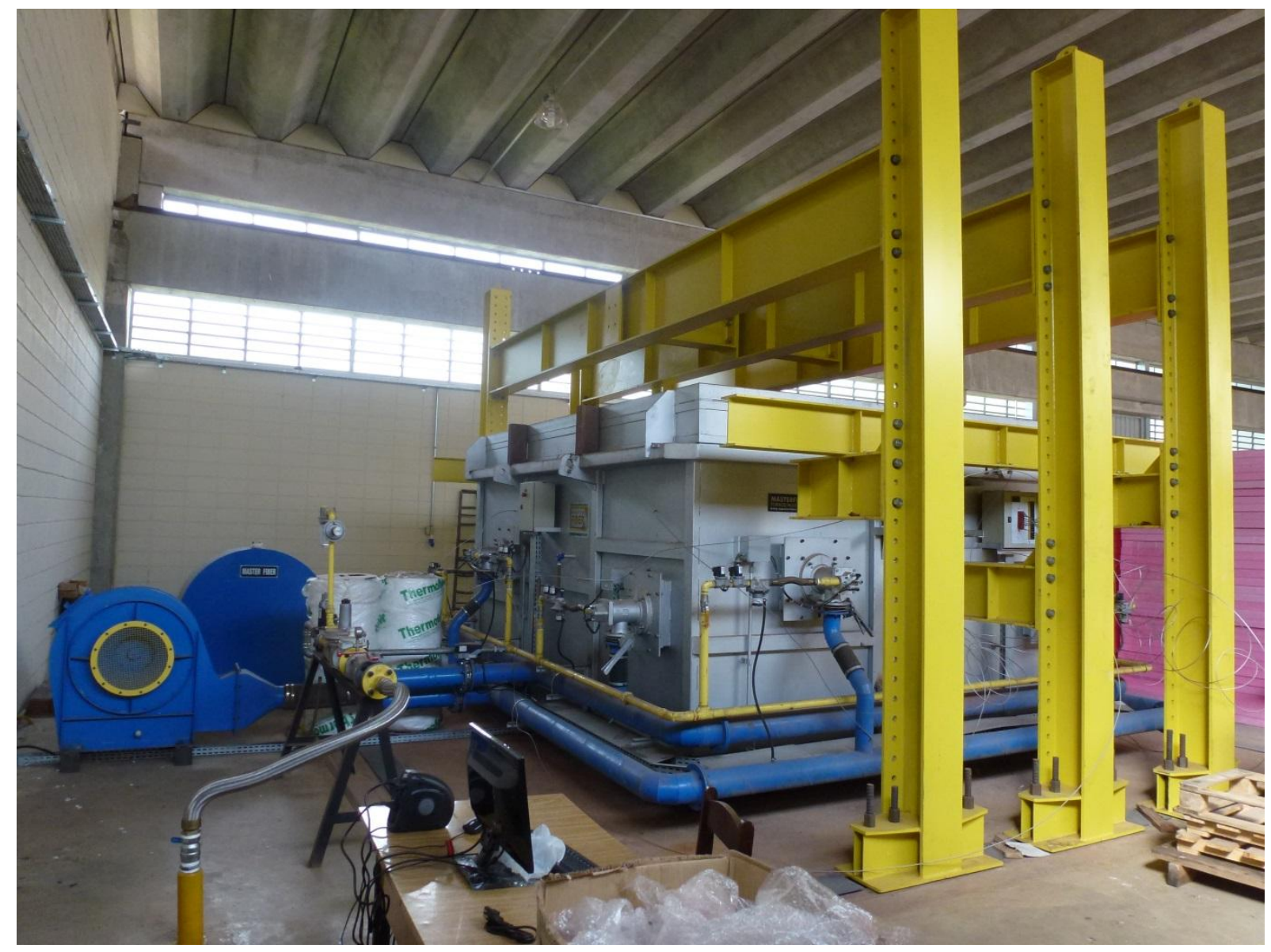

Figura 2.25 - Forno adquirido pelo Departamento de Engenharia de Estruturas da EESC/USP

Este forno permite o ensaio de resistência ao fogo dos seguintes elementos, tendo como base a curva de incêndio padrão:

- Vigas e pilares de madeira;

- Vigas e pilares de aço;

- Vigas e pilares de concreto;

- Vigas mistas de madeira e concreto;

- Vigas mistas de aço e concreto;

- Lajes de concreto, lajes mistas de madeira-concreto e lajes mistas aço-concreto.

WANG (2002) faz uma crítica aos ensaios realizados com base no incêndio-padrão de estruturas em situação de incêndio. Segundo esse autor esses ensaios não são muito adequados para o entendimento do real comportamento estrutural, devido a algumas deficiências, como seguem:

- A exposição ao incêndio-padrão é somente um dos numerosos tipos de condições reais de incêndio; 
- Os ensaios são realizados em elementos individuais, não permitindo uma avaliação da interação estrutural;

- Ensaios são realizados para objetivos específicos e a instrumentação usualmente não é adequada para uma análise retroativa minuciosa;

- Simulação de um número limitado de condições de contorno;

- Os critérios de ruptura geralmente não descrevem adequadamente o uso real pretendido.

Apesar dessas deficiências, resultados de ensaios padrão de resistência ao fogo têm dado grande contribuição para o entendimento do comportamento estrutural de elementos de aço e mistos de aço e concreto em situação de incêndio (WANG, 2002).

\subsubsection{Ensaios em escala real}

Alguns ensaios já foram realizados em escala real, conforme citado por WALD et al. (2006). Desses ensaios, o que mais contribuiu para o progresso do estudo em lajes mistas foi o realizado num edifício de 8 pavimentos, com dimensões de $21 \mathrm{mx} 45 \mathrm{~m}$, no laboratório do British Research Establishment (BRE) em Cardington, Reino Unido (Figura 2.26) na década de 1990. As lajes eram mistas com altura de concreto de $130 \mathrm{~mm}$ e possuíam somente armaduras de distribuição (malha $\mathrm{A} 142^{10}$ ).
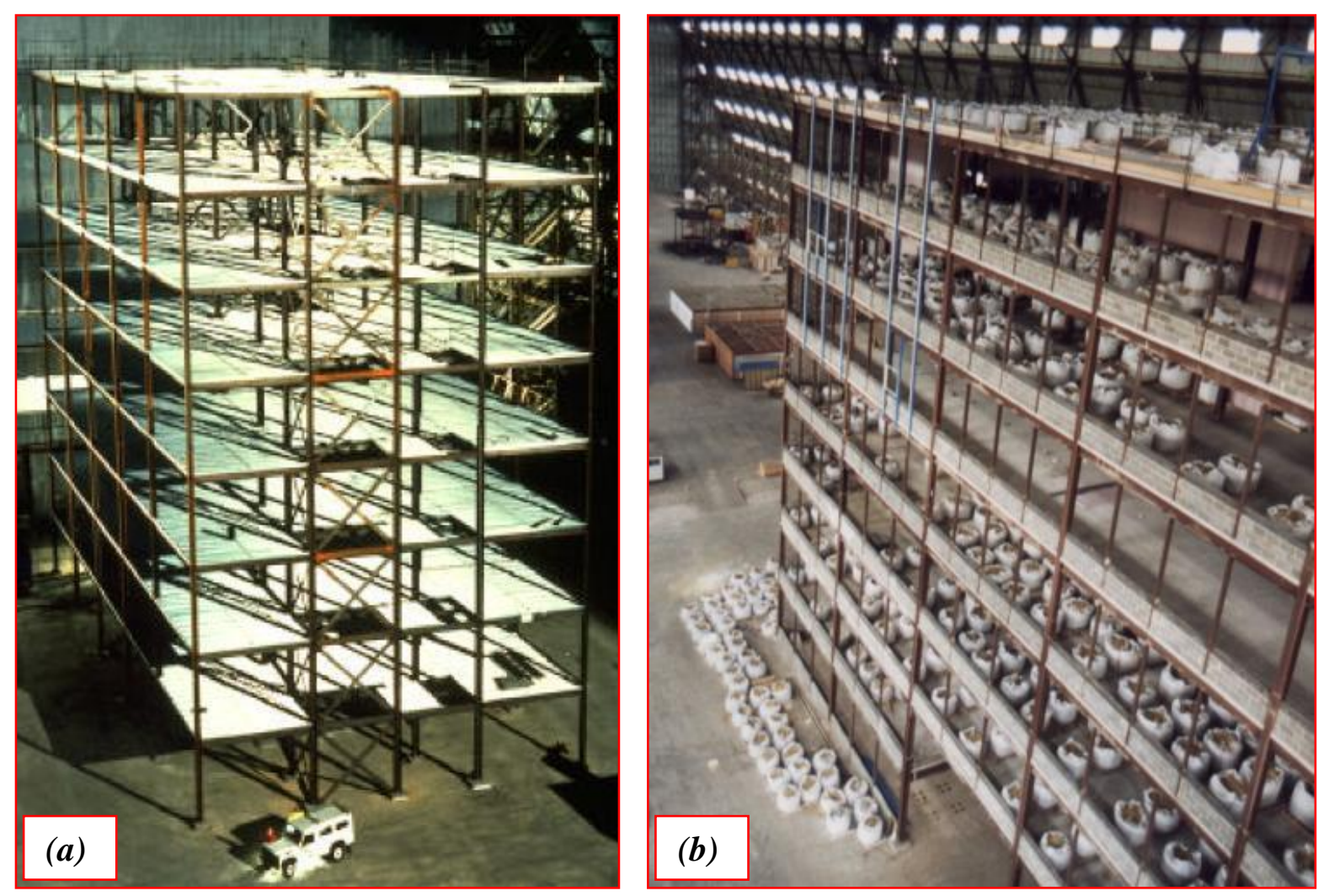

Figura 2.26 - Edifício do BRE em Cartington, Reino Unido: (a) Estrutura do edifício e (b) Cargas estáticas. Fonte: http://911research.wtc7.net/mirrors/guardian2/fire/cardington.htm

\footnotetext{
${ }^{10}$ Malha com espaçamento de $200 \mathrm{~mm}$ e diâmetro da armadura de $6 \mathrm{~mm}$ nas duas direções 56
} 
Nesse edifício foram realizados diversos ensaios em compartimentos isolados. Em um desses ensaios, realizado num compartimento com área de $136 \mathrm{~m}^{2}$ e com carga de incêndio de $45 \mathrm{~kg} / \mathrm{m}^{2}$ de madeira, observou-se que a temperatura do incêndio atingiu $900^{\circ} \mathrm{C}$ após $10 \mathrm{~min}$ de ignição. Após $62 \mathrm{~min}$ de ensaio o deslocamento máximo da viga foi de $640 \mathrm{~mm}$ e a estrutura ainda continuava resistindo aos carregamentos (ação da membrana de tração) e sem a perda da estanqueidade. A Figura 2.27a apresenta a vista externa do incêndio e a Figura 2.27b a situação pós-incêndio.
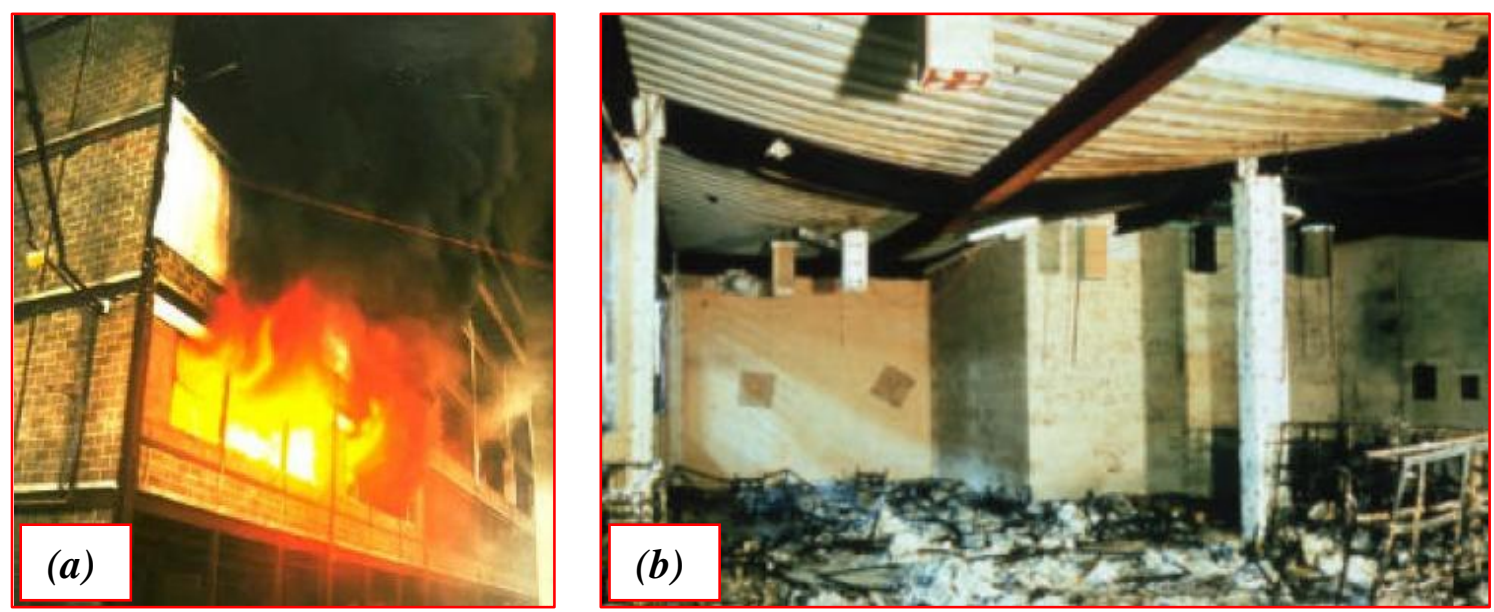

Figura 2.27 - Vista do incêndio realizado em um compartimento do edifício: (a) Vista externa do incêndio e (b) Vista do compartimento após o incêndio. Fonte: http://911research.wtc7.net/mirrors/guardian2/fire/SCI.htm

Mais detalhes sobre o programa experimental realizado no BRE em Cardington pode ser encontrado em WALD et al. (2006), onde foi avaliada a distribuição de temperatura em vários elementos estruturais, distribuição de força interna e comportamento da laje mista.

\subsubsection{Outras pesquisas}

Neste item são apresentadas algumas pesquisas realizadas no contexto numérico e experimental sobre as lajes mistas, tanto em temperatura ambiente quanto em situação de incêndio, no intuito de fornecer subsídios para as análises térmicas e termoestrutural, a serem realizadas nos capítulos 4 e 5 respectivamente.

\subsubsection{ABDEL-HALIM et al (1999)}

Nessa referência, por meio de trabalho intitulado "Fire resistance of composite floor slabs using a model fire test facility", o objetivo da pesquisa foi determinar a resistência ao fogo com relação à estanqueidade e isolamento térmico de lajes mistas.

Os ensaios foram realizados em dois modelos (Painel 1 e 2) com dimensões iguais a $1200 \mathrm{~mm}$ x $900 \mathrm{~mm}$ x $110 \mathrm{~mm}$, bem como com resistência à compressão do concreto aos 28 
dias igual a 33,7MPa. Ambos os modelos apresentavam armaduras de distribuição com cobrimento de $25 \mathrm{~mm}$, sendo que no painel 2 foram adicionadas armaduras positivas, conforme apresentado nas Figuras 2.28 e 2.29.

A curva de aquecimento do forno seguiu a curva temperatura vs. Tempo referente ao incêndio padrão. É importante ressaltar que os modelos ensaiados foram submetidos somente a carregamento térmico. Para não ter influência do peso próprio, as lajes foram ensaiadas na posição vertical.

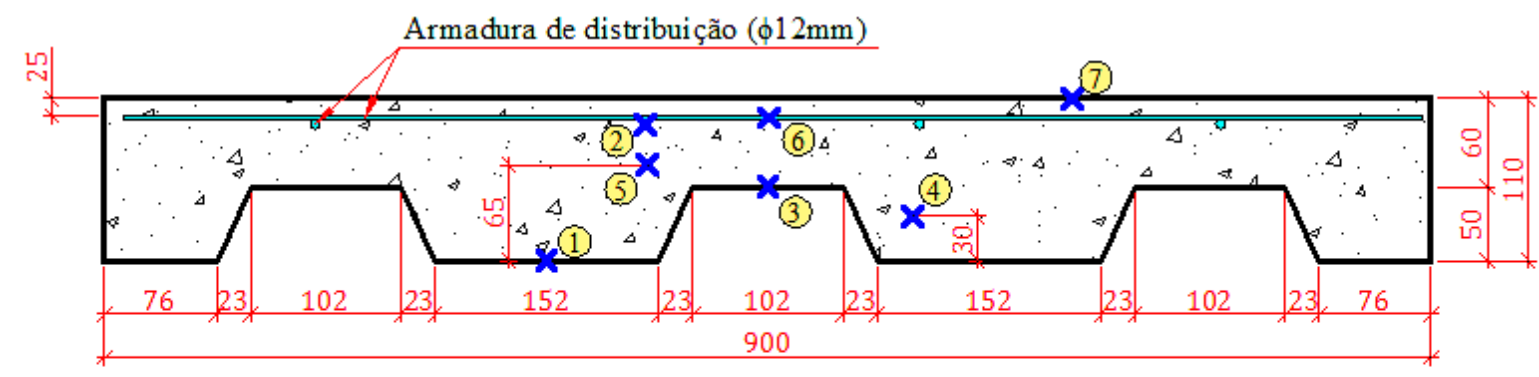

$\mathbf{X}$ (1) (2) (3) (4) (5) (6) Termopares

$\underline{\text { Painel } 1}$

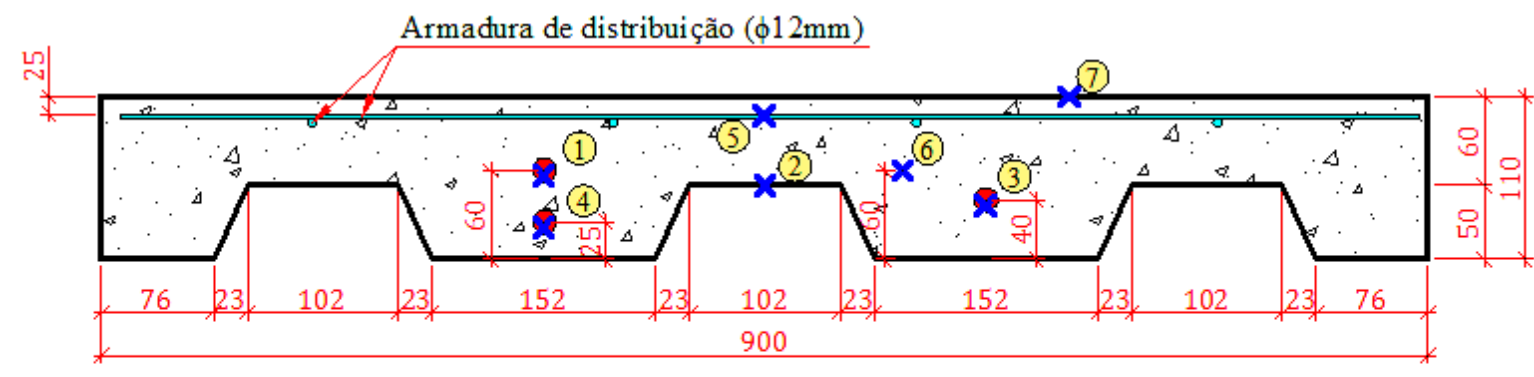

(1) (2) (3) (4) (5) (6) (7) Termopares

Espessura da fôrma de aço $=1,0 \mathrm{~mm}$

Armadura de reforço

Painel 2

Figura 2.28 - Seção transversal dos painéis estudados e localização dos termopares (Dimensões em mm, Adaptado)

Por meio de consulta ao trabalho apresentado em ABDEL-HALIM, HAKMI \& O'LEARY (1997), merecem destaque algumas observações importantes decorrentes da realização dos ensaios:

- Aos 13 min de ensaio (temperatura do forno $\cong 710{ }^{\circ} \mathrm{C}$ ): começa a sair vapor d'água na parte superior dos cantos da laje e este se espalha para diferentes lugares;

- Aos $20 \mathrm{~min}$ de ensaio (temperatura do forno $\cong 770{ }^{\circ} \mathrm{C}$ ): surge a primeira fissura e a água começa a sair por essa fissura;

- Aos 75 min de ensaio (temperatura do forno $\cong 968^{\circ} \mathrm{C}$ ): é cessado o surgimento de fissuras e a saída de água;

- Após o resfriamento, foi verificado o destacamento da fôrma de aço em relação ao concreto. 


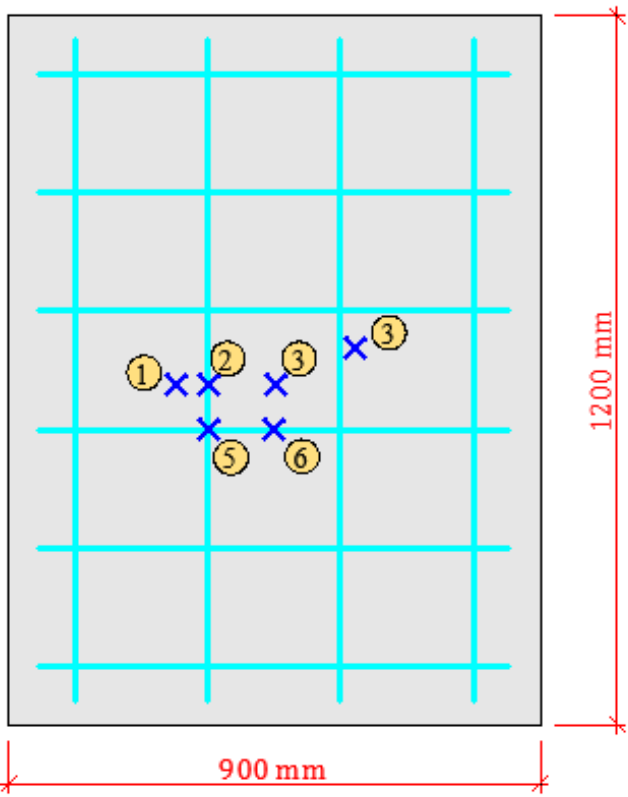

$\underline{\text { Painel } 1}$

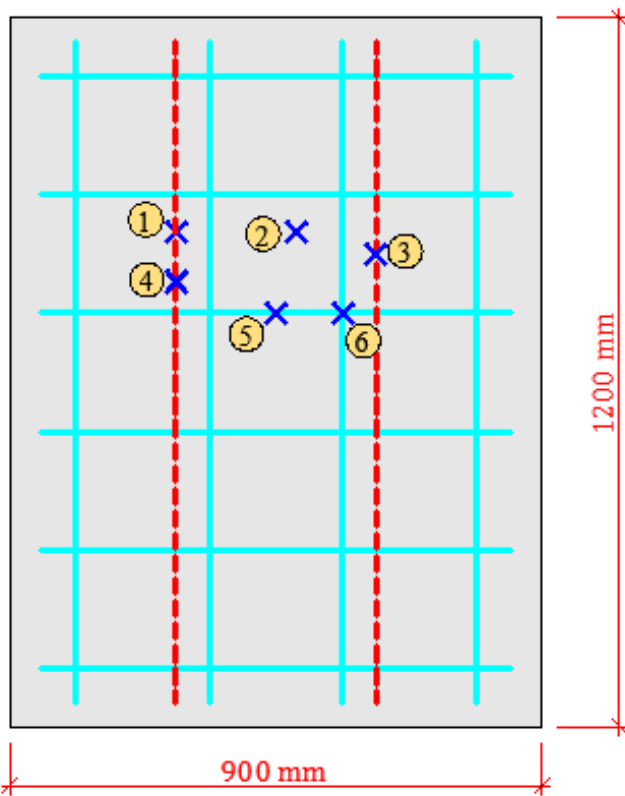

$\underline{\text { Painel } 2}$

Armadura de distribuição ( $\phi 12 \mathrm{~mm})$

Armadura de reforço $(\phi 16 \mathrm{~mm})$

X (1) (2) (3) (4) (5) (6) Localização dos termopares

Figura 2.29 - Planta baixa indicando a posição das armaduras e termopares para os painéis 1 e 2 (Adaptado)

Os resultados dos ensaios são apresentados na Figura 2.30 e Figura 2.31 para os painéis 1 e 2 respectivamente.

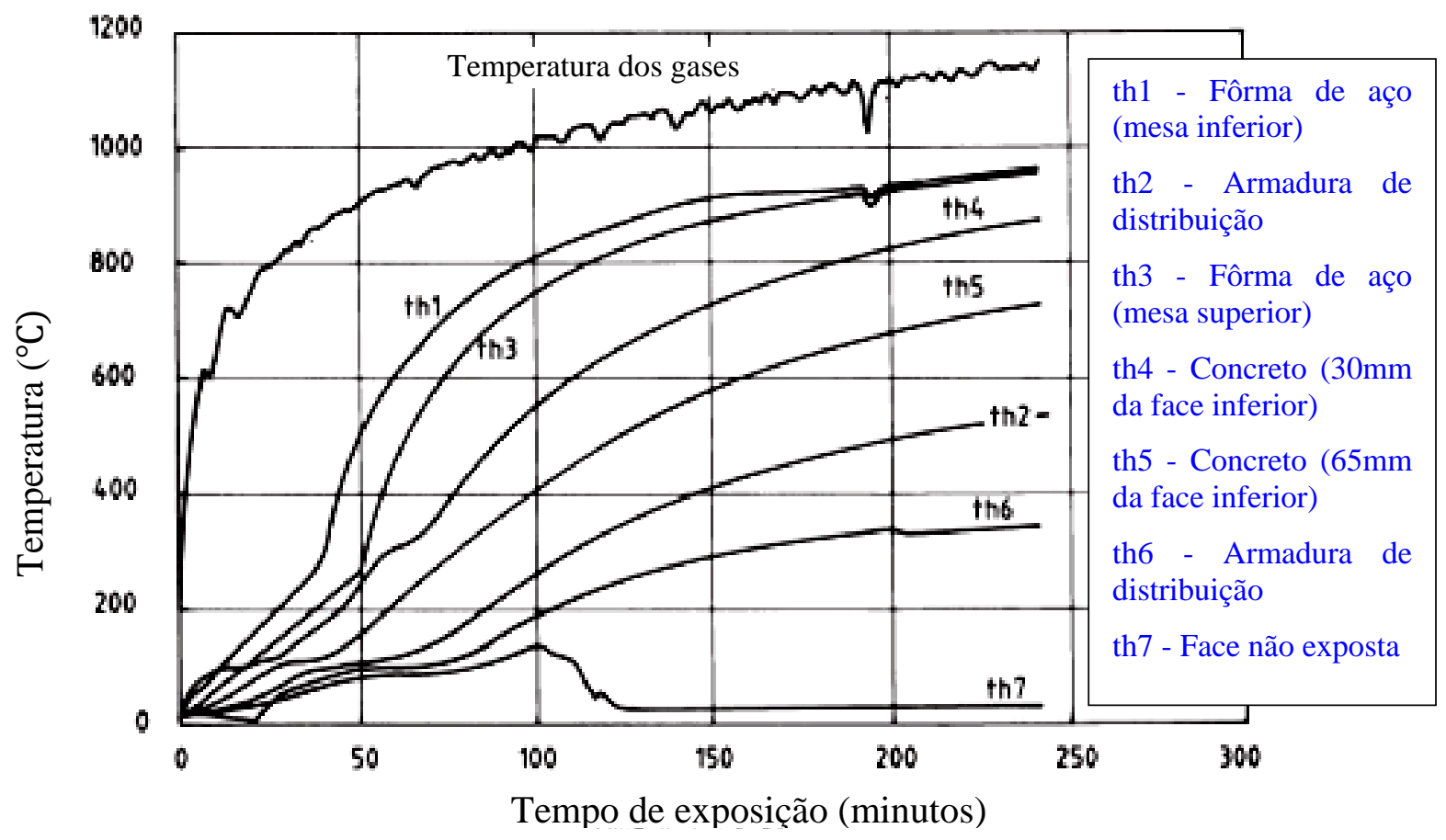

Figura 2.30 - Resultado do ensaio para o painel 1 


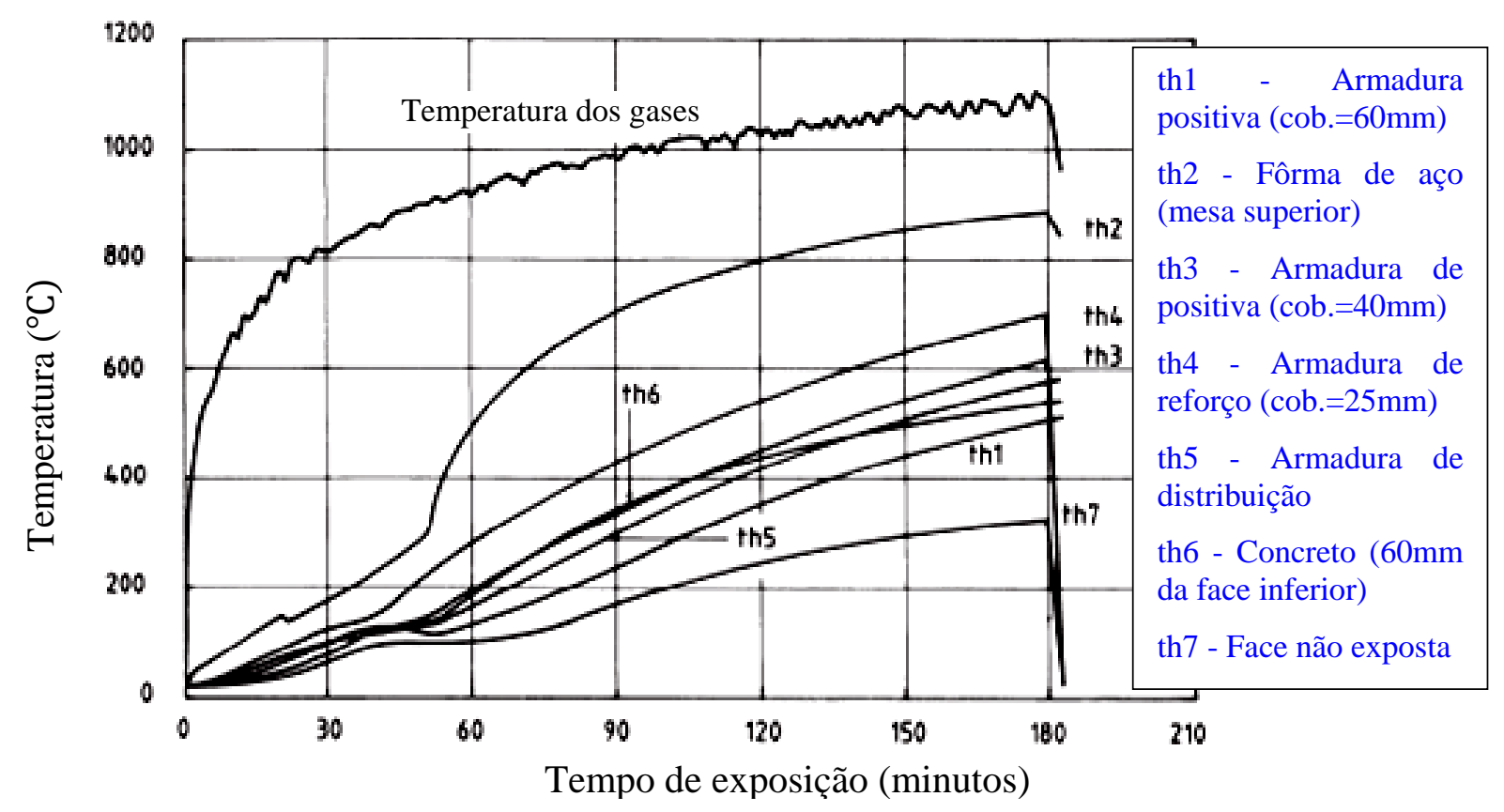

Figura 2.31 - Resultado do ensaio para o painel 2

A perda de isolamento ocorreu após 86 minutos de ensaio para o painel 1, bem como 80 minutos para o painel 2, enquanto que a perda de estanqueidade ocorreu após 192 minutos e 180 minutos para os painéis 1 e 2 , respectivamente.

\subsubsection{FERRAZ (1999)}

Foram realizados 12 ensaios à temperatura ambiente em lajes mistas formadas por perfil de aço MF-75 apresentado na Figura 2.13, sendo 6 ensaios com fôrma de aço de espessura igual a $0,80 \mathrm{~mm}$ e $6 \mathrm{com}$ espessura igual a $1,25 \mathrm{~mm}$. Aqui serão apresentados apenas os resultados para dois ensaios (protótipo 1 e 7), tomados como representativos, cujo esquema de carregamento é apresentado na Figura 2.32, cujas características e propriedades são apresentadas na Tabela 2.8 .

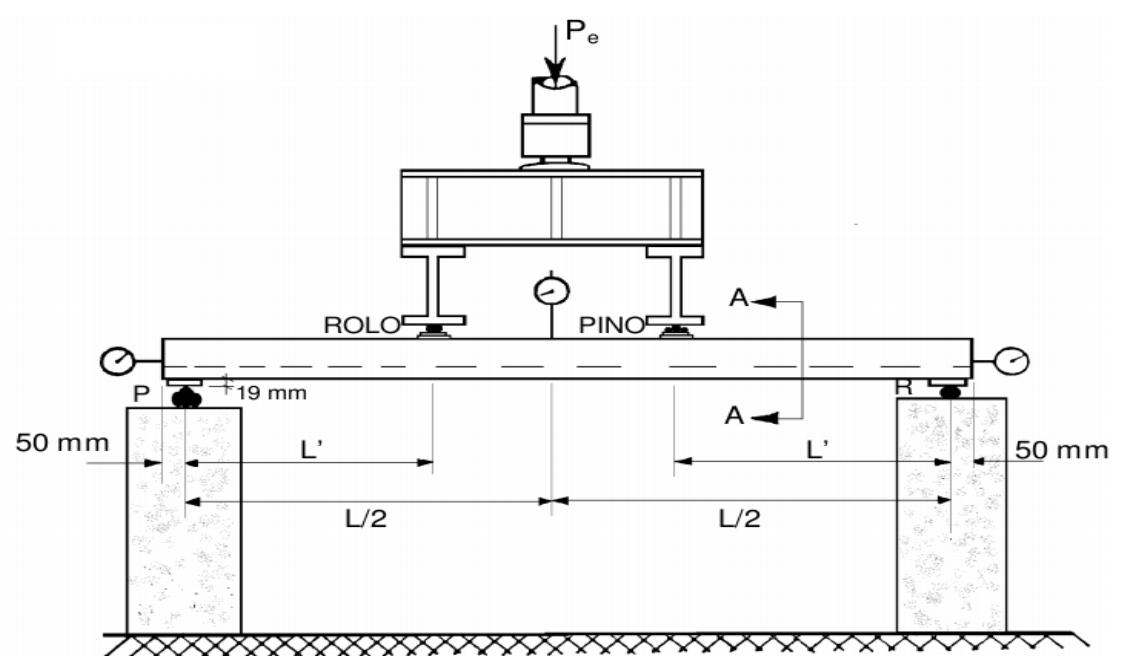

Figura 2.32 - Esquema de aplicação de carga usado nos ensaios 
Tabela 2.8 - Características e propriedades dos protótipos 1 e 7

\begin{tabular}{l|c|c}
\hline \multicolumn{1}{c|}{ Características e propriedades } & Protótipo & Protótipo \\
& $\mathbf{1}$ & $\mathbf{7}$ \\
\hline Espessura nominal da fôrma de aço $(\mathrm{mm})$ & 0,80 & 1,25 \\
\hline Vão do protótipo $-L(\mathrm{~mm})$ & 1800 & 1800 \\
\hline Altura total do protótipo $(\mathrm{mm})$ & 130 & 130 \\
\hline Vão de cisalhamento $-L^{\prime}(\mathrm{mm})$ & 450 & 450 \\
\hline Resistência ao escoamento da fôrma de aço $-f_{y}(\mathrm{MPa})^{*}$ & 351 & 345 \\
\hline Módulo de elasticidade da fôrma de aço $-E_{s}(\mathrm{MPa})^{*}$ & 220.889 & 221.129 \\
\hline Resistência à compressão do concreto no momento do ensaio $-f_{c k}$ & 29,0 & 28,2 \\
$($ MPa)* & & 28.354 \\
\hline Modulo de elasticidade do concreto no momento do ensaio $(\mathrm{MPa})^{*}$ & 27.653 & 28. \\
\hline
\end{tabular}

(*) Valores obtidos com base em ensaios

Durante a realização dos ensaios foram medidas as flechas no meio do vão e deslizamento relativo de extremidade, apresentado na forma gráfica Carga vs. Flechas no meio do vão e Carga vs. Deslizamento relativo de extremidade, por meio da Figura 2.33 e Figura 2.34, respectivamente. Análises mais detalhada sobre esses resultados são apresentadas no capítulo 5.

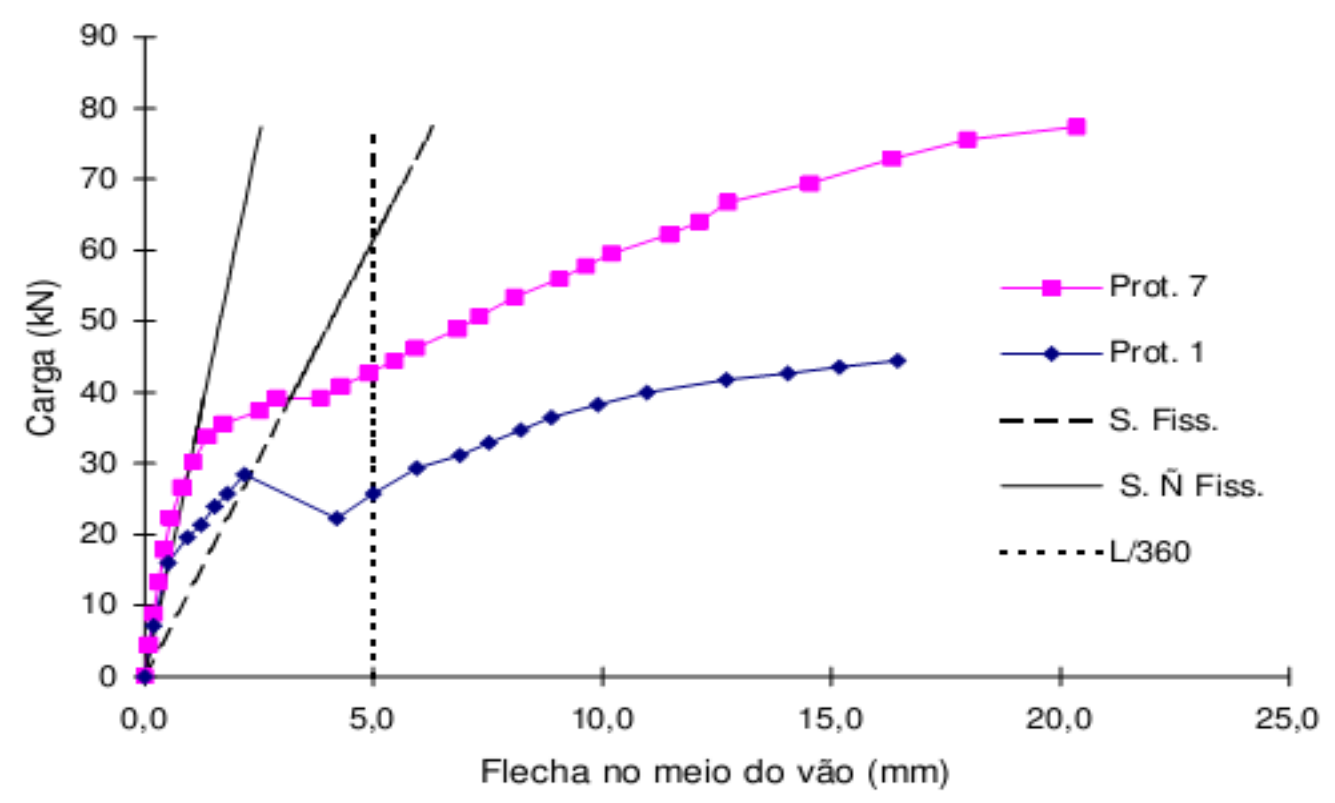

Figura 2.33 - Gráfico Carga vs. Flecha no meio do vão 


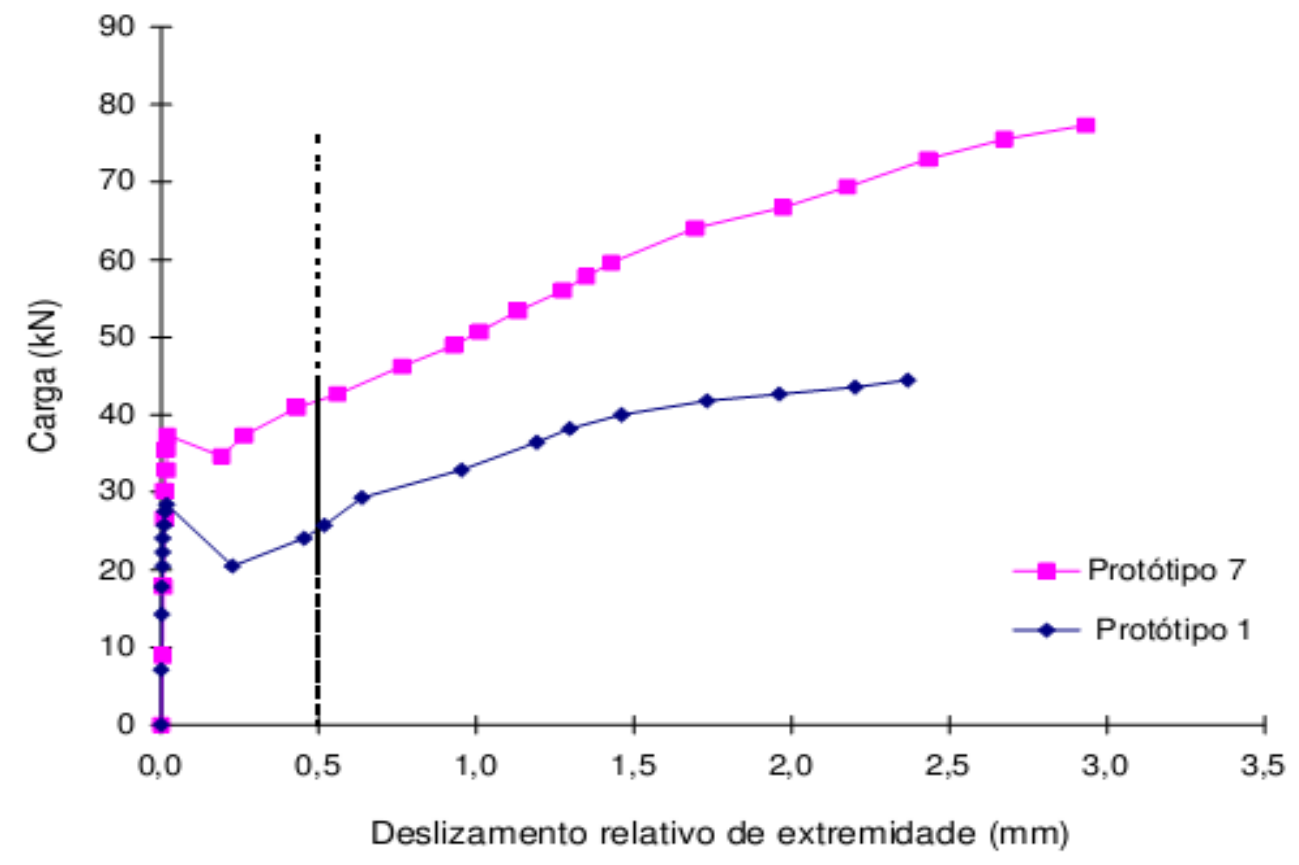

Figura 2.34 - Gráfico Carga vs. Deslizamento relativo de extremidade

O modo de colapso observado durante a realização dos ensaios foi por cisalhamento longitudinal. Porém vale a pena ressaltar que nesses ensaios não foram utilizados mecanismos para melhorar a resistência ao cisalhamento longitudinal, como as ancoragens de extremidade.

\subsubsection{HUANG (2010)}

HUANG (2010) apresenta um procedimento não linear para a modelagem da aderência mecânica entre o concreto e a armadura considerando a redução dessa aderência com a temperatura. A curva tensão de aderência vs. escorregamento utilizada foi a definida no CEB-FIB Model Code 90 (1990) e sua redução com a temperatura definida para dois casos de armaduras, enrugadas ou lisas, conforme apresentados nas Equações 2.29 e 2.30 e na Figura 2.35. Essas curvas de redução da tensão de aderência foram calibradas por meio de ensaios realizados em vigas simplesmente apoiadas e com um trecho lateral em balanço.

\section{- Para armaduras enrugadas:}

$$
\begin{array}{ll}
\frac{\tau_{b, T}}{\tau_{b, 20}}=\left(1,0-\frac{0,22}{360}(T-20)\right) & \text { para } 20^{\circ} \mathrm{C} \leq T \leq 380^{\circ} \mathrm{C} \\
\frac{\tau_{b, T}}{\tau_{b, 20}}=\left(0,78-\frac{0,75}{270}(T-380)\right) & \text { para } 380^{\circ} \mathrm{C}<T \leq 650^{\circ} \mathrm{C} \\
\frac{\tau_{b, T}}{\tau_{b, 20}}=0,03 & \text { para } T>650^{\circ} \mathrm{C}
\end{array}
$$


- Para armaduras lisas:

$$
\begin{aligned}
& \frac{\tau_{b, T}}{\tau_{b, 20}}=\left(1,0-\frac{0,35}{180}(T-20)\right) \quad \text { para } 20^{\circ} \mathrm{C} \leq T \leq 200^{\circ} \mathrm{C} \\
& \frac{\tau_{b, T}}{\tau_{b, 20}}=\left(0,65-\frac{0,27}{200}(T-200)\right) \quad \text { para } 200^{\circ} \mathrm{C}<T \leq 400^{\circ} \mathrm{C} \\
& \frac{\tau_{b, T}}{\tau_{b, 20}}=\left(0,38-\frac{0,35}{140}(T-400)\right) \quad \text { para } 400^{\circ} \mathrm{C}<T \leq 540^{\circ} \mathrm{C} \\
& \frac{\tau_{b, T}}{\tau_{b, 20}}=0,03 \quad \text { para } T>540^{\circ} \mathrm{C}
\end{aligned}
$$

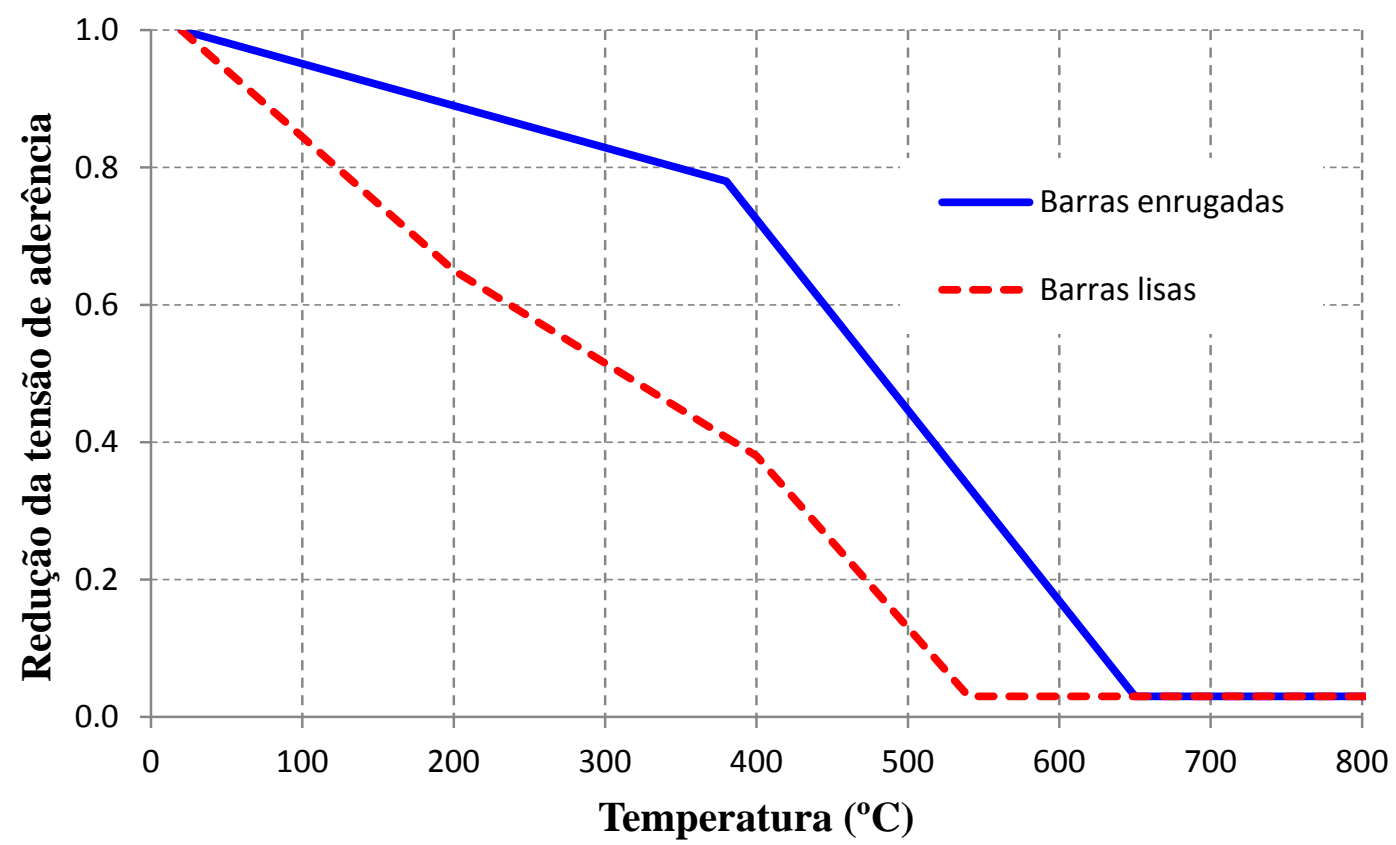

Figura 2.35 - Redução da resistência de aderência com a temperatura (modelo de HUANG, 2010)

O estudo realizado indica a necessidade da consideração da aderência entre o concreto e as armaduras lisas, principalmente em elementos estruturais sem continuidades nos apoios, porém são necessários mais estudos sobre o assunto.

\subsubsection{CHEN \& SHI (2011)}

Foram realizadas modelagens numéricas para avaliar a capacidade resistente da laje mista com a consideração da ruptura por cisalhamento longitudinal na interface da fôrma de aço com o concreto à temperatura ambiente. $\mathrm{O}$ modelo numérico foi calibrado e comparado com resultados experimentais. $\mathrm{O}$ esquema da modelagem numérica para o ensaio de flexão é ilustrado na Figura 2.36. 


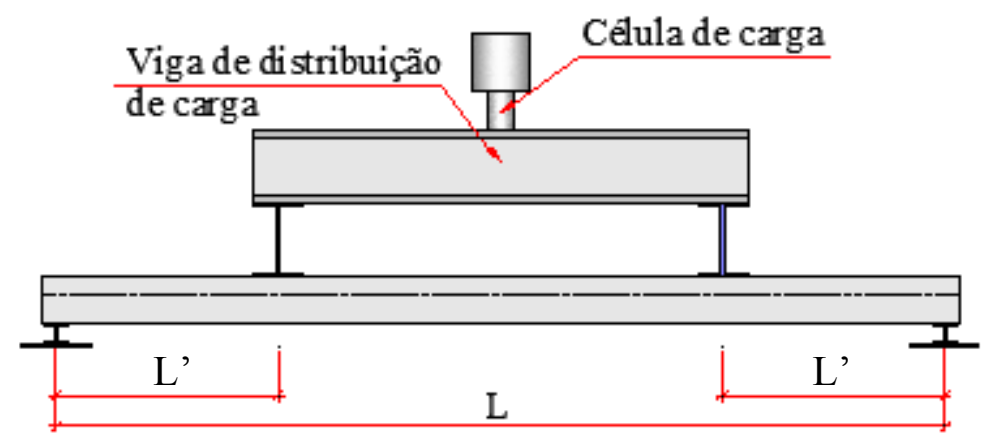

Figura 2.36 - Esquema da modelagem numérica para o ensaio de flexão (Adaptado)

Também foram considerados dois tipos de fôrmas de aço, no caso, trapezoidal e com nervuras reentrantes, com dimensões apresentadas na Figura 2.37.

(a)

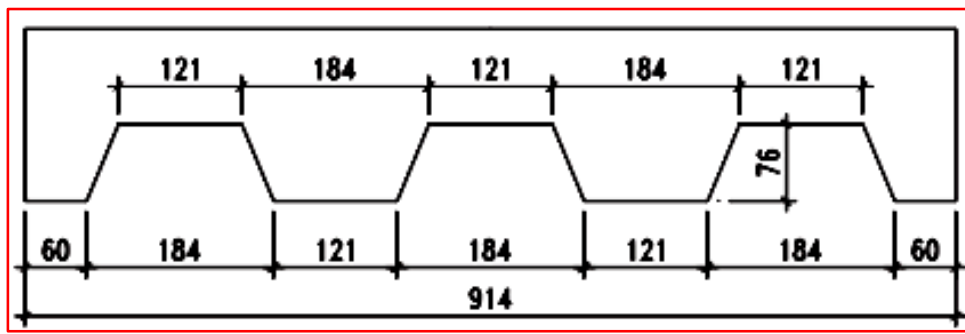

(b)

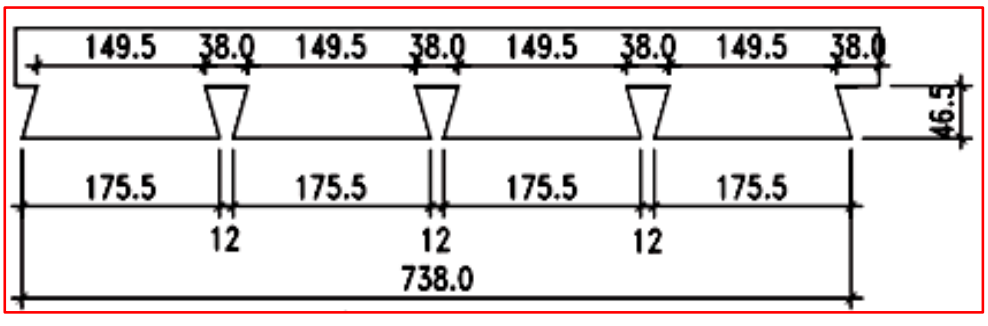

Figura 2.37 - Tipos e dimensões das fôrmas de aço utilizadas na modelagem: (a) Trapezoidal (3D-DECK) e (b) Com nervuras reentrantes (Holorib-2000)

A modelagem da resistência da interface foi realizada com elementos de contato, baseado no modelo de atrito de Coulomb, com coesão de valores iguais a 0,06 MPa e 0,08 $\mathrm{MPa}$ para a fôrma de aço trapezoidal e com nervura reentrante, respectivamente. O coeficiente de atrito adotado foi igual a 0,3 e o módulo de elasticidade do aço igual a $210 \mathrm{GPa}$. Os detalhes dos modelos estão apresentados na Tabela 2.9.

Tabela 2.9 - Dimensões e características dos modelos modeladas

\begin{tabular}{c|c|c|c|c|c|c}
\hline Modelo & Tipo de fôrma & Vão $\mathbf{L} \mathbf{L}(\mathbf{m m})$ & $\begin{array}{c}\text { Altura total } \\
\text { de concreto } \\
(\mathbf{m m})\end{array}$ & $\begin{array}{c}\text { Vão de } \\
\text { cisalhamento }-\mathbf{L}, \\
(\mathbf{m m})\end{array}$ & $\boldsymbol{f}_{\boldsymbol{c k}}(\mathbf{M P a})$ & $\boldsymbol{f}_{\boldsymbol{y}}(\mathbf{M P a})$ \\
\hline A-5 & 3D-DECK & 2600 & 165 & 650 & 20,1 & 275 \\
\hline P1-2 & Holorib-2000 & 1800 & 75 & 600 & 21,6 & 317 \\
\hline P2-2 & Holorib-2000 & 1800 & 98 & 600 & 28,6 & 317 \\
\hline
\end{tabular}


As comparações entre os resultados numéricos e experimentais estão apresentadas na Figura 2.38 para o modelo A-5 e Figura 2.39 para os modelos P1-2 e P2-2. Neste estudo observou-se que a ruptura do modelo sempre ocorreu devido à ruptura por cisalhamento longitudinal entre a fôrma de aço e o concreto.
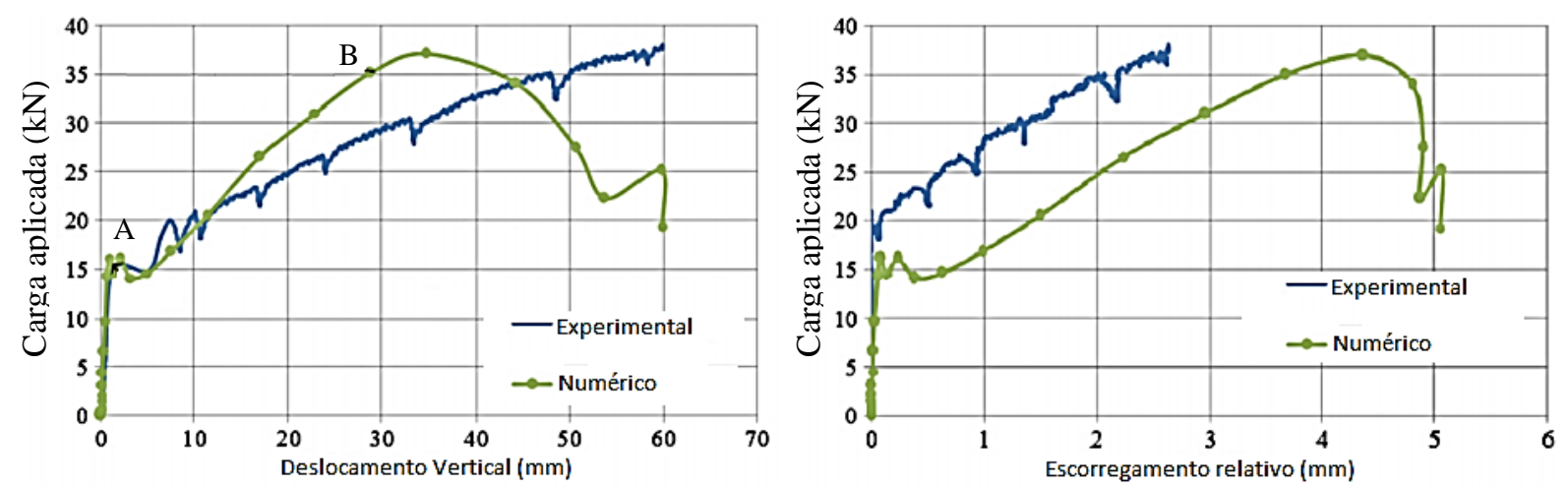

Figura 2.38 - Comparação entre os resultados numéricos e experimentais para o modelo A-5

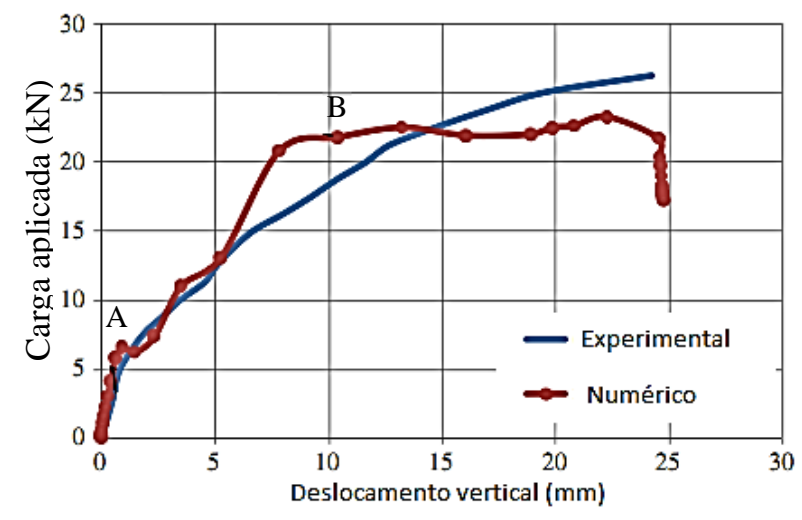

(a) Modelo P1-2

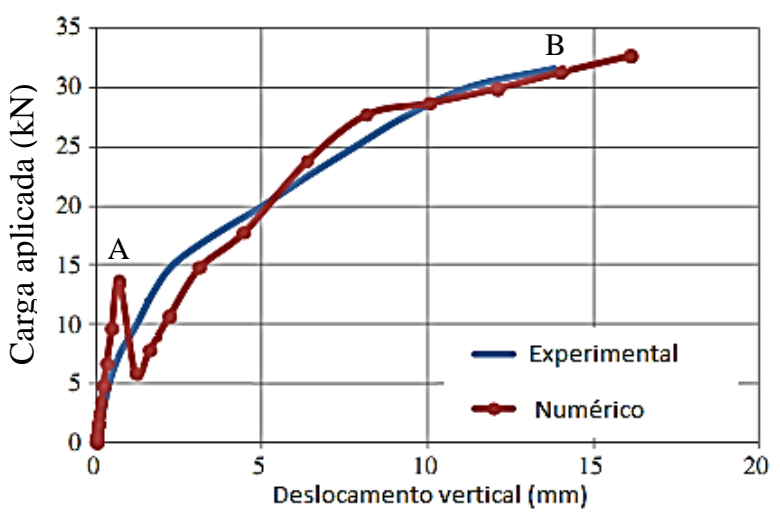

(b) Modelo P2-2

Figura 2.39 - Comparação da análise numérica e experimental: curvas Carga vs. Deslocamento para o modelo P1-2 e P2-2

Pelos resultados apresentados se observa que existem dois pontos da curva que caracterizam o comportamento estrutural da laje mista. O ponto A corresponde ao instante em que se inicia a primeira fissura do concreto e o ponto B ao início do esmagamento do concreto (CHEN \& SHI, 2011). Conforme também se pode observar a curva de escorregamento relativo para o modelo A-5 (Figura 2.38) medida numericamente ficou inferior à curva experimental, isso pode ser explicado pelos valores adotados da resistência à tração do concreto e da coesão e do coeficiente de atrito adotados para o modelo de Coulomb, que corretamente calibrados poderiam aproximar melhor a curva do modelo numérico da curva experimental.

O mesmo acontece para o modelo P2-2, porém neste caso considerando a curva de deslocamento vertical, onde é possível observar um ponto de queda da carga aplicada (ponto A), correspondente à primeira fissura do concreto, que não foi observada no modelo experimental. 


\subsubsection{GUO \& BAILEY (2011)}

Em GUO \& BAILEY (2011) são apresentados resultados de um total de nove ensaios experimentais ( 2 em temperatura ambiente e 7 em temperatura elevada) realizados para avaliar o comportamento de laje mista considerando curvas de incêndio natural (com as fases de aquecimento e resfriamento), com diferentes valores de temperaturas máximas e tempo para atingir essa temperatura. Os ensaios foram realizados em regime transiente e em lajes contínuas trabalhando em uma direção, conforme apresentado na Figura 2.40, compreendendo um vão interno de 4,0m e dois vão externos de 1,1m cada. Os níveis de cargas aplicados em cada ensaio foram correspondentes a $4 \%, 14 \%$ e $22 \%$ da resistência da laje à temperatura ambiente.

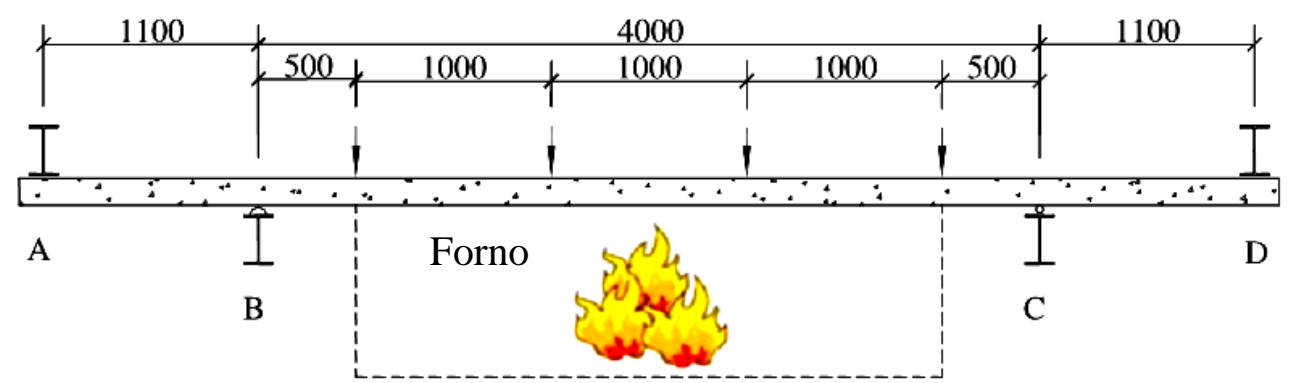

Figura 2.40 - Esquema típico dos ensaios realizados por GUO \& BAILEY (2011)

As dimensões (em mm) da seção transversal dos protótipos ensaiados são apresentadas na Figura 2.41, em que fôrma de aço apresenta uma espessura de 1,2mm e resistência ao escoamento medida experimentalmente de $378 \mathrm{MPa}$. A armadura de distribuição utilizada (A193), consiste de uma malha de armaduras de $7 \mathrm{~mm}$ de diâmetro espaçadas a cada $200 \mathrm{~mm}$ em ambas as direções, com resistência ao escoamento de $650 \mathrm{MPa}$.

(a) ${ }^{30}$
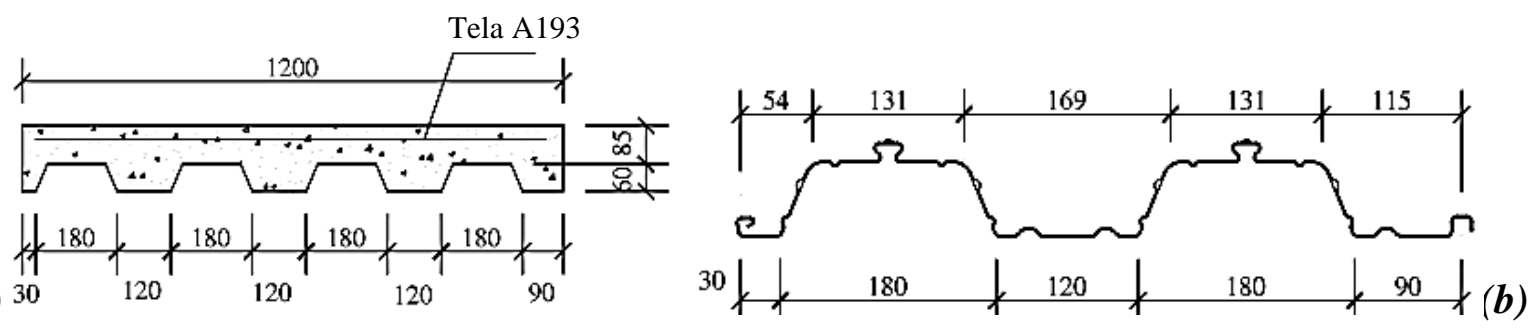

Figura 2.41 - Dimensões da seção transversal dos protótipos ensaiados: (a) lajes e (b) fôrma de aço (GUO \& BAILEY, 2011)

Para avaliar o comportamento estrutural para diferentes regimes de aquecimento e resfriamento, foram utilizadas três curvas de incêndio. A primeira delas ("Fire l") compreendia um tempo de aquecimento até 40 minutos seguida do resfriamento. A segunda ("Fire 2") compreendia um tempo de aquecimento até 90 minutos seguida do resfriamento. Já a terceira ("Fire 3") seguiu a mesma curva de aquecimento da primeira, porém com uma taxa 
de resfriamento menor. Para a segunda curva de aquecimento, as propriedades dos protótipos ensaiados são apresentadas na Tabela 2.10.

Tabela 2.10 - Resumo das propriedades do protótipos ensaiados ("Fire 2")

\begin{tabular}{c|c|c|c}
\hline Laje & Carga aplicada $(\mathbf{k N})$ & $\begin{array}{c}\text { Resistência do } \\
\text { concreto (MPa) }\end{array}$ & $\begin{array}{c}\text { Umidade do concreto } \\
(\mathbf{\%})\end{array}$ \\
\hline F4 & 72 & 34,8 & 2,0 \\
\hline F5 & 44 & 37,8 & 2,0 \\
\hline F6 & 14 & 32,2 & 1,0 \\
\hline
\end{tabular}

O carregamento foi aplicado em quatro pontos de apoio, espaçados de 1,0m, conforme Figura 2.40, sendo que o peso da laje corresponde a $9,6 \mathrm{kN}$ e dos aparatos de ensaio a $8,18 \mathrm{kN}$.

Nos ensaios em temperatura elevada foram mensurados dados como a evolução de temperaturas em pontos específicos da laje bem como o deslocamento vertical no meio do vão central, cujos resultados serão utilizados para calibração dos modelos numéricos aqui propostos (Capítulos 5 e 6).

Nesse trabalho concluiu-se que as temperaturas da face não exposta e da armadura de distribuição foram maiores durante a fase de resfriamento, sendo que essas temperaturas dependiam não somente da temperatura máxima do incêndio, mas também da taxa de resfriamento. Com relação aos deslocamentos verticais máximos, esses foram maiores para maiores temperaturas máximas do incêndio e dependentes da carga inicial aplicada, como já era previsto.

A depender do nível de carregamento aplicado, foi observado que pode haver inversão do momento fletor no meio do vão após o resfriamento da laje, ocorrendo em resposta a uma maior taxa de resfriamento da fôrma de aço em relação ao concreto. Esse comportamento também depende da taxa de resfriamento do forno.

Durante o ensaio também se observou uma redistribuição de esforço na laje, principalmente pela redução do momento fletor resistente no meio do vão, devido à perda de resistência da fôrma de aço.

\subsubsection{GUO (2011)}

Este trabalho é uma continuação do apresentado em GUO \& BAILEY (2011), porém desta vez apresentando resultados numéricos realizados no código computacional ABAQUS. Foram realizados dois tipos de análises, a térmica e a termoestrutural acoplada.

$\mathrm{Na}$ análise térmica se utilizou elementos finitos planos bidimensionais para simular o concreto, a fôrma de aço e a interface do aço com o concreto. Já para a análise termoestrutural se utilizou elementos sólidos para representar o concreto, de superfícies para o aço e molas para simular a interface aço/concreto. Em ambos os tipos de análises, para evitar o grande 
esforço computacional, modelou-se apenas meia nervura, conforme apresentado na Figura 2.42 .

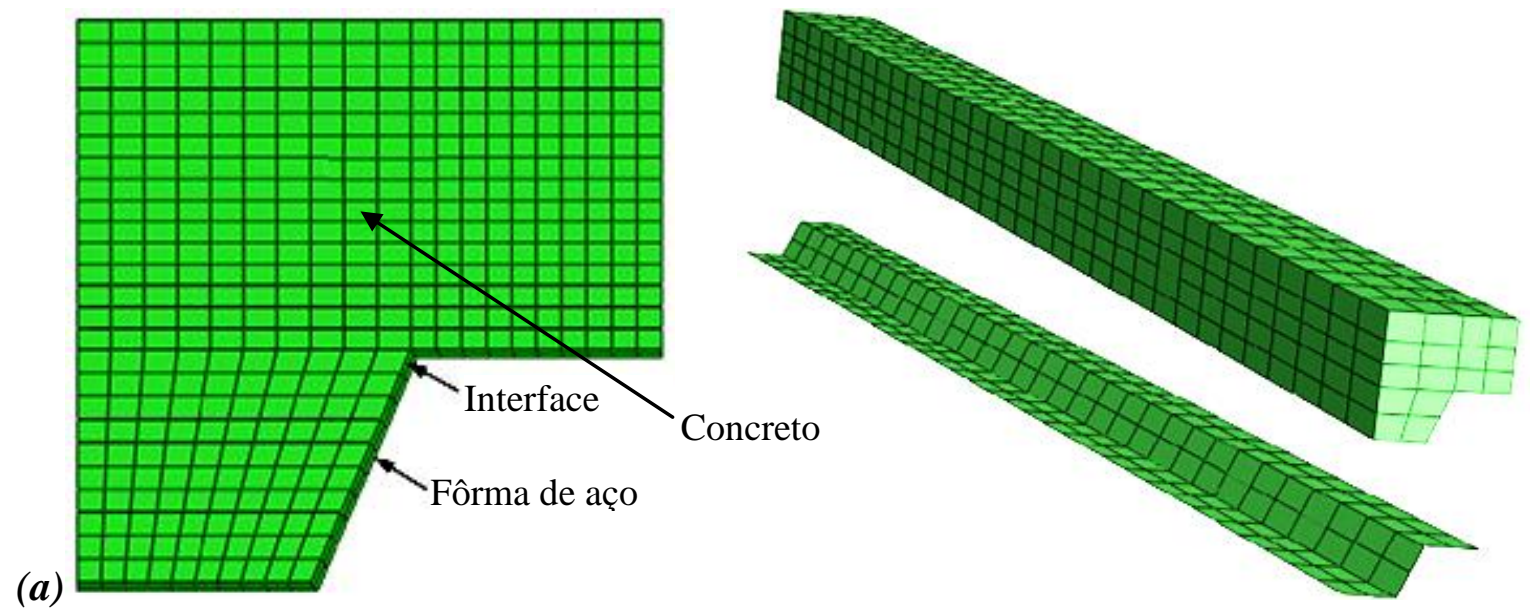

(b)

Figura 2.42 - (a) Modelo para análise térmica e (b) para análise termoestrutural

Nos modelos térmicos foi modelada uma camada de 1,0 $\mathrm{mm}$ entre a fôrma de aço e o concreto para simular a resistência térmica na interface. A essa camada foi atribuído um valor de $0,8 \mathrm{~W} / \mathrm{mK}$ para a condutividade térmica. Para a face exposta ao fogo adotou-se um coeficiente de transferência de calor por convecção de $25 \mathrm{~W} / \mathrm{m}^{2} \mathrm{~K}$ e para a face superior da laje (face não exposta) um valor de $10 \mathrm{~W} / \mathrm{m}^{2} \mathrm{~K}$. Já a emissividade do aço foi considerada igual a 0,70 .

No modelo termoestrutural foi adotado o modelo constitutivo do EUROCODE 4 (1994) para o concreto a compressão e para o aço um modelo bilinear para o concreto tracionado, sendo que no trecho descendente a resistência foi atribuída em função da abertura de fissura. A resistência mecânica na interface foi considerada igual a 0,3 MPa, tornando-se igual a zero para um deslocamento relativo de $5 \mathrm{~mm}$.

GUO (2011) destaca que tão importante quanto o carregamento mecânico aplicado é a expansão térmica dos materiais no comportamento mecânico da laje. Nesse sentido, buscou-se avaliar inicialmente, por meio de modelos numéricos, o comportamento mecânico da laje somente com o efeito do carregamento térmico. Neste caso, com um aumento da temperatura da fôrma de aço, a laje deforma verticalmente no sentido da face aquecida. Para lajes apoiadas em quatro pontos, como nos ensaios experimentais realizados, surgirão momentos negativos sobre os apoios intermediários somente devido à expansão térmica.

Nesse estudo, observou se que um aumento de $40 \%$ da resistência do concreto não influenciou significativamente o comportamento mecânico da laje em situação de incêndio, sendo que uma mudança na espessura da fôrma de aço muda o comportamento mais significativamente, principalmente durante a fase de resfriamento. Neste caso, quanto maior a espessura da fôrma de aço maior a tendência da laje voltar para sua posição inicial durante o resfriamento e descarregamento. 
Durante a fase inicial de aquecimento, o efeito da armadura de distribuição no comportamento da laje é pouco significativo. Após os minutos iniciais de aquecimento, esse efeito passa a ser mais evidente, de modo que quanto maior a área de armadura menor é o deslocamento vertical. Já na fase de resfriamento a armadura de distribuição apresenta pouca contribuição no comportamento da laje, sendo que neste caso a fôrma de aço é que governa o comportamento.

\subsubsection{Outros estudos - Breve comentário}

BAILEY \& TOH (2007) publicaram resultados de ensaios em lajes simplesmente apoiadas e sem restrição axial à temperatura ambiente e temperatura elevada em modelos com escala reduzida com dimensões iguais a $1,20 \mathrm{~m} \times 1,20 \mathrm{~m}$ e $1,80 \mathrm{mx} 1,20 \mathrm{~m}$, com altura de $20 \mathrm{~mm}$ e cobrimento de $5 \mathrm{~mm}$, bem como desenvolveram um método, com base em observações experimentais, para previsão da resistência da laje, considerando o efeito da membrana de tração. O princípio do método é calcular a carga distribuída com a qual a laje resistiria sem a consideração do efeito de membrana pela teoria das linhas de ruptura e, posteriormente, majorar essa carga para levar em consideração o efeito de membrana, a partir da distribuição de tensões no plano da laje.

CASHELL, ELGHAZOULI e IZZUDDIN (2010) realizaram ensaios à temperatura ambiente em lajes apoiadas em apenas uma direção e com restrição axial, buscando avaliar o efeito de membrana, e propuseram um modelo analítico simplificado para a previsão da resistência da laje (à temperatura ambiente e elevada). Neste modelo foram considerados a concentração de tensões na armadura, o escorregamento da armadura no concreto e a formação de fissura (apenas uma fissura no meio do vão). Os tipos de armadura utilizados nos experimentos foram barras lisas e enrugadas, ambas com $6 \mathrm{~mm}$ de diâmetro. As barras lisas eram laminadas a quente, com resistência ao escoamento de $250 \mathrm{MPa}$, enquanto que as barras enrugadas eram formadas a frio, com tensão de escoamento de $585 \mathrm{MPa}$. Essas barras não correspondem a nenhuma armadura utilizada na prática da construção civil brasileira.

POTHISIRI e PANEDPOJAMAN (2012) propuseram um modelo teórico avançado para prever a resistência à aderência entre a armadura e o concreto em temperaturas elevadas baseado na teoria de distribuição de fissuras e na teoria do cilindro de parede espessa considerando o concreto como parcialmente fissurado. Nesse modelo aspectos como a variação da resistência do concreto, cobrimento da armadura e diferentes expansões térmicas do concreto e do aço são considerados.

\subsubsection{Resumo das pesquisas}

Os ensaios realizados em escala real no edifício em Cardington demonstraram que as lajes mistas continuam resistindo ao incêndio para deslocamentos superiores a $640 \mathrm{~mm}$. Esse comportamento também será observado nos modelos numéricos termoestrutural, apresentados 
no capítulo 5, onde as lajes mistas continuam resistindo às ações termomecânicas para deslocamento superiores àqueles estabelecidos pela ISO 834 (1999).

Uma pesquisa de grande importância neste trabalho é a realizada por ABDEL-HALIM et al. (1999), cujos campos térmicos obtidos experimentalmente para a fôrma de aço e o concreto serão utilizados para calibração dos modelos térmicos. Com os resultados desses ensaios é possível observar que existe uma grande diferença entre a temperatura dos gases aquecidos e a temperatura da fôrma de aço. Conforme será observado no capítulo 4, o modelo numérico não conseguiu representar bem esse comportamento, que também pode estar associado a erros experimentais.

FERRAZ (1999) e ARAUJO (2008) apresentaram uma série de ensaios à temperatura ambiente para lajes mistas simplesmente apoiadas. Desses ensaios se observou que a ruptura dos modelos sempre ocorreu pelo escorregamento na interface entre a fôrma de aço e o concreto (cisalhamento longitudinal). Entretanto, vale mencionar que esses modelos experimentais não apresentavam nenhum mecanismo de ancoragem de extremidade, para resistir às elevadas tensões de cisalhamento que existem próximas aos apoios. Alguns desses resultados serão utilizados para calibração dos modelos numéricos à temperatura ambiente, apresentados no capítulo 5.

Um estudo numérico sobre o comportamento de lajes mistas à temperatura ambiente é apresentado por CHEN \& SHI (2011). Desse estudo também se concluiu que a ruptura dos modelos ocorre por cisalhamento longitudinal. Nos modelos numéricos foi adotado o modelo de atrito de Coulomb para representar a interface e o valor calibrado para a coesão foi de $0,06 \mathrm{MPa}$, que é um valor muito baixo se comparado à resistência à tração do concreto. Esse valor servirá de parâmetro para calibração da resistência ao cisalhamento longitudinal do modelo bond-slip, apresentado no capítulo 5.

GUO \& BAILEY (2011) realizaram diversos ensaios em lajes mistas em temperatura elevada, variando a curva de incêndio e a carga total aplicada. Nesses ensaios os modelos foram submetidos ao aquecimento e resfriamento, onde se observou que a fase de resfriamento é tão importante quanto a fase de resfriamento. O trabalho apresentado por GUO (2011) faz um estudo numérico em lajes mistas por meio dos resultados experimentais apresentados em GUO \& BAILEY (2011). Nesses modelos numéricos foi utilizada a simetria de seção, visando a redução do esforço computacional para processamento dos modelos, e elementos de interface entre a fôrma de aço e o concreto. Esses aspectos também serão avaliados no capítulo 5 deste trabalho. 


\section{Aspectos referentes à estratégia de modelagem numérica}

\subsection{Introdução}

A análise do comportamento de um sistema estrutural, ou mesmo de um elemento estrutural, em situação de incêndio por meio da realização de ensaios em laboratório (ou similares) demanda elevados tempo e recursos financeiros. Deste modo, a escolha pela simulação numérica utilizando o método dos elementos finitos é uma alternativa interessante, pois permite também a realização de análise paramétrica com relativa facilidade. Essa análise pode ser realizada por meio de diversos códigos computacionais, que podem ser específicos para estruturas em situação de incêndio (geralmente desenvolvidos em universidades) ou para as mais diversas análises estruturais. Como códigos computacionais específicos para análise de estruturas em situação de incêndio se destacam o ADAPTIC, o FEAST, o SAFIR e o VULCAN, enquanto para análises gerais podem ser citados o ABAQUS, o ANSYS e o DIANA, todos disponíveis comercialmente.

Uma breve introdução sobre os códigos computacionais ADAPTIC, FEAST, SAFIR e VULCAN, incluindo ABAQUS e DIANA é apresentada por WANG (2002), cujo resumo de suas aplicações é apresentado nas Tabela 3.1 e Tabela 3.2, para análise dos comportamentos local e global de uma estrutura, respectivamente.

Tabela 3.1 - Aplicações dos programas ADAPTIC, FEAST, SAFIR, VULCAN, ABAQUS e DIANA para análise do comportamento local de uma estrutura (WANG, 2002)

\begin{tabular}{|c|c|c|c|c|c|c|}
\hline \multirow[b]{2}{*}{ Nome } & \multicolumn{2}{|c|}{ Flexão/Cisalhamento } & \multirow{2}{*}{$\begin{array}{l}\text { Flambagem } \\
\text { distorcional } \\
\text { e local }\end{array}$} & \multirow{2}{*}{$\begin{array}{l}\text { Flambagem } \\
\text { lateral por } \\
\text { torção }\end{array}$} & \multirow{2}{*}{$\begin{array}{c}\text { Laje } \\
\text { mista/Ação } \\
\text { de } \\
\text { membrana }\end{array}$} & \multirow[b]{2}{*}{ Ligação } \\
\hline & Aço & Mista & & & & \\
\hline ADAPTIC & $\bar{\checkmark}$ & $\bar{x}$ & $\bar{x}$ & $\bar{x}$ & $\checkmark$ & $\bar{x}$ \\
\hline FEAST & $\checkmark$ & $x$ & $\checkmark$ & $\checkmark$ & $x$ & $\checkmark$ \\
\hline SAFIR & $\checkmark$ & $\checkmark$ & $\checkmark$ & $\checkmark$ & $x$ & $x$ \\
\hline VULCAN & $\checkmark$ & $\checkmark$ & $x$ & $\checkmark$ & $\checkmark$ & $x$ \\
\hline ABAQUS & $\checkmark$ & $\checkmark$ & $\checkmark$ & $\checkmark$ & $\checkmark$ & $\checkmark$ \\
\hline DIANA & $\checkmark$ & $\checkmark$ & $\checkmark$ & $\checkmark$ & $\checkmark$ & $\checkmark$ \\
\hline
\end{tabular}


Tabela 3.2 - Aplicações dos programas ADAPTIC, FEAST, SAFIR, VULCAN, ABAQUS e DIANA para análise do comportamento global de uma estrutura (WANG, 2002)

\begin{tabular}{c|c|c|c|c|c}
\hline Nome & $\begin{array}{c}\text { Análise } \\
\text { térmica }\end{array}$ & $\begin{array}{c}\text { Análise } \\
\text { estrutural }\end{array}$ & $\begin{array}{c}\text { Não- } \\
\text { linearidade } \\
\text { do material }\end{array}$ & $\begin{array}{c}\text { Grandes } \\
\text { deflexões }\end{array}$ & $\begin{array}{c}\text { Ruptura } \\
\text { progressiva }\end{array}$ \\
\hline ADAPTIC & $x$ & $\checkmark$ & $\checkmark$ & $\checkmark$ & $\checkmark$ \\
\hline FEAST & $x$ & $x$ & $\checkmark$ & $\checkmark$ & $\checkmark$ \\
\hline SAFIR & $\checkmark$ & $\checkmark$ & $\checkmark$ & $\checkmark$ & $x$ \\
\hline VULCAN & $x$ & $\checkmark$ & $\checkmark$ & $\checkmark$ & $x$ \\
\hline ABAQUS & $\checkmark$ & $\checkmark$ & $\checkmark$ & $\checkmark$ & $\checkmark$ \\
\hline DIANA & $\checkmark$ & $\checkmark$ & $\checkmark$ & $\checkmark$ & $\checkmark$ \\
\hline
\end{tabular}

Atualmente, no Departamento de Engenharia de Estruturas da EESC/USP, os códigos ANSYS e DIANA são os dois pacotes computacionais mais utilizados. Como o elemento estrutural em estudo no presente trabalho se refere a uma laje mista de aço e concreto, optouse por utilizar o código DIANA para as análises numéricas. Essa escolha também é justificada pelo fato de o código DIANA apresentar modelos mais precisos para a consideração dos efeitos de fissuração do concreto (ROCHA, 2012), bem como de sua recente ampliação de uso dentro do Departamento de Engenharia de Estruturas da EESC/USP para análise de estruturas de concreto e mistas de aço e concreto, à temperatura ambiente e em situação de incêndio.

\subsection{Sobre o código computacional TNO DIANA}

O código DIANA foi desenvolvido em 1972 por engenheiros civis da TNO Building and Construction Research Company (Holanda). Seu campo de aplicação é vasto, sendo utilizado também na engenharia mecânica, biomecânica, geotécnica, entre outras. Porém, o diferencial do código DIANA para os demais códigos em elementos finitos está associado ao fato de esse ter sido totalmente desenvolvido por engenheiros civis e, por isso, resulta em ferramenta adequada para a simulação do comportamento estrutural do concreto, considerando seus fenômenos complexos como fissuração, plasticidade, fluência, retração, cura, efeitos de temperatura e instabilidade, entre outros (RAMOS, 2010).

No código DIANA diversos tipos de análises podem ser feitas, dentre as quais são citadas: Linear estática, não linear física, dinâmica, estabilidade de Euller, fásica, fluxo térmico e termoestrutural. Neste trabalho serão utilizadas as análises de fluxo térmico e termoestrutural, baseadas no modelo numérico adotado e apresentado em ROCHA (2012) e incluindo as particularidades das lajes mistas de aço e concreto. A seguir são descritas de forma sucinta as etapas de definição do modelo de fluxo térmico e o modelo termoestrutural tridimensional. 


\subsection{Definição do modelo térmico no DIANA}

Foram considerados dois tipos de modelos para a análise de fluxo térmico: com elemento de interface entre a fôrma de aço e o concreto (Figura 3.1a) e sem esse elemento de interface (Figura 3.1b). O objetivo do modelo com interface é avaliar uma possível resistência térmica na interface entre a fôrma de aço e o concreto. A seguir são apresentadas as etapas para a definição do modelo térmico. Visando maior velocidade de processamento computacional será modelada apenas meia nervura da laje mista (Figura 3.1), cuja estratégia também é apresentada em GUO (2011) e não tem interferência nos campos térmicos, já que as laterais do modelo são tratadas como adiabáticas.

(a)
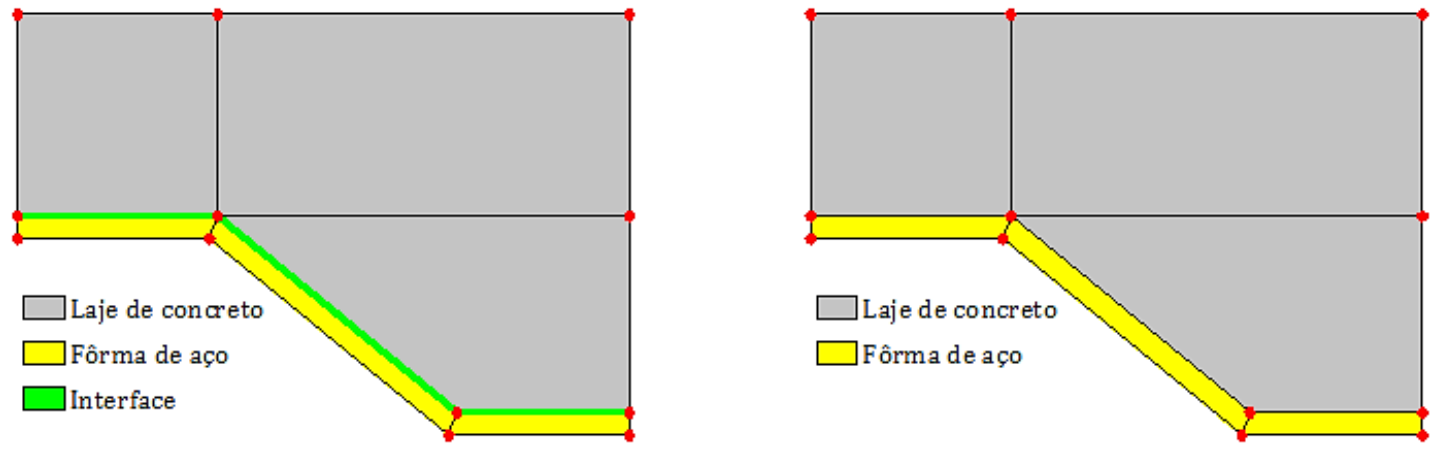

(b)

Figura 3.1 - Geometria dos modelos térmicos: $(a)$ com interface e $(b)$ sem interface

\subsubsection{Considerações com relação à etapa de Pré-processamento}

O pré-processamento de um modelo numérico consiste na definição de todos os parâmetros necessários para a execução da análise de interesse, tais como geometria, tipos de elementos finitos utilizados, geração da malha de elementos finitos, aplicação dos carregamentos, aplicação das condições de contorno e definição das propriedades térmicas e mecânicas dos materiais. O pacote computacional DIANA possui um pré-processador próprio, denominado $\mathrm{iDIANA}$.

Para criar um novo modelo de fluxo térmico no iDIANA basta acionar o comando "File > New" e escolher a opção "Heat Flow 2D" em "Model Type". Quando se inicia um novo modelo deve-se ter o cuidado de definir as unidades que se deseja trabalhar para evitar erros, caso contrário o resultado do modelo pode não estar correto. Neste trabalho se adotou as unidades de tempo em segundos, comprimento em metro e temperatura em graus Celsius. O pré-processamento no iDIANA pode ser feito de três formas: (i) navegador de comando (command browser), (ii) digitação em linhas de comando ou (iii) leitura dos comandos em arquivos batch (os quais consistem de arquivos de texto que contem todos os comandos necessários para a geração do modelo). Neste trabalho foram utilizados os arquivos batch para o pré-processamento, desenvolvido em uma planilha eletrônica, apresentado no Apêndice B. Apesar de trabalhoso, os arquivos batch facilitam a realização de análises paramétricas. 
No Apêndice A (item A.1) é apresentado um resumo dos principais comandos do iDIANA utilizados para a definição da geometria, elementos finitos, carregamentos, condições de contorno e propriedades dos materiais, visando auxiliar na aprendizagem de outros eventuais usuários interessados em pré-processar modelos numéricos no iDIANA.

\subsubsection{Definição da geometria}

A definição da geometria no iDIANA é feita de forma hierárquica, ou seja, primeiro são criados pontos para depois criar linhas, superfícies e sólidos. Também se tem a opção de criar superfícies por meio de pontos. Como o modelo aqui é bidimensional somente são criados pontos, linhas e superfícies.

Durante a definição da geometria do modelo, no intuito de facilitar a aplicação de carregamentos, condições de contorno, propriedades dos materiais, visualização e tabulação dos resultados é interessante a criação de SETs, que são agrupamentos de elementos da geometria (pontos, linhas, superfícies e volumes).

\subsubsection{Definição dos elementos finitos}

Conforme mencionado no Capítulo 1, os tipos de elementos finitos utilizados para o modelo térmico são os denominados $\mathbf{Q 4 H T}$, para as superfícies de aço e de concreto, o ILAHT para a interface entre a fôrma de aço e o concreto, bem como o B2HT para simular o efeito da transferência de calor entre o meio e a estrutura. Tais elementos são apresentados na Figura 3.2.
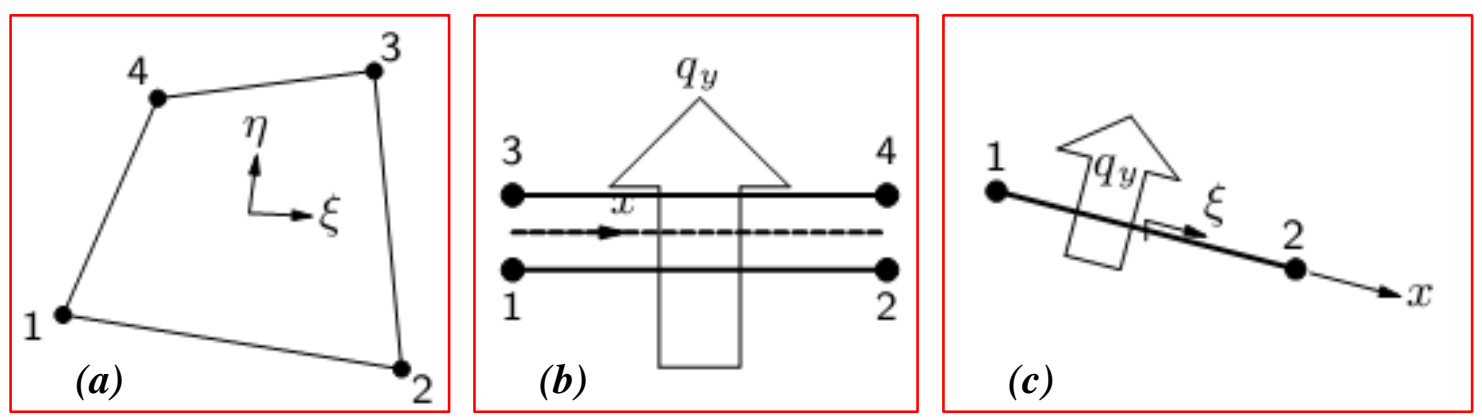

Figura 3.2 - Elementos finitos utilizados para a análise térmica: (a) Q4HT, (b) IL4HT e (c) B2HT

O elemento Q4HT é um elemento finito isoparamétrico quadrilateral de quatro nós para análise geral de fluxo térmico, com interpolação linear. O elemento IL4HT é um elemento finito de interface para fluxo térmico, com interpolação linear. O fluxo é perpendicular à interface e varia linearmente nessa interface. Já o elemento B2HT é um elemento finito isoparamétrico de dois nós usado para aplicar as condições de contorno em problemas de fluxo térmico, com fluxo perpendicular à superfície e variando linearmente nessa superfície. Para atribuir esses elementos finitos a seus respectivos SETs (superfícies ou 
volumes) utiliza-se o comando "MESHING TYPES". Após atribuir os tipos de elementos finitos para todos os elementos do modelo é necessário gerar a malha de elementos finitos, a qual é realizada através do comando "MESHING GENERATE ALL".

É importante ressaltar que os nós dos elementos finitos pertencentes às faces inferior e superior da interface, face inferior do concreto e face superior da fôrma de aço devem estar sobrepostos, bem como os nós da face inferior da fôrma, da superfície em contato com o fogo, da face superior do concreto e da superfície de troca de calor com o ambiente. Inicialmente esses nós estão desconectados, para conectá-los é necessário criar SETs contendo os elementos de interface que se deseja conectar para, em seguida, utilizar o comando MERGE após gerar a malha de elementos finitos.

\subsubsection{Definição dos carregamentos térmicos}

No modelo em questão, a face inferior da laje mista estará em contato com os gases aquecidos do ambiente em chamas, razão pela qual receberá calor dos gases por meio dos mecanismos de transferência de calor associados à convecção e à radiação. Desse modo são criados dois tipos de carregamentos para a face exposta ao fogo, por meio dos comandos “PROPERTY LOADS EXTTEMP” e "PROPERTY LOADS RADTEMP”.

Já a face superior do modelo está submetida à temperatura ambiente e, portanto, a troca de calor está sujeita ao efeito de convecção, deste modo se cria somente um carregamento por meio do comando "PROPERTY LOADS EXTTEMP”.

As curvas de aumento de temperatura dos gases aquecidos em contato com a face inferior da laje mista, bem como a consideração de temperatura ambiente constante para a face superior, são criadas a partir de curvas de fatores de multiplicação da intensidade em função do tempo, chamadas de TCURVEs. Para o problema em questão, se fez necessário criar duas TCURVEs, uma para a face exposta ao fogo e outra para a face não exposta, através do comando "CONSTRUCT TCURVE". Após criar as TCURVEs se faz necessário aplicá-las aos correspondentes carregamentos por meio do comando "PROPERTY ATTACH".

Tem-se também a necessidade de definir uma temperatura inicial para todos os elementos do modelo, a qual é tomada igual à temperatura ambiente, por meio do comando “PROPERTY INITIAL INITEMP”.

\subsubsection{Condições de contorno e definição dos materiais}

A definição das propriedades dos materiais pode ser feita por meio do comando Property Manager no iDIANA (View > Property Manager), ou por meio de arquivos de texto. Como as propriedades térmicas do aço e do concreto são dependentes da temperatura, só é possível defini-las por meio de arquivos de texto. Deste modo, são criados dois arquivos que 
contenham tais propriedades, no caso, forma.mat e conc.mat para as propriedades térmicas da fôrma de aço e do concreto, respectivamente, ambos apresentados no Apêndice C.

Para o modelo aqui de interesse se faz necessário criar cinco tipos de materiais, para o aço, concreto, superfície em contato com o fogo, superfície em contato com o ambiente e interface aço-concreto, nomeados respectivamente de MATACO, MATCON, MATFOG, MATAMB e MATINT. Para o aço e o concreto, pelo fato de suas propriedades térmicas serem lidas em arquivos de texto, é utilizado o comando "PROPERTY MATERIAL" para leitura de dados externos.

Para a superfície em contato com o fogo (sujeita aos efeitos de convecção e radiação), o coeficiente de transferência de calor por convecção $\left(\alpha_{c}\right)$ é tomado igual a $25 \mathrm{~W} / \mathrm{m}^{2}{ }^{\circ} \mathrm{C}$ e a emissividade resultante igual a 0,70 , de acordo com as prescrições normativas. Entretanto, outros valores de emissividade têm sido adotados na bibliografia técnica pesquisada, tais como $0,50,0,40$ e até mesmo variável entre $0,09\left(\mathrm{~T} \leq 250^{\circ} \mathrm{C}\right)$ e $0,40\left(\mathrm{~T} \geq 800^{\circ} \mathrm{C}\right)$. Essa variação, dependendo da faixa de temperatura, ocorre em resposta ao derretimento da camada de zinco presente na fôrma de aço (BOTH et al., 1997).

Já na superfície superior da laje (sujeita apenas aos efeitos de convecção) é adotado o coeficiente de transferência de calor por convecção $\left(\alpha_{c}\right)$ igual a $9 \mathrm{~W} / \mathrm{m}^{2}{ }^{\circ} \mathrm{C}$. Para a superfície de interface, no Capítulo 5, será estudada qual a melhor resistência da interface, já que não foi encontrada nenhuma informação sobre essa resistência na bibliografia pesquisada para o caso de lajes mistas. A definição desses materiais é feita através do comando "PROPERTY MATERIAL".

Após criar os materiais faz-se necessário atribuí-los aos SETs de interesse, utilizandose para tanto o comando "PROPERTY ATTACH".

Caso não seja adotada qualquer condição de contorno para alguma superfície externa do modelo, esta será considerada como adiabática, ou seja, não haverá troca de calor nessa superfície. Após a definição de todos os parâmetros do modelo utiliza-se o comando "UTILITY WRITE DIANA" para a geração do arquivo.dat que contem todas as informações do modelo e que será utilizado na fase de processamento.

\subsubsection{Considerações com relação à etapa de Processamento}

O processamento no DIANA se faz por meio de leitura do arquivo de dados (.dat) gerado ao final do pré-processamento. No caso aqui apresentado, por se pretender avaliar a evolução da temperatura no tempo, a análise a ser realizada será do tipo térmica transiente. Desse modo, é necessária a definição dos intervalos de tempo (time steps) em que serão calculados os campos térmicos. Para os primeiros 10 minutos de incêndio, o intervalo de tempo adotado foi igual a 30 segundos e, posteriormente, alterado para 60 segundos, mesma estratégia adotada por ROCHA (2012). 
Durante o processamento também são definidos diversos parâmetros como o método de resolução das equações (aqui será utilizado o método de Newton-Rapson regular), critérios de convergência e forma de visualização dos resultados (tabular ou gráfica). Na visualização tabular é possível identificar os resultados exatos nos elementos ou nós desejados por meio de arquivos de texto, enquanto que a visualização gráfica é realizada pela interface gráfica do iDIANA, a qual oferece uma melhor visualização global dos resultados. Essas configurações de processamento podem ser salvas em arquivo com a extensão .com ou .dcf, dependendo da versão do DIANA, apresentado no Apêndice C.4.

\subsubsection{Considerações com relação à etapa de Pós-processamento}

A etapa de pós-processamento refere-se às análises dos resultados, realizadas por meio de dados tabulares ou gráficos. A visualização gráfica do iDIANA será utilizada para a identificação dos campos térmicos da seção transversal e também para a geração de arquivos de texto que contenham determinada informação desejada, como, por exemplo, a evolução de temperatura de um nó da malha de elementos finitos em função do tempo de aquecimento.

Nesta etapa também serão calculados os momentos plásticos da seção, visando futura comparação com as prescrições normativas e com os resultados do modelo termoestrutural, calculados por meio das informações da geometria da seção contidas no arquivo de dados (arquivo.dat) e dos resultados tabulados, definidos na etapa de processamento, através de um código computacional desenvolvido na linguagem Visual Basic 11.0 disponível no Visual Studio 2012 da Microsoft.

A Figura 3.3 apresenta o fluxograma simplificado utilizado para implementação computacional do pós-processador desenvolvido para cálculo do momento fletor plástico da laje mista em temperaturas elevadas, o qual recebeu a denominação de LaMix. Mais detalhes sobre o procedimento de cálculo do momento fletor plástico, resultados gerados pelo código computacional desenvolvido e as sub-rotinas implementadas são apresentados nos Apêndices D e E.

O código desenvolvido possui um banco de dados gerado pelo processamento de vários modelos no DIANA para diversas variáveis incluindo 3 tipos de fôrma de aço, 3 casos de emissividade, 19 alturas totais diferentes para a laje, 3 valores de umidade do concreto e 2 casos de resistência térmica na interface, totalizando 1026 modelos. 


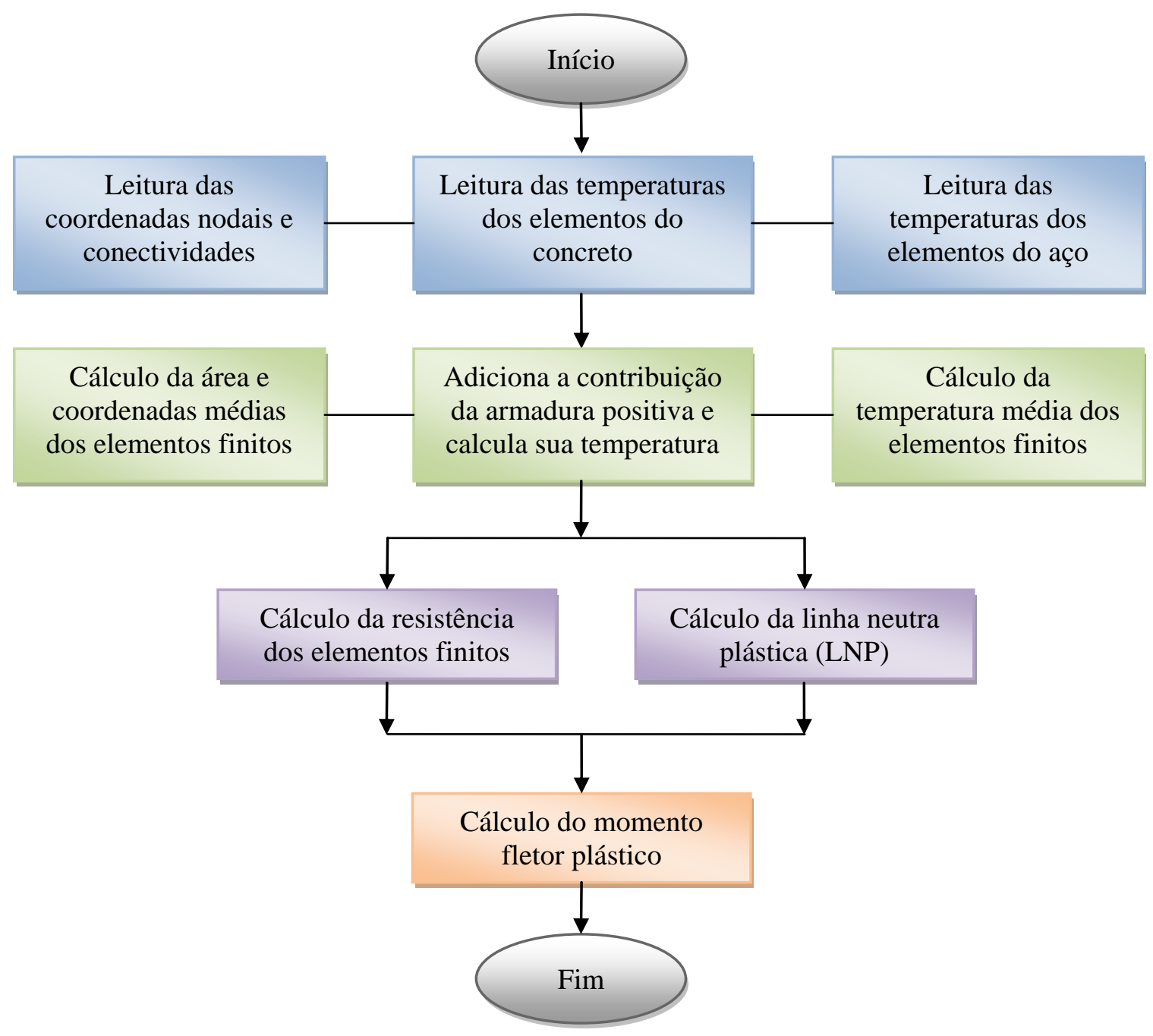

Figura 3.3 - Fluxograma simplificado para cálculo do momento fletor plástico da laje mista

\subsubsection{Pré-processamento e processamento em arquivo de lotes}

Quando se trata de grandes quantidades de modelos numéricos, como no caso de análise paramétrica, o processamento de modelos individuais se torna exaustivo. Neste caso, o código DIANA oferece a possibilidade de realizar o pré-processamento e o processamento através de arquivos de lotes (Prompt de comandos ou arquivos .bat).

Para o processamento em arquivo de lotes é necessário ter alguns cuidados, como, por exemplo, o correto refinamento de malha de elementos finitos do modelo, pois não se tem uma visualização gráfica do modelo, em que é possível visualizar somente a janela do "DOS" e o acompanhamento do processo de convergência.

No Apêndice A (item A.2) são apresentados o passo-a-passo para o processamento em arquivos de lotes. 


\subsection{Definição do modelo termoestrutural no DIANA}

As etapas de definição do modelo termoestrutural no código computacional DIANA são as mesmas apresentadas para o modelo térmico. Aqui serão apresentadas apenas algumas particularidades do modelo estrutural e termoestrutural, já que neste caso se trata de um modelo tridimensional, alterando as considerações adotadas para os modelos constitutivos para o aço e o concreto e outras considerações sobre o modelo.

O modelo foi desenvolvido com elementos de interface entre a fôrma de aço e o concreto, visando simular possíveis resistências térmica e mecânica nessa interface. Vale ressaltar que esse modelo também permite simular comportamentos termomecânicos com perfeita aderência entre a fôrma de aço e o concreto (interação total) adotando-se valores estratégicos para os coeficientes de condução térmica e a rigidez linear tangencial da interface. Por exemplo, pode-se utilizar valores na ordem de $10000 \mathrm{~W} / \mathrm{m}^{2{ }^{\circ}} \mathrm{C}$ para o coeficiente de condução térmica e $1,0 \times 10^{18} \mathrm{~N} / \mathrm{m}^{3}$ para o coeficiente de rigidez linear tangencial para simular um caso com interação total. Nos itens subsequentes serão vistas mais informações sobre esses coeficientes. No presente modelo também há a possibilidade de utilizar armaduras positivas e de distribuição.

Na Figura 3.4 são apresentados os diversos elementos estruturais e térmicos que compõem o modelo termoestrutural: superfícies de troca de calor com o ambiente, superfícies de aquecimento, concreto, fôrma de aço e interface.

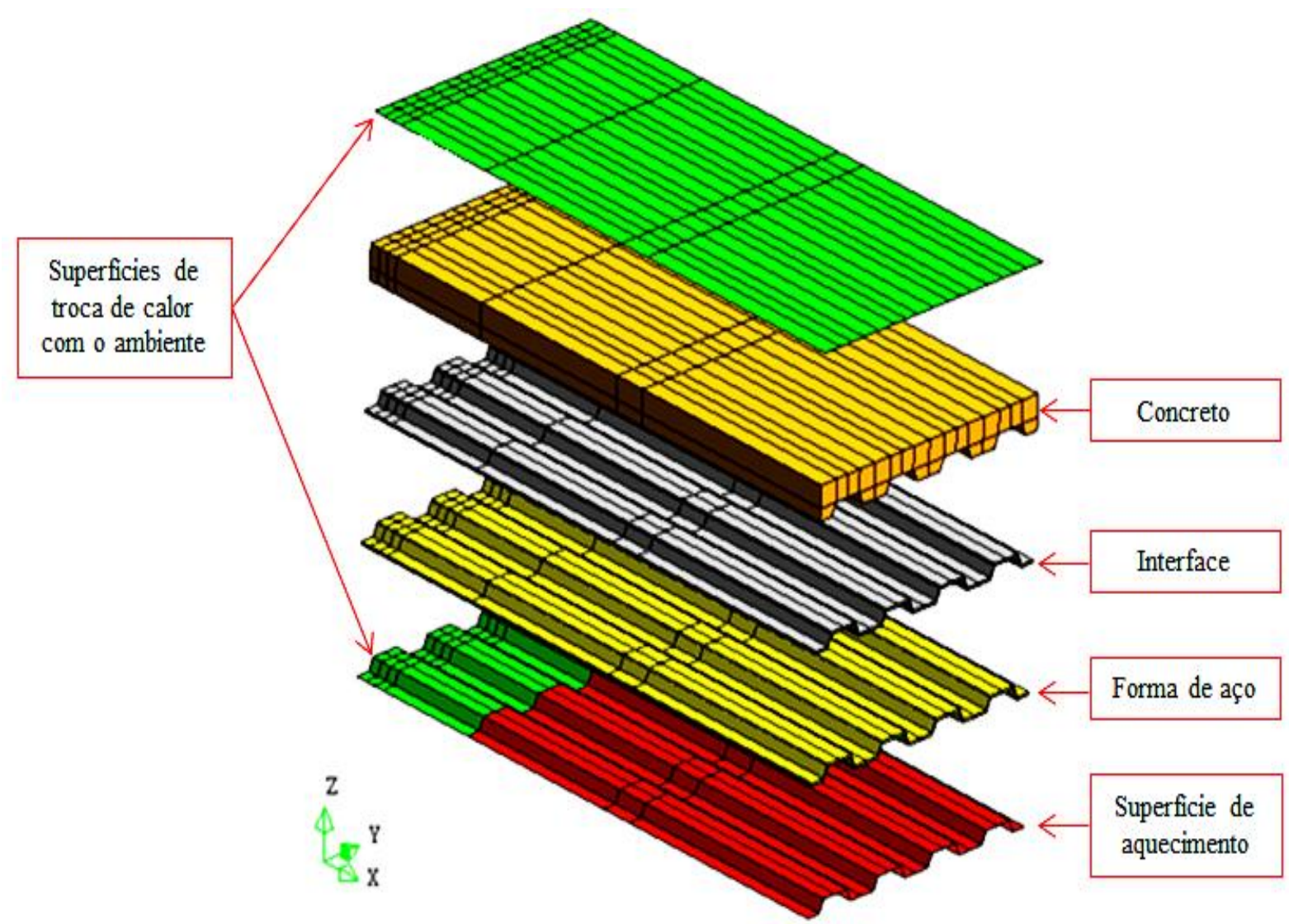

Figura 3.4 - Elementos estruturais e térmicos que compõem o modelo termoestrutural 
A interface é composta por um tipo de elemento especial: elemento sólido, porém com duas superfícies sobrepostas, tornando um sólido com espessura igual a zero. A superfície superior desta interface é acoplada ao concreto e a inferior é acoplada à fôrma de aço, permitindo reproduzir o comportamento termomecânico particular dessa interface.

\subsubsection{Pré-processamento do modelo}

Para criar um novo modelo termoestrutural tridimensional no iDIANA basta acionar o comando "File > New" e escolher a opção "Heatflow-Stress Staggered 3D" em "Model Type" e escolher as unidades que se deseja trabalhar em "Units Definiton".

Assim como feito na análise térmica, o pré-processamento do modelo é realizado por meio de arquivos de texto, os arquivos batch, que contêm todas as informações necessárias para o modelo em questão. Para geração desses arquivos foi desenvolvido um código computacional em Visual Basic 11.0, cuja janela principal é apresentada na Figura 3.5. O Apêndice $\mathrm{F}$ apresenta o script completo para geração do modelo termoestrutural.

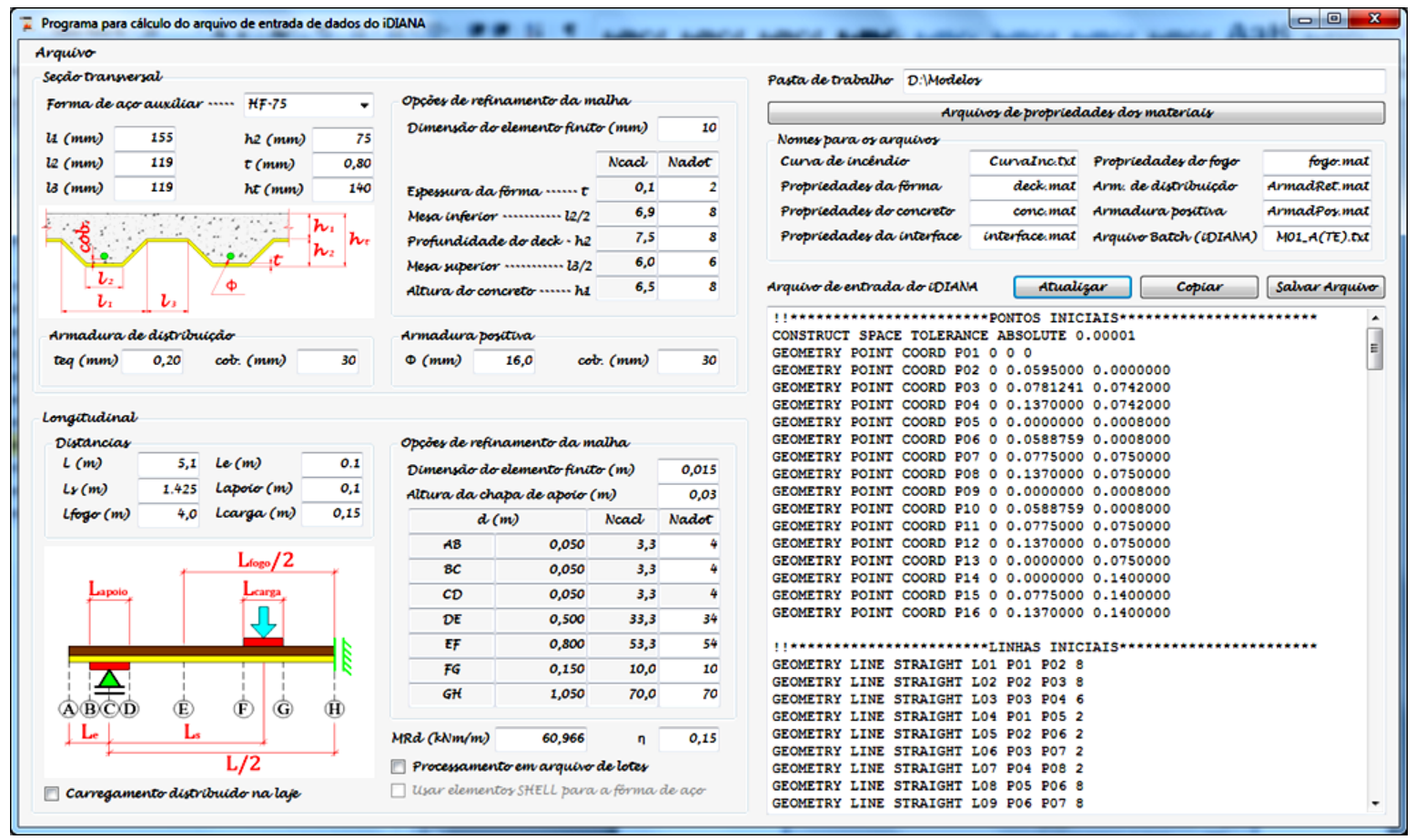

Figura 3.5 - Janela principal do código computacional para geração do modelo termoestrutural

\subsubsection{Definição da geometria}

O processo para criação de linhas, superfícies e SETs é o mesmo apresentado para o modelo térmico, devendo no entanto, incrementar a coordenada $z$ ao final do comando GEOMETRY POINT COORD. 
A criação de elementos sólidos no DIANA pode ser feita por meio da indicação das seis superfícies laterais que compõem o sólido para o caso de elementos hexaédricos. Porém este é um processo muito trabalhoso, pois se tem a necessidade de criar individualmente todos os sólidos, linhas e superfícies do modelo, tornando também o script muito longo. O processo utilizado para geração da geometria do modelo parte do conhecimento das linhas e superfícies de uma seção transversal qualquer do modelo e utiliza o comando de extrusão do DIANA “GEOMETRY SWEEP”. Quando o comando é aplicado em ponto cria-se linha, em uma linha cria-se superfície e em superfície cria-se sólido.

É importante lembrar que todas as linhas, superfícies e sólidos do modelo onde serão aplicados os materiais e as condições de contorno devem ser devidamente nomeados e armazenados em SETs. A Tabela 3.3 sintetiza alguns SETs utilizados para geração do modelo.

Tabela 3.3 - Tipo e descrição de alguns SETs utilizados no modelo

\begin{tabular}{c|c|l}
\hline SET & Tipo & \multicolumn{1}{c}{ Descrição } \\
\hline CONCR & Sólido & Laje de concreto \\
\hline FORMA & Sólido & Fôrma de aço \\
\hline INTERF & Sólido & Interface aço/concreto \\
\hline SFOGO & Superfície & Aplicação do aquecimento \\
\hline SAMBI & Superfície & Aplicação da temperatura ambiente \\
\hline SCARGA & Superfície & Aplicação do carregamento \\
\hline
\end{tabular}

\subsubsection{Elementos finitos utilizados}

Conforme mencionado no capítulo 1 , os tipos de elementos finitos utilizados para a modelagem do concreto e da fôrma de aço são os denominados HX8HT e CHX60 para as análises térmica e estrutural, respectivamente. Para a modelagem da interface entre a fôrma de aço e o concreto, serão utilizados os elementos IQ8HT e CQ48I para as análises térmica e estrutural, respectivamente. Já o elemento BQ4HT simula as condições de contorno em análises termoestruturais acoplada e será utilizado neste trabalho para simular a troca de calor entre o meio e a estrutura. Esses elementos são apresentados na Figura 3.6 e Figura 3.7.
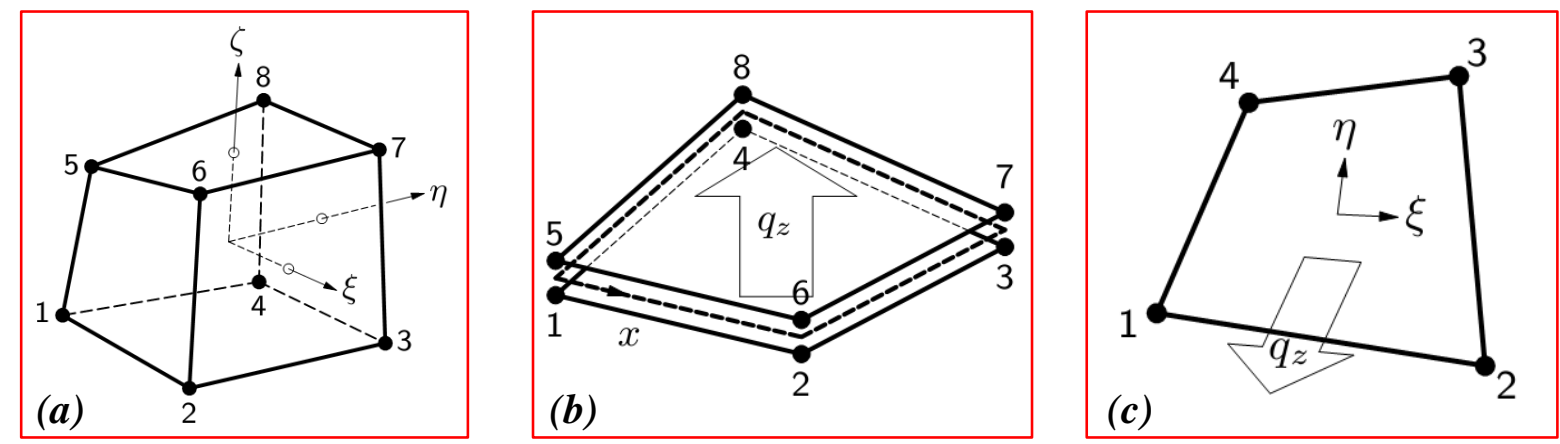

Figura 3.6 - Elementos finitos que serão utilizados para análise térmica: (a) HX8HT (b) IQ8HT e (c) BQ4HT. (DIANA, 2005b) 

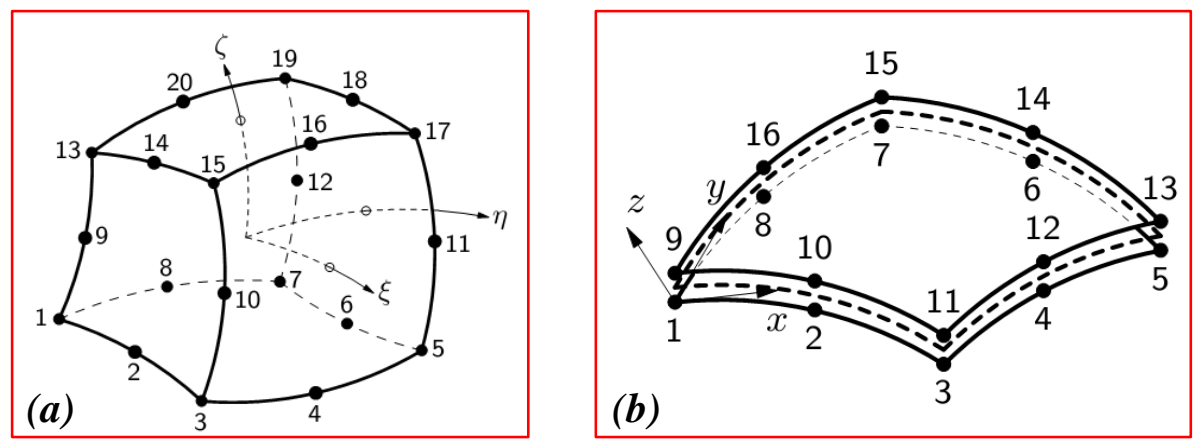

Figura 3.7 - Elementos finitos que serão utilizados para análise estrutural: (a) CHX60 (b) CQ48I. (DIANA, 2005b)

Conforme pode ser observado pelas Figura 3.6 e Figura 3.7, os elementos finitos que serão utilizados para análise estrutural possuem interpolação quadrática para deslocamento, enquanto que aqueles para análise térmica possuem apenas interpolação linear. Desta forma as temperaturas só são calculadas para os nós de extremidade dos elementos na análise térmica e transferidas para a análise termoestrutural acoplada. Já os nós intermediários dos elementos finitos da análise estrutural não têm influência na análise térmica.

A atribuição dos tipos de elementos finitos aos seus respectivos SETs utiliza os mesmos comandos da análise térmica. Porém neste caso somente é necessário atribuir os tipos de elementos CHX60 para a fôrma de aço e o concreto, CQ48I para a interface e BQ4HT para as superfícies de aquecimento. No código DIANA, a conversão dos elementos CHX60 para HX8HT e CQ48I para IQ8HT se faz automaticamente durante a análise termoestrutural.

\subsubsection{Carregamentos considerados na análise}

O procedimento para a aplicação dos carregamentos térmicos é o mesmo para o caso do modelo térmico bidimensional. Já para a aplicação dos carregamentos mecânicos, consideram-se dois tipos de ações para o modelo em questão: o peso próprio da estrutura e a carga aplicada antes de iniciar o ensaio, com o comando PROPERTY LOADS do iDIANA.

O modelo desenvolvido permite a consideração de dois casos de carregamento: duas cargas concentradas ou apenas carga uniformemente distribuída na laje (Figura 3.8). Esses dois casos de carregamento foram implementados, pois são os dois casos utilizados neste presente trabalho. A carga concentrada será aplicada em superfície com comprimento " $L c$ ", visando evitar concentração de tensões na região de aplicação de carga. 
(a)

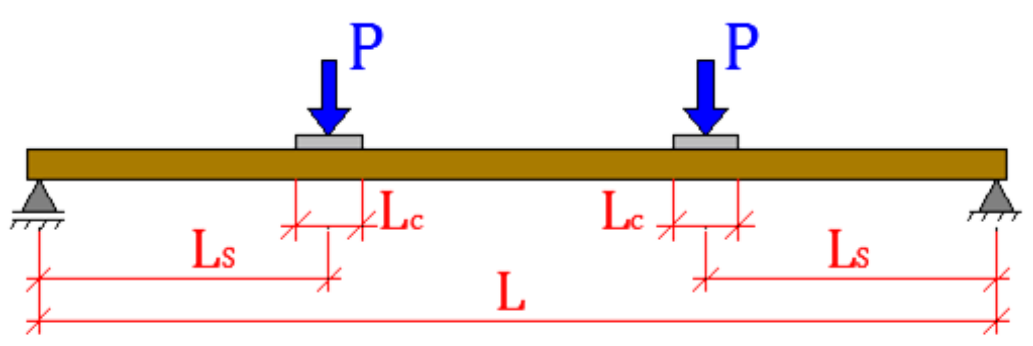

(b)
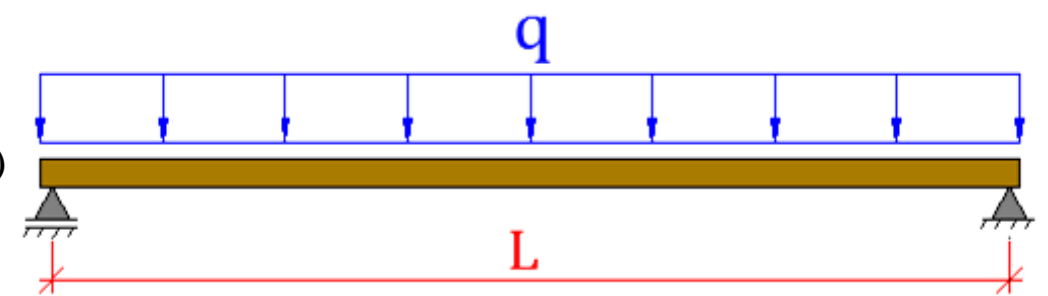

Figura 3.8 - Tipos de carregamento aplicados no modelo termo estrutural: (a) duas cargas concentradas e (b) uma carga uniformemente distribuída

\subsubsection{Condições de contorno}

As condições de contorno em temperatura elevada do modelo termoestrutural são as mesmas utilizadas no modelo térmico bidimensional, ou seja, superfície superior da laje de concreto à temperatura ambiente, superfícies laterais do modelo adiabáticas e a superfície inferior da fôrma de aço estará parte em contato com os gases aquecidos e parte à temperatura ambiente, conforme pode ser observado pela Figura 3.4.

Com relação à vinculação da estrutura, podem-se destacar três casos de vínculos para simular um apoio vertical. O primeiro deles é usar um apoio em linha diretamente na fôrma de aço (Figura 3.9a), porém neste caso pode haver concentrações de tensões no aço nas proximidades do apoio. Para evitar esse problema pode-se utilizar uma chapa de apoio sob a fôrma de aço (Figura 3.9b), distribuindo as tensões no contato da chapa com a fôrma. Por último pode-se utilizar o MPC (Multi-Point Constraints), em que se faz necessário definir um nó mestre (Master node) e os nós escravos (Slave nodes) que terão determinados graus de liberdade dependentes do nó mestre (Figura 3.9b). Desta forma, utilizando o MPC, as tensões do apoio são distribuídas ao longo da seção transversal do elemento estrutural.

Neste trabalho, conforme será visto no capítulo 5, serão analisados os dois primeiros casos supracitados: apoio em linha diretamente na fôrma de aço e chapas de apoio. No iDIANA, para atribuir esses vínculos ao modelo faz-se o uso do comando "PROPERTY BOUNDARY CONSTRAINT". 


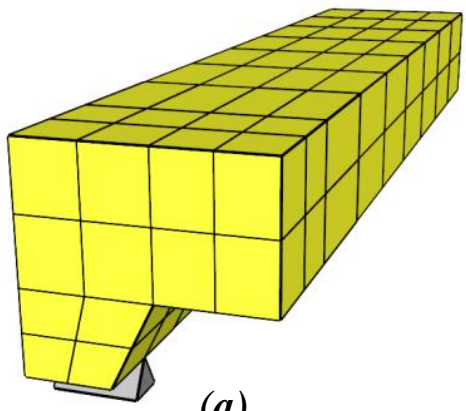

(a)

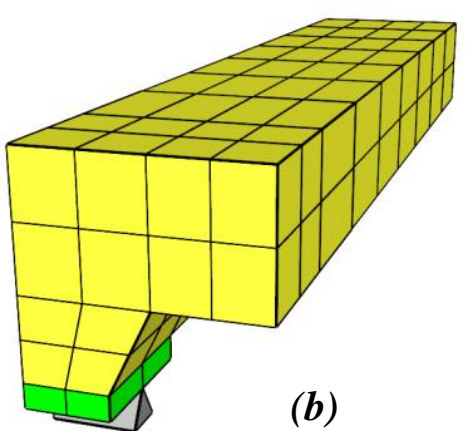

Master node

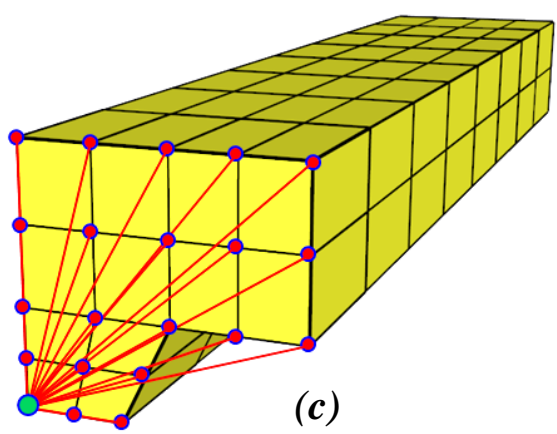

Slave nodes

Figura 3.9 - Possíveis configurações para apoio rotulado: (a) Sem chapa de apoio, (b) Com chapa de apoio e (c) MPC

Para o caso do modelo reduzido ( $1 / 2$ nervura e simetria no meio do vão) são adotadas as condições de contorno apresentadas na Figura 3.10, ou seja, é impedido o deslocamento horizontal (UX) na direção perpendicular à direção de trabalho da laje e o deslocamento horizontal (UY) da seção localizada no meio do vão. Este último caso permite o deslocamento vertical e impede a rotação da seção, simulando um engaste móvel.

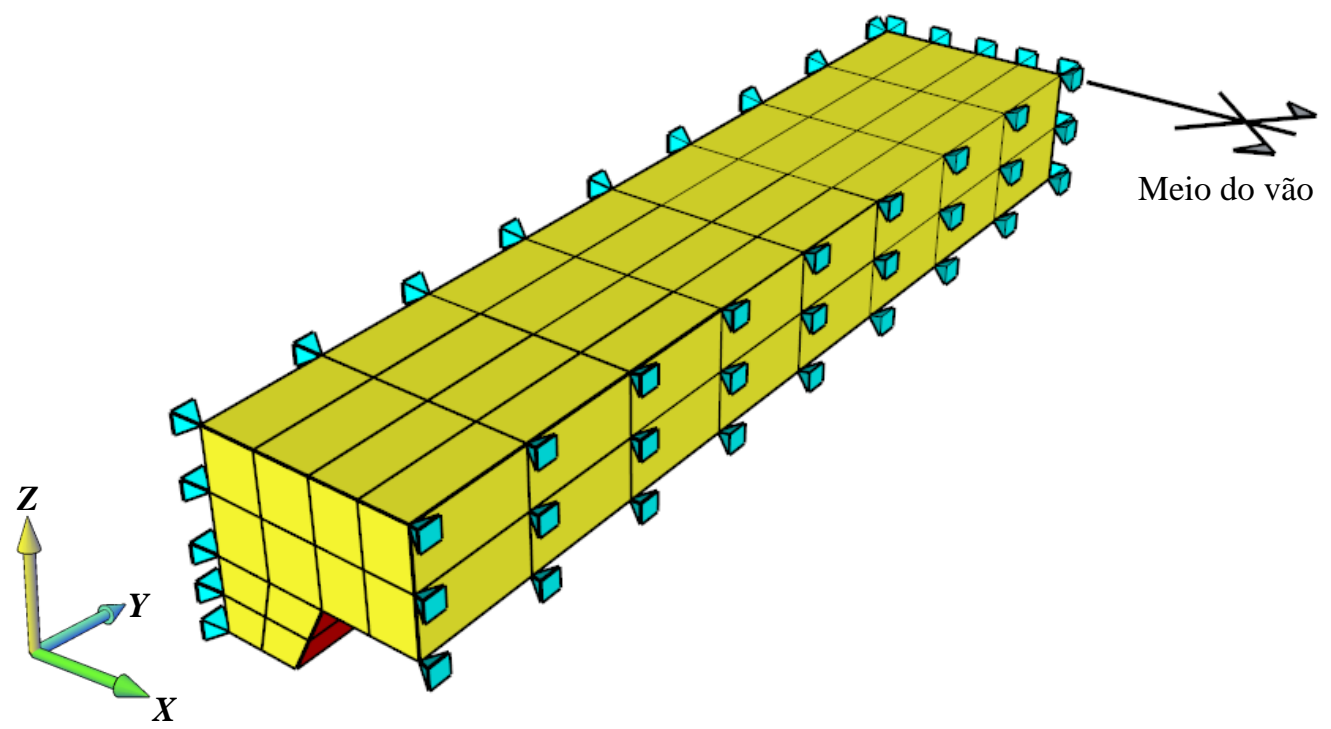

Figura 3.10 - Aplicação das condições de contorno para o modelo reduzido

Vale lembrar que o tipo de modelo apresentado na Figura 3.10 é amplamente utilizado em simulações numéricas de lajes mistas, uma vez que reduz significativamente o número de elementos finitos, reduzindo o tempo de processamento. Este tipo de modelo também é apresentado em GUO (2011). 


\subsubsection{Propriedades dos materiais}

Como as propriedades dos materiais, em sua maioria, são dependentes do tempo, só é possível estabelece-las em arquivos de texto que contenham todas as informações necessárias para um determinado material. Neste caso o arquivo de texto deve ter as informações compatíveis com a entrada de dados do DIANA.

Para facilitar a geração dos arquivos de propriedades dos materiais, desenvolveu-se um aplicativo (Figura 3.11) que é acionado pressionando o botão "Arquivos de propriedades dos materiais" na janela principal do programa apresentado da Figura 3.5. Por meio deste é possível gerar os arquivos que contenham as propriedades da fôrma de aço, armaduras, concreto, interface aço/concreto e a superfícies em contato com o fogo, tendo a possibilidade da escolha do modelo constitutivo elasto-plástico ou segundo o EUROCODE 4 para o aço.

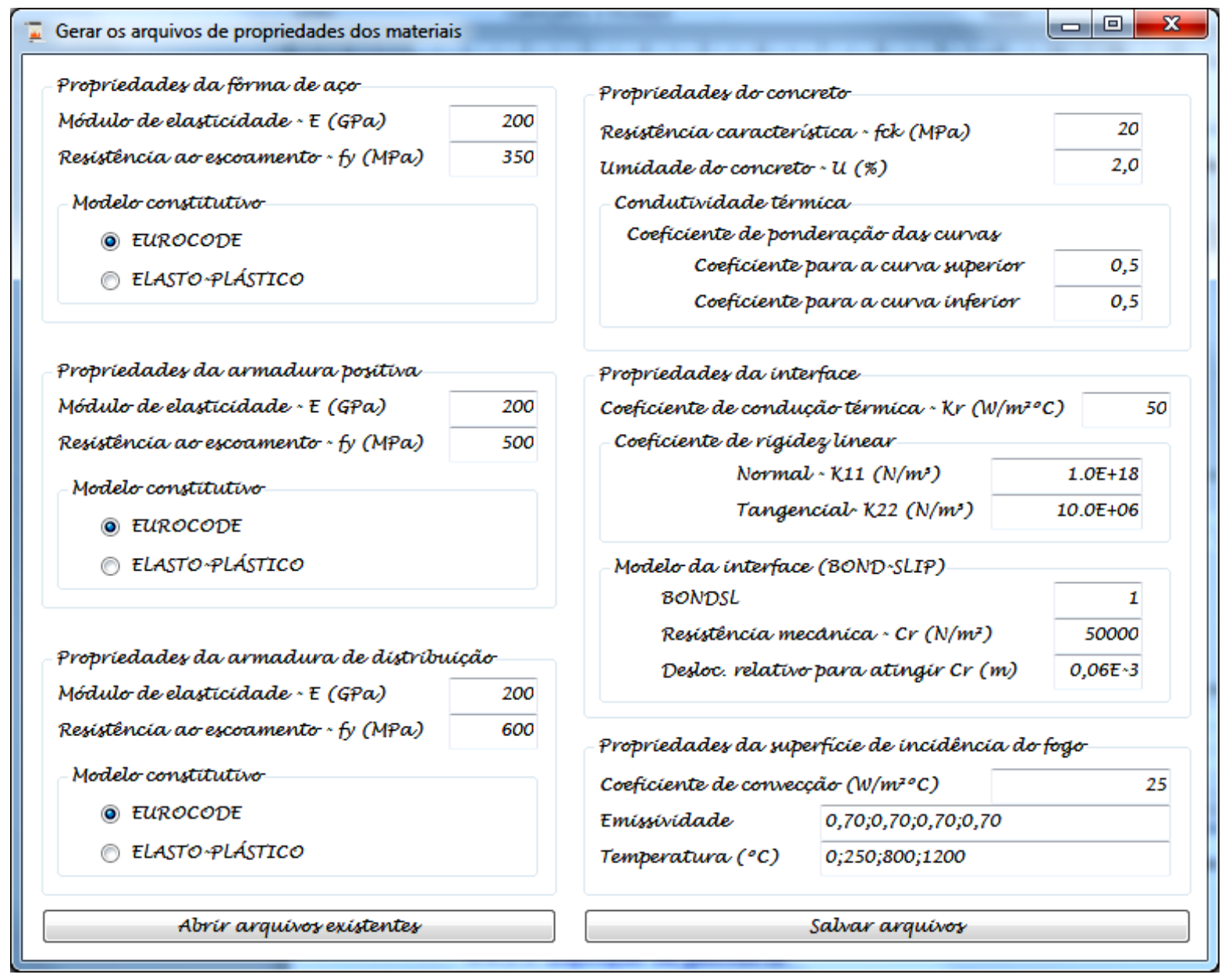

Figura 3.11 - Aplicativo para geração dos arquivos de propriedades dos materiais

A seguir serão descritas as principais considerações adotadas para os modelos constitutivos do aço e do concreto e para a interface entre a fôrma de aço e o concreto. 
Modelo constitutivo para o aço. O código DIANA não oferece a possibilidade de considerar um diagrama tensão $v s$. deformação multilinear para o aço em função da temperatura, como em outros códigos computacionais como o ANSYS e o ABAQUS. A solução adotada para esse problema foi a mesma apresentada em ROCHA (2012): a adoção de um modelo constitutivo com encruamento com critério de plastificação de Von Mises, sendo possível especificar para cada nível de deformação plástica a tensão do material para cada nível de temperatura. A deformação plástica do material é calculada com base na Equação 3.1 e apresentada na Figura 3.12, em que $\varepsilon_{\theta}$ é a deformação total, $\sigma_{\theta}$ a tensão do material e $E_{a, \theta}$ o módulo de elasticidade do aço, todos esses parâmetros em função da temperatura $\theta$.

$$
\kappa_{\theta}=\varepsilon_{\theta}-\sigma_{\theta} / E_{a, \theta}
$$

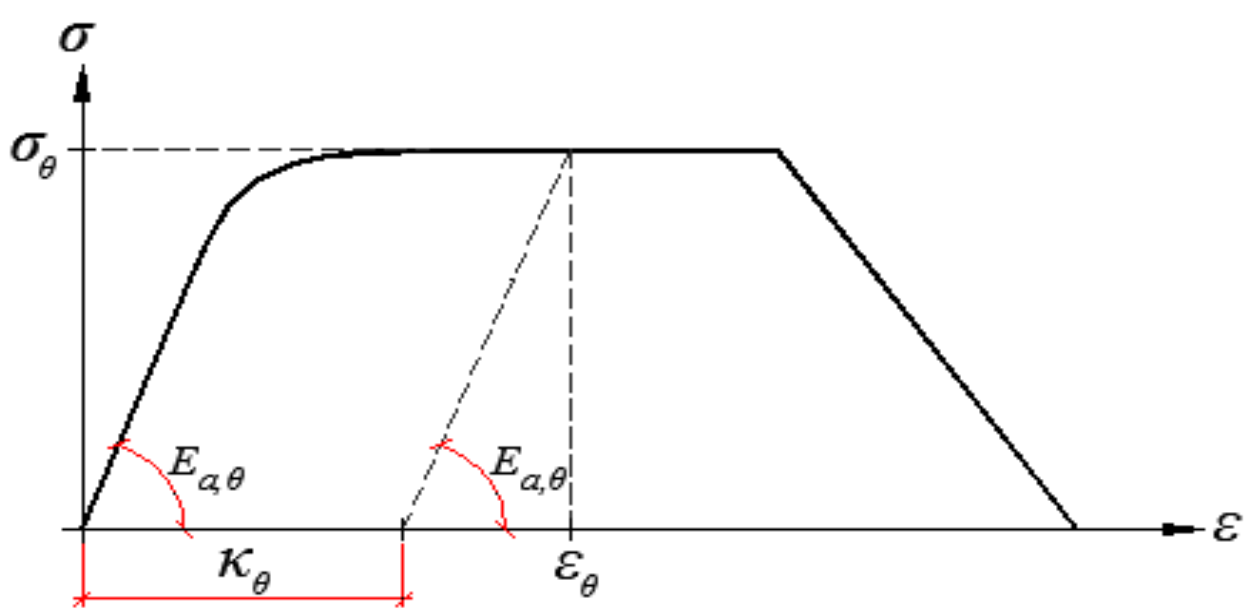

Figura 3.12 - Obtenção da deformação plástica a partir do diagrama tensão vs. deformação do aço

$\mathrm{O}$ arquivo de propriedades do aço (forma.dat), considerando o modelo constitutivo com encruamento, deve estar de acordo com a sintaxe apresentada no Apêndice A, para que possa ser compatível com a entrada de dados do DIANA.

Modelo constitutivo para o concreto. Assim como no caso do aço, o código DIANA não oferece a possibilidade de considerar um modelo multilinear para o concreto (tracionado e comprimido) em função da temperatura. Desse modo é necessário utilizar outros modelos constitutivos oferecidos pelo DIANA, baseados na deformação total dos elementos, também conhecidos como "Total Strain crack models". Nesses modelos, os comportamentos à tração e à compressão do concreto são descritos pelo diagrama "tensão vs. Deformação".

Os modelos constitutivos para representar o comportamento à tração do concreto estão apresentados na Figura 3.13, dentre os quais os mais utilizados em simulação numérica são o Linear (Figura 3.13d) e o Exponencial (Figura 3.13e). Nesse trabalho será adotado o modelo Exponencial para o concreto tracionado, sendo esse testado e avaliado por ROCHA (2012), representado satisfatoriamente o comportamento do concreto tracionado. 


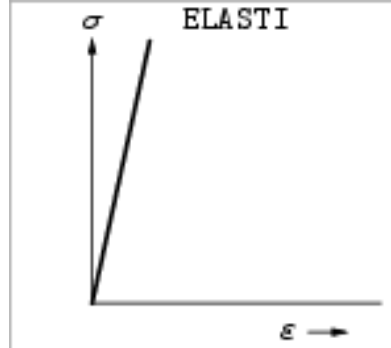

(a) elastic

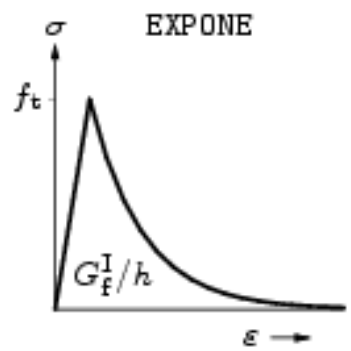

(e) exponential

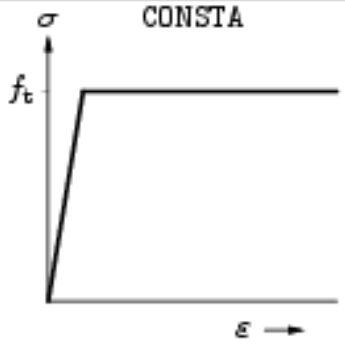

(b) ideal

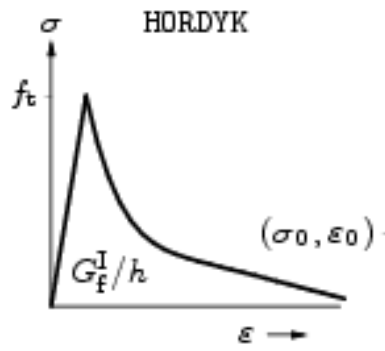

(f) Hordijk

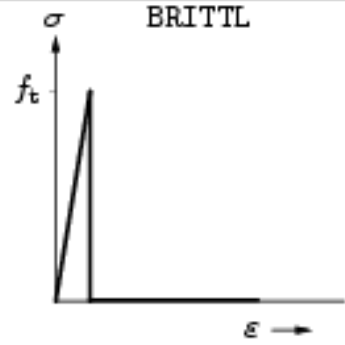

(c) brittle

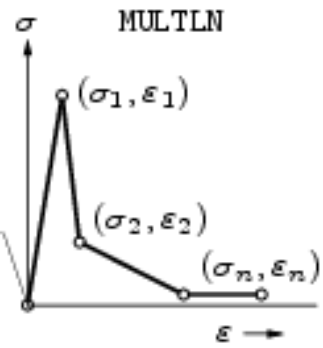

(g) multi-linear

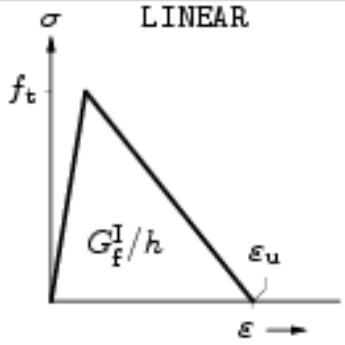

(d) linear

Figura 3.13 - Modelos constitutivos disponíveis no DIANA para o concreto tracionado (DIANA, 2005)

Para o caso do concreto comprimido, o DIANA também oferece sete tipos de modelos constitutivos, conforme apresentado na Figura 3.14. Em ROCHA (2012) foi avaliado o modelo de Thorenfeldt (Figura 3.14c) e o modelo parabólico (Figura 3.14g), os quais apresentaram respostas termoestruturais semelhantes e satisfatórias, mesmo o modelo parabólico não tendo como estabelecer a energia de fratura do concreto comprimido $\left(G_{c}\right)$ em função da temperatura. Deste modo, no presente trabalho será adotado o modelo constitutivo parabólico para representar o comportamento à compressão do concreto.

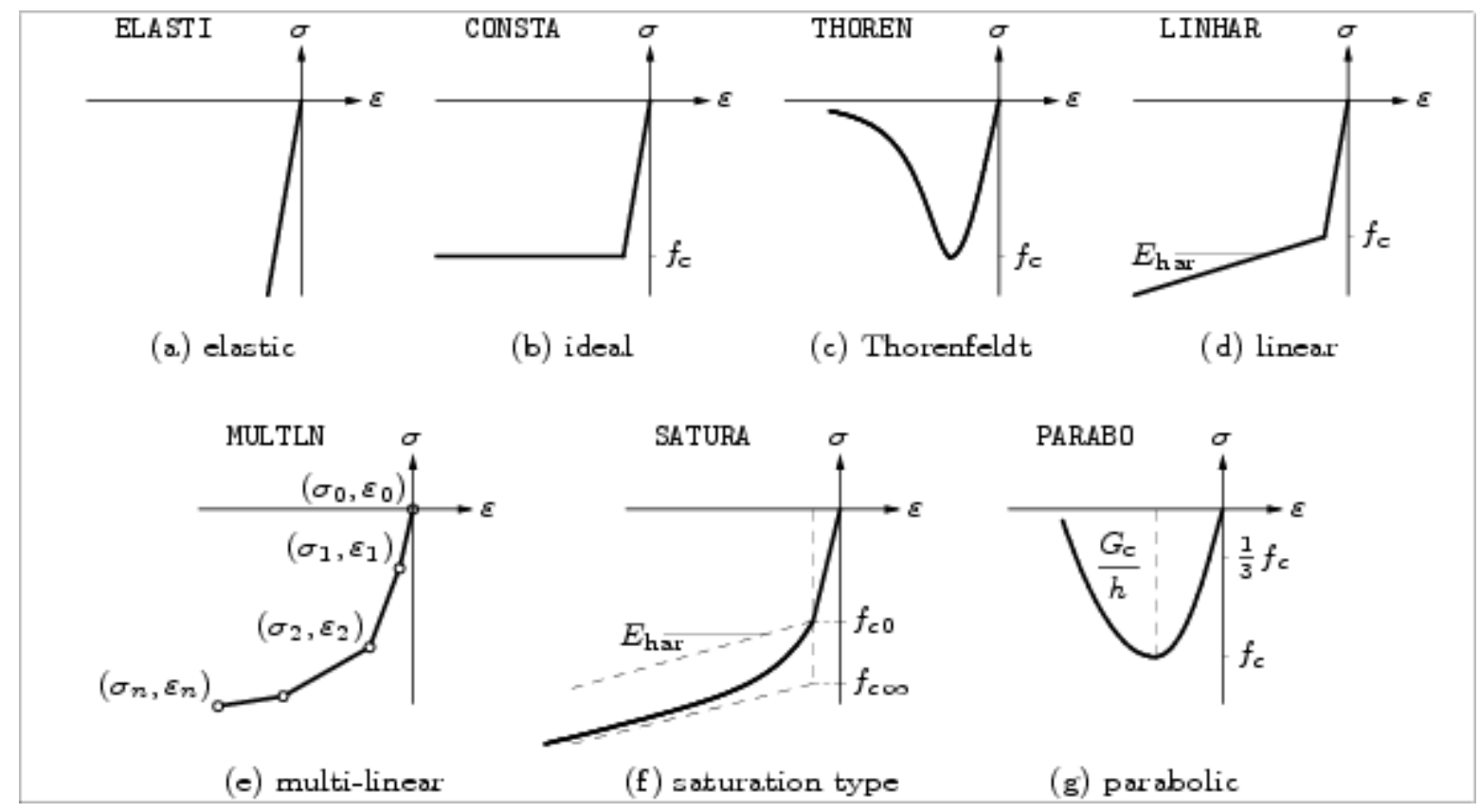

Figura 3.14 - Modelos constitutivos disponíveis no DIANA para o concreto comprimido (DIANA, 2005) 
A sintaxe para geração do arquivo de propriedades do concreto, utilizando os modelos constitutivos exponencial e parabólico para o concreto tracionado e comprimido respectivamente, é apresentada no Apêndice A (item A.2.8). O Apêndice H apresenta um exemplo desses arquivos, utilizados durante a análise numérica.

Interface aço/concreto. A interface entre a fôrma de aço e o concreto possui características termomecânicas particulares diferentes daquelas do aço e do concreto, devidos principalmente aos diversos tipos de aderência, conforme apresentado no Capítulo 1. Para simular essa interface no DIANA é necessário criar um elemento sólido com espessura igual a zero (duas superfícies sobrepostas). Os nós da malha de elementos finitos pertencentes à superfície inferior dessa interface são acoplados aos nós da superfície superior da fôrma de aço enquanto que os nós da face superior da interface são acoplados aos nós da laje de concreto, conforme mostrado na Figura 3.15.

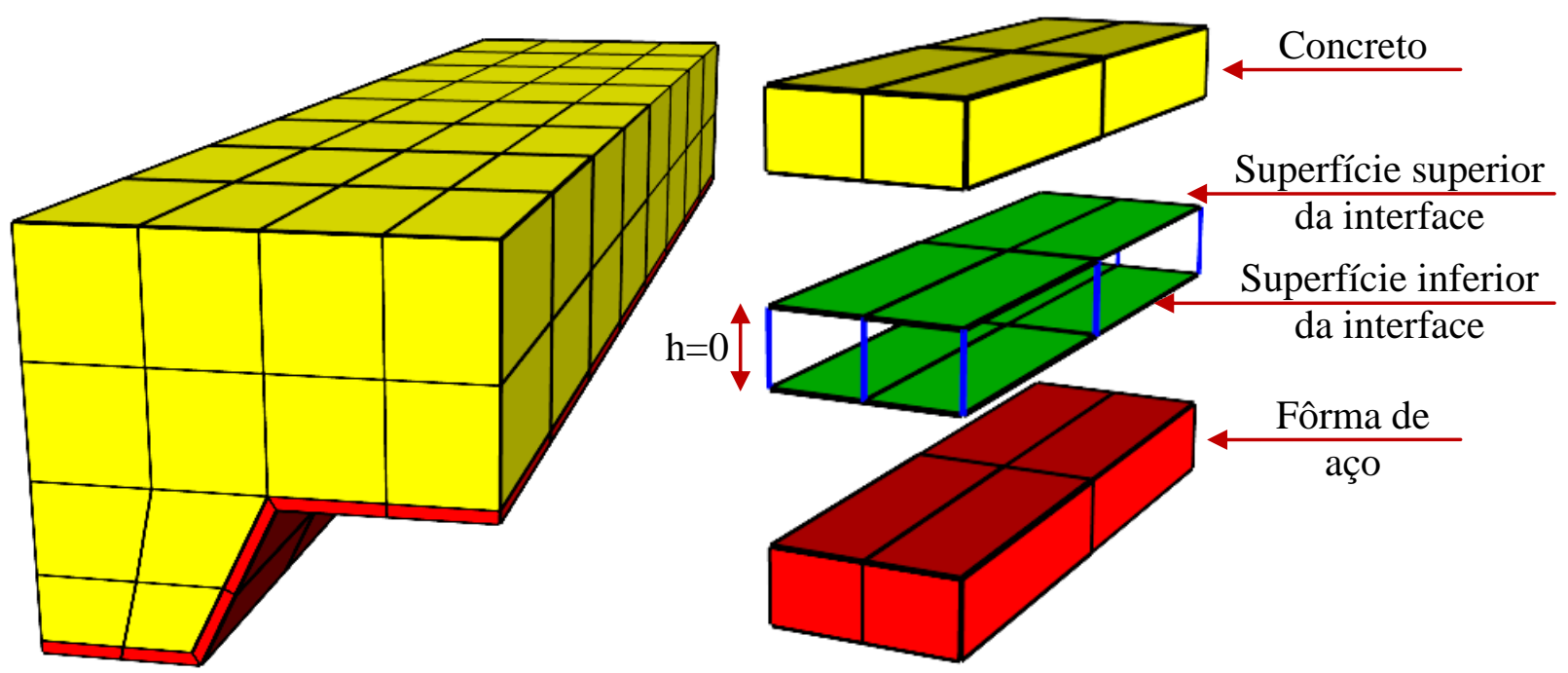

Figura 3.15 - Modelagem da interface entre a fôrma de aço e o concreto

No DIANA há diversos modelos para simular o comportamento da interface, dentre os quais se pode destacar o modelo de rigidez linear e o bond-slip. No modelo de rigidez linear a relação entre a tensão normal à interface $\left(t_{n}\right)$ e o deslocamento normal $\left(\Delta u_{n}\right)$ é medido pelo coeficiente $D_{11}$, enquanto a relação ente a tensão de cisalhamento longitudinal na interface $\left(t_{t}\right)$ e o deslocamento longitudinal $\left(\Delta u_{t}\right)$ é medido pelo coeficiente $D_{22}$, conforme Equações 3.2 e 3.3 .

$$
\begin{aligned}
& D_{11}=\frac{t_{n}}{\Delta u_{n}} \\
& D_{22}=\frac{t_{t}}{\Delta u_{t}}
\end{aligned}
$$

Já para o modelo bond-slip, o código DIANA o subdivide em três modelos: cúbico, potencial e multi-linear, conforme apresentado na Figura 3.16. 


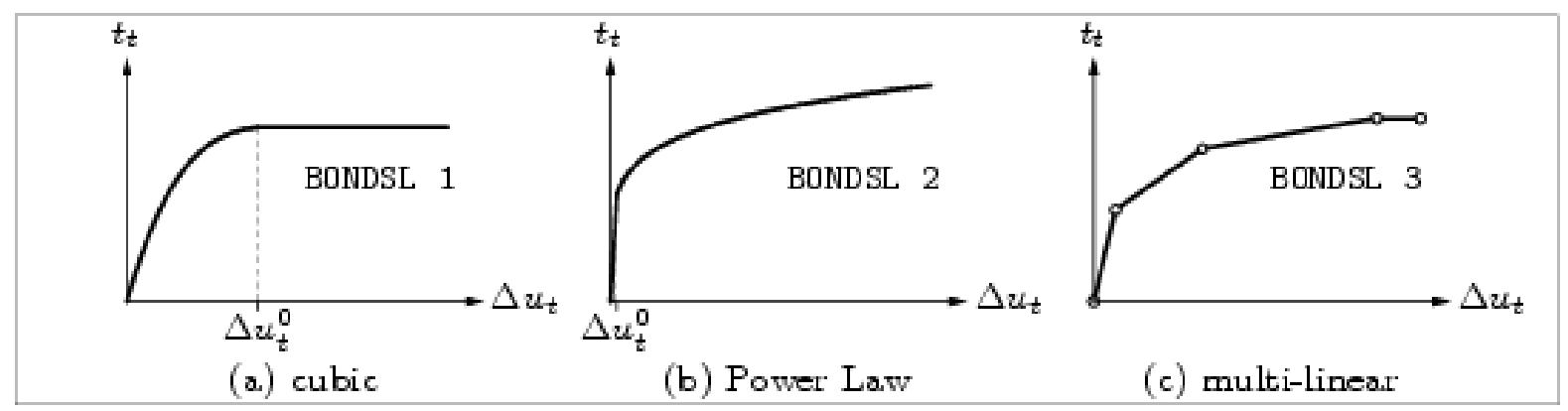

Figura 3.16 - Modelos bond-slip (DIANA, 2005)

Dentre os modelos bond-slip, o que será avaliado neste trabalho é o cúbico (Figura 3.16a), proposto por DÖR (1980) apud DIANA (2005). Nesse modelo, a relação entre a tensão de cisalhamento longitudinal $\left(t_{t}\right)$ e o deslocamento longitudinal $\left(\Delta u_{t}\right)$ é governada por um polinômio de terceiro grau até um deslocamento $\Delta u_{t}^{0}$. Com o deslocamento superior a $\Delta u_{t}^{0}$ a tensão de cisalhamento resistente passa a ser constante, de acordo a Equação 3.4.

$$
t_{t}= \begin{cases}c\left(5\left(\frac{\Delta u_{t}}{\Delta u_{t}^{0}}\right)-4,5\left(\frac{\Delta u_{t}}{\Delta u_{t}^{0}}\right)^{2}+1,4\left(\frac{\Delta u_{t}}{\Delta u_{t}^{0}}\right)^{3}\right) & \text { se } 0 \leq \Delta u_{t}<\Delta u_{t}^{0} \\ 1,9 c & \text { se } \Delta u_{t} \geq \Delta u_{t}^{0}\end{cases}
$$

Na Equação 3.4, $c$ é o valor da resistência ao cisalhamento longitudinal. Segundo as referências técnicas apresentadas no DIANA, o valor recomendado para $c$ é a resistência à tração do concreto e para $\Delta u_{t}^{0}=0,06 \mathrm{~mm}$. Neste trabalho, as propriedades termomecânicas da interface serão lidas pelo DIANA por meio de arquivos de texto (interface.mat), que possui a sintaxe apresentada no Apêndice A (item A.2.9).

\subsubsection{Quanto ao Processamento}

Como a análise a ser realizada é do tipo termoestrutural acoplada, o processamento do modelo é feito em três etapas. Na primeira etapa é feito o processamento do modelo térmico, na qual a análise é do tipo térmico transiente. Nessa etapa é importante a definição dos time steps, ou seja, os intervalos de tempo nos quais serão calculados os campos térmicos. Durante os primeiros 10 minutos de aquecimento, devido ao aumento brusco da temperatura dos gases, é adotado time steps menores, variando de 10 a 30 segundos. Com a redução da taxa de aquecimento, é possível adotar time steps maiores na ordem de 60 a 120 segundos, após os 10 minutos de aquecimento. Essa estratégia é importante, pois reduz o tempo de processamento do modelo sem afetar os resultados.

Na segunda etapa é realizado o carregamento mecânico do modelo até o nível de carga desejado, utilizando o módulo de análise estrutural não linear, onde também são 
utilizados o método do comprimento de arco e o line search. Os valores do passo de carga aplicados no modelo variam entre 0,005 e 0,05 da carga de ruptura.

Por fim, na terceira etapa, é realizada a análise termoestrutural acoplada. Nessa etapa os campos térmicos calculados previamente são aplicados ao modelo carregado, simulando um caso com regime transiente, como o que ocorre na prática. Assim como durante a análise térmica, nessa etapa também se tem a necessidade de definir "time steps", que neste caso são os passos de tempo em que serão aplicados os campos térmicos, podendo ser adotado os mesmos "time steps" da análise térmica. O modelo termoestrutural também pode ser utilizado para análise estrutural simples, e neste caso é necessário somente processar a temperatura inicial do modelo $\left(20^{\circ} \mathrm{C}\right)$ e realizar a análise estrutural não linear.

Todos esses comando para processamento do modelo podem ser salvos em arquivos com extensão *.com ou *.dcf, dependendo da versão do DIANA, facilitando a automatização da modelagem, conforme apresentado no Apêndice I.

\subsubsection{Quanto ao Pós-processamento}

Para o pós-processamento do modelo o código DIANA oferece duas possibilidade de visualização dos resultados: gráfica e tabular. Na visualização gráfica do iDIANA, o femview, é possível visualizar informações como os campos térmicos, estrutura deformada, vetores de fluxo, tensões, gráficos, entre outros. Já os dados tabulados são salvos pelo DIANA em arquivos com a extensão *.tb durante a etapa de processamento e contém informações selecionadas pelo usuário como temperatura, tensão, reação, deslocamento, entre outras em função dos passos de carga ou de tempo.

Visando facilitar o pós-processamento dos dados tabulados, foram desenvolvidos diversos códigos computacionais em linguagem FORTRAN capazes de ler as saídas de dados dos arquivos *.tb e processá-las para serem utilizadas em uma planilha eletrônica. Dentre esses códigos desenvolvidos pode-se citar o de cálculo de reações e o de temperatura média de um ponto qualquer do modelo $v s$. tempo de aquecimento, dentre outros.

Vale ressaltar que é possível salvar dados em arquivos de texto diretamente na interface gráfica do DIANA utilizando o comando "UTILITY TABULATE PRINTFILE". Quando se utiliza este comando, todos os comandos de visualização gráfica dos resultados realizados em são automaticamente salvos em arquivo de texto, que contem as coordenadas $\mathrm{XY}$ do gráfico visualizado. 


\subsection{Outras considerações sobre o modelo termoestrutural}

\subsubsection{Energia de fratura do concreto}

A energia de fratura do concreto na tração é calculada de acordo o modelo do CEBFIP (1990), também apresentada no manual do DIANA (2005d), de acordo a Equação 3.5.

$$
G_{f}=G_{f 0}\left(\frac{f_{c m}}{f_{c m 0}}\right)^{0,7}
$$

$\mathrm{Na}$ Equação $3.5 f_{c m 0}$ é igual a $10 \mathrm{MPa}, f_{c m}$ é dada pela Equação 3.6 e $G_{f 0}$ é o valor básico da energia de fratura, que depende do tamanho máximo do agregado de acordo a Tabela 3.4.

$$
f_{c m}=f_{c k}+8[M P a]
$$

Tabela 3.4 - Valores de $G_{f 0}$ em função do diâmetro máximo do agregado

\begin{tabular}{c|c}
\hline $\boldsymbol{d}_{\max }(\mathbf{m m})$ & $\boldsymbol{G}_{\boldsymbol{f} \boldsymbol{0}}\left(\mathbf{N} \cdot \mathbf{m} / \mathbf{m}^{2}\right)$ \\
\hline 8 & 25 \\
\hline 16 & 30 \\
\hline 32 & 58 \\
\hline
\end{tabular}

Já com relação à energia de fratura do concreto à compressão $\left(G_{c}\right)$, experimentos têm mostrado que esta varia de 10 a $25 \mathrm{~N} . \mathrm{mm} / \mathrm{mm}^{2}$, aproximadamente de 50 a 100 vezes a energia de fratura do concreto à tração (FEENESTRA, 1993). Neste trabalho será adotado o valor da energia de fratura do concreto à compressão igual a 50 vezes o valor correspondente à tração $\left(\boldsymbol{G}_{\boldsymbol{c}}=\mathbf{5 0} \boldsymbol{G}_{\boldsymbol{f}}\right)$. Esse valor da energia de fratura do concreto à compressão também foi adotado por ROCHA (2012).

\subsubsection{Largura de banda da fissura}

A largura de banda da fissura $(h)$ corresponde a uma dimensão representativa da malha de elementos finitos e tem a função de caracterizar o aparecimento de fissuras e do efeito de dano irreversível em um elemento finito (ROCHA, 2012). No código DIANA o valor da largura de banda da fissura pode ser dado pelo usuário ou calculado automaticamente pelo DIANA (opção default). O último caso foi adotado neste trabalho e é calculada de acordo a Equação 3.7, em que $V_{e}$ é o volume do elemento finito.

$$
h=\sqrt[3]{V_{e}}
$$

Se o valor da largura de banda da fissura $(h)$ for muito elevado, o código DIANA faz uma redução na resistência à tração do concreto para adequar o modelo constitutivo em função da relação $G_{f} / h$, conforme será visto no item 4.5.5. 


\subsubsection{Módulo de elasticidade do concreto em temperaturas elevadas}

A ABNT NBR 14323:2013 e a ABNT NBR 15200:2012 não apresentam modelos para cálculo do módulo de elasticidade do concreto em temperaturas elevadas. Porém esse pode ser deduzido por meio da Equação B.19 (Anexo B), que representa o modelo constitutivo do concreto comprimido em temperaturas elevadas, tomando-o como a inclinação inicial da curva, conforme Equação 3.8, cujos parâmetros são definidos no Anexo B.

$$
E_{c, \theta}=\left.\frac{\partial\left(\sigma\left(\varepsilon_{c, \theta}\right)\right)}{\partial \varepsilon_{c, \theta}}\right|_{\varepsilon_{c, \theta}=0}=\frac{3}{2} \frac{f_{c, \theta}}{\varepsilon_{c u, \theta}}
$$

Porém, utilizando a Equação 3.8, se nota que o módulo de elasticidade do concreto é significativamente afetado pela temperatura. Por exemplo, para a temperatura ambiente (20 ${ }^{\circ} \mathrm{C}$ ) o valor de $\varepsilon_{c u, \theta}$ dado pela ABNT NBR 15200:2012 é igual a 0,25\%, ou seja, o módulo de elasticidade inicial do concreto à temperatura ambiente calculado pela Equação 3.8 é igual a 600 vezes sua resistência à compressão. Esse valor é aproximadamente a metade daquele calculado de acordo a ABNT NBR 6118:2007, dado pela Equação 3.9, em que $f_{c}$ é a resistência à compressão do concreto a temperatura ambiente em MPa.

$$
E_{c, 0}=5600 \sqrt{f_{c}}
$$

Na Figura 3.17 são apresentados diferentes valores para o módulo de elasticidade do concreto em função da temperatura, sendo eles calculados de acordo os coeficientes de redução apresentados em ROCHA (2012), de acordo a Equação 3.8 e valores experimentais (MORENO JUNIOR, 2013) disponibilizados pela CODEME Engenharia S.A. No presente trabalho adotaram-se coeficientes de redução do módulo de elasticidade do concreto de acordo os resultados experimentais apresentados em MORENO JUNIOR (2013). Porém esses ensaios foram realizados para temperaturas inferiores a $600^{\circ} \mathrm{C}$, logo a partir dessa temperatura os valores adotados foram calculados de acordo a Equação 3.8.

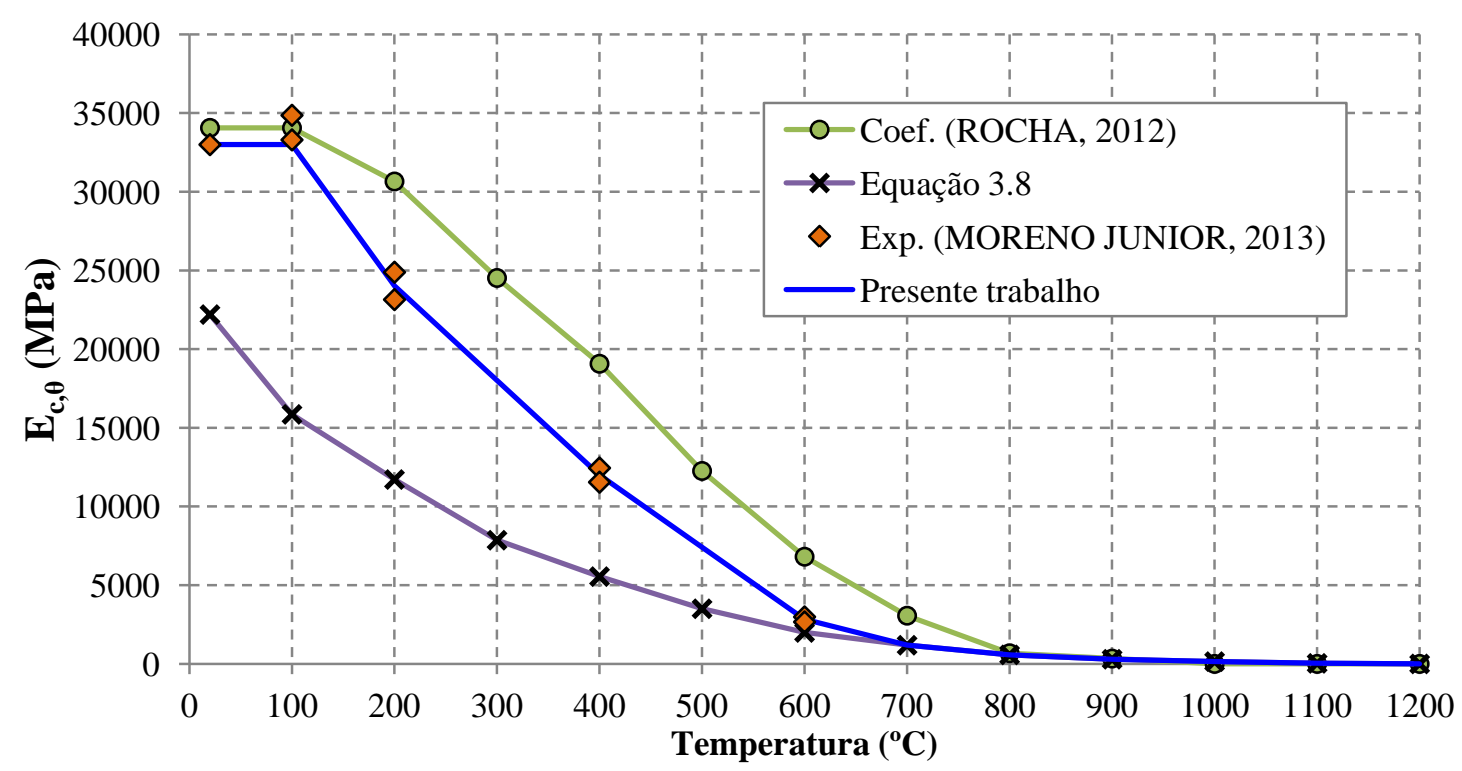

Figura 3.17 - Módulo de elasticidade do concreto em função da temperatura 
Na Figura 3.18 são apresentados os coeficientes de redução do módulo de elasticidade do concreto apresentados em ROCHA (2012) e aqueles adotados no presente trabalho, fazendo as considerações supracitadas.

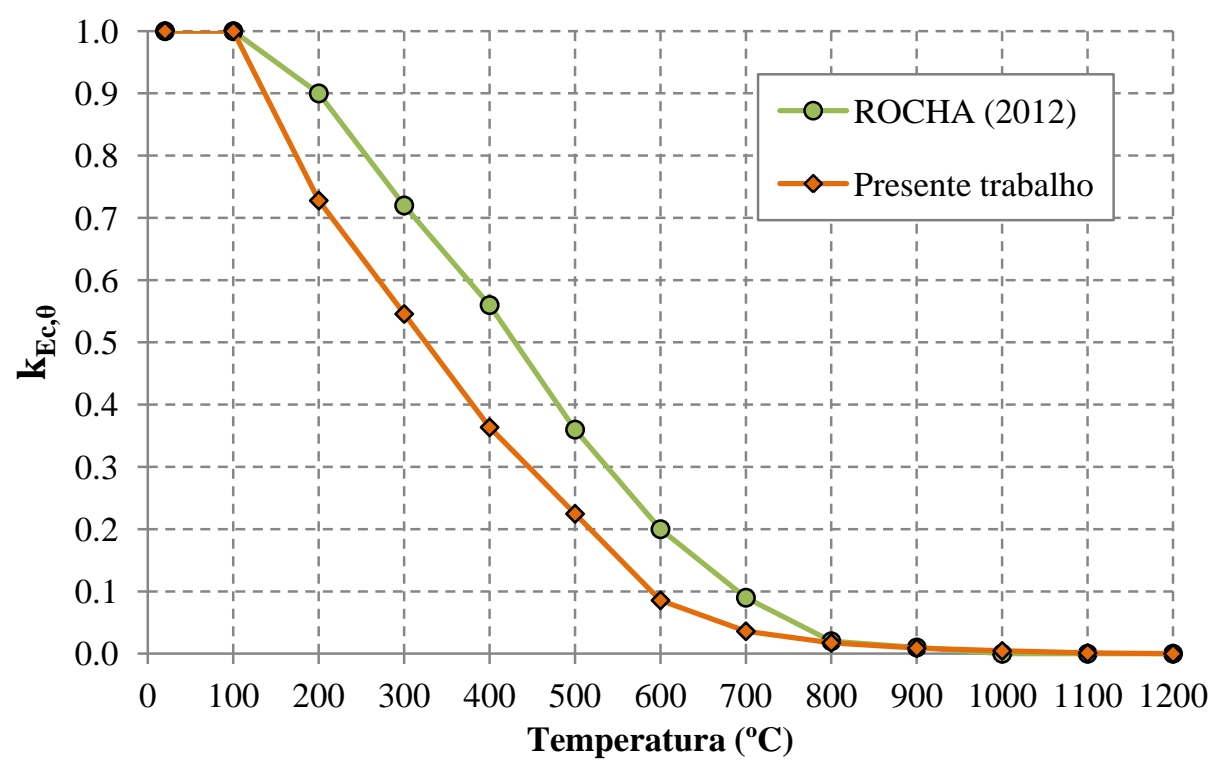

Figura 3.18 - Coeficientes de redução do modulo de elasticidade do concreto em função da temperatura

\subsubsection{O modelo constitutivo parabólico para o concreto comprimido}

O modelo constitutivo parabólico para o concreto à compressão disponível no DIANA foi proposto por FEENESTRA (1993). A curva "tensão vs. Deformação" apresenta três trechos característicos, um linear e dois parabólicos, conforme apresentado na Figura 3.19.

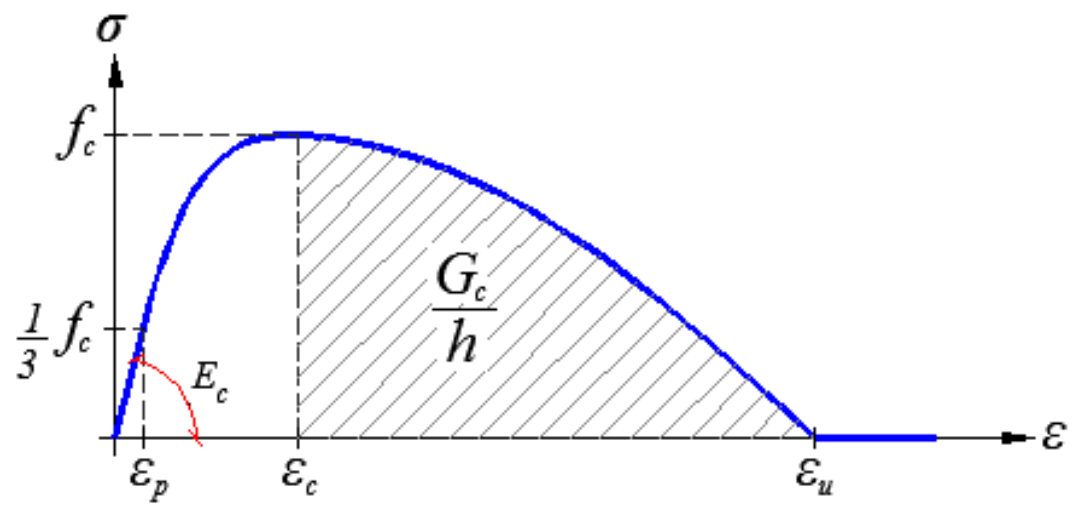

Figura 3.19 - Modelo constitutivo parabólico para o concreto a compressão

A deformação $\varepsilon_{p}$ é um parâmetro que corresponde a 1/3 da resistência à compressão, a deformação $\varepsilon_{c}$ é um parâmetro que corresponde a resistência à compressão $\left(f_{c}\right)$ e $\varepsilon_{u}$ é a deformação última do concreto à compressão. Essas três deformações são apresentadas por meio das Equações 3.10, 3.11 e 3.12, respectivamente. 


$$
\begin{aligned}
\varepsilon_{p} & =\frac{1}{3} \frac{f_{c}}{E_{c}} \\
\varepsilon_{c} & =\frac{5}{3} \frac{f_{c}}{E_{c}}=5 \varepsilon_{p} \\
\varepsilon_{u} & =\varepsilon_{c}+\frac{3}{2} \frac{G_{c}}{h f_{c}}
\end{aligned}
$$

A curva que descreve o comportamento parabólico à compressão do concreto é obtida por uma equação linear no primeiro trecho e mais duas equações do segundo grau para o segundo e terceiro trecho. Para encontrar todos os coeficientes da equação da curva também é necessário estabelecer que a derivada no ponto $\varepsilon=\varepsilon_{p}$ é igual a zero. Desta forma, obtém-se a curva "tensão vs. deformação" dada pelas Equações em 3.13.

$$
\sigma= \begin{cases}\frac{1}{3} f_{c} \frac{\varepsilon}{\varepsilon_{p}} & \text { para } 0 \leq \varepsilon \leq \varepsilon_{p} \\ \frac{1}{3} f_{c}\left(1+4\left(\frac{\varepsilon-\varepsilon_{p}}{\varepsilon_{c}-\varepsilon_{p}}\right)-2\left(\frac{\varepsilon-\varepsilon_{p}}{\varepsilon_{c}-\varepsilon_{p}}\right)^{2}\right) & \text { para } \varepsilon_{p} \leq \varepsilon \leq \varepsilon_{c} \\ f_{c}\left(1-\left(\frac{\varepsilon-\varepsilon_{c}}{\varepsilon_{u}-\varepsilon_{c}}\right)^{2}\right) & \text { para } \varepsilon_{c} \leq \varepsilon \leq \varepsilon_{u} \\ 0 & \text { para } \varepsilon_{u} \leq \varepsilon\end{cases}
$$

A Figura 3.20 apresenta curvas "tensão vs. deformação" para o concreto à compressão segundo o modelo da ABNT NBR 15200:2012 e o modelo parabólico, para temperaturas de $20,400,600$ e $800{ }^{\circ} \mathrm{C}$.

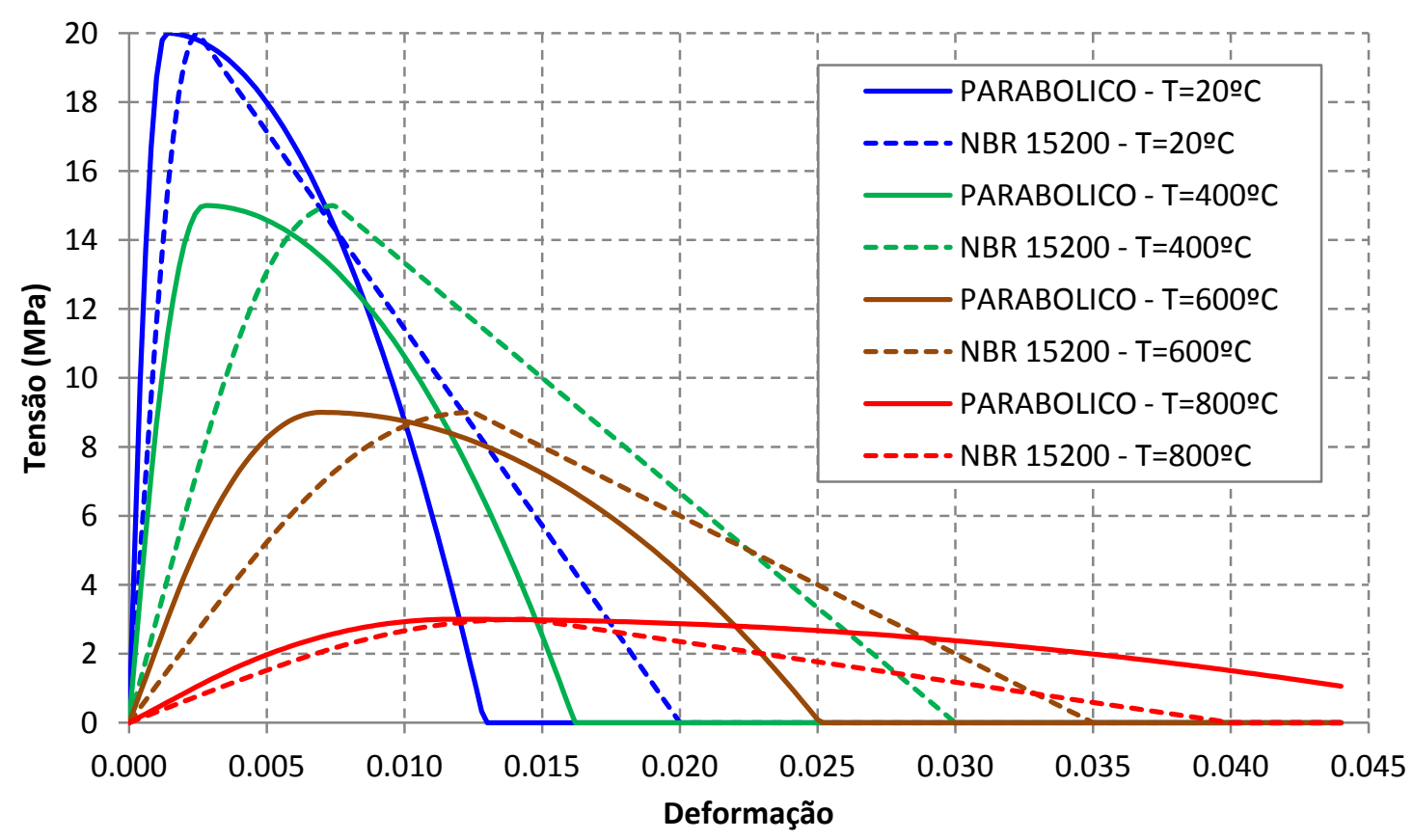

Figura 3.20 - Curvas Tensão vs. Deformação para o concreto comprimido segundo o modelo da ABNT NBR 15200:2012 e o modelo parabólico 
O modelo segundo a ABNT NBR 15200:2012, apresenta inclinações iniciais e tangentes menores que aquelas do modelo parabólico. Isso ocorre pelo fato de o modelo da ABNT NBR 15200:2012 apresentar o módulo de elasticidade tangente inicial inferior àquele calculado pelos coeficientes de redução do módulo de elasticidade a temperatura ambiente, adotados neste presente trabalho, conforme apresentado no item anterior.

\subsubsection{O modelo constitutivo exponencial para o concreto tracionado}

O modelo constitutivo exponencial considera uma relação exponencial entre a tensão $\left(\sigma_{n n}\right)$ e a deformação $\left(\varepsilon_{n n}\right)$ na direção normal à fissura de acordo a Figura 3.21 e a Equação 3.14. Note que o trecho linear inicial não aparece nessa curva, uma vez que a tensão $\left(\sigma_{n n}\right)$ é plotada em função da deformação $\left(\varepsilon_{n n}\right)$ na direção normal à fissura, diferente do apresentado na Figura 3.13.

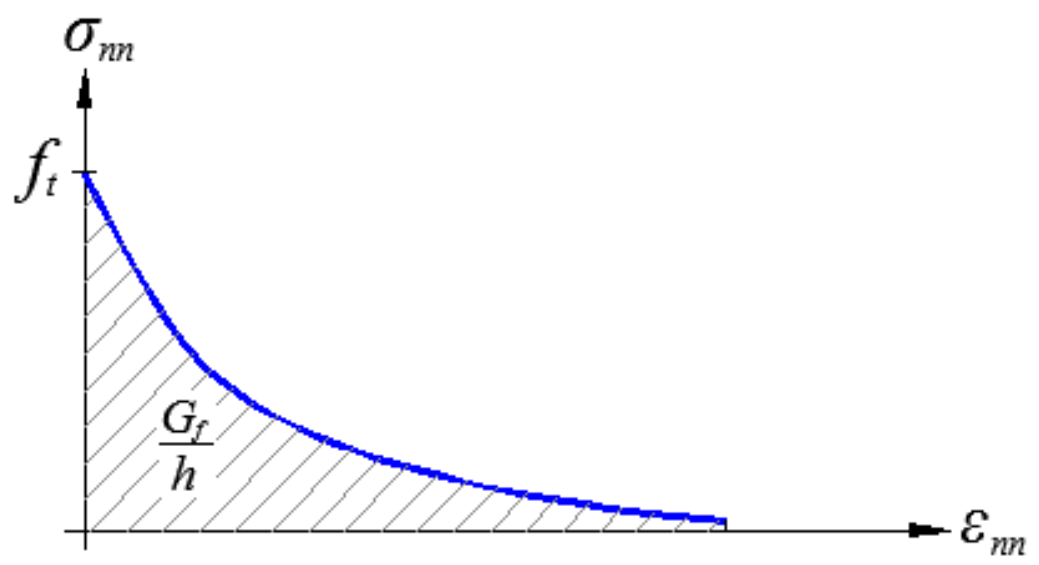

Figura 3.21 - Diagrama Tensão vs. Deformação na fissura para o modelo exponencial

$$
\sigma_{n n}=f_{t} e^{\left(-\frac{\varepsilon_{n n}}{\varepsilon_{u l t}}\right)}
$$

$\mathrm{Na}$ Equação $3.14 f_{t}$ é a resistência à tração do concreto e $\varepsilon_{u l t}$ é um parâmetro de dano associado à fissura obtido pela integração da curva apresentada na Figura 3.21, calculado de acordo a Equação 3.16.

$$
\begin{aligned}
& \frac{G_{f}}{h}=\int_{0}^{\infty} \sigma_{n n} d \varepsilon_{n n}=\int_{0}^{\infty} f_{t} e^{\left(-\frac{\varepsilon_{n n}}{\varepsilon_{u l t}}\right)} d \varepsilon_{n n}=f_{t} \varepsilon_{u l t} \\
& \varepsilon_{u l t}=\frac{G_{f}}{h \cdot f_{t}}
\end{aligned}
$$

É possível que alguns elementos finitos do modelo discretizado possuam comprimento característico muito grande, resultando em um "snap-back" no modelo constitutivo e, neste caso, o conceito de energia de fratura assumido não é mais satisfeito. Isso é possível quando a 
inclinação inicial em módulo da curva for superior ao módulo de elasticidade do material, para que isso não ocorra, a condição estabelecida na Equação 3.17 deve ser satisfeita.

$$
-\left.\frac{d \sigma_{n n}}{d \varepsilon_{n n}}\right|_{\varepsilon_{n n}=0}=-\left.f_{t} \frac{-1}{\varepsilon_{u l t}} e^{\left(-\frac{\varepsilon_{n n}}{\varepsilon_{u l t}}\right)}\right|_{\varepsilon_{n n}=0}=\frac{f_{t}}{\varepsilon_{u l t}} \leq E_{c}
$$

Substituindo o valor de $\varepsilon_{u l t}$ na Equação 3.17 chega-se na Equação 3.18.

$$
h \leq \frac{G_{f} \cdot E_{c}}{f_{t}^{2}}
$$

Caso a condição estabelecida na Equação 3.18 não for atendida é feita uma redução na resistência à tração $f_{t, r e d}$ de acordo a Equação 3.19, resultando em um fratura frágil.

$$
f_{t, r e d}=\sqrt{\frac{G_{f} \cdot E_{c}}{h}}
$$

\subsubsection{Coeficiente de expansão térmica}

Conforme apresentado no Anexo $\mathrm{B}$, as referências normativas estabelecem o alongamento térmico $\left(\Delta L / L_{0}\right)$ para o aço e concreto em função da temperatura $(\theta)$. Porém, no código DIANA não é possível criar uma curva para o alongamento térmico em função da temperatura, ou seja, isso deve ser feito por meio do coeficiente de expansão térmica $(\alpha)$. Para calcular o valor de $\alpha$ parte-se inicialmente da equação do alongamento térmico em função da temperatura conforme Equação 3.20, em que $a_{i}$ são coeficientes para a curva conforme apresentado no Anexo B.

$$
\frac{\Delta L}{L_{0}}=a_{0}+a_{1} \theta+a_{2} \theta^{2}+a_{3} \theta^{3}=f(\theta)
$$

Sabendo que $\Delta L=L-L_{0}$, em que $L$ é o comprimento do elemento na temperatura $\theta$, a Equação 3.20 pode ser reescrita na forma da Equação 3.21.

$$
L=L_{0}(1+f(\theta))
$$

Com um aumento de temperatura de $\theta_{1}$ para $\theta_{2}$ o comprimento do elemento passa de $L_{l}$ para $L_{2}$, conforme as Equações 3.22 e 3.23.

$$
\begin{aligned}
& L_{1}=L_{0}\left(1+f\left(\theta_{1}\right)\right) \\
& L_{2}=L_{0}\left(1+f\left(\theta_{2}\right)\right)
\end{aligned}
$$

Logo, o alongamento térmico do elemento entre $\theta_{1}$ e $\theta_{2}\left(\Delta L_{1-2}=L_{2}-L_{1}\right)$ é dado pela Equação 3.24.

$$
\Delta L_{1-2}=L_{0}\left(f\left(\theta_{2}\right)-f\left(\theta_{1}\right)\right)
$$


O alongamento térmico também pode ser calculado por meio da Equação 3.25, em que $\Delta \theta_{1-2}$ é o aumento de temperatura entre $\theta_{1}$ e $\theta_{2}$.

$$
\Delta L_{1-2}=L_{1} \cdot \alpha \cdot \Delta \theta_{1-2}=L_{0}\left(1+f\left(\theta_{1}\right)\right) \cdot \alpha \cdot\left(\theta_{2}-\theta_{1}\right)
$$

Igualando as Equações 3.24 e 3.25, tem-se que o coeficiente de expansão térmica é dado pela Equação 3.26.

$$
\alpha=\frac{1}{1+f\left(\theta_{1}\right)} \frac{f\left(\theta_{2}\right)-f\left(\theta_{1}\right)}{\theta_{2}-\theta_{1}}
$$

Por meio da Equação 3.26, pode-se chegar a dois casos para o cálculo de $\alpha$. O primeiro deles, o valor de $\alpha$ é calculado considerando que a análise é feita com incrementos de temperatura muito pequeno, tomando $\theta_{2}$ igual a temperatura do passo de carga (time step) corrente $(\theta)$ e $\theta_{1}$ igual a temperatura do passo de carga anterior. Neste caso o valor do coeficiente de expansão térmica pode ser calculado por meio da Equação 3.27.

$$
\alpha=\frac{1}{1+f(\theta)} \frac{\partial f(\theta)}{\partial \theta}
$$

No segundo caso, o valor de $\alpha$ é calculado considerando $\theta_{2}$ igual a temperatura do passo de carga corrente $(\theta)$ e $\theta_{1}$ a temperatura inicial do modelo $\left(\theta_{0}\right)$, igual a temperatura ambiente. Logo $\theta_{0}=20^{\circ} \mathrm{C}, f\left(\theta_{0}\right)=0$ e o valor do coeficiente de expansão térmica é calculado por meio da Equação 3.28.

$$
\alpha=\frac{f(\theta)}{\theta-20}
$$

Na Figura 3.22 apresentam-se os coeficientes de expansão térmica para o aço e o concreto considerando os dois casos descritos, em que o Caso 1 refere-se à Equação 3.27 e o Caso 2 à Equação 3.28. Como no código computacional TNO DIANA a análise é realizada com incremento de temperatura muito pequeno é adotado o caso 1 para cálculo do coeficiente de expansão térmica.
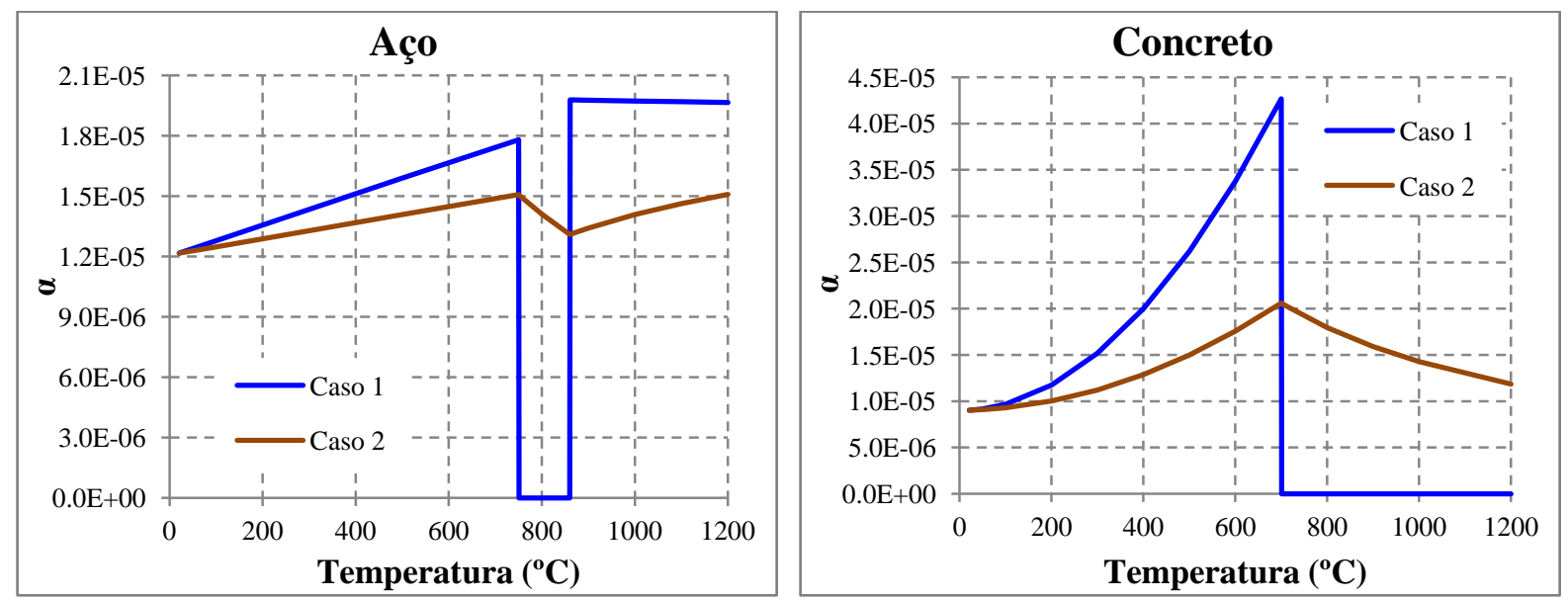

Figura 3.22 - Coeficiente de expansão térmica para o aço e o concreto. 
Com as considerações apresentadas neste capítulo, referentes às propriedades térmicas e mecânicas dos materiais, levando em consideração as particularidades do código computacional TNO DIANA, principalmente sobre os modelos constitutivos do concreto, são realizadas nos próximos capítulos análises térmicas e termoestruturais acoplada. Nessas análises primeiramente será feita a validação dos modelos numéricos por meio dos resultados experimentais apresentados no capítulo 2, seguida da comparação dos resultados numéricos com os procedimentos normativos, especialmente a ABNT NBR 14323:2013. 


\section{CAPÍTULO 4}

\section{Análises térmicas - Considerações e procedimentos adotados}

\subsection{Introdução}

No presente capítulo são apresentados resultados e considerações referentes à influência da ação térmica no comportamento estrutural de lajes mistas de aço e concreto em situação de incêndio por meio de modelos térmicos bidimensionais desenvolvidos no pacote computacional TNO DIANA 9.4.4, considerando basicamente duas etapas. Em uma primeira etapa se faz a calibração do modelo por meio dos resultados experimentais obtidos em ABDEL-HALIM et al. (1997) e GUO \& BAILEY (2011), tomando como variáveis a emissividade do aço, a umidade e a condutividade térmica do concreto, bem como a resistência térmica na interface entre a fôrma de aço e o concreto.

Em uma segunda etapa se faz análises dos modelos de cálculo adotados pelo EUROCODE 4 (EN 1994-1-1:2005) e pela ABNT NBR 14323:2013 por meio dos resultados numéricos adotando-se a curva de incêndio-padrão. Para esta finalidade, conforme comentado no Capítulo 3, desenvolveu-se um pós-processador em Visual Basic, o qual permite ler os campos térmicos disponibilizados pelo código TNO DIANA e, por consequência, calcular o momento fletor resistente em situação de incêndio em função do tempo de exposição ao fogo, correspondente ao momento de plastificação da seção transversal.

Vale ressaltar que as propriedades mecânicas e térmicas para o aço e para o concreto são aquelas apresentadas no Anexo B, sendo que para o concreto foram consideradas as propriedades para o caso de concreto com densidade normal e com agregados siliciosos.

\subsection{Influência da malha de elementos finitos}

No presente item são apresentados aspectos analisados com relação à influência do refinamento da malha de elementos finitos nos campos térmicos da seção transversal da laje mista, permitindo comparações de interesse entre os resultados obtidos. Para tanto se adotou 
as dimensões da laje e os pontos de medida da temperatura apresentados na Figura 4.1, umidade do concreto igual a 4\%, emissividade do aço igual a 0,70 e o limite superior para a curva da condutividade térmica do concreto, conforme apresentado no Anexo B.
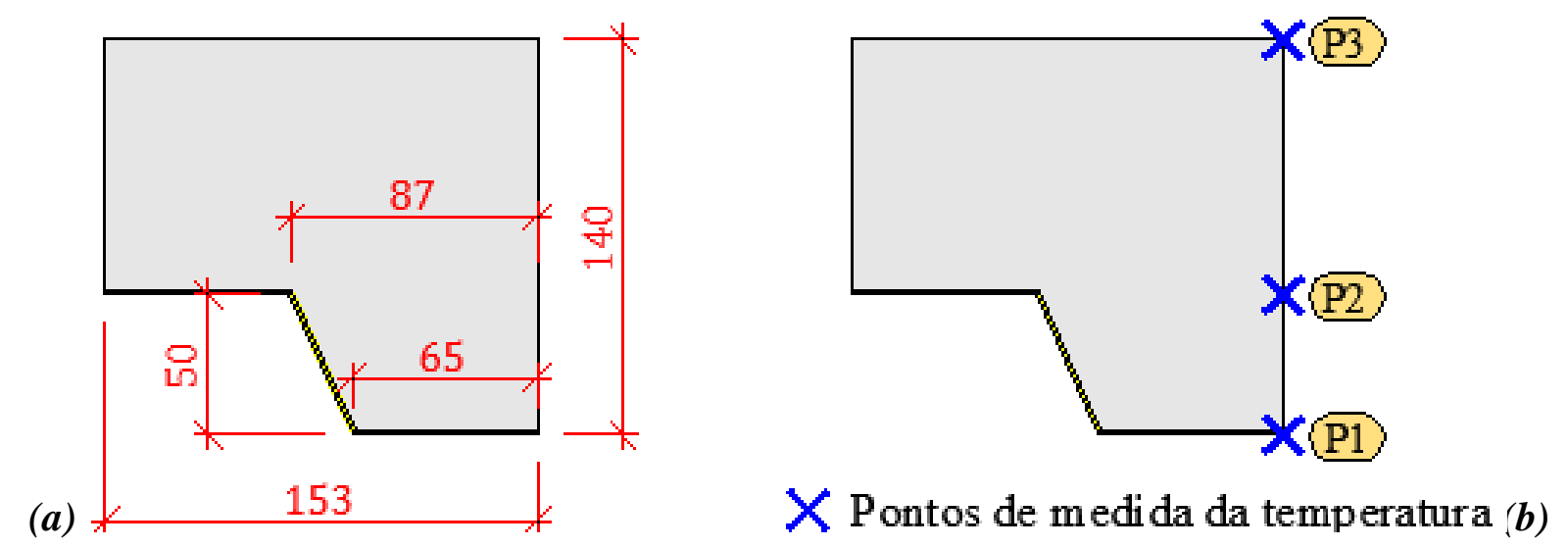

Figura 4.1 - Laje de interesse: (a) dimensões do modelo e (b) pontos de medida da temperatura.

Os resultados apresentados, conforme Figura 4.2, se referem a três opções de malha: Malha 1 com dimensões médias dos elementos iguais a 4,5 mm, Malha 2 com dimensões médias iguais a 12,0 mm e Malha 3 com dimensões médias iguais a 20 mm.
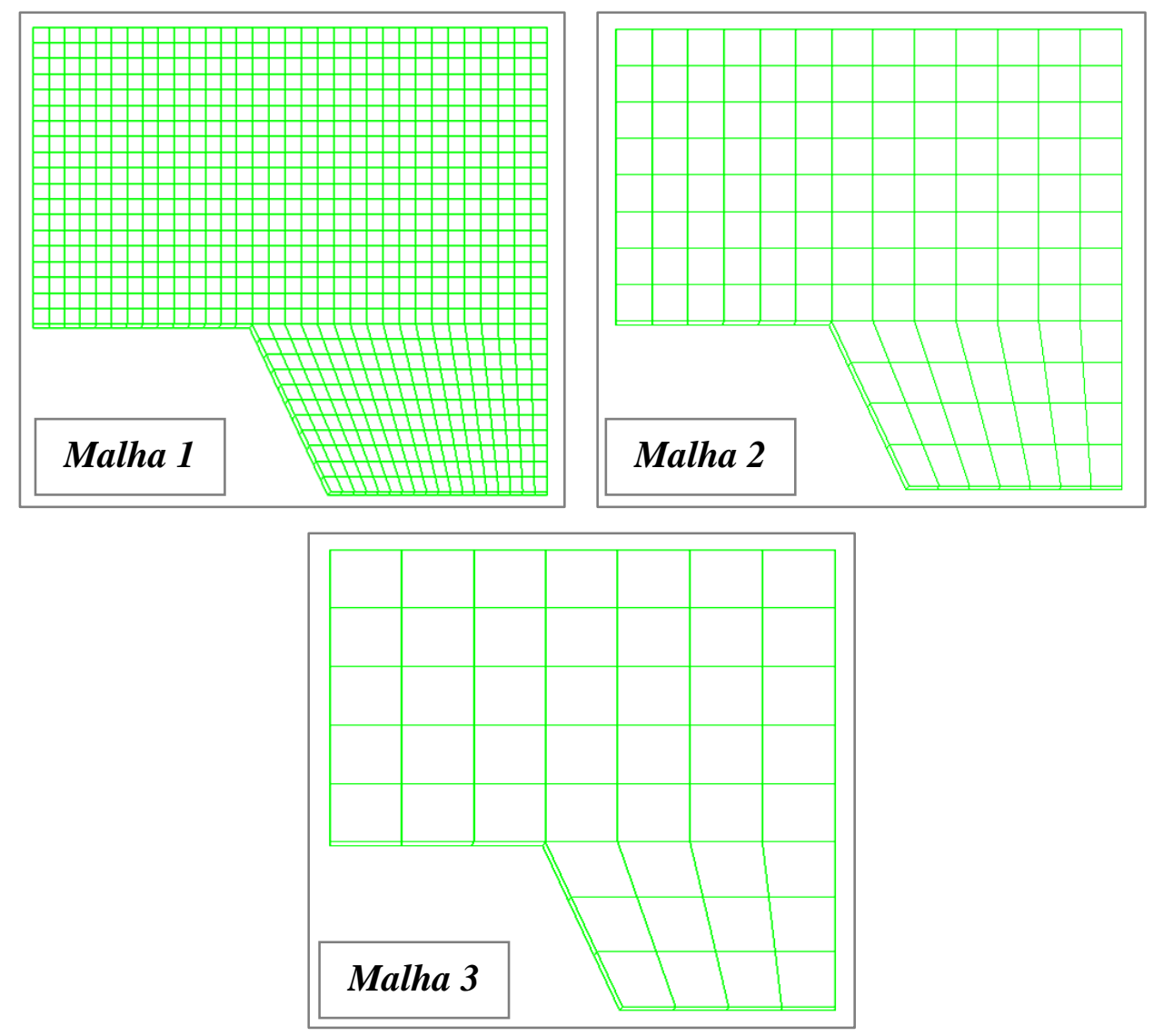

Figura 4.2 - Opções de malhas avaliadas em função do grau de refinamento do modelo. 
Na Figura 4.3 são apresentados os resultados para as três opções de malha e os três pontos de medida da temperatura. Conforme observado, para os três pontos de medida, as três opções de malha apresentaram resultados bem próximos.

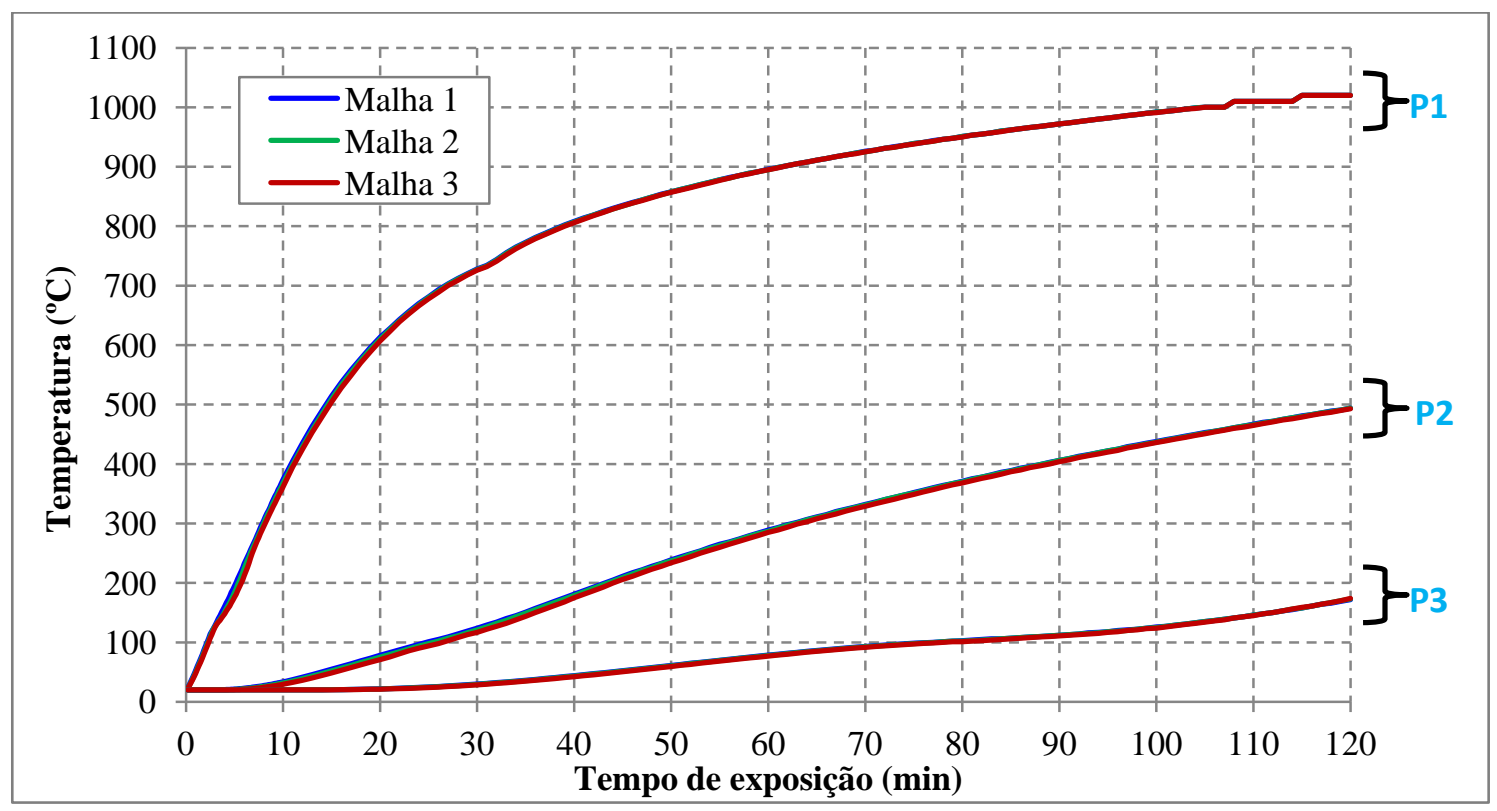

Figura 4.3 - Temperatura $\left({ }^{\circ} \mathrm{C}\right) v s$. Tempo de exposição $(\min )$ para as três opções de malha, considerando os três pontos de medida para a temperatura.

Embora as três opções de malha apresentassem resultados coerentes, deve-se, no entanto, evitar malhas com grau de discretização reduzido, pois neste caso o método dos elementos finitos pode conduzir a resultados irreais dos campos térmicos (redução da temperatura com o tempo de exposição), podendo obter até valores negativos de temperatura para tempos iniciais de aquecimento, conforme pode ser observado pela Figura 4.4 para um tempo de 10 minutos, ainda que à medida que o tempo de exposição vá aumentando a distribuição de temperatura tende a estabilizar. Tal fenômeno também foi observado em outros pacotes computacionais, conforme mencionado e apresentado em ROCHA (2012).
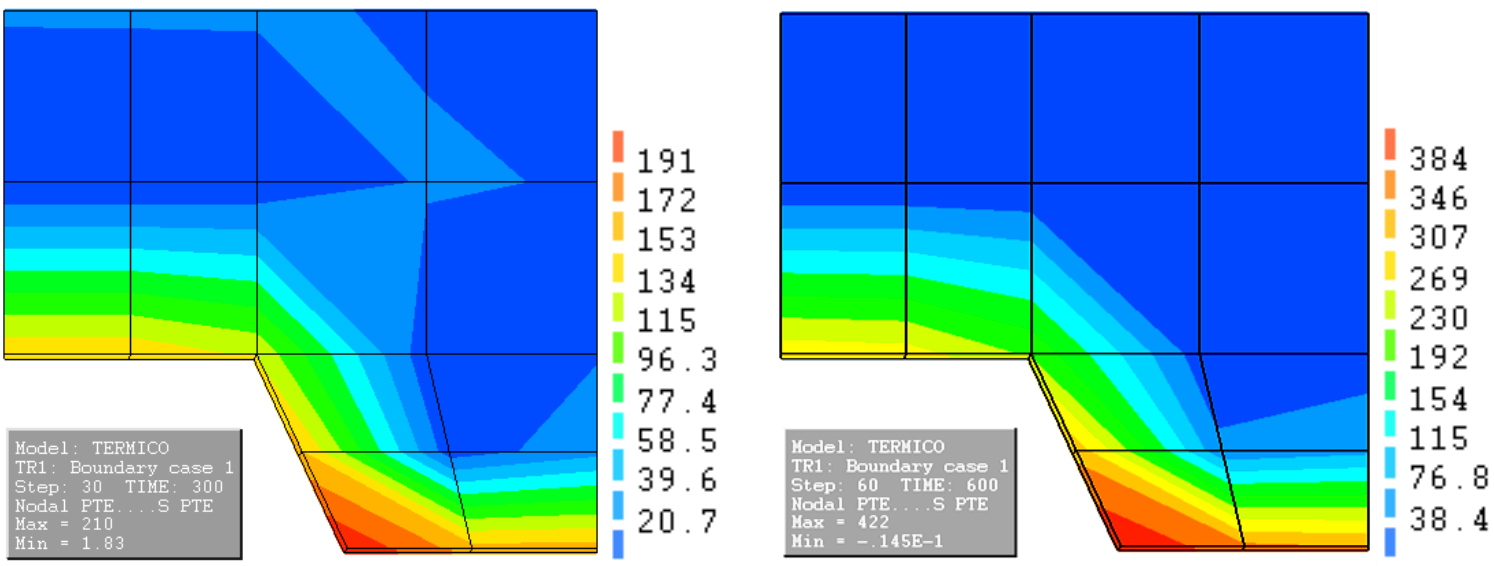

Figura 4.4 - Campos térmicos para uma malha mal refinada de elementos finitos para tempos de exposição de 5 e 10 minutos 
Como os modelos térmicos apresentam baixo custo computacional, nas análises subsequentes serão utilizadas uma malha de elementos finitos com dimensões médias dos elementos de $5 \mathrm{~mm}$. Essa menor dimensão também foi escolhida para uma maior precisão no cálculo do momento fletor plástico resistente, que depende da malha de elementos finitos.

\subsection{Validação dos modelos térmicos}

Para validação dos modelos numéricos térmicos, referentes à distribuição de temperatura na seção transversal, comparou-se inicialmente os resultados obtidos via modelos numéricos com resultados experimentais obtidos em ABDEL-HALIM et al. (1999). As dimensões do modelo e a localização dos pontos de medidas da temperatura, de acordo com a última referência, são apresentadas na Figura 4.5.

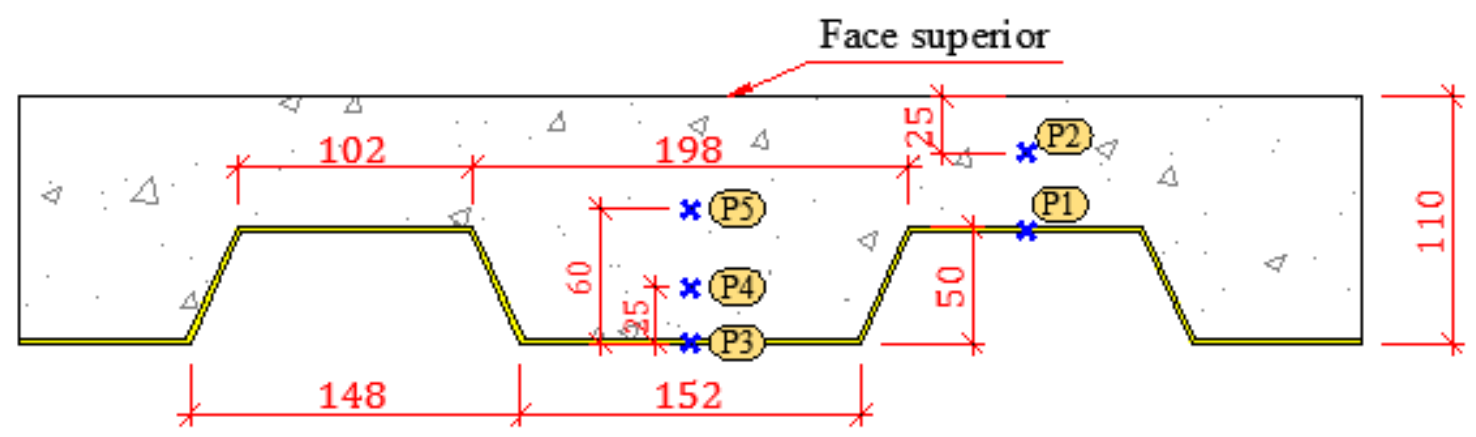

Figura 4.5 - Dimensões do modelo e localização dos pontos de medidas de temperatura (adaptado de ABDEL-HALIM et al. (1999))

Diversos parâmetros dos modelos numéricos influenciam na obtenção dos campos térmicos, sendo que desses se pode destacar a resistência térmica na interface, a condutividade térmica do concreto, a emissividade resultante entre fôrma de aço e gases aquecidos (incêndio), bem como a umidade do concreto. Nesse sentido, se faz a seguir avaliações com base nos parâmetros citados, buscando obter a melhor distribuição de temperatura do modelo numérico quando comparado com resultados experimentais.

\subsubsection{Análise da influência da resistência térmica na interface}

A resistência térmica na interface entre a fôrma de aço e o concreto pode ser avaliada no pacote computacional TNO DIANA por meio do coeficiente de condução térmica $\left(C_{r}\right)$ em $\mathrm{W} / \mathrm{m}^{2}{ }^{\circ} \mathrm{C}$. Para tanto, se adotou modelos numéricos com e sem interface, bem como dois casos de emissividade do aço: o primeiro caso com emissividade igual a 0,70 independente da temperatura (valor recomendado pela ABNT NBR 14323:2013 e o EUROCODE 4 EN 19941-2:2005), e um segundo caso com emissividade dependente da temperatura, sendo igual a 0,09 para temperaturas inferiores a $250^{\circ} \mathrm{C}$, bem como igual a 0,40 para temperaturas superiores a $800^{\circ} \mathrm{C}$, variando linearmente entre $250^{\circ} \mathrm{C}$ e $800^{\circ} \mathrm{C}$, de acordo BOTH et al. (1997). Também se adotou a curva superior para a condutividade térmica do concreto. 
Os resultados da evolução da temperatura em função do tempo de exposição ao fogo, obtidos com base nos modelos numéricos e dos resultados experimentais apresentados em ABDEL-HALIM et al. (1999) são apresentados graficamente na Figura 4.6 para os pontos de medida da temperatura localizados na fôrma de aço, bem como nas Figuras 4.7 e 4.8 para os pontos de medida da temperatura localizados na laje de concreto.
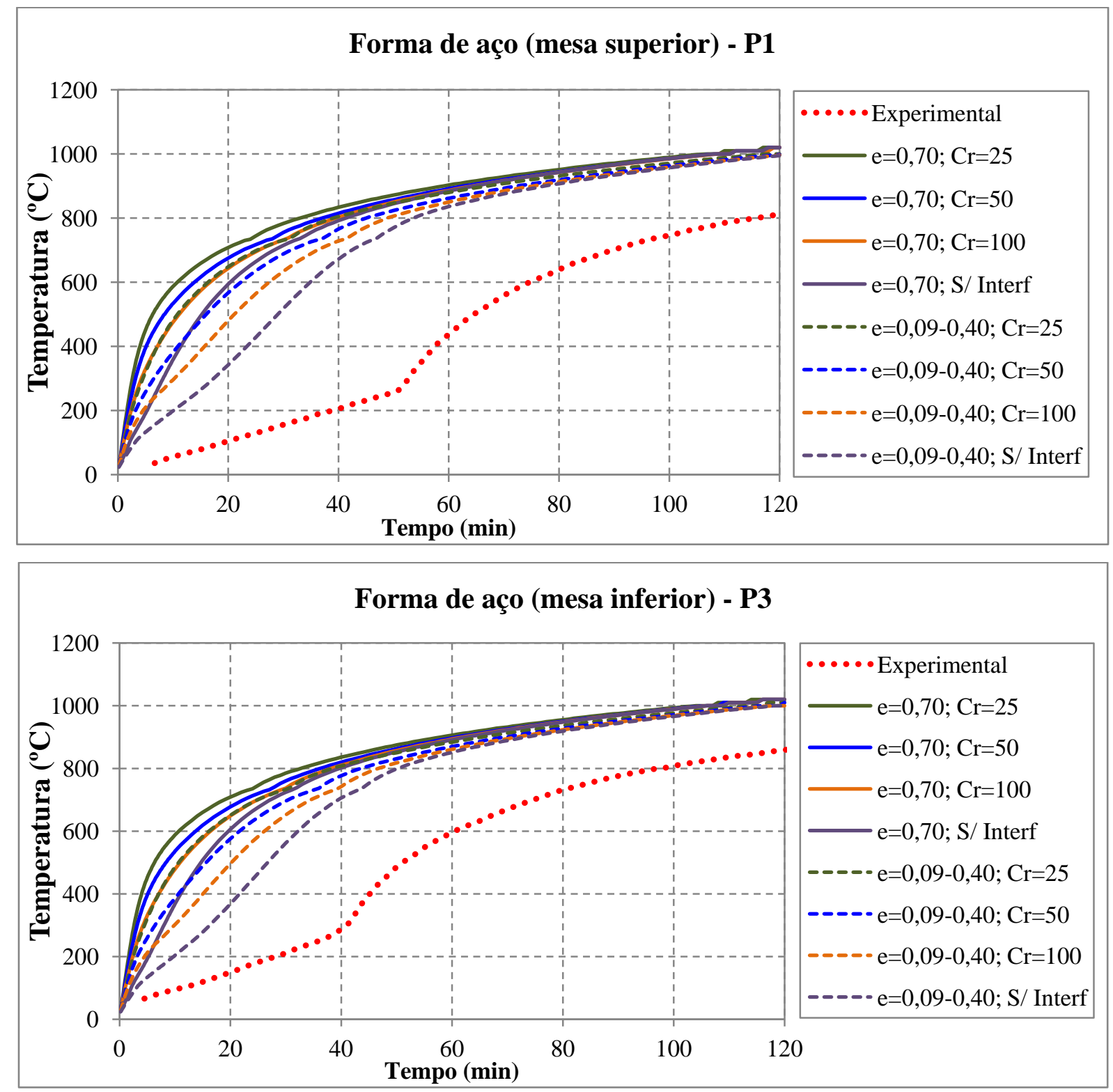

Figura 4.6 - Evolução da temperatura da fôrma de aço (pontos P1 e P3) vs. Tempo de exposição ao fogo

Pela Figura 4.6 se observa que a evolução da temperatura da fôrma de aço com o tempo de exposição ao fogo (modelo numérico) resulta superior àquelas obtidas experimentalmente, ressaltando-se que os resultados do modelo numérico sem interface e com emissividade variável entre 0,090 e 0,40 são os que menos se afastam dos resultados experimentais. Com um valor baixo para o coeficiente de condução térmica $\left(C_{r}\right)$ a temperatura mensurada numericamente é maior que para o caso com alto valor de $C_{r}$, e isso ocorre pelo fato de que quando maior o $C_{r}$ maior a facilidade de o calor ser conduzido ao 
longo da interface entre a fôrma de aço e o concreto, fazendo com que o aço perca calor mais facilmente para o concreto.

Essa maior temperatura para a fôrma de aço, obtida via modelo numérico, também foi observada por LAMONT et al. (2001) e justificada pela presença de umidade no concreto que, com o aumento da temperatura, se condensa e desloca em direção à face da laje não exposta ao fogo. No entanto, parte desse vapor se junta formando uma pequena porção de água que, quando em contato com a fôrma de aço, reduz sua respectiva temperatura. Trata-se de fenômeno de difícil obtenção em contexto computacional e requer modelos numéricos mais sofisticados para sua correta identificação. Essa diferença entre os resultados numéricos e experimentais também pode estar associada com a obtenção das temperaturas nos ensaios (que podem apresentar problemas pontuais de coleta).
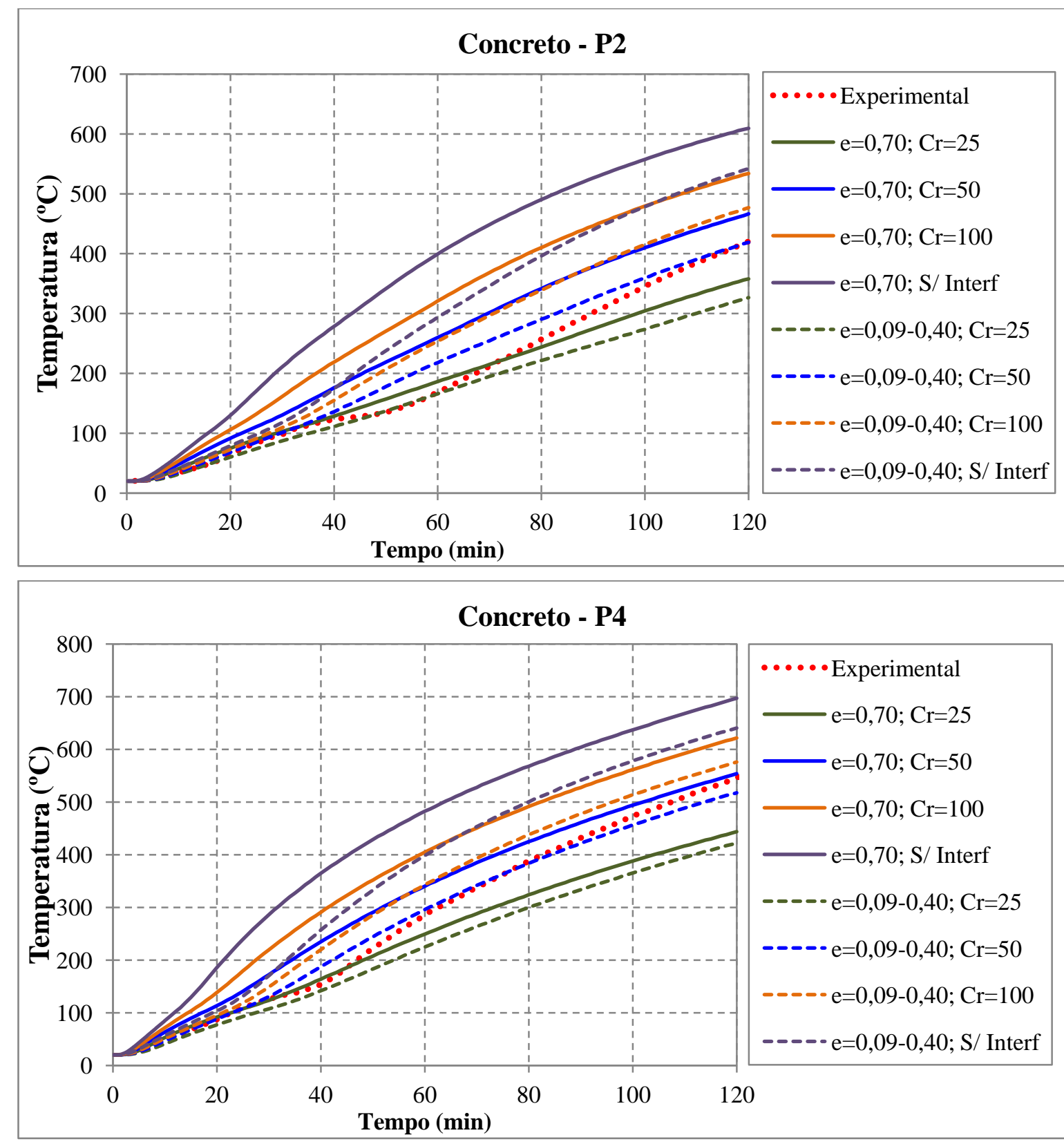

Figura 4.7 - Evolução da temperatura no concreto (pontos P2 e P4) vs. Tempo de exposição ao fogo. 
Já para a representação da temperatura do concreto, conforme Figura 4.7, nos pontos de medida da temperatura localizados mais próximos da fôrma de aço (P2 e P4), o modelo numérico com interface, considerando $C_{r}=50 \mathrm{~W} / \mathrm{m}^{2 \circ} \mathrm{C}$ e emissividade variável melhor se correlacionou com os resultados experimentais, enquanto que os pontos de medida da temperatura localizados mais próximos da face não exposta ao fogo, conforme Figura 4.8, considerando $C_{r}=50 \mathrm{~W} / \mathrm{m}^{2}{ }^{\circ} \mathrm{C}$ e emissividade igual a 0,70 melhor se adequou aos resultados experimentais.

Esse comportamento evidencia que, considerando o modelo com emissividade igual a 0,70 e $C_{r}=50 \mathrm{~W} / \mathrm{m}^{2 \circ} \mathrm{C}$, a porção de concreto localizada mais próxima da fôrma de aço, deveria apresentar menores temperaturas. Isso também pode ser explicado pelo fato de essa região apresentar maior umidade que a parte de concreto em contato com o ambiente.
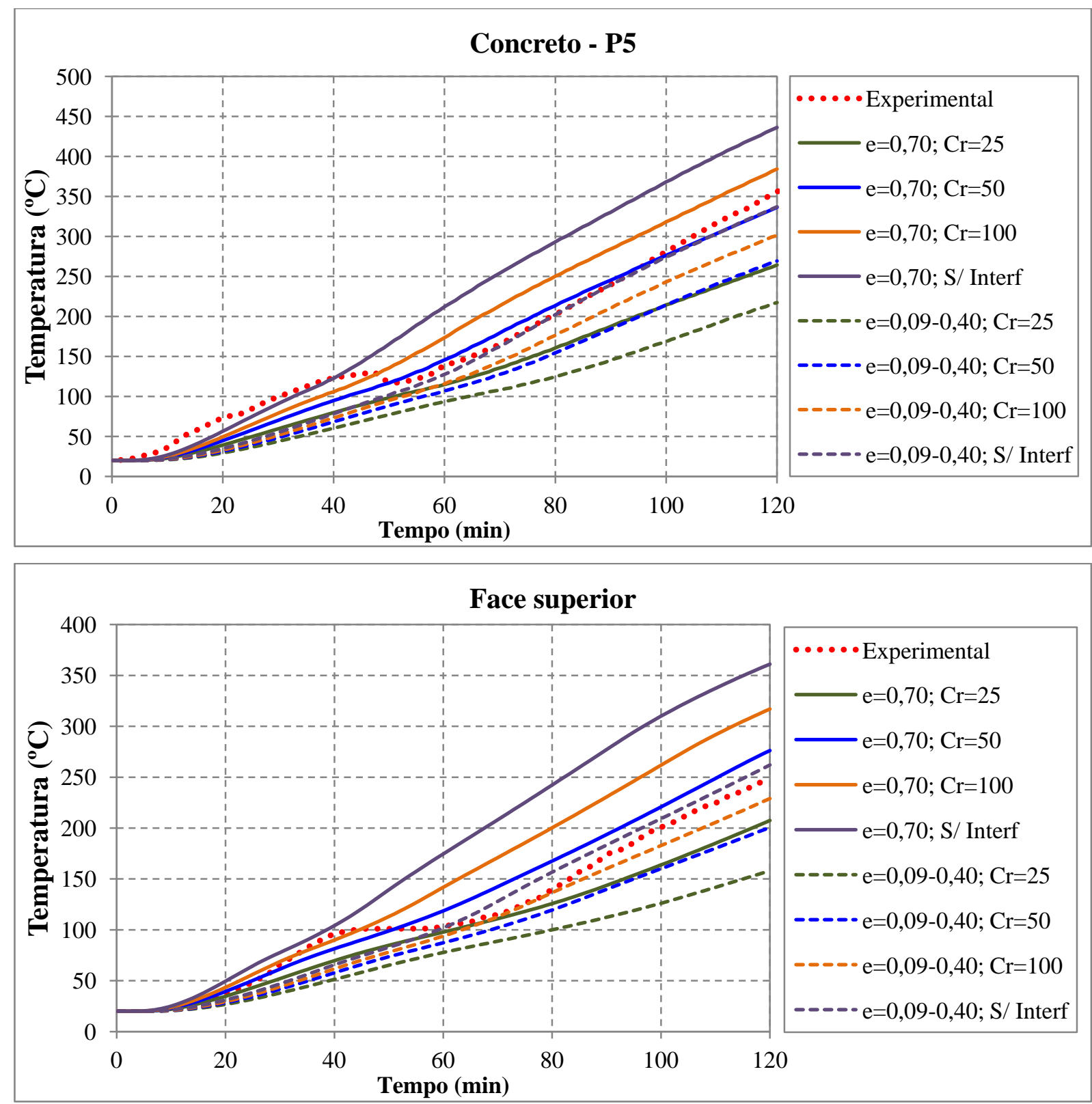

Figura 4.8 - Evolução da temperatura no concreto (ponto P5 e face superior) vs. Tempo de exposição ao fogo. 
Os resultados experimentais também apresentam um patamar de temperatura do concreto próximo dos $100^{\circ} \mathrm{C}$ que não foi observado nos modelos numéricos. Segundo LAMONT et al. (2001) isso ocorre pelo fato de a concentração de umidade localizada ser maior que a umidade constante adotada no modelo.

Na Figura 4.9 são apresentados graficamente os resultados de temperatura vs. distância em relação à mesa inferior da laje $(y)$. Conforme se pode observar, no modelo numérico com interface existe uma diferença de temperatura entre a face superior da fôrma de aço e a face inferior do concreto. Mais uma vez se observa que o modelo numérico com interface melhor representou a distribuição de temperatura na laje. As temperaturas da fôrma de aço medidas experimentalmente apresentaram valores próximos das temperaturas do modelo numéricos medidas na face inferior do concreto.

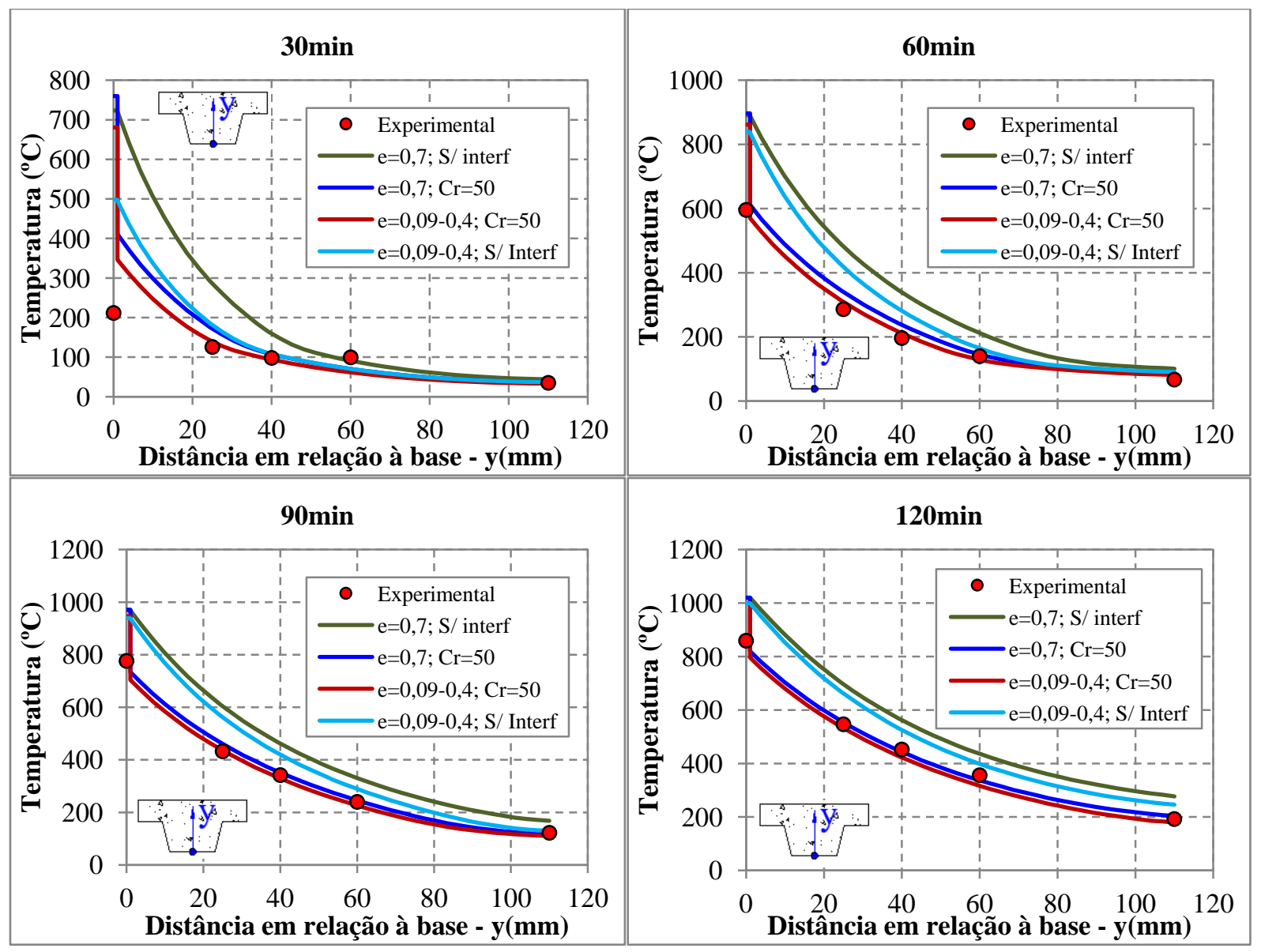

Figura 4.9 - Temperatura ao longo da altura da laje para a emissividade do aço igual a 0,70 e variando entre 0,09 e 0,40 para os modelos numéricos com e sem interface

\subsubsection{Análise da influência da condutividade térmica do concreto}

Quanto maior a condutividade térmica de um material maior será sua capacidade de transmitir calor. Para se avaliar a influência da condutividade térmica do concreto na determinação da temperatura dos modelos numéricos foram analisados dois casos extremos utilizando as curvas inferior e superior, conforme apresentado no Anexo B, considerando para 
os modelos numéricos emissividade do aço constante e igual a 0,70 , sem interface e com interface (neste caso, $C_{r}=50 \mathrm{~W} / \mathrm{m}^{2}{ }^{\circ} \mathrm{C}$ ).

Os resultados de evolução da temperatura com o tempo de exposição para os pontos de medida localizados no concreto são apresentados na Figura 4.10. Conforme se pode observar, para os pontos de medida localizados próximos à fôrma de aço (P2 e P4) o modelo com interface e adotando o limite inferior da curva de condutividade térmica melhor se correlacionou com os dados experimentais. Já para os pontos de medidas mais próximos da face superior da laje, pontos P5 e face superior, o modelo com interface e adotando o limite superior da curva de condutividade térmica melhor se correlacionou com os resultados experimentais.

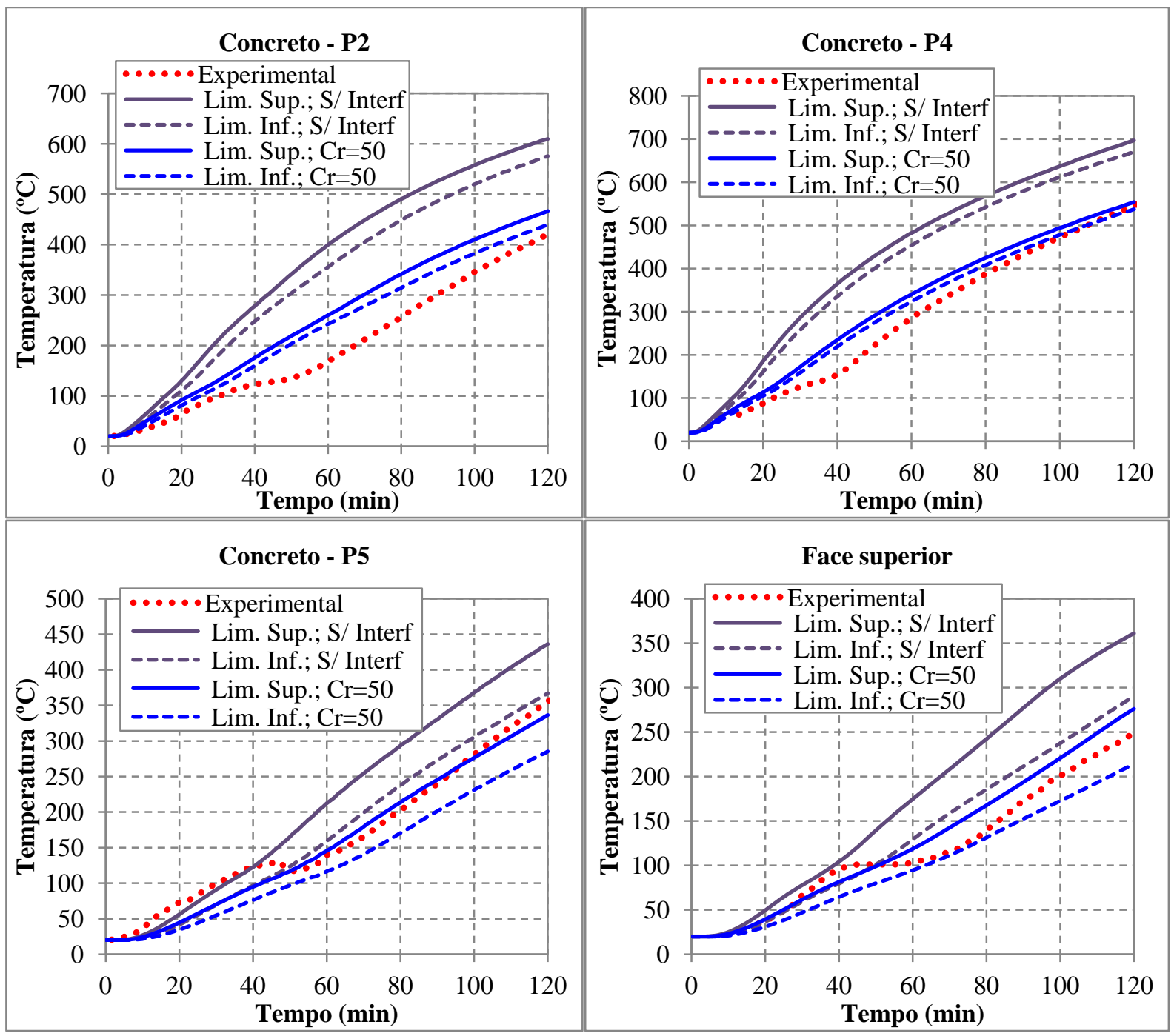

Figura 4.10 - Evolução da temperatura no concreto (pontos P2, P4, P5 e face superior) vs. Tempo de exposição ao fogo.

Dos resultados apresentados na Figura 4.10, mais uma vez se nota que a porção de concreto localizada mais próxima da fôrma de aço deveria apresentar menores valores de temperatura. Isso pode ser explicado devido a dois fatores. O primeiro é que essa região possui uma maior umidade, intensificando o processo de movimento de água, conforme dito 
anteriormente. O segundo devido à própria condutividade térmica do concreto que, neste caso, apresenta valores maiores de condutividade térmica para baixas temperaturas e valores menores para altas temperaturas.

\subsubsection{Análise da influência da umidade do concreto}

No intuito de avaliar a influência da umidade do concreto na determinação dos campos térmicos, foram estudados três casos de umidade do concreto: um primeiro com umidade igual a 1,2\%, um segundo com umidade igual a $5 \%$ e, por fim, um caso especial considerando a umidade do concreto dentro da nervura (U1) em $10 \%$ e acima da nervura (U2) em 2\%. Para tanto, se adotou o modelo numérico com interface $\left(C_{r}=50 \mathrm{~W} / \mathrm{m}^{2 \circ} \mathrm{C}\right)$, emissividade do aço igual a 0,70 e a curva superior para a condutividade térmica do concreto.

Os resultados para a evolução da temperatura em função do tempo de exposição são apresentados graficamente na Figura 4.11 para os pontos de medida de temperatura P4 e P5. Os resultados numéricos obtidos considerando uma umidade superior para o concreto dentro da nervura da fôrma de aço melhor representou a distribuição de temperatura no concreto. Para efeito de resultados numéricos, se observou que a variação da umidade do concreto tem pouca influência na determinação da temperatura da fôrma de aço.

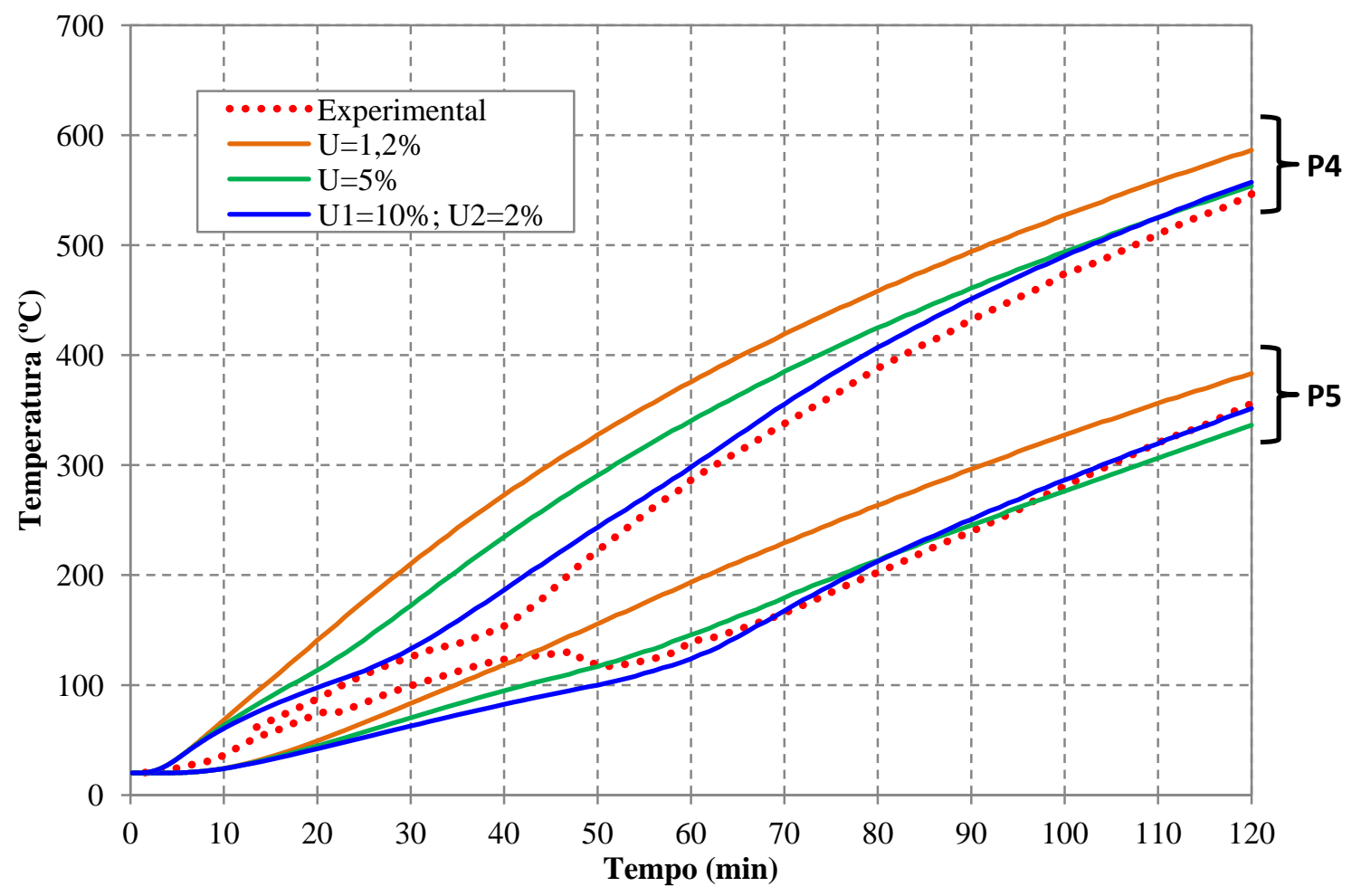

Figura 4.11 - Temperatura vs. Tempo de exposição para diferentes umidades do concreto. 


\subsubsection{Outros resultados experimentais - Análises complementares}

Realizam-se neste item validações complementares dos modelos numéricos por meio dos resultados experimentais obtidos em GUO (2011), cujas dimensões e localização dos pontos de medida da temperatura, são apresentadas na Figura 4.12. Na última referência foi adotada uma curva de incêndio cuja elevação de temperatura é apresentada juntamente com os resultados apresentados na Figura 4.13 e Figura 4.14.

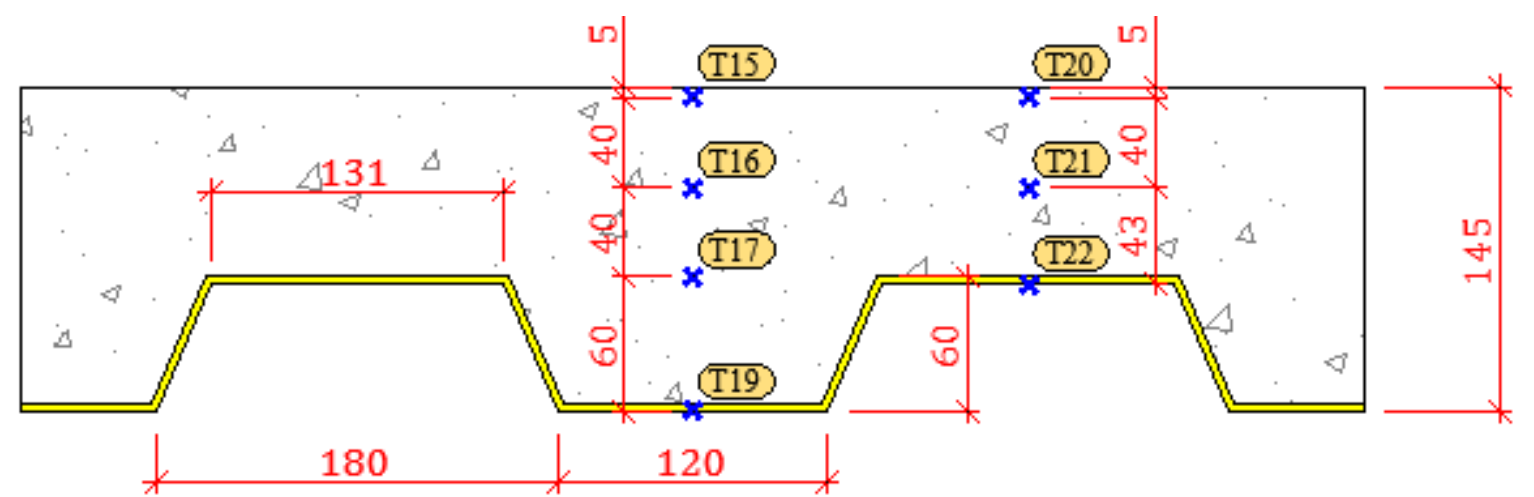

Figura 4.12 - Dimensões do modelo e localização dos pontos de medida de temperatura (Adaptado de GUO (2011))

Para os modelos numéricos adotou-se a umidade do concreto igual a $2 \%$ (medida experimentalmente) e o limite superior da curva de condutividade térmica para o concreto, bem como se analisou a influência de dois casos de emissividade resultante $(0,70$ e variável entre 0,09 e 0,40 para as temperaturas de 250 e $800^{\circ} \mathrm{C}$ ), bem como modelo numérico sem e com interface (considerando o coeficiente de condução térmica $C_{r}=50 \mathrm{~W} / \mathrm{m}^{2 \circ} \mathrm{C}$ ).

Os resultados numéricos são apresentados até um tempo de exposição ao incêndio de 90 minutos, tendo em vista que os ensaios experimentais foram realizados com aquecimento até esse instante de tempo. A partir dos 90 minutos os modelos foram submetidos ao resfriamento, ressaltando-se que tal aspecto não fará parte do escopo deste trabalho.

\subsubsection{Temperatura da fôrma de aço}

A evolução da temperatura da fôrma de aço em função do tempo de exposição é apresentada na Figura 4.13 para a mesa inferior (ponto de medida T19), bem como Figura 4.14 para a mesa superior (ponto de medida T22).

Conforme se pode observar, a temperatura da fôrma de aço (mesa superior e mesa inferior) considerando o modelo numérico sem interface e emissividade variando entre 0,09 e 0,40 melhor se correlacionou com os resultados experimentais. A presença de uma resistência térmica na interface entre a fôrma de aço e o concreto, dificulta o fluxo de calor nessa interface fazendo com que o aço perca menos calor para o concreto, justificando uma maior elevação de temperatura para a fôrma de aço quando se considera a interface. 


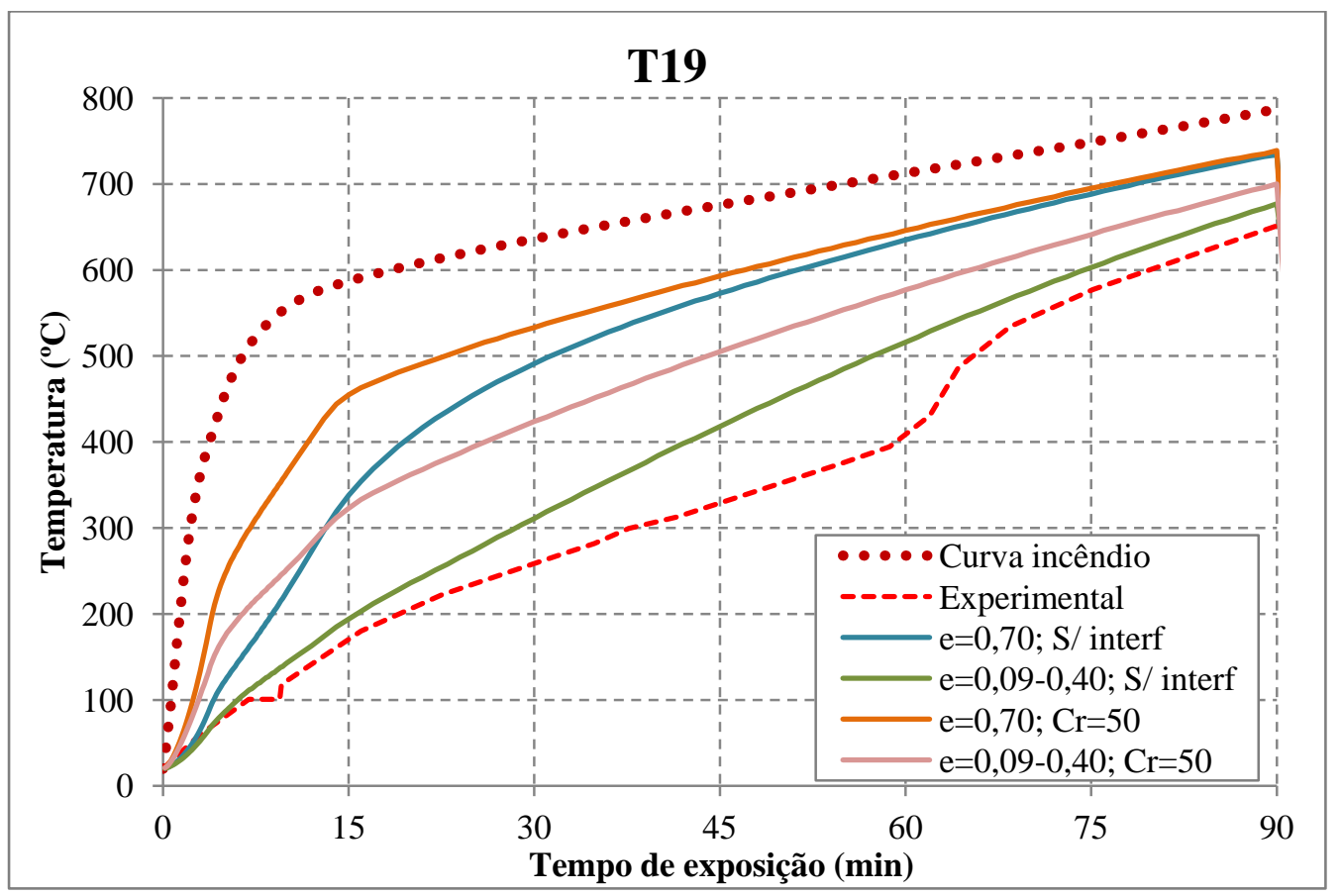

Figura 4.13 - Temperatura da mesa inferior da fôrma de aço (T19) vs. Tempo de exposição ao fogo.

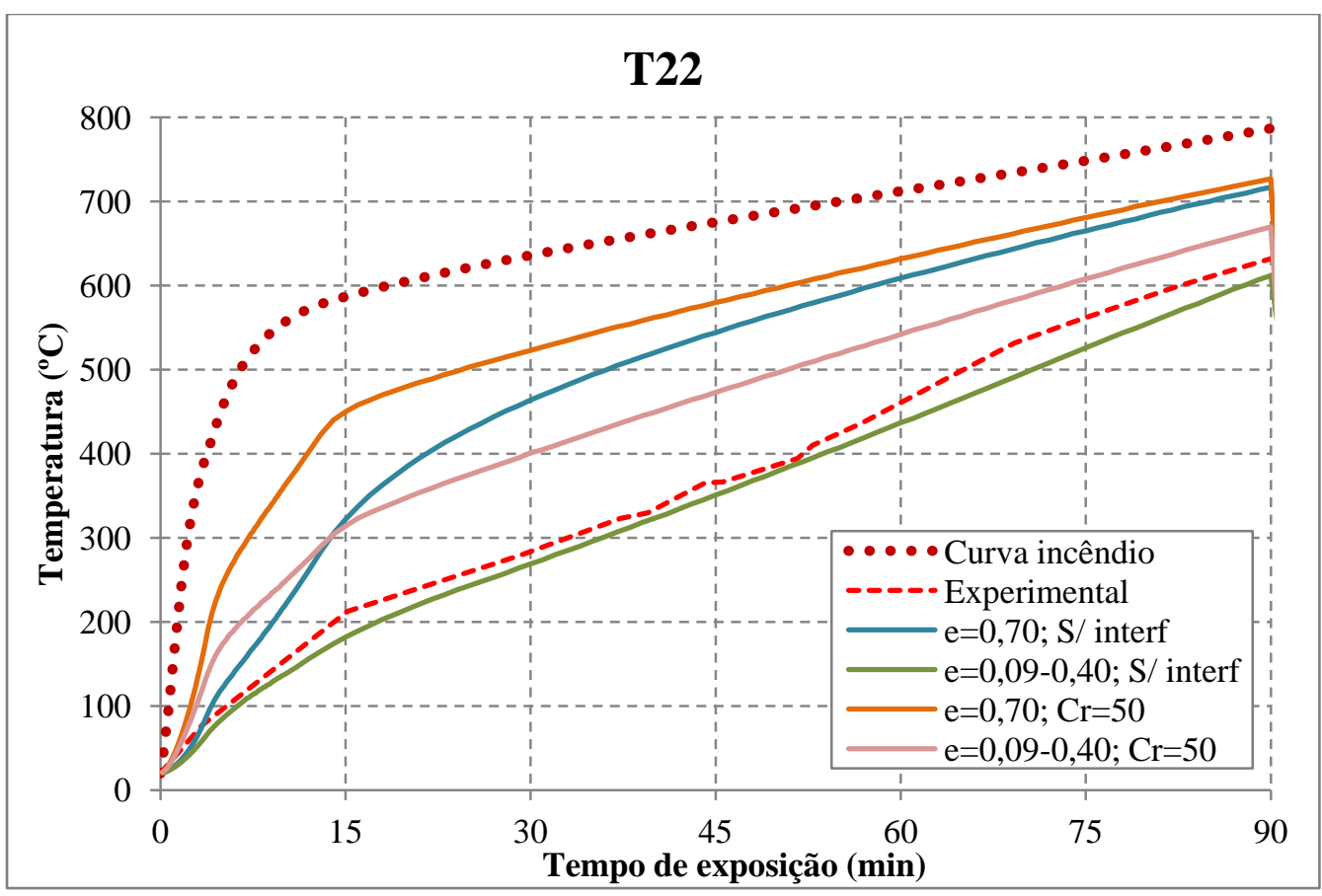

Figura 4.14 - Temperatura da mesa superior da fôrma de aço (T22) vs. Tempo de exposição ao fogo.

Os resultados numéricos e experimentais para a mesa inferior e superior da fôrma de aço considerando tempos de exposição de 30, 60 e 90 minutos também são apresentados na Figura 4.15. 

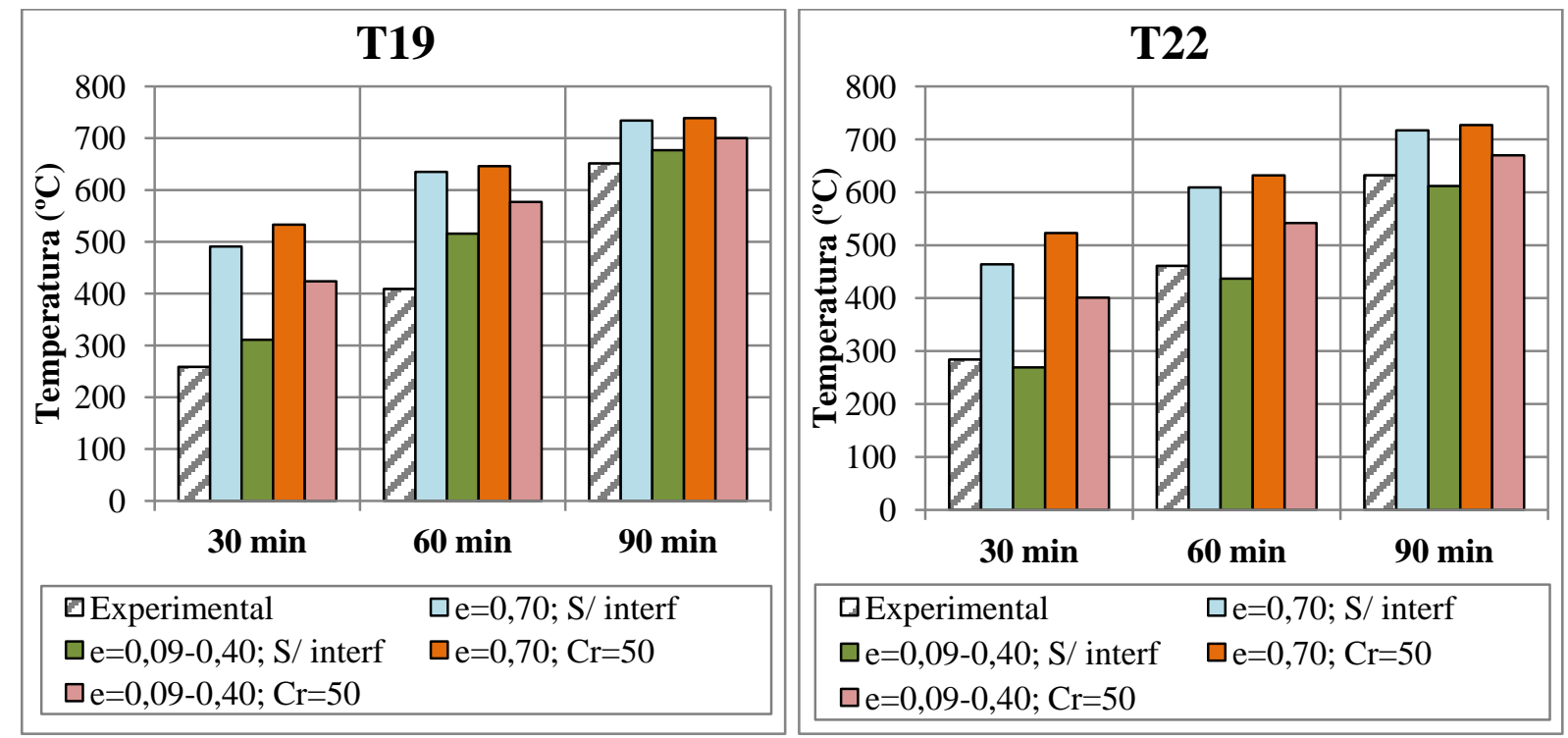

Figura 4.15 - Comparação entre a temperatura da fôrma de aço (pontos de medida T19 e T22) para 30, 60 e 90 minutos de exposição ao fogo.

\subsubsection{Temperatura do concreto}

Na Figura 4.16 e Figura 4.17 são apresentados os resultados numéricos e experimentais referentes à evolução de temperatura para os pontos de medidas T15 e T17 em função do tempo de exposição. Para os demais pontos de medida da temperatura (T16, T20 e T21) os resultados são apresentados no Apêndice J.

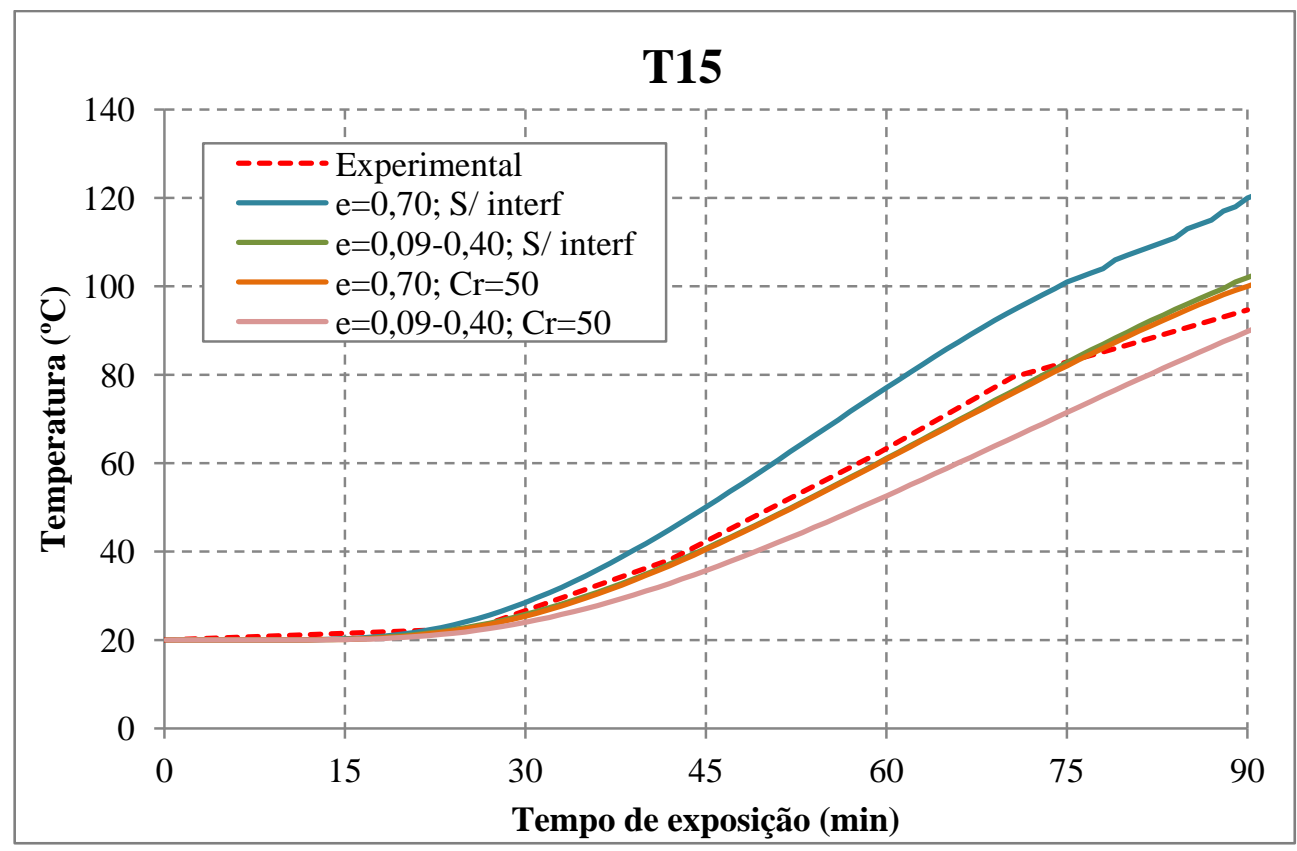

Figura 4.16 - Temperatura do concreto (T15) vs. Tempo de exposição ao fogo. 


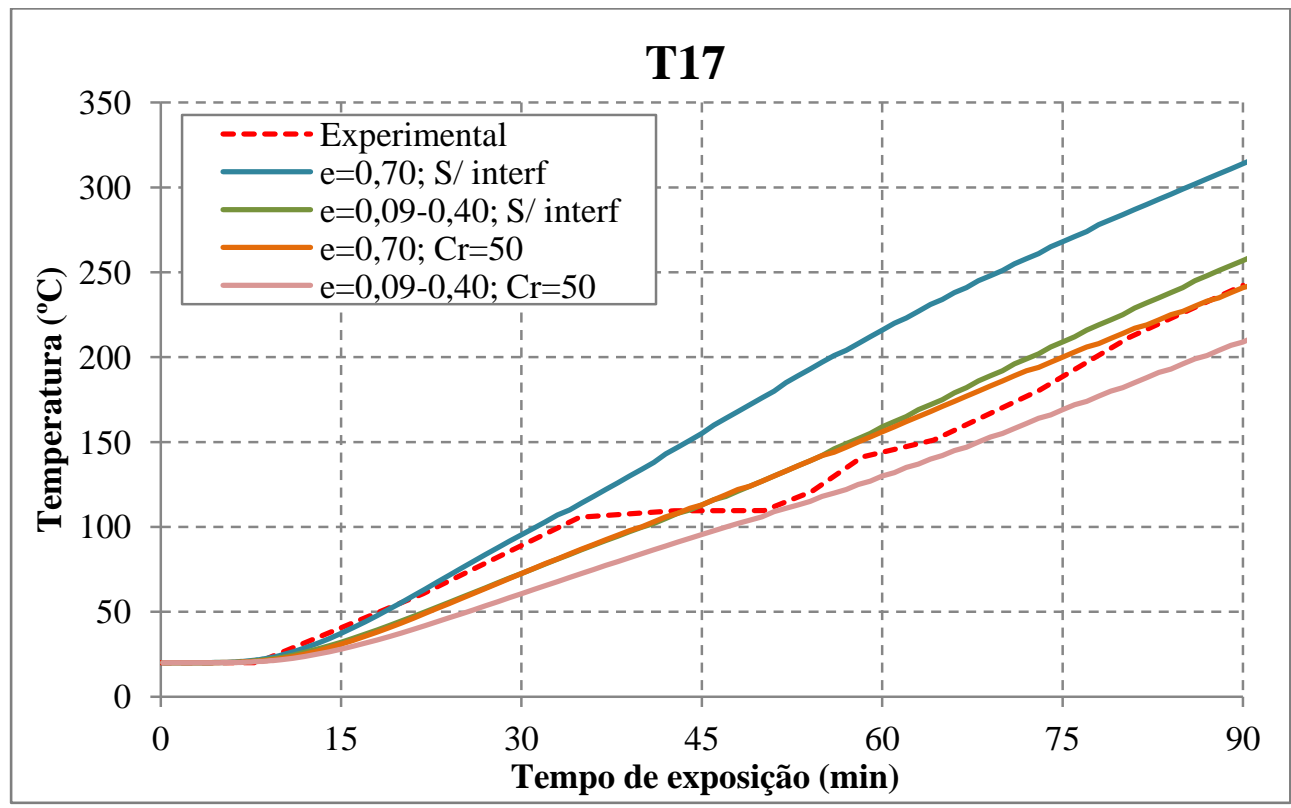

Figura 4.17 - Temperatura do concreto (T17) vs. Tempo de exposição ao fogo.

Para a representação da temperatura do concreto, o modelo numérico com interface (considerando $\mathrm{C}_{\mathrm{r}}=50 \mathrm{~W} / \mathrm{m}^{2 \circ} \mathrm{C}$ ) e emissividade igual a 0,70 , bem como o modelo numérico sem interface e com emissividade variável entre 0,09 e 0,40 tiveram resultados semelhantes e se correlacionaram muito bem com os resultados experimentais. Para melhor comparação relativa entre os resultados, também são apresentadas as temperaturas referentes aos pontos de medidas T15 e T17 para tempos de exposição de 30, 60 e 90 minutos, conforme Figura 4.18.
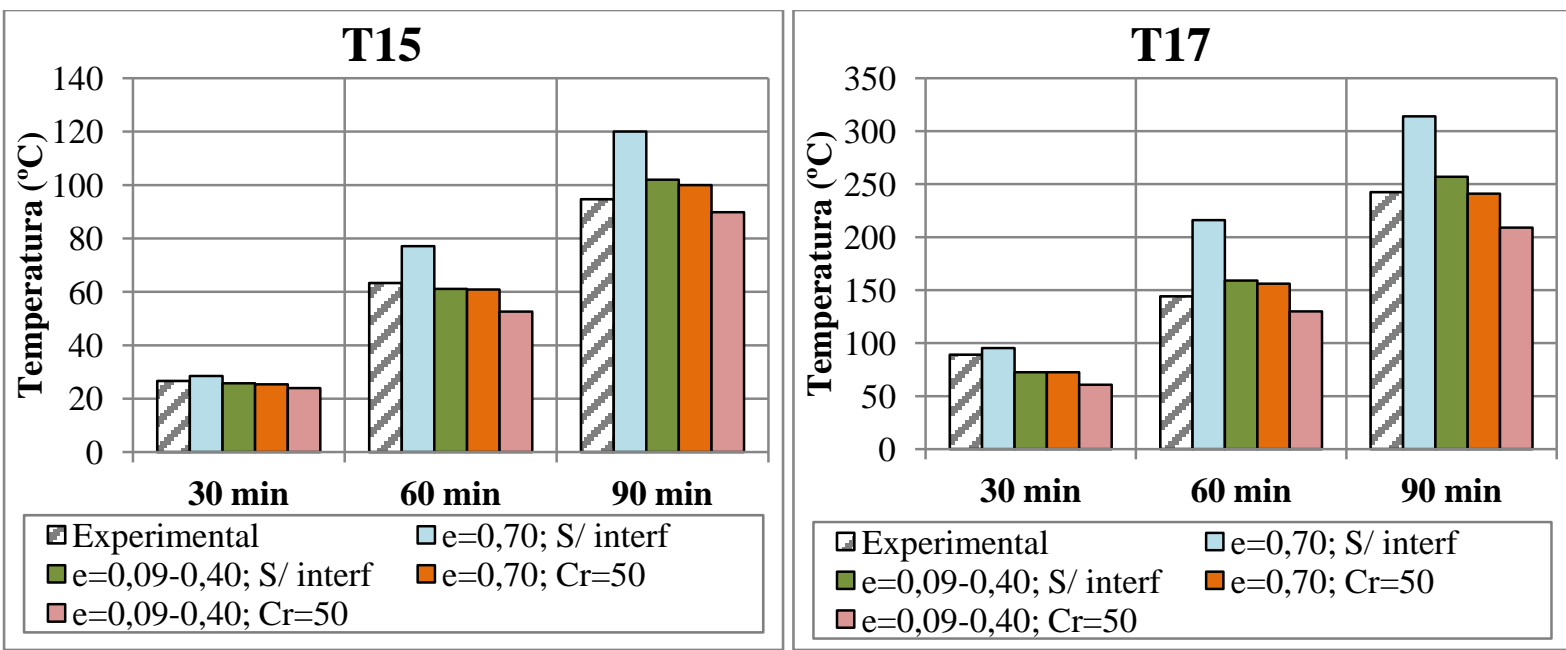

Figura 4.18 - Comparação entre a temperatura do concreto (pontos de medida T15 e T17) para 30, 60 e 90 minutos de exposição ao fogo.

Dos resultados apresentados neste item 4.3, de modo geral os modelos numéricos com emissividade variável entre 0,09 a 0,40 e sem interface melhor representou os campos térmicos tanto no concreto quanto na fôrma de aço. Entretanto para os resultados experimentais obtidos em ABDEL-HALIM et al. (1999) a temperatura da fôrma de aço não ficou bem representada em nenhum dos modelos avaliados, pelos motivos já comentados. 


\subsection{Comparações da proposta de estratégia de modelagem numérica com prescrições normativas}

Para realizar uma breve avaliação do modelo de cálculo adotado pela ABNT NBR 14323:2013 serão adotados três modelos numéricos com as dimensões apresentadas na Figura 4.19, todos com fôrma de aço com espessura igual a $0,8 \mathrm{~mm}$ e resistência ao escoamento igual a $280 \mathrm{MPa}$, e concreto com resistência à compressão característica igual a $20 \mathrm{MPa}$.

Os modelos M01 e M02 possuem a mesma altura total da laje $(120 \mathrm{~mm})$, porém com alturas diferentes para a fôrma de aço, no caso, 75 e $50 \mathrm{~mm}$, respectivamente. Já o modelo M03 possui uma altura total da laje igual a $150 \mathrm{~mm}$ e com altura da fôrma de aço igual a 75 $\mathrm{mm}$. Essas características dos modelos permitem avaliar a influência da altura da laje e das características geométricas da fôrma de aço na capacidade resistente da laje mista submetida a temperaturas elevadas.

Quando se tem uma maior altura da fôrma de aço, a área do aço em contato com o incêndio também é maior e a altura efetiva da laje é menor. Essas características favorecem uma maior taxa de aquecimento da laje, fazendo com essa mesma laje mista, teoricamente, perca capacidade resistente mais rapidamente.
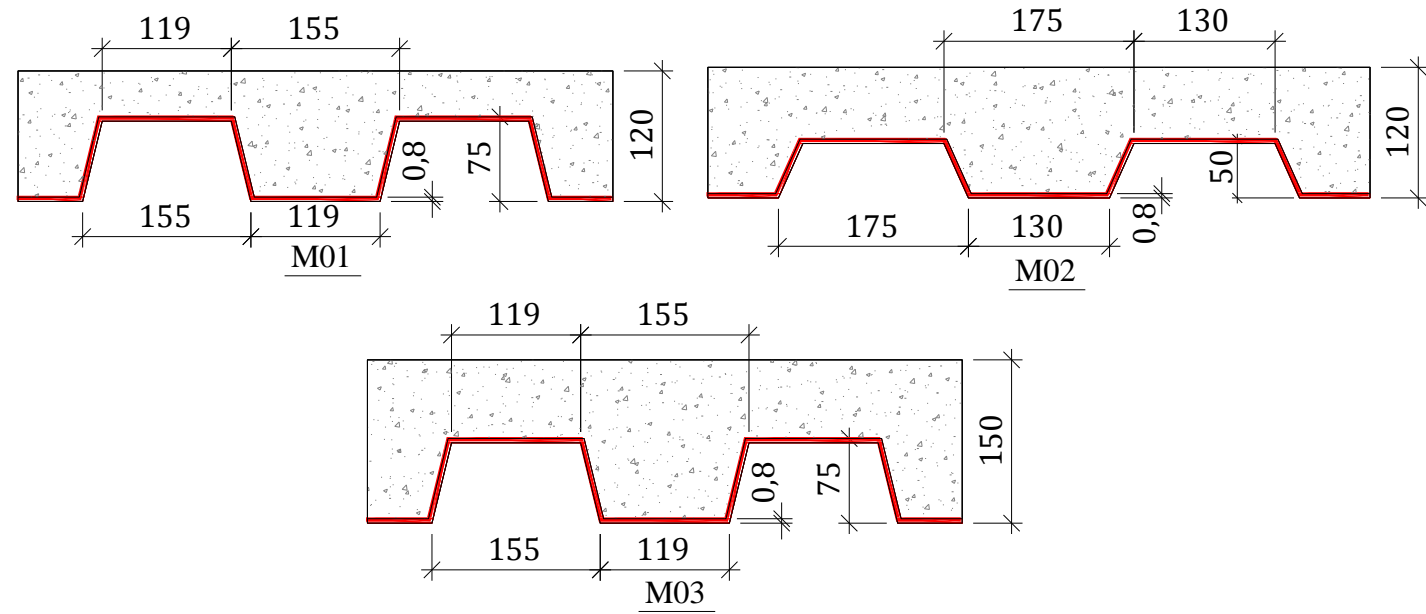

Figura 4.19 - Dimensões consideradas para os modelos avaliados.

Nos modelos aqui propostos também foram adotados como parâmetros de interesse a umidade do concreto igual a $2 \%$ e o limite superior para sua curva de condutividade térmica, sendo que serão estudados casos considerando os modelos numéricos sem interface e com interface $\left(\mathrm{C}_{\mathrm{r}}=50 \mathrm{~W} / \mathrm{m}^{2 \circ} \mathrm{C}\right)$ e dois casos de emissividade resultante, o primeiro igual a $0,70 \mathrm{e}$ outro variável entre 0,09 e 0,40 para as temperaturas de 250 e $800^{\circ} \mathrm{C}$, conforme análises já realizadas anteriormente. Vale lembrar que os resultados apresentados foram gerados pelo programa LaMix, desenvolvido para realizar o pós processamento dos dados gerados pelo TNO DIANA, cujas principais sub-rotinas computacionais estão apresentadas no Apêndice E. 


\subsubsection{Com relação à temperatura na fôrma de aço}

A ABNT NBR 14323:2013 apresenta uma formulação para cálculo da temperatura de cada componente da fôrma de aço (mesa superior, alma e mesa inferior), conforme apresentado no Capítulo 2. Esses valores de temperatura, juntamente com as temperaturas médias para cada componente, obtidas do modelo numérico M01, são apresentados na Figura 4.20, por meio da qual se pode constatar que os valores de temperaturas para os diversos componentes da fôrma de aço calculados de acordo a ABNT NBR 14323:2013 e o EUROCODE 4 (EN 1994-1-2:2005) estão abaixo dos valores obtidos por meio do modelo numérico.

Essa menor temperatura, obtida e observada por meio do modelo de cálculo da ABNT NBR 14323:2013, conduz a um maior momento fletor resistente em situação de incêndio, caso se opte por considerar a influência da fôrma de aço na determinação do momento fletor resistente. Essa mesma tendência de temperatura também se observa para fôrma de aço com altura menor (modelo M02) e laje com altura maior (M03), cujos resultados são apresentados no Apêndice K.

Entretanto, vale destacar que os valores de temperaturas, obtidos via modelos numéricos identificados nos diversos componentes da fôrma de aço, resultam acima de $800^{\circ} \mathrm{C}$ e, para esta faixa de temperatura, vale ressaltar que o aço já perdeu aproximadamente $90 \%$ de sua resistência ao escoamento, tendo pouca influência na determinação do momento resistente da laje mista em situação de incêndio.

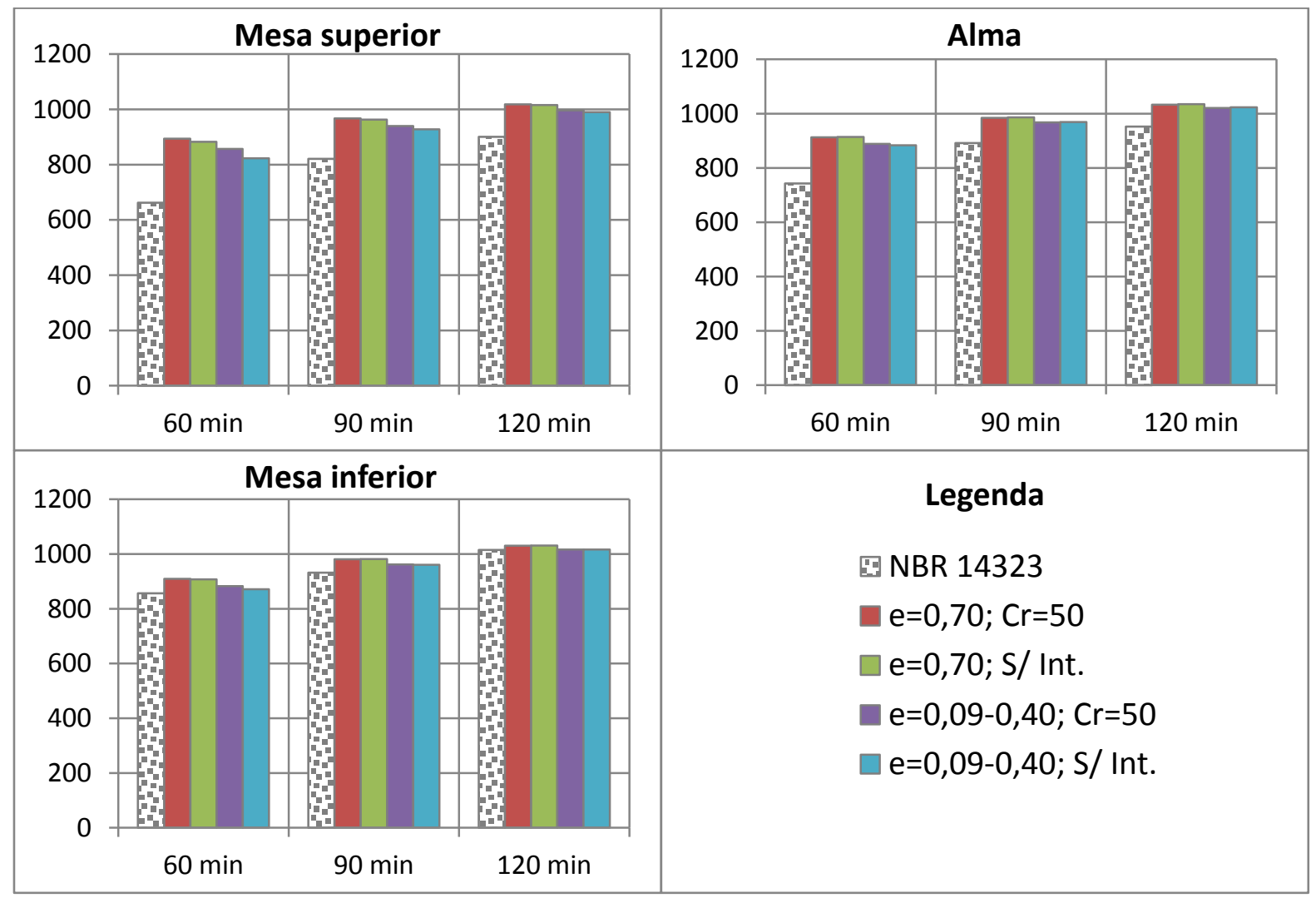

Figura 4.20 - Temperatura para cada componente da fôrma de aço para tempos de exposição de 60, 90 e 120 minutos de exposição ao fogo (Modelo M01) 
As temperaturas dos diversos componentes da fôrma de aço, mesa superior, alma e mesa inferior, também são apresentadas nas Tabelas 4.1, 4.2 e 4.3, lembrando que a ABNT NBR 14323:2013 não apresenta um procedimento para cálculo dessas temperaturas para um tempo requerido de resistência ao fogo igual a 30 minutos.

Tabela 4.1 - Temperatura da mesa superior da fôrma de aço para tempos de exposição de 60, 90 e 120 minutos (Modelo M01)

\begin{tabular}{c|c|c|c|c|c}
\hline \multicolumn{6}{c}{ Mesa superior } \\
\hline Tempo (min) & NBR 14323 & $\mathbf{\varepsilon = 0 , 7 0 ; ~ C r = 5 0}$ & $\mathbf{\varepsilon = 0 , 7 0 ; ~ S / ~ I n t , ~}$ & $\begin{array}{c}\boldsymbol{\varepsilon = 0 0 , 0 9 - 0 , 4 0 ;} \\
\mathbf{C r = 5 0}\end{array}$ & $\begin{array}{c}\boldsymbol{\varepsilon = 0 0 , 0 9 - 0 , 4 0 ;} \\
\text { S/ Int, }\end{array}$ \\
\hline 30 & - & 759,8 & 716,7 & 682,2 & 497,0 \\
\hline 60 & 676,9 & 893,9 & 882,8 & 857,1 & 823,0 \\
\hline 90 & 829,1 & 967,4 & 962,7 & 939,9 & 927,5 \\
\hline 120 & 912,9 & 1018,2 & 1015,7 & 996,3 & 989,8 \\
\hline
\end{tabular}

Tabela 4.2 - Temperatura da alma da fôrma de aço para tempos de exposição de 60, 90 e 120 minutos (Modelo M01)

\begin{tabular}{c|c|c|c|c|c}
\hline \multicolumn{6}{c}{ Alma } \\
\hline Tempo (min) & NBR 14323 & $\mathbf{\varepsilon = 0 , 7 0 ; ~ C r = 5 0}$ & $\mathbf{\varepsilon = 0 , 7 0 ; ~ S / ~ I n t , ~}$ & $\begin{array}{c}\mathbf{\varepsilon = 0 0 , 0 9 - 0 , 4 0 ;} \\
\mathbf{C r = 5 0}\end{array}$ & $\begin{array}{c}\mathbf{\varepsilon = 0 0 , 0 9 - 0 , 4 0 ;} \\
\text { S/ Int, }\end{array}$ \\
\hline 30 & - & 781,4 & 766,0 & 716,0 & 627,1 \\
\hline 60 & 744,6 & 913,1 & 914,0 & 888,7 & 883,8 \\
\hline 90 & 883,5 & 984,2 & 986,2 & 967,7 & 969,1 \\
\hline 120 & 959,2 & 1033,0 & 1035,0 & 1021,0 & 1023,4 \\
\hline
\end{tabular}

Tabela 4.3 - Temperatura da mesa inferior da fôrma de aço para tempos de exposição de 60, 90 e 120 minutos (Modelo M01)

\begin{tabular}{c|c|c|c|c|c}
\hline \multicolumn{6}{c}{ Mesa inferior } \\
\hline Tempo (min) & NBR 14323 & $\mathbf{\varepsilon = 0 , 7 0 ; ~ C r = 5 0}$ & $\mathbf{\varepsilon = 0 , 7 0 ; ~ S / ~ I n t , ~}$ & $\begin{array}{c}\boldsymbol{\varepsilon = 0 0 , 0 9 - 0 , 4 0 ;} \\
\mathbf{C r = 5 0}\end{array}$ & $\begin{array}{c}\mathbf{\varepsilon = 0 0 , 0 9 - 0 , 4 0 ;} \\
\text { S/ Int, }\end{array}$ \\
\hline 30 & - & 777,4 & 756,4 & 709,6 & 601,5 \\
\hline 60 & 844,6 & 909,4 & 907,7 & 882,6 & 871,5 \\
\hline 90 & 948,2 & 980,9 & 981,5 & 962,2 & 960,6 \\
\hline 120 & 1009,3 & 1030,2 & 1031,3 & 1016,2 & 1016,7 \\
\hline
\end{tabular}

\subsubsection{Com relação à temperatura na armadura}

Assim como no caso da fôrma de aço, a ABNT NBR 14323:2013 e o EUROCODE 4 (EN 1994-1-2:2005) também apresentam um equacionamento para cálculo da temperatura da armadura positiva, conforme apresentado no Capítulo 2. Para o uso desse procedimento de cálculo a armadura deve estar dentro da nervura da fôrma de aço. A temperatura da armadura ao longo da altura da nervura $\left(u_{f 3}\right)$, medida a partir da face superior da fôrma de aço, para os 
três modelos apresentados e tempos de exposição de 60, 90 e 120 minutos são apresentados nas Figuras 4.21 a 4.23.

Para um tempo de exposição de 60 minutos (Figura 4.21), a temperatura da armadura calculada de acordo o procedimento de cálculo apresentado na ABNT NBR 14323:2013, quando posicionada até a metade da nervura, apresentou valores intermediários às temperaturas dos modelos numéricos. Já quando a armadura se aproxima da face superior da laje (maior $u_{f 3}$ ), os resultados normativos tendem a serem inferiores aos numéricos.

Para tempos de exposição ao incêndio de 90 e 120 minutos os resultados normativos apresentaram boa correlação com aqueles obtidos dos modelos numéricos sem interface e com emissividade variável $(0,09$ a 0,40$)$.

Tanto a ABNT NBR 14323:2013 quanto o EUROCODE 4 (2005) não mencionam nenhum caso de emissividade resultante diferente de 0,70, e nem mesmo a consideração de resistência térmica na interface entre a fôrma de aço e o concreto. Porém, para os modelos numéricos sem a consideração de interface entre a fôrma de aço e o concreto, a temperatura nas armaduras resulta sempre maior se comparada àquela calculada pelos procedimentos normativos. Isso implica em um maior momento fletor resistente da laje calculado pelos procedimentos normativos quando comparado com o momento plástico resistente calculado por meio dos campos térmicos obtidos dos modelos numéricos usando os parâmetros (como emissividade e resistência térmica na interface) recomendados pelas mesmas normas.

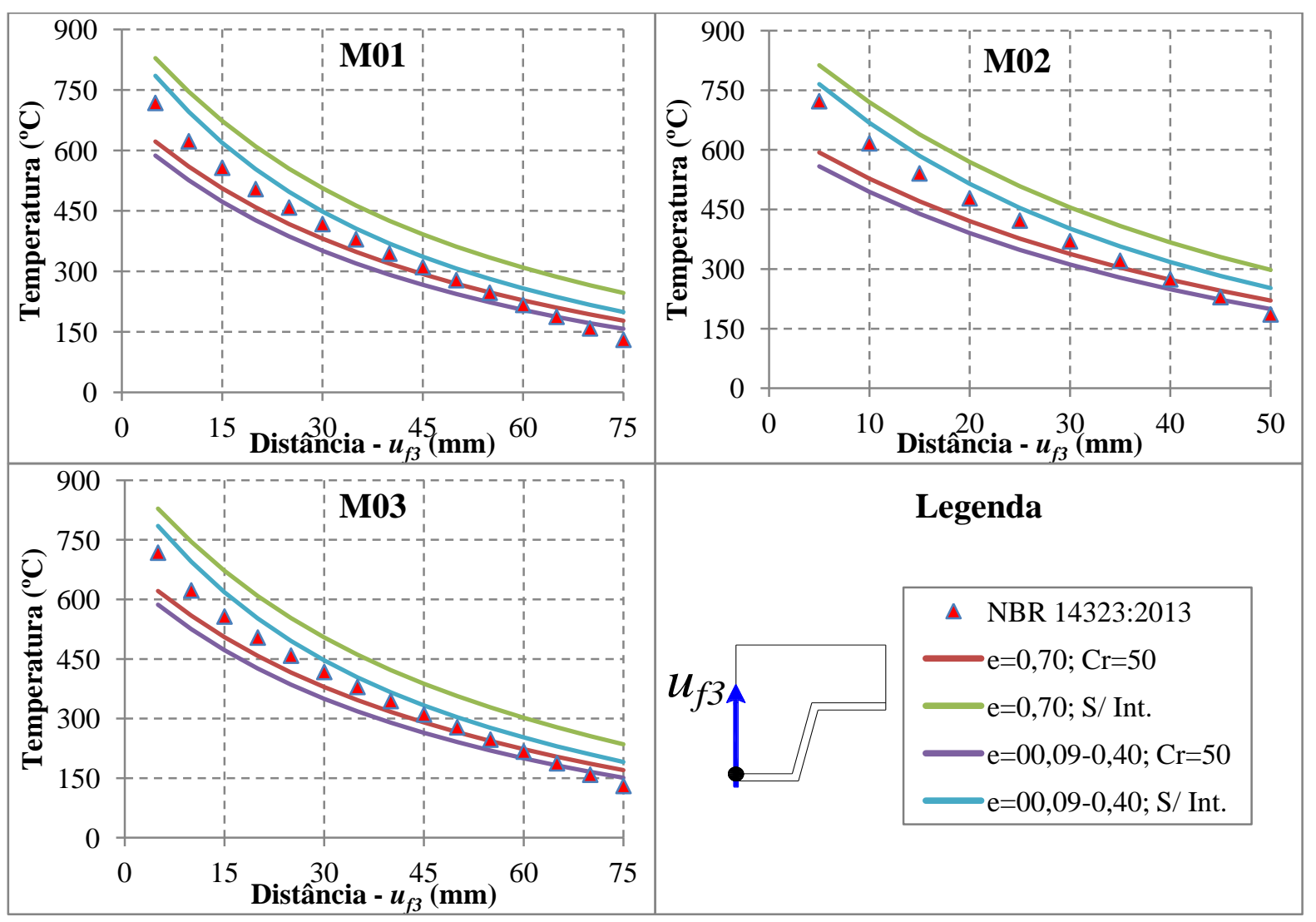

Figura 4.21 - Gráfico temperatura da armadura positiva em função da sua posição em relação à base da laje para tempo de exposição de 60 minutos 

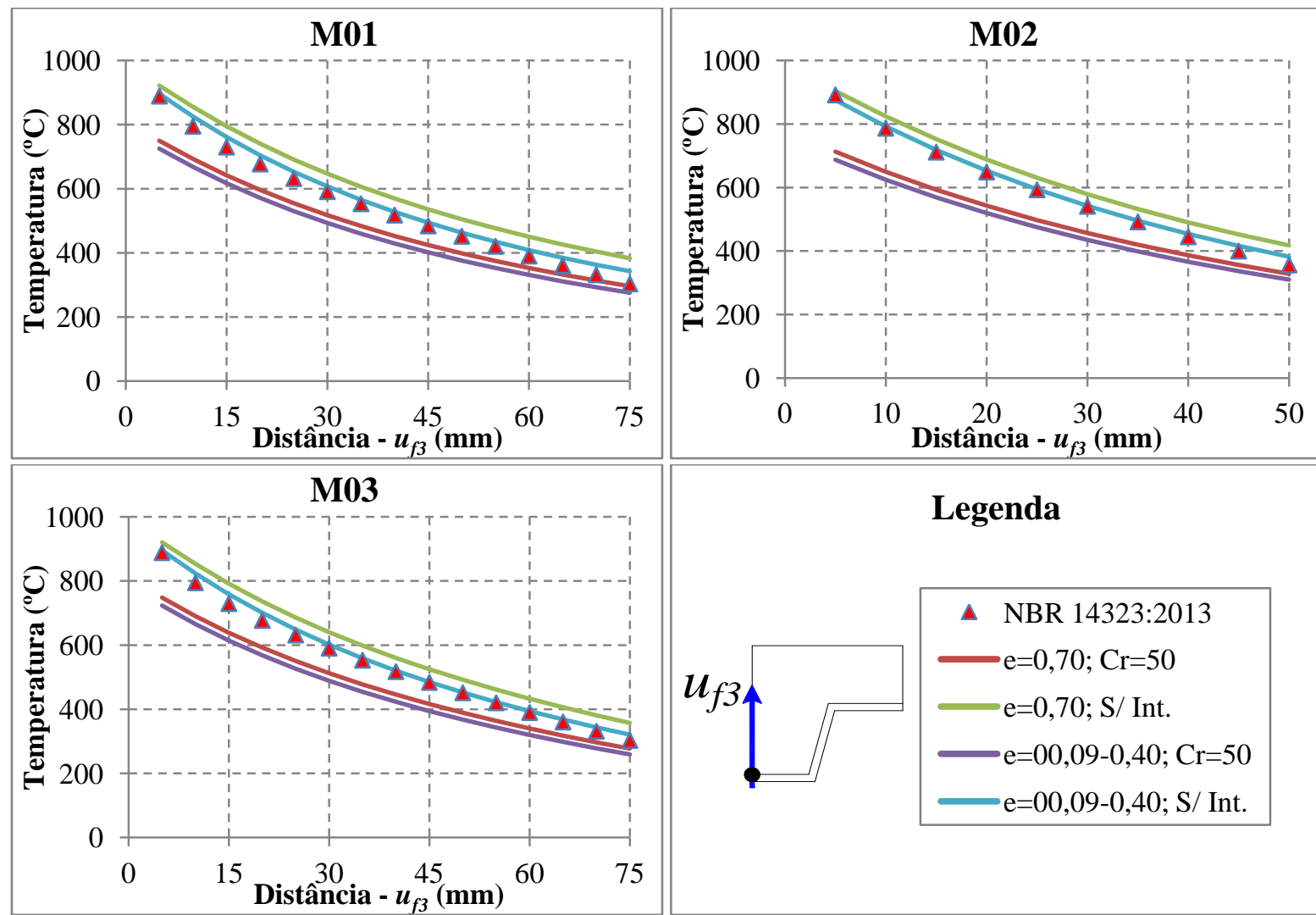

Legenda

Figura 4.22 - Gráfico temperatura da armadura positiva em função da sua posição em relação à base da laje para tempo de exposição de 90 minutos
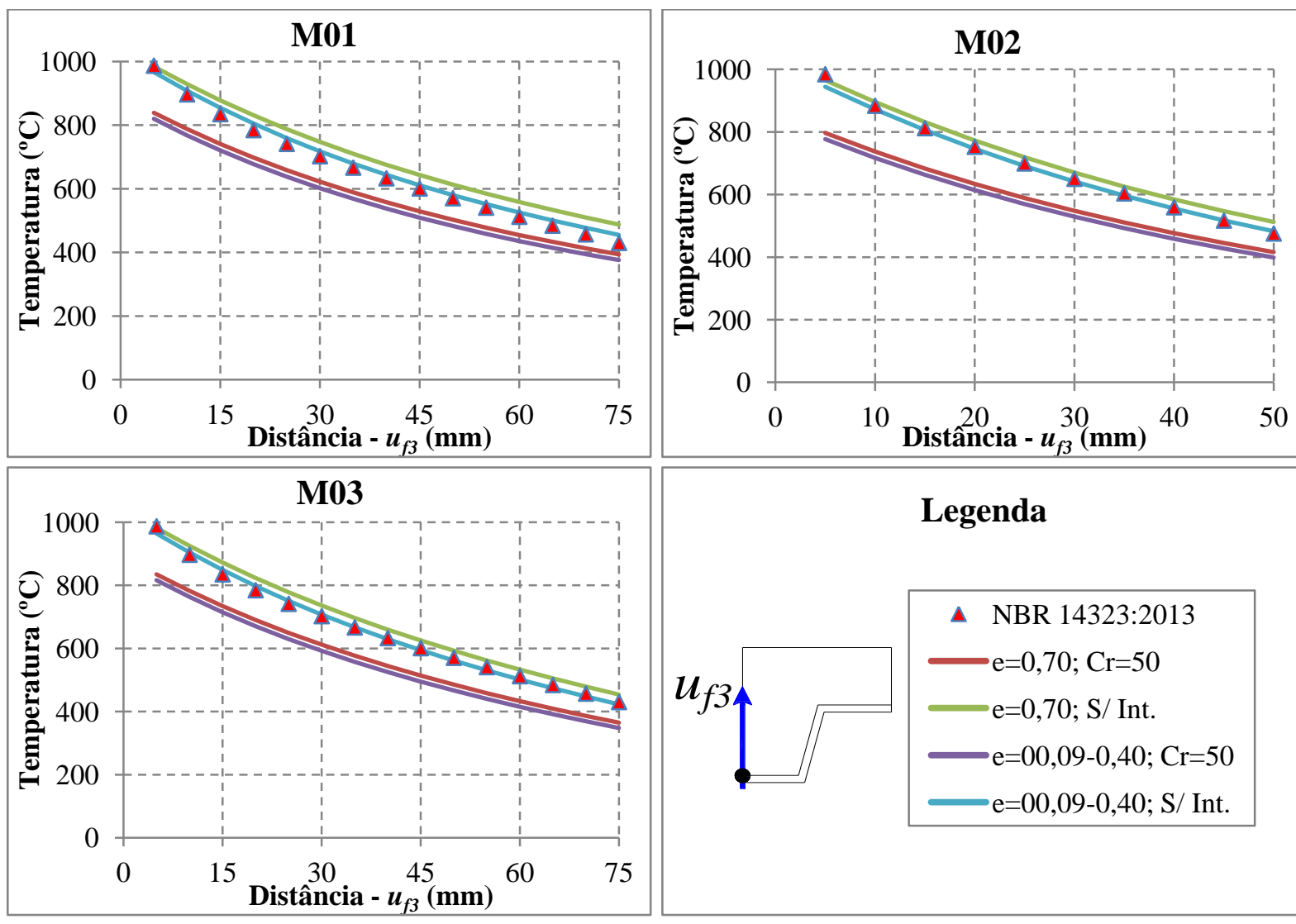

Legenda

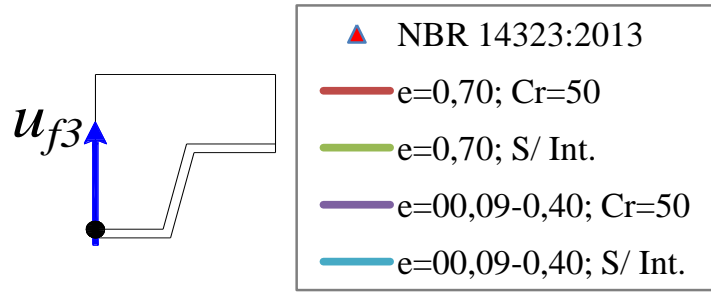

Figura 4.23 - Gráfico temperatura da armadura positiva em função da sua posição em relação à base da laje para tempo de exposição de 120 minutos 


\subsubsection{Determinação do Momento fletor resistente}

Neste item será avaliada a capacidade resistente das lajes mistas quanto ao momento fletor positivo resistente, comparando os resultados obtidos via modelagem numérica com aqueles determinados de acordo a ABNT NBR 14323:2013, a qual possui o mesmo procedimento de cálculo apresentado no EUROCODE 4 (EN 1994-1-2:2005).

\subsubsection{Momento fletor resistente devido à fôrma de aço}

Os resultados para o momento fletor resistente calculados considerando somente a contribuição da fôrma de aço em função do tempo de exposição ao fogo com base no incêndio-padrão são apresentados graficamente na Figura 4.24. Conforme se pode observar, a maior diferença entre os resultados dos modelos numéricos, considerando os dois casos de emissividade e resistência térmica na interface, ocorre nos primeiros 60 minutos de exposição ao fogo. A partir desse tempo de exposição, os resultados numéricos tendem a um mesmo valor, independente dos casos de emissividade e resistência térmica na interface.
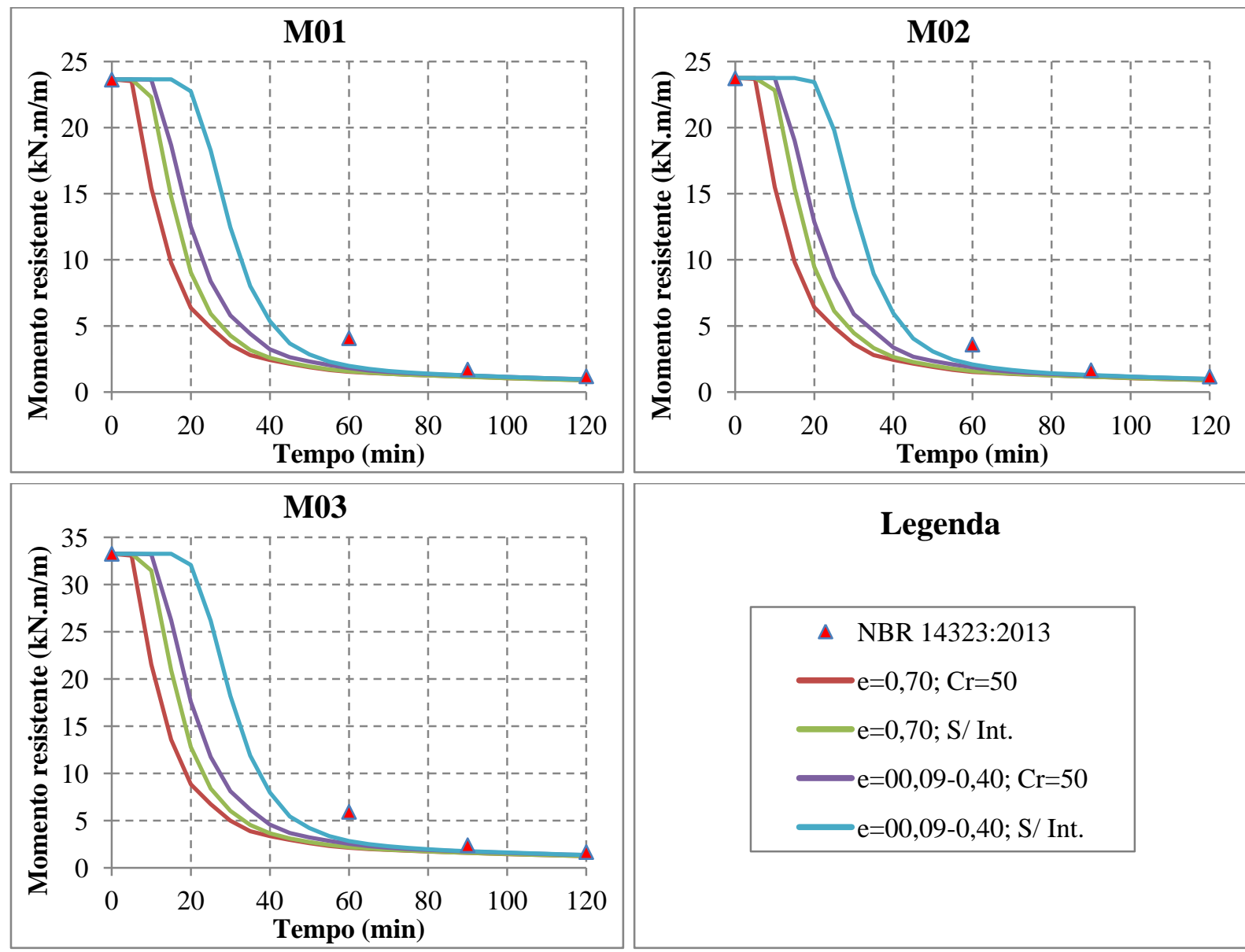

\section{Legenda}

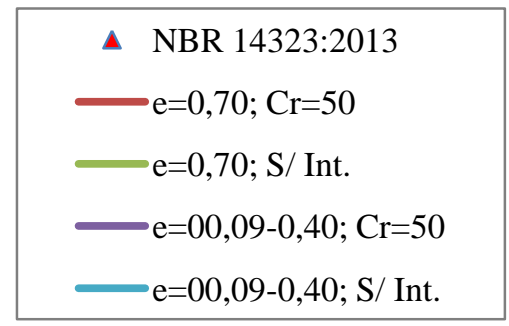

Figura 4.24 - Momento fletor positivo resistente vs. Tempo de exposição ao fogo, considerando somente a influência da fôrma de aço. 
Pela Figura 4.24 também se observa que quando se considera uma emissividade resultante igual a 0,70 o momento fletor resistente é reduzido para valores entre 15 e $18 \%$ se comparado com relação ao calculado à temperatura ambiente ${ }^{11}$. Esse resultado pode indicar a necessidade de utilização de armaduras positivas para garantir a resistência de lajes mistas simplesmente apoiadas em situação de incêndio, mesmo para um tempo requerido de resistência ao fogo (TRRF) de 30 minutos. Entretanto, vale ressaltar que a ABNT NBR 14323:2013 menciona que a resistência das lajes mistas, com ou sem armadura positiva, pode ser considerada de no mínimo 30 minutos, desde que garantido o critério de isolamento térmico.

O momento fletor resistente calculado numericamente, levando em conta somente a contribuição da fôrma de aço, é aproximadamente a metade daquele calculado pelos procedimentos normativos, para um tempo de exposição de 60 minutos. Entretanto, para 90 e 120 minutos esses resultados se correlacionam melhor. Porém esses valores de resistências são muitos baixos se comparados com aqueles obtidos à temperatura ambiente. Outro fato importante que deve ser ressaltado é que tanto o modelo numérico quanto a ABNT NBR 14323:2013, ambos consideram perfeita aderência entre a fôrma de aço e o concreto. Porém, em situação de incêndio, após certo tempo de exposição, tem-se verificado por meio de procedimentos experimentais que a fôrma de aço se desprende do concreto. Nessa situação não é mais possível contar com a aderência entre a fôrma de aço e o concreto.

\subsubsection{Momento fletor resistente devido à armadura positiva}

Para se avaliar a capacidade resistente da laje mista levando em conta somente a contribuição da armadura positiva, foi adotada uma armadura por nervura com diâmetro igual a $16 \mathrm{~mm}$, com cobrimento de $20 \mathrm{~mm}$ e resistência ao escoamento $\left(f_{y}\right)$ igual a $500 \mathrm{MPa}$. Os resultados para o momento fletor resistente em função do tempo de exposição ao fogo estão apresentados graficamente na Figura 4.25.

Quando se considera os modelos numéricos com emissividade resultante igual a 0,70 e sem interface, somente há redução da capacidade resistente após 40 minutos de exposição ao fogo para os modelos M01 e M03, os quais possuem maior área em contato com o incêndio, enquanto que para o modelo M02 a redução da capacidade resistente se verifica após 45 minutos de exposição ao fogo.

Pela Figura 4.25 também se observa que os resultados para o momento fletor resistente calculados de acordo a ABNT NBR 14323:2013 melhor se aproximaram dos numéricos quando se considera a emissividade resultante variável entre 0,09 e 0,40. Entretanto nos modelos numéricos foi considerada uma umidade de $2 \%$ para o concreto. Quando se adota um maior valor para a umidade (em torno de 8 a 10\%) os resultados numéricos considerando uma emissividade resultante de 0,70 também se correlacionam bem com os normativos.

\footnotetext{
11 Nos gráficos de momento fletor resistente versus tempo de exposição, o momento fletor resistente à temperatura ambiente é referente a um tempo de exposição igual a zero minuto.
} 


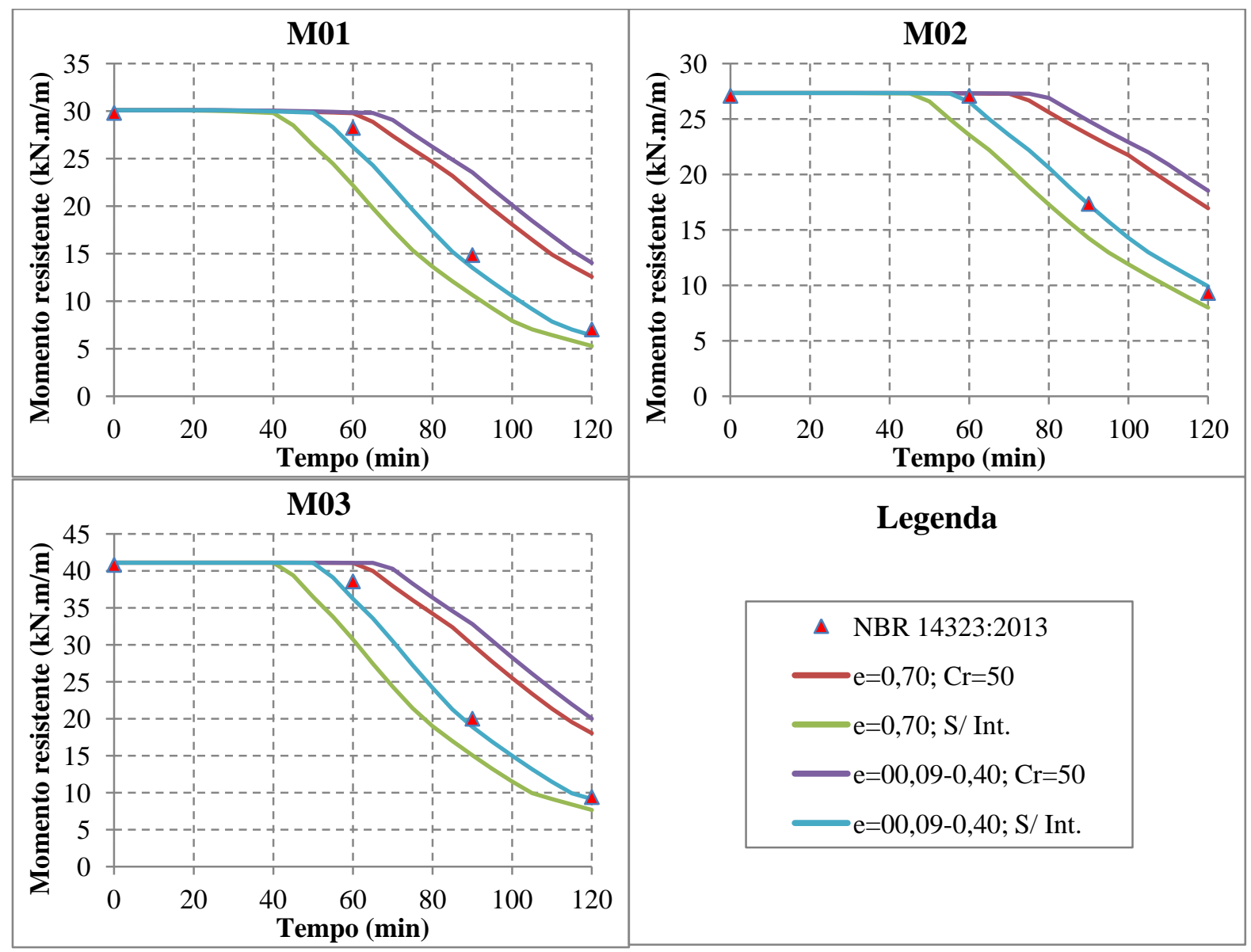

Figura 4.25 - Momento fletor positivo resistente vs. Tempo de exposição considerando somente a influência da armadura positiva

A ABNT NBR 14323:2013 passou a considerar a resistência à compressão do concreto comprimido (acima da linha neutra plástica) em função da temperatura, diferentemente dos projetos de revisão anteriores. Entretanto, essa consideração tem pouca influência na determinação do momento fletor resistente, uma vez que a temperatura média da porção do concreto comprimido considerando um caso extremo (TRRF igual a 120 minutos, altura da laje igual a $120 \mathrm{~mm}$ e altura da fôrma de aço igual a $75 \mathrm{~mm}$ ) resulta aproximadamente $400{ }^{\circ} \mathrm{C}$, sendo que para essa faixa de temperatura, o concreto perdeu aproximadamente $25 \%$ da sua resistência à compressão.

Uma perda de resistência da ordem de $25 \%$ não resulta em grandes reduções no momento resistente. Nesse caso, a redução da resistência à compressão aumentará a altura de concreto comprimido, sendo que o momento fletor resistente ficará praticamente constante. Essa explicação é verdadeira quando a laje é projetada para que a ruptura ocorra no aço (ruptura dúctil), ou seja, a laje não deve estar excessivamente armada. Para ilustrar a pouca influência da variação na resistência à compressão do concreto na determinação do momento resistente, é apresentada na Figura 4.26 a relação "momento fletor positivo resistente $v s$. tempo de exposição ao fogo" considerando resistências à compressão $\left(f_{c}\right)$ iguais a $20 \mathrm{MPa}$ e $15 \mathrm{MPa}$ para o concreto. Neste caso uma redução de $25 \%$ na resistência do concreto provocou 
uma redução máxima de $2,9 \%$ na resistência da laje (reduziu de $37,4 \mathrm{kNm} / \mathrm{m}$ para $36,3 \mathrm{kNm} / \mathrm{m}$ à temperatura ambiente), sendo que com o aumento do tempo de exposição ao fogo essa diferença vai reduzindo ainda mais.

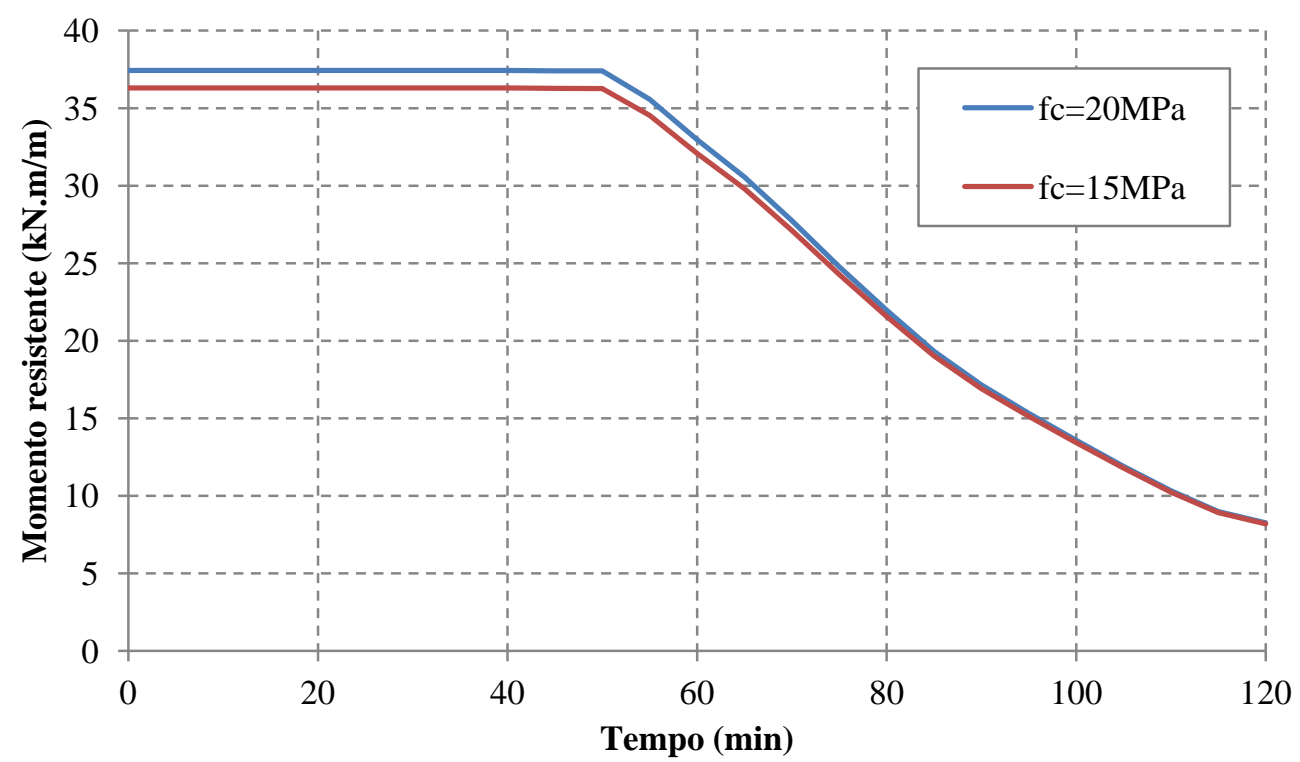

Figura 4.26 - Momento fletor positivo resistente vs. Tempo de exposição considerando resistência característica de 20 e 15 MPa para o concreto.

\subsection{Posição da armadura positiva}

Quando a armadura positiva se encontra mais próxima da fôrma de aço, o braço de alavanca para o cálculo do momento fletor positivo é maior, o que aumentaria a resistência por flexão. Porém, nesse caso, a armadura estará sujeita a um maior aquecimento reduzindo a capacidade resistente da laje de concreto. Desse modo é possível haver um posicionamento ótimo da armadura que proporciona uma maior capacidade resistente da laje em situação de incêndio $\left(u_{f 3, \text { ótimo }}\right)($ SANTOS \& MUNAIAR NETO, 2013). Pela Figura 4.27 é possível observar que essa posição depende do tempo requerido de resistência ao fogo (TRRF) e também da emissividade resultante. Com o aumento do tempo de exposição ao fogo, há

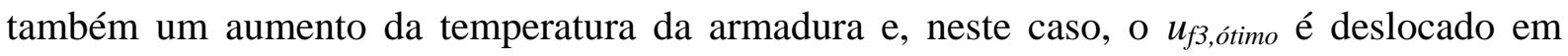
direção a face superior da laje.

Na Figura 4.28 é apresentada graficamente a relação " $u_{f 3, \text { ótimo }} v s$. altura total da laje" considerando TRRF iguais a 30, 60, 90 e 120 minutos para diversos casos de área da armadura positiva $\left(A_{s}\right)$, onde é possível observar que essa distância também depende da área da armadura, de tal forma que quanto menor a área da armadura, a mesma deve estar posicionada mais próxima da face superior da laje. Pela Figura 4.28 também é possível

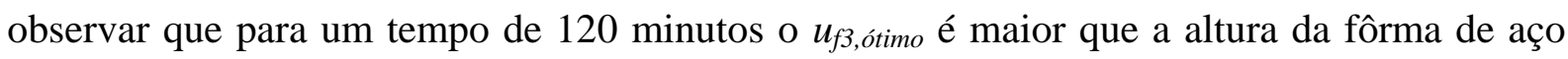
$(50 \mathrm{~mm})$, indicando que a armadura positiva já não é tão efetiva para cálculo da resistência à flexão da laje, e neste caso poderia recorrer ao uso de armaduras negativas, já que conforme 
apresentado em SANTOS \& MUNAIAR NETO (2013) a resistência à flexão da laje quanto ao momento negativo não é tão afetada como ocorre nas armaduras positivas, para tempos superiores a 90 minutos.

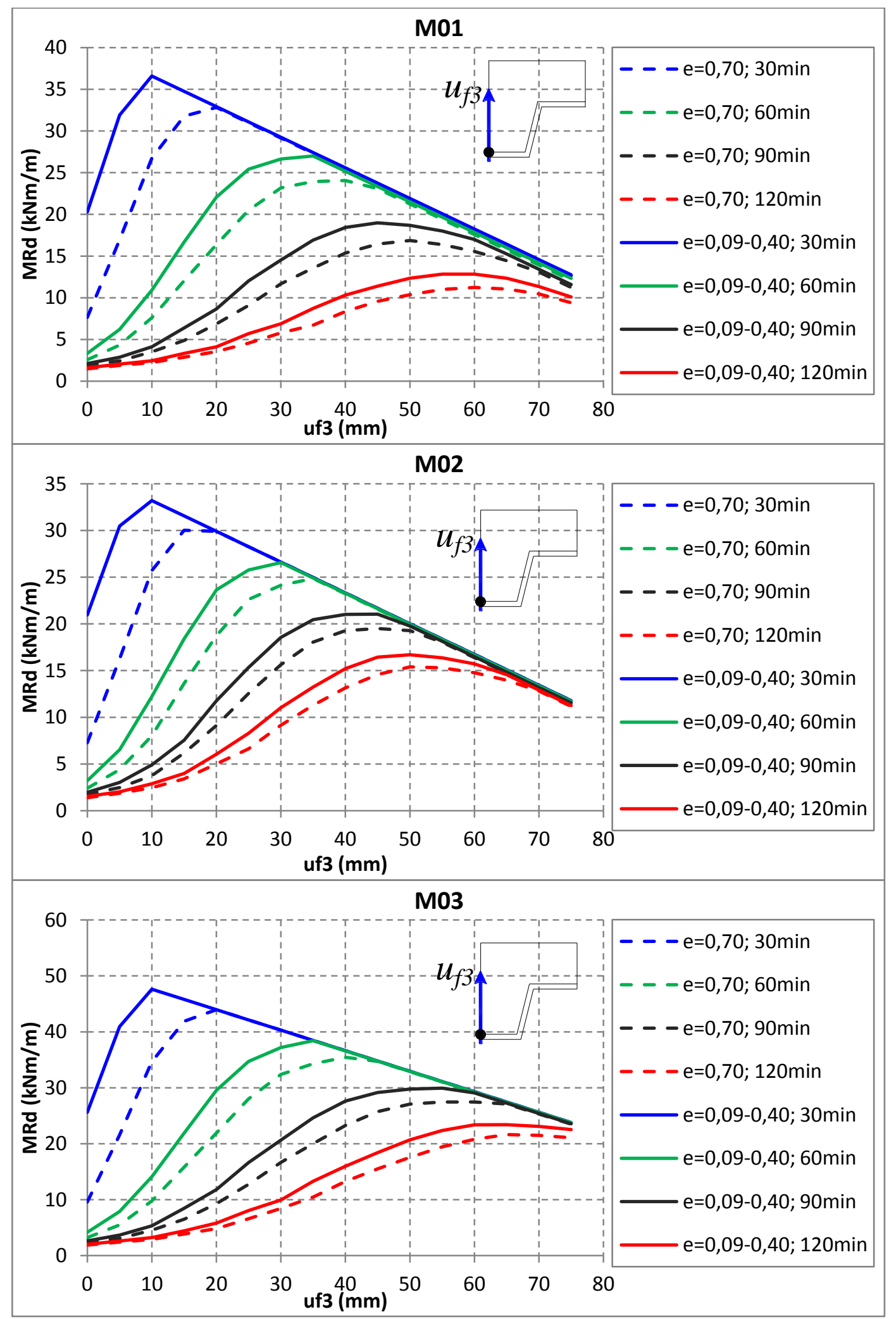

Figura 4.27 - Momento positivo resistente vs. Distância do CG da armadura positiva à mesa inferior da fôrma de aço (uf3) para tempos de exposição de 30, 60, 90 e 120 minutos 


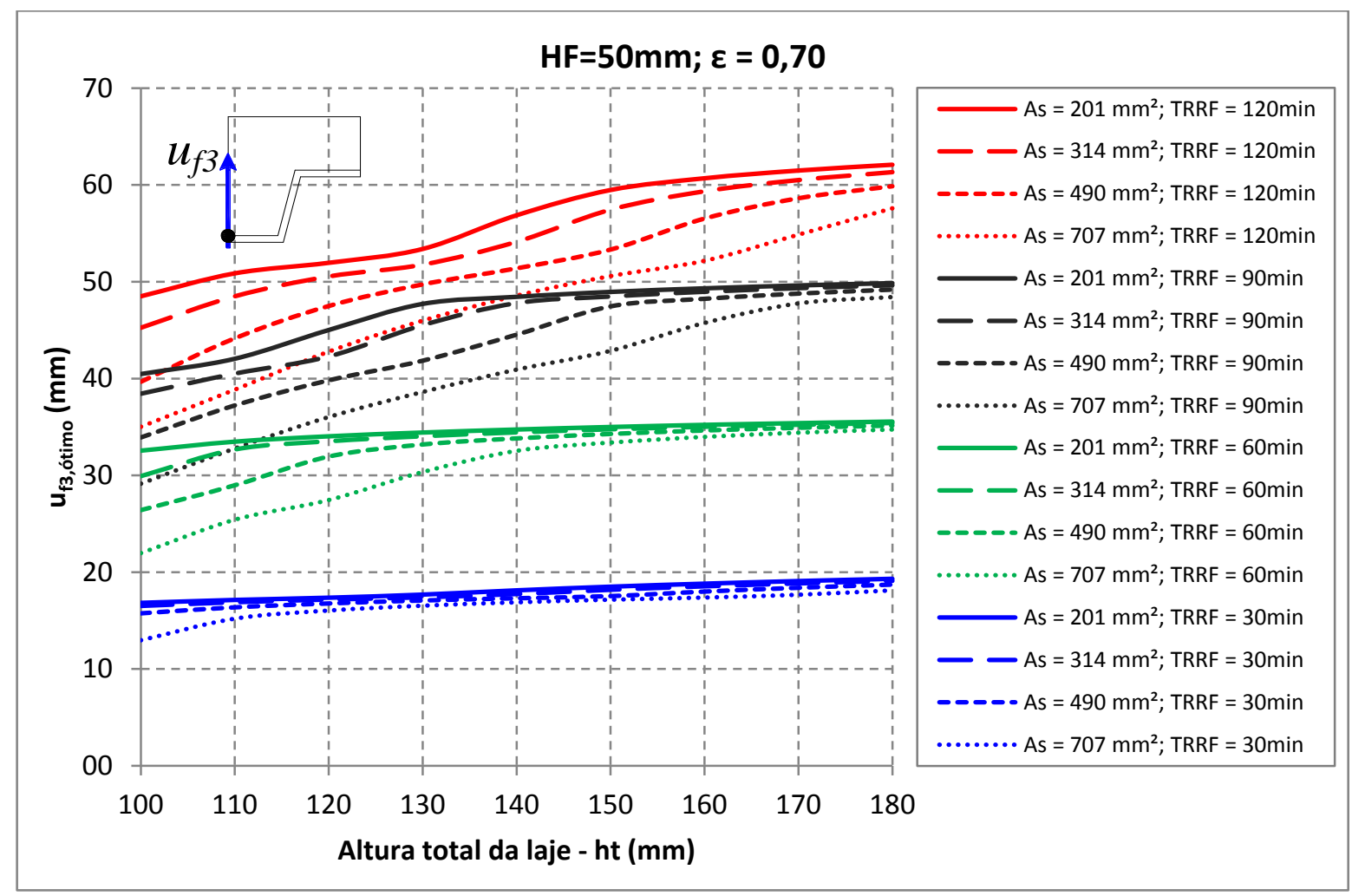

Figura 4.28 - $u_{f 3, \text {,timo }} v s$. Altura total da laje para TRRF de 30, 60, 90 e 120 minutos e área da armadura positiva $\left(A_{s}\right)$ iguais a $201,314,490$ e $707 \mathrm{~mm}^{2}$.

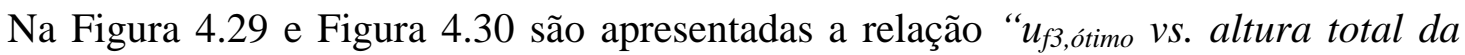
laje” considerando a influência da emissividade resultante e da altura da fôrma de aço, respectivamente. Quando se considera uma maior emissividade resultante a armadura está sujeita a um maior aquecimento, e desta forma se faz necessário que a mesma esteja posicionada mais distante da face em contato com o fogo (Figura 4.29). O mesmo também se observa quando se tem uma maior altura da fôrma de aço (Figura 4.30). Neste caso, há uma maior área da fôrma de aço em contato com o incêndio e a temperatura da armadura também é aumentada mais rapidamente em relação a uma menor altura de fôrma, sendo necessário deslocá-la em direção a face superior da laje para aumentar a resistência em situação de incêndio.

No Apêndice L são apresentados demais gráficos para cálculo do posicionamento da armadura que maximize a resistência à flexão da laje. Por esses gráficos se observa que para

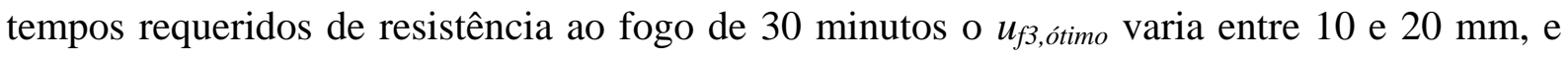
neste caso o que vai governar o posicionamento da armadura é o cobrimento mínimo

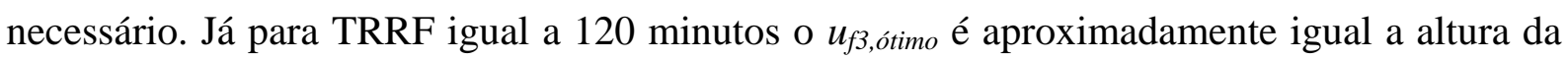
fôrma de aço. 


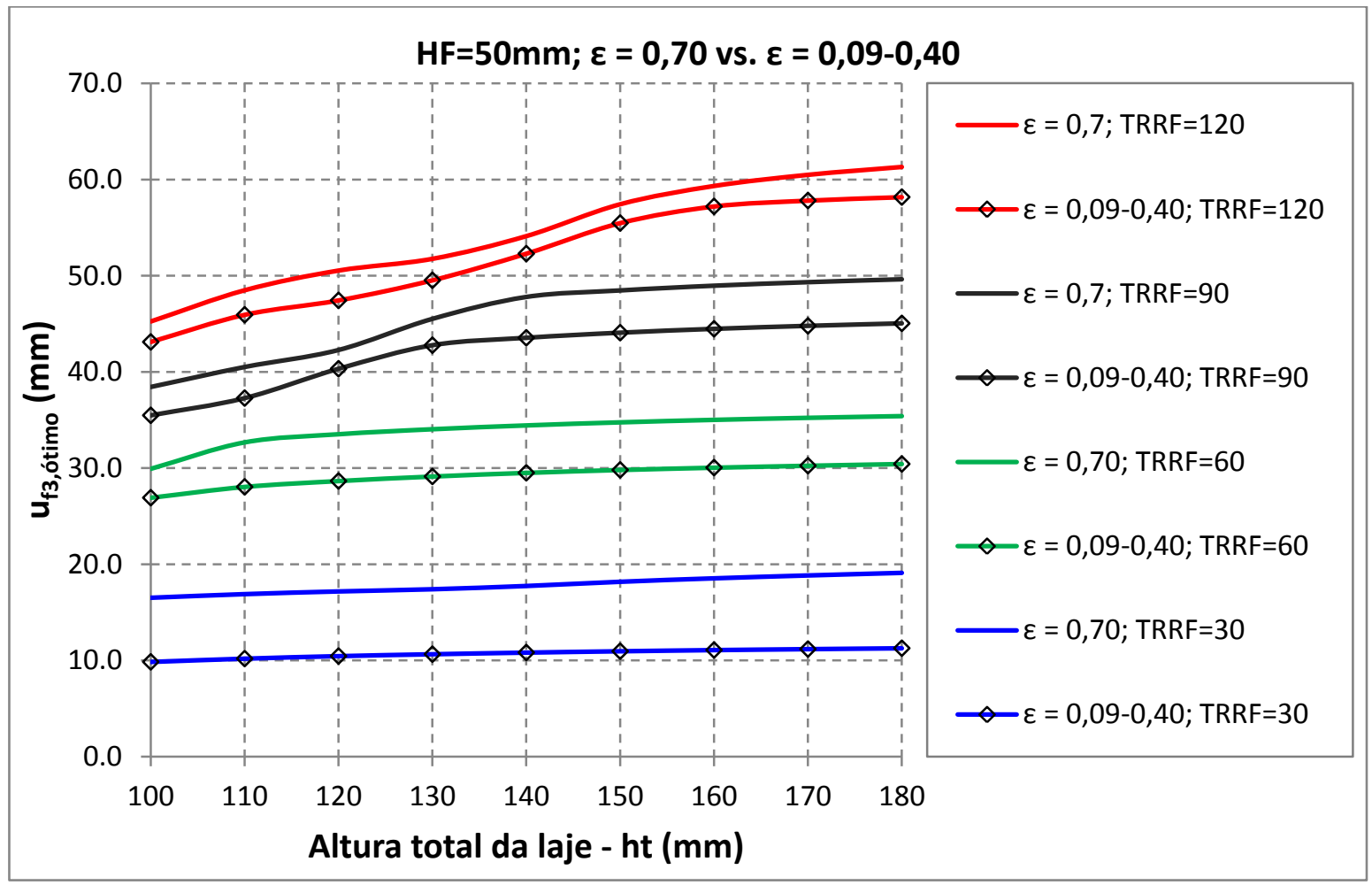

Figura 4.29 - $u_{f 3, \text { t́timo }} v s$. Altura total da laje para TRRF de 30, 60, 90 e 120 minutos e emissividade resultante $\left(\varepsilon_{r}\right)$ iguais a 0,70 e variável entre 0,09 a 0,40 .

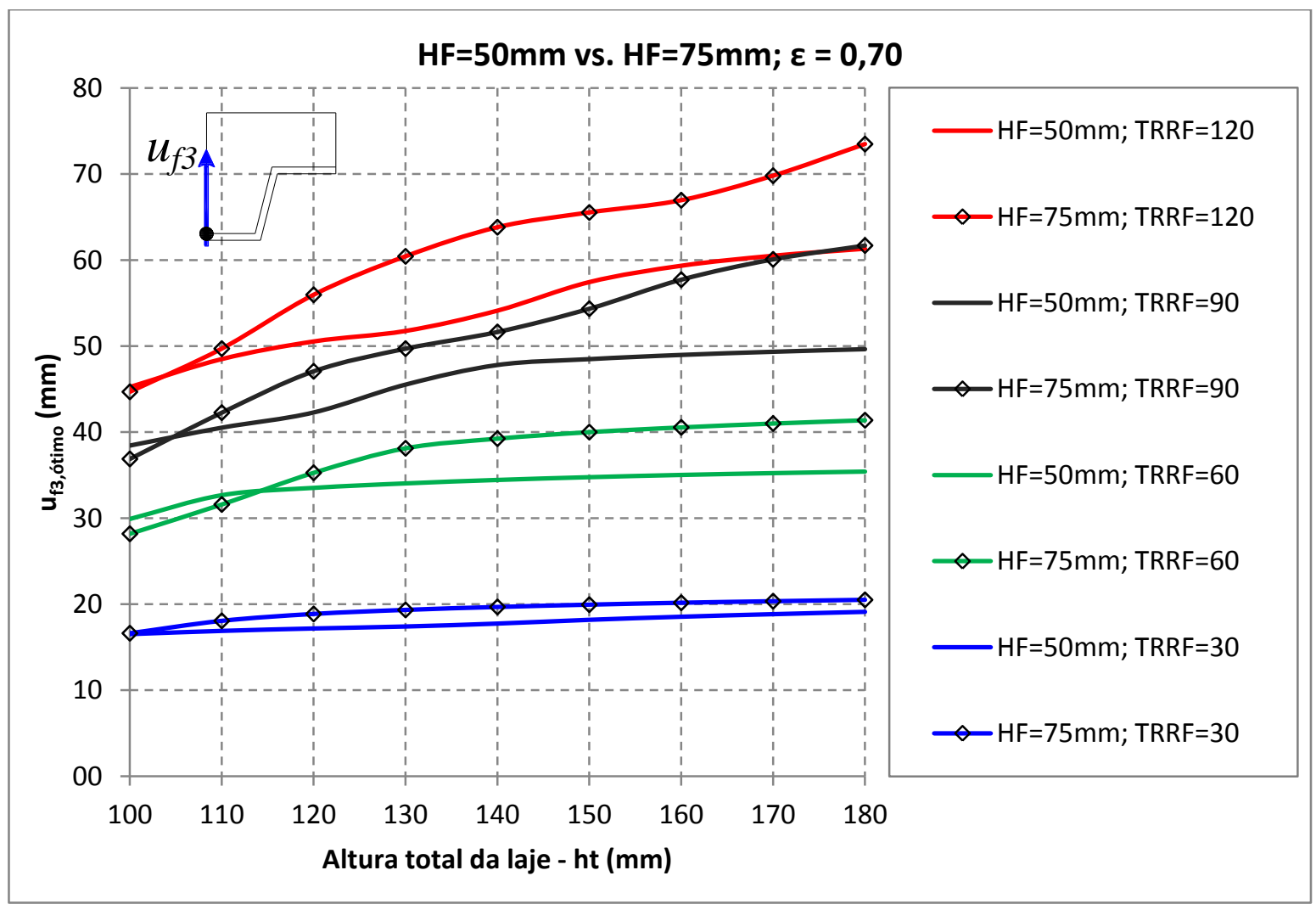

Figura 4.30 - $u_{f 3, \text { ótimo }} v s$. Altura total da laje para TRRF de 30, 60, 90 e 120 minutos e altura da fôrma de aço (HF) de 50 e $75 \mathrm{~mm}$ 


\section{CAPÍTULO 5}

\section{Análises estruturais e termoestruturais: resultados e discussões}

\subsection{Introdução}

No presente capítulo são apresentados resultados e consequentes considerações de modelos numéricos referentes às análises estruturais (à temperatura ambiente) e termoestruturais (em temperaturas elevadas) voltadas às lajes mistas de aço e concreto. Para esta finalidade, conforme apresentado nos capítulos anteriores, são utilizados modelos numéricos tridimensionais desenvolvidos no pacote computacional TNO DIANA 9.4.4.

Dois grandes entraves das análises termoestruturais são: o elevado tempo de processamento e o esforço computacional para processamento dos modelos numéricos. Dessa forma, buscando minimizar esses fatores, realizou-se inicialmente uma análise estrutural à temperatura ambiente, objetivando a calibração do modelo numérico por meio de resultados experimentais, cujos parâmetros serão depois utilizados na análise termoestrutural.

Com o modelo numérico calibrado à temperatura ambiente, realizou-se a validação do modelo termoestrutural por meio de resultados experimentais, porém neste caso não se encontrou na literatura ensaios com lajes mistas simplesmente apoiadas em situação de incêndio. Desse modo, se utilizou resultados experimentais obtidos e apresentados em GUO (2011) para lajes mistas apoiadas em quatro pontos.

Após a calibração dos modelos numéricos à temperatura ambiente e em situação de incêndio, os resultados de resistência ao fogo serão comparados com aqueles obtidos pelo processamento dos modelos térmicos bidimensionais e o modelo de cálculo da ABNT NBR 14323:2013. Por fim, serão feitas análises dos resultados dos modelos termoestruturais, considerando as influências dos seguintes aspectos paramétricos: da armadura positiva, da fôrma de aço, da resistência à compressão do concreto, da altura e do vão entre apoios da laje mista. 


\subsection{Validação do modelo numérico à temperatura ambiente}

Para validação do modelo estrutural à temperatura ambiente se utilizou os resultados experimentais obtidos em FERRAZ (1999) e ARAUJO (2008), cujas características e propriedades dos protótipos ensaiados e utilizados neste trabalho são apresentadas na Tabela 5.1. Nesses ensaios, conforme visto no Capítulo 2, as cargas transmitidas aos protótipos foram aplicadas por um atuador hidráulico em dois pontos, simulando duas cargas concentradas com uma distância $L$ ' do apoio (vão de cisalhamento).

Tabela 5.1 - Características e propriedades dos protótipos 1 e 7 (FERRAZ, 1999) e protótipo 01A (ARAUJO, 2008)

\begin{tabular}{|c|c|c|c|c|}
\hline \multirow{2}{*}{\multicolumn{2}{|c|}{ Características e propriedades }} & \multicolumn{2}{|c|}{ FERRAZ (1999) } & \multirow{2}{*}{$\begin{array}{c}\text { ARAUJO (2008) } \\
\text { Protótipo 01A }\end{array}$} \\
\hline & & $\begin{array}{l}\text { Protótipo } \\
01\end{array}$ & $\begin{array}{l}\text { Protótipo } \\
07\end{array}$ & \\
\hline \multicolumn{2}{|l|}{ Vão do protótipo $-L(\mathrm{~mm})$} & 1800 & 1800 & 2500 \\
\hline \multicolumn{2}{|l|}{ Vão de cisalhamento $-L^{\prime}(\mathrm{mm})$} & 450 & 450 & 800 \\
\hline \multicolumn{2}{|l|}{ Largura do modelo $-\mathrm{b}(\mathrm{mm})$} & 820 & 820 & 860 \\
\hline \multicolumn{2}{|c|}{ Tensão de escoamento da fôrma de aço $-f_{y}(\mathrm{MPa})$} & 351 & 345 & 340 \\
\hline \multicolumn{2}{|c|}{$\begin{array}{l}\text { Resistência à compressão do concreto no momento } \\
\text { do ensaio }-f_{c k}(\mathrm{MPa})\end{array}$} & 29,0 & 28,2 & 24,7 \\
\hline \multicolumn{2}{|c|}{ Espessura nominal da fôrma de aço $(\mathrm{mm})$} & 0,80 & 1,25 & 0,80 \\
\hline \multicolumn{2}{|l|}{ Altura total da laje (mm) } & 130 & 130 & 110 \\
\hline \multirow{4}{*}{ Dimensões da fôrma de aço (mm) } & $l_{1}$ & 155 & 155 & 160,6 \\
\hline & $l_{2}$ & 119 & 119 & 119,1 \\
\hline & $l_{3}$ & 119 & 119 & 119,1 \\
\hline & $h_{2}$ & 75 & 75 & 60 \\
\hline
\end{tabular}

Esses protótipos foram utilizados como referência para calibração do modelo numérico, que inclui a análise da influência de diversos parâmetros nos resultados numéricos como a simetria do modelo numérico, energia de fratura do concreto a compressão $\left(G_{c}\right)$, método de solução das equações, resistência mecânica na interface entre a fôrma de aço e o concreto, modelo constitutivo para representação numérica dessa interface e chapa de apoio para melhorar a distribuição de tensões no contato com os apoios.

\subsubsection{Modelo numérico de laje mista com interação completa}

O modelo numérico com interação completa refere-se àqueles com perfeita aderência entre a fôrma de aço e o concreto, ou seja, não se considera deslocamento relativo entre esses materiais. Na Figura 5.1 são apresentados os resultados experimentais e numéricos para o protótipo 01 considerando interação completa bem como modelos numéricos completo (sem simetria), com simetria de $1 / 4$ de laje e com simetria de $1 / 2$ nervura da laje, conforme 
esquematiza a Figura 5.2, com vista à redução de esforço computacional. Para esses modelos também foram adotadas malhas de elementos finitos com dimensões médias de $10 \mathrm{~mm}$.

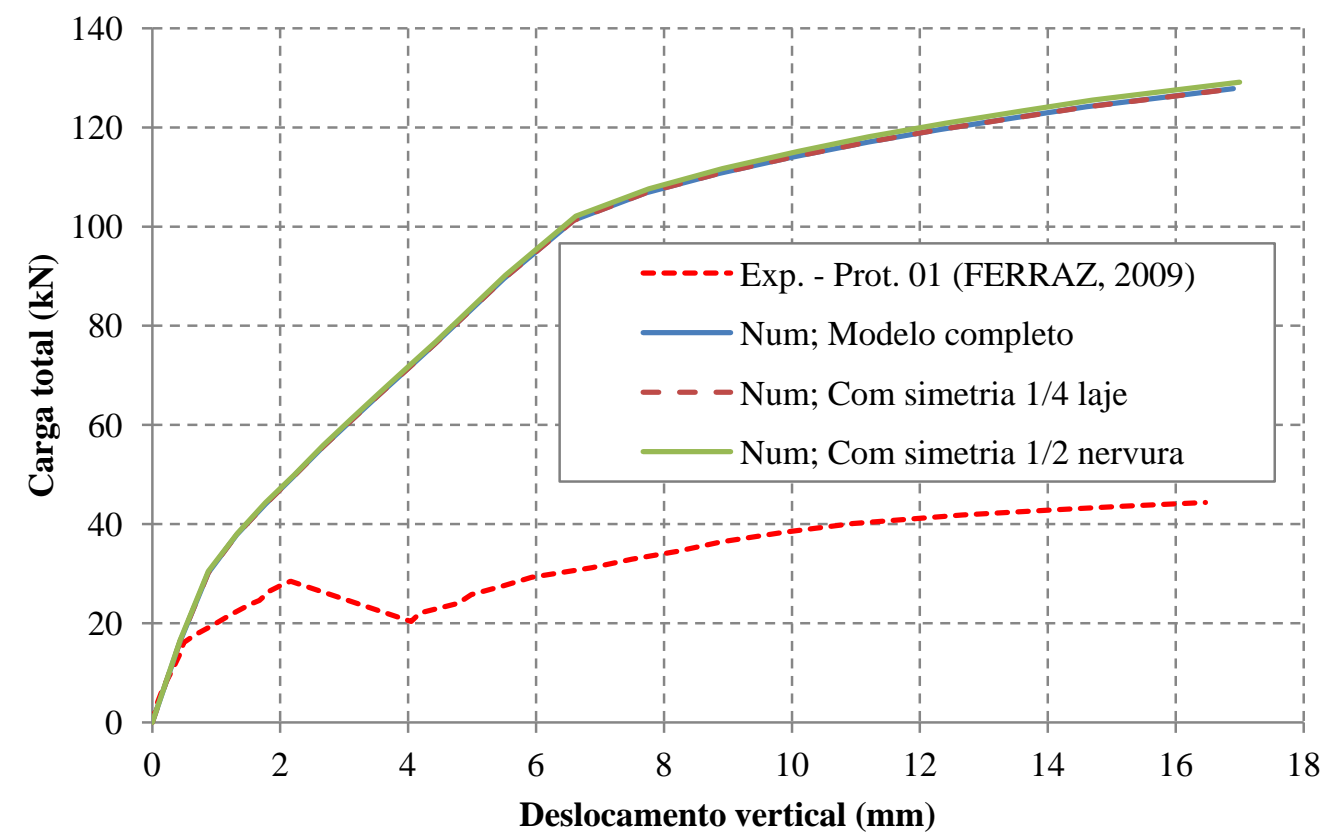

Figura 5.1 - Gráfico Carga total aplicada no modelo vs. Deslocamento vertical para o modelo numérico com e sem simetria e iteração completa (Protótipo 01)

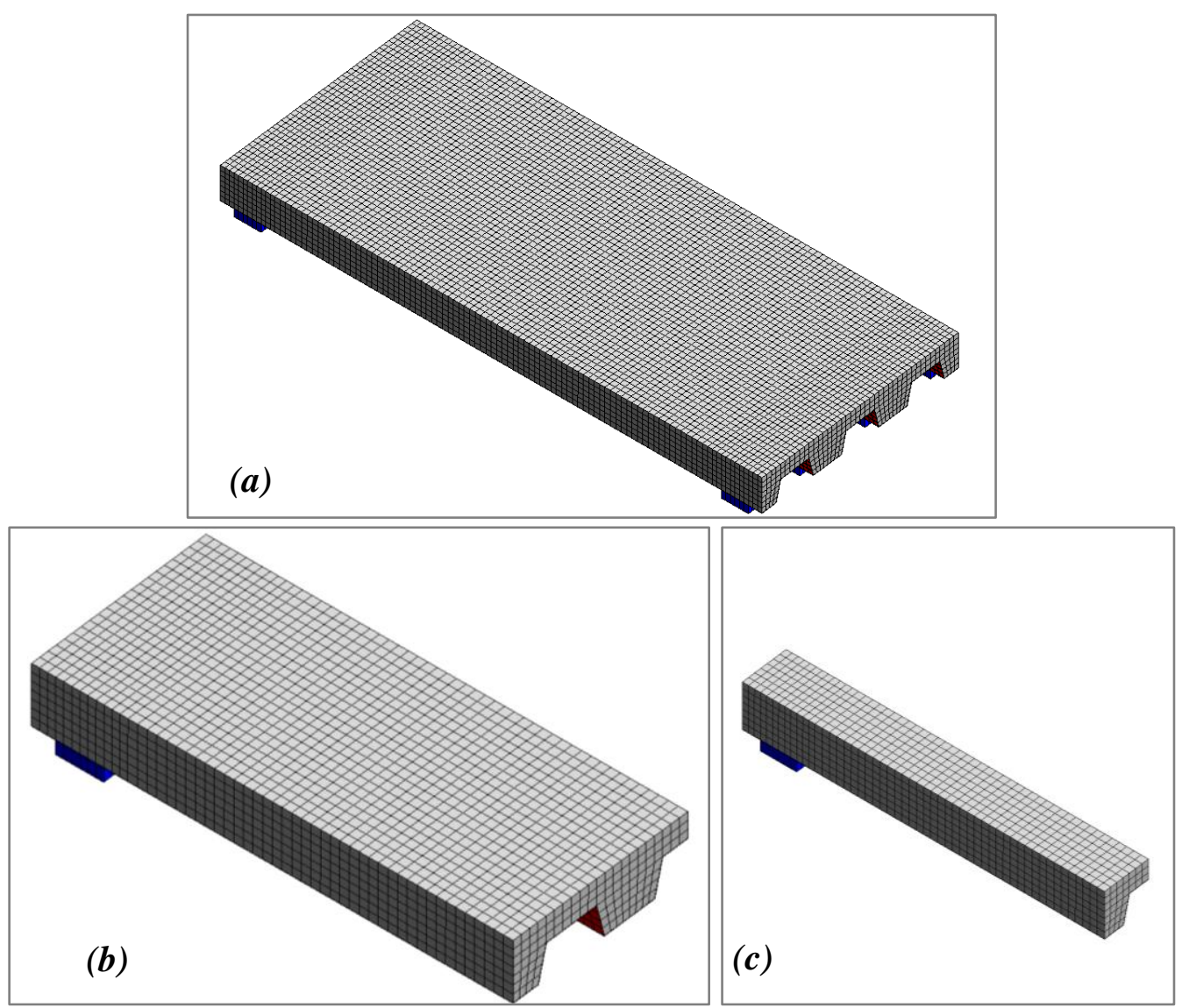

Figura 5.2 - Modelos numéricos: (a) completo, (b) simétrico com 1/4 de laje e (c) simétrico com 1/2 nervura 
No modelo numérico completo (laje total) se mantem todas as características e dimensões do modelo experimental (Figura 5.2a), enquanto que no modelo simétrico com $1 / 4$ de laje é modelado apenas $1 / 4$ da laje (Figura 5.2b). Já o modelo simétrico com $1 / 2$ nervura tem suas dimensões reduzidas em função da simetria do modelo e das nervuras (Figura 5.2c). Nos dois últimos casos são impostas condições de contorno no meio do vão e nas laterais do modelo de modo a simular o modelo completo, conforme apresentado no Capítulo 4. Vale mencionar que o modelo simétrico com $1 / 4$ de laje também pode ser utilizado para simular lajes apoiadas nas quatro bordas, enquanto aquele simétrico com $1 / 2$ nervura somente pode ser utilizado para simulação numérica de lajes simplesmente apoiadas.

Pela Figura 5.1 se observa que não há diferenças significativas entre os resultados dos modelos numéricos completo, simétrico com $1 / 4$ de laje e simétrico com $1 / 2$ nervura, sendo que os resultados para os dois primeiros casos foram praticamente coincidentes. Essa semelhança entre os resultados já era esperado, uma vez que nos modelos experimental e numérico somente há flexão na direção longitudinal das nervuras.

O modelo numérico completo demandou elevado esforço computacional, pois o mesmo possui uma quantidade significativa de elementos finitos (aproximadamente 49000), fato esse que demandava um tempo aproximado de 4 horas para processamento de cada iteração (dependendo da configuração do computador). Como para o processamento de um modelo numérico são necessários vários passos de carga (em torno de 50), e como para cada passo de carga (dependendo do processo de fissuração do concreto) são necessárias várias iterações, há uma demanda de vários dias para processamento do modelo completo.

Já o modelo simétrico com $1 / 2$ nervura possui aproximadamente uma quantidade de 4000 elementos finitos e apresentou um tempo de processamento de apenas algumas horas. Logo, o modelo completo não é eficiente computacionalmente para análise do comportamento de lajes mistas. Vale aqui destacar que em GUO (2011) também se adotou nas simulações numéricas o modelo numérico simétrico com $1 / 2$ nervura (Figura 5.2c).

Pela Figura 5.1 se observa que os resultados numéricos, considerando interação completa entre a fôrma de aço e o concreto, ficaram bem superiores aos experimentais, sendo que tal aspecto pode estar associado ao fato de os modelos experimentais ensaiados não apresentarem resistência mecânica na interface suficiente para garantir interação completa entre os materiais.

De acordo com as propriedades do protótipo 01, apresentadas na Tabela 5.1, tem se que o momento fletor plástico resistente $\left(M_{R d, p l}\right)$ resulta igual a $27,3 \mathrm{kNm} / \mathrm{m}$. Entretanto, nos ensaios de referência, a força de colapso $\left(P_{u}\right)$ atingida foi igual a $44,48 \mathrm{kN}$, cujo momento fletor correspondente a essa força (Equação 5.1), em que $p$ é o peso próprio da laje, se obtém como segue:

$$
M_{R d, \text { ensaio }}=\frac{P_{u}}{2} \frac{L^{\prime}}{b}+\frac{p \cdot L^{2}}{8}=\frac{44,48 \mathrm{kN}}{2} \frac{0,45 \mathrm{~m}}{0,82 \mathrm{~m}}+\frac{2,3 \mathrm{kN} / \mathrm{m}^{2} \cdot(1,8 \mathrm{~m})^{2}}{8}=13,1 \mathrm{kNm} / \mathrm{m}
$$


Pela Equação 5.1 se observa que o momento fletor atingido durante o ensaio

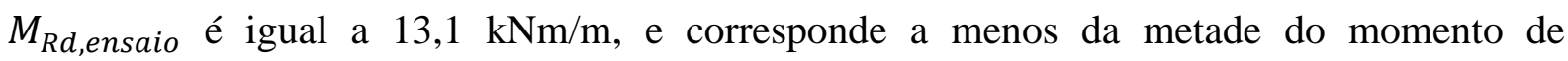
plastificação da seção transversal $\left(M_{R d, p l}\right)$ igual a $27,3 \mathrm{kNm} / \mathrm{m}$. Tal fato explica a diferença dos resultados numéricos para o experimental quando se considera interação completa entre a fôrma de aço e o concreto. De fato, nos experimentos também se observou que a ruptura dos modelos ocorreu devido ao deslocamento relativo entre a fôrma de aço e o concreto.

Nos modelos numéricos com interação completa entre a fôrma de aço e o concreto os nós da malha de elementos finitos da fôrma de aço são acoplados aos nós da malha do concreto, entretanto, durante a simulação numérica também se observou que a utilização de valores elevados para os parâmetros referentes à rigidez linear $\mathrm{D}_{11}$ e $\mathrm{D}_{22}$, da ordem de $10^{18}$ $\mathrm{N} / \mathrm{m}^{3}$, também são eficientes para a consideração da interação completa.

É importante ressaltar que no presente trabalho, conforme comentado no capítulo 4, foi adotado o critério de plastificação de von Mises para o aço. Neste caso, tanto para modelos estruturais à temperatura ambiente ou em temperatura elevada, podem ocorrer tensões no aço superiores a resistência ao escoamento nos estados biaxial ou triaxial de tensões. Por exemplo, para um estado plano de tensões, a verificação por meio do critério de von Mises se faz pela Equação 5.2, em que $\sigma_{x x} \mathrm{e} \sigma_{y y}$ são as tensões principais (máxima e mínima) consideradas atuantes nas direções x e y (direções principais), respectivamente.

$$
\sigma_{v}=\sqrt{\sigma_{x x}^{2}-\sigma_{x x} \sigma_{y y}+\sigma_{y y}^{2}} \leq f_{y}
$$

Por meio da aplicação da Equação 5.2, se pode demonstrar que a máxima tensão que um elemento pode resistir, em módulo, deve ser igual a $(2 / \sqrt{3}) f_{y}$, em que $f_{y}$ é a resistência ao escoamento do aço, e ocorre quando $\sigma_{x x}=2 \cdot \sigma_{y y}$ ou $\sigma_{y y}=2 \cdot \sigma_{x x}$.

\subsubsection{Modelo numérico com elementos de interface}

Como o modelo com interação completa não se ajustou bem aos resultados experimentais, realiza-se neste item uma análise dos modelos constitutivos para a representação numérica da interface, ou seja, desconsideração de interação completa, com calibração dos parâmetros relativos a cada modelo constitutivo avaliado.

No pacote computacional TNO DIANA, há diversos modelos constitutivos para a interface, dentre os quais se pode destacar o modelo de rigidez linear, o bond-slip e o de atrito de Coulomb. Os dois primeiros foram apresentados no capítulo 4 (item 4.4.1.5), enquanto que o modelo de atrito de Coulomb foi descartado para a análise numérica, uma vez que a sua utilização apresentou problemas de convergência do modelo e, portanto, não se mostrou adequado para as finalidades propostas no presente trabalho. 


\subsubsection{Interface com rigidez linear}

Os parâmetros de rigidez linear $\mathrm{D}_{11}$ e $\mathrm{D}_{22}$ simulam, respectivamente, as rigidezes nas direções normal e tangencial à interface. Para se determinar os valores desses parâmetros buscando um melhor ajuste aos resultados experimentais, adotou-se inicialmente os resultados do protótipo 01 e $01 \mathrm{~A}$ e variou os valores dos parâmetros de rigidez linear, $\mathrm{D}_{11}$ e $\mathrm{D}_{22}$.

Os resultados permitem observar que, ao se adotar valores reduzidos para $\mathrm{D}_{11}$ (por exemplo, da ordem de $\left.100.000 \mathrm{~N} / \mathrm{m}^{3}\right)^{12}$, o concreto deforma verticalmente como um corpo rígido, apresentando valores absolutos de deslocamentos superiores ao da fôrma de aço. Dessa forma, se notou a necessidade de utilizar valores elevados de $D_{11}$, da ordem de $10^{18} \mathrm{~N} / \mathrm{m}^{3}$. Neste caso está se assumindo que no modelo numérico aqui utilizado, por simplificação, praticamente não ocorrerá deslocamento relativo normal à interface entre a fôrma de aço e o concreto.

Na Figura 5.3 é apresentado um exemplo da deformação que ocorre na laje mista, considerando um valor de $\mathrm{D}_{11}$ de $100.000 \mathrm{~N} / \mathrm{m}^{3}$ e carga total aplicada ao modelo igual a 26 $\mathrm{kN}$, em que é possível observar que o concreto se desloca (segundo a vertical) de modo mais evidente se comparado à fôrma de aço, como se a fôrma de aço penetrasse dentro do concreto.

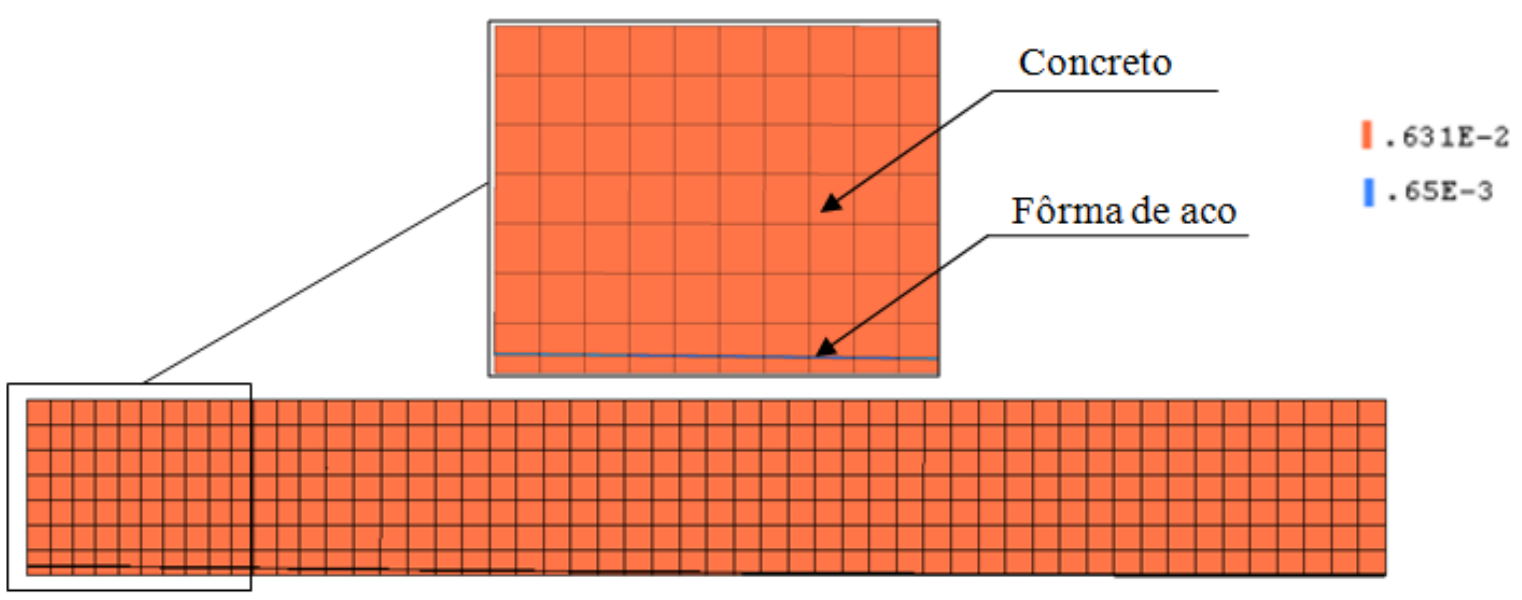

Figura 5.3 - Exemplo de deslocamento da laje (em m) para D11=100.000N/m $\mathrm{m}^{3}$ e carga de $26,0 \mathrm{kN}$

Na Figura 5.4 e Figura 5.5 são apresentados graficamente os resultados experimentais e numéricos de carga total aplicado no modelo vs. deslocamento vertical no meio do vão e deslocamento relativo de extremidade para o protótipo 01 e protótipo $01 \mathrm{~A}$, considerando uma variação de $\mathrm{D}_{22}$ entre $1,0 \times 10^{6}$ e $100,0 \times 10^{6} \mathrm{~N} / \mathrm{m}^{3}$. Com base em análise prévia com relação às Figuras 5.4 e 5.5, é possível considerar que valores para o parâmetro de rigidez tangencial $\mathrm{D}_{22}$ que melhor se ajustam aos resultados experimentais ocorrem no intervalo de $10,0 \times 10^{6}$ a $20,0 \times 10^{6} \mathrm{~N} / \mathrm{m}^{3}$.

Para o deslocamento relativo de extremidade, são apresentados dados experimentais considerando duas curvas, referentes às duas extremidades dos modelos. Conforme pode ser

\footnotetext{
${ }^{12} \mathrm{O}$ valor de $\mathrm{D} 11=100.000 \mathrm{~N} / \mathrm{m}^{3}$ é equivalente a $1,0\left(\mathrm{kN} / \mathrm{m}^{2}\right) / \mathrm{cm}$, ou seja, há um incremento de deslocamento normal à interface de $1,0 \mathrm{~cm}$ para cada incremento de carga de $1,0 \mathrm{kN} / \mathrm{m}^{2}$, sendo a área de aplicação de carga a mesma da interface.

130
} 
observado, existe uma diferença entre o deslocamento relativo de extremidade para o mesmo modelo, principalmente para o protótipo $01 \mathrm{~A}$, e está associado à dificuldade experimental em controlar a simetria longitudinal do modelo.

Pela Figura 5.4 também se observa que, com um deslocamento vertical de aproximadamente $2 \mathrm{~mm}$, há um decaimento da força total aplicada no modelo, ponto esse que corresponde ao instante em que ocorre a primeira fissura no concreto, provocando um maior deslocamento relativo de extremidade entre a fôrma de aço e o concreto. Já para o protótipo 01A (Figura 5.5), ocorre um deslocamento da ordem de $3 \mathrm{~mm}$. Esse maior deslocamento observado para o protótipo $01 \mathrm{~A}$ ocorre devido ao fato de este possuir uma menor altura e maior vão total da laje.
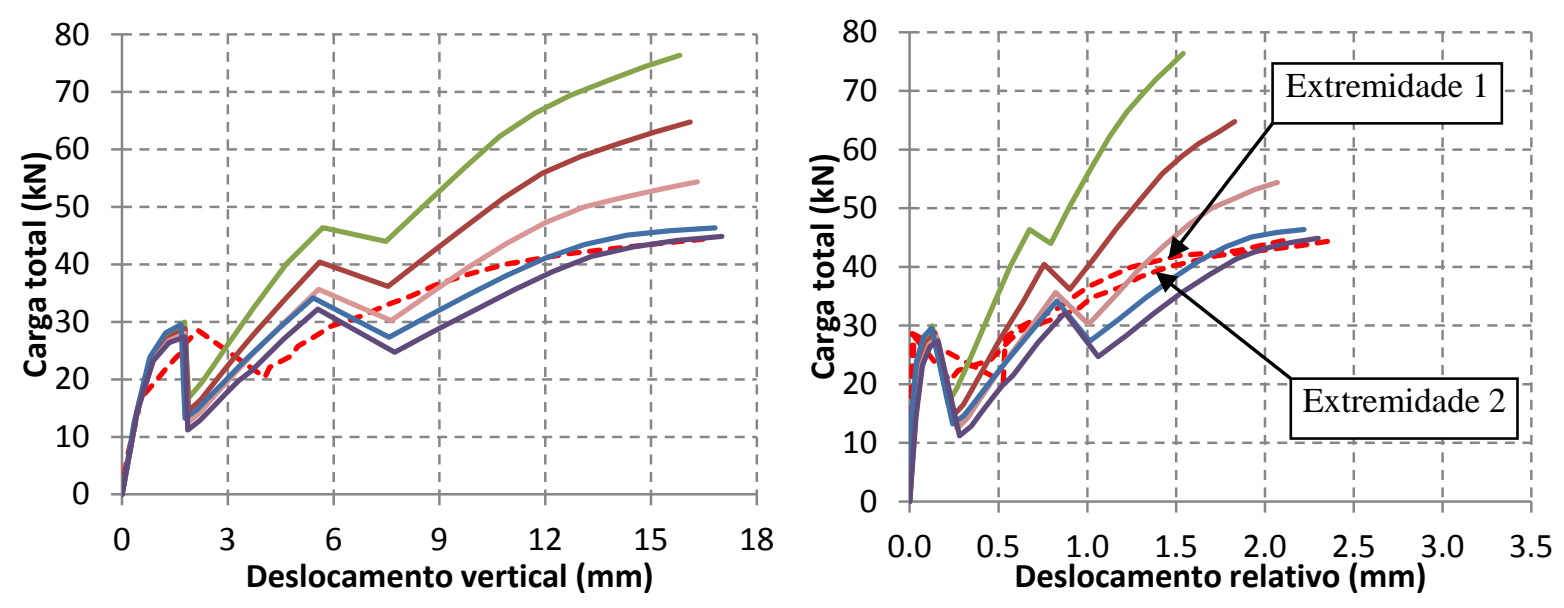

\begin{tabular}{|c|c|c|}
\hline $\begin{array}{l}\ldots \text { Exp; Prot. } 01 \\
\text { Num; D22=20,0E6 }\end{array}$ & $\begin{array}{l}\text { Num; D22=100,0E6 } \\
\text { Num; D22=10,0E6 }\end{array}$ & $\begin{array}{l}\text { Num; D22=50,0E6 } \\
\text { Num; D22=1,0E6 }\end{array}$ \\
\hline
\end{tabular}

Figura 5.4 - Carga total aplicada no modelo vs. Deslocamento vertical no meio do vão e deslocamento relativo de extremidade para o modelo com interface linear (Protótipo 01)
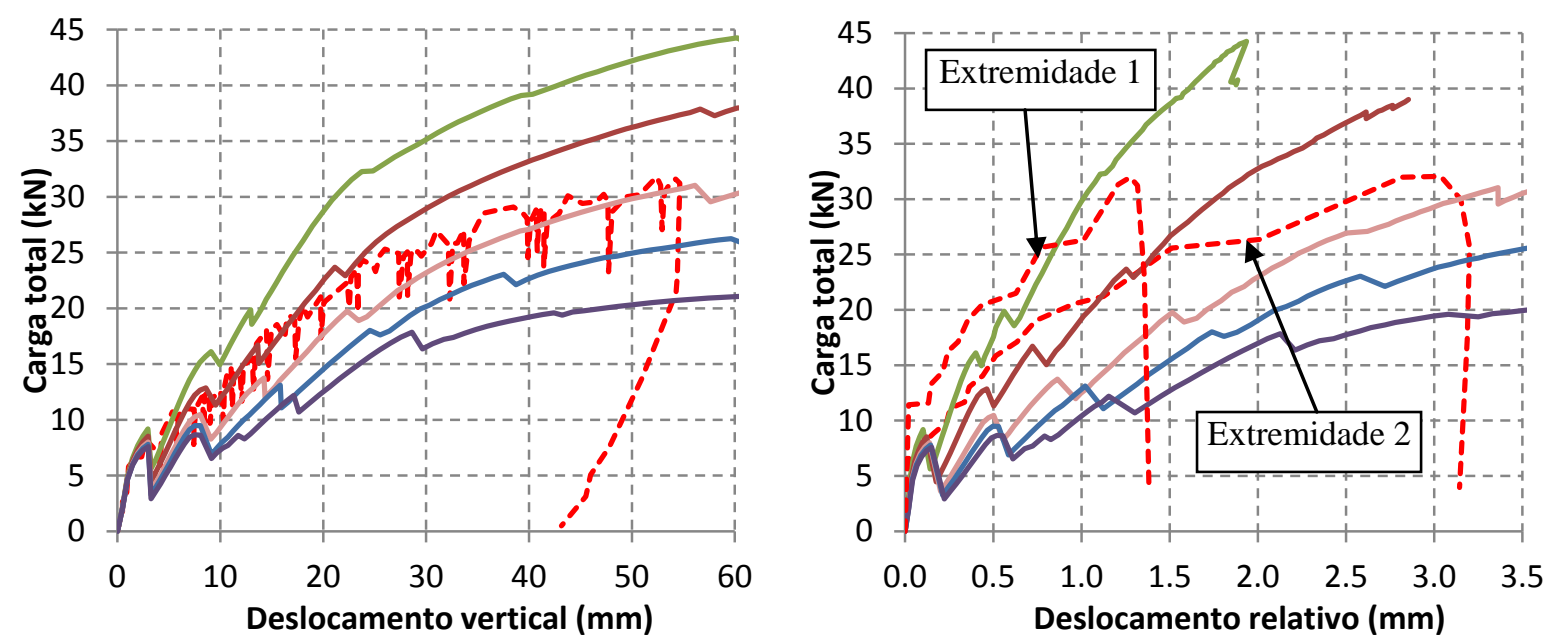

\begin{tabular}{lll|}
\hline- Exp; Prot. 01A & Num; D22=100,0E6 & Num; D22=50,0E6 \\
Num; D22=20,0E6 Num; D22=10,0E6 & Num; D22=1,0E6
\end{tabular}

Figura 5.5 - Carga total aplicada no modelo vs. Deslocamento vertical no meio do vão e deslocamento relativo de extremidade para o modelo com interface linear (Protótipo 01A) 


\subsubsection{Interface considerando bond-slip}

Conforme visto no Capítulo 4, para o modelo bond-slip o principal parâmetro que governa o deslocamento relativo entre a fôrma de aço e a laje de concreto é a resistência ao cisalhamento longitudinal (c), com unidade em N/m². Para o modelo bond-slip, o código computacional DIANA também exige que se especifique os parâmetros de rigidez linear $\left(\mathrm{D}_{11}\right.$ e $\mathrm{D}_{22}$ ), porém, analisando a influência do parâmetro $\mathrm{D}_{22}$ quando se utilizou o modelo bondslip, se observou que o mesmo não influencia nos resultados numéricos. Entretanto, como no caso do modelo de interface com rigidez linear, recomenda-se adotar valores elevados para o parâmetro $\mathrm{D}_{11}$.

Na Figura 5.6, Figura 5.7 e Figura 5.8 são apresentados graficamente os resultados numéricos e experimentais de carga total aplicada no modelo vs. deslocamento vertical e deslocamento relativo de extremidade para os protótipos 01, 07 e $01 \mathrm{~A}$, respectivamente.
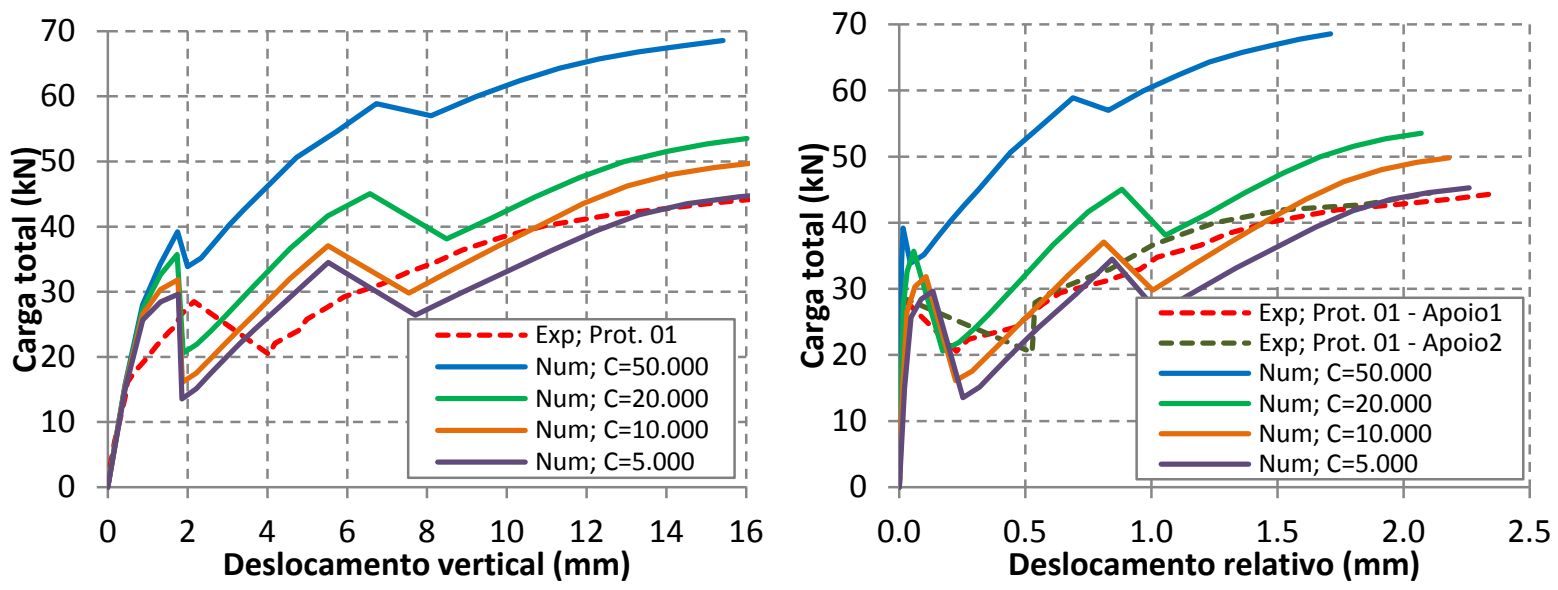

Figura 5.6 - Carga total aplicada no modelo vs. Deslocamento vertical no meio do vão e deslocamento relativo de extremidade para o modelo de interface bond-slip (Protótipo 01)
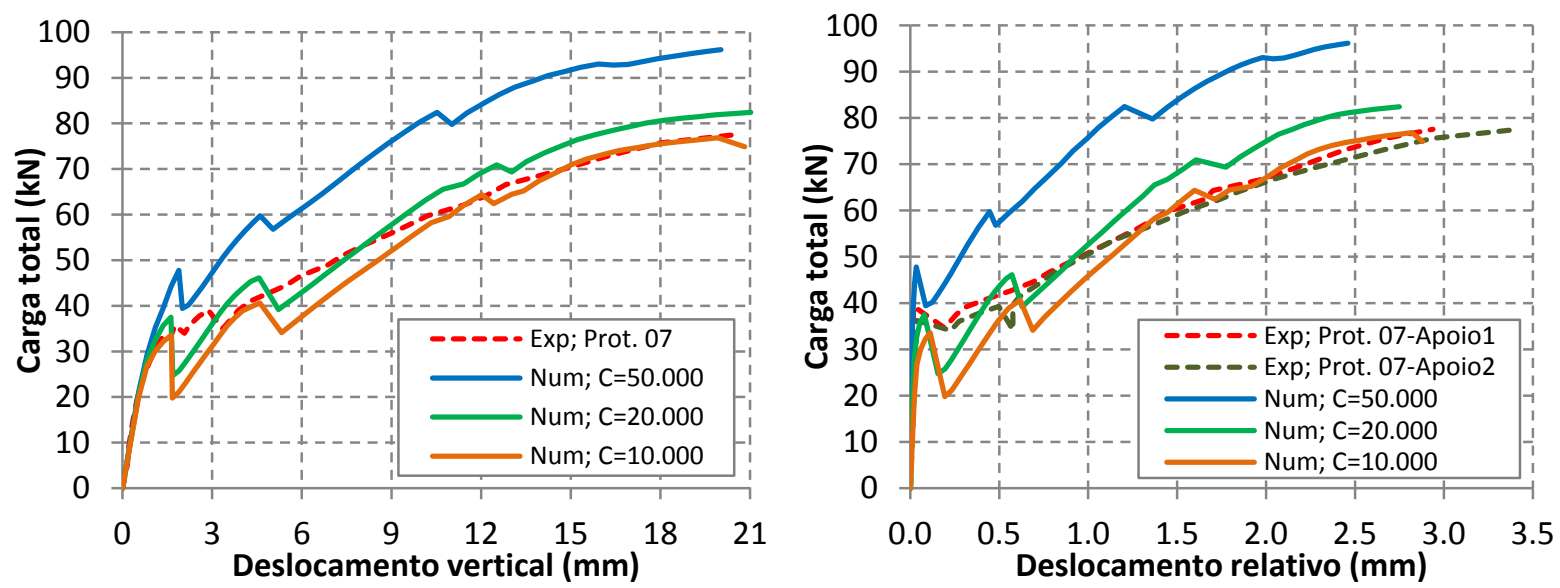

Figura 5.7 - Carga total aplicada no modelo vs. Deslocamento vertical no meio do vão e deslocamento relativo de extremidade para o modelo de interface bond-slip (Protótipo 07) 

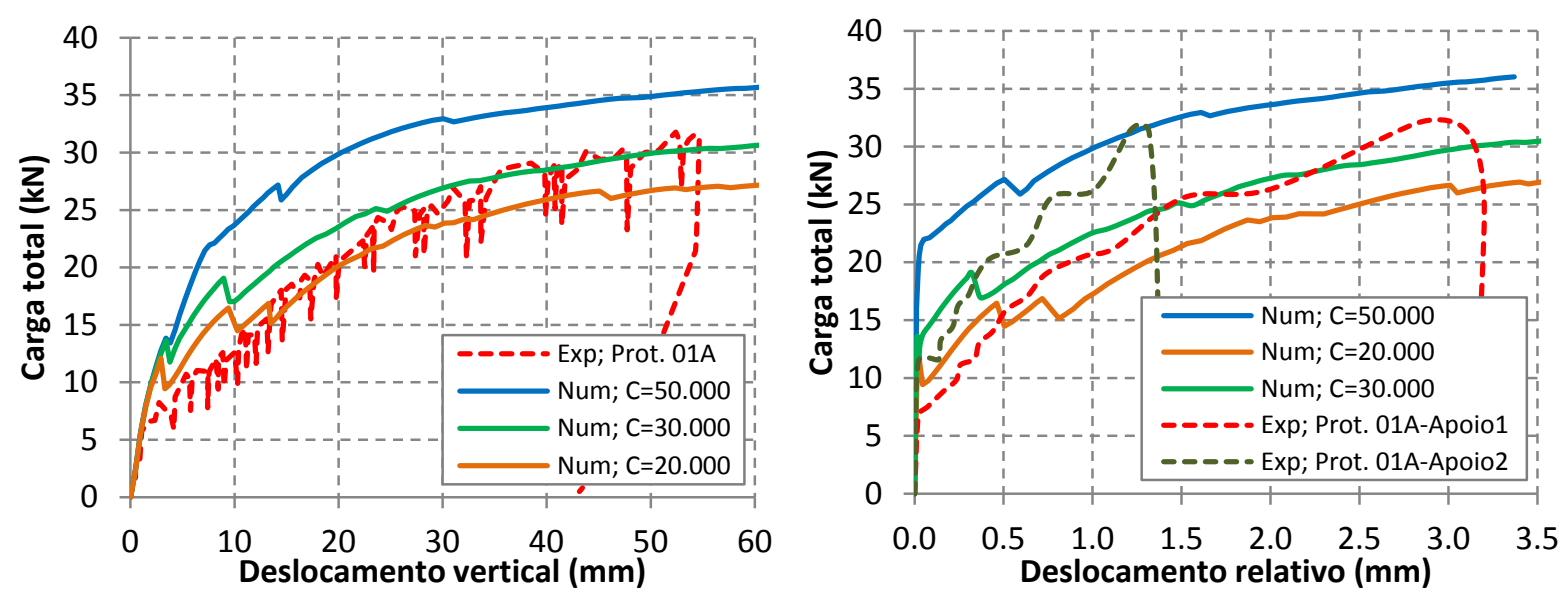

Figura 5.8 - Carga total aplicada no modelo vs. Deslocamento vertical no meio do vão e deslocamento relativo de extremidade para o modelo de interface bond-slip (Protótipo 01A)

Por meio de análises com relação às figuras em destaque, é possível observar que os valores da resistência ao cisalhamento longitudinal (c) que melhor se ajustaram os resultados numéricos dos experimentais são da ordem de $10.000,20.000$ e $30.000 \mathrm{~N} / \mathrm{m}^{2}(0,01,0,02$ e 0,03 MPa) para os protótipos 01, 07 e 01A, respectivamente, que são valores muito baixos se comparados com a resistência à tração do concreto. Essa faixa de variação da resistência ao cisalhamento longitudinal pode ser justificada por diversos motivos, dentre os quais se destacam: os diferentes procedimentos de concretagem, transporte dos modelos experimentais e resistência característica do concreto. Além disso, cada fabricante possui diferentes procedimentos de conformação das mossas na fôrma de aço, garantindo diferentes resistências mecânicas na interface entre a fôrma de aço e laje de concreto.

O valor de $c$ de $30.000 \mathrm{~N} / \mathrm{m}^{2}(0,03 \mathrm{MPa})$ é a metade daquele proposto por CHEN \& SHI (2011) para o valor da coesão do modelo de atrito de Coulomb. Entretanto, vale lembrar que no modelo bond-slip esse valor é multiplicado por 1,9 para representar o patamar de resistência ao cisalhamento longitudinal, conforme Equação 3.4.

Pelos resultados numéricos e experimentais apresentados, se observa que o modelo considerando bond-slip permite melhor simular o comportamento mecânico da interface entre a fôrma de aço e laje de concreto, principalmente se referindo ao deslocamento relativo de extremidade, em que é possível observar que quando se utiliza o modelo com rigidez linear há um deslocamento relativo desde o início de aplicação da força, enquanto que quando se utiliza o modelo bond-slip esse deslocamento se inicia de maneira mais brusca, como ocorre de fato nos resultados obtidos experimentalmente.

\subsubsection{Influência da chapa de apoio}

Na Figura 5.9 são apresentados os resultados experimentais e numéricos de carga total versus deslocamento vertical para o protótipo 07, considerando os modelos numéricos com e sem chapa de apoio. A chapa de apoio é modelada na parte inferior da fôrma de aço, conforme ilustrado no capítulo 4 , no intuito de melhorar a distribuição de tensões nessa região e, consequentemente, evitando a concentração destas de modo a evitar problemas numéricos 
enquanto convergência do modelo. Para não haver problemas de escoamento local dessa chapa (na região onde se aplica a condição de contorno em deslocamento), é atribuído para a mesma um comportamento mecânico linear de tensão versus deformação.

Conforme pode ser observado pela Figura 5.9, não há diferenças significativas no comportamento da curva de carga total versus deslocamento vertical considerando os modelos numéricos com e sem chapa de apoio. Entretanto, quando se avalia as tensões atuantes no concreto (Figura 5.10 e Figura 5.11) e na fôrma de aço (Figura 5.12 e Figura 5.13), se verifica que o modelo numérico com chapa de apoio sinaliza uma melhor distribuição das tensões verticais (SZZ) na região dos apoios melhorando, como já esperado, a convergência dos modelos numéricos. Vale ressaltar que nos procedimentos experimentais também foram utilizadas chapa de apoio para evitar concentrações de tensões e o consequente esmagamento localizado dos materiais nessa região.

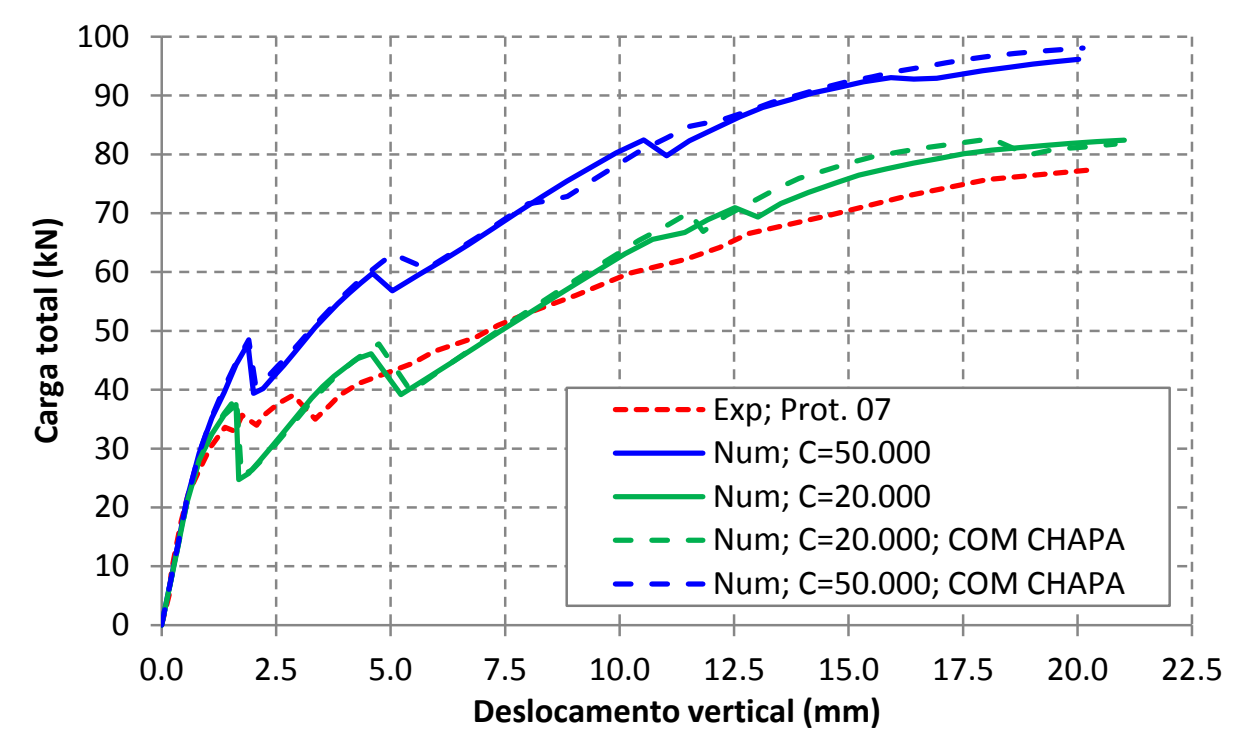

Figura 5.9 - Carga total aplicada no modelo vs. Deslocamento vertical no meio do vão para o modelo numérico com e sem chapa de apoio (Protótipo 07 e modelo bond-slip)

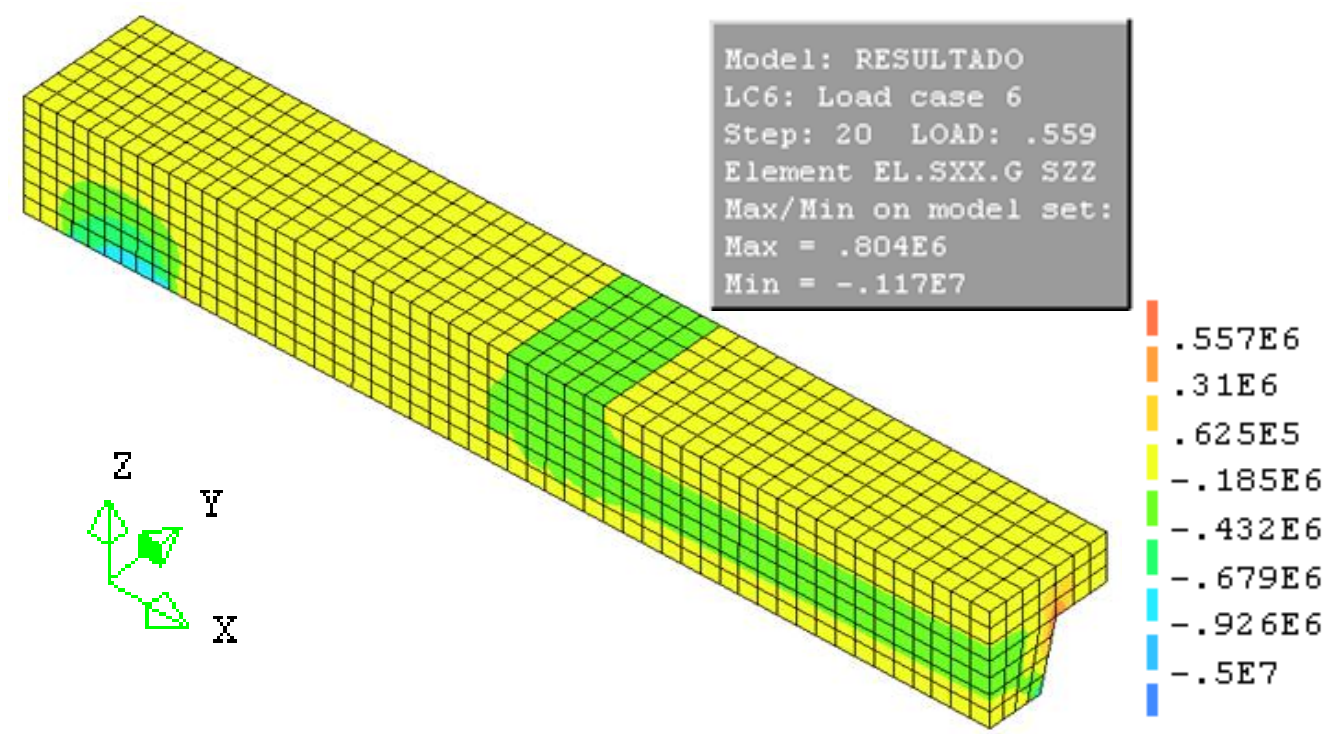

Figura 5.10 - Tensões em Z (SZZ) atuantes no concreto (com chapa de apoio) 


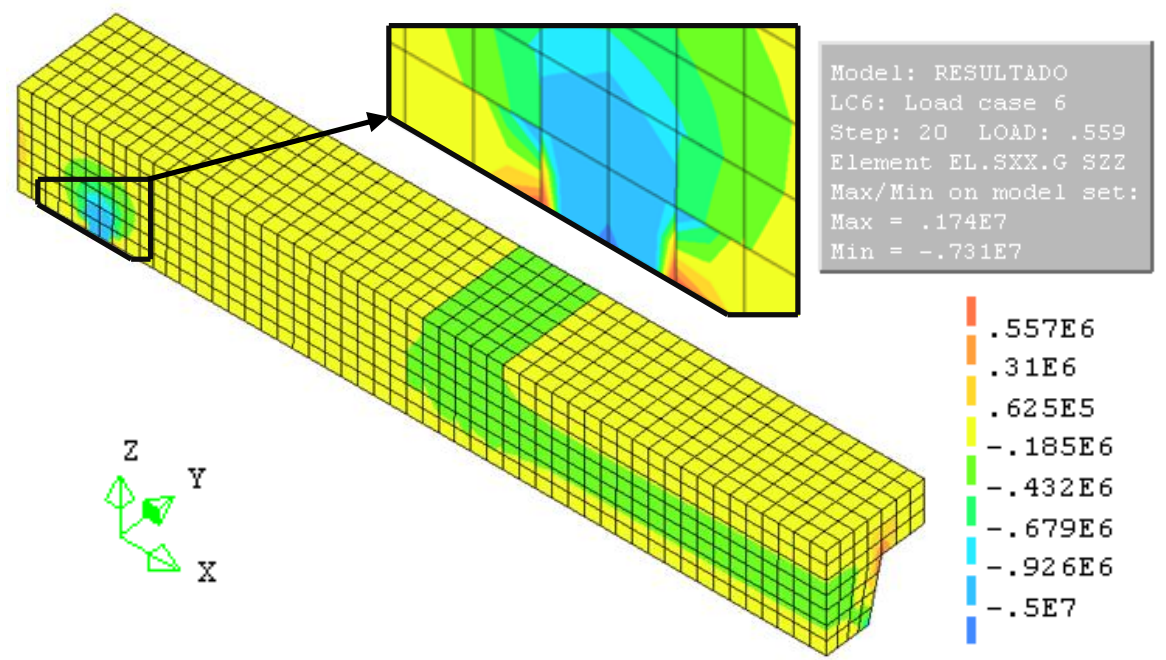

Figura 5.11 - Tensões em Z (SZZ) atuantes no concreto (sem chapa de apoio)

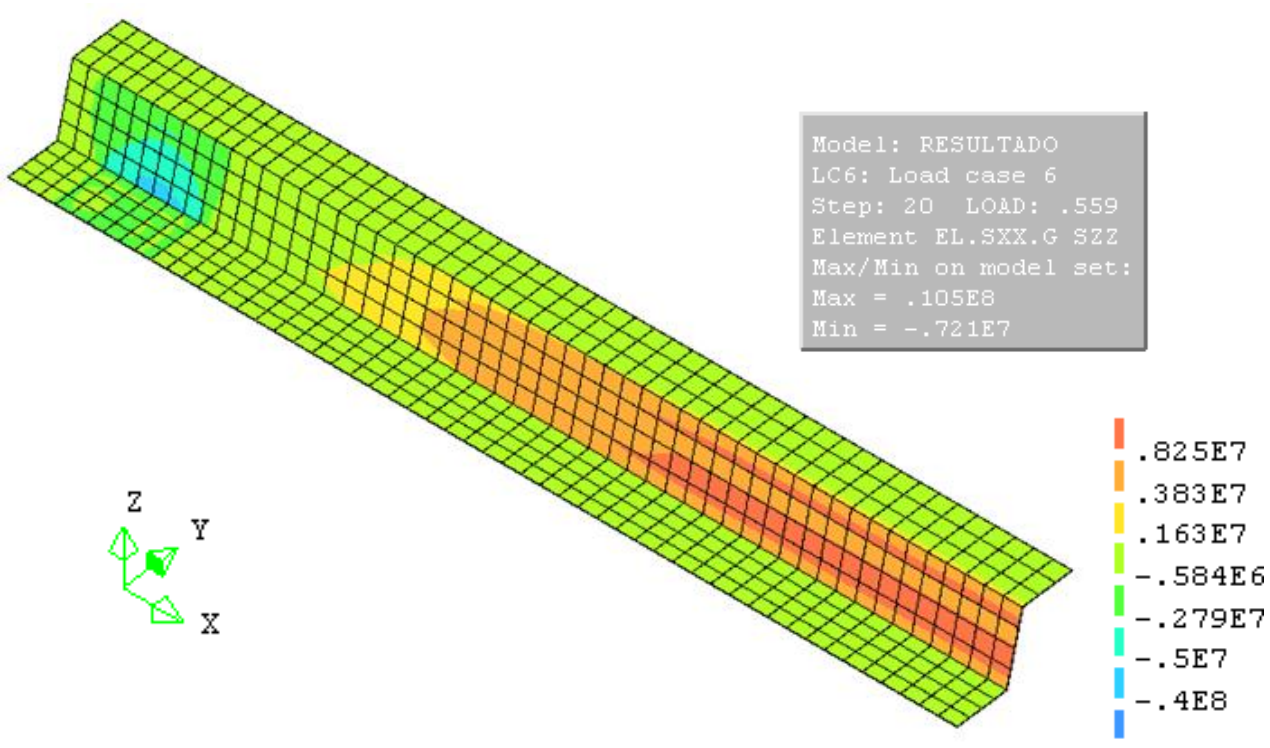

Figura 5.12 - Tensões em Z (SZZ) atuantes na fôrma de aço (com chapa de apoio)

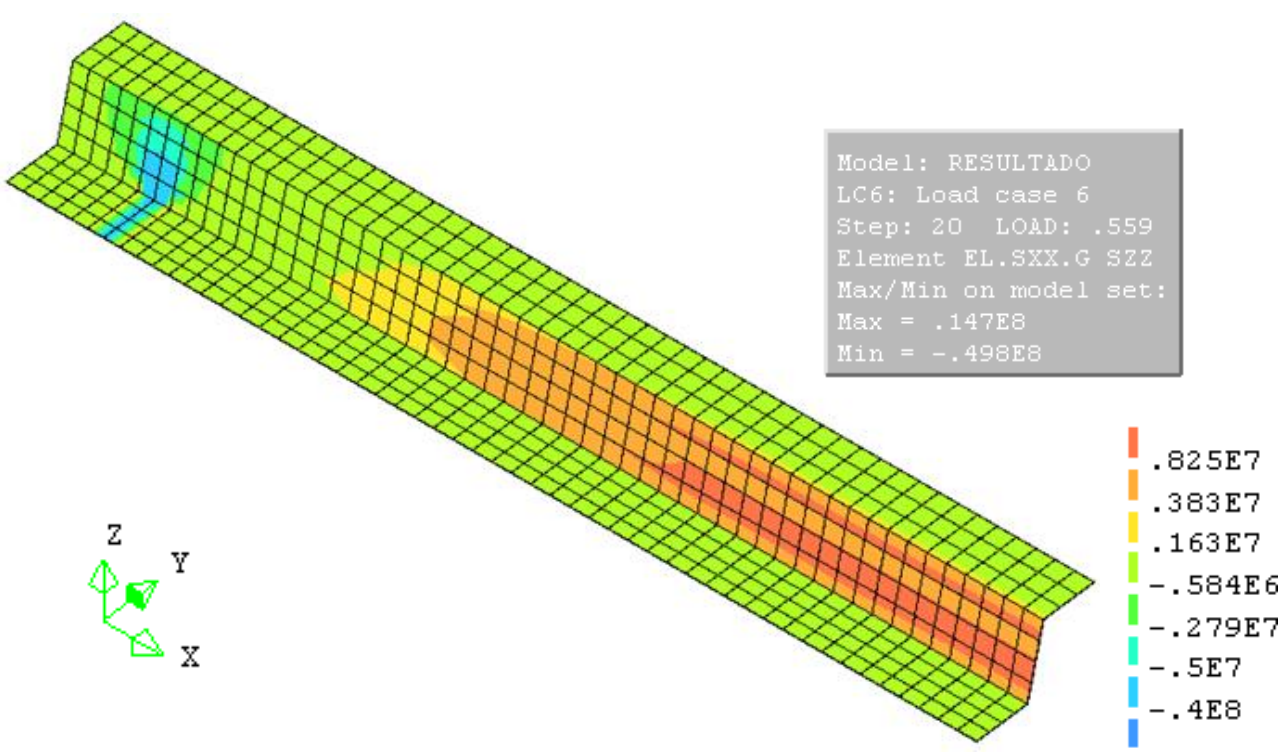

Figura 5.13 - Tensões em Z (SZZ) atuantes na fôrma de aço (sem chapa de apoio) 


\subsubsection{Energia de fratura do concreto}

Conforme apresentado do Capítulo 4, a energia de fratura do concreto à compressão foi considerada igual a 50 vezes a energia de fratura à tração, já que os resultados experimentais indicam que esse valor varia entre 50 e 100 vezes (FEENESTRA, 1993). Entretanto, quando se avaliou a variação da energia de fratura do concreto à compressão, não foi observada nenhuma mudança dos resultados numéricos. Isso se deve ao fato de o concreto não atingir o esmagamento nos modelos numéricos, ou seja, as tensões de compressão no concreto não atingiram o valor da resistência à compressão do concreto, mas sim ocorrendo primeiro a ruptura por cisalhamento longitudinal na interface entre a fôrma de aço e laje de concreto.

\subsubsection{Métodos de iteração}

Como a análise realizada é do tipo não linear, o processamento do modelo numérico ocorre em incrementos de passo de carga, e a cada incremento o comportamento da estrutura depende das tensões e deslocamentos do passo de carga anterior. Nesse sentido o TNO DIANA oferece diversos métodos para encontrar a posição de equilíbrio da estrutura a cada iteração, desses podem-se citar os métodos de Newton-Rapson regular, Newton-Rapson modificado, secante (ou Quasi-Newton), rigidez linear e rigidez constante.

No método de Newton-Rapson regular a matriz de rigidez da estrutura é atualizada a cada iteração, enquanto que no método de Newton-Rapson modificado essa atualização é feita a cada início do passo de carga. No método secante é utilizado o vetor de solução da iteração anterior para encontrar uma melhor aproximação do equilíbrio da estrutura, e neste caso não é feita uma atualização completa da matriz de rigidez. Já no método de rigidez linear, a matriz de rigidez é mantida constante durante todo o processamento, apresentando convergência mais lenta com relação aos demais. O método de rigidez constante é igual ao da rigidez linear se utilizado desde o início do processamento. A diferença somente existe quando, em uma fase inicial, o processamento é feito utilizando o método de Newton-Rapson e, em uma segunda fase, se utiliza o método de rigidez constante, que neste caso utiliza a matriz de rigidez atualizada no final da primeira fase.

Para a obtenção dos resultados apresentados anteriormente, bem como com relação àqueles que serão apresentados futuramente, foi utilizado o método de Newton-Rapson regular.

No intuito de permitir uma comparação dos resultados numéricos considerando a utilização de diferentes métodos de iteração, apresentam-se na Figura 5.14 os resultados numéricos e experimentais de carga total aplicada no modelo vs. deslocamento vertical para o protótipo 01. Observa-se que os resultados numéricos apresentaram valores próximos quando se utilizou os métodos de Newton e o secante. Entretanto quando se utilizou os métodos de rigidez linear e constante, os resultados numéricos ficaram superiores aos demais, bem como 
resultando em um comportamento mais suave da curva. Neste caso talvez fosse necessário utilizar passos de carga menores.

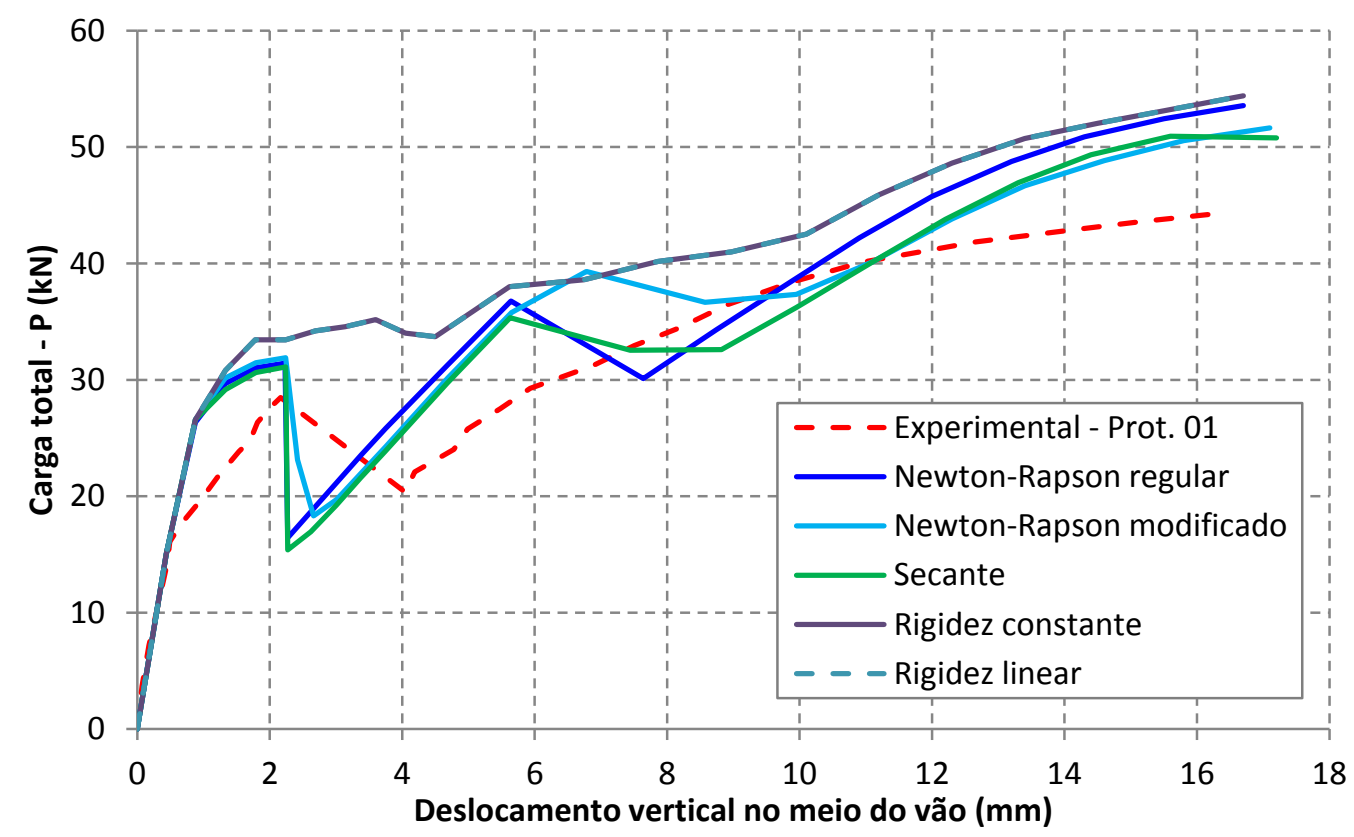

Figura 5.14 - Carga total aplicada no modelo vs. Deslocamento vertical no meio do vão considerando diferentes métodos de iteração

$\mathrm{Na}$ Figura 5.15 é apresentado o tempo de processamento relativo por iteração e o número total de iteração para processamento do modelo em função do método de iteração. Como era esperado, o método de Newton-Rapson regular apresentou um tempo de processamento por iteração superior aos demais métodos, pois esse método sempre atualiza a matriz de rigidez a cada iteração. Os métodos de rigidez linear e de rigidez constante apresentaram tempos de processamento menores que os demais, entretanto o comportamento de carga total aplicada vs. deslocamento (Figura 5.14) não ficou satisfatório, principalmente pelo fato de não captar muito bem o processo de fissuração do concreto.
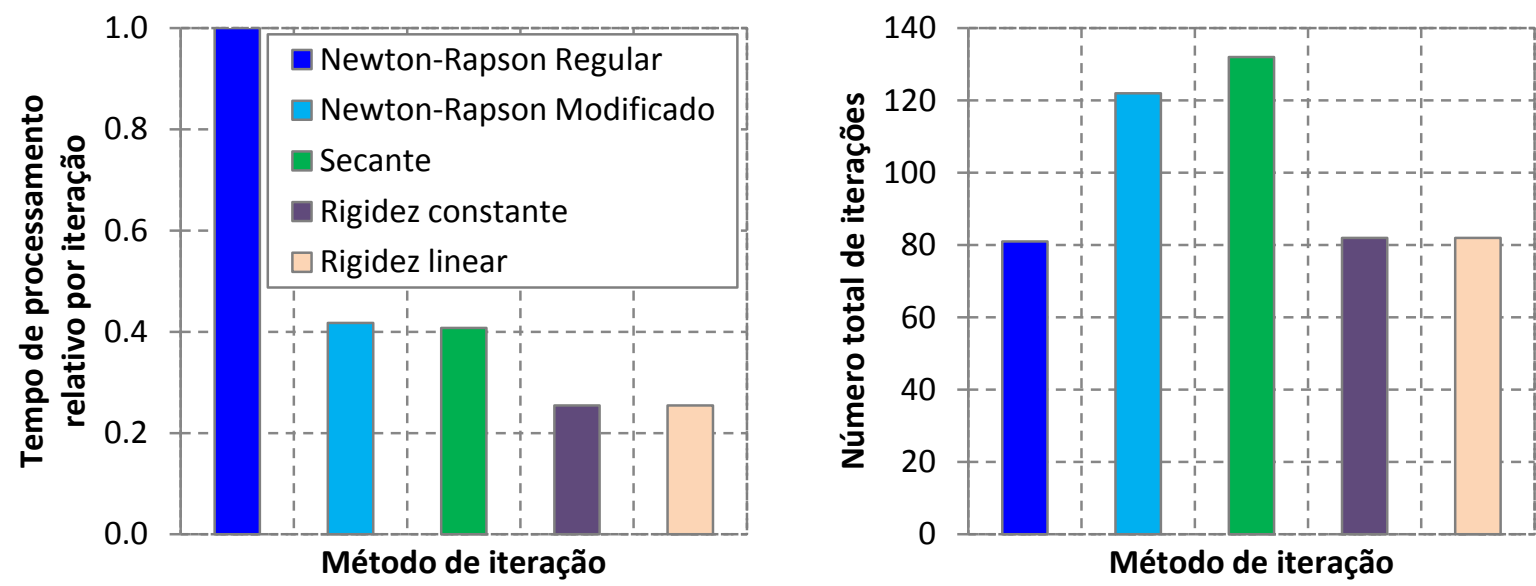

Figura 5.15 - Tempo de processamento relativo por iteração e número total de iterações em função do método de iteração 
O manual do código DIANA (2005a) também recomenda a utilização do método de Newton-Rapson regular. A utilização do método de rigidez linear ou constante é recomendada após o método de Newton-Rapson ou o secante não convergir.

Com base nos resultados apresentados e recomendação do próprio manual do código DIANA será utilizado o método de Newton-Rapson regular nas análises termoestruturais que se seguem.

\subsection{Validação do modelo termoestrutural}

Com o modelo numérico previamente calibrado à temperatura ambiente, realiza-se neste item a validação do modelo numérico em temperatura elevada. Como na bibliografia não foi encontrado nenhum resultado experimental para lajes mistas simplesmente apoiadas, utilizou-se os resultados experimentais obtidos em GUO \& BAILEY (2011) para lajes mistas apoiadas em quatro pontos, conforme Figura 2.40 do Capítulo 2, reapresentada na Figura 5.16. Neste caso, a presença da armadura de distribuição da laje tem grande influência na resistência e no comportamento mecânico da laje, já que surgem momentos fletores negativos nos apoios intermediários (apoios B e C).

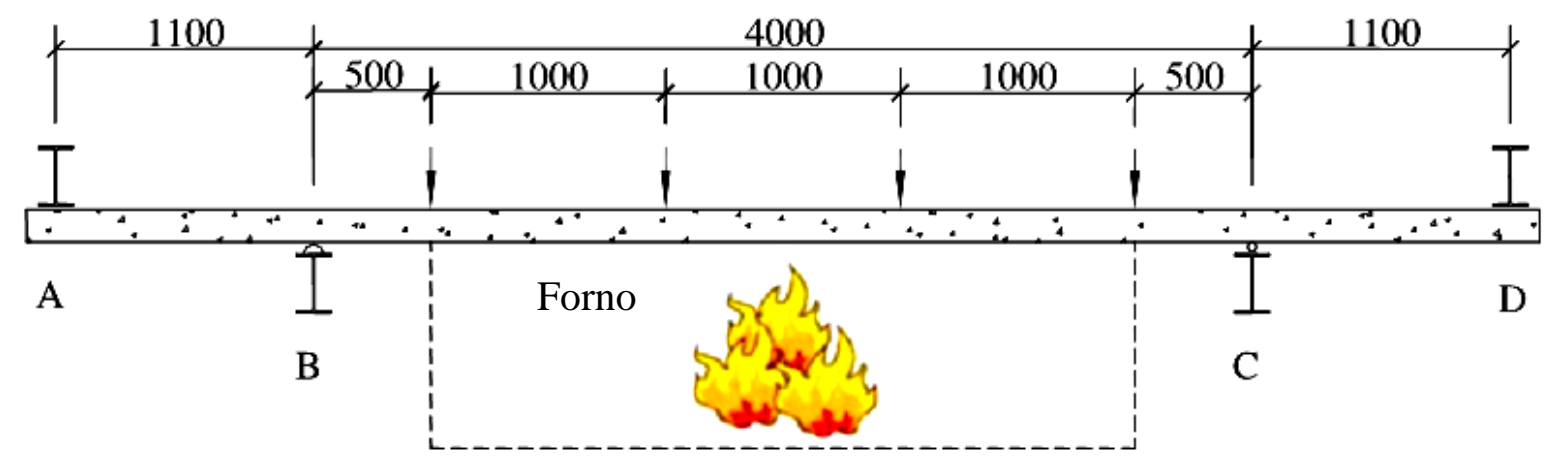

Figura 5.16 - Esquema típico dos ensaios realizados por GUO \& BAILEY (2011)

Foram adotados três ensaios experimentais para calibração e validação do modelo numérico, lajes F4, F5 e F6, que possuem as mesmas características geométricas, porém com cargas totais aplicadas iguais a 72, 44 e $12 \mathrm{kN}$ respectivamente, cujos detalhes dos experimentos foram apresentados no Capítulo 2.

Nos modelos numéricos adotou-se a simetria de $1 / 2$ nervura, no intuito de reduzir o custo computacional para processamento e armazenamento dos dados, já que nos modelos numéricos à temperatura ambiente não foram observadas diferenças significativas entre os resultados considerando o modelo completo e o modelo numérico com simetria de 1/2 nervura, lembrando novamente que este último também foi adotado por GUO (2011) em simulações numéricas de lajes mistas em situação de incêndio. Do mesmo modo que em temperatura ambiente, também foram adotadas malhas de elementos finitos com dimensões médias de $10 \mathrm{~mm}$. 


\subsubsection{Comparação com resultados experimentais}

Nas Figuras 5.17, 5.18 e 5.19 são apresentados os resultados numéricos e experimentais de deslocamento vertical no meio do vão versus tempo de exposição ao fogo para as lajes F4, F5 e F6 respectivamente. Pela Figura 5.17 se observa que o modelo numérico considerando interação completa e emissividade de 0,70 parou de convergir aos 72 minutos, tempo em que houve a ruptura do modelo por deslocamento excessivo. Isso ocorreu para a emissividade de 0,70 e interação completa e não para os demais casos, pois neste caso o concreto apresenta uma maior taxa de aquecimento, fazendo com que o mesmo tenha sua resistência mais rapidamente penalizada.

É importante ressaltar que em análises termoestruturais acopladas, o deslocamento vertical da laje ocorre em resposta ao carregamento mecânico e às deformações provenientes da penalização da resistência do material, da penalização da rigidez (E) e dos efeitos associados à expansão térmica, ou seja, a influência da não linearidade física e a influência da temperatura nas propriedades mecânicas do material.

Os aspectos mencionados no último parágrafo podem ser notados pelas curvas com emissividade de 0,70 na Figura 5.17. Neste caso, nos primeiros 38 minutos de aquecimento a curva com interação parcial apresentou deslocamento superior, devido tanto ao deslocamento relativo entre a fôrma de aço e o concreto quanto à maior taxa de aquecimento da fôrma de aço. Após 38 minutos, a curva com interação total apresentou deslocamento superior, pois neste caso o concreto apresenta uma maior taxa de aquecimento, reduzindo mais rapidamente suas propriedades mecânicas, como o módulo de elasticidade e a resistência à compressão, além de apresentar uma maior deformação térmica, enquanto que no caso anterior a presença de uma resistência térmica na interface dificulta a propagação de calor para o concreto.

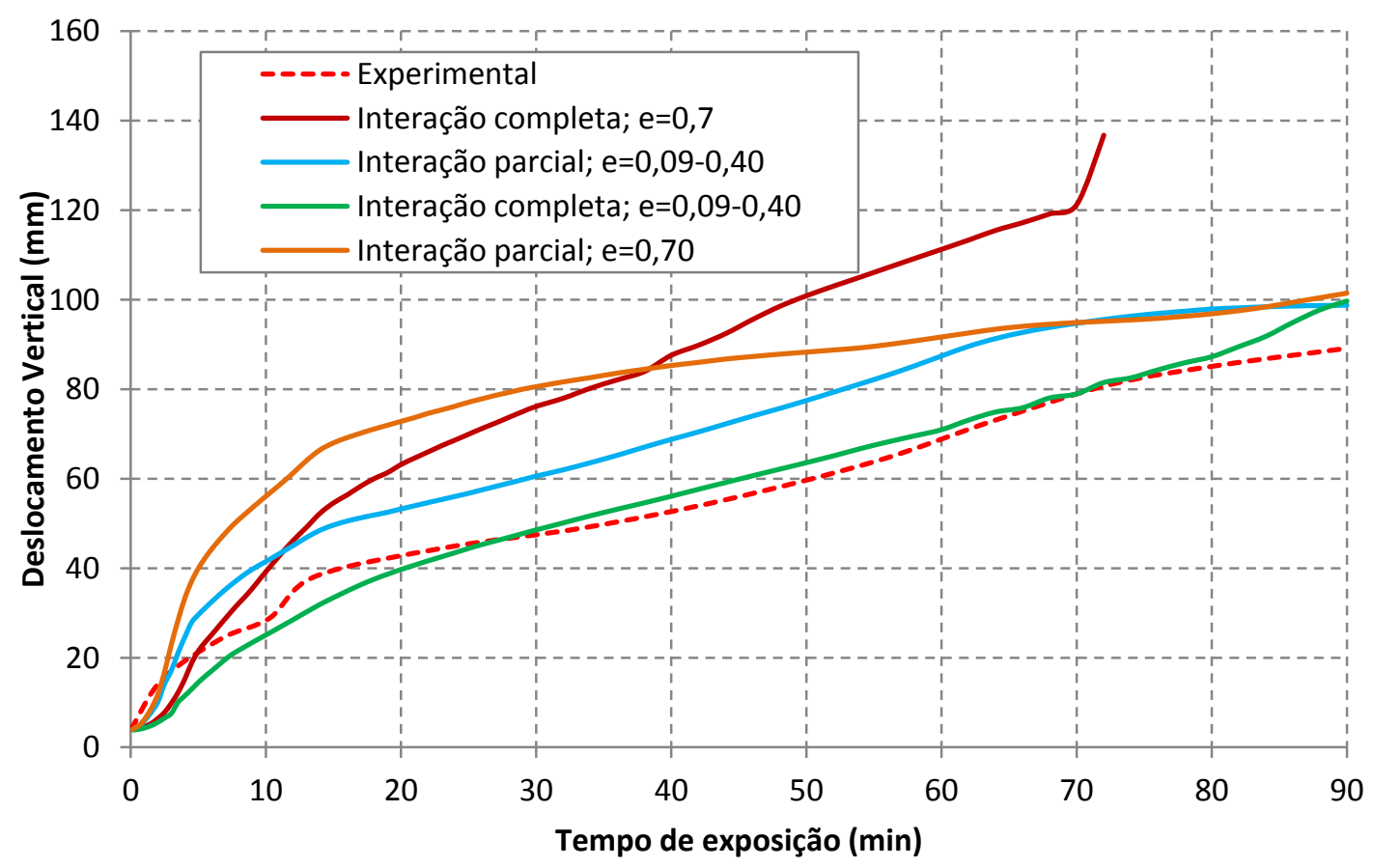

Figura 5.17 - Resultados numéricos e experimentais de Deslocamento vertical no meio do vão vs. Tempo de exposição para a laje F4. 


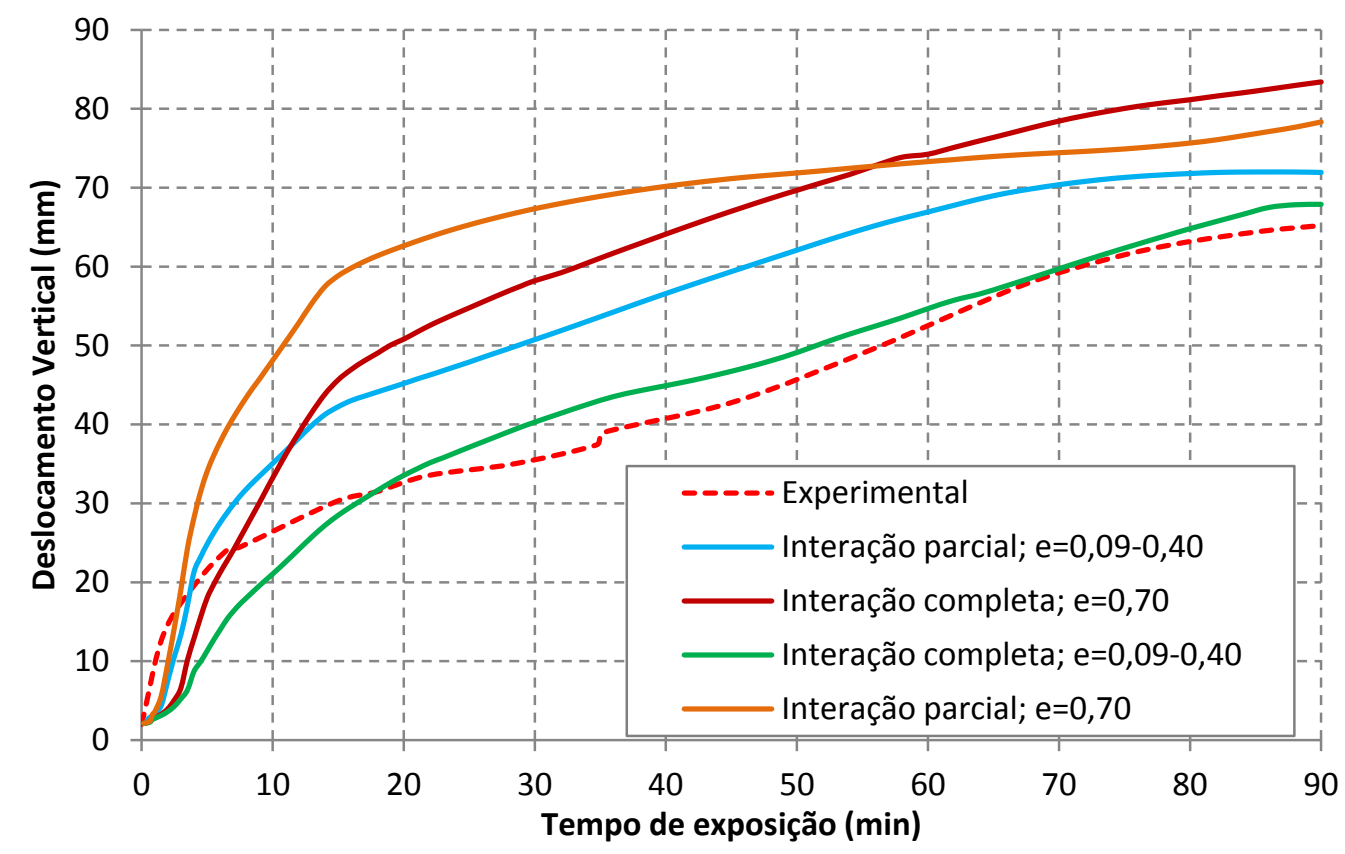

Figura 5.18 - Resultados numéricos e experimentais de Deslocamento vertical no meio do vão vs. Tempo de exposição para a laje F5.

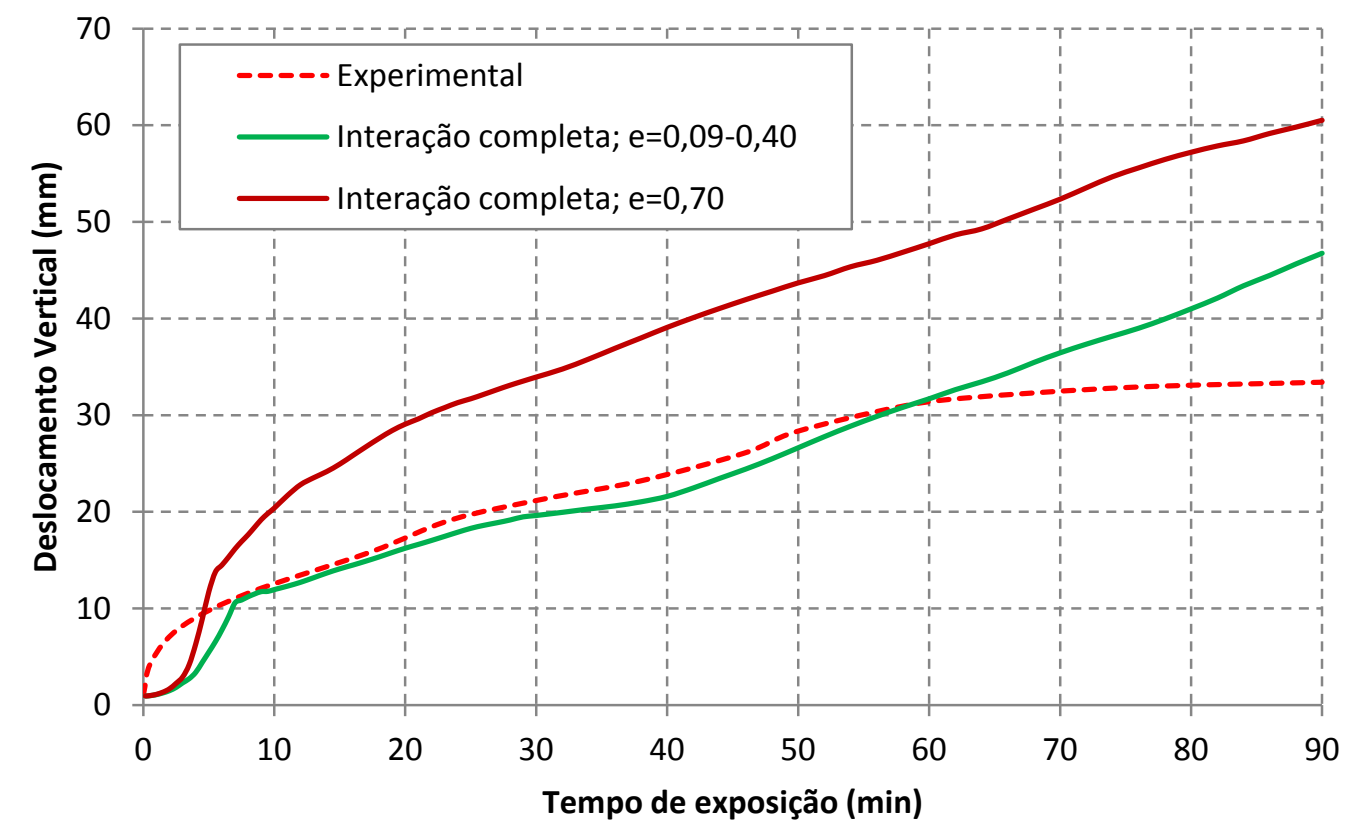

Figura 5.19 - Resultados numéricos e experimentais de Deslocamento vertical no meio do vão vs. Tempo de exposição para a laje F6.

Pelas Figuras 5.17 a 5.19 também se observa que os modelos numéricos com interação completa entre a fôrma de aço e o concreto e com emissividade variável entre 0,09 a 0,40 (para as temperaturas de 250 e $800^{\circ} \mathrm{C}$ ), apresentaram melhores correlações com os resultados experimentais. Pelas análises térmicas realizadas no Capítulo 5, isso já era esperado, uma vez que os campos térmicos na seção transversal da laje ficaram melhores representados com essas hipóteses. 
Já pelas análises realizadas à temperatura ambiente era esperado que a presença da interface melhorasse o comportamento mecânico. Porém, tal fato não foi observado nos modelos termoestruturais, sendo que a presença da interface além de não melhorar o comportamento mecânico dificultou a convergência dos modelos numéricos. Outro fato que merece atenção, é que nas análises numéricas à temperatura ambiente foram utilizados ensaios de lajes mistas com fôrma de aço de fabricação brasileira, enquanto que no presente item os ensaios e materiais utilizados nos modelos experimentais são de origem europeia, que podem oferecer diferentes resistências ao cisalhamento longitudinal entre a fôrma de aço e o concreto.

Como análise complementar, vale mencionar que o modelo constitutivo adotado para o aço foi segundo o EUROCODE 4 (EN 1994-1-1:2005), entretanto quando se utilizou o modelo constitutivo elastoplástico para o aço, se observou que não houve diferenças significativas entre os resultados numéricos, conforme pode ser observado pela Figura 5.20, para a laje F4, considerando interação completa entre a fôrma de aço e o concreto e emissividade variável. Essa resposta era esperada uma vez que as deformações na fôrma de aço e armadura de distribuição não atingiram o limite de 0,15 para o patamar de escoamento, especificado pelas referências normativas. Entretanto, em alguns casos, se observou que, quando se utiliza o modelo constitutivo para o aço segundo as normas brasileira e europeia, quando a deformação do aço supera o limite de 0,15 o modelo numérico apresenta problemas de convergência.

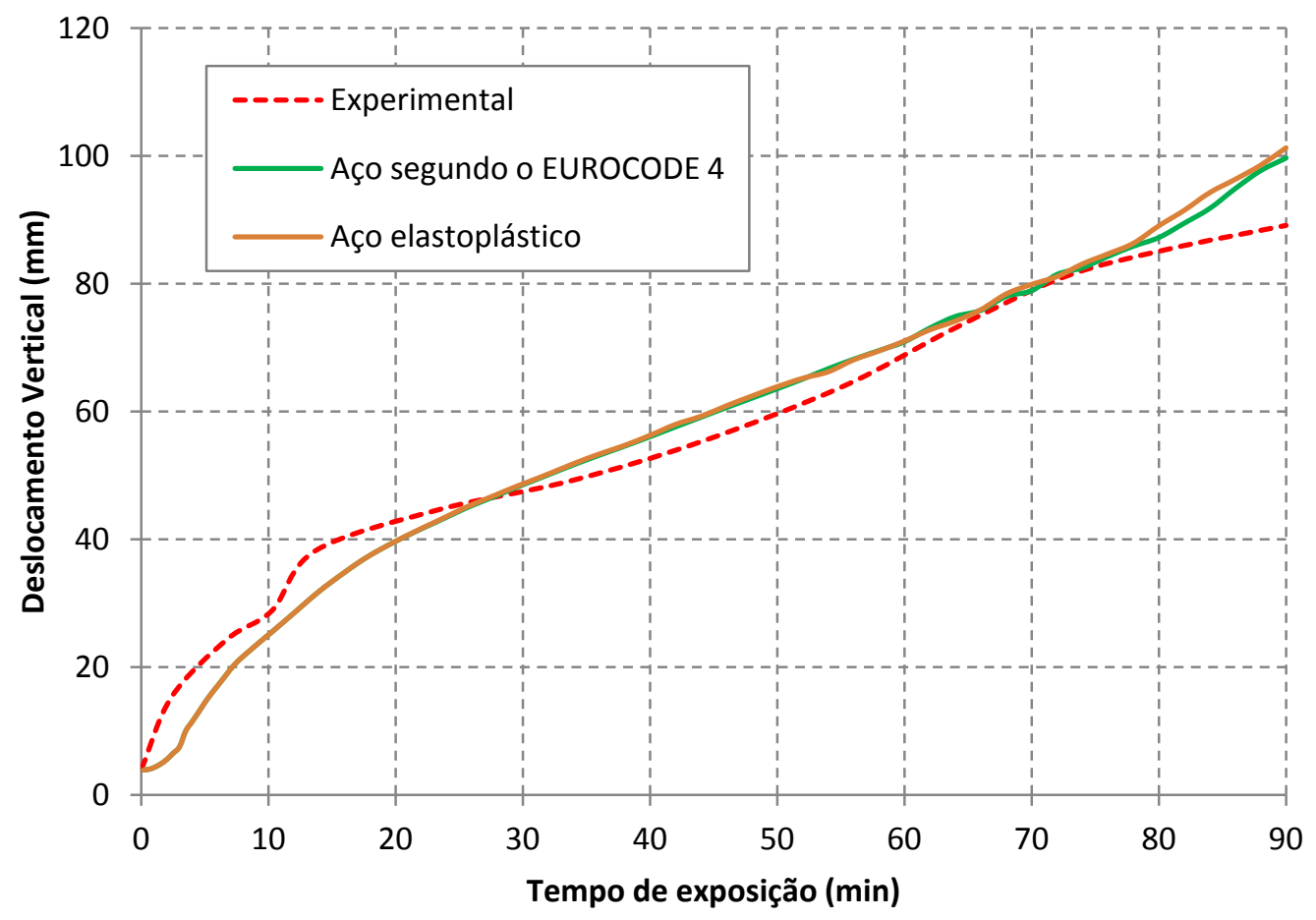

Figura 5.20 - Resultados experimentais e numéricos considerando o modelo constitutivo segundo o EUROCODE 4 e elastoplástico para o aço 
No que segue, serão apresentados resultados numéricos referentes aos campos térmicos e deformação da laje, processo de fissuração do concreto e tensões na fôrma de aço, considerando o modelo numérico com emissividade variável entre 0,09 e 0,40 e interação completa entre a fôrma de aço e laje de concreto.

\subsubsection{Campos térmicos na laje}

A Figura 5.21 apresenta a distribuição de temperatura na laje para tempos de exposição ao fogo iguais a 30, 60 e 90 minutos. Nos ensaios experimentais somente a parte central da laje foi submetida ao aquecimento, razão pela qual se observa que o vão externo da laje (lado esquerdo superior da Figura 5.21) apresenta temperaturas próximas à temperatura ambiente $\left(20^{\circ} \mathrm{C}\right)$, indicando que essa região apresentou pouca influência do fluxo de calor proveniente dos gases aquecidos.
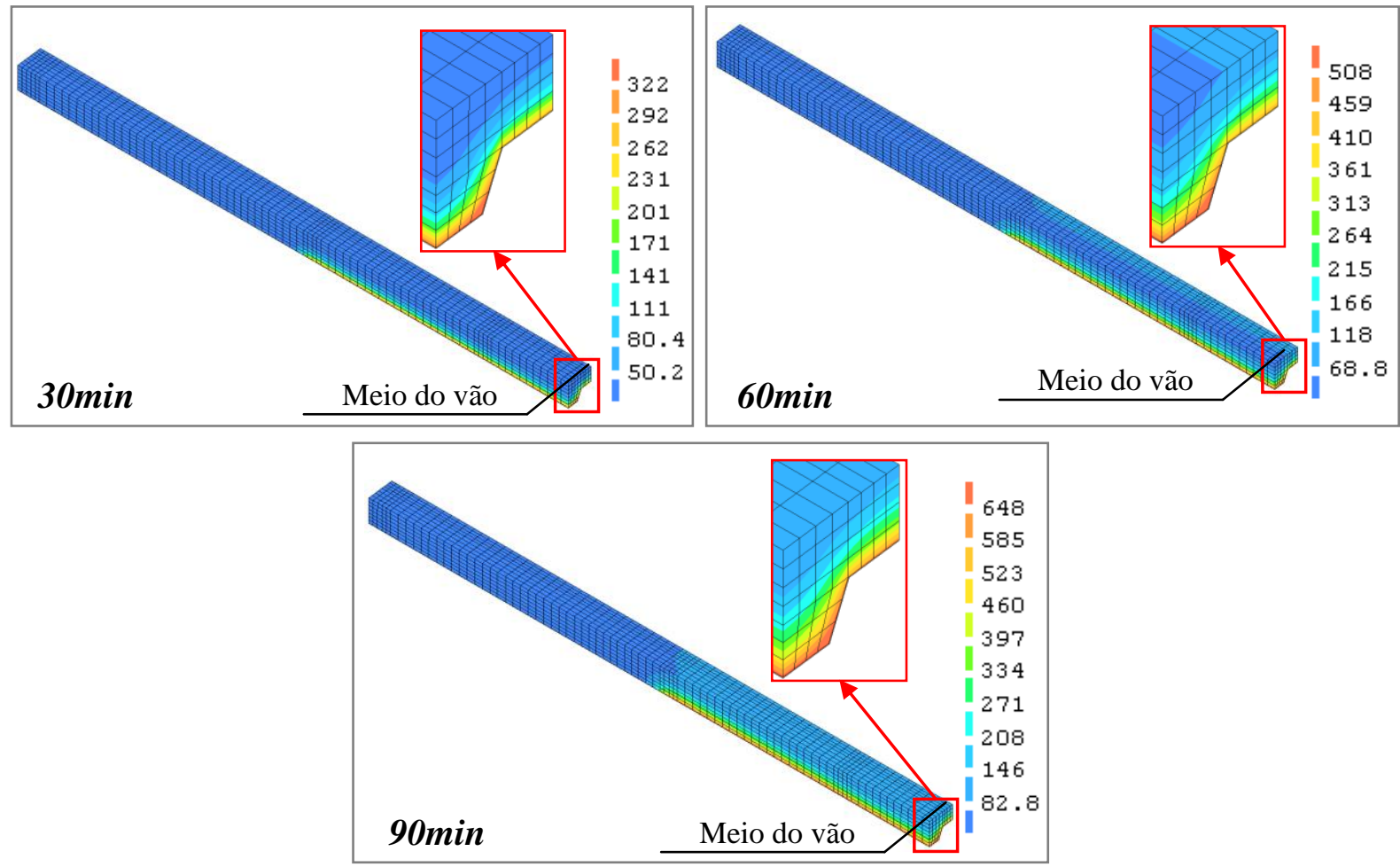

Figura 5.21 - Campos térmicos na laje para tempos de exposição de 30, 60 e 90 minutos

Já na Figura 5.22 são apresentados os campos térmicos na seção transversal da laje, também para tempos de exposição ao fogo iguais a 30, 60 e 90 minutos, porém para o modelo térmico bidimensional (apresentado e validado no Capítulo 5), com vistas a validar os campos térmicos do modelo termoestrutural. Como o modelo térmico demanda menor custo computacional, adotou-se uma malha mais refinada de elementos finitos. Observa-se que os resultados para a seção central da laje do modelo termoestrutural (Figura 5.21) apresentam resultados satisfatórios se comparados com aqueles do modelo térmico (Figura 5.22). 


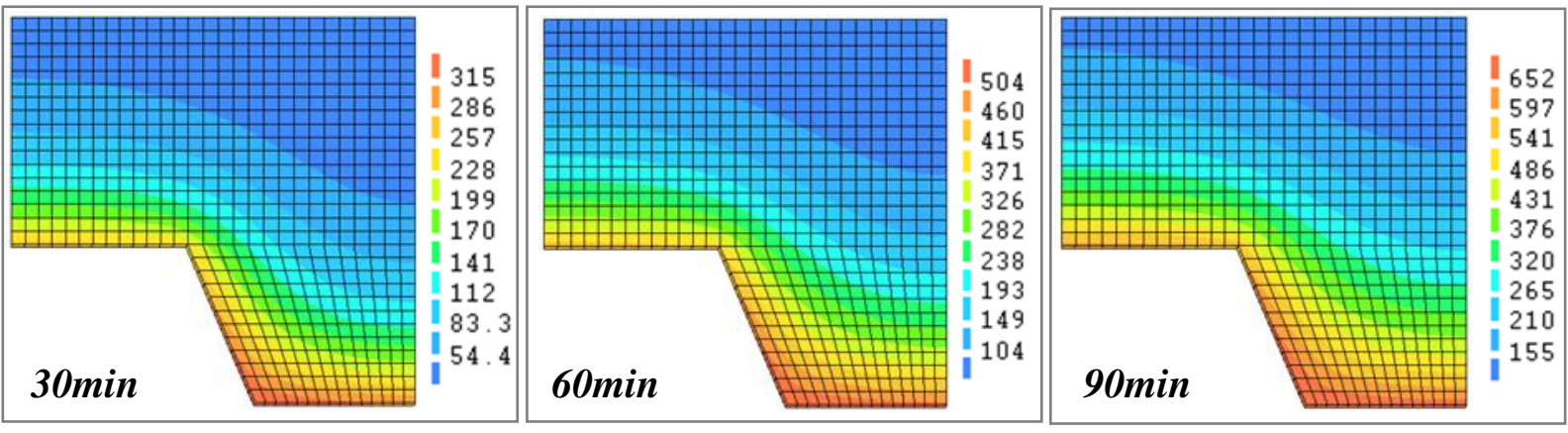

Figura 5.22 - Campos térmicos na seção transversal para tempos de exposição de 30, 60 e 90 minutos (modelo térmico)

\subsubsection{Deformação da laje}

A Figura 5.23 apresenta os campos de deslocamentos da laje para tempos de exposição ao fogo iguais a 0, 30, 60 e 90 minutos, com escala de deslocamento ampliada em cinco vezes, em que o tempo de 0 minuto refere-se ao final da etapa de carregamento mecânico (ou instante imediatamente antes do início da aplicação do carregamento térmico).

Observa-se que aos 30 minutos de exposição o deslocamento máximo da laje corresponde a aproximadamente a metade do deslocamento máximo atingido aos 90 minutos. Isso ocorre em resposta à maior taxa de aquecimento da laje nos primeiros minutos de exposição ao fogo. Aos 90 minutos de exposição o elemento de concreto sobre o apoio intermediário (em destaque na Figura 5.23) apresenta-se visualmente com uma deformação bem superior se comparada ao tempo de 0 minuto, indicando que essa região se encontra em processo avançado de fissuração.

\subsubsection{Fissuração do concreto}

Na Figura 5.24 é apresentado o processo de fissuração do concreto, relativo à deformação normal à fissura, para tempos de exposição ao fogo iguais a 0, 30, 60 e 90 minutos. Observa-se que desde o início de aplicação do carregamento térmico uma parcela do concreto sobre o apoio intermediário (na face superior da laje) e no meio do vão (na face inferior da laje) encontra-se parcialmente fissurada, devido às tensões de tração nessa região, porém em níveis relativamente baixos.

Aos 30 minutos de exposição ao fogo, as fissuras já se propagaram para quase toda a laje, enquanto que após os 60 minutos somente a parte da laje próxima aos apoios externos ainda não fissurou, uma vez que nessa região as tensões de tração atuantes no concreto não atingiram as tensões de tração resistente. 


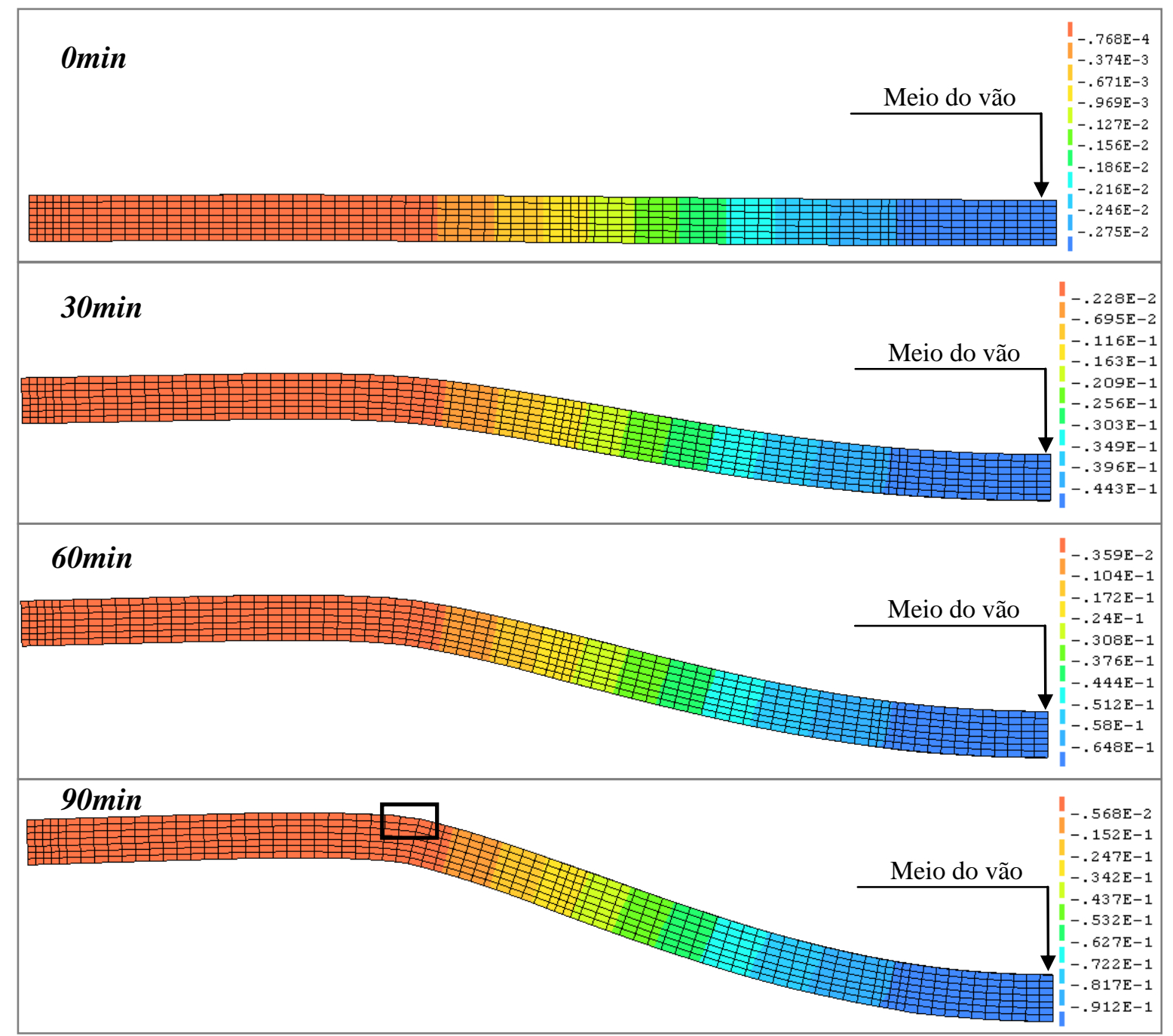

Figura 5.23 - Campos de deslocamentos da laje para tempos de exposição de 0, 30, 60 e 90 minutos (escala ampliada em 5 vezes e legenda em metros)

Para uma análise quantitativa, apresenta-se na Figura 5.25 a tensão atuante na fissura e a deformação normal à fissura versus o tempo de exposição, para os elementos de concreto 1 e 2, sendo que o Elemento 1 refere-se aquele da malha de elementos finitos localizado acima do apoio intermediário e na face superior da laje, enquanto o Elemento 2 está localizado na parte central e inferior da laje. Após 10 minutos de exposição, a tensão de tração nesses elementos decai para menos de $30 \%$ do valor da resistência à tração atribuída ao concreto à temperatura ambiente ( $3 \mathrm{MPa})$ devido ao aumento de temperatura e deformação do concreto.

Essa tensão na fissura pode ser plotada em função da deformação normal à fissura, resultando no comportamento apresentado na Figura 5.26, recuperando o comportamento exponencial adotado para o concreto tracionado (Ver capítulo 3). 

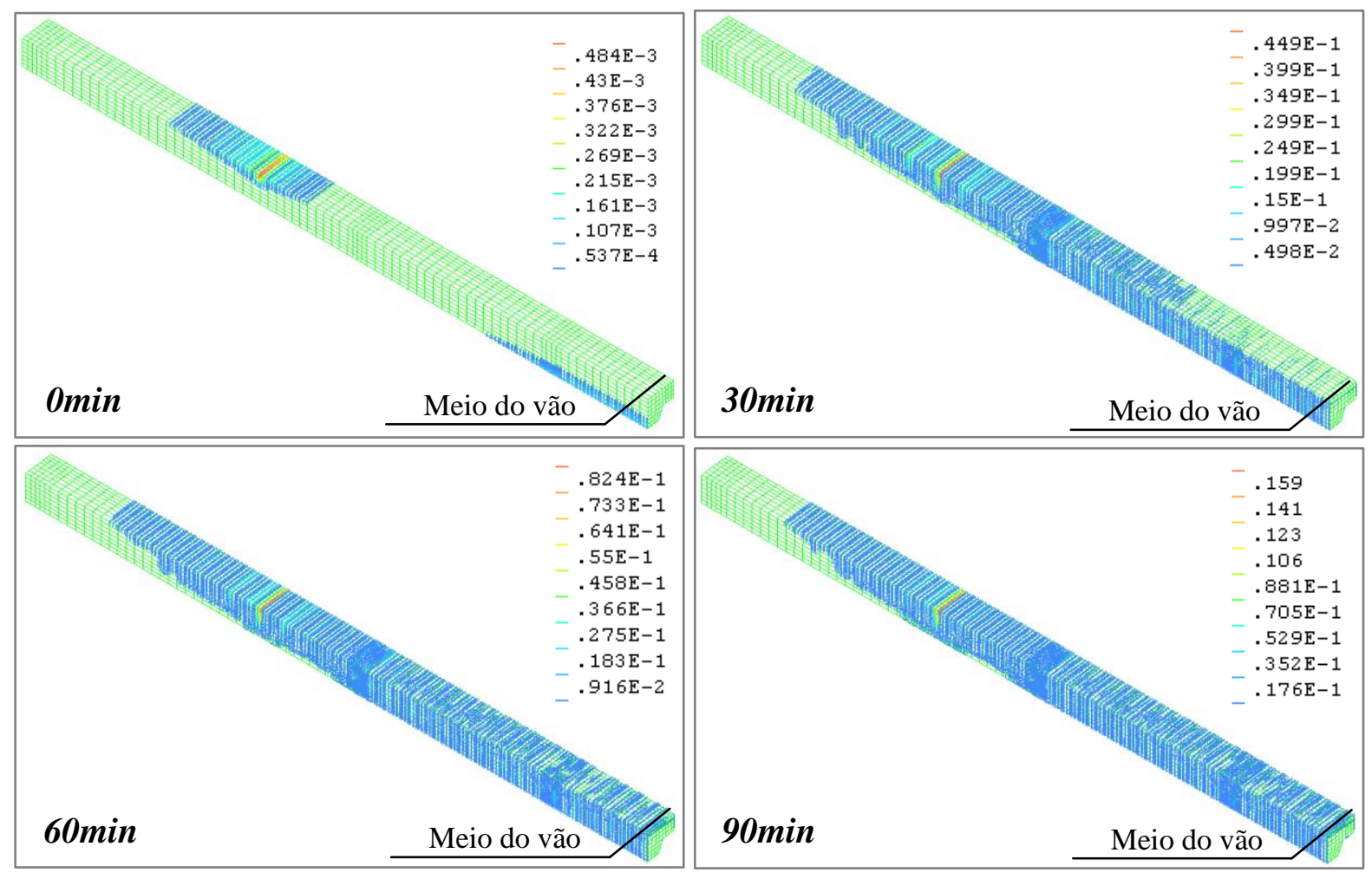

Figura 5.24 - Fissuração do concreto: Deformação normal à fissura para tempos de 0, 30, 60 e 90 minutos
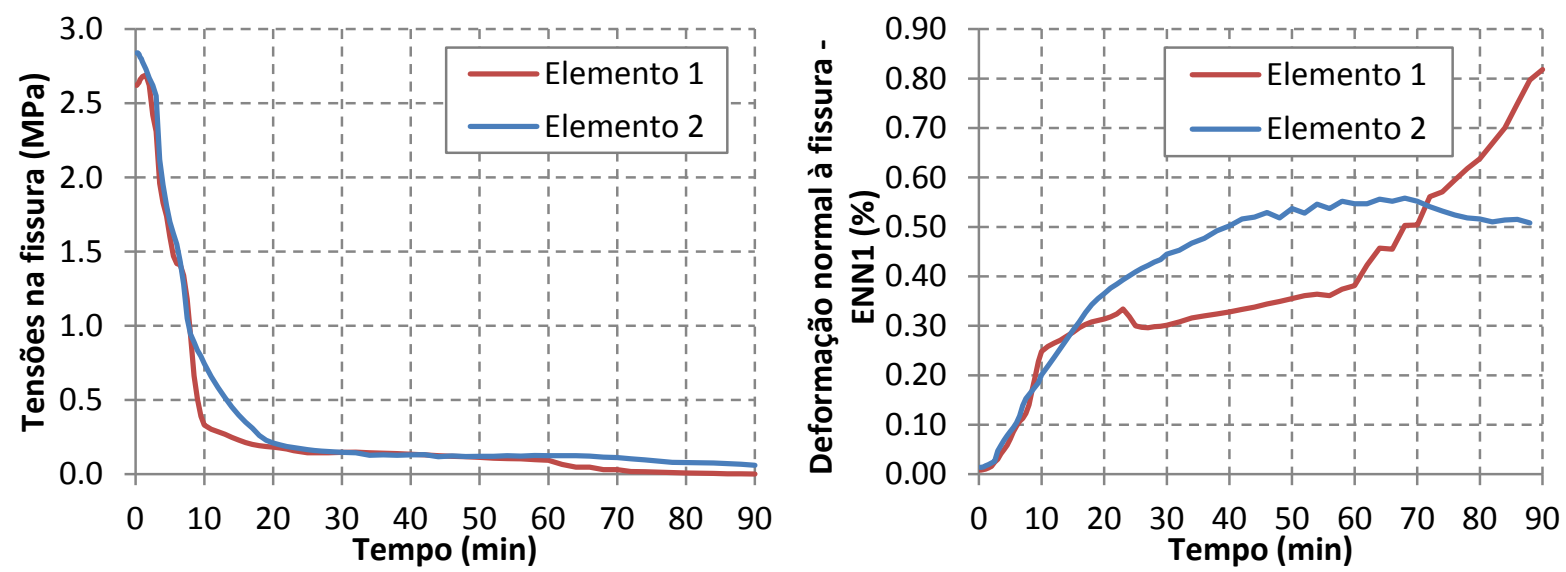

Figura 5.25 - Tensões e deformações normais à fissura versus tempo de exposição para os elementos 1 e 2.

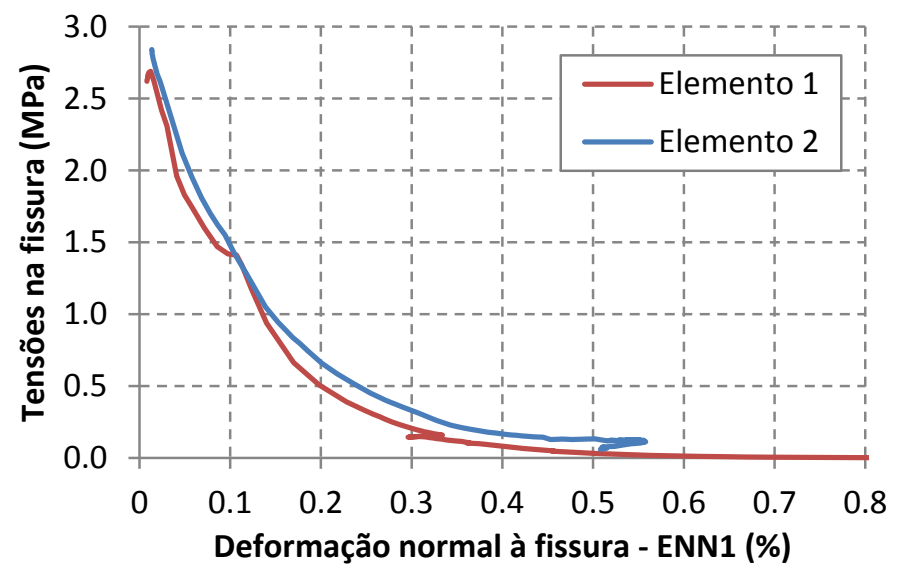

Figura 5.26 - Tensão na fissura versus deformação normal à fissura para os elementos 1 e 2 


\subsubsection{Tensões na fôrma de aço}

Apresenta-se na Figura 5.27 a distribuição de tensões na direção longitudinal $\left(\sigma_{x x}\right)$ na fôrma de aço para tempos de exposição ao fogo iguais a 0, 30, 60 e 90 minutos. Neste caso, com o aumento do tempo de aquecimento, se verifica um aumento das tensões próximas ao apoio intermediário, em resposta à redistribuição de esforços devida à perda de resistência da parte central da laje, aumentando o momento fletor negativo sobre os apoios intermediários.

Já na Figura 5.28 são apresentados os resultados de tensões na direção longitudinal $\left(\sigma_{x x}\right)$ para a mesa inferior e superior da fôrma de aço versus tempo de exposição ao fogo para o elemento localizado no meio do vão da laje. A mesa inferior da fôrma de aço permaneceu tracionada durante toda simulação numérica, enquanto que a mesa superior, após os primeiros minutos de exposição ao fogo, passou a ficar comprimida. Esse comportamento depende de fatores como níveis de aplicação de carga, tipo de carregamento, expansão térmica da fôrma de aço e concreto, condições de vinculação da estrutura, dentre outros.

Pela Figura 5.28 também se observa que após aproximadamente 25 minutos de exposição ao fogo há uma decaimento (em valor absoluto) das tensões atuantes na fôrma de aço. Esse comportamento é influenciado predominantemente pela perda da resistência ao escoamento da fôrma de aço devido ao aumento de temperatura, formando uma rótula plástica no meio do vão e, como consequência, ocorre uma redistribuição de esforços na laje.

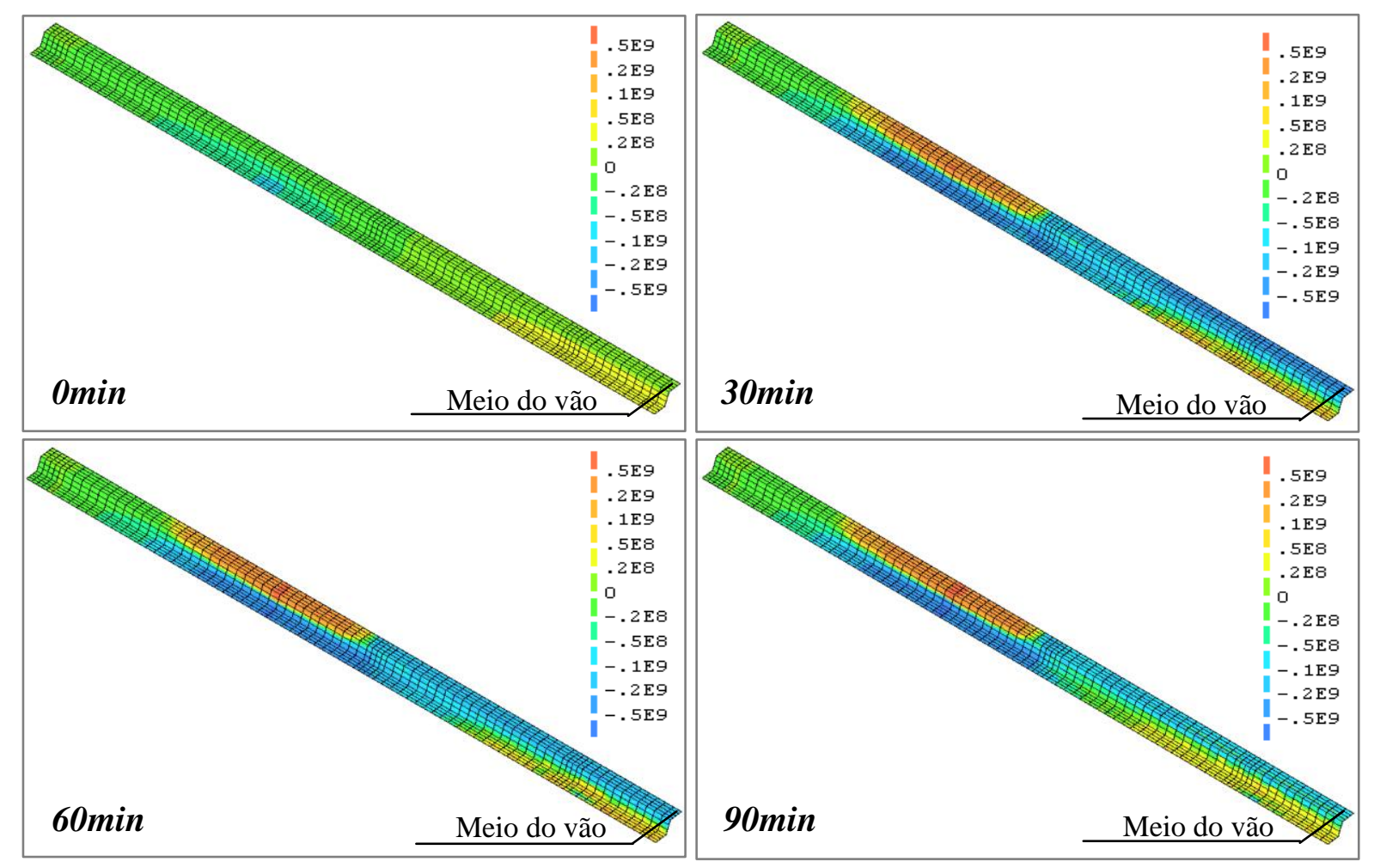

Figura 5.27 - Tensões longitudinal $\left(\sigma_{x x}\right) \mathrm{em} \mathrm{N} / \mathrm{m}^{2}$ na fôrma de aço para tempos de exposição de $0,30,60 \mathrm{e}$ 90 minutos 


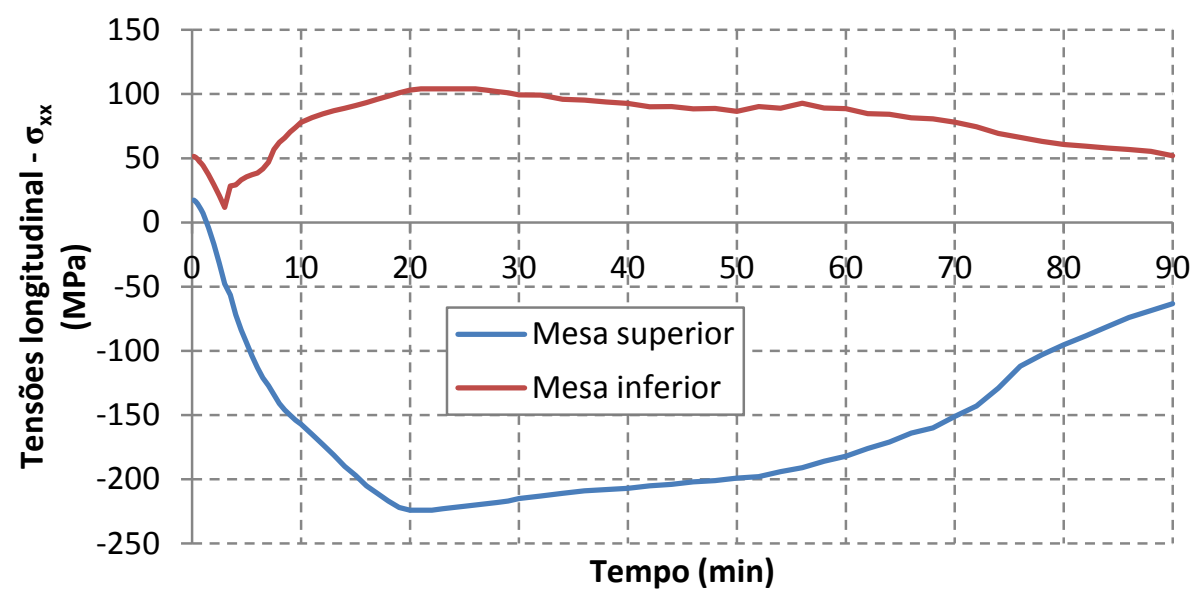

Figura 5.28 - Tensões longitudinal $\left(\sigma_{x x}\right)$ na fôrma de aço (meio do vão) versus tempo de exposição

\subsection{Resultados e discussões adicionais dos modelos numéricos}

\subsubsection{Considerações iniciais}

Pelas análises dos resultados numéricos do capítulo 5, referentes aos campos térmicos da laje mista, se observou que os modelos numéricos considerando a emissividade resultante entre a fôrma de aço e o fogo variável entre 0,09 e 0,40 para as temperaturas de 250 e $800{ }^{\circ} \mathrm{C}$ e sem resistência térmica na interface melhor representou a distribuição de temperatura na seção transversal da laje, tanto para a fôrma de aço quanto para o concreto, enquanto que a utilização de uma emissividade resultante de 0,70 e com resistência térmica na interface somente representou satisfatoriamente os campos térmicos no concreto, sendo que neste caso as temperaturas da fôrma de aço ficaram superiores às experimentais.

Já os resultados dos modelos numéricos tridimensionais à temperatura ambiente indicaram que os modelos experimentais avaliados não apresentaram resistência ao cisalhamento longitudinal suficiente para garantir interação completa entre a fôrma de aço e o concreto. Entretanto a interação entre a fôrma de aço e o concreto pode ser melhorada por meio de ancoragem de extremidade, que não foram utilizados nos modelos experimentais.

Conforme era esperado pelos resultados dos modelos térmicos, o modelo numérico termoestrutural apresentou melhor correlação com os experimentais quando se utilizou emissividade variável e interação completa. Neste caso, a consideração da interação parcial dificultou a convergência dos modelos numéricos e os resultados para deslocamentos foram superiores aos experimentais, na ordem de 20 a $30 \%$.

O fato de os resultados numéricos termoestruturais com interação completa terem correlacionado melhor com os experimentais pode ser explicado pelo desenvolvimento de uma melhor resistência ao cisalhamento longitudinal na interface entre a fôrma de aço e o concreto. Outro fator que pode ter contribuído é que, quando se considera a interface, surge uma diferença de temperatura da fôrma de aço para o concreto em contato com essa fôrma, de tal modo que o concreto passa a absorver menos calor, aumentando a temperatura da fôrma de 
aço. Com essa diferença de temperatura, a expansão térmica, principalmente na direção longitudinal da laje, também é modificada. Como os campos térmicos da fôrma de aço e do concreto ficaram melhores representados com interação completa e emissividade variável, o modelo termoestrutural também ficou mais representativo com essas hipóteses, já que a expansão térmica longitudinal também influencia no deslocamento vertical da laje.

Do exposto e dos resultados numéricos obtidos, caso não sejam utilizados mecanismos que possam garantir a interação completa entre a fôrma de aço e o concreto, recomenda-se utilizar o modelo bond-slip para representação numérica da interface com uma resistência ao cisalhamento longitudinal de $30.000 \mathrm{~N} / \mathrm{m}^{2}(0,03 \mathrm{MPa})$. Este valor foi adotado por estar dentro da faixa dos valores obtidos durante a calibração do modelo à temperatura ambiente $\mathrm{e}$ equivale a um valor muito baixo de resistência ao cisalhamento longitudinal, ou seja, existe pouca passagem de esforço entre a fôrma de aço e o concreto. Já com relação à obtenção dos campos térmicos na laje mista será utilizado o valor variável para a emissividade resultante, por apresentar melhores correlações com os resultados experimentais.

Nas análises realizadas nos itens subsequentes serão utilizados modelos numéricos cujas características são apresentadas na Tabela 5.2, em que $h_{t}$ é a altura total da laje, $t$ a espessura da fôrma de aço, $\Phi$ o diâmetro da armadura, $L$ o vão da laje (simplesmente apoiada), $f_{c k}$ a resistência característica do concreto e o fator de carga (FC) como sendo a relação entre o carregamento aplicado no modelo e o carregamento resistente em temperatura ambiente.

Tabela 5.2 - Modelos utilizados na análise numérica

\begin{tabular}{|c|c|c|c|c|c|c|c|}
\hline Modelo & $h_{t}(\mathbf{m m})$ & $t(\mathbf{m m})$ & $\Phi(\mathbf{m m})$ & $L(\mathbf{m})$ & $f_{c k}(\mathbf{M P a})$ & $\begin{array}{c}\text { Carga aplicada } \\
\qquad\left(k N / m^{2}\right)\end{array}$ & Fator de carga \\
\hline TE01 & 140 & 0,8 & - & 3 & 20 & 16,$51 ; 11,01 ; 5,51$ & 0,$75 ; 0,50 ; 0,25$ \\
\hline TE02 & 140 & 0,8 & 16 & 3 & 20 & 41,$38 ; 27,59 ; 13,79$ & 0,$75 ; 0,50 ; 0,25$ \\
\hline TE03 & 120 & 0,8 & - & 2,5 & 20 & 5,85 & 0,25 \\
\hline TE04 & 160 & 0,8 & - & 2,5 & 20 & 5,85 & 0,20 \\
\hline TE05 & 120 & 1,25 & - & 2,5 & 20 & 5,85 & 0,19 \\
\hline TE06 & 160 & 1,25 & - & 2,5 & 20 & 5,85 & 0,16 \\
\hline TE07 & 120 & 0,8 & 16 & 2,5 & 20 & 5,85 & 0,11 \\
\hline TE08 & 120 & 0,8 & - & 4 & 20 & 5,85 & 0,54 \\
\hline TE09 & 120 & 0,8 & 16 & 4 & 20 & 5,85 & 0,24 \\
\hline TE10 & 120 & 0,8 & - & 2,5 & 40 & 5,85 & 0,24 \\
\hline TE11 & 120 & 0,8 & 16 & 2,5 & 40 & 5,85 & 0,10 \\
\hline
\end{tabular}

Como características para todos os modelos, não apresentadas na Tabela 5.2, também se adotou a resistência ao escoamento de $280 \mathrm{MPa}$ para a fôrma de aço e de $500 \mathrm{MPa}$ para a armadura positiva, umidade do concreto de $2 \%$, carregamento distribuído em toda laje, armadura de distribuição de $2,0 \mathrm{~cm}^{2} / \mathrm{m}$ (equivalente a barras de $5 \mathrm{~mm}$ espaçadas a cada 150 $\mathrm{mm}$ ) e altura da forma de aço de $75 \mathrm{~mm}$ cujas dimensões são apresentadas na Figura 2.13 (Capítulo 2). 
Os modelos TE01 e TE02 foram processados com fatores de cargas de 0,75, 0,50 e 0,25 , os demais modelos foram processados com uma carga típica em situação de incêndio de $5,85 \mathrm{kN} / \mathrm{m}^{2}$, equivalente a uma carga permanente de $4,5 \mathrm{kN} / \mathrm{m}^{2}$ e uma sobrecarga de 3,0 $\mathrm{kN} / \mathrm{m}^{2}$, logo os fatores de carga aplicados nesses modelos variam de 0,10 a 0,54 , conforme apresentado na Tabela 5.2. Todos os modelos também foram processados com interação completa e parcial na interface entre a fôrma de aço e concreto.

\subsubsection{Critério para cálculo do tempo resistente}

A única referência encontrada na literatura para cálculo do tempo de resistência ao fogo foi o critério da ISO 834:1999, geralmente utilizado em ensaios experimentais. Esse critério depende do deslocamento máximo e da taxa de deslocamento máxima permitidos, de acordo as Equações 5.3 e 5.4, em que $L$ e $d$ são, respectivamente, o vão e a altura total da laje. A taxa de deslocamento máxima somente é aplicada após o deslocamento vertical exceder o valor de $\mathrm{L} / 30$.

$$
\begin{aligned}
& D_{\text {max }}=\frac{L^{2}}{400 d}(\mathrm{~mm}) \\
& \left(\frac{\partial D}{\partial t}\right)_{\max }=\frac{L^{2}}{9000 d}(\mathrm{~mm} / \mathrm{min})
\end{aligned}
$$

Neste caso o deslocamento máximo permitido ocorre geralmente entre L/30 e L/20, a depender da taxa de aquecimento. Entretanto, ensaios realizados em escala real no edifício em Cardington demonstraram que a capacidade resistente de elementos mistos de aço e concreto em situação de incêndio pode ocorrer para deslocamentos superiores aos estabelecidos pela ISO 834:1999 (BRE, 2005).

A ABNT NBR 14323:2013 não estabelece nenhum critério de deslocamentos máximos para prever a capacidade resistente de elementos mistos de aço e concreto em situação de incêndio (estado limite de serviço), neste caso são permitidos elevados valores de deslocamentos verticais. No presente trabalho, será utilizado o critério da ISO 834:1999 para estabelecer o deslocamento e taxa de deslocamentos máximos no intuito de prever a capacidade resistente de lajes mistas de aço e concreto em situação de incêndio. Nos casos em que os modelos numéricos pararem de convergir antes desses limites, adotar-se-á o tempo de resistência ao fogo referente ao final do processamento do modelo.

\subsubsection{Resultados de interesse com base em análise paramétrica}

\subsubsection{Análise com base no fator de carga}

Realiza-se neste item uma avaliação da resistência de laje mista em temperatura elevada quando se utiliza o método do momento fletor plástico (MFP) cujos campos térmicos 
são obtidos pelo processamento do modelo numérico bidimensional e o modelo termoestrutural tridimensional, relativos aos modelos TE01 e TE02. Esses resultados também serão comparados com os modelos de cálculo da ABNT NBR 14323:2013.

Antes de iniciar a análise termoestrutural acoplada, realizou-se o processamento dos modelos numéricos (TE01 e TE02) em temperatura ambiente com interação completa (IC) e interação parcial (IP) no intuito de calcular o momento fletor resistente da laje mista, cujos resultados de momento fletor versus deslocamento vertical no meio do vão são apresentados na Figura 5.29. O momento fletor resistente para o modelo TE01 considerando interação parcial foi da ordem de $39 \%$ inferior quando se considera interação total. Já com a presença da armadura (modelo TE02) essa diferença foi de 15\%. Em valores absolutos, o momento fletor resistente em temperatura ambiente considerando interação parcial é de 24,3 e 61,6 $\mathrm{kN} . \mathrm{m} / \mathrm{m}$ para os modelos TE01 e TE02 respectivamente. Para níveis baixos de carregamentos, aproximadamente abaixo de $40 \%$ a 50\% do momento de plastificação, se observa que não há diferenças significativas no comportamento estrutural da laje quando se considera interação parcial ou completa, pois, para esses níveis de carregamento, ainda não se iniciou o escorregamento relativo entre a fôrma de aço e o concreto.
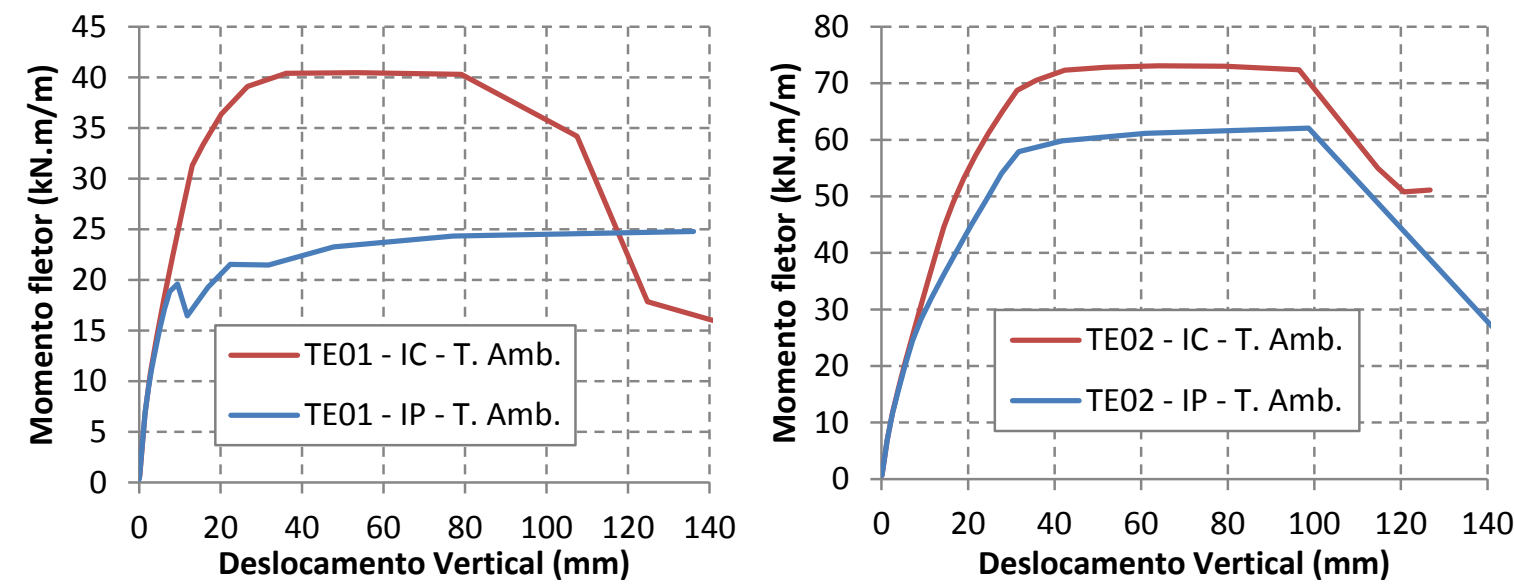

Figura 5.29 - Momento fletor no meio do vão vs. deslocamento vertical no meio do vão para os modelos TE01 e TE02 em temperatura ambiente

Nas Figuras 5.30, 5.31, 5.33 e 5.34 são apresentados os resultados de deslocamento vertical e deslocamento relativo de extremidade versus tempo de exposição para os modelos TE01 e TE02. Os gráficos de deslocamentos relativos de extremidade são apresentados para os casos com interação parcial, já que os modelos com interação completa não apresenta deslocamento relativo entre a fôrma de aço e o concreto. Um valor de deslocamento relativo positivo indica que a fôrma de aço apresenta valores de deslocamento longitudinal (em módulo) menor que o concreto e um deslocamento negativo o contrário. A primeira situação é típica de uma laje submetida a carregamento mecânico vertical e a segunda para carregamentos térmicos, pois nesse último caso a fôrma de aço em contato com o fogo apresenta deformações superiores às do concreto em contato com a interface, visto que está sujeita a maiores valores de temperaturas. 
Já nas Figuras 5.32 e 5.35 são apresentados os resultados de momentos fletores resistentes (calculados pelo método do momento plástico resistente, modelo de cálculo da ABNT NBR 14323:2013 e pelos resultados do modelo termoestrutural, adotando o critério da ISO 834:1999) versus o tempo de exposição ao fogo.

Pela Figura 5.30 é possível observar que quanto maior o fator de carga há uma maior redução do tempo de resistência ao fogo quando se considera interação parcial em relação ao caso com interação completa. Já para fatores de cargas menores os resultados considerando interação parcial e completa são parecidos. Também se observa que a laje continuou resistindo aos carregamentos térmicos e mecânicos além do limite de deslocamento máximo estabelecido pela ISO 834:1999, principalmente para níveis de carga mais baixos $(\mathrm{FC}=0,25)$.

Considerando as curvas com $\mathrm{FC}=0,25$ pela Figura 5.31, se observa que são baixos os valores de deslocamento relativo de extremidade e esses ocorrem entre $-1,0$ e 1,0 mm, esse comportamento justifica o fato dos resultados considerando interação completa e parcial serem parecidos. Entretanto esse comportamento em que o deslocamento relativo ocorre para valores próximos de zero dificulta a convergência do modelo numérico, sendo necessárias várias iterações para atingir os critérios de convergência estabelecidos durante o processamento do modelo.

O momento resistente da laje mista sem armadura, modelo TE01 (Figura 5.32), são inferiores àqueles calculados pelo método do momento fletor plástico (MFP). Isso era esperado uma vez que para o modelo termoestrutural se adotou o critério da ISO 834:1999 para cálculo do tempo resistente. Por esses resultados também se observa que quando não se tem armadura positiva na laje mista o tempo resistente da laje dificilmente chega aos 60 minutos, a não ser para valores de níveis de cargas mais baixos que os utilizados. Os valores de momentos resistente calculados pelo modelo de cálculo da ABNT NBR 14323:2013 foram maiores que os calculados pelo MFP. Entretanto o procedimento de cálculo da ABNT NBR 14323:2013 somente permite o cálculo do momento resistente para tempos de 60, 90 e 120 minutos de exposição e os resultados do modelo termoestrutural para os níveis de cargas avaliados não atingiram esses valores de tempo.

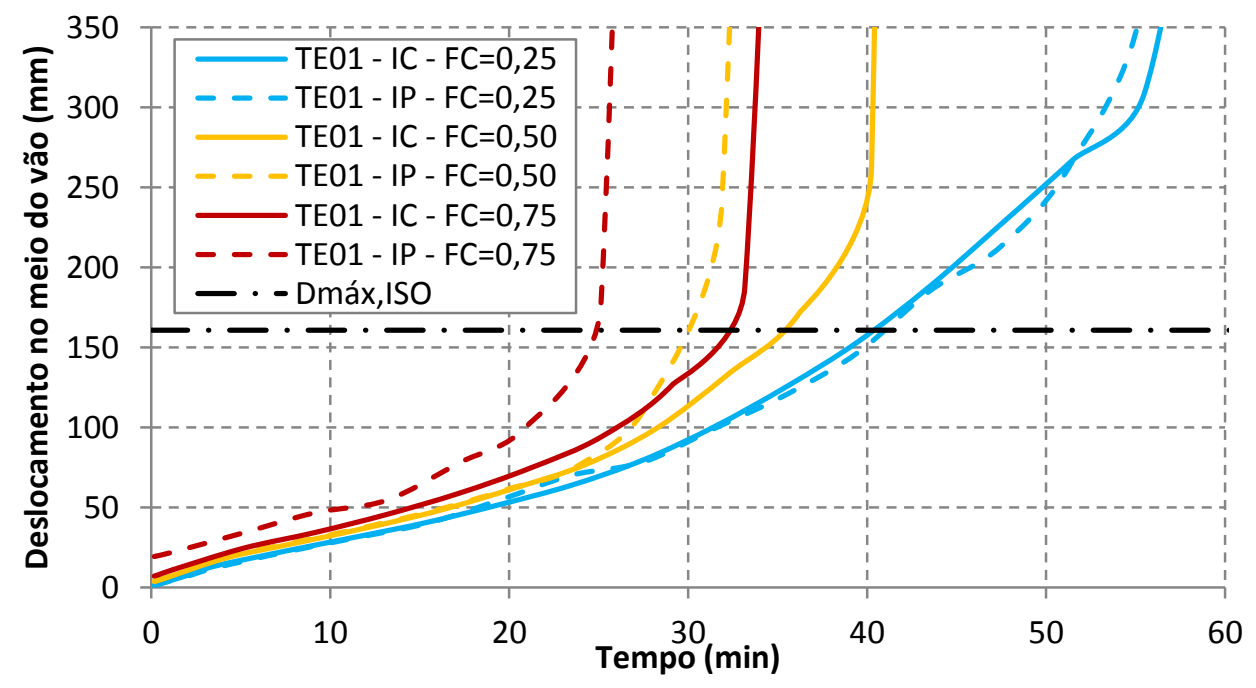

Figura 5.30 - Deslocamento no meio do vão vs. Tempo de exposição para o modelo TE01 


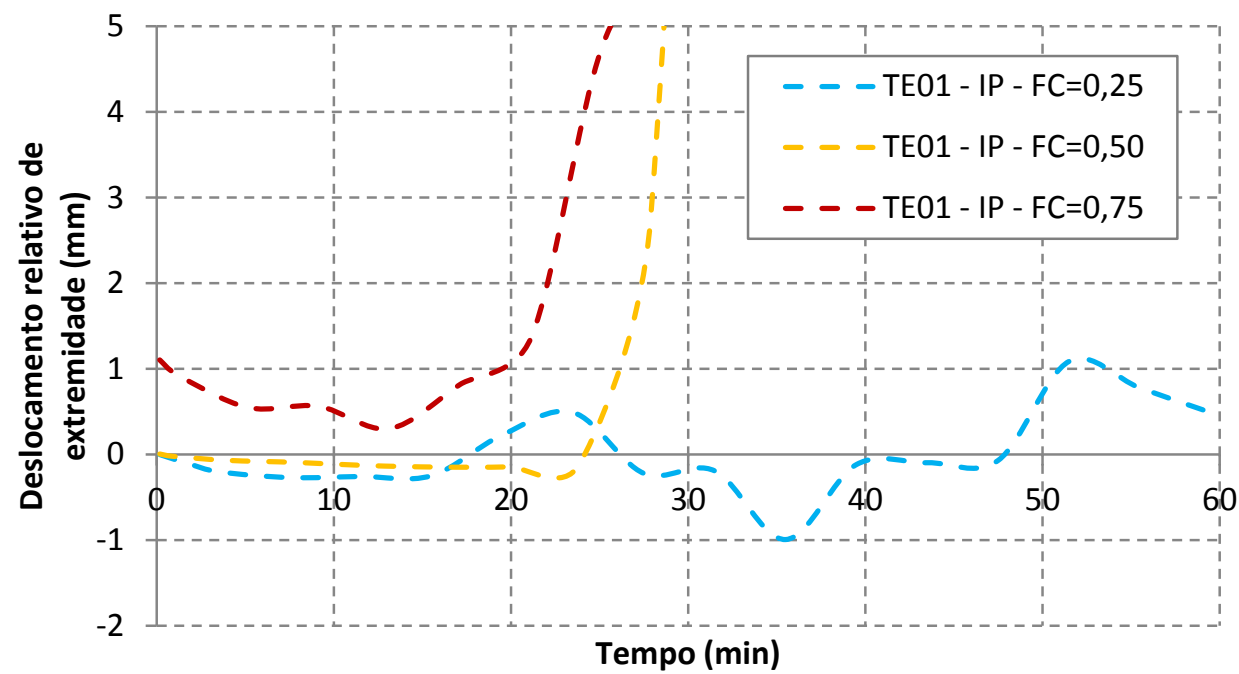

Figura 5.31 - Deslocamento relativo de extremidade $v s$. Tempo de exposição para o modelo TE01

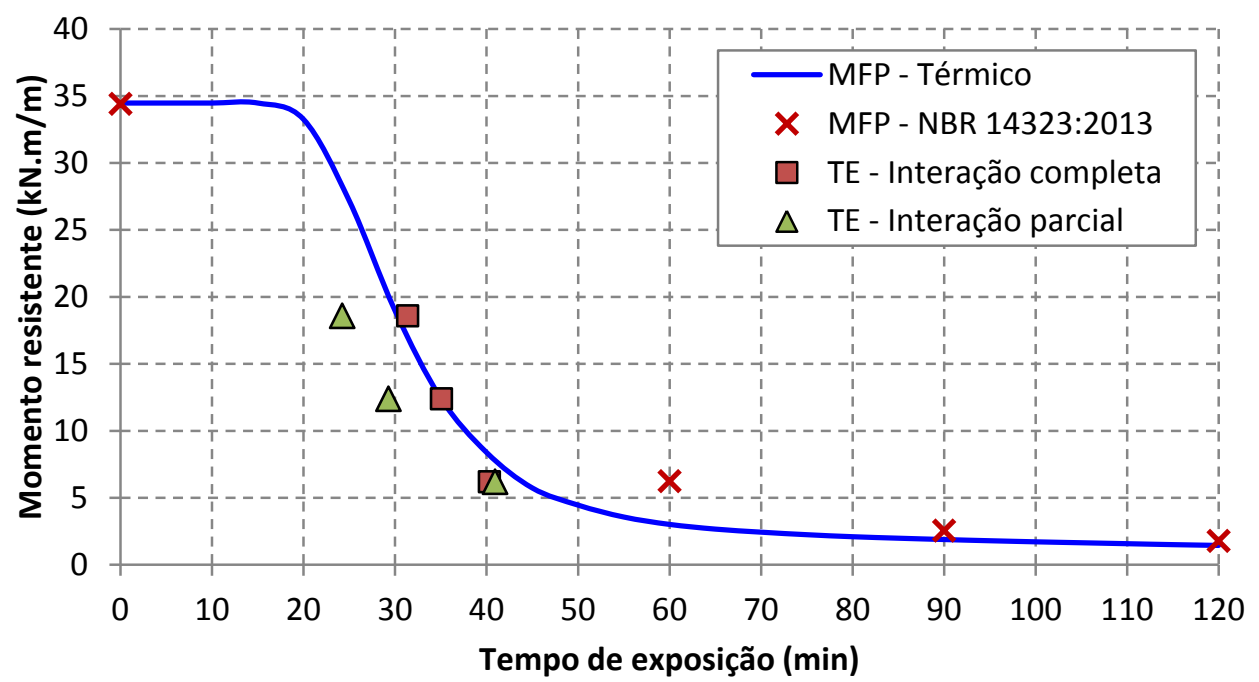

Figura 5.32 - Momento fletor resistente vs. tempo de exposição considerando o MFP, o modelo termoestrutural e o modelo de cálculo da ABNT NBR 14323:2013 (TE01)

Pelos resultados do modelo termoestrutural com armadura, Figuras 5.33 a 5.35, os resultados de deslocamentos verticais no meio do vão versus tempo de exposição foram similares quando se considera interação parcial ou completa entre a fôrma de aço e o concreto, o que pode ter contribuído para isso foi o fato de se considerar interação total entre a armadura positiva e o concreto, hipótese válida para o caso de armaduras nervuradas. Entretanto, mais uma vez, os modelos numéricos com interação parcial apresentaram dificuldades para convergir.

Pela Figura 5.34 é possível fazer algumas considerações sobre o comportamento do deslocamento relativo de extremidade, quando se considera interação parcial. Antes de se iniciar o aquecimento ( $\mathrm{T}=0,0$ minutos) se observa que o deslocamento relativo é positivo, influenciado pelo carregamento mecânico aplicado. À medida que o tempo de aquecimento vai aumentando a fôrma de aço tende a apresentar deslocamentos relativos superiores aos do concreto em contato com a interface, devido sua maior expansão térmica, fazendo com que o 
deslocamento relativo se torne negativo. Com o tempo de exposição superior a aproximadamente 35 minutos, a expansão térmica da fôrma de aço e do concreto passa a ter menor influência no escorregamento entre esses materiais e a fôrma de aço se desloca no sentido do meio do vão, devido às perdas de rigidez e resistência da laje, podendo até a apresentar valores positivos de deslocamento relativos.

A presença da armadura no interior da nervura da fôrma de aço melhorou significativamente a resistência da laje mista em temperatura elevada (Figura 5.35) quando comparada ao caso sem armadura (modelo TE01). Os resultados do modelo termoestrutural foram inferiores aos calculados pelo MFP e pelo procedimento de cálculo apresentado pela ABNT NBR 14323:2013. Mais uma vez isso pode ser justificado pelos critérios de ruptura da ISO 834:1999 adotados, já que no MFP se considera plastificação total da seção transversal e pelos resultados dos modelos termoestruturais se observa que para atingir a plastificação da seção transversal são necessários valores de deslocamentos verticais superiores aos estabelecidos pela ISO.

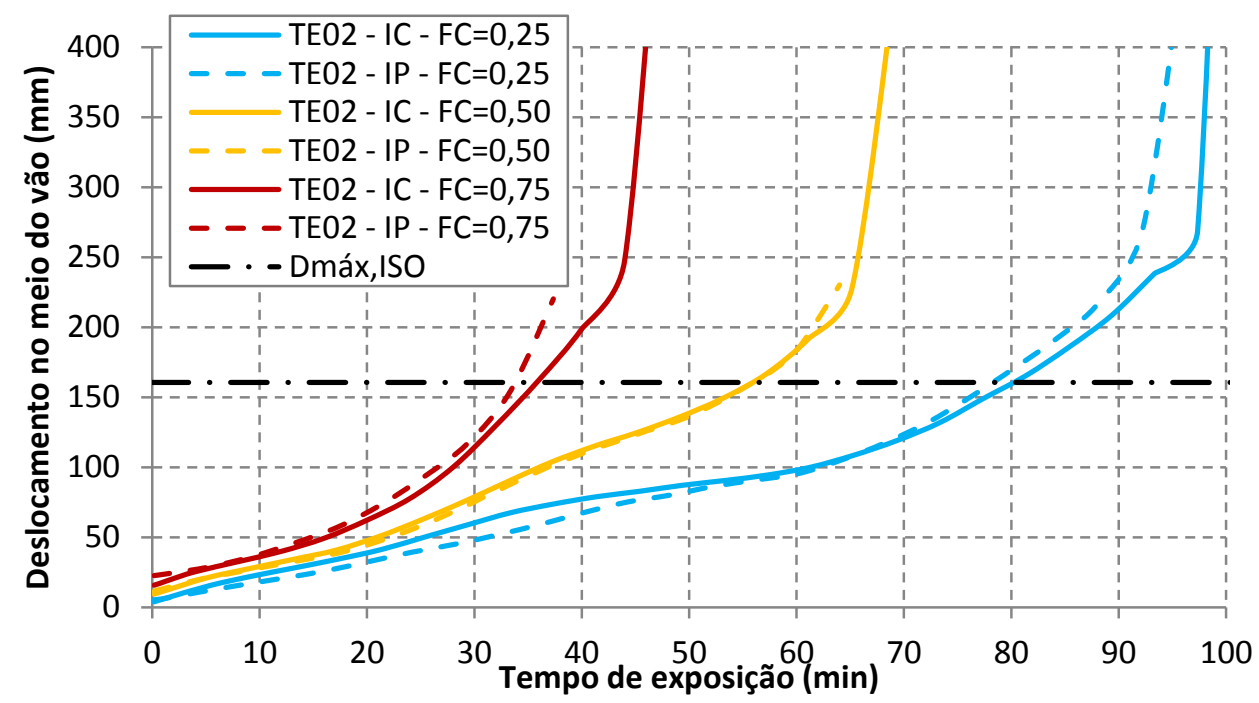

Figura 5.33 - Deslocamento no meio do vão vs. Tempo de exposição para o modelo TE02

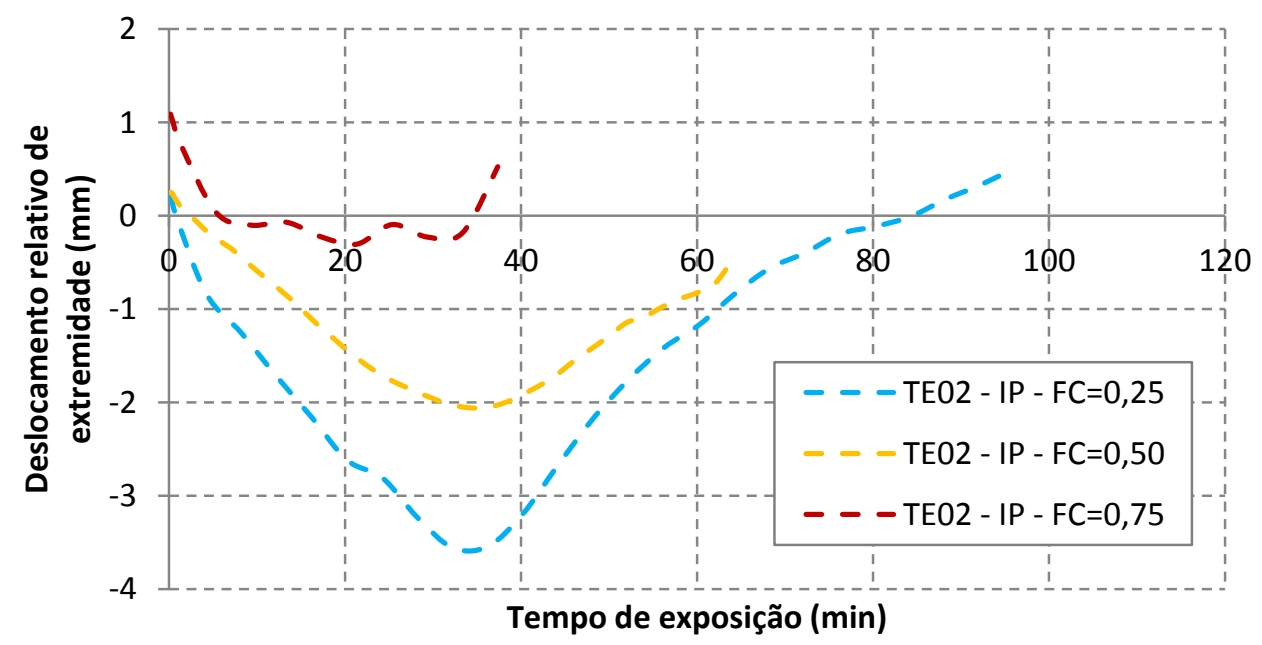

Figura 5.34 - Deslocamento relativo de extremidade vs. Tempo de exposição para o modelo TE02 


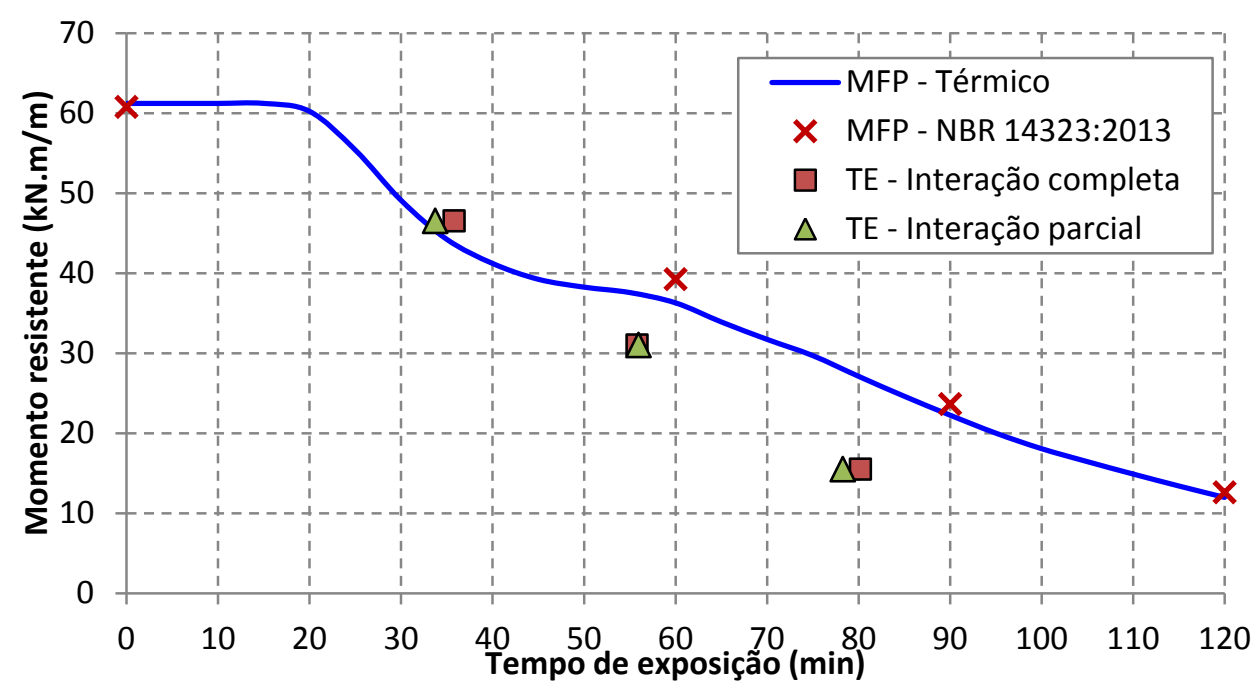

Figura 5.35 - Momento fletor resistente vs. tempo de exposição considerando o MFP, o modelo termoestrutural e o modelo de cálculo da ABNT NBR 14323:2013 (TE02)

Pelos resultados apresentados para os modelos TE01 e TE02 se conclui que, para baixos valores de fator de carga ou quando se utiliza armaduras positivas, o comportamento estrutural de lajes mistas em situação de incêndio é similar quando se considera interação parcial ou completa.

A seguir são apresentados os resultados e análises dos modelos termoestruturais TE03 a TE11. As características geométricas e físicas desses modelos foram selecionadas no intuito de se avaliar a influência da armadura positiva, da espessura da fôrma de aço, da altura total da laje, do vão entre apoios e da resistência característica do concreto. Para facilitar a visualização dos resultados, as curvas contínuas referem-se aos casos considerando interação completa e as tracejadas com interação parcial.

\subsubsection{Influência da armadura positiva e espessura da fôrma de aço}

Na Figura 5.36 são apresentados os resultados numéricos de deslocamento vertical no meio do vão versus tempo de exposição ao fogo para os modelos TE03 (com espessura da fôrma de aço de 0,80mm), TE05 (com espessura da fôrma de aço de 1,25mm) e TE07 (com espessura da fôrma de aço de $0,80 \mathrm{~mm}$ e com uma armadura de $16 \mathrm{~mm}$ de diâmetro dentro da nervura).

O aumento do tempo de resistência ao fogo com o aumento da espessura da fôrma de aço, considerando o critério da ISO $834: 1999$, foi de $11 \%$ (38,0min para 42,3min), resultado pouco significativo considerando um aumento de área da fôrma de aço de $56 \%$ (espessura de $0,80 \mathrm{~mm}$ para $1,25 \mathrm{~mm}$ ). Esse aumento de área equivale aproximadamente a uma armadura de diâmetro de 16mm (modelo TE07) dentro da nervura da fôrma. Entretanto, neste caso o ganho de resistência (conforme pode ser observado pela Figura 5.36) é evidente, passando dos 120 minutos. Isso é justificado pelo fato da armadura está imersa no concreto, protegida do 
contado direto com o fogo. Esses resultados evidenciam que para elevados tempos requeridos de resistência ao fogo (TRRF) seja interessante que se utilize armaduras positivas ao invés de aumentar a espessura da fôrma de aço.

Esses resultados também evidenciam que para deslocamentos verticais abaixo daqueles estabelecidos pela ISO, para os modelos TE03 e TE05, praticamente não há diferença entre os resultados com interação parcial e completa. A partir desse valor de deslocamento começa a surgir uma pequena variação dos resultados, instante em que há o início do deslocamento relativo entre a fôrma de aço e o concreto. Já para o modelo com armadura (TE07) praticamente não houve diferença entre os resultados numéricos considerando interação parcial ou completa. Esse comportamento também poderá ser observado pelos resultados dos demais modelos numéricos (Figuras 5.37 a 5.42).

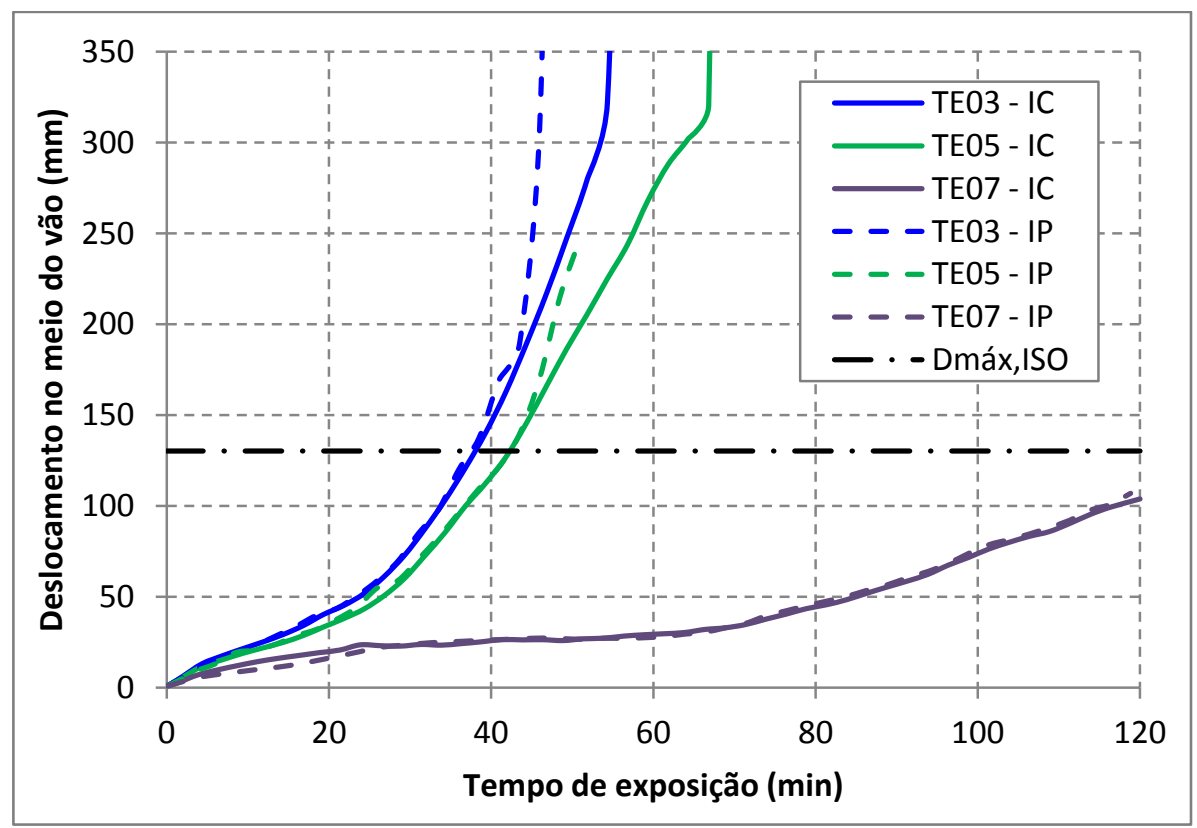

Figura 5.36 - Resultados numéricos para os modelos TE03 $(t=0,80 \mathrm{~mm})$, TE05 $(t=1,25 \mathrm{~mm})$ e TE07 $(t=0,80 \mathrm{~mm}$ e com armadura)

\subsubsection{Influência da altura total da laje e do vão entre apoios}

A altura total da laje e o vão entre apoios influenciam no modo como ocorre a ruptura dos modelos. Neste caso, uma maior altura da laje ou um menor vão entre apoios (menor relação entre vão e altura total da laje) favorece o deslizamento entre a fôrma de aço e o concreto, devido à predominância das tensões de cisalhamento. Já o contrário, a ruptura dos modelos ocorre preferencialmente por flexão, havendo pouca influência do escorregamento relativo na interface.

O comportamento supracitado pode ser observado pelos resultados numéricos de deslocamento vertical no meio do vão versus tempo de exposição ao fogo, apresentados nas 
Figuras 5.37 a 5.40, onde é possível observar que para os modelos com altura total da laje de $160 \mathrm{~mm}$ e com vão entre apoios de 2,5m, surge, após o limite de deslocamento máximo permitido pela ISO 834:1999, uma maior diferença entre os resultados considerando interação parcial ou completa, a exceção fica nos casos em que se utiliza armadura positiva, cujos resultados são similares independentemente dos valores de deslocamento.

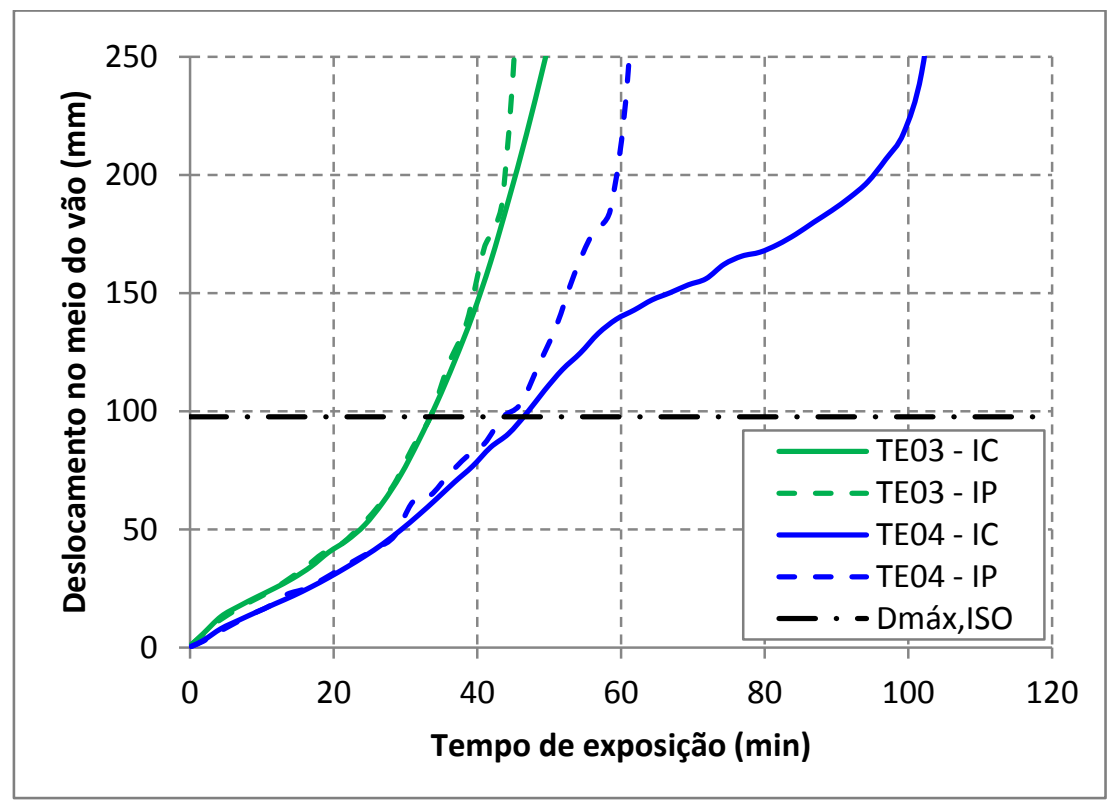

Figura 5.37 - Resultados numéricos para os modelos TE03 $\left(h_{t}=120 \mathrm{~mm}\right)$ e TE04 $\left(h_{t}=160 \mathrm{~mm}\right)$ ambos com vão de 2,5m e espessura da fôrma de aço de $0,80 \mathrm{~mm}$

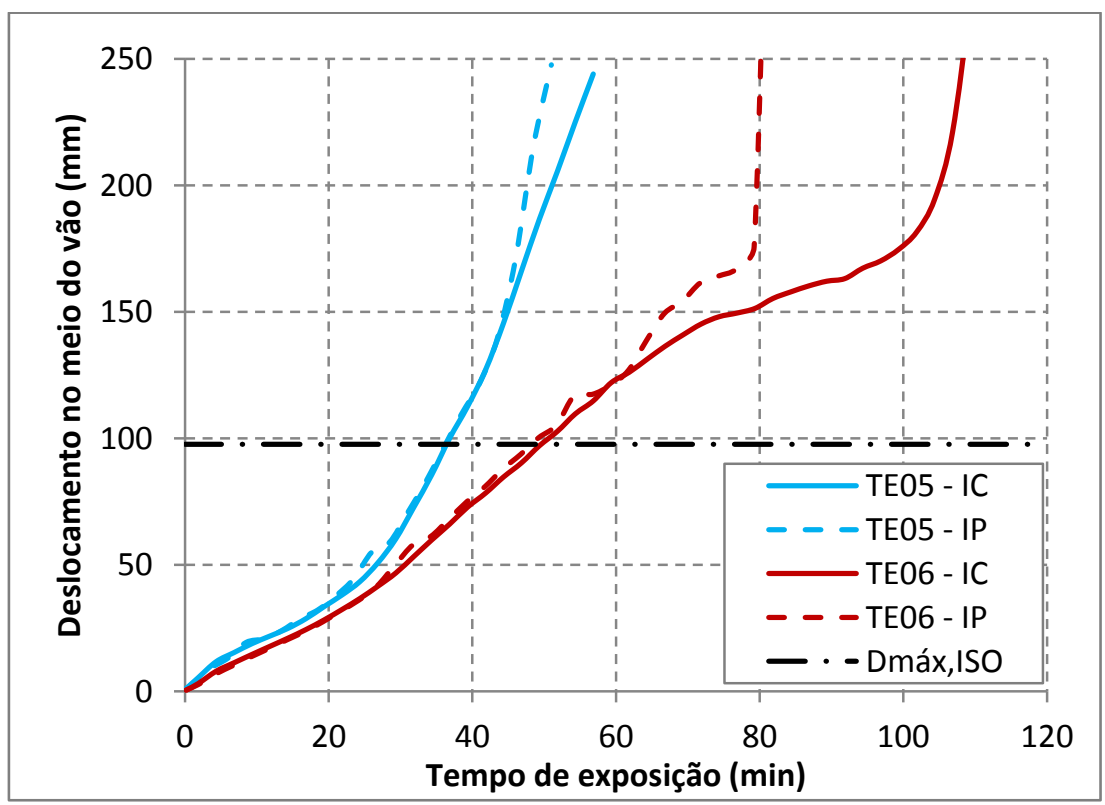

Figura 5.38 - Resultados numéricos para os modelos TE05 $\left(h_{t}=120 \mathrm{~mm}\right)$ e TE06 $\left(h_{t}=160 \mathrm{~mm}\right)$ ambos com vãos de $2,5 \mathrm{~m}$ e espessura da fôrma de aço de $1,25 \mathrm{~mm}$ 


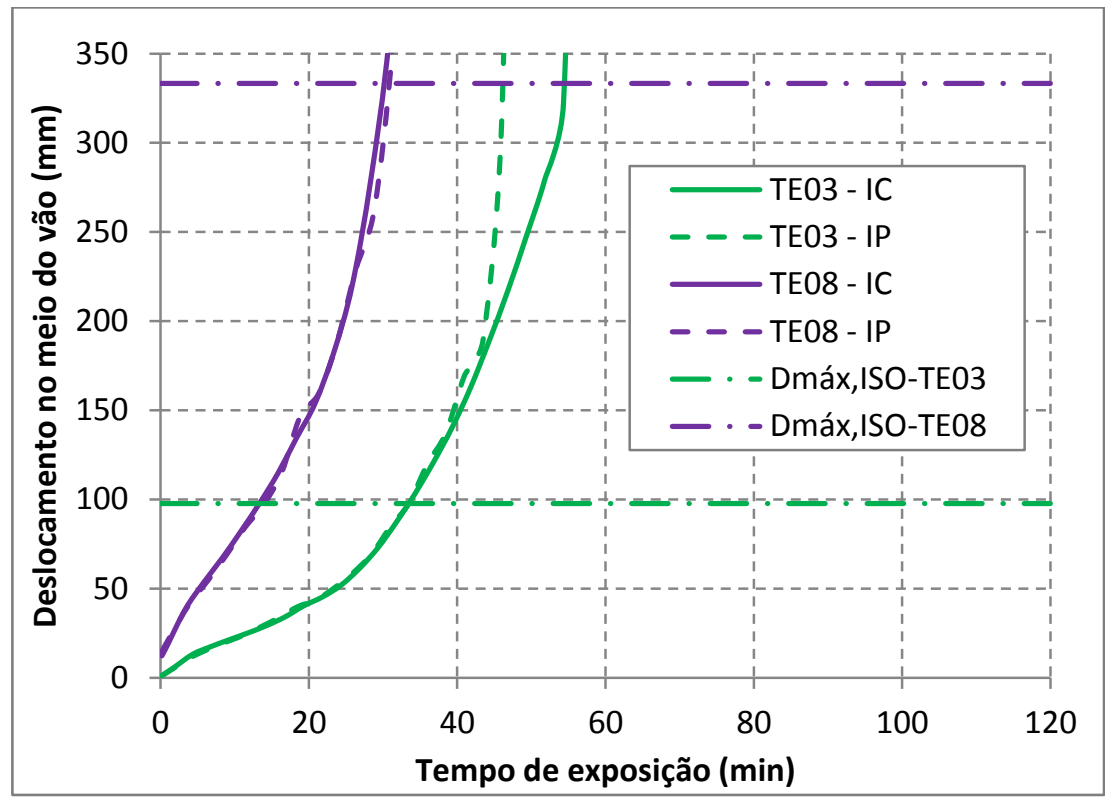

Figura 5.39 - Resultados numéricos para os modelos TE03 (Vão=2,5m) e TE08 (Vão=4,0m) ambos com altura total da laje de $120 \mathrm{~mm}$

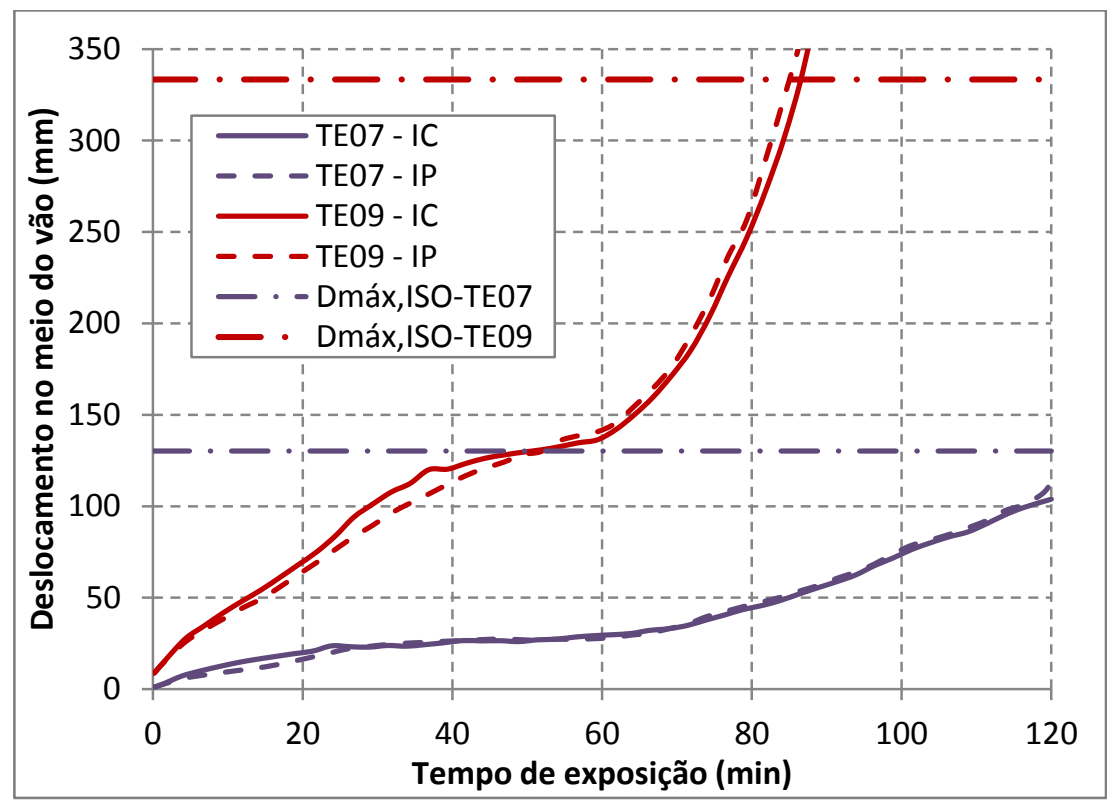

Figura 5.40 - Resultados numéricos para os modelos TE07 (Vão=2,5m) e TE09 (Vão=4,0m) ambos com altura total da laje de $120 \mathrm{~mm}$ e com armaduras positivas

Pela Figura 5.40 também se observa que com um maior vão entre apoios, a taxa de deslocamento vertical da laje é maior que no caso com menor vão, conforme esperado, porém o valor de deslocamento máximo permitido pela ISO 834:1999 não aumenta na mesma proporção, de modo que quanto maior o vão menor será o tempo de resistência ao fogo. Neste caso, o critério de taxa de deslocamento máxima passa a ser preponderante. 


\subsubsection{Influência da resistência característica do concreto}

Na Figura 5.41 são apresentados os resultados numéricos de deslocamento vertical no meio do vão versus tempo de exposição para os modelos TE03 (com resistência à compressão do concreto de 20MPa) e TE10 (com resistência à compressão do concreto de 40MPa), ambos sem armaduras positivas. Na Figura 5.42 são apresentados esses mesmos resultados, porém para os modelos TE07 e TE11, ambos com armaduras positivas.

Com o aumento da resistência à compressão do concreto também se tem um aumento do módulo de elasticidade do mesmo, neste caso é de se esperar um menor deslocamento vertical. Porém para deslocamentos verticais inferiores aos valores máximos estabelecidos pela ISO 834:1999 (Figura 5.41) não se observa diferenças expressivas entre os resultados. Esse comportamento ocorre devido principalmente à expansão térmica do modelo, que independe do módulo de elasticidade.

Já quando se adiciona uma armadura dentro da nervura da fôrma de aço (Figura 5.42) se observa um menor deslocamento vertical da laje após 30 minutos de exposição ao fogo para o caso com $f_{c k}=40 M P a$ (TE11) se comparado com modelo com $f_{c k}=20 M P a$ (TE07), porém também não foi observado ganho no tempo de resistência ao fogo. Esse menor deslocamento observado para o modelo TE11 pode ser explicado pelo fato do modelo ser mais rígido além de fissurar menos em relação ao modelo com resistência à compressão do concreto de $20 \mathrm{MPa}$ (TE07). Entretanto vale mencionar que a resistência à compressão do concreto influencia na umidade de equilíbrio final da laje, fenômeno este que não está sendo considerado nas análises numéricas.

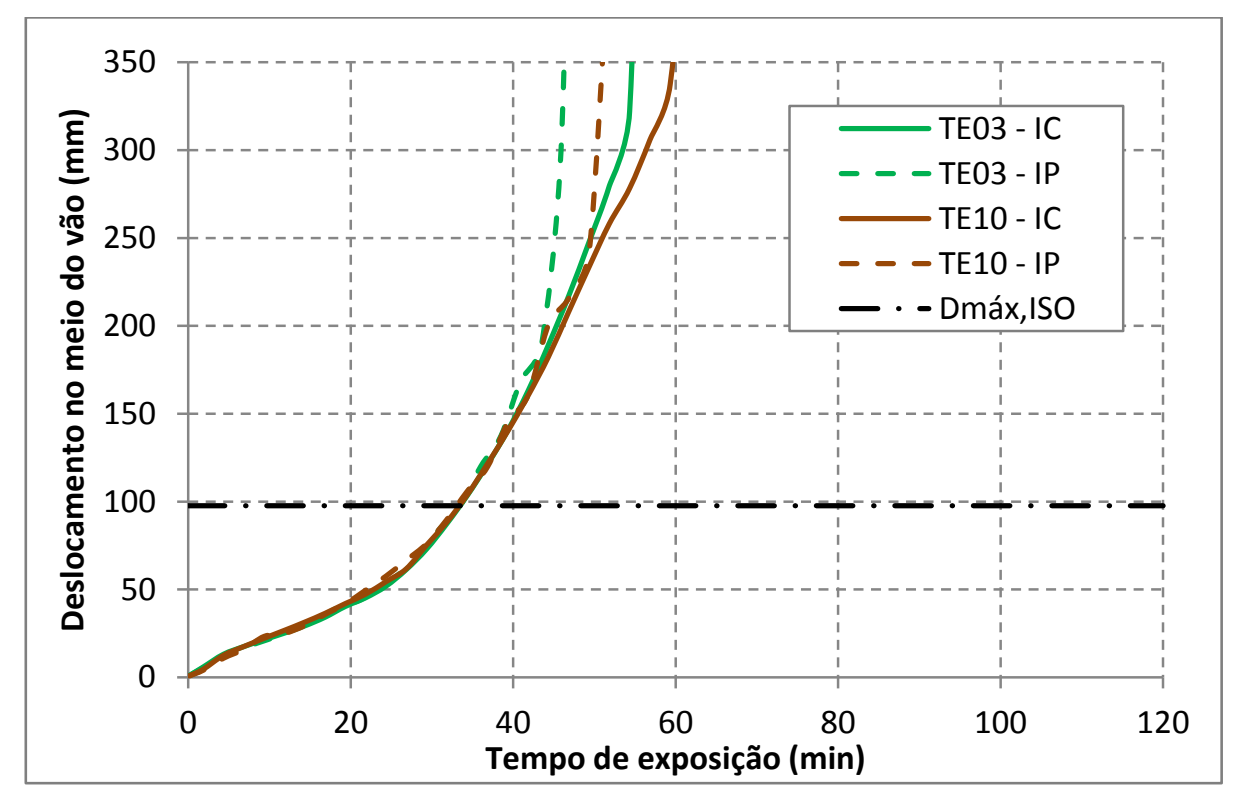

Figura 5.41 - Resultados numéricos para os modelos TE03 $\left(f_{c k}=20 M P a\right)$ e TE10 $\left(f_{c k}=40 M P a\right)$ 


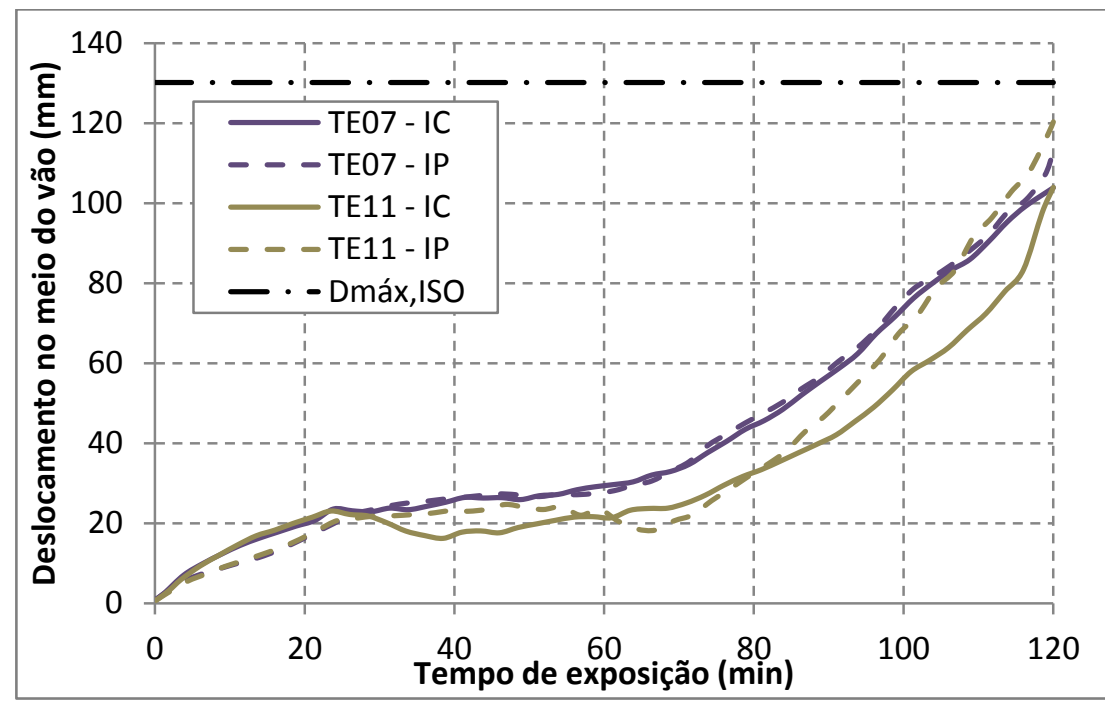

Figura 5.42 - Resultados numéricos para os modelos TE07 $\left(f_{c k}=20 M P a\right)$ e TE11 $\left(f_{c k}=40 M P a\right)$

\subsubsection{Resumo dos resultados}

Os resultados para o tempo de resistência atingido nos modelos numéricos termoestruturais para os casos com interação completa e parcial, bem como aqueles calculados pelo método do momento fletor plástico utilizando os campos de temperatura do modelo térmico bidimensional e pelo procedimento de cálculo da ABNT NBR 14323:2013 são apresentados na Figura 5.43. Como a ABNT NBR 14323:2013 somente permite calcular o momento fletor resistente para tempos de 60, 90 e 120 minutos e o tempo de resistência ao fogo pode ser considerado de no mínimo 30 minutos, desde que seja garantido o critério de isolamento térmico, os resultados de acordo com esta norma são apresentados para esses valores de tempo.

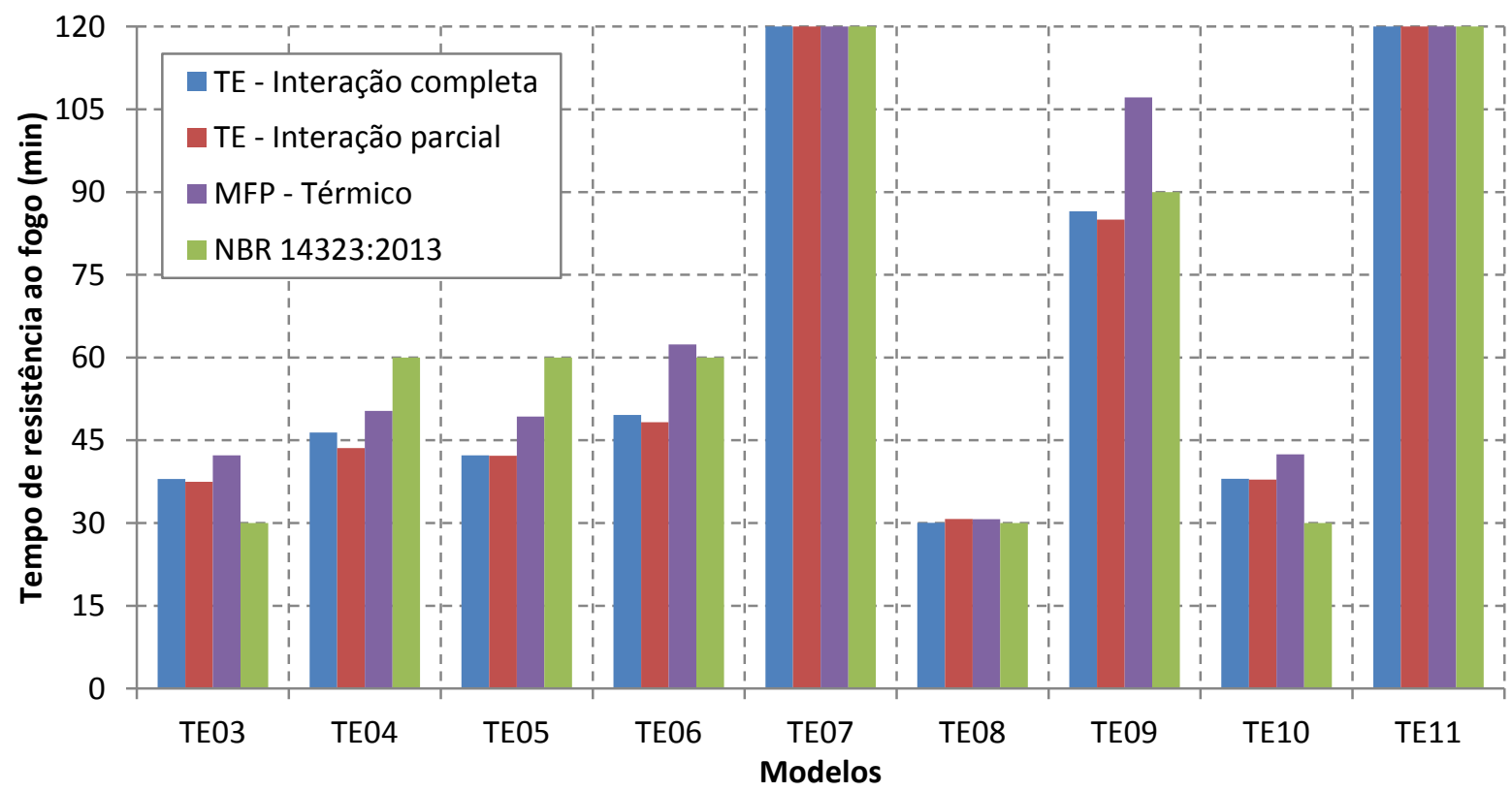

Figura 5.43 - Resultados para os tempos de resistência considerando os modelos com interação completa, interação parcial, momento plástico resistente do modelo térmico e a ABNT NBR 14323:2013 
Quatro modelos numéricos (TE04, TE05, TE06 e TE09) resultaram em tempos de resistência inferiores aos calculados de acordo a ABNT NBR 14323:2013. Isso se deve principalmente pelo fato de se ter adotado o critério de ruptura da ISO 834:1999 para cálculo do tempo de resistência ao fogo, sendo que os modelos numéricos continuaram resistindo para valores de deslocamentos bem superiores aos estabelecidos pela ISO.

Caso não seja estabelecido o critério de deslocamento para cálculo do tempo de resistência ao fogo e esse tempo seja truncado em valores de 30, 60, 90 e 120 minutos (TRRF), conforme os resultados numéricos apresentados nas Figuras 5.36 a 5.42, os valores dos TRRF calculados pelos modelos termoestruturais são os mesmos calculados de acordo a ABNT NBR 14323:2013. 


\section{CAPÍtulo 6}

\section{Conclusão e sugestões para trabalhos futuros}

\subsection{Conclusão}

Com base nos resultados obtidos referentes aos modelos numéricos construídos para fins de análises térmicas, estruturais e termoestruturais, pode-se concluir que:

\section{Da análise térmica}

A temperatura do concreto ficou bem representada numericamente, com relação aos resultados experimentais, quando se utilizou elementos de interface entre a fôrma de aço e o concreto para o caso em que a emissividade resultante entre a fôrma de aço e o incêndio é tomada igual a 0,70. Porém quando se considera o modelo numérico sem interface, a temperatura do concreto só resulta bem representada quando se utiliza a emissividade resultante dependente da temperatura e igual a 0,09 para temperaturas menores que $250^{\circ} \mathrm{C}$, 0,40 para temperaturas maiores que $800^{\circ} \mathrm{C}$ e variando linearmente entre esses 250 e $800^{\circ} \mathrm{C}$.

Para os resultados experimentais obtidos em ABDEL-HALIM et al. (1999), as temperaturas da fôrma de aço obtidas por meio dos modelos numéricos ficaram superiores àquelas obtidas experimentalmente. Entretanto se observou que houve uma tendência dos resultados numéricos se aproximarem dos experimentais quando se utiliza a emissividade resultante variável entre 0,09 e 0,40, bem como modelo numérico sem interface. Isso ocorre devido ao movimento de água entre a fôrma de aço e o concreto em situação de incêndio, que surgem devido à umidade do concreto, comportamento difícil de simular computacionalmente e requer modelos numéricos mais sofisticados.

Já para os resultados experimentais obtidos em GUO (2011) a evolução da temperatura da fôrma de aço com o tempo de exposição ao incêndio ficou bem representada 
numericamente quando se utilizou o modelo numérico com emissividade variável entre 0,09 e 0,40 e o modelo numérico sem interface.

Com relação às referências normativas, a temperatura da armadura obtida dos modelos numéricos sem interface entre a fôrma de aço e o concreto e a emissividade resultante igual a 0,70, para tempos de exposição ao incêndio iguais a 60, 90 e 120 minutos, foi superior àquela calculada de acordo o procedimento de cálculo apresentado na ABNT NBR 14323:2013 e o EUROCODE 4 (2005). Entretanto, os resultados obtidos de acordo os procedimentos de cálculo normativos apresentaram boa correlação quando se utiliza nos modelos numéricos emissividade variável entre 0,09 e 0,40. Porém tanto a ABNT NBR 14323:2013 quanto o EUROCODE 4 (2005) não mencionam nenhum caso com emissividade resultante diferente de 0,70 para o aço.

Pelos resultados numéricos também se observou que os modelos numéricos com interface adotando um coeficiente de condução térmica $\left(C_{r}\right)$ na ordem de $10000 \mathrm{~W} / \mathrm{m}^{2 \circ} \mathrm{C}$, equivale ao modelo numérico sem interface (mesmos campos térmicos). Para a determinação dos campos térmicos numericamente (correspondente à fase de aquecimento), recomenda-se a utilização do limite superior da curva de condutividade térmica apresentada na ABNT NBR 14323:2013 e no EUROCODE 4 (2005), já que neste caso os campos térmicos na seção transversal ficaram melhor representados com relação aos experimentais.

Dos resultados numéricos também se observou que uma maior diferença de temperatura da fôrma de aço para os diversos casos de emissividade e resistência térmica na interface, só é observada nos primeiros 60 minutos de exposição ao fogo. A partir desse tempo a emissividade não tem muita influência nos campos térmicos.

\section{Da análise do momento plástico resistente}

Quando se considera uma emissividade resultante de 0,70 o momento fletor resistente considerando somente a contribuição da fôrma de aço é reduzido para 15 a 18\% em relação ao calculado à temperatura ambiente aos 30 minutos de exposição. Esse resultado pode indicar a necessidade de utilização de armaduras positivas para garantir a resistência de lajes mistas simplesmente apoiadas em situação de incêndio.

O momento fletor resistente calculado numericamente, levando em conta somente a contribuição da fôrma de aço, é aproximadamente a metade daquele calculado pelos procedimentos normativos, para um tempo de exposição de 60 minutos. Entretanto para 90 e 120 minutos esses resultados se correlacionam melhor. Porém, vale mencionar que o modelo numérico aqui proposto não simula adequadamente o movimento de água na laje mista, sendo que nos ensaios experimentais foi observado que esse comportamento reduz a temperatura da fôrma de aço.

Quando se considerou somente a contribuição da armadura positiva, somente se observou redução do momento fletor resistente após 40 minutos de exposição ao fogo, porém 
esse tempo depende da geometria da laje e da posição da armadura. Nesse caso os resultados para o momento fletor resistente calculados de acordo a ABNT NBR 14323:2013 melhor se correlacionaram com os numéricos quando se adotou uma emissividade resultante entre $0,09 \mathrm{e}$ 0,40 e o modelo numérico sem interface. Entretanto essa mesma norma recomenda a utilização de uma emissividade resultante de 0,70, independentemente da faixa de temperatura.

Os resultados obtidos da análise do momento fletor positivo resistente em situação de incêndio mostraram que há um posicionamento da armadura no interior do concreto que oferece maior resistência à flexão da laje. Essa posição depende de diversos fatores como a altura total da laje, da altura da fôrma de aço, da emissividade resultante, da área da armadura positiva e principalmente do tempo requerido de resistência ao fogo, de modo que quanto maior a influência desses fatores na determinação da temperatura da armadura, essa deve estar posicionada mais próxima da face superior da laje (face não exposta ao fogo). Porém para cada caso deve ser feita uma análise adicional, uma vez que quando se aproxima a armadura da face superior da laje está reduzindo a resistência em temperatura ambiente.

\section{$>$ Do modelo estrutural à temperatura ambiente}

Os resultados numéricos quando se utiliza o modelo com interação completa entre a fôrma de aço e o concreto não se correlacionaram bem com os experimentais, entretanto quando se utiliza o modelo numérico com interface os resultados numéricos e experimentais se correlacionam bem.

Foram avaliados dois modelos constitutivos para quantificar o valor da resistência ao cisalhamento longitudinal na interface, o modelo bond-slip e o de rigidez linear. $\mathrm{O}$ valor da resistência ao cisalhamento longitudinal na interface calibrada para o modelo numérico, adotando o modelo constitutivo bond-slip, variou entre 10.000 a $30.000 \mathrm{~N} / \mathrm{m}^{2}$. Entretanto, no modelo bond-slip, essa resistência é multiplicada por 1,9, conforme apresentado na Equação 3.4. Já com relação à interface com rigidez linear, valores entre $10 \times 10^{6}$ e $20 \times 10^{6} \mathrm{~N} / \mathrm{m}^{3}$ para o parâmetro de rigidez tangencial à interface $\mathrm{D}_{22}$, melhor se ajustou aos resultados experimentais. Essa faixa pode ser justificada pelas diferentes resistências características do concreto e conformação das mossas da fôrma de aço. Para ambos os modelos se observou que é recomendado utilizar valores altos para o parâmetro de rigidez normal à interface D11, na ordem de $10^{18} \mathrm{~N} / \mathrm{m}^{2}$.

Os resultados numéricos considerando modelo bond-slip melhor se ajustou aos resultados experimentais quando comparado com os resultados dos modelos de interface com rigidez linear, principalmente se referindo ao deslocamento relativo de extremidade entre a fôrma de aço e o concreto. Entretanto, vale mencionar que os valores apresentados para os parâmetros de resistência na interface foram calibrados por meio de resultados experimentais sem ancoragens de extremidade, portanto esses valores podem ser diferentes ou mesmo garantir resistência completa na interface caso sejam adotados mecanismos para melhorar a resistência ao cisalhamento longitudinal na interface. 
Também se observou que não houve diferenças significativas entre os resultados dos modelos numéricos com simetria e o modelo completo. Entretanto o modelo completo demanda elevado custo computacional e gera arquivos de resultados muito "pesados" que rapidamente consome toda memória do computador.

A utilização de chapas para aplicação das condições de contorno em deslocamento na vertical melhorou a distribuição e tensões próximas ao apoio, melhorando a convergência dos modelos numéricos. Entretanto não houve diferenças no comportamento global da laje quando se utiliza ou não chapas de apoio.

\section{Do modelo termoestrutural}

Os resultados dos modelos numéricos termoestruturais com emissividade variável entre 0,09 e 0,40 apresentaram melhores correlações com os experimentais. Isso já era esperado pelas análises térmicas realizadas previamente, uma vez que essa consideração resultara em uma melhor distribuição dos campos térmicos na seção transversal da laje mista quando comparada com os resultados experimentais.

Os modelos termoestruturais com elementos de interface não apresentaram melhoras nos resultados numéricos quando comparados com os experimentais, sendo que neste caso os modelos numéricos com interação parcial previam deslocamentos verticais superiores. Isso ocorre em resposta à maior expansão térmica da fôrma de aço quando se considera interação parcial, devido à sua maior temperatura, em relação aos casos com interação completa. Os modelos numéricos com interação parcial também apresentaram dificuldade para convergir, neste caso era necessário rever os critérios de convergência adotados, como número de iteração máxima e passos de carga, e reprocessar o modelo.

Para baixos fatores de carga (menores que 0,25) ou quando se considera armadura positiva na laje, os resultados numéricos considerando interação parcial ou completa foram parecidos, pois neste caso não há deslocamento relativo significativo na interface entre a fôrma de aço e o concreto.

O aumento da espessura da fôrma de aço se mostrou pouco eficiente no aumento do tempo de resistência ao fogo. Já quando se tem a presença de armaduras positivas esse tempo é aumentado consideravelmente. Também não foi observado ganho significativo de resistência ao fogo quando se tem um aumento na resistência à compressão do concreto de 20MPa para 40MPa.

A relação entre o vão entre apoios e a altura total da laje determinará qual será o modo de falha do modelo, de modo que quanto maior esta relação menor há uma influência das tensões de cisalhamento entre a fôrma de aço e o concreto. Neste caso a ruptura dos modelos ocorre predominantemente por flexão, não havendo diferenças significativas entre os resultados com interação completa ou parcial. 
Os tempos de resistência ao fogo obtidos dos modelos termoestruturais foram inferiores ou iguais àqueles calculados pelo modelo de cálculo da ABNT NBR 14323:2013, cujo procedimento é o mesmo adotado pelo EUROCODE 4 (EN 1994-1-2:2005), o que não era esperado. Isso se deve principalmente ao critério de ruptura da ISO 834:1999 adotado, que prevê deslocamento máximo e taxa máxima de deslocamento em temperaturas elevadas, sendo que para esta consideração a seção transversal da laje não se plastificou totalmente e os modelos numéricos continuaram resistindo às ações termomecânicas para deslocamentos superiores aos estabelecidos pela ISO.

Caso não sejam estabelecidos critérios em deslocamento para determinar a resistência ao fogo das lajes mistas, adotando neste caso a resistência referente ao instante em que o modelo numérico para de convergir, os TRRFs calculados por meio dos resultados dos modelos termoestruturais são idênticos àqueles calculados pela ABNT NBR 14323:2013. Logo, para cálculo da resistência das lajes mistas simplesmente apoiadas em situação de incêndio a norma brasileira (ABNT NBR 14323:2013) não apresentou resultados antieconômicos quando comparados com os numéricos, conforme era esperado inicialmente.

\subsection{Sugestões para trabalhos futuros}

Tendo em vista as considerações feitas durante a realização do trabalho, são propostas algumas sugestões para trabalhos futuros, visando aperfeiçoar o modelo numérico e dar continuidade ao tema em estudo:

- Construção de modelos numéricos com o uso de elementos do tipo shell para representação da fôrma de aço;

- Realização de ensaios em lajes mistas simplesmente apoiadas em temperaturas elevadas, no intuito de definir valores de resistência ao cisalhamento da interface dependentes da temperatura, deslocamento relativo e resistência do concreto, nos casos em que não se tem a presença de conectores de cisalhamento;

- Realizar novos estudos considerando o efeito de membrana e lajes contínuas;

- Analisar a influência da proteção passiva em lajes mistas bem como uma avaliação do fator econômico;

- Estudar casos considerando concreto de baixa densidade e com fibras. 



\section{Referências Bibliográficas}

ABDEL-HALIM, M. A. H.; HAKMI, M. R.; O'LEARY, D. C. (1999). Fire resistance of composite floor slabs using a model fire test facility. Engineering Structures 21 (2), p. 176182.

AMERICAN SOCIETY TESTING AND MATERIALS. ASTM E119: Standard test methods for fire tests of building construction and materials. West Conshohocken, 2000.

ARAUJO, G. S. (2008). Análise do comportamento e da resistência de um sistema de lajes mistas pelo método da interação parcial. 136p. Dissertação (Mestrado) Universidade Federal de Minas Gerais, Belo Horizonte.

ASSOCIAÇÃO BRASILEIRA DE NORMAS TÉCNICAS. ABNT NBR 14323 (2013): Projeto de estruturas de aço e de estruturas mistas de aço e concreto de edifícios em situação de incêndio. Rio de Janeiro.

. ABNT NBR 14432 (2001): Exigências de resistência ao fogo de elementos construtivos de edificações - Procedimento. Rio de Janeiro.

ABNT NBR 15200 (2012): Projeto de estruturas de concreto em situação de incêndio. Rio de Janeiro.

ABNT NBR 6118 (2007) - Projeto de estruturas de concreto - Procedimento. Rio de Janeiro.

ABNT NBR 8800 (2008): Projeto e execução de estruturas de aço de edifícios. Rio de Janeiro.

ABNT NBR 14762 (2010): Dimensionamento de estruturas de aço constituídas por perfis formados a frio. Rio de Janeiro.

ALVA, G. M. S. (2000). Sobre o projeto de edifícios em estrutura mista aço-concreto. 296 p. Dissertação (Mestrado) - Escola de Engenharia de São Carlos, Universidade de São Paulo, São Carlos.

BAILEY C. G.; TOH W. S. (2007). Behaviour of concrete floor slabs at ambient and elevated temperatures. Fire Safety Journal 42 (6-7), p. 425-436. 
BOTH, C., FELLINGER, J.H.H., TWILT, L. (1997). Shallow floor construction with deep composite deck: from fire tests to simple calculation rules. TNO Building and Construction Research, Centre for Fire Research. Delft, Netherlands.

BUCHANAN, A. H. (2002). Structural design for FIRE safety. John Wiley \& Sons; Chichester.

BRE - BUILDING RESEARCH ESTABLISHMENT LTDA (2005). The Integrity of Compartmentation in Building During a Fire. 174p. Project report number 213140(1), Cardington, Reino Unido.

CASHELL, K. A.; ELGHAZOULI, A. Y.; IZZUDDIN, B. A. (2010). Ultimate behavior of idealized composite floor elements at ambient and elevated temperature. Fire Technology 46 (1), p. 67-89.

CEB-FIP. Model code 90 (1990). First draft, Committee euro-international du beton, Bulletin d'information No. 195, 196.

CHEN, S.; SHI, X. (2011). Shear bond mechanism of composite slabs - A universal FE approach. Journal of Constructional Steel Research 67 (10), p. 1475-1484.

COSTA, c. n. (2008). Dimensionamento de elementos de concreto armado em situação de incêndio. 405 p. Tese (Doutorado) - Escola Politécnica da Universidade de São Paulo, São Paulo.

CREA-RS (2013). Conselho Regional de Engenharia e Agronomia do Rio Grande do Sul. Relatório técnico - Análise do sinistro na boate Kiss, em Santa Maria, RS. Porto Alegre, Rio Grande do Sul.

CRISINEL, M.; O'LEARY, D. (1996). Composite floor slab design and construction. Structural Engineering International, v.6, n.1, p. 41-6.

De NARDIN, S. et al. (2005). Estruturas mistas aço-concreto: origem, desenvolvimento e perspectivas. In: $\mathbf{4 7}^{\circ}$ CONGRESSO BRASILEIRO DO CONCRETO, 2005, Olinda. $47^{\circ}$ CONGRESSO BRASILEIRO DO CONCRETO - CBC2005. Olinda : Jacintho, A. E. P. G. A.; Monteiro, E. C. B.; Bittencourt, T. N., 2005. v. IV. p. IV69-IV84.

DIANA. (2005a) Finite Element Analysis: Users Manual release 9 - Analysis Procedures. Delft, Netherlads: TNO DIANA, 636p.

DIANA. (2005b) Finite Element Analysis: Users Manual release 9 - Element Library. Delft, Netherlads: TNO DIANA, 662p.

DIANA. (2005c) Finite Element Analysis: Users Manual release 9 - Getting Started. Delft, Netherlads: TNO DIANA, 144p.

DIANA. (2005d) Finite Element Analysis: Users Manual release 9 - Material Library. Delft, Netherlads: TNO DIANA, 534p. 
EUROPEAN COMMITTEE FOR STANDARDIZATION (2002). prEN 1991-1-2: Eurocode 1 - Basis of design and actions on structures. Part 1-2: Actions on structurs - Actions on structures exposed to fire, final draft, Brussels.

EUROPEAN COMMITTEE FOR STANDARDIZATION (2005). EN 1993-1-1:2005 Eurocode 3 - Design of steel structures. Part 1-1: General rules and rules for buildings. Stage 34 draft, Brussels.

. EN 1993-1-2:2005 Eurocode 3 - Design of Steel Structures. Part 1-2: General rules Structural Fire Design. Brussels.

EN 1994-1-2:2005 Eurocode 4 - Design of composite steel and concrete structures. Part 1-2: General rules - Structural Fire Design. Brussels.

FEENSTRA, P. H. (1993). Computational Aspects of Biaxial Stress in Plain and Reinforced Concrete. 159 p. PhD thesis, Delft University of Technology.

FERRAZ, C. B. (1999). Análise do comportamento e da resistência do sistema de lajes mistas. 168 p. Dissertação (Mestrado) - Escola de Engenharia, Universidade Federal de Minas Gerais, Belo Horizonte.

GUO, S. (2011). Experimental and numerical study on restrained composite slab during heating and cooling. Journal of Constructional Steel Research 69 (2012), p. 95-105.

GUO, S.; BAILEY C. G. (2011). Experimental behaviour of composite slabs during the heating and cooling fire stages. Engineering Structures 33 (2), p. 563-571.

HUANG, Z. (2010). Modelling the bond between concrete and reinforcing steel in a fire. Engineering Structures 32 (11), p. 3660-3669.

INTERNATIONAL STANDARD. ISO 834-1:1999: Fire-resistance tests - Elements of building construction — Part 1: General requirements. Genève, Switzerland, 1999.

KIMURA, E. F. A. (2009). Análise termo-estrutural de pilares de aço em situação de Incêndio. 225 p. Dissertação (Mestrado) - Escola de Engenharia de São Carlos, Universidade de São Paulo, São Carlos.

KIRCHHOF, L. D. (2004). Uma contribuição ao estudo de vigas mistas aço-concreto simplesmente apoiadas em temperatura ambiente e em situação de incêndio. 142 p. Dissertação (Mestrado) - Escola de Engenharia de São Carlos, Universidade de São Paulo, São Carlos.

LAMONT, S; USMANI, A. S; DRYSDALE, D. D. (2001). Heat transfer analysis of the composite slab in the Cardington frame fire tests. Fire Safety Journal 36 (2001) 815-839. School of Civil and Environmental Engineering, Edinburgh University, UK.

LAWSON, R.M. (2001). Fire engineering design of steel and composite buildings (Review). Journal of Constructional Steel Research, v 57, n 12, p 1233-1247. 
MARTINS, M. M. (2000). Dimensionamento de estruturas de aço em situação de incêndio. 232 p. Dissertação (Mestrado) - Escola de Engenharia, Universidade Federal de Minas Gerais. Belo Horizonte, Minas Gerais.

MORENO JUNIOR, A. L. (2013). Caracterização de concreto, com e sem adição de fibras de aço, sob temperaturas elevadas. Relatório de ensaios - CODEME Engenharia S.A, Betim, Minas Gerais.

POTHISIRI, T.; PANEDPOJAMAN, P. (2012). Modeling of bonding between steel rebar and concrete at elevated temperatures. Construction and Building Materials 27 (1), p. 130-140.

RAMOS, A.L. (2010). Análise numérica de pisos mistos aço-concreto de pequena altura. 138 p. Dissertação (Mestrado) - Escola de Engenharia de São Carlos, Universidade de São Paulo. São Carlos, São Paulo.

REGOBELlO, R. (2007). Análise numérica de seções transversais e de elementos estruturais de aço e mistos de aço e concreto em situação de incêndio. 269 p. Dissertação (Mestrado) - Escola de Engenharia de São Carlos, Universidade de São Paulo. São Carlos, São Paulo.

RIBEIRO, J. C. L. (2004). Simulação via método dos elementos finitos da distribuição tridimensional de temperatura em estruturas em situação de incêndio. Dissertação (Mestrado) - Escola de Engenharia, Universidade Federal de Minas Gerais. Belo Horizonte, Minas Gerais.

ROCHA, F. M. (2012). Modelos numéricos de vigas mistas de aço e concreto pertencentes a sistemas de pisos mistos de baixa altura em situação de incêndio. 269 p. Dissertação (Mestrado) - Escola de Engenharia de São Carlos, Universidade de São Paulo, São Carlos.

SANTOS, D. B. R.; MUNAIAR NETO, J. (2013). Análise numérica de lajes mistas de aço e concreto em situação de incêndio: Influência dos campos térmicos no método do momento fletor plástico. In: XXXIV CILAMCE - Congresso Iberolatinoamericano de mecânica computacional em engenharia. Pirenópolis, Goiás, Brasil.

SILVA, V. P. (2001). Estruturas de aço em situação de incêndio. São Paulo, Zigurarte;

SSEDTA, Structural Steelwork Eurocodes - Development of a Trans-National Approach (2001). Course: Eurocode 4.

WALD F. et al. (2006). Experimental behaviour of a steel structure under natural fire. Fire Safety Journal, v 41, n 7 p 509-522.

WANG, Y. C. (2002). Steel and Composite Structures - Behaviour and Design for Fire Safety. Spon Press, London.

WANG, Y. C. (2005). Performance of steel-concrete composite structures in fire (Review). Progress in Structural Engineering and Materials, v 7, n 2, p 86-102. 
Referências Bibliográficas 

Anexos 



\section{Anexo A - Os processos de transferência de calor}

\section{A.1. Condução}

Quanto maior a temperatura do material maior é a agitação de suas moléculas e, consequentemente, maior a energia cinética molecular. Regiões com maior energia cinética molecular transferem essa energia para regiões de menor energia por meio de colisões moleculares. Esse processo é conhecido como condução. Na condução não existe movimento macroscópico de matéria.

Considerando um caso unidimensional e estacionário (Figura A.1), o fluxo de calor ao longo da espessura do material é expresso segundo a lei de Fourier, apresentada na Equação A.1.

$$
\dot{Q}=-\lambda \frac{d T}{d x}
$$

Na Equação A.1, $\lambda$ é a condutividade térmica do material e $d T$ é a diferença de temperatura ao longo da espessura infinitesimal $d x$ (Figura A.1).

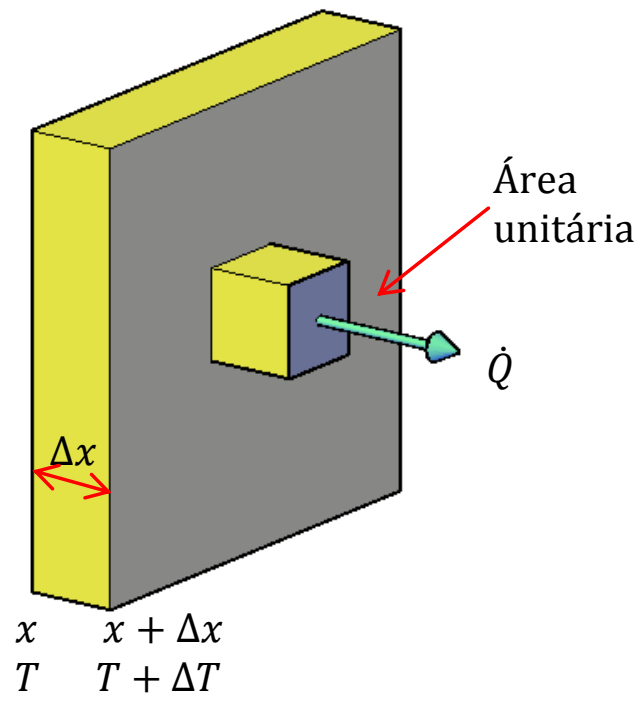

Figura A.1 - Transferência de calor por condução (caso unidimensional)

Aproximando a condutividade térmica como constante, dentro dos limites de temperatura estabelecidos, obtém-se a equação de diferenças finitas equivalentes:

$$
\dot{Q}=-\lambda \frac{T_{2}-T_{1}}{\Delta x}
$$

Onde $T_{1}$ e $T_{2}$ são as temperaturas em ambos os lados do material e $\Delta x$ a espessura. 
Para o caso de um material formado por " $n$ " camadas de materiais diferentes, conforme apresentado na Figura A.2, o fluxo de calor em cada camada é o mesmo. Logo, tem-se que:

$$
\begin{gathered}
\dot{Q}=-\lambda_{12} \frac{T_{2}-T_{1}}{\Delta x_{12}}=-\lambda_{23} \frac{T_{3}-T_{2}}{\Delta x_{23}}=\cdots-\lambda_{i, i+1} \frac{T_{i+1}-T_{i}}{\Delta x_{i, i+1}} \ldots \\
=-\lambda_{n, n+1} \frac{T_{n+1}-T_{n}}{\Delta x_{n, n+1}}
\end{gathered}
$$

Onde,

$T_{i}$ e $T_{i+1}$ são as temperaturas em ambos os lados da camada "i";

$\Delta x_{i, i+1}$ é a espessura da camada "i".

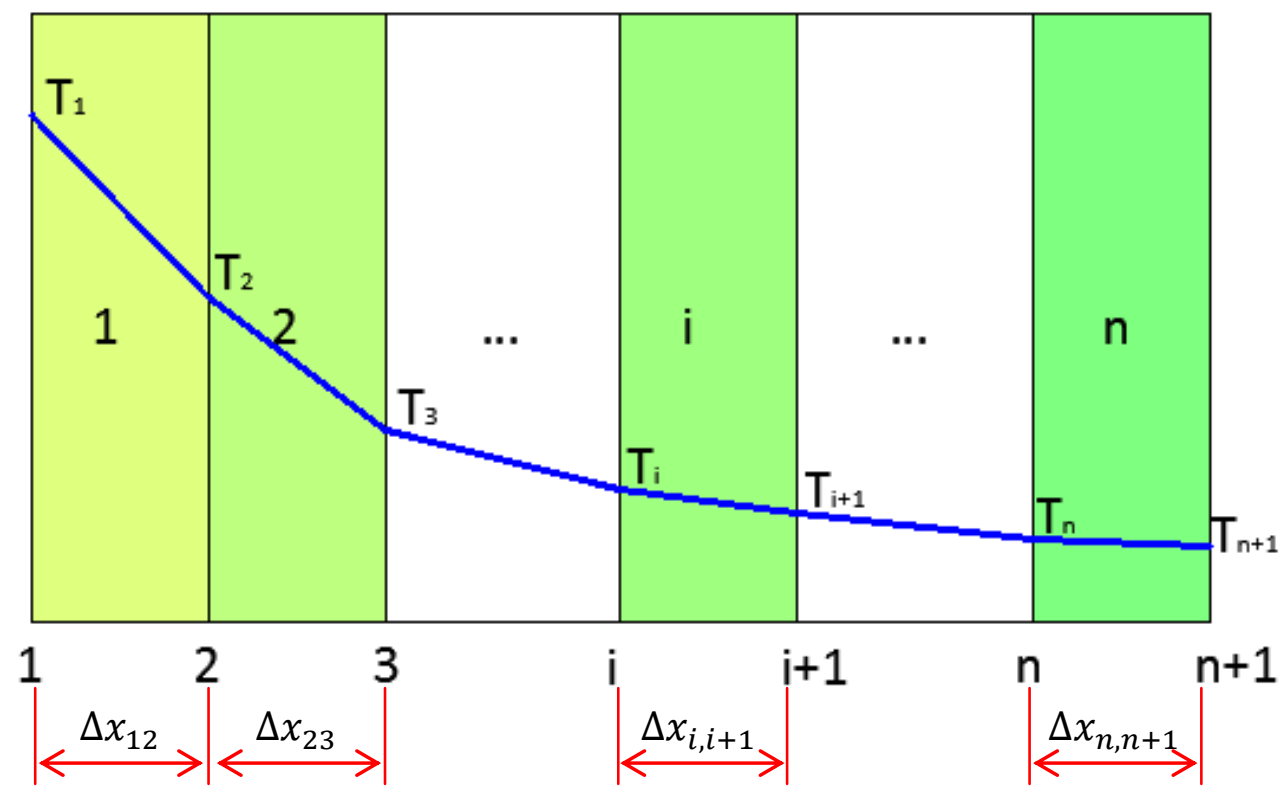

Figura A.2 - Transferência de calor por condução em um material compósito (Modificado de WANG, 2002)

Trabalhando com a Equação A.3, é possível demonstrar que a diferença de temperatura entre as extremidades do material é dada pela Equação A.4, em que a relação $\frac{\Delta x_{i, i+1}}{\lambda_{i, i+1}}$ expressa a resistência térmica da camada "i”".

$$
T_{1}-T_{n+1}=\dot{Q} \sum_{i=1}^{n} \frac{\Delta x_{i, i+1}}{\lambda_{i, i+1}}
$$

Pela Equação A.4 conhecendo-se a temperatura nas extremidades do material é possível calcular o fluxo de calor $(\dot{Q})$. Porém em aplicações de segurança contra incêndio as temperaturas nas faces externas de um elemento não são conhecidas. Entretanto a temperatura 
dos gases em contato com este elemento é conhecida, logo é possível determinar a distribuição de temperatura ao longo do elemento.

Supondo que a face 1 (Figura A.2) esteja em contato com o fogo e a face " $n+1$ " não exposta ao fogo, o fluxo de calor entre os gases aquecidos e a face 1 e o fluxo de calor entre a face " $n+1$ " e a temperatura ambiente são dados pelas Equações A.5 e A.6 respectivamente.

$$
\begin{aligned}
& \dot{Q}=h_{f i}\left(T_{f i}-T_{1}\right) \\
& \dot{Q}=h_{a}\left(T_{n+1}-T_{a}\right)
\end{aligned}
$$

Nas Equações A.5 e A.6, valem:

$h_{f i}$ - Coeficiente de troca de calor entre os gases aquecidos e a superfície do material, com valor dependendo da transferência de calor por convecção e radiação;

$h_{a}$ - Coeficiente de troca de calor entre a superfície não exposta ao fogo e o ambiente, com valor dependendo da transferência de calor por convecção e radiação;

$T_{f i}$ - Temperatura dos gases aquecidos;

$T_{a}$ - Temperatura do ambiente.

Trabalhando com as Equações A.3, A.5 e A.6, se chega à Equação A.7. Nesta Equação somente o fluxo de calor $(\dot{Q})$ é desconhecido. Portanto, o primeiro passo para a determinação da distribuição de temperatura ao longo do elemento consiste em calcular o fluxo de calor pela Equação A.7 e, em seguida, calcular a temperatura em cada extremidade das camadas pelas Equações A.3, A.5 e A.6.

$$
T_{f i}-T_{a}=\dot{Q}\left(\frac{1}{h_{f i}}+\sum_{i=1}^{n} \frac{\Delta x_{i, i+1}}{\lambda_{i, i+1}}+\frac{1}{h_{a}}\right)
$$

Para o caso tridimensional considere um elemento infinitesimal de comprimentos $d x$, $d y$ e $d z$ apresentado na Figura A.3.

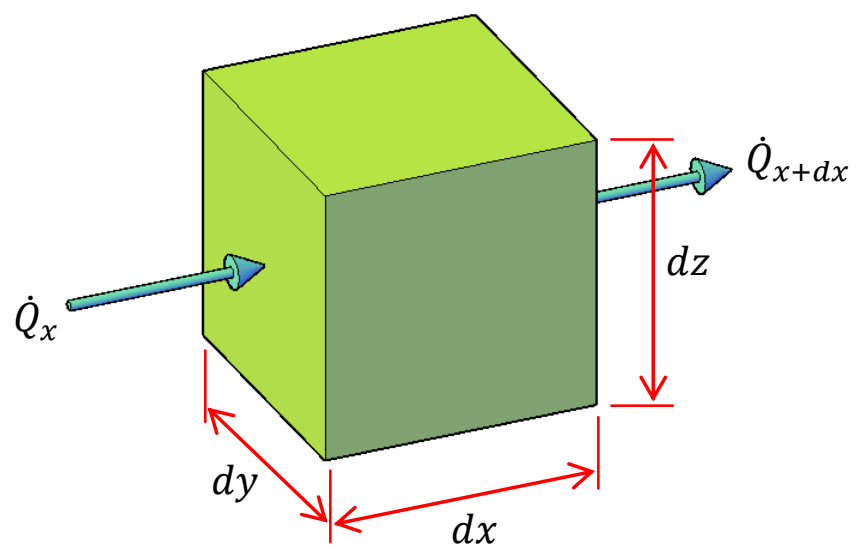

Figura A.3 - Transferência de calor por condução em um elemento infinitesimal 
O fluxo de calor na direção $x$ que entra e sai desse elemento infinitesimal são dados pelas Equações A.8 e A.9 respectivamente.

$$
\begin{aligned}
& \dot{Q}_{x}=-\lambda_{x} \frac{\partial T}{\partial x} d y d z \\
& \dot{Q}_{x+d x}=-\lambda_{x+d x} \frac{\partial\left(T+\frac{\partial T}{\partial x} d x\right)}{\partial x} d y d z
\end{aligned}
$$

Tomando o fluxo de calor líquido na direção $x$, dado pela diferença entre o fluxo de calor que sai e entra no elemento infinitesimal, e assumindo que a condutividade térmica é constante no domínio desse elemento $\left(\lambda_{x}=\lambda_{x+d x}\right)$, tem-se a Equação A.10.

$$
\Delta \dot{Q}_{x}=\dot{Q}_{x+d x}-\dot{Q}_{x}=-\lambda_{x} \frac{\partial^{2} T}{\partial x^{2}} d x d y d z
$$

De forma análoga, os fluxos de calor líquido nas direções $y$ e $z$ são dados pelas Equações A.11 e A.12 respectivamente.

$$
\begin{aligned}
\Delta \dot{Q}_{y} & =-\lambda_{y} \frac{\partial^{2} T}{\partial y^{2}} d x d y d z \\
\Delta \dot{Q}_{z} & =-\lambda_{z} \frac{\partial^{2} T}{\partial z^{2}} d x d y d z
\end{aligned}
$$

Pelo princípio de conservação da energia, a equação para a condução de calor no estado estacionário se dá por meio da Equação A.13.

$$
\Delta \dot{Q}_{x}+\Delta \dot{Q}_{y}+\Delta \dot{Q}_{z}=0 \rightarrow \lambda_{x} \frac{\partial^{2} T}{\partial x^{2}}+\lambda_{y} \frac{\partial^{2} T}{\partial y^{2}}+\lambda_{z} \frac{\partial^{2} T}{\partial z^{2}}=0
$$

No caso transiente a temperatura varia com o tempo, havendo uma parcela adicional de energia para elevar a temperatura do elemento infinitesimal, dada por $\rho C \frac{\partial T}{\partial t} d x d y d z$. Assim a equação de condução de calor para o caso transiente é dada pela Equação A.14, em que $\rho$ é a densidade do material e $C$ o calor específico.

$$
\lambda_{x} \frac{\partial^{2} T}{\partial x^{2}}+\lambda_{y} \frac{\partial^{2} T}{\partial y^{2}}+\lambda_{z} \frac{\partial^{2} T}{\partial z^{2}}=\rho C \frac{\partial T}{\partial t}
$$

\section{A.2. Convecção}

Segundo WANG (2002) convecção é a transferência de calor que ocorre na interface de um fluido e uma superfície sólida, devida ao movimento desse fluido. Assim, para que haja a troca de calor por convecção, é necessário que o fluido aquecido esteja em contato com o sólido. A convecção pode ocorrer de duas maneiras: forçada ou natural. 
Na convecção forçada, a troca de calor ocorre devido ao movimento de um fluido aquecido em contato com o sólido, sob a influência de alguma força externa. Já na convecção natural a troca de calor ocorre devido ao movimento de um fluido ocasionado pelo gradiente densidade, quando existe um gradiente de temperatura.

De modo geral o fluxo de calor por convecção é proporcional à diferença de temperatura dos gases aquecidos $\left(T_{g}\right)$ e a temperatura na superfície do elemento $\left(T_{m}\right)$, dado pela Equação A.15, em que $\alpha_{c}$ é o coeficiente de transferência de calor por convecção.

$$
\dot{Q}=\alpha_{c}\left(T_{g}-T_{m}\right)
$$

Esse coeficiente depende de diversos fatores, tais como a velocidade dos gases na interface com o sólido (indicando se o escoamento é laminar ou turbulento), diferença de temperatura entre os gases e a superfície do sólido $(\Delta T)$, viscosidade, densidade, calor específico, condutividade térmica, etc. Dessa forma, o cálculo preciso desse coeficiente se torna muito trabalhoso. Felizmente, na maioria dos casos práticos envolvendo problema de transferência de calor, é possível tomar algumas simplificações, devido a alguns critérios como seguem (WANG, 2002):

- A radiação é o mecanismo dominante da transferência de calor;

- O cálculo da temperatura não será muito sensível mesmo a uma grande variação em $\alpha_{c}$

- O processo de convecção se deve, principalmente, à convecção natural;

- Na interface entre os gases aquecidos e o elemento o processo de convecção é usualmente turbulento.

Adotando esses critérios, tem-se que o coeficiente de transferência de calor por convecção para a face em contato com o fogo e a face em contato com o ar são dados pelas Equações A.16 e A.17 respectivamente.

$$
\begin{aligned}
& \alpha_{c, f i}=\zeta(\Delta T)^{1 / 3} \\
& \alpha_{c, a r}=\zeta(\Delta T)^{1 / 4}
\end{aligned}
$$

Nas Equações A.16 e A.17, $\zeta$ é um coeficiente que depende de diversos parâmetros (mencionados anteriormente para o cálculo de $\alpha_{c}$ ). Segundo WANG (2002), para a superfície em contato com o fogo o valor de $\zeta$ varia entre 0,6 e 1,0 (podendo tomar 1,0 a favor da segurança) e para a face em contato com o ar o valor de $\zeta$ vale aproximadamente 2,2.

\section{A.3. Radiação}

Radiação é a transferência de calor devido às ondas eletromagnéticas que podem ser absorvidas, transmitidas ou refletidas em uma superfície. Segundo WANG (2002) a quantidade de radiação de cada uma dessas parcelas depende da temperatura, do comprimento de onda eletromagnética e das propriedades do corpo atingido pela radiação. Quando toda radiação incidente é absorvida pelo corpo, esse é chamado de "corpo negro", que também é 
um emissor perfeito. A quantidade de radiação emitida por uma superfície de corpo negro $\left(E_{b}\right)$ é dada pela lei de Stefan-Boltzmann, Equação A.18, em que $\sigma$ é a constante de StefanBoltzmann (igual a $5,67.10^{-8} \mathrm{~W} / \mathrm{m}^{2} \mathrm{~K}^{4}$ ) e T é a temperatura absoluta em $\mathrm{K}$.

$$
E_{b}=\sigma T^{4}
$$

Entretanto nenhum corpo real emite ou absorve toda radiação de acordo com a lei do corpo negro. Assim se adiciona um novo parâmetro na Equação A.18, conhecido como emissividade $(\varepsilon)$. A emissividade representa a relação entre a radiação total emitida pela superfície e aquela emitida pela superfície de corpo negro. Portanto, a radiação total emitida por uma superfície geral é dada pela Equação A.19.

$$
E=\varepsilon \sigma T^{4}
$$

Se a emissividade for independente do comprimento de onda da energia radiante, da temperatura da superfície e do ângulo de incidência, a superfície radiante é chamada de superfície de corpo cinza, adotada em problemas de engenharia de incêndio. Segundo WANG (2002) a solução analítica para problemas de troca de calor entre superfícies de corpo cinza somente existe para casos muito simples, como o exemplo de duas placas paralelas. Neste caso, utilizando a lei de Kirchhoff $^{13}$, é possível demonstrar que o fluxo de calor por radiação é dado pela Equação A.20.

$$
\dot{Q}=\varepsilon_{r} \sigma\left(T_{1}^{4}-T_{2}^{4}\right)
$$

Na Equação A.20, $T_{1}$ e $T_{2}$ são as temperaturas das superfícies 1 e 2 respectivamente e $\varepsilon_{r}$ a emissividade resultante, dada pela Equação A.21, em que $\varepsilon_{1}$ e $\varepsilon_{2}$ são as emissividades das superfícies 1 e 2 , respectivamente.

$$
\varepsilon_{r}=\frac{1}{1 / \varepsilon_{1}+1 / \varepsilon_{2}-1}
$$

Porém, nem todos os casos a serem analisados tratam de superfícies paralelas. Nesse caso é necessário usar um fator de configuração $(\Phi)$ e o fluxo de calor passa a ser dado pela Equação A.22. Segundo o EUROCODE 1 Part 1-2 (2005) o fluxo de calor é dado pela Equação A.23.

$$
\begin{aligned}
& \dot{Q}=\Phi \varepsilon_{r} \sigma\left(T_{1}^{4}-T_{2}^{4}\right) \\
& \dot{Q}=\Phi \varepsilon_{m} \varepsilon_{f} \sigma\left(T_{1}^{4}-T_{2}^{4}\right)
\end{aligned}
$$

Nas Equações A.22 e A.23, $\varepsilon_{m}$ e $\varepsilon_{f}$ são as emissividades da superfície do material de construção e do fogo, respectivamente, podendo adotar $\Phi=1, \varepsilon_{m}=0,7$ e $\varepsilon_{f}=1,0$.

\footnotetext{
${ }^{13}$ Segundo a Lei de Kirchhoff a emissão de um corpo cinzento é igual a sua absorção. 180
} 


\section{Anexo B - Propriedades térmicas e mecânicas dos materiais}

\section{B.1. Aço}

As propriedades físicas do aço (fôrma de aço e armaduras) aqui apresentadas foram obtidas do EUROCODE 3 e 4 Part 1-2 (1994) e da ABNT NBR 14323:2013. A fôrma geralmente é de aço galvanizado, ASTM A 653 Grau 40 (ZAR-280 ou ZAR-345) e possui espessura muito fina, geralmente igual a $0,80 \mathrm{~mm}, 0,95 \mathrm{~mm}$ ou $1,25 \mathrm{~mm}$, de acordo os catálogos técnicos dos fabricantes brasileiros.

\section{B.1.1. Condutividade térmica}

A condutividade térmica (expressa $\mathrm{em} \mathrm{W} / \mathrm{m}^{\circ} \mathrm{C}$ ) é a capacidade do material em conduzir calor. Sua variação com a temperatura do aço $\left(T_{a}\right)$ é dada pela Equação B.1, de acordo o EUROCODE 3 e 4 Part 1-2.

$$
\begin{array}{ll}
\lambda_{a}=54-\frac{T_{a}}{30} ; & 20^{\circ} \mathrm{C} \leq T_{a} \leq 800^{\circ} \mathrm{C} \\
\lambda_{a}=27,3 ; & T_{a} \geq 800^{\circ} \mathrm{C}
\end{array}
$$

De acordo o EUROCODE 4 (1994) Part 1-2, para análise simplificada pode-se assumir o valor de $45 \mathrm{~W} / \mathrm{m}^{\circ} \mathrm{C}$. A ABNT NBR 14323:2013 utiliza a mesma formulação do EUROCODE. A Figura B.1 apresenta, de forma gráfica, a variação da condutividade térmica com a temperatura.

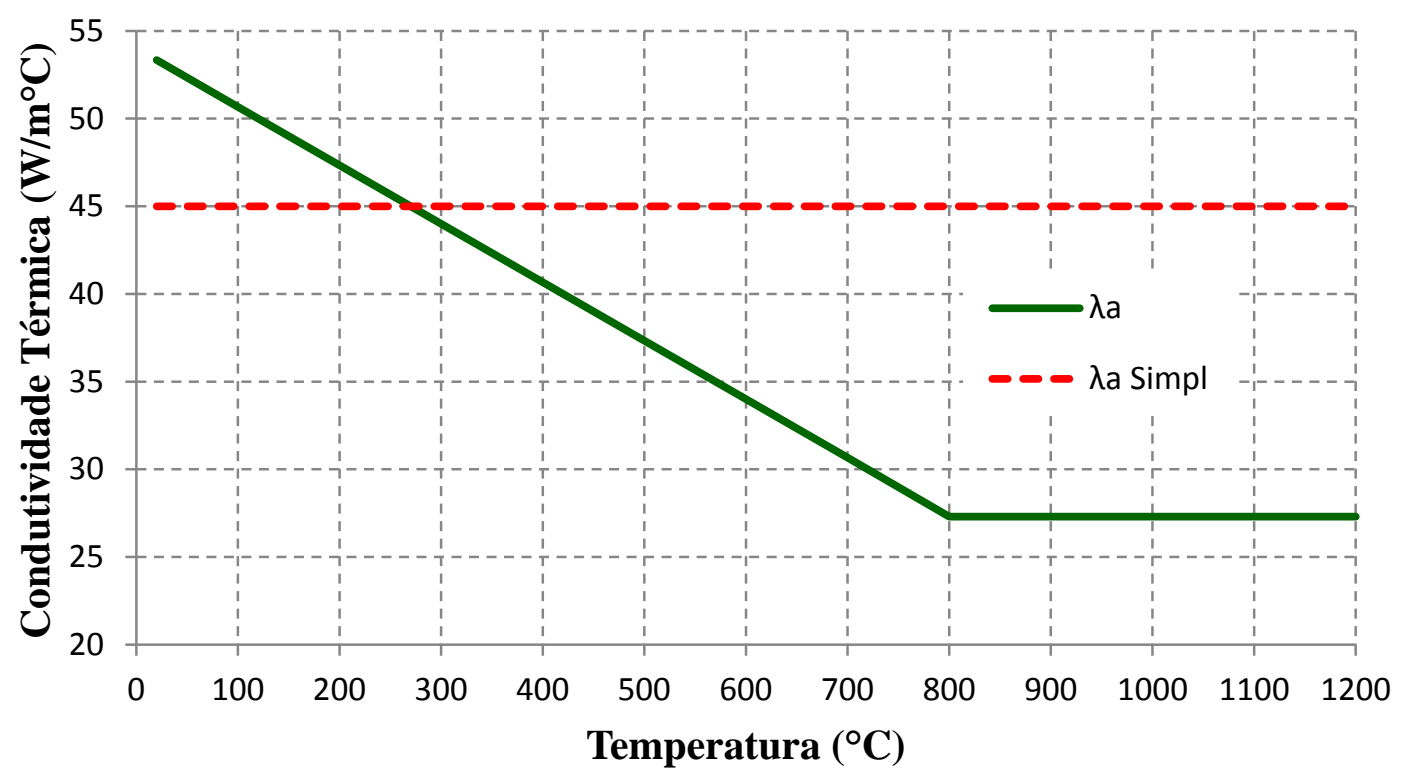

Figura B.1 - Variação da condutividade térmica do aço com a temperatura 


\section{B.1.2. Calor específico e capacitância}

Calor específico é a quantidade de calor necessária para elevar em um grau a temperatura de uma unidade de massa de um material. Capacitância tem um significado equivalente, relativo ao aumento da temperatura em uma unidade de volume. O EUROCODE 4 Part 1-2 apresenta a formulação dada pela Equação B.2, também adotada pela ABNT NBR 14323:2013.

$$
\begin{array}{ll}
c_{a}=425+0,773 T_{a}-\frac{1,69}{10^{3}} T_{a}{ }^{2}+\frac{2.22}{10^{6}} T_{a}{ }^{3} ; & 20^{\circ} \mathrm{C} \leq T_{a} \leq 600^{\circ} \mathrm{C} \\
c_{a}=666-\frac{13002}{T_{a}-738} ; & 600^{\circ} \mathrm{C} \leq T_{a} \leq 735^{\circ} \mathrm{C} \\
c_{a}=545+\frac{17820}{T_{a}-731} ; & 735^{\circ} \mathrm{C} \leq T_{a} \leq 900^{\circ} \mathrm{C} \\
c_{a}=650 ; & 900^{\circ} \mathrm{C} \leq T_{a} \leq 1200^{\circ} \mathrm{C}
\end{array}
$$

De acordo o EUROCODE 4 Part 1-2 e ABNT NBR 14323:2013, para análise simplificada pode-se assumir valor constante e igual a $600 \mathrm{~J} / \mathrm{kg}^{\circ} \mathrm{C}$. A Figura B.2 apresenta, de forma gráfica, a variação do calor específico com a temperatura.

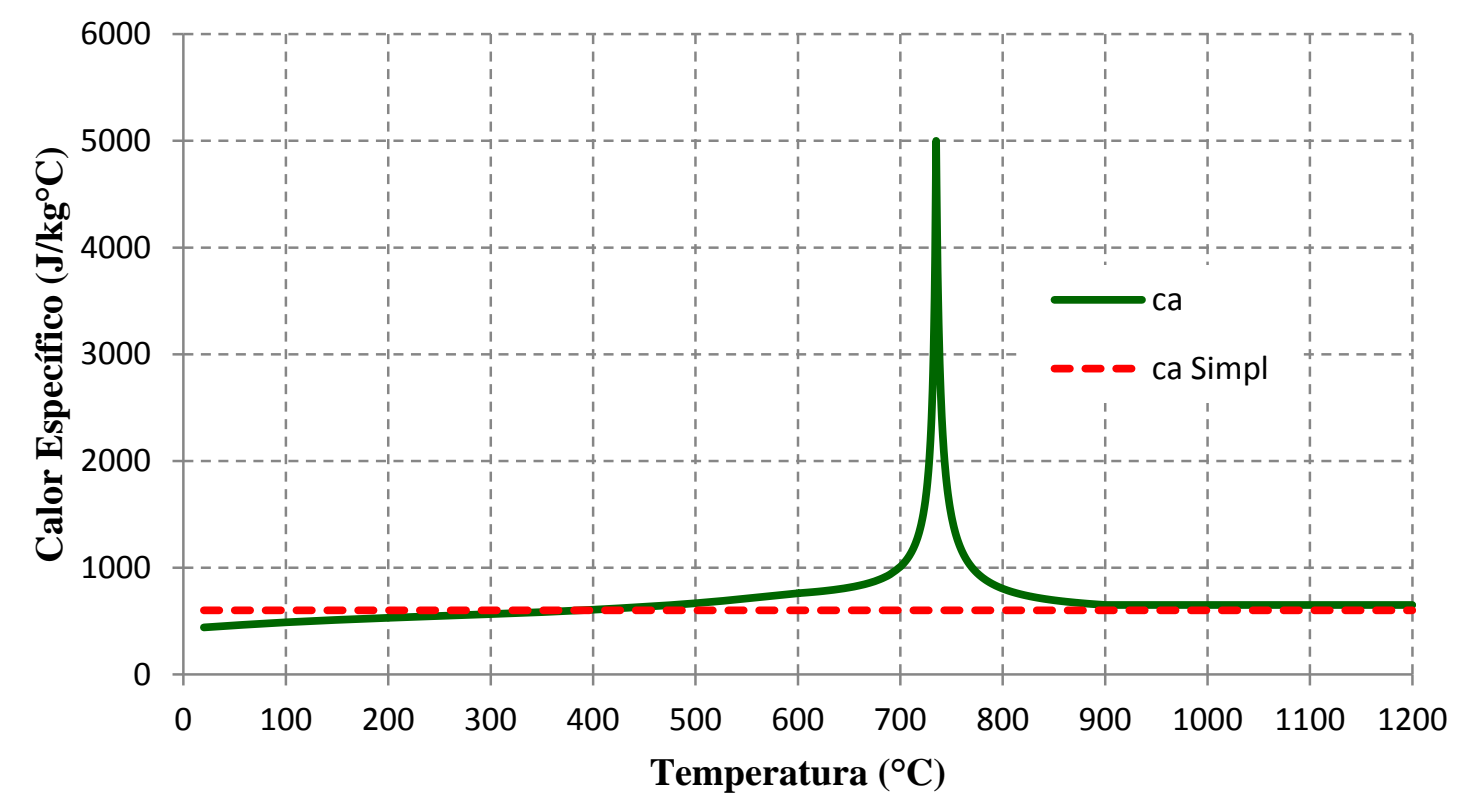

Figura B.2 - Variação do calor específico do aço com a temperatura

Assumindo que a densidade do aço é igual a $7850 \mathrm{~kg} / \mathrm{m}^{3}$, tem-se que a capacitância $\left(C_{p, a}\right)$ é dada pela Equação B.3. 


$$
C_{p, a}=\rho_{a} \cdot c_{a}=7850 \cdot c_{a}
$$

\section{B.1.3. Alongamento térmico}

O alongamento térmico é expresso pela relação entre expansão térmica $(\Delta l)$ sofrida por uma barra unidimensional de comprimento $l$ e sem restrição ao deslocamento axial quando esta é aquecida a uma temperatura $\left(T_{a}\right)$, dada pela Equação B.4.

$$
\begin{array}{ll}
\frac{\Delta l}{l}=1,2 \times 10^{-5} T_{a}+0,4 \times 10^{-8} T_{a}{ }^{2}-2,416 \times 10^{-4} ; 20^{\circ} \mathrm{C} \leq T_{a} \leq 750^{\circ} \mathrm{C} \\
\frac{\Delta l}{l}=1,1 \times 10^{-2} ; & 750^{\circ} \mathrm{C} \leq T_{a} \leq 860^{\circ} \mathrm{C} \\
\frac{\Delta l}{l}=2 \times 10^{-5} T_{a}-6,2 \times 10^{-3} ; & 860^{\circ} \mathrm{C} \leq T_{a} \leq 1200^{\circ} \mathrm{C}
\end{array}
$$

O EUROCODE 4 Part 1-2 também apresenta uma relação linear (Equação B.5) entre o alongamento térmico e a temperatura, que pode ser utilizada para cálculos simplificados. Essa mesma expressão é utilizada pela ABNT NBR 14323:2013.

$$
\frac{\Delta l}{l}=14 \times 10^{-6}\left(T_{a}-20\right)
$$

A Figura B.3 apresenta o gráfico Alongamento térmico vs. Temperatura para os dois casos citados.

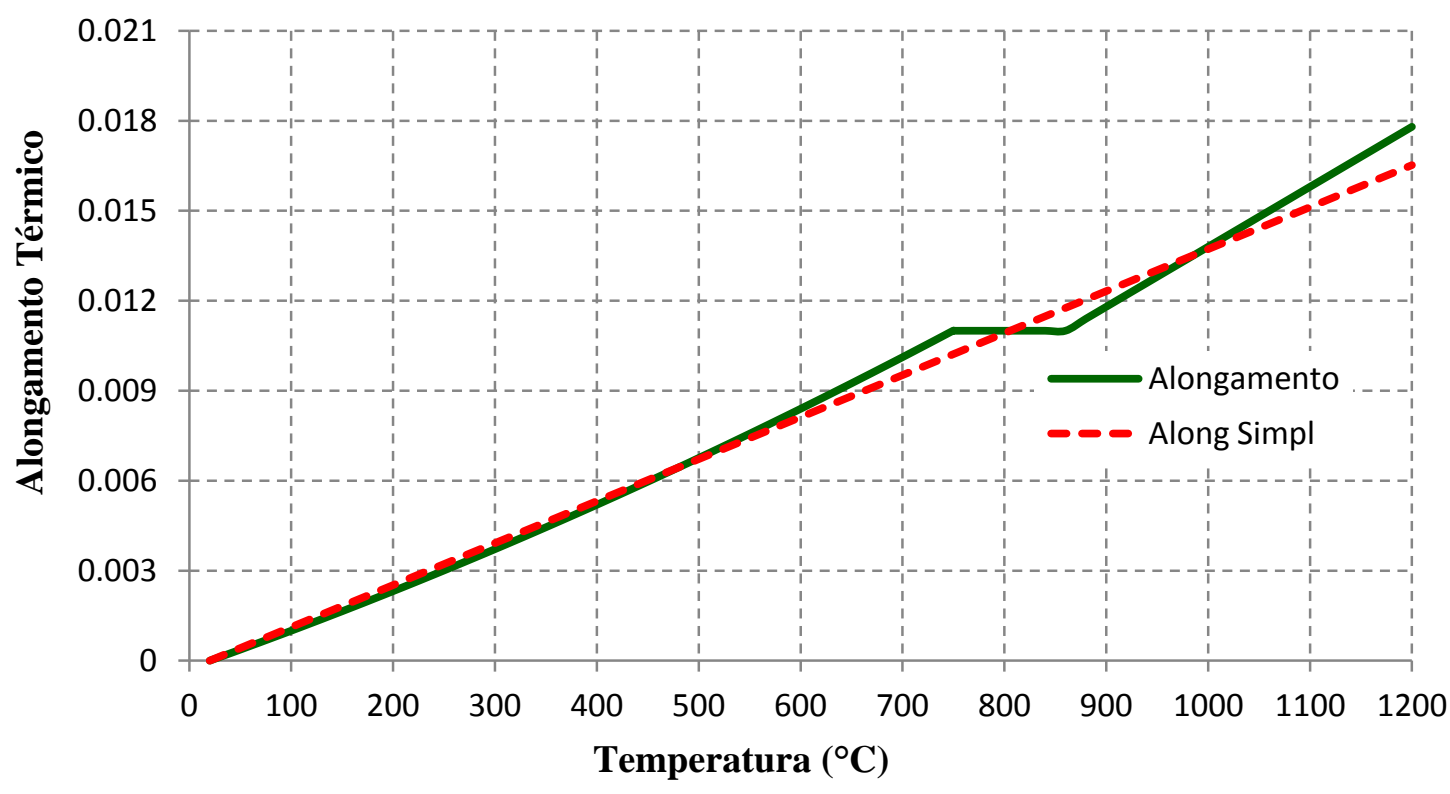

Figura B.3 - Variação do calor específico do aço com a temperatura 


\section{B.1.4. Relação Tensão vs. Deformação}

A relação Tensão vs. Deformação do aço aqui apresentadas são referentes ao aço formado a frio (para a fôrma de aço incorporada) e ao aço laminado a quente CA-50 (para as armaduras). Sabe-se que tanto a resistência ao escoamento quanto o módulo de elasticidade do aço diminuem com o aumento da temperatura. A quantificação dessa diminuição é feita por meio de coeficientes específicos conforme será apresentado a seguir. Na Figura B.4 é apresentado o modelo constitutivo para o aço de acordo o EUROCODE 4 para taxas de aquecimento entre 2 e $50{ }^{\circ} \mathrm{C} / \mathrm{min}$.

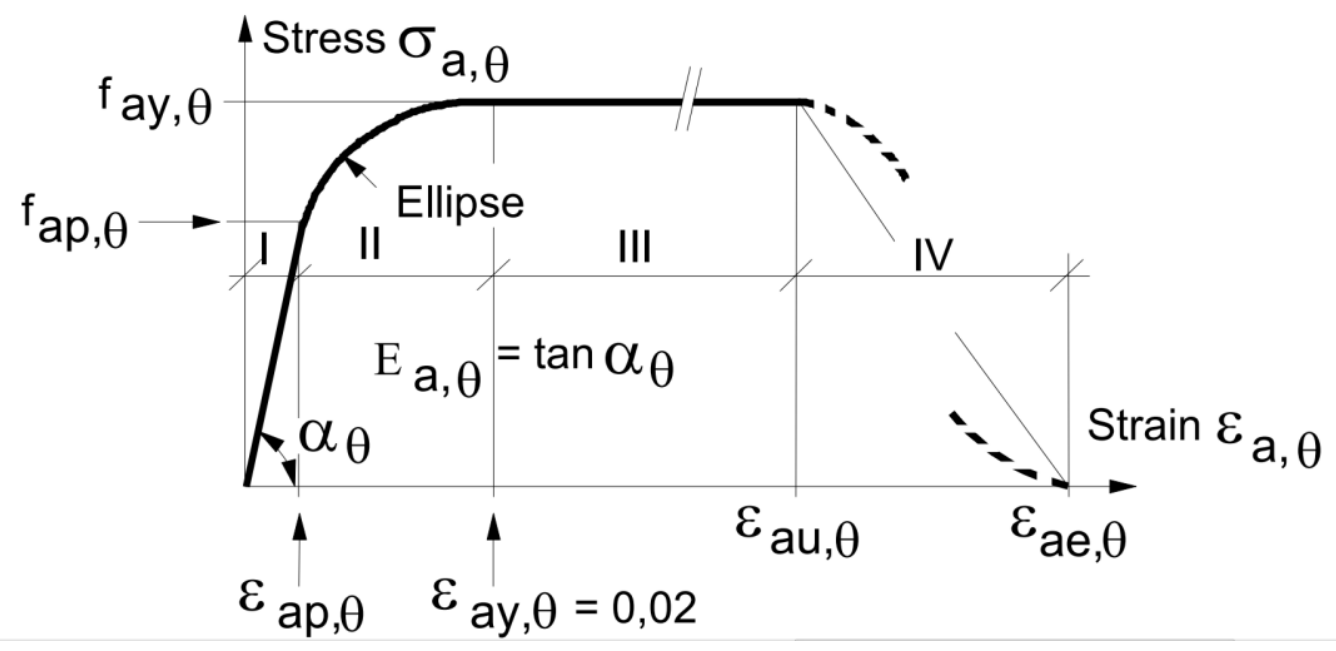

Figura B.4 - Modelo constitutivo do aço apresentado no EUROCODE 4 Part 1.2

Com relação à Figura B.4valem:

$f_{a y, \theta}-$ Resistência ao escoamento;

$f_{a p, \theta}$ - Tensão limite de proporcionalidade;

$E_{a, \theta}$ - Módulo de elasticidade na fase elástica;

$\varepsilon_{a p, \theta}$ - Deformação relativa à tensão limite de proporcionalidade;

$\varepsilon_{a y, \theta}$ - Deformação no início do escoamento;

$\varepsilon_{a u, \theta}$ - Deformação limitante para a resistência ao escoamento;

$\varepsilon_{a e, \theta}$ - Deformação última.

Primeiramente, calcula-se a resistência ao escoamento $\left(f_{a y, \theta}\right)$, a tensão limite de proporcionalidade $\left(f_{a p, \theta}\right)$ e o módulo de elasticidade na fase elástica $\left(E_{a, \theta}\right)$ por meio dos coeficientes de redução desses parâmetros relativos à temperatura ambiente $\left(k_{p, \theta}, k_{E, \theta}\right.$ e $k_{y, \theta}$ respectivamente), apresentados na Tabela B.1 e na forma gráfica por meio da Figura B.5, utilizando as expressões B.6, B.7 e B.8. 
Tabela B.1 - Fatores de redução ${ }^{14}$ para o aço a temperaturas elevadas

\begin{tabular}{c|c|c|c}
\hline $\begin{array}{c}\text { Temperatura } \\
\left(\boldsymbol{T}_{\boldsymbol{a}}\right)\end{array}$ & $\boldsymbol{k}_{\boldsymbol{y}, \boldsymbol{\theta}}$ & $\boldsymbol{k}_{\boldsymbol{p}, \boldsymbol{\theta}}$ & $\boldsymbol{k}_{\boldsymbol{E}, \boldsymbol{\theta}}$ \\
\hline $\mathbf{2 0}^{\circ} \mathbf{C}$ & 1,00 & 1,0000 & 1,0000 \\
\hline $\mathbf{1 0 0}^{\circ} \mathbf{C}$ & 1,00 & 1,0000 & 1,0000 \\
\hline $\mathbf{2 0 0}^{\circ} \mathbf{C}$ & 1,00 & 0,8070 & 0,9000 \\
\hline $\mathbf{3 0 0}^{\circ} \mathbf{C}$ & 1,00 & 0,6130 & 0,8000 \\
\hline $\mathbf{4 0 0}^{\circ} \mathbf{C}$ & 1,00 & 0,4200 & 0,7000 \\
\hline $\mathbf{5 0 0}^{\circ} \mathbf{C}$ & 0,78 & 0,3600 & 0,6000 \\
\hline $\mathbf{6 0 0}^{\circ} \mathbf{C}$ & 0,47 & 0,1800 & 0,3100 \\
\hline $\mathbf{7 0 0}^{\circ} \mathbf{C}$ & 0,23 & 0,0750 & 0,1300 \\
\hline $\mathbf{8 0 0}^{\circ} \mathbf{C}$ & 0,11 & 0,0500 & 0,0900 \\
\hline $\mathbf{9 0 0}^{\circ} \mathbf{C}$ & 0,06 & 0,0375 & 0,0675 \\
\hline $\mathbf{1 0 0 0}^{\circ} \mathbf{C}$ & 0,04 & 0,0250 & 0,0450 \\
\hline $\mathbf{1 1 0 0}^{\circ} \mathbf{C}$ & 0,02 & 0,0125 & 0,0225 \\
\hline $\mathbf{1 2 0 0}^{\circ} \mathbf{C}$ & 0,00 & 0,0000 & 0,0000 \\
\hline & & &
\end{tabular}

$$
\begin{aligned}
& f_{a y, \theta}=k_{y, \theta} \cdot f_{y} \\
& f_{a p, \theta}=k_{p, \theta} \cdot f_{y} \\
& E_{a, \theta}=k_{E, \theta} \cdot E_{a}
\end{aligned}
$$

Com relação às Equações B.6 a B.8, $f_{y}$ e $E_{a}$ são, respectivamente, a resistência ao escoamento e o modulo de elasticidade à temperatura ambiente. A construção do diagrama Tensão $v s$. Deformação é feito com base nas equações apresentadas na Tabela B.2.

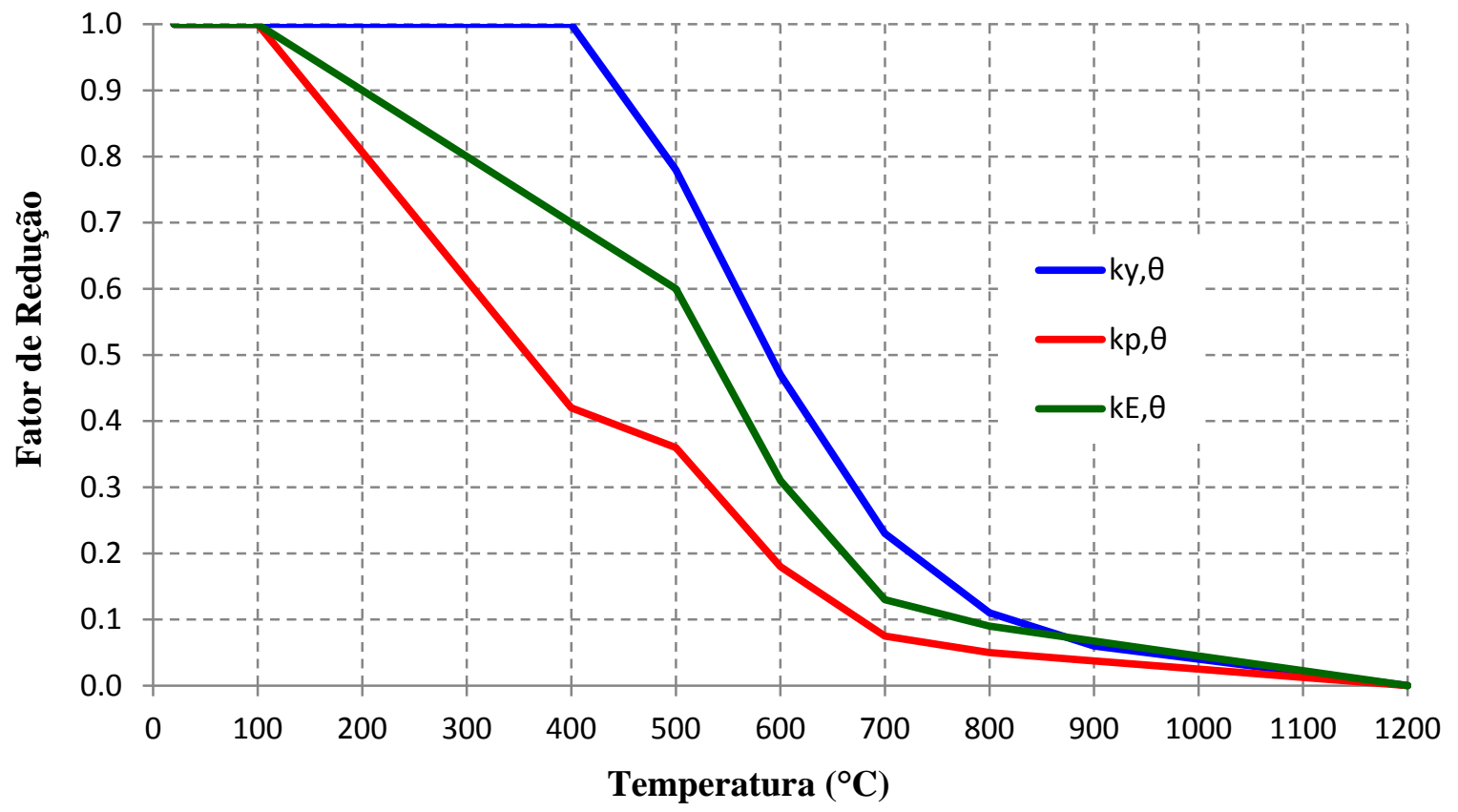

Figura B.5 - Fatores de redução para o aço a temperaturas elevadas

\footnotetext{
${ }^{14}$ A ABNT NBR 15200:2012 e a ABNT NBR 14323:2013 apresenta os mesmos fatores de redução para $k_{y, \theta}$ e $k_{E, \theta}$, porém não traz nenhuma informação a respeito do coeficiente de proporcionalidade $\left(k_{p, \theta}\right)$.
} 
Tabela B.2 - Relação entre os parâmetros do modelo matemático apresentado na Figura B.4

\begin{tabular}{|c|c|c|c|}
\hline $\begin{array}{c}\text { Faixa de } \\
\text { deformação }\end{array}$ & Tensão & \multicolumn{2}{|c|}{ Módulo de Elasticidade } \\
\hline$\varepsilon<\varepsilon_{a p, \theta}$ & $\varepsilon E_{a, \theta}$ & & $E_{a, \theta}$ \\
\hline$\varepsilon_{a p, \theta}<\varepsilon<\varepsilon_{a y, \theta}$ & $f_{a p, \theta}-c+\left(\frac{b}{a}\right)\left[a^{2}-\left(\varepsilon_{a y, \theta}-\varepsilon\right)^{2}\right]^{0,5}$ & \multicolumn{2}{|c|}{$\frac{b\left(\varepsilon_{a y, \theta}-\varepsilon\right)}{a\left[a^{2}-\left(\varepsilon_{a y, \theta}-\varepsilon\right)^{2}\right]^{0,5}}$} \\
\hline$\varepsilon_{a y, \theta}<\varepsilon<\varepsilon_{a u, \theta}$ & $f_{a y, \theta}$ & & 0 \\
\hline$\varepsilon_{a u, \theta}<\varepsilon<\varepsilon_{a e, \theta}$ & $f_{a y, \theta}\left[1-\left(\frac{\varepsilon-\varepsilon_{a u, \theta}}{\varepsilon_{a e, \theta}-\varepsilon_{a u, \theta}}\right)\right]$ & & - \\
\hline$\varepsilon=\varepsilon_{a e, \theta}$ & 0,00 & & - \\
\hline Parâmetros & $\varepsilon_{a p, \theta}=f_{a p, \theta} / E_{a, \theta} \quad \varepsilon_{a y, \theta}=0,02$ & $\varepsilon_{a u, \theta}=0,15$ & $\varepsilon_{a e, \theta}=0,20$ \\
\hline Funções & $\begin{array}{r}a^{2}=\left(\varepsilon_{a y, \theta}-\varepsilon_{a p, \theta}\right)\left(\varepsilon_{c}\right. \\
b^{2}=c\left(\varepsilon_{a y, \theta}-\varepsilon\right. \\
c=\frac{\left(f_{a y, \theta}\right.}{\left(\varepsilon_{a y, \theta}-\varepsilon_{a p, \theta}\right) E_{a}}\end{array}$ & $\begin{array}{l}\theta-\varepsilon_{a p, \theta}+c / t \\
o, \theta) E_{a, \theta}+c^{2} \\
\left.f_{a p, \theta}\right)^{2} \\
-2\left(f_{a y, \theta}-f_{a p}\right.\end{array}$ & \\
\hline
\end{tabular}

Com base no procedimento descrito, a Figura B.6 apresenta o diagrama Tensão vs. Deformação para 5 temperaturas diferentes: $20^{\circ} \mathrm{C}, 400{ }^{\circ} \mathrm{C}, 500{ }^{\circ} \mathrm{C}, 600{ }^{\circ} \mathrm{C}$ e $800{ }^{\circ} \mathrm{C}$, todas correspondentes a um aço com resistência ao escoamento igual a $250 \mathrm{MPa}$ e módulo de elasticidade igual a 200GPa à temperatura ambiente.

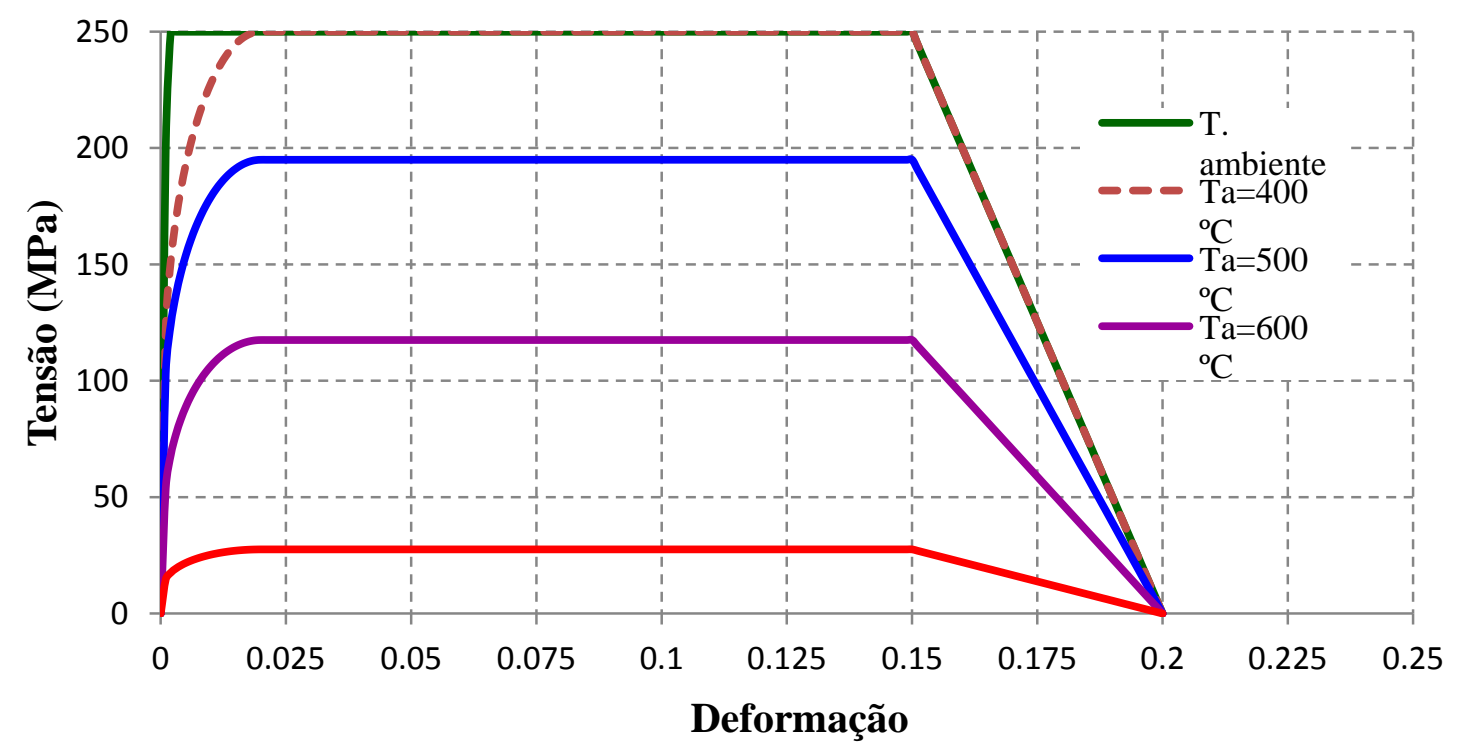

Figura B.6 - Diagrama Tensão vs. Deformação do aço para $20^{\circ} \mathrm{C}, 400{ }^{\circ} \mathrm{C}, 500{ }^{\circ} \mathrm{C}, 600{ }^{\circ} \mathrm{C}$ e $800{ }^{\circ} \mathrm{C}$. 


\section{B.2. Concreto}

As propriedades térmicas e mecânicas do concreto aqui apresentadas são baseadas no modelo do EUROCODE 4 Part 1-2, que são as mesmas adotadas pela ABNT NBR 14323:2013. Em geral, essas propriedades dependem da massa específica e do tipo de agregado utilizado no concreto.

\section{B.2.1. Condutividade térmica}

\section{$\rightarrow$ Concreto de densidade normal}

O EUROCODE 4 apresenta um intervalo de valores para a condutividade térmica $\left(\mathrm{W} / \mathrm{m}^{\circ} \mathrm{C}\right)$ dos concreto com densidade normal dado pelos limites superior e inferior apresentados nas Equações B.9 e B.10, respectivamente, em que $T_{c}$ é a temperatura do concreto.

\section{Limite superior:}

$$
\lambda_{C}=2-0,2451\left(T_{c} / 100\right)+0,0107\left(T_{c} / 100\right)^{2} ; \quad 20^{\circ} \mathrm{C} \leq T_{c} \leq 1200^{\circ} \mathrm{C}
$$

\section{Limite inferior:}

$$
\lambda_{C}=1,36-0,136\left(T_{c} / 100\right)+0,0057\left(T_{c} / 100\right)^{2} ; \quad 20^{\circ} \mathrm{C} \leq T_{c} \leq 1200^{\circ} \mathrm{C}
$$

O EUROCODE 4 recomenda o uso do limite superior, pois este foi obtido por meio de ensaios realizados em elementos estruturais mistos de aço e concreto. A mesma norma também permite o uso do valor de condutividade térmica constante com a temperatura e igual a $1,60 \mathrm{~W} / \mathrm{m}^{\circ} \mathrm{C}$ para modelos de cálculo simplificados.

\section{$\rightarrow$ Concretos leves}

A condutividade térmica para concretos leves é calculada de acordo a Equação B.11. A Figura B.7 apresenta a condutividade térmica em função da temperatura para os casos citados.

$$
\begin{array}{ll}
\lambda_{C}=1,0-\left(T_{c} / 1600\right) ; & 20^{\circ} \mathrm{C} \leq T_{C} \leq 800^{\circ} \mathrm{C} \\
\lambda_{C}=0,5 ; & T_{C} \geq 800^{\circ} \mathrm{C}
\end{array}
$$




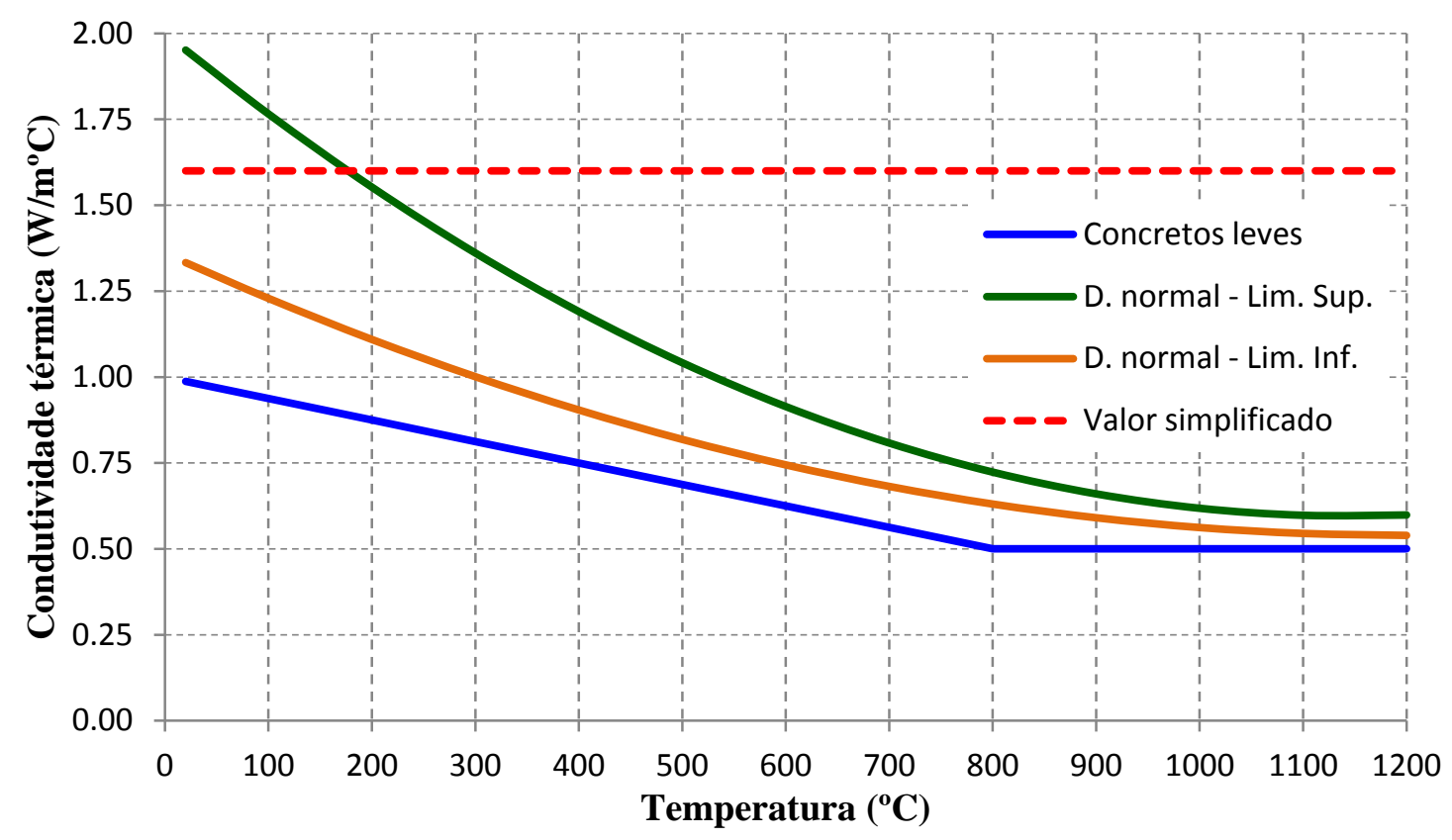

Figura B.7 - Condutividade térmica vs. Temperatura para os concretos normal e leve.

\section{B.2.2. Calor específico e capacitância}

O calor específico para concreto de densidade normal e seco (umidade $=0 \%$ ), de acordo o EUROCODE 4 Part 1-2, é determinado de acordo a Equação B.12.

$$
\begin{array}{ll}
c_{c}=900 ; & 20^{\circ} \mathrm{C} \leq T_{c} \leq 100^{\circ} \mathrm{C} \\
c_{c}=900+\left(T_{c}-100\right) ; & 100^{\circ} \mathrm{C} \leq T_{c} \leq 200^{\circ} \mathrm{C} \\
c_{c}=1000+\left(T_{c}-200\right) / 2 ; & 200^{\circ} \mathrm{C} \leq T_{c} \leq 400^{\circ} \mathrm{C} \\
c_{c}=1100 ; & 400^{\circ} \mathrm{C} \leq T_{c} \leq 1200^{\circ} \mathrm{C}
\end{array}
$$

Para considerar o efeito da umidade do concreto, o EUROCODE 4 Part 1-2 considera um valor de pico do calor específico iniciando em $100^{\circ} \mathrm{C}$, atingindo o valor máximo à $115^{\circ} \mathrm{C}$ e decaindo linearmente até $200^{\circ} \mathrm{C}$. Este pico é dado de acordo a umidade do concreto:

$\rightarrow c_{c, p i c o}=2020 \mathrm{~J} / \mathrm{kg}^{\circ} \mathrm{C}$ para concretos com 3,0\% de umidade em função do peso

$\rightarrow c_{c, p i c o}=5600 \mathrm{~J} / \mathrm{kg}^{\circ} \mathrm{C}$ para concretos com $10,0 \%$ de umidade em função do peso

A umidade do concreto deve ser tomada igual à umidade de equilíbrio. Se esta não for conhecida, a umidade do concreto não deve ser tomada superior a $4 \%$. 
Para concretos de baixa densidade o calor específico é considerado independente da temperatura e igual a $840 \mathrm{~J} / \mathrm{kg}^{\circ} \mathrm{C}$. A Figura B.8 apresenta a variação do calor específico em função da temperatura de acordo com as equações apresentadas.

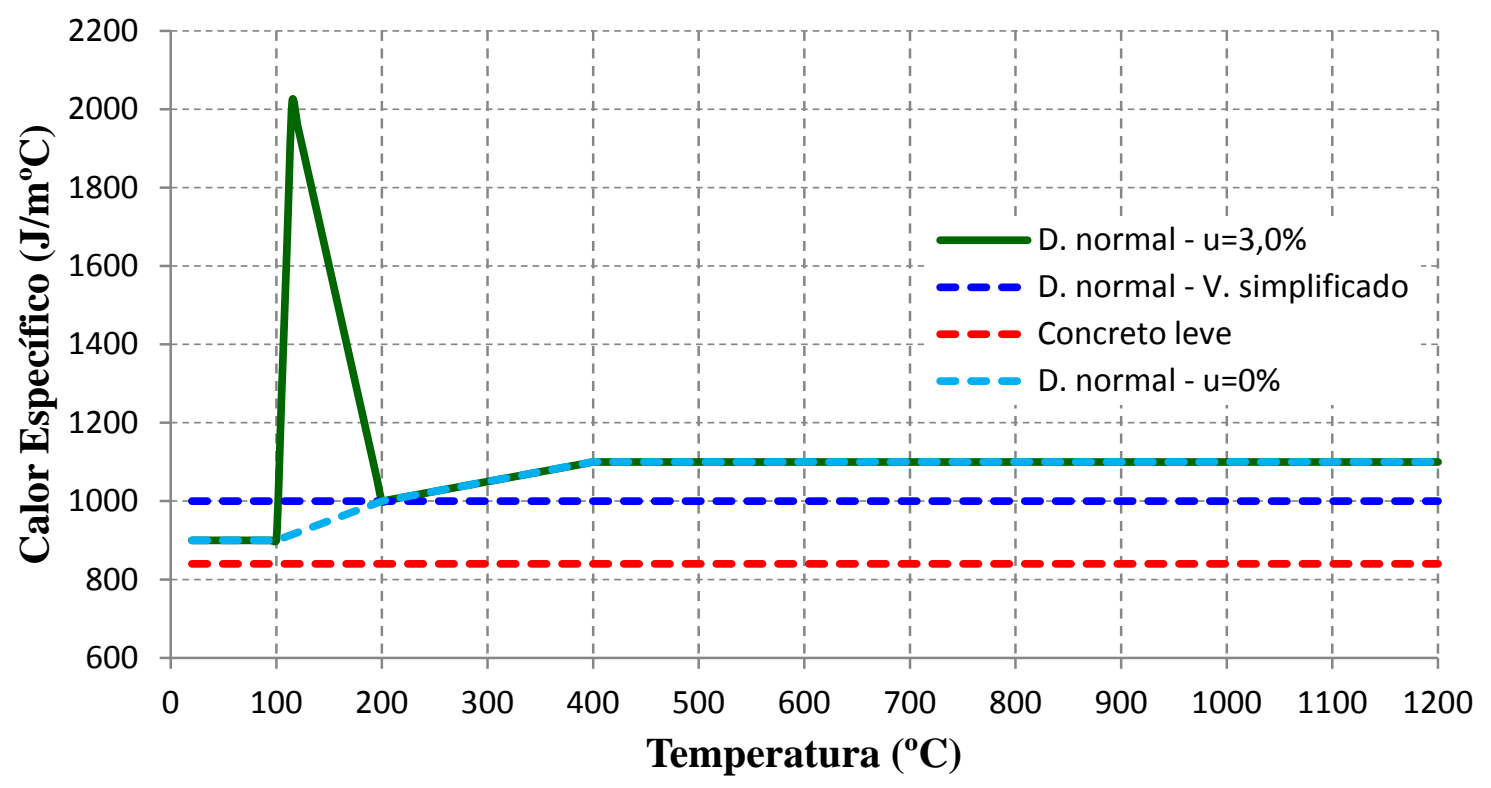

Figura B.8 - Calor específico vs. Temperatura do concreto

A capacitância do concreto é calculada analogamente à Equação B.3. Deste modo, se necessita do conhecimento da densidade do concreto em função da temperatura, calculada por meio da Equação B.13, de acordo o EUROCODE 4.

$$
\begin{array}{ll}
\rho=\rho_{20^{\circ} \mathrm{C}} ; & 20^{\circ} \mathrm{C} \leq T_{C} \leq 115^{\circ} \mathrm{C} \\
\rho=\rho_{20^{\circ} \mathrm{C}}\left[1-0,02\left(T_{C}-115\right) / 85\right] ; & 115^{\circ} \mathrm{C} \leq T_{c} \leq 200^{\circ} \mathrm{C} \\
\rho=\rho_{20^{\circ} \mathrm{C}}\left[0,98-0,03\left(T_{C}-200\right) / 200\right] ; & 200^{\circ} \mathrm{C} \leq T_{C} \leq 400^{\circ} \mathrm{C} \\
\rho=\rho_{20^{\circ} \mathrm{C}}\left[0,95-0,07\left(T_{C}-400\right) / 800\right] ; & 400^{\circ} \mathrm{C} \leq T_{C} \leq 1200^{\circ} \mathrm{C}
\end{array}
$$

Ou, de maneira simplificada, por meio da Equação B.14.

$$
\rho_{c, T}=2354-23,47\left(\frac{T_{c}}{100}\right)
$$

Para cargas estáticas, o EUROCODE 4 também permite utilizar o valor constante de 2300 $\mathrm{kg} / \mathrm{m}^{3}$.

\section{B.2.3. Alongamento térmico}

\section{$\rightarrow$ Concreto de densidade normal}

O EUROCODE 4 part 1.2, apresenta a equação do alongamento térmico do concreto com agregados silicosos e remete ao EUROCODE 2 para o caso de concretos com agregados calcários. 


\section{Para agregados silicosos:}

$$
\begin{array}{ll}
\frac{\Delta l}{l}=-1,8 \times 10^{-4}+\frac{9}{10^{6}} T_{a}+\frac{2,3}{10^{11}} T_{a}{ }^{3} ; & 20^{\circ} \mathrm{C} \leq T_{a} \leq 700^{\circ} \mathrm{C} \\
\frac{\Delta l}{l}=14 \times 10^{-3} ; & 700^{\circ} \mathrm{C} \leq T_{a} \leq 1200^{\circ} \mathrm{C}
\end{array}
$$

Para agregados calcários:

$$
\begin{array}{ll}
\frac{\Delta l}{l}=\frac{-1,2}{10^{4}}+\frac{6}{10^{6}} T_{a}+\frac{1,4}{10^{11}} T_{a}{ }^{3} ; & 20^{\circ} \mathrm{C} \leq T_{a} \leq 805^{\circ} \mathrm{C} \\
\frac{\Delta l}{l}=12 \times 10^{-3} ; & 700^{\circ} \mathrm{C} \leq T_{a} \leq 1200^{\circ} \mathrm{C}
\end{array}
$$

De maneira simplificada pode-se adotar uma relação linear entre o alongamento térmico e a temperatura dada pela Equação B.17. A Figura B.9 apresenta a variação do alongamento térmico em função da temperatura na forma gráfica.

$$
\frac{\Delta l}{l}=18 \times 10^{-6}\left(T_{c}-20\right)
$$

\section{$\rightarrow$ Concretos leves}

O EUROCODE 4 adota a relação linear para o alongamento térmico dos concretos leves, apresentada na forma da Equação B.18.

$$
\frac{\Delta l}{l}=8 \times 10^{-6}\left(T_{c}-20\right)
$$

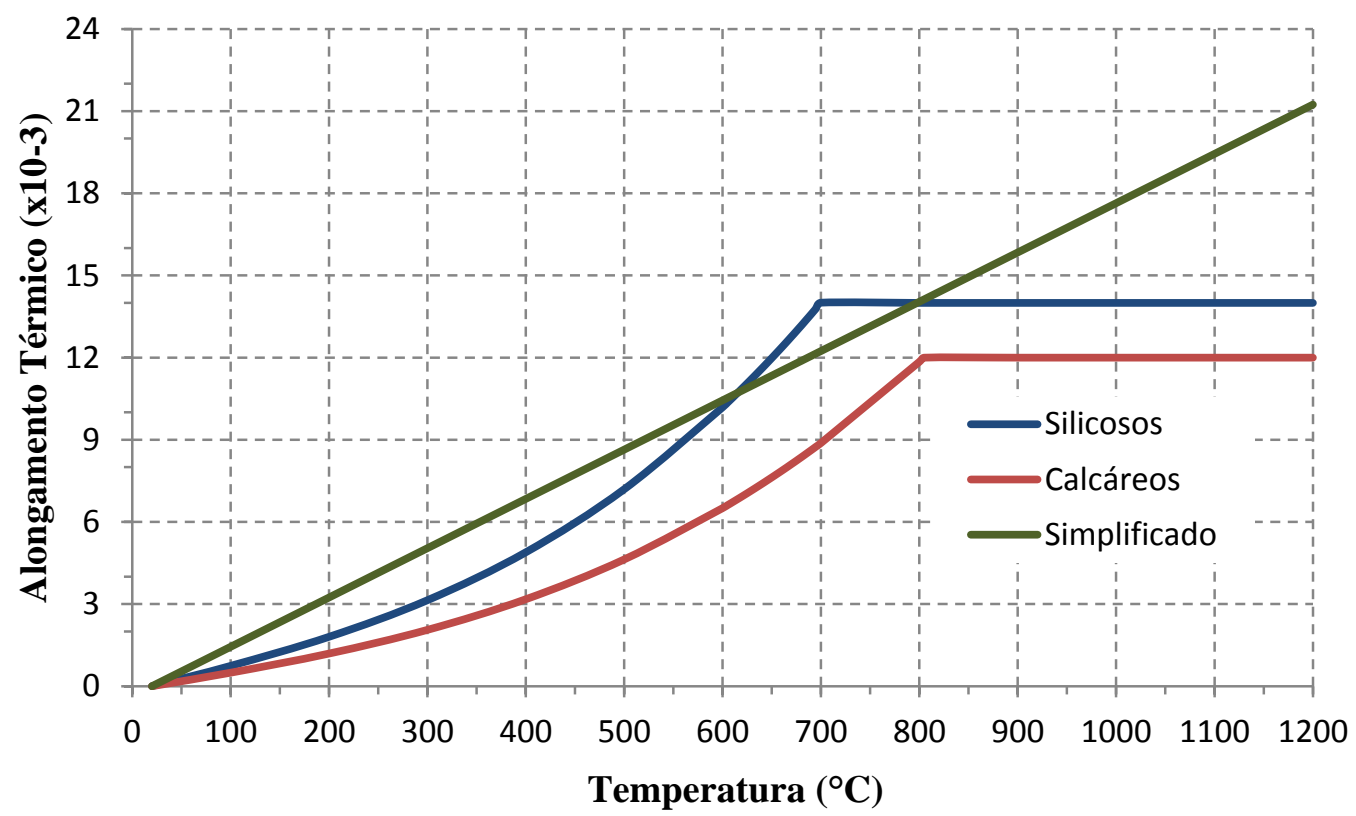

Figura B.9 - Alongamento térmico do concreto em função da temperatura para concretos de densidade normal 


\section{B.2.4. Relação Tensão vs. Deformação}

As propriedades do concreto aqui apresentadas se referem a situações em que a taxa de aquecimento esteja entre 2 e $50{ }^{\circ} \mathrm{C} / \mathrm{min}$.

\section{$\rightarrow$ Concreto comprimido}

De maneira semelhante ao aço, o modelo constitutivo do concreto comprimido possui dois ramos: um ascendente e outro descendente, conforme pode ser observado na Figura B.10.

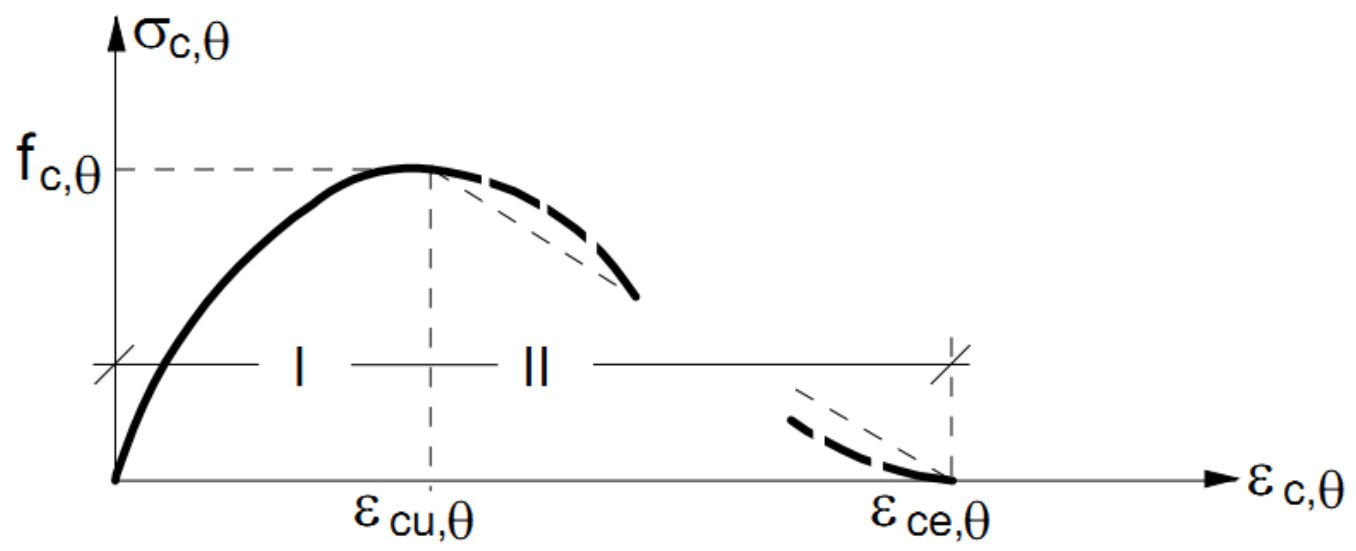

Figura B.10 - Modelo constitutivo do concreto (EUROCODE 4, Part 1-2)

Para o trecho ascendente (trecho I) é adotada uma relação tensão vs. deformação apresentada na Equação B.19, em que $f_{c, \theta}=k_{c, \theta} \cdot f_{c}$.

$$
\sigma\left(\varepsilon_{c, \theta}\right)=\frac{3 \varepsilon_{c, \theta} f_{c, \theta}}{\varepsilon_{c u, \theta}\left[2+\left(\frac{\varepsilon_{c, \theta}}{\varepsilon_{c u, \theta}}\right)^{3}\right]}
$$

Para a Equação B.19, valem:

$k_{c, \theta}:$ Fator de redução da resistência do concreto;

$f_{c}$ : resistência do concreto à temperatura ambiente;

$f_{c, \theta}$ : resistência do concreto à temperatura analisada;

$\varepsilon_{c u, \theta}:$ deformação correspondente a $f_{c, \theta}$.

Para o trecho descendente (trecho II) é adotada uma relação linear, onde a deformação $\varepsilon_{c e, \theta}$ corresponde à deformação última do concreto. Os valores de $k_{c, \theta}, \varepsilon_{c u, \theta}$ e $\varepsilon_{c e, \theta}$ para concretos de densidade normal formados por agregados silicosos e calcáreos são apresentados na Tabela B.3. Para concretos leves o EUROCODE 4 não fornece todos os parâmetros para construção da curva para agregados silicosos e calcários. A ABNT NBR 14323:2013 recomenda a utilização do modelo constitutivo apresentado na ABNT NBR 15200:2012, também calculado de acordo a Equação B.19, porém com coeficientes $\varepsilon_{c u, \theta} \mathrm{e}$ $\varepsilon_{c e, \theta}$ um pouco diferentes daqueles apresentados na Tabela B.3. 
Tabela B.3 - Fatores de redução e deformações de interesse para o modelo constitutivo do concreto (densidade normal) de acordo o EUROCODE

\begin{tabular}{c|c|c|c|c|c|c}
\hline \multirow{2}{*}{$\begin{array}{c}\text { Temperatura } \\
\left({ }^{\circ} \mathbf{C}\right)\end{array}$} & \multicolumn{3}{|c|}{ Agregados Silicosos } & \multicolumn{3}{c}{ Agregados Calcários } \\
\cline { 2 - 7 } & $k_{c, \theta}$ & $\varepsilon_{c u, \theta}$ & $\varepsilon_{c e, \theta}$ & $k_{c, \theta}$ & $\varepsilon_{c u, \theta}$ & $\varepsilon_{c e, \theta}$ \\
\hline $\mathbf{2 0}$ & 1,00 & 0,0025 & 0,0200 & 1,00 & 0,0025 & 0,0200 \\
\hline $\mathbf{1 0 0}$ & 1,00 & 0,0040 & 0,0225 & 1,00 & 0,0040 & 0,0225 \\
\hline $\mathbf{2 0 0}$ & 0,95 & 0,0055 & 0,0250 & 0,97 & 0,0055 & 0,0250 \\
\hline $\mathbf{3 0 0}$ & 0,85 & 0,0070 & 0,0275 & 0,91 & 0,0070 & 0,0275 \\
\hline $\mathbf{4 0 0}$ & 0,75 & 0,0100 & 0,0300 & 0,85 & 0,0100 & 0,0300 \\
\hline $\mathbf{5 0 0}$ & 0,60 & 0,0150 & 0,0325 & 0,74 & 0,0150 & 0,0325 \\
\hline $\mathbf{6 0 0}$ & 0,45 & 0,0250 & 0,0350 & 0,60 & 0,0250 & 0,0350 \\
\hline $\mathbf{7 0 0}$ & 0,30 & 0,0250 & 0,0375 & 0,43 & 0,0250 & 0,0375 \\
\hline $\mathbf{8 0 0}$ & 0,15 & 0,0250 & 0,0400 & 0,27 & 0,0250 & 0,0400 \\
\hline $\mathbf{9 0 0}$ & 0,08 & 0,0250 & 0,0425 & 0,15 & 0,0250 & 0,0425 \\
\hline $\mathbf{1 0 0 0}$ & 0,04 & 0,0250 & 0,0450 & 0,06 & 0,0250 & 0,0450 \\
\hline $\mathbf{1 1 0 0}$ & 0,01 & 0,0250 & 0,0475 & 0,02 & 0,0250 & 0,0475 \\
\hline $\mathbf{1 2 0 0}$ & 0,00 & - & - & 0,00 & - & - \\
\hline
\end{tabular}

\section{$\rightarrow$ Concreto tracionado}

Para análises conservativas, a resistência à tração do concreto pode ser desprezada. Para análises mais rigorosas a Equação B.20 leva em conta a redução da resistência à tração do concreto com o aumento da temperatura.

$$
f_{c t, T c}=k_{c t, T c} f_{c t}
$$

Com relação à Equação B.20, vale o conjunto de Equações B.21 e $f_{c t}$ é a resistência à tração do concreto.

$$
\begin{array}{ll}
k_{c, t, T c}=1,0 ; & 20^{\circ} \mathrm{C} \leq T_{c} \leq 100^{\circ} \mathrm{C} \\
k_{c, t, T c}=1,0-1,0\left(T_{c}-100\right) / 500 ; & 100^{\circ} \mathrm{C} \leq T_{c} \leq 600^{\circ} \mathrm{C} \\
k_{c, t, T c}=0 ; & T_{C}>600^{\circ} \mathrm{C}
\end{array}
$$


Apêndices 



\section{Apêndice A - Comandos do iDIANA e processamento em arquivos de lotes}

\section{A.1. Comandos para pré-processamento no iDIANA}

Neste Apêndice é apresentado um resumo dos principais comandos do iDIANA utilizados para a definição da geometria, elementos finitos, carregamentos, condições de contorno e propriedades dos materiais. Nos procedimentos apresentados no que seguem, os campos em letra maiúscula são os padrões do iDIANA, enquanto aqueles entre colchetes devem ser preenchidos pelo usuário.

\section{A.1.1. Definição da Geometria}

GEOMETRY POINT COORD [nome do ponto] [coordenada $x$ ] [coordenada y]

GEOMETRY LINE STRAIGHT [nome da linha] [ponto inicial] [ponto final] [número de divisões na geração da malha]

GEOMETRY SURFACE 4SIDES [linha 1] [linha 2] [linha 3] [linha 4]

GEOMETRY SWEEP $[L I][L F][N D I V]$ TRANSLATE $[d x][d y][d z]$

GEOMETRY SWEEP $[S I][S F][N D I V]$ TRANSLATE $[d x][d y][d z]$

Nessa sintaxe, $[L I]$ e $[L F]$ são as linhas (ou SETs) iniciais e finais da superfície de extrusão, [SI] e [SF] as superfícies (ou SETs) iniciais e finais do sólido, [NDIV] o número de divisão para a geração da malha de elementos finitos na direção da extrusão e $[d x][d y]$ e $[d z]$ as distâncias de extrusão nas direções $x, y$ e $z$ respectivamente

\section{A.1.2. Construção de SETs}

CONSTRUCT SET [nome do SET] APPEND LINES [linha 1] [linha 2] ...

CONSTRUCT SET [nome do SET] APPEND SURFACES [sup 1] [sup 2] ...

A.1.3. Definição dos elementos finitos

MESHING TYPES [Nome do SET] [Tipo de elemento finito]

MESHING GENERATE ALL

MESHING MERGE [Nome do SET] [Precisão]

A.1.4. Definição dos carregamentos térmicos

PROPERTY LOADS EXTTEMP [Load case] [Nome do SET onde o carregamento será aplicado] [Intensidade do carregamento ${ }^{(a)}$ ]

PROPERTY LOADS RADTEMP [Load case] [Nome do SET onde o carregamento será aplicado] [Intensidade do carregamento ${ }^{(a)}$ ]

CONSTRUCT TCURVE [Nome da curva] LIST FILE [Nome do arquivo] 


\section{CONSTRUCT TCURVE [Nome da curva] LIST $\left[t_{1}\right]\left[T_{1}\right]\left[t_{2}\right]\left[T_{2}\right]$}

PROPERTY ATTACH LOADCASE [ID] TCURVE [Nome da curva]

PROPERTY INITIAL INITEMP ALL [Temperatura inicial]

(a) Para facilitar a entrada de dados, a intensidade do carregamento é tomada igual à unidade.

Nos comandos CONSTRUCT TCURVE apresentados, cada conjunto de valores $\left[t_{i}\right]$ $\left[T_{i}\right]$ representam os pares de pontos da curva em questão, sendo $t_{i}$ o tempo e $T_{i}$ a sua temperatura associada. O [Nome do arquivo] refere-se a um arquivo de texto que contenha todos os pontos da curva de incêndio

\section{A.1.5. Arquivos de propriedades térmicas}

CONDUC $[\lambda]$

CAPACI $\left[C_{p}\right]$

TEMPER $\left[T_{1}\right]\left[T_{2}\right] \ldots\left[T_{i}\right] \ldots\left[T_{n}\right]$

CONDIS $\left[\lambda_{T 1}\right]\left[\lambda_{T 2}\right] \ldots\left[\lambda_{T i}\right] \ldots\left[\lambda_{T n}\right]$

CAPATT $\left[C_{p, T l}\right]\left[C_{p, T l}\right] \ldots\left[C_{p, T i}\right] \ldots\left[C_{p, T n}\right]$

Onde, $\lambda$ é a condutividade térmica à temperatura ambiente, $C_{p}$ é a capacitância térmica à temperatura ambiente, $T_{i}$ representa as temperaturas de referência para as propriedades térmicas variáveis, $\lambda_{T i}$ a condutividade térmica para a temperatura $T_{i}$ e $C_{p, T i}$ é a capacitância para a temperatura $T_{i}$.

\section{A.1.6. Arquivos de propriedades mecânicas do aço}

No início do arquivo de propriedades do aço devem ser apresentadas as propriedades térmicas em função da temperatura conforme a sintaxe apresentada para o caso do modelo térmico.

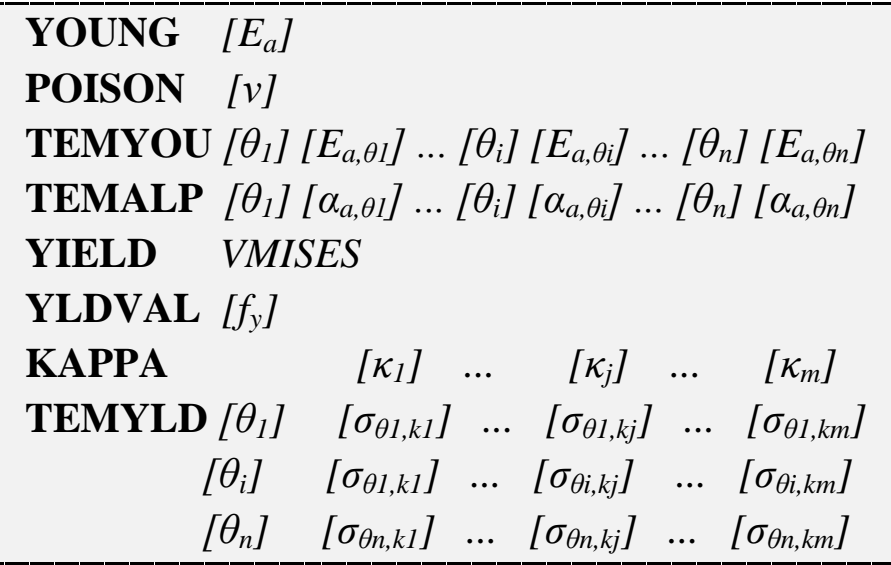

Na última sintaxe apresentada $E_{a}$ é o módulo de elasticidade do aço em temperatura ambiente, $v$ o coeficiente de Poisson, $E_{a, \theta i}$ o módulo de elasticidade do aço na temperatura $\theta_{\mathrm{i}}$, $\alpha_{a, \theta 1}$ o coeficiente de alongamento térmico na temperatura $\theta_{i}, f_{y}$ a tensão de escoamento do aço em temperatura ambiente e $f_{a y, \theta i}$ a tensão de escoamento do aço na temperatura $\theta_{i}$. O Apêndice $\mathrm{G}$ apresenta um exemplo de arquivo de propriedade do aço de acordo a sintaxe apresentada. 


\section{A.1.7. Arquivos de propriedades mecânicas do concreto}

No início do arquivo de propriedades do concreto devem ser apresentadas as propriedades térmicas em função da temperatura conforme a sintaxe apresentada para o caso do modelo térmico.

YOUNG $\left[E_{c}\right]$
POISON $\left[v_{c}\right]$
TEMYOU $\left[\theta_{1}\right]\left[E_{c, \theta]}\right] \ldots\left[\theta_{i}\right]\left[E_{c, \theta i}\right] \ldots\left[\theta_{n}\right]\left[E_{c, \theta n}\right]$
TEMALP $\left[\theta_{l}\right]\left[\alpha_{c, \theta]}\right] \ldots\left[\theta_{i}\right]\left[\alpha_{c, \theta i}\right] \ldots\left[\theta_{n}\right]\left[\alpha_{c, \theta n}\right]$
TOTCRK FIXED
TENCRV EXPONE
TENSTR $\left[f_{c t}\right]$
GF1 $\left[G_{f}\right]$
TEMTST $\left[\theta_{1}\right]\left[f_{c t, \theta l}\right] \ldots\left[\theta_{i}\right]\left[f_{c t, \theta i}\right] \ldots\left[\theta_{n}\right]\left[f_{c t, \theta n}\right]$
TEMGF1 $\left[\theta_{1}\right]\left[G_{f, \theta 1}\right] \ldots\left[\theta_{i}\right]\left[G_{f, \theta i}\right] \ldots\left[\theta_{n}\right]\left[G_{f, \theta n}\right]$
COMCRV PARABO
COMSTR $\left[f_{c c}\right]$
GC $\left[G_{c}\right]$
TEMCST $\left[\theta_{1}\right]\left[f_{c c, \theta i}\right] \ldots\left[\theta_{i}\right]\left[f_{c c, \theta i}\right] \ldots\left[\theta_{n}\right]\left[f_{c c, \theta n}\right]$
SHRCRV $C O N S T A$
BETA $[\beta]$

Na última sintaxe valem:

* $E_{c} \quad-$ Módulo de elasticidade do concreto em temperatura ambiente;

* $v_{c} \quad$ - Coeficiente de Poisson do concreto;

* $E_{c, \theta i} \quad$ Módulo de elasticidade do concreto na temperatura $\theta_{i}$;

* $\alpha_{c, \theta i} \quad$ Coeficiente de dilatação térmica do concreto na temperatura $\theta_{i}$;

* $f_{c t} \quad$ - Resistência à tração do concreto em temperatura ambiente;

* $G_{f} \quad$ Energia de fraturamento do concreto à tração em temperatura ambiente;

- $f_{c t, \theta i}$ - Resistência à tração do concreto na temperatura $\theta_{i}$;

* $G_{f, \theta i} \quad$ Energia de fraturamento do concreto à tração na temperatura $\theta_{i}$.

* $f_{c c} \quad$ - Resistência à compressão do concreto em temperatura ambiente;

* $G_{c} \quad$ Energia de fraturamento do concreto à compressão em temperatura ambiente;

- $f_{c c, \theta i}$ - Resistência à compressão do concreto na temperatura $\theta_{i}$;

* $\beta \quad$ Coeficiente de retenção de cisalhamento adotado igual a 0,99.

O comando "TOTCRK FIXED" apresentado na última sintaxe estabelece que o modelo de fissuras adotado é o "fixed crack model", indicando que as fissuras têm suas direções fixas em relação às direções principais do vetor de deformação. 
A.1.8. Arquivo de propriedades da interface aço/concreto

\author{
DFLUX $\left[K_{r}\right]$ \\ DSTIF $\left[D_{11}\right]\left[D_{22}\right]$ \\ BONDSL 1 \\ SLPVAL $[c]\left[\Delta u_{t}^{0}\right]$
}

Onde $K_{r}\left(W / m^{2 o} C\right)$ é o coeficiente de condução térmica na interface. Caso as duas últimas linhas dessa sintaxe sejam retiradas, o modelo de cálculo para a interface se torna com rigidez linear. O comando "BONDSL 1" indica que o modelo utilizado é o Bond-slip cúbico (Figura 3.16a). Para definição de $D_{11}, D_{22}, c$ e $\Delta u_{t}^{0}$ ver item 3.4.1.5.

\title{
A.1.9. Carregamentos mecânicos
}

PROPERTY LOADS GRAVITY [Load name] [Load case] ALL [g] Z

PROPERTY LOADS PRESSURE [Load name] [Load case] [SUP] [q]

Onde, $g$ é o valor da aceleração da gravidade (no caso, considerada na direção $Z$ ) e SUP a superfície onde é aplicada a carga distribuída $q$.

A.1.10. Definição dos materiais e atribuição aos SETs

PROPERTY MATERIAL [Nome do material] EXTERNAL EXTERNAL [arquivo]

PROPERTY MATERIAL [Nome do material] FLOW BOUNDARY CONVECRA [ $\alpha_{c}$ ] [convective power] [emissividade]

PROPERTY MATERIAL [Nome do material] FLOW BOUNDARY CONVECTI $\left[\alpha_{c}\right.$ ] [convective power]

PROPERTY MATERIAL [Nome do material] FLOW INTERFACE [resistência da interface]

PROPERTY ATTACH [Nome do SET] MATERIAL [Nome do material]

OBS: O convective power funciona como um expoente na diferença de temperatura entre o meio e o material, acelerando o processo de troca de calor, considerado com valor unitário.

\section{A.1.11. Condições de contorno}

PROPERTY BOUNDARY CONSTRAINT [Part] [Dir]

PROPERTY BOUNDARY MPC RBEAM [SlavePart] [Master Node] [Dir]

Onde, Part é a parte da estrutura (pontos, superfícies, sólidos ou SETs) onde serão aplicados as condições de contorno, SlavePart a parte da estrutura aos quais fazem parte os slaves nodes e Dir a direção da restrição. 


\section{A.2. Comandos para processamento em arquivos de lotes}

O primeiro passo para realizar o processamento em arquivos de lotes é configurar o script de leitura do iDIANA (ArqEnt.txt), apresentado no Apêndice B. Deve-se incrementar no início do script as seguintes linhas de comando:

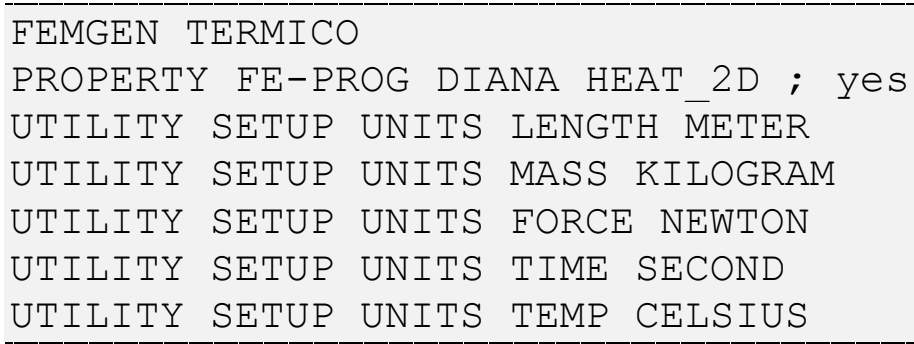

E no final do script os comandos para encerramento do iDIANA:

Com o script configurado, o próximo passo é colocar todos os arquivos de dados (o script de entrada de dados, os arquivos de propriedades do aço, concreto, interface e superfície de troca de calor, a curva de incêndio e o arquivo de comando [MODELO.com]) em uma única pasta, abrir um editor de texto (Bloco de notas, por exemplo), inserir o código abaixo e salvar na mesma pasta com a extensão ".bat".

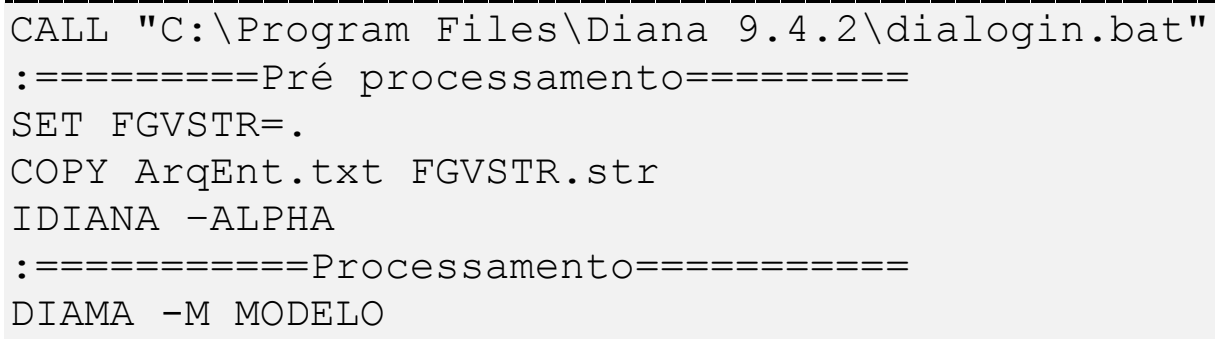

Vale notar que o arquivo de comando (MODELO.com) deve possuir o mesmo nome do arquivo de dados gerados pelo iDIANA (MODELO.dat). No caso do processamento de vários modelos, alguns arquivos se tornam interessante de serem excluídos para evitar muito "lixo" na pasta, isso pode ser realizado por meio do comado "DEL [nome_do_arquivo]". Em alguns casos também é interessante renomear alguns arquivos com o comando "REN [nome_do_arquivo] [Novo_nome]". Esses comandos devem estar no arquivo com a extensão ".bat".

Para o funcionamento do arquivo de lotes é necessário adicionar o DIANA na variável de ambiente do sistema. Neste caso basta abrir a janela de propriedades do sistema (disponível no Painel de controle do Windows), clicar em "variáveis de ambiente" e em "Variáveis do sistema" adicionar a pasta "C: $\backslash$ Program Files Diana 9.4.2 Vin" (ou a pasta onde se encontra o arquivo executável do DIANA) no final da variável "path". 


\section{Apêndice B - Arquivo Batch para análise térmica}

Nas Figuras B1 e B2 são apresentadas as nomenclaturas dos pontos, linhas, superfícies e SETs utilizados para a modelagem numérica, de acordo as Figuras A.1 e A.2, visando auxiliar no entendimento do script para geração da geometria do modelo numérico.

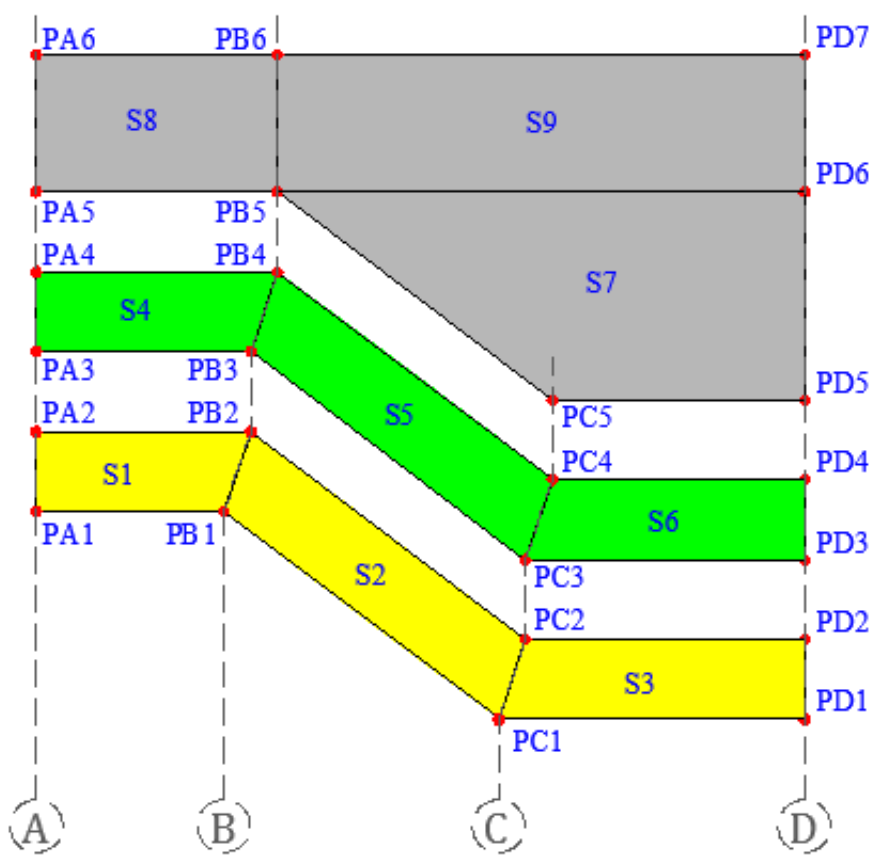

Figura B1 - Nomenclatura adotada para os pontos (Pij) e superfícies $(\mathrm{Sj})$ do modelo térmico

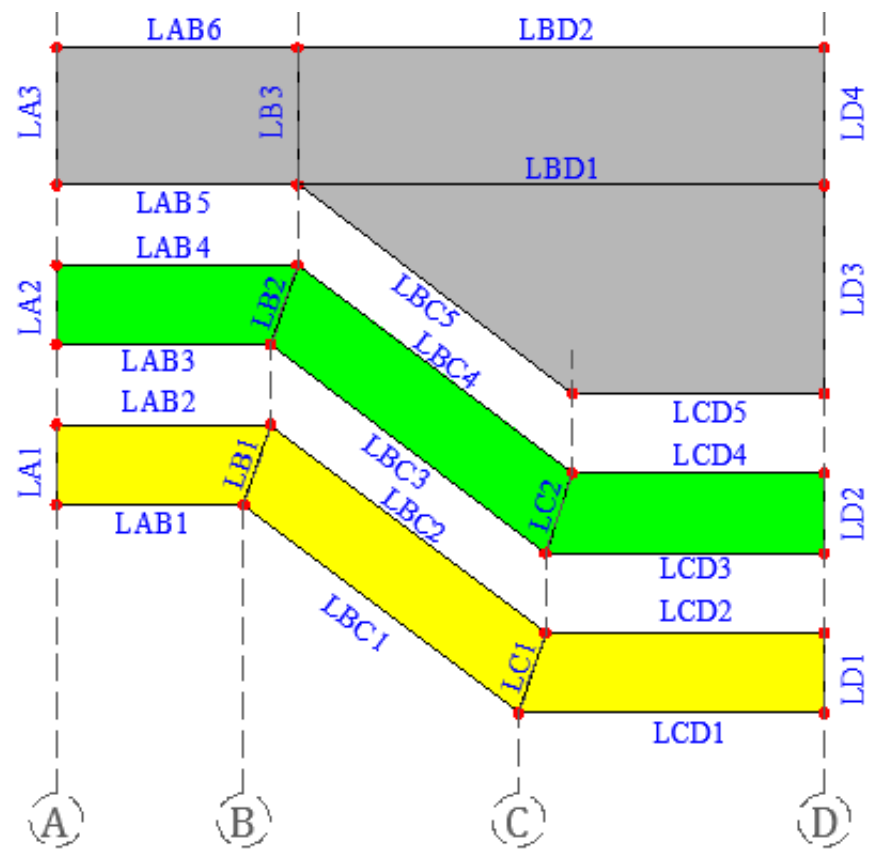

Figura B2 - Nomenclatura adotada para as linhas do modelo térmico

A seguir, um exemplo do arquivo de texto utilizado para a geração do modelo térmico bidimensional. 


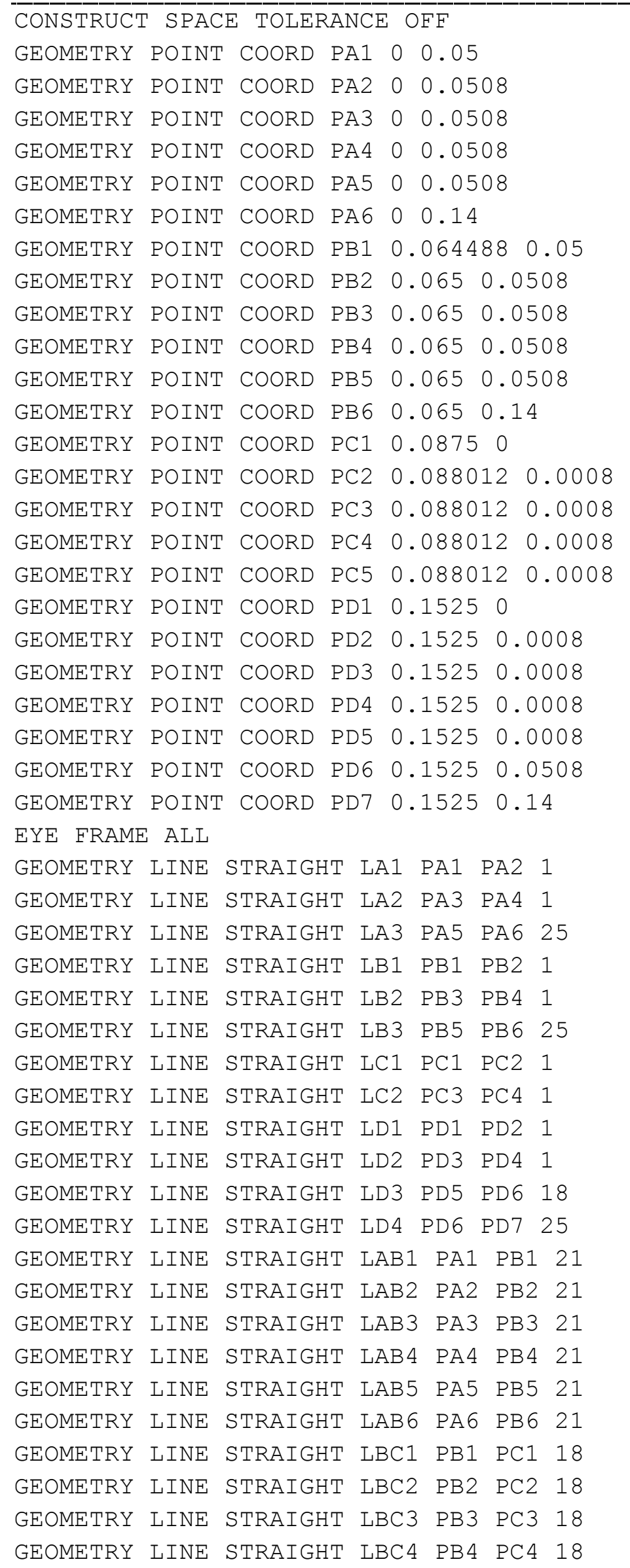




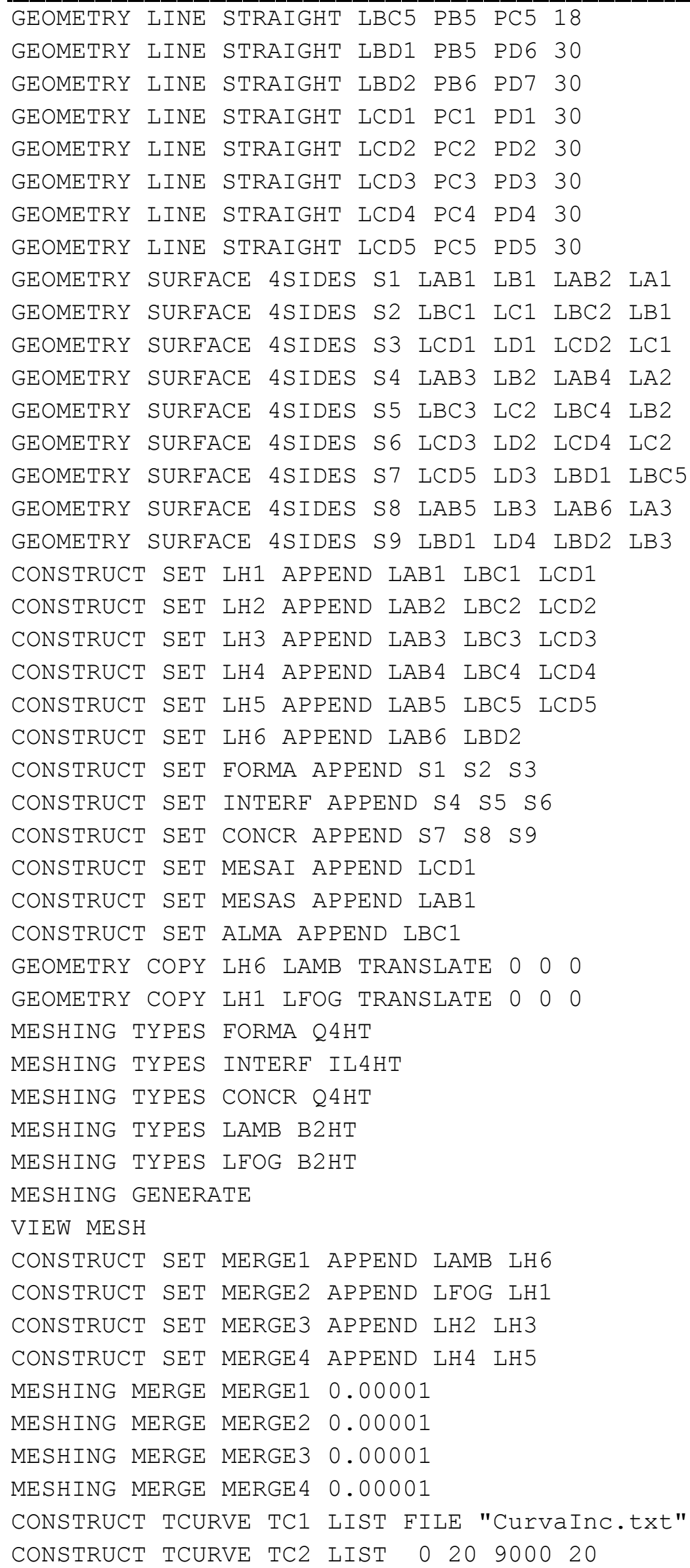




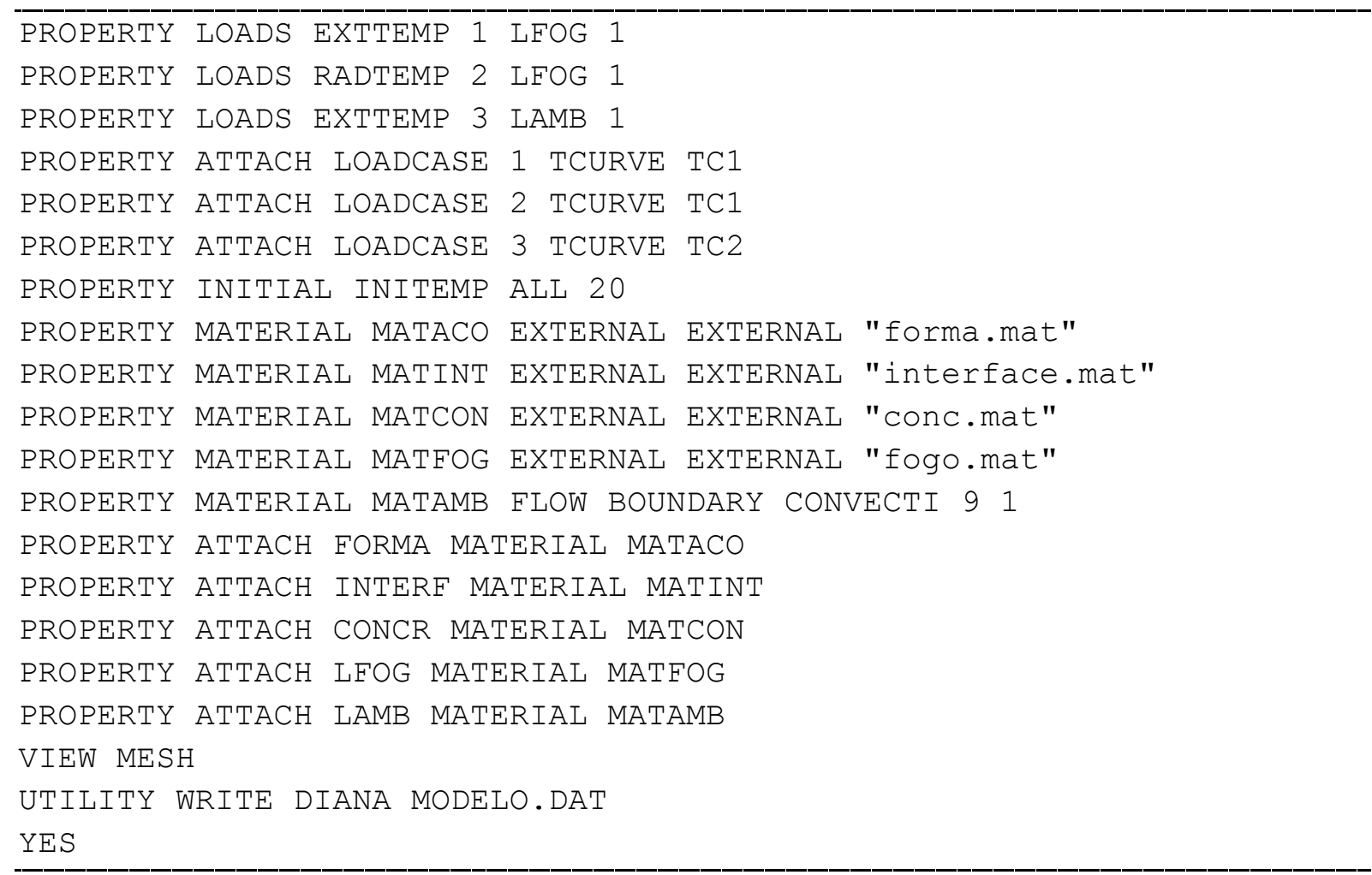




\section{Apêndice C - Arquivos de propriedades térmica dos materiais e de processamento}

\section{C.1. Arquivo de propriedade do aço (aço.dat)}

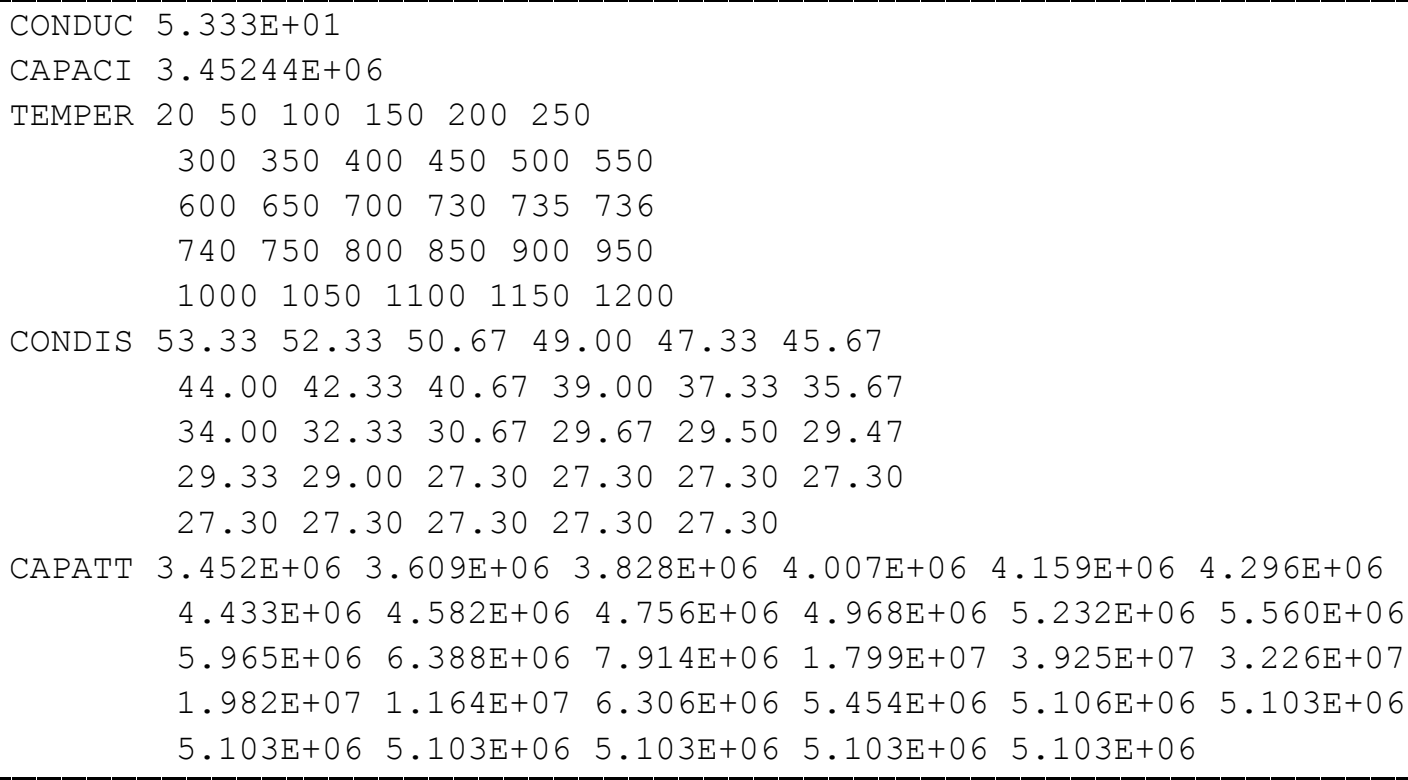

\section{C.2. Arquivo de propriedade do concreto (conc.dat)}

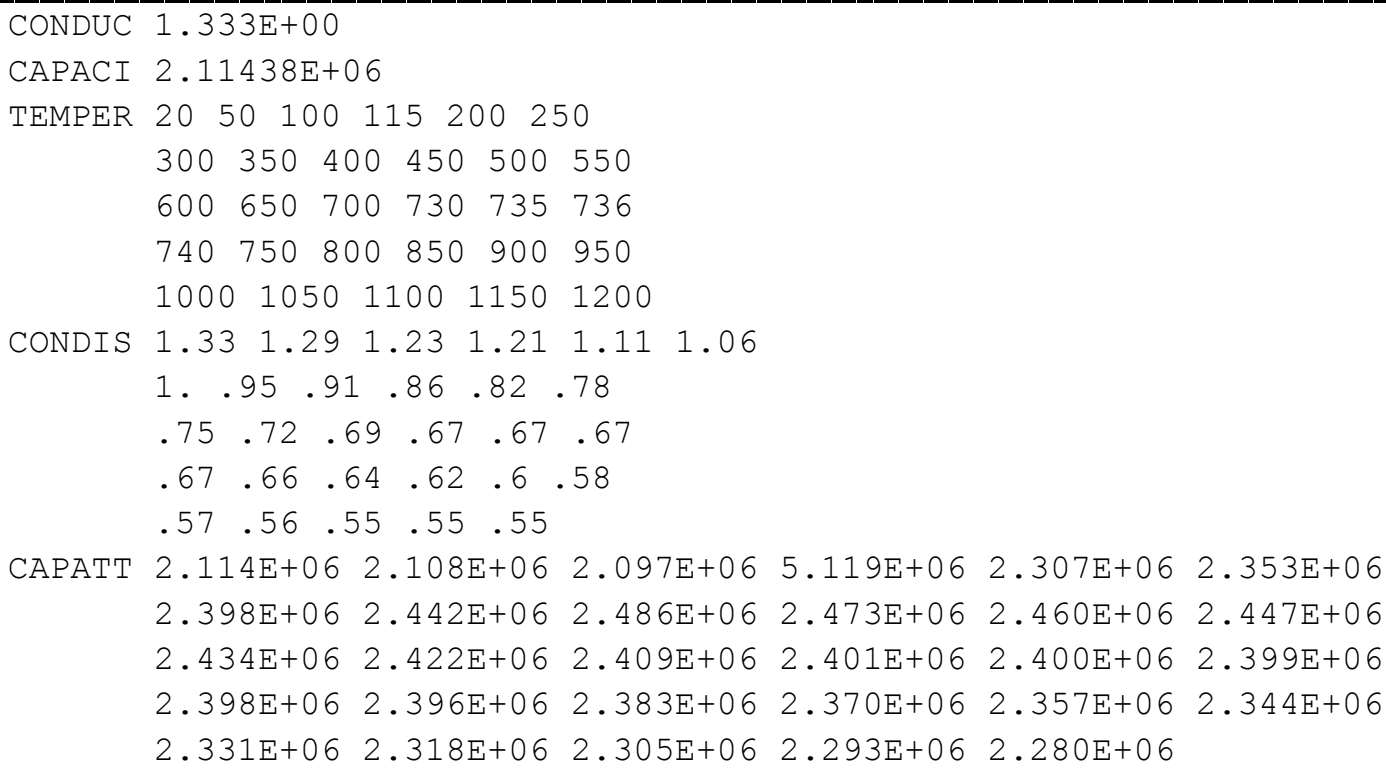

C.3. Arquivo de propriedade da superfície em contato com o fogo (fogo.dat) 


\section{C.4. Arquivo de processamento do modelo térmico}

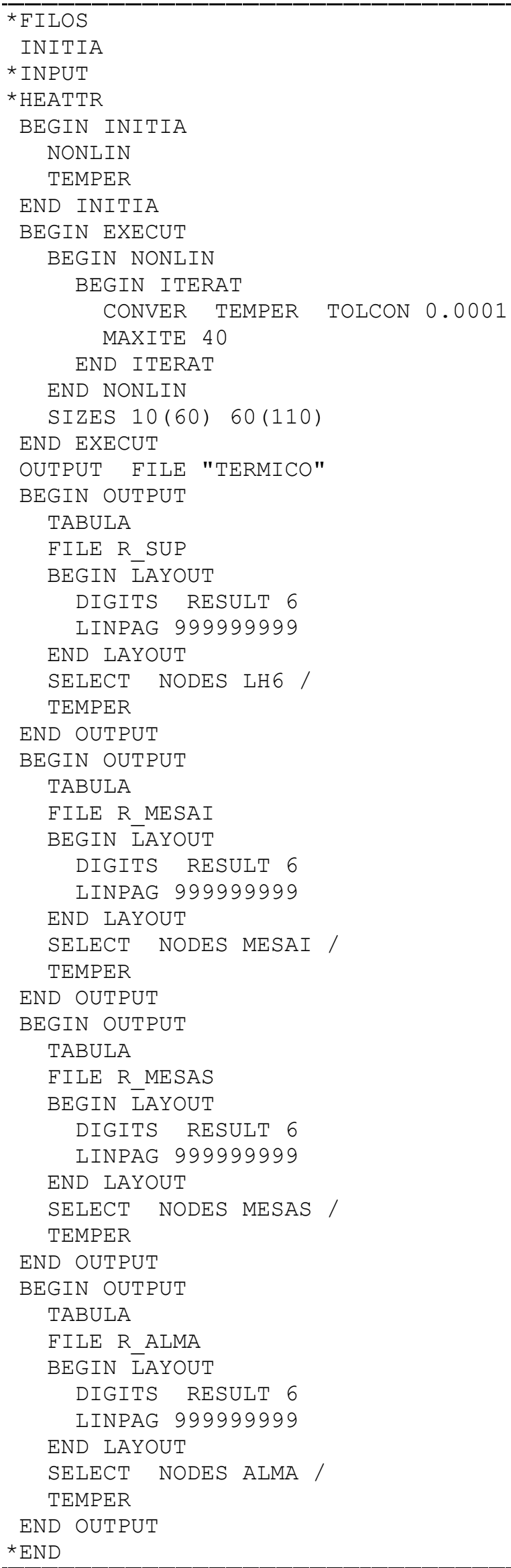




\section{Apêndice D - Procedimento para cálculo do momento fletor plástico}

O código computacional foi desenvolvido na linguagem Visual Basic disponível no Visual Studio 2012 da Microsoft e recebeu a denominação de LaMix. O programa possui um banco de dados onde ficam armazenados os campos térmicos, as coordenadas nodais e as conectividades dos elementos finitos gerados pelo pacote computacional DIANA, para diversas alturas de laje, emissividade do aço, resistência térmica na interface e umidade do concreto. A Figura D.1 apresenta o fluxograma simplificado utilizado para implementação computacional do pós-processador desenvolvido.

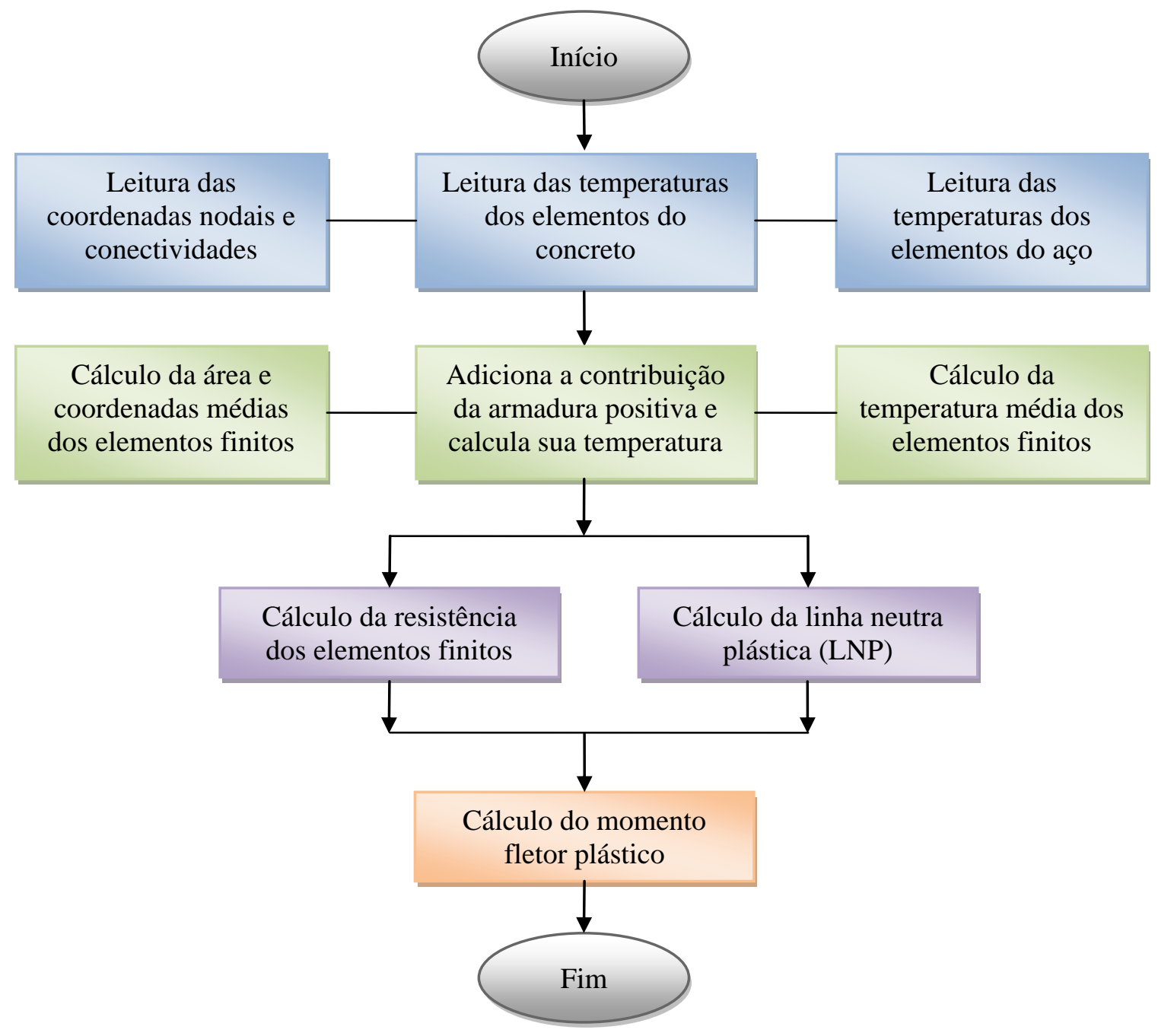

Figura D.1 - Fluxograma simplificado para cálculo do momento fletor plástico da laje mista

$\mathrm{Na}$ etapa inicial faz-se a leitura das coordenadas nodais e conectividades dos elementos finitos e leitura das temperaturas dos elementos finitos do concreto e da fôrma de aço. Esses dados ficam armazenados em arquivos de texto e correspondem às saídas de dados 
do DIANA, porém foram resumidos para redução de espaço ocupado na memória do computador.

Posteriormente calculam-se as temperaturas e coordenadas médias e as áreas de cada elemento finito. Com isso obtém-se a resistência de cada elemento finito em função da temperatura e a posição da linha neutra plástica, que é determinada por um procedimento iterativo que finaliza do instante em que o somatório das forças resistentes de compressão de cada elemento finito do concreto $\left(\mathrm{F}_{\mathrm{c}, \theta \mathrm{i}}\right)$ se iguala ao somatório das forças resistentes de tração de cada elemento finito do aço $\left(\mathrm{F}_{\mathrm{s}, \theta \mathrm{j}}\right)$, ou seja,

$$
\sum_{i=1}^{N c} F_{c, \theta i}=\sum_{j=1}^{N s} F_{s, \theta j}
$$

Por fim calcula-se o momento fletor plástico resistente, que é tomado igual ao somatório dos produtos das forças resistentes dos elementos infinitesimais $\left(F_{c, \theta i}\right.$ e $\left.F_{s, \theta j}\right)$ pela sua distância da linha neutra plástica $\left(\mathrm{y}_{\mathrm{ci}}\right.$ e $\left.\mathrm{y}_{\mathrm{s}, \mathrm{j}}\right)$, de acordo a Equação D.2.

$$
M F P=\sum_{i=1}^{N c} F_{c, \theta i} \times y_{c, i}+\sum_{j=1}^{N s} F_{s, \theta j} \times y_{s, i}
$$

Para cálculo do momento plástico resistente considerou-se as seguintes hipóteses:

- Iteração total entre a fôrma de aço e o concreto;

- Armaduras e fôrma de aço resistindo somente à tração;

- Concreto resistindo somente a compressão.

No Apêndice E são apresentadas todas as sub-rotinas e funções utilizadas para cálculo do momento fletor plástico da laje mista em temperatura elevada e ambiente.

Nas Figuras D.2 a D.14 são apresentados a tela principal do programa e as telas de resultados gráficos e tabulados. Para todas as opções gráficas, o programa também apresenta os resultados numéricos na parte inferior da tela.

Na tela principal do programa (Figura D.2), existe diversas opções para entrar com os dados da laje mista. Os resultados exibidos nesta tela referem-se aos momentos fletores resistentes positivo e negativo, numérico e segundo o EUROCODE 4 Part 1-2 (2005) ou ABNT NBR 14323:2013. À medida que o usuário escolhe as opções nas caixas de listagem, como altura total da laje, umidade do concreto, coeficiente de condução térmica, tipo de fôrma de aço e emissividade resultante, o código computacional desenvolvido buscas os campos térmicos da laje em um banco de dados que foi previamente processado no DIANA e calcula os resultados apresentados. Esse procedimento é bem rápido para processar, uma vez que os campos térmicos já estão calculados. 


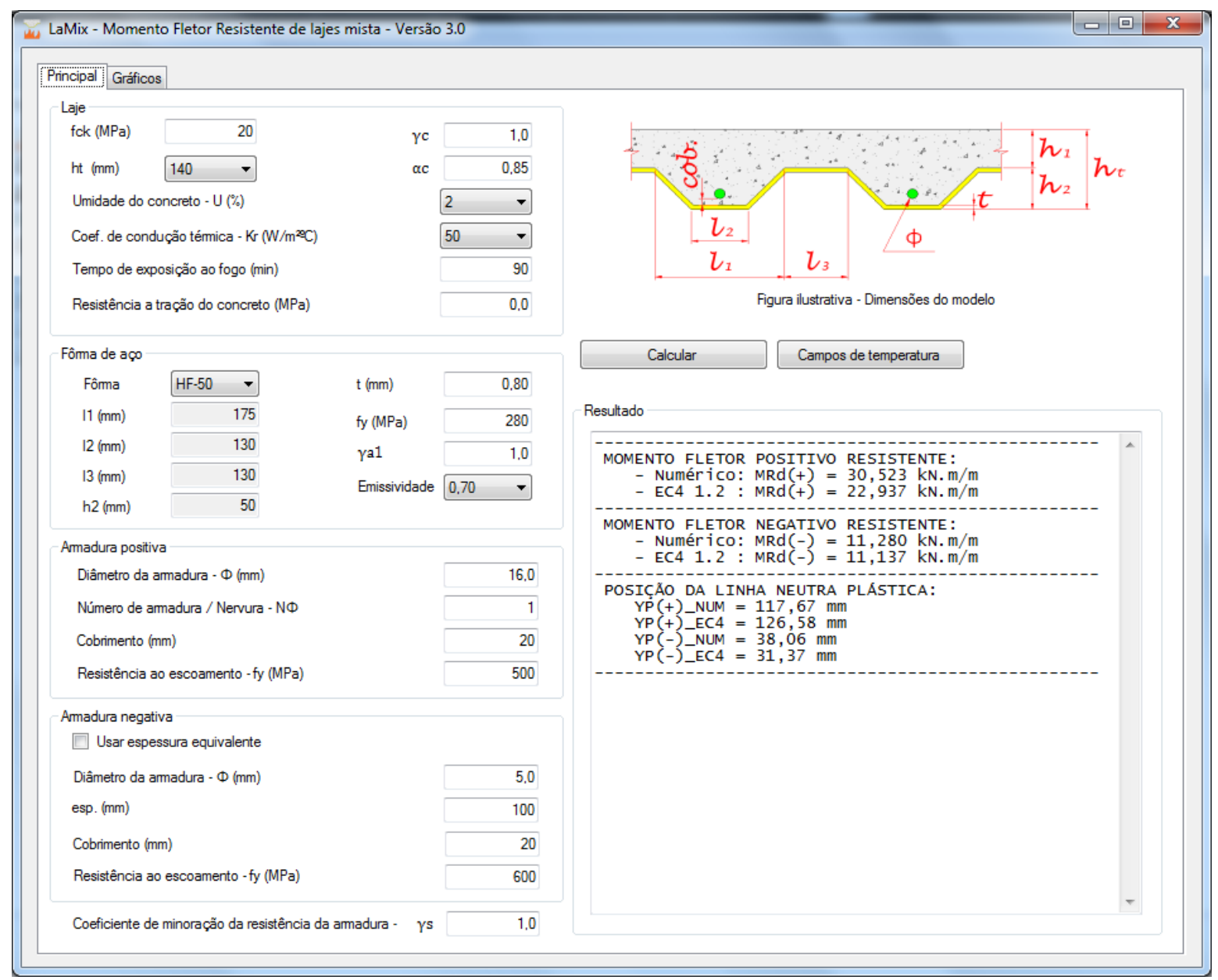

Figura D.2 - Tela principal de entrada de dados e resultados

Quando o usuário clica no botão "Campos de temperatura" é apresentada a tela na forma da Figura D.3. Nessa tela é possível observar a evolução dos campos térmicos na laje para diversos tempos de exposição (variando de 5 em 5 minutos) ao clicar no botão “+”, “_“ ou clicar na "caixa de texto" referente ao tempo e pressionar "seta para cima" ou "seta para baixo" para aumentar ou diminuir o tempo respectivamente.

Pela Figura D.3, quando o usuário escolhe a opção dos limites de temperatura manual, somente são plotadas as temperaturas que apresentam limites dentro dos valores estabelecidos. Neste caso se tem os campos térmicos apresentados na Figura D.4, onde é possível observar que os elementos finitos que apresentam temperaturas abaixo e acima dos limites estabelecidos aparecem em preto. Isso permite visualizar um coisa interessante, que é definir um limite manual (por exemplo, 300 a $500{ }^{\circ} \mathrm{C}$ ), clicar na "caixa de texto" referente ao tempo e pressionar e segurar "seta para cima" ou "seta para baixo". Neste caso é possível observar um "caminhamento" do fluxo térmico ao longo da altura da laje. 


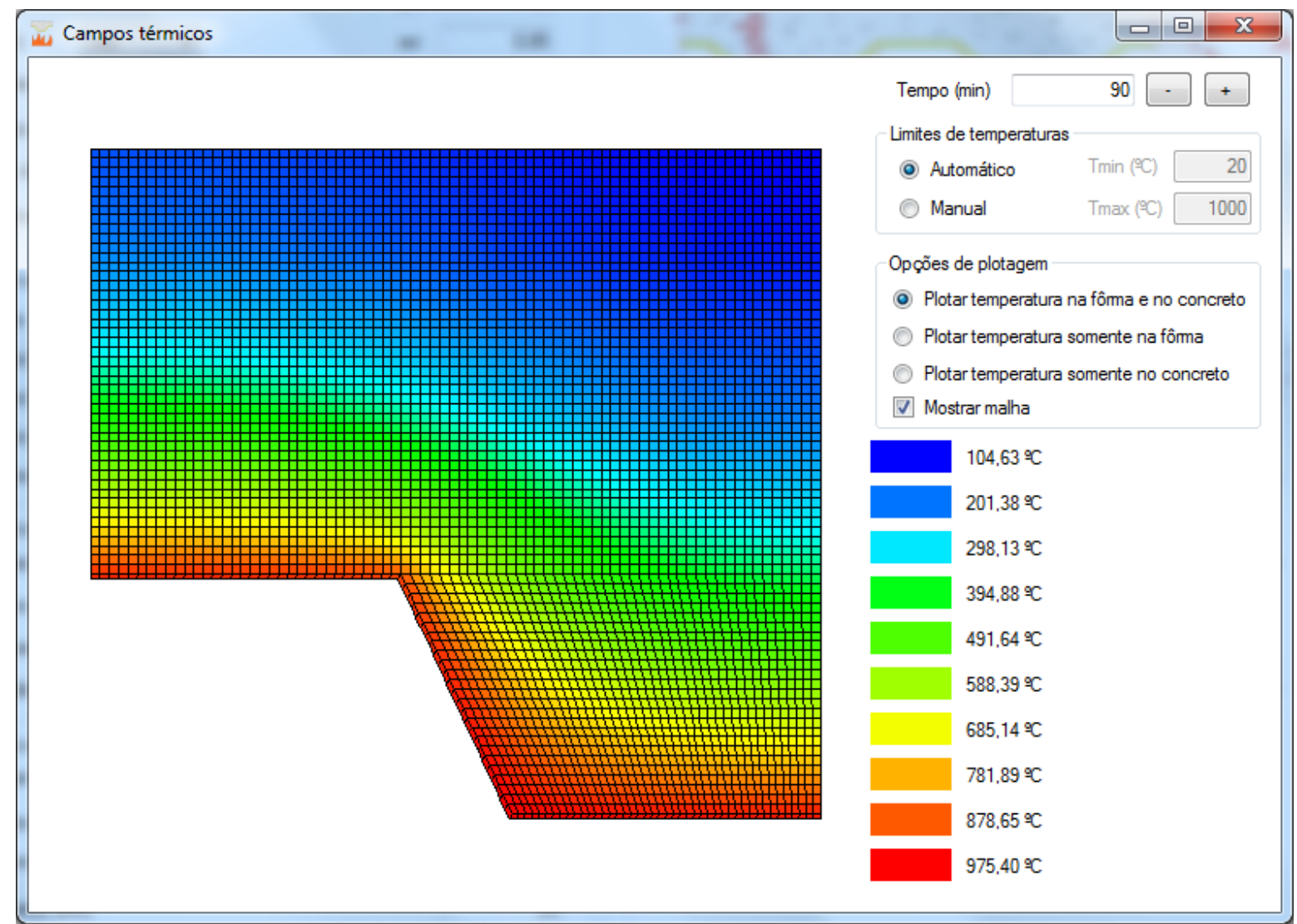

Figura D.3 - Exemplo de campos térmicos na laje (limites te temperatura automático).

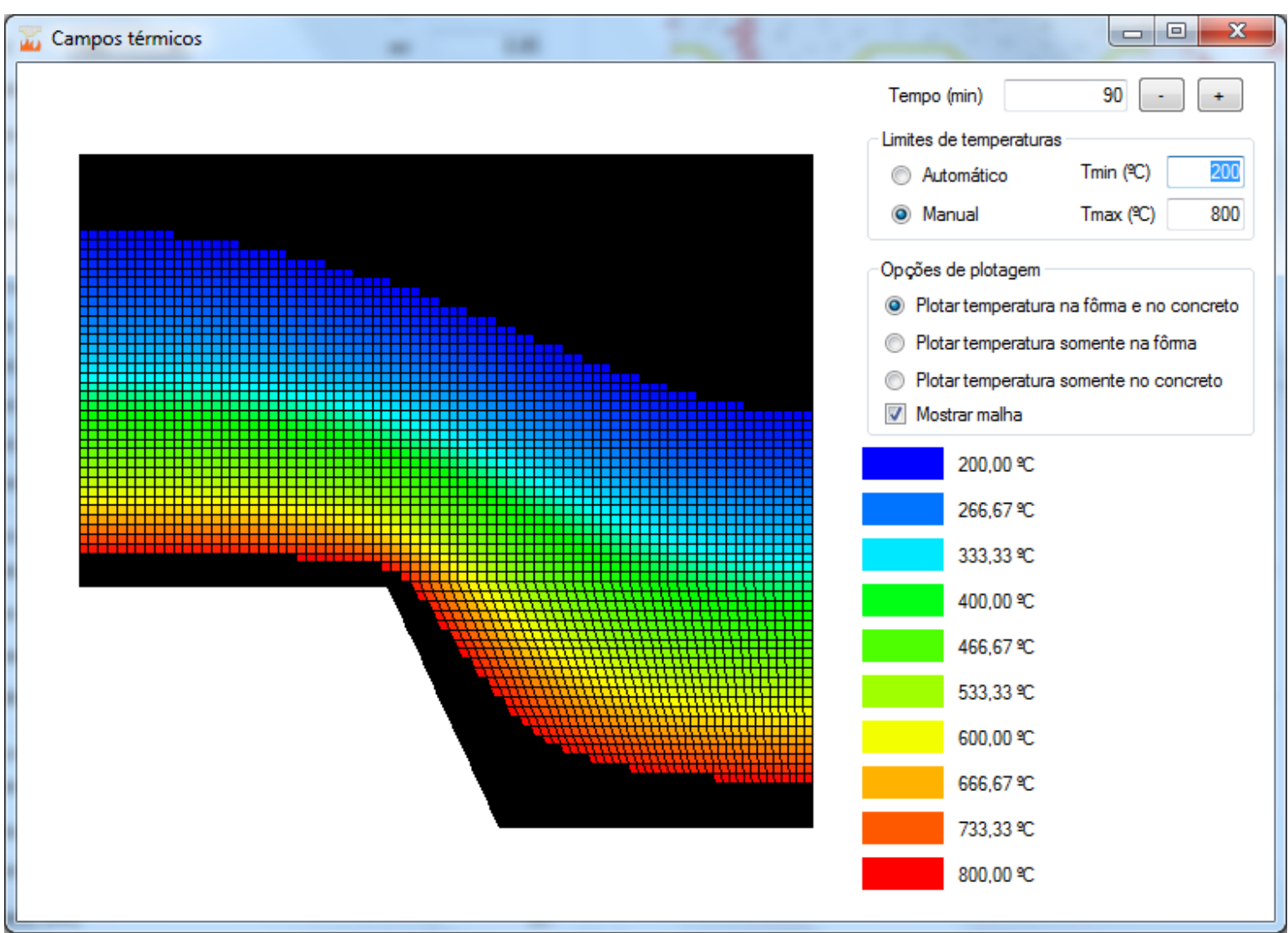

Figura D.4 - Exemplo de campos térmicos na laje (limites te temperatura manual). 
A seguir são apresentadas as telas de resultados gráficos e numéricos gerado pelo aplicativo. Vale mencionar que os dados utilizados para cálculo são aqueles estabelecidos pelo usuário na tela principal do programa, a não ser quando é variável gráfica. Neste caso o programa altera os valores internamente para plotar o gráfico, como tempo, $u_{f 3}$ e $h_{t}$.

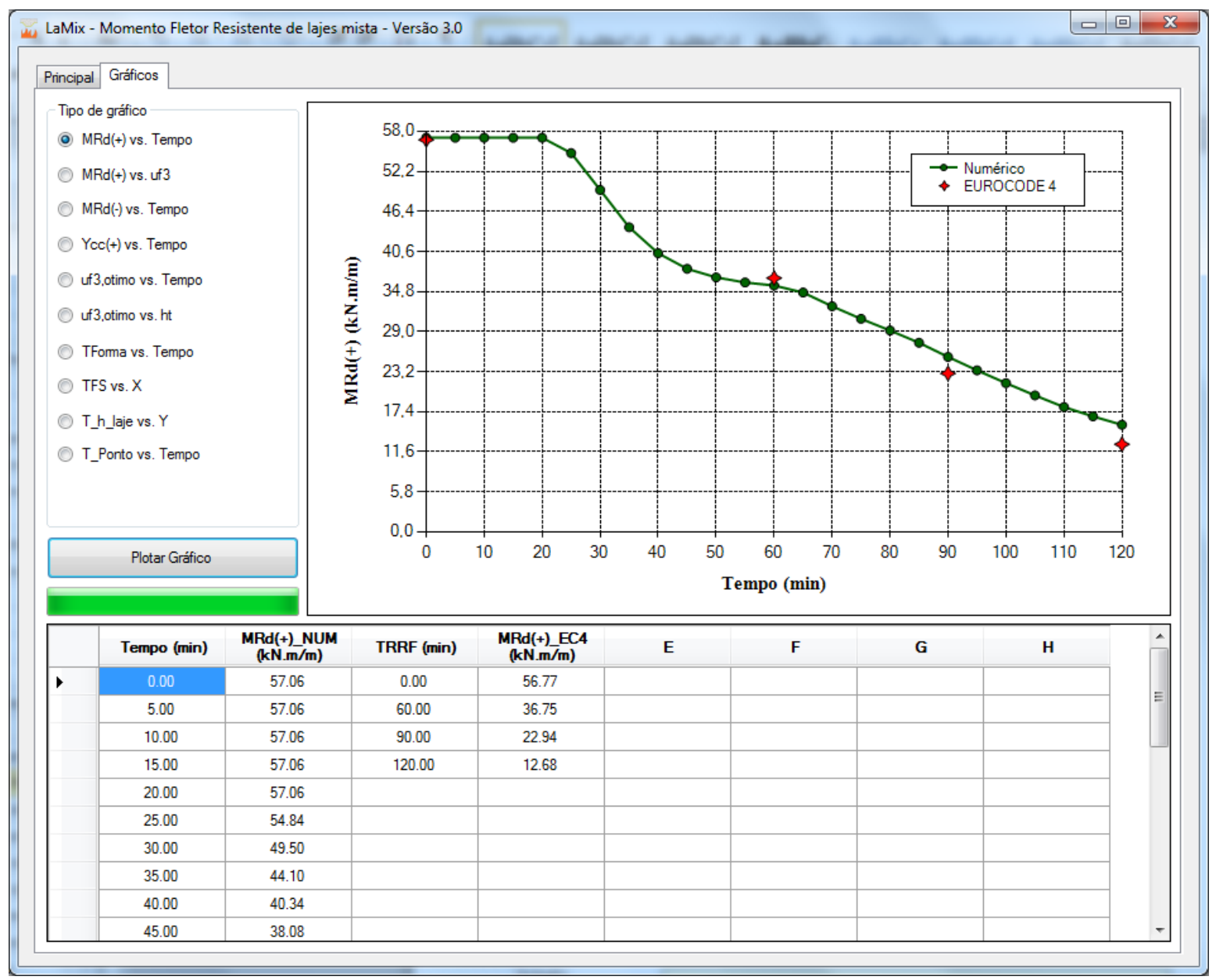

Figura D.5 - Resultados gráficos: Momento fletor plástico resistente vs. Tempo de exposição.
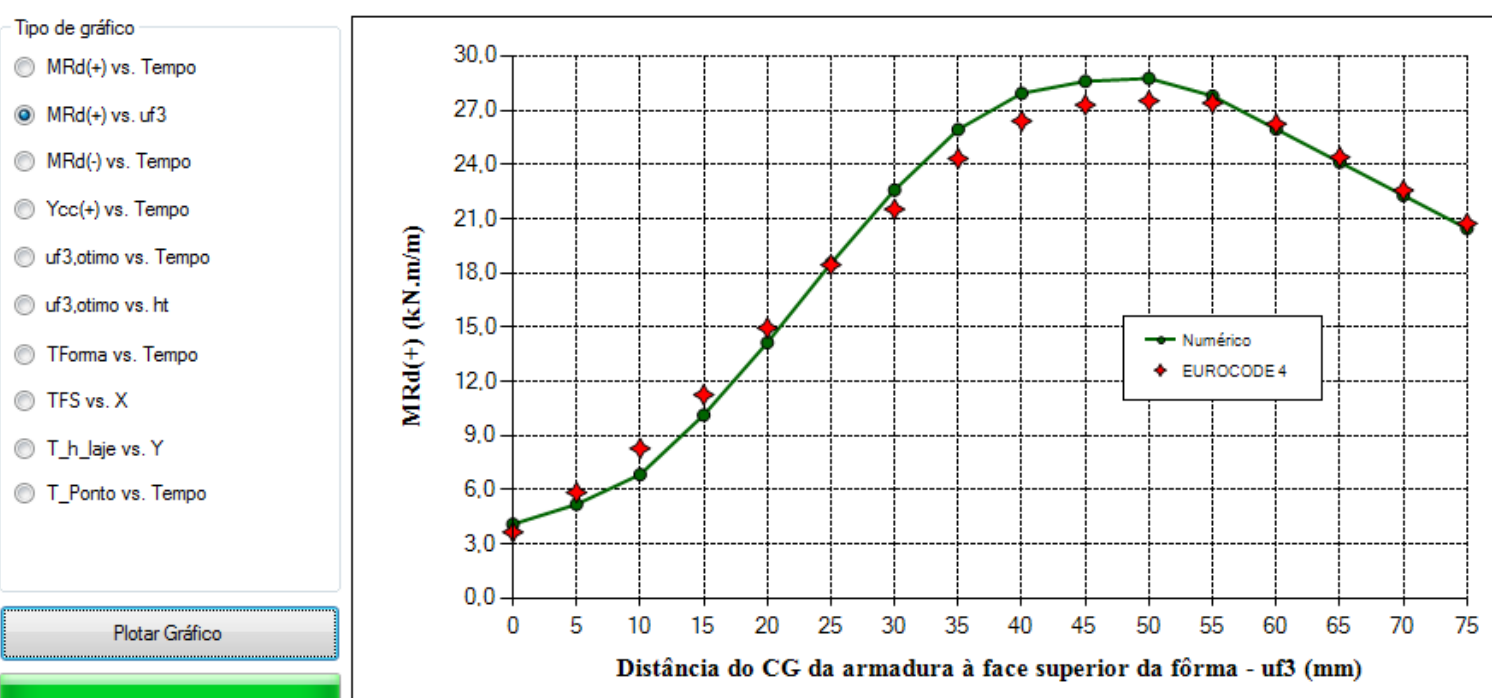

Figura D.6 - Resultados gráficos: Momento fletor plástico resistente vs. Distância do CG da armadura à face superior da forma $\left(u_{f 3}\right)$. 


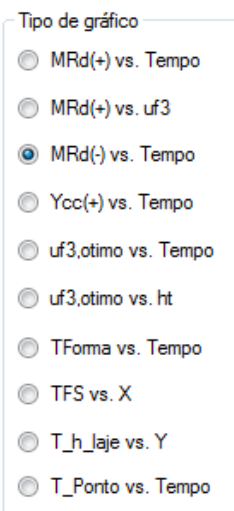

Plotar Gráfico

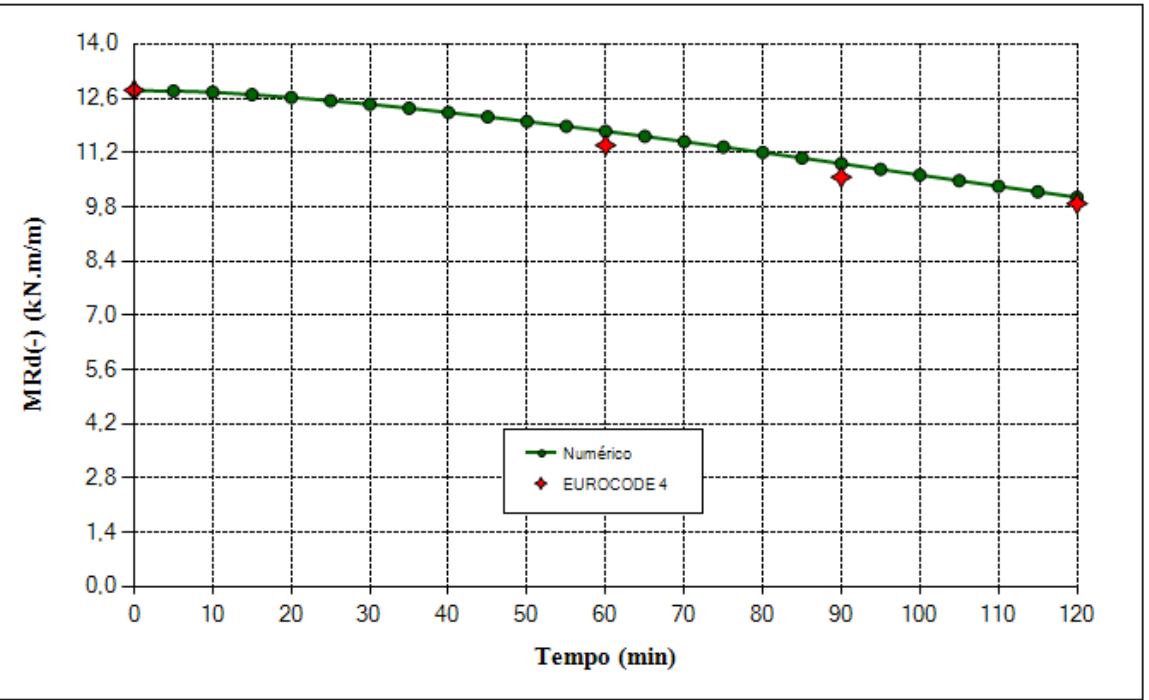

Figura D.7 -Resultados gráficos: Momento fletor negativo resistente vs. Tempo de exposição.

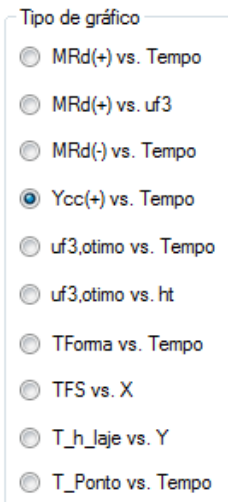

Plotar Gráfico

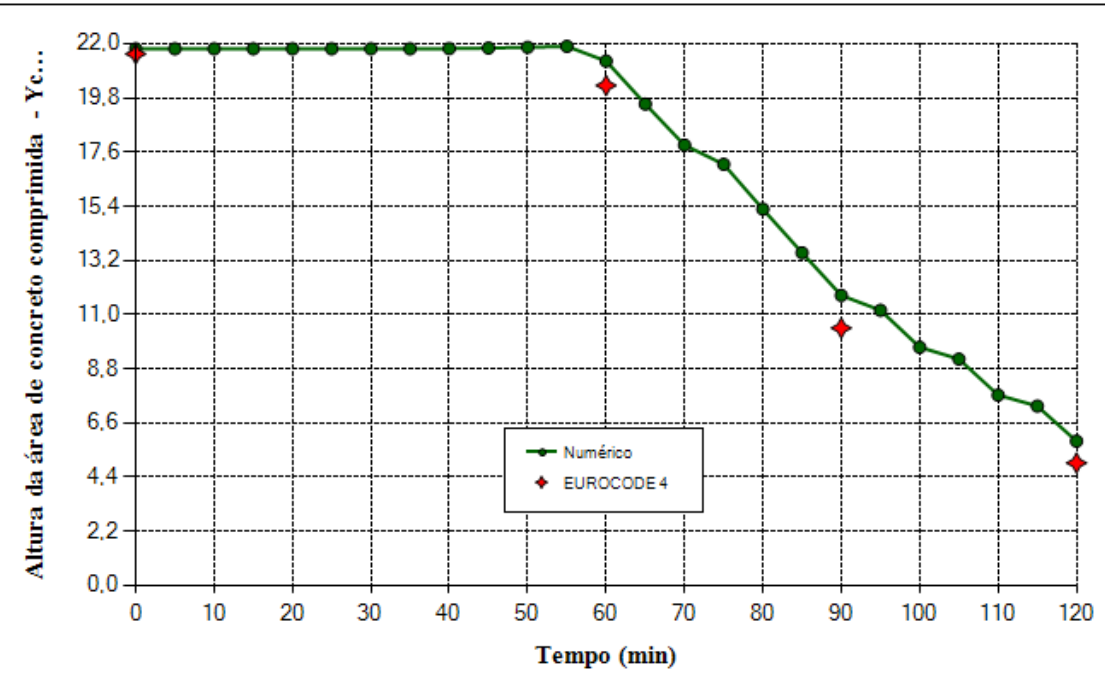

Figura D.8 - Resultados gráficos: Altura da porção de concreto comprimido vs. Tempo de exposição.
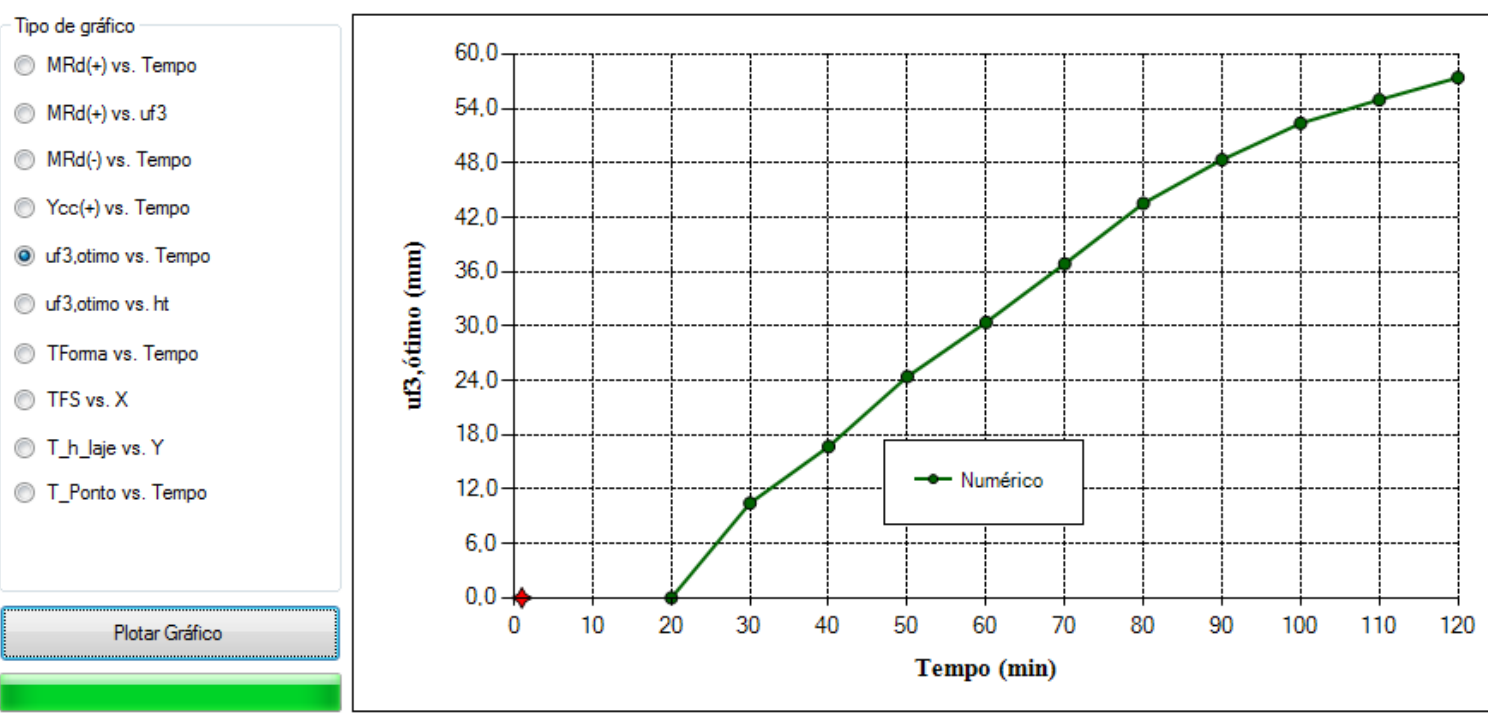

Figura D.9 - Resultados gráficos: $u_{f 3, \text { titimo }} v s$. Tempo de exposição. 


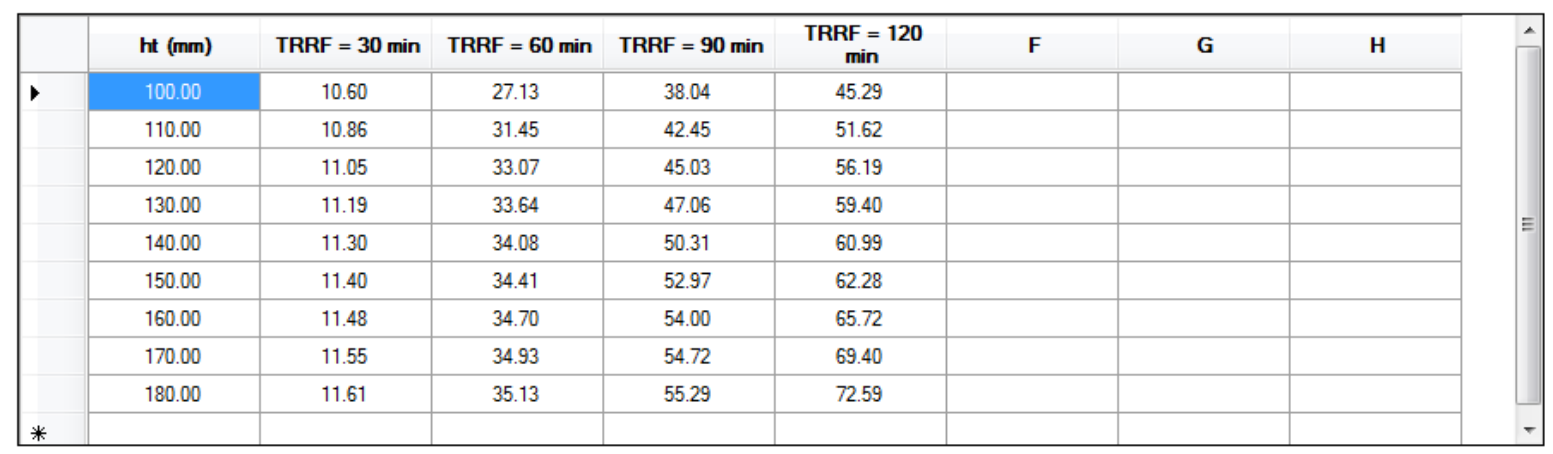

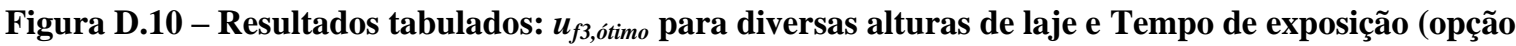
"uf3,ótimo vs. ht")

\begin{tabular}{|c|c|c|c|c|c|c|c|c|}
\hline & Tempo (min) & TMS_NUM ( $\left.{ }^{\circ} \mathrm{C}\right)$ & TA_NUM $\left({ }^{\circ} \mathrm{C}\right)$ & TMI_NUM ('C) & Tempo (min) & TMS_NBR ( $\left.{ }^{\circ} \mathrm{C}\right)$ & TA_NBR $\left({ }^{\circ} \mathrm{C}\right)$ & TMI_NBR ( $\left.{ }^{\circ} \mathrm{C}\right)$ \\
\hline \multirow[t]{4}{*}{ • } & 30.00 & 494.55 & 627.09 & 601.28 & 30.00 & 0.00 & 0.00 & 0.00 \\
\hline & 60.00 & 818.82 & 883.69 & 871.09 & 60.00 & 676.91 & 744.60 & 844.59 \\
\hline & 90.00 & 922.96 & 968.98 & 960.04 & 90.00 & 829.11 & 883.55 & 948.21 \\
\hline & 120.00 & 985.88 & 1023.19 & 1016.04 & 120.00 & 912.95 & 959.24 & 1009.29 \\
\hline * & & & & & & & & \\
\hline
\end{tabular}

Figura D.11 - Resultados tabulados: Temperatura dos componentes da fôrma de aço (mesa inferior, alma e mesa superior) numéricos e segundo a ABNT NBR 14323:2013 (opção “TForma vs. Tempo")

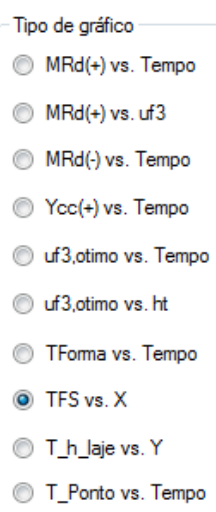

Plotar Gráfico

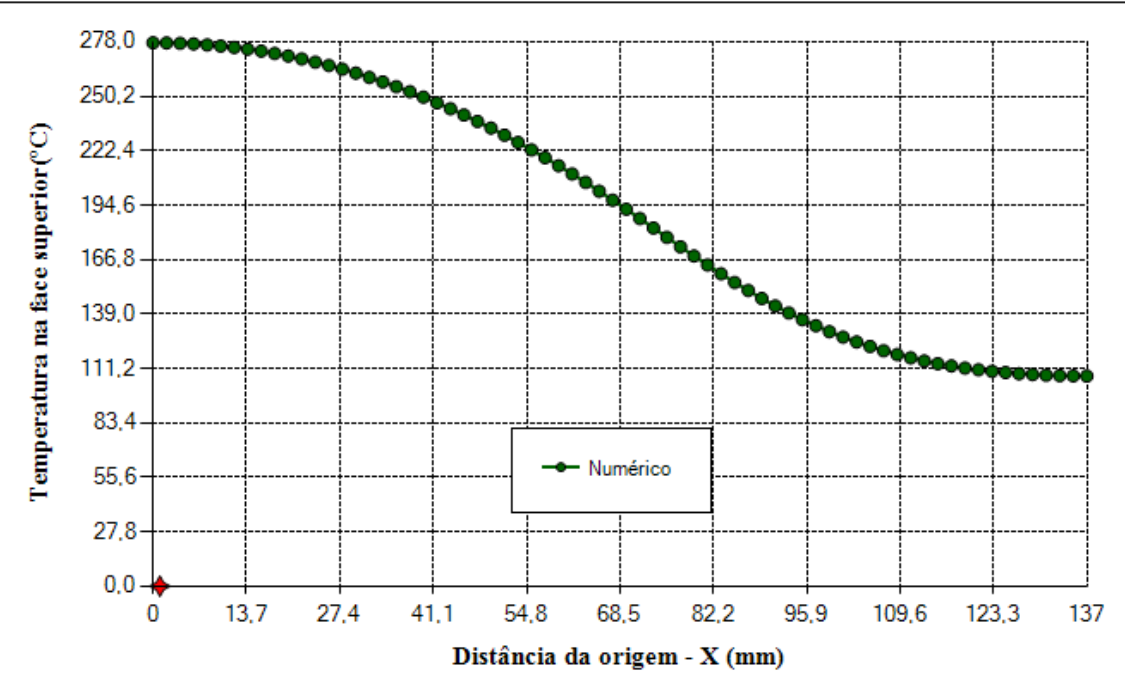

Figura D.12 - Resultados gráficos: Variação da temperatura da face superior do concreto 

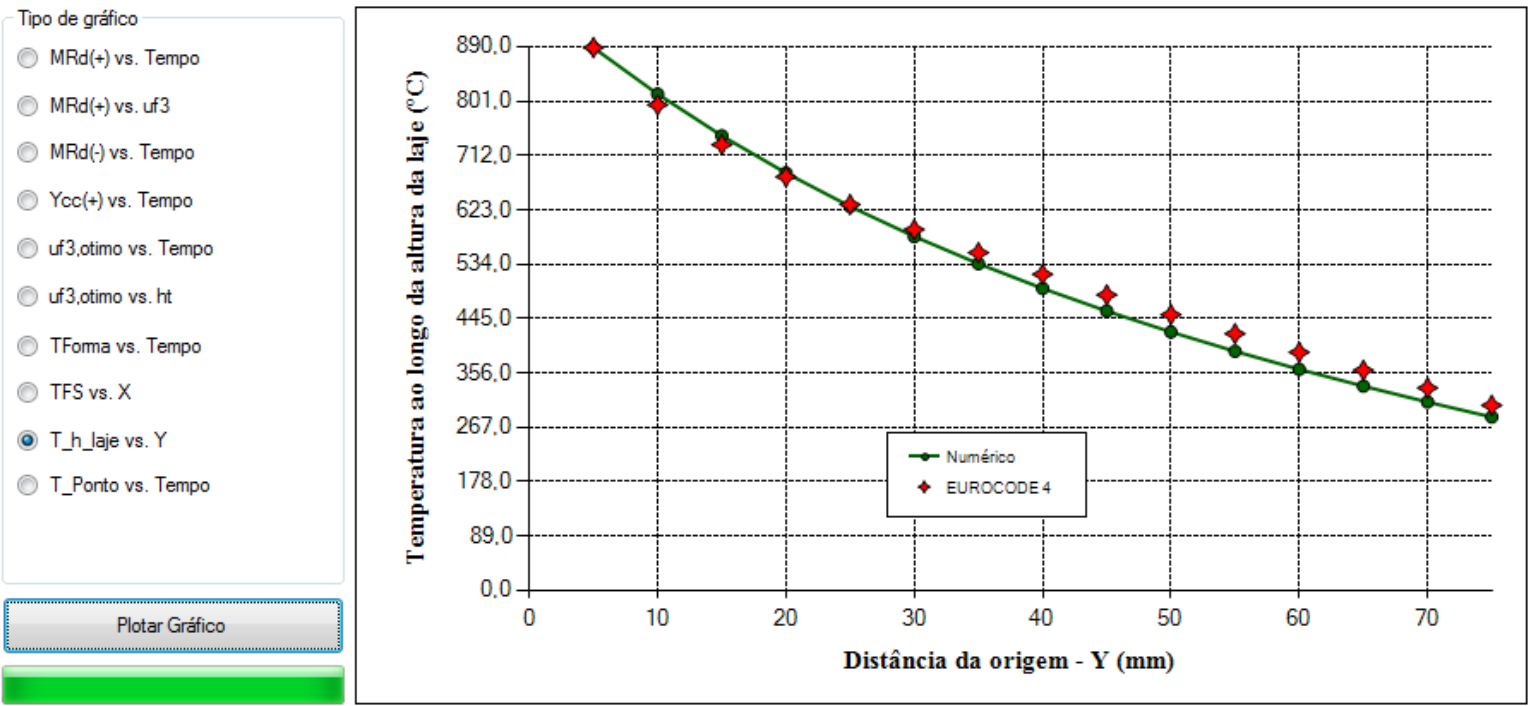

Figura D.13 - Resultados gráficos: Temperatura ao longo da altura da laje (ou temperatura da armadura) vs. Distância da origem (Y).
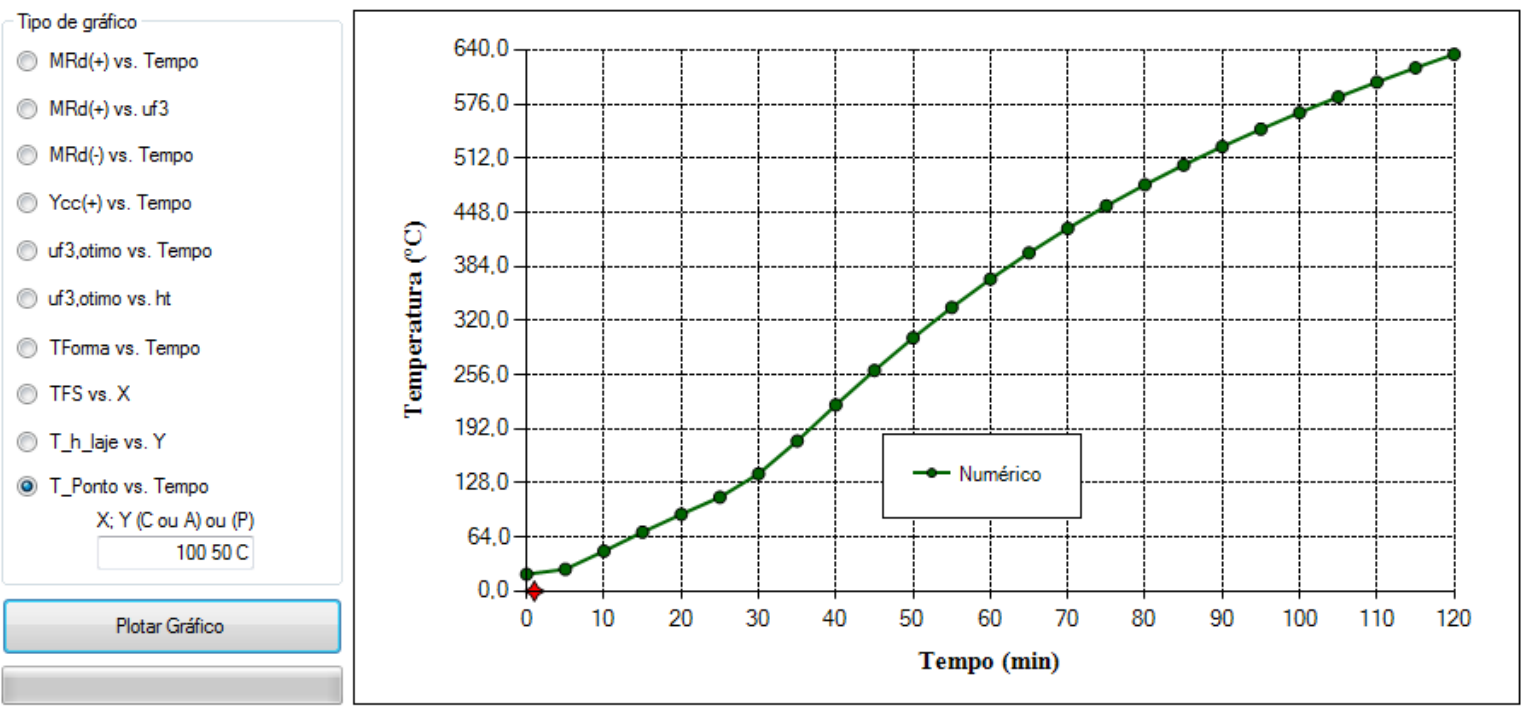

Figura D.14 - Resultados gráficos: Temperatura em um ponto específico da laje vs. Tempo de exposição

Com relação à Figura D.14 os resultados referentes à caixa de texto "X Y (C ou A) ou (P)" referem-se a três valores: coordenadas $\mathrm{X}, \mathrm{Y}$ e se o ponto refere ao concreto $(\mathrm{C})$ ou ao aço (A), separados por espaço. Ou, se preferir, o usuário pode digitar um único valor de 1 a 7 , neste caso as temperaturas referem-se a pontos característicos (1 a 7) de acordo a Figura D.15.

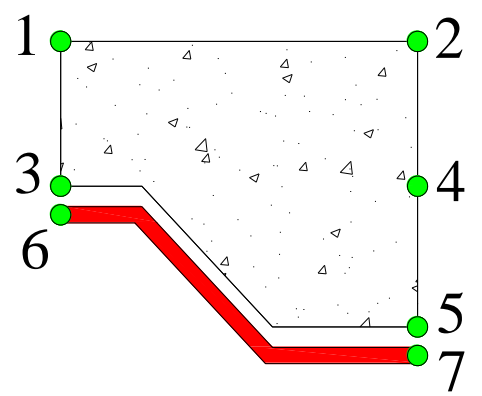

Figura D.15 Pontos característicos para plotagem da temperatura 


\section{Apêndice E - Subrotinas computacionais para cálculo do momento fletor plástico resistente}

Neste apêndice são apresentadas as principais sub-rotinas e funções utilizadas para cálculo do momento fletor plástico da laje mista em temperatura elevada e ambiente.

\section{E.1. Subrotina principal}

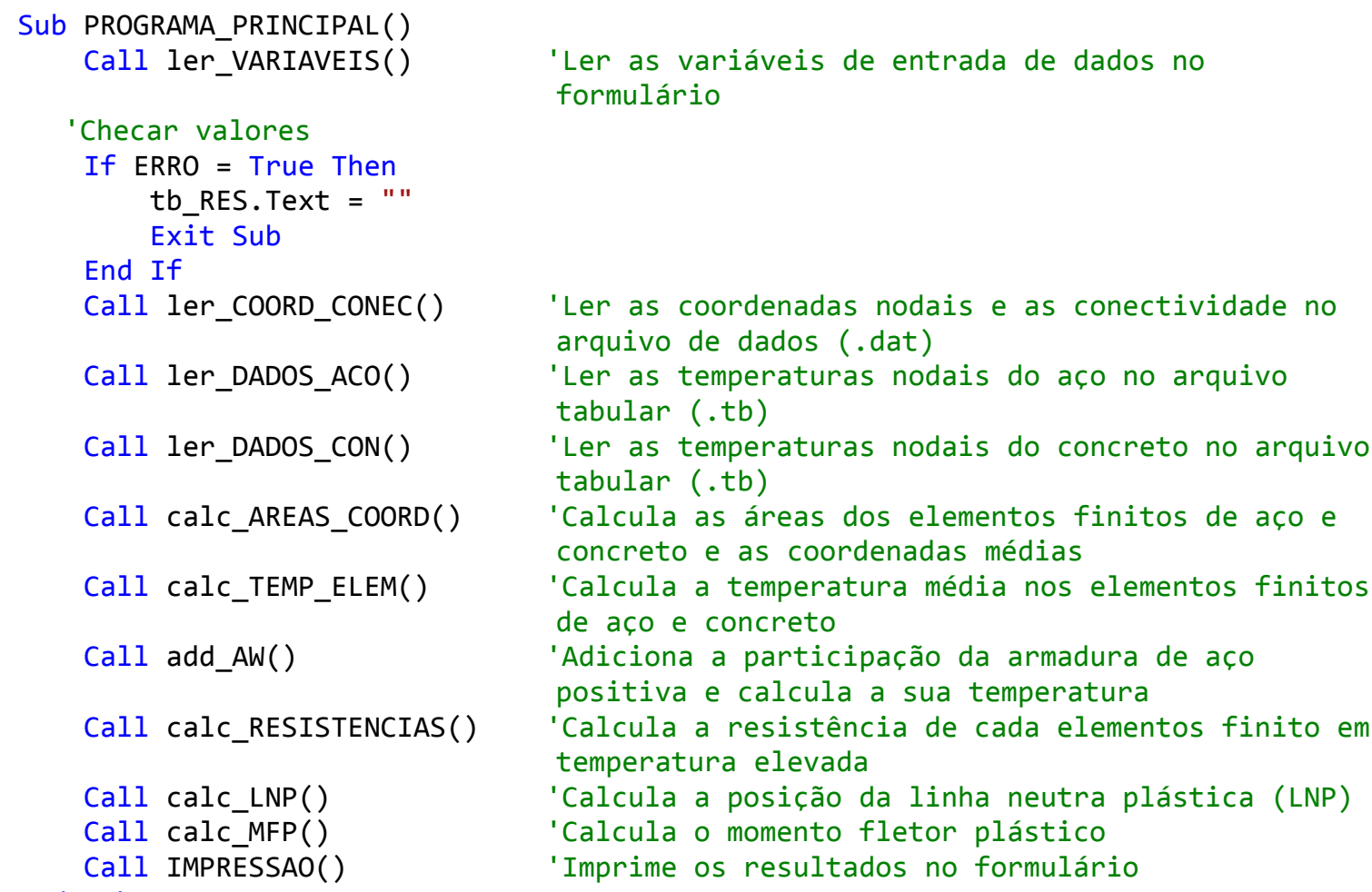

\section{E.2. Subrotina para leitura de dados do formulário}

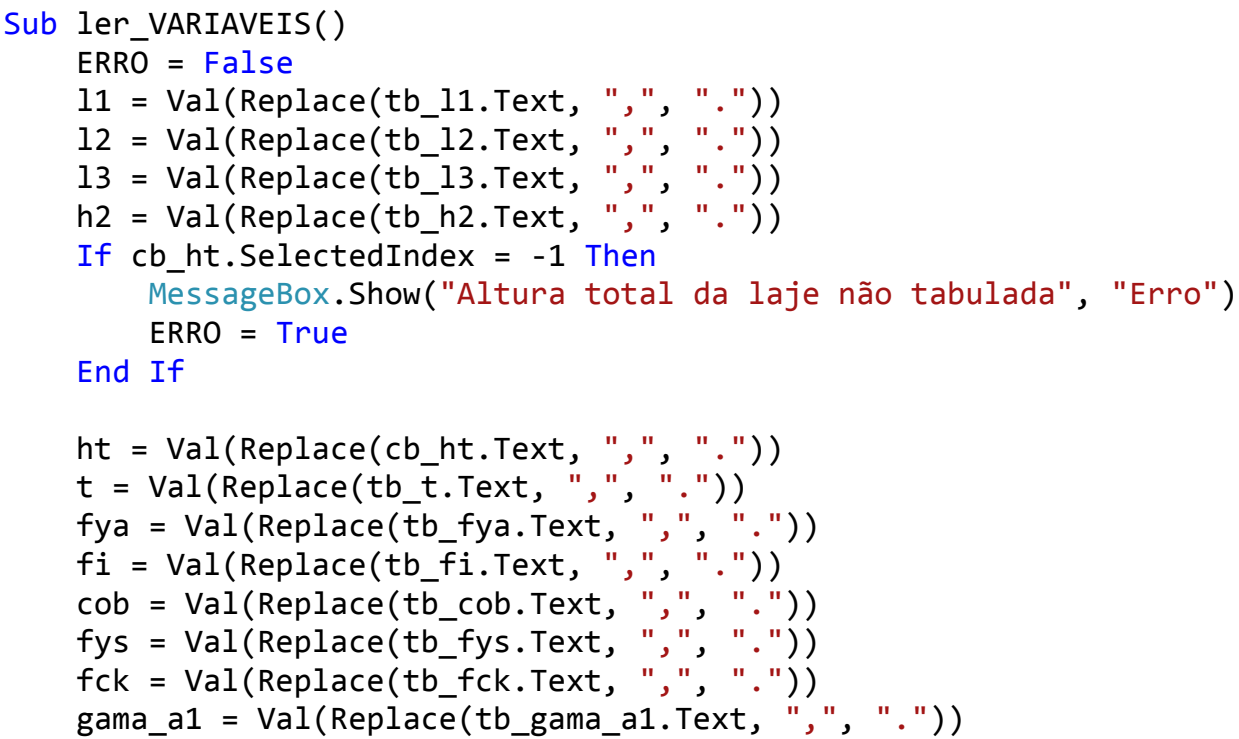




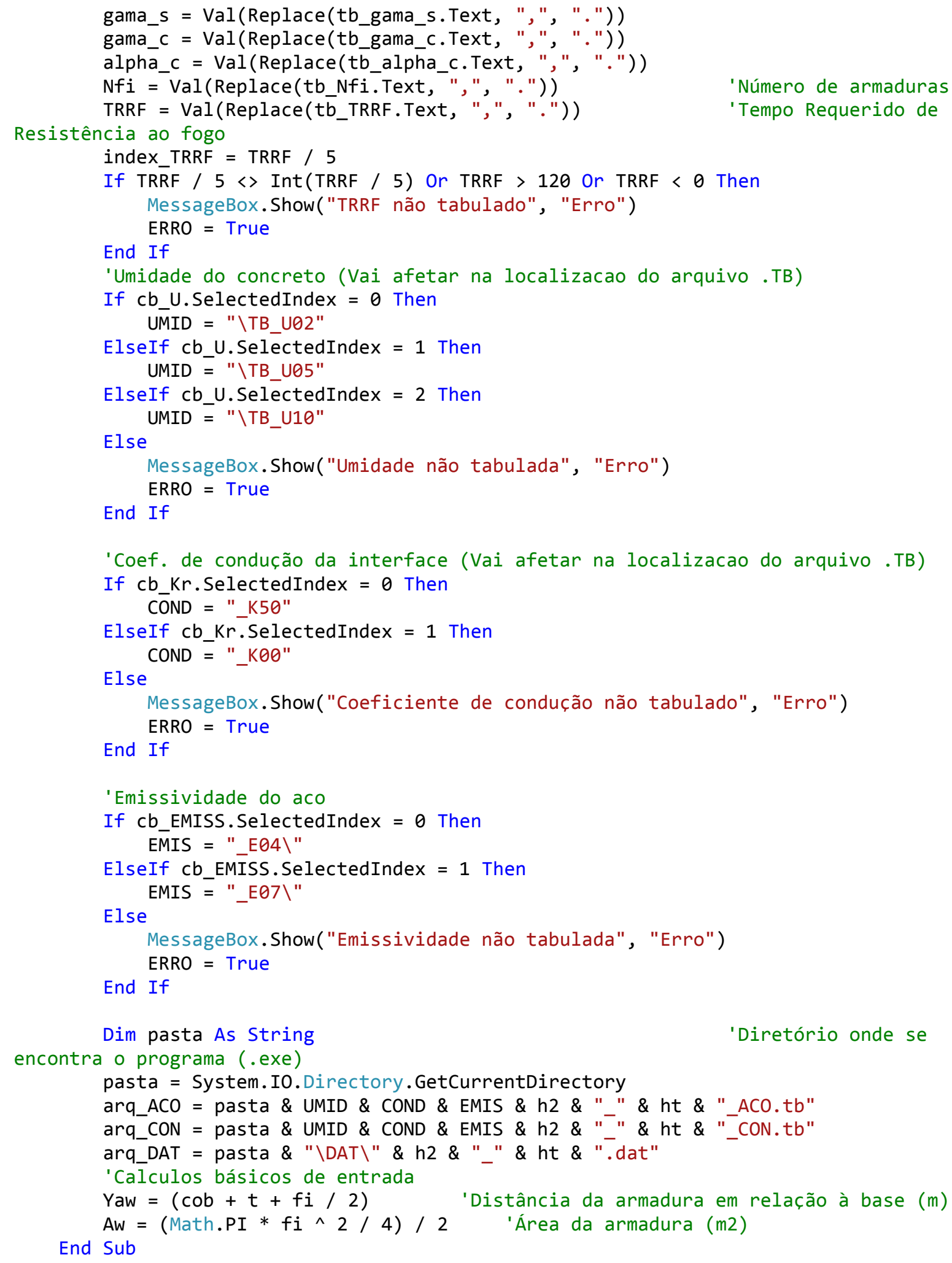

E.3. Subrotina para leitura das coordenadas nodais e conectividades dos elementos finitos

Sub ler_COORD_CONEC( )

Dim linha

FileOpen(1, arq_DAT, OpenMode.Input) 


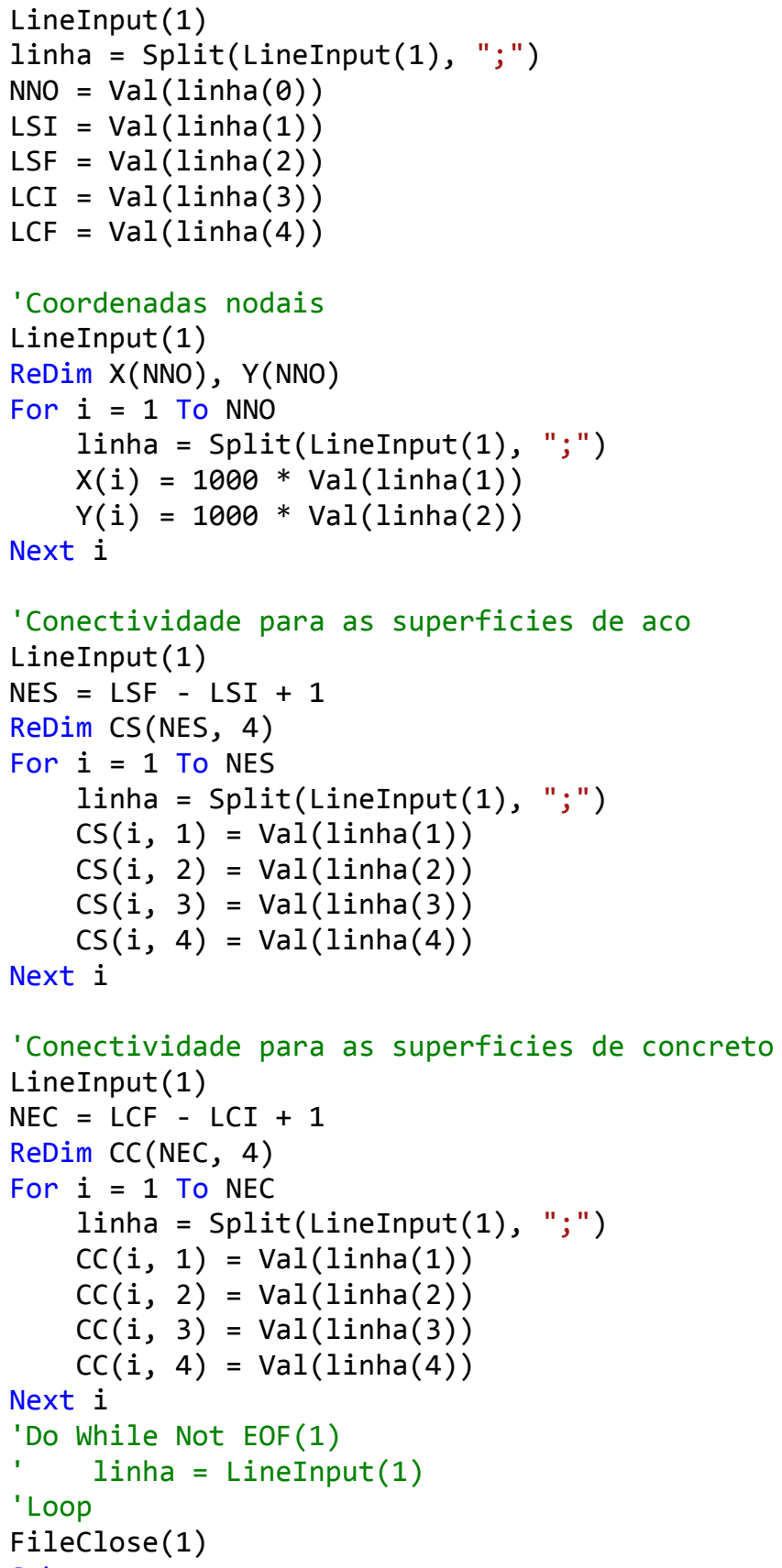

'Conectividade para as superficies de concreto LineInput (1)

\section{E.4. Subrotina para leitura dos campos térmicos do aço}

Sub ler_DADOS_ACO( )

Dim linha

Fileopen(1, arq_ACO, OpenMode.Input)

LineInput(1)

linha $=$ Split (LineInput $(1), " ; ")$

NNS $=\operatorname{Val}(\operatorname{linha}(0))$

LNS $=\operatorname{Val}(\operatorname{linha}(1))$

ReDim TNS(24, LNS)

LineInput (1)

Dim M As Integer

For $i=1$ To NNS

linha $=\operatorname{Split}(\operatorname{LineInput}(1), "$;") 


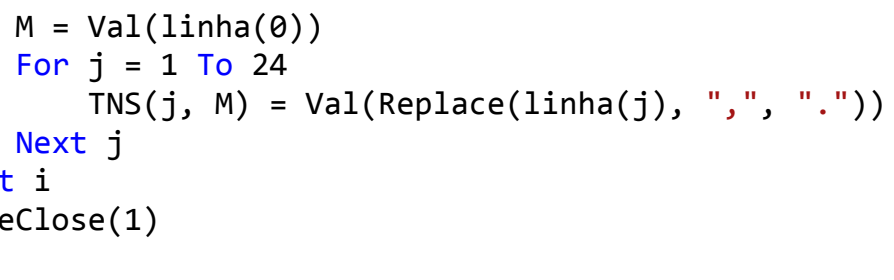

\section{E.5. Subrotina para leitura dos campos térmicos do concreto}

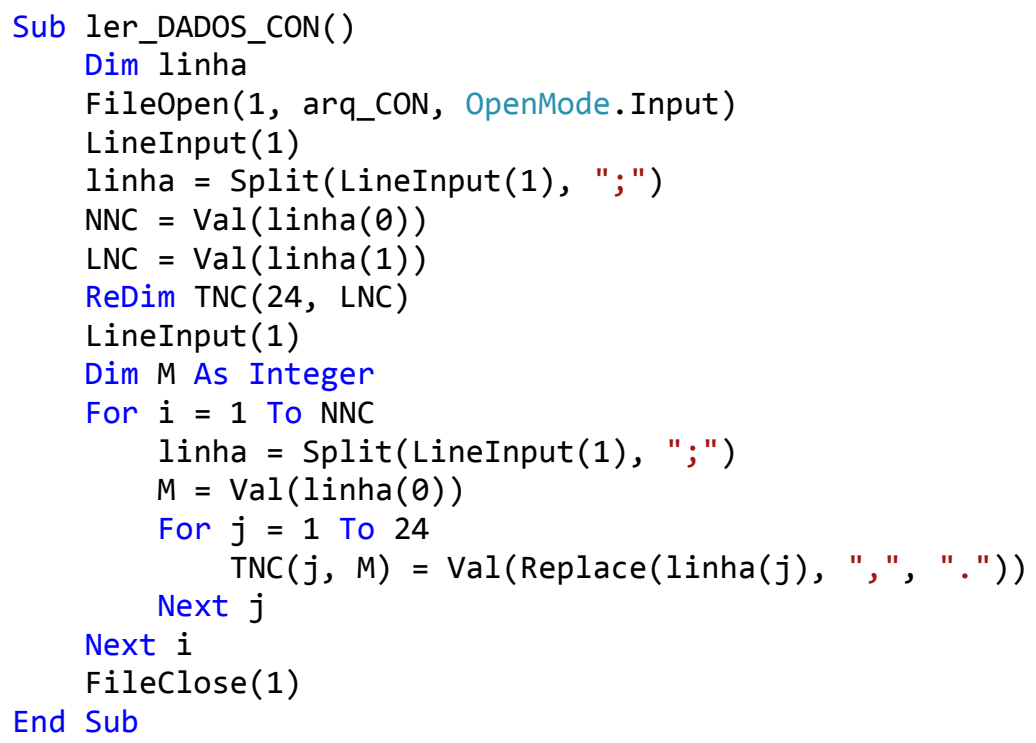

E.6. Subrotina para cálculo das áreas e coordenadas médias dos elementos finitos

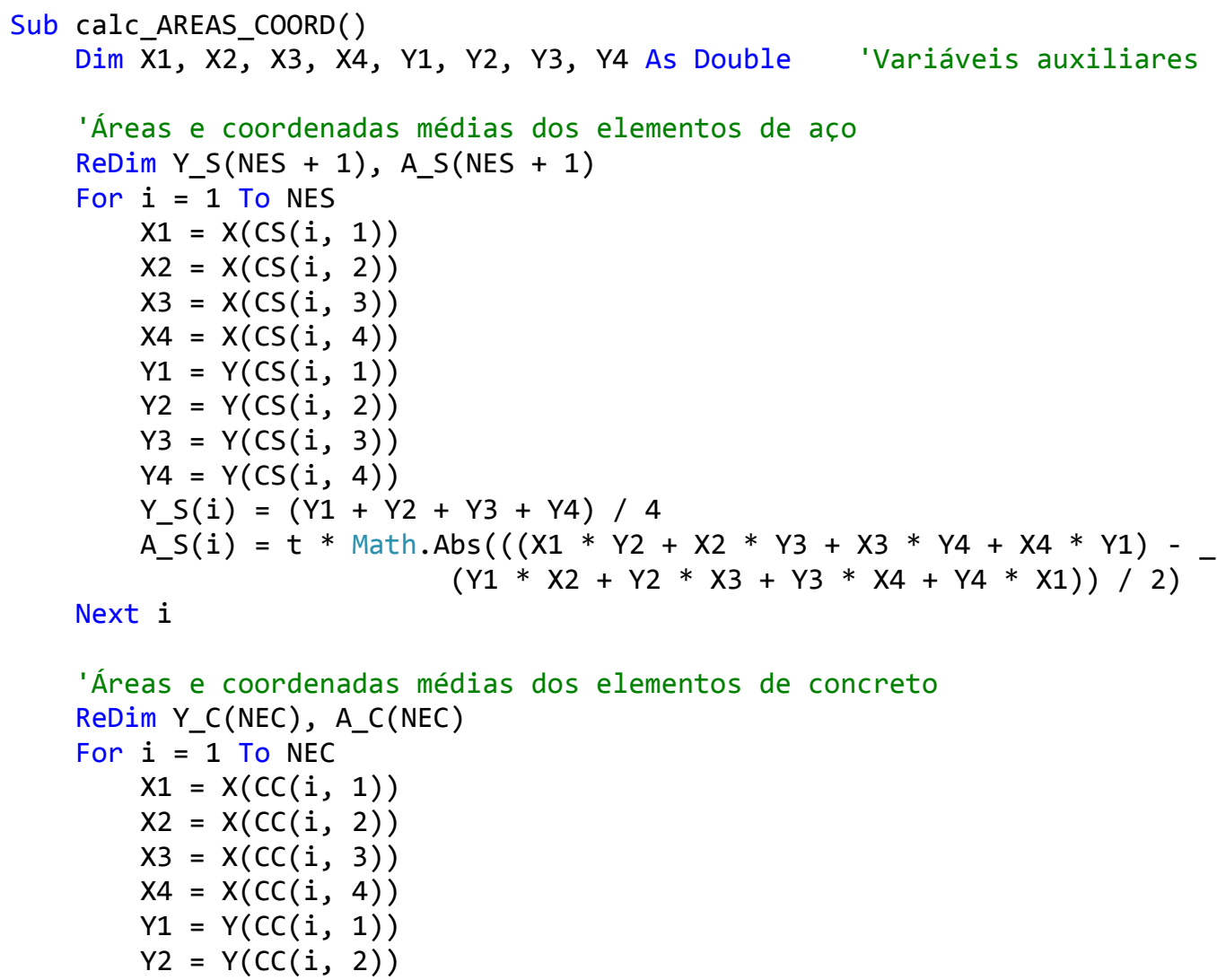




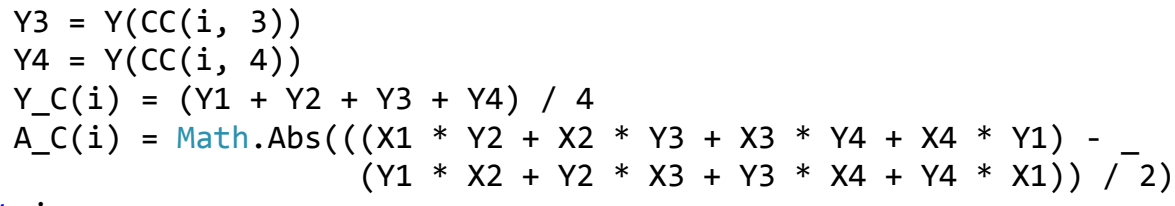

\section{E.7. Subrotina para cálculo das temperaturas médias dos elementos finitos}

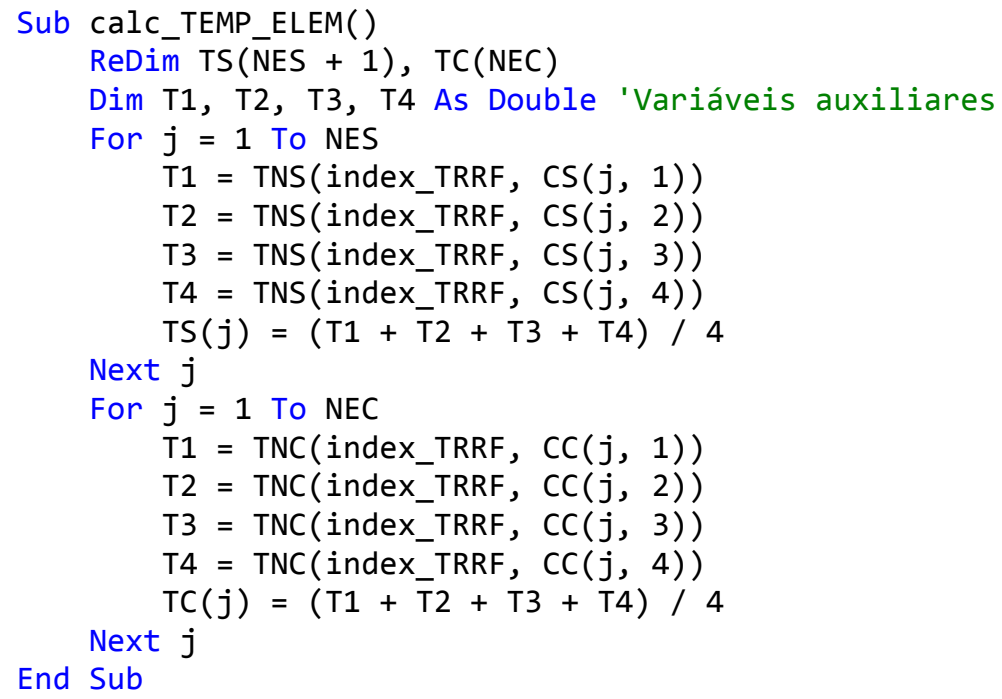

\section{E.8. Subrotina para adicionar a participação da armadura de aço positiva}

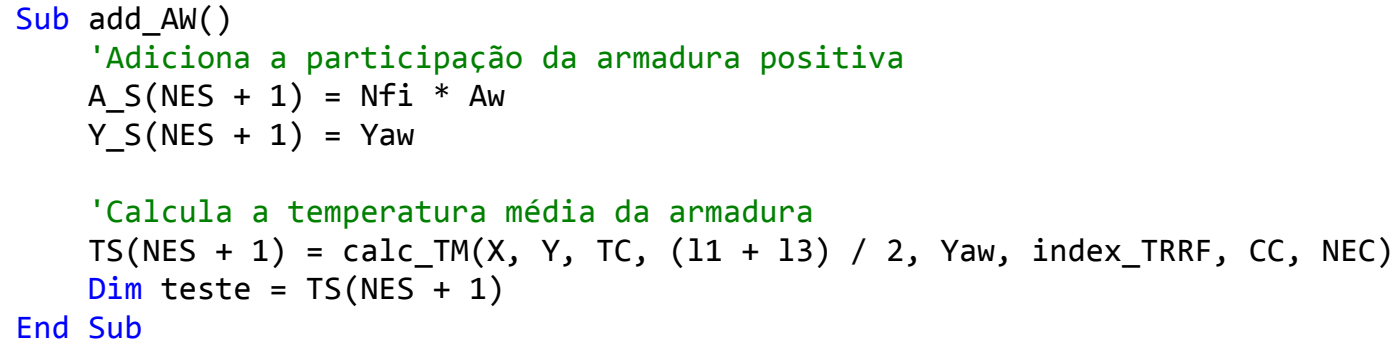

E.9. Subrotina para cálculo das resistências de cada elemento finito em temperatura elevada

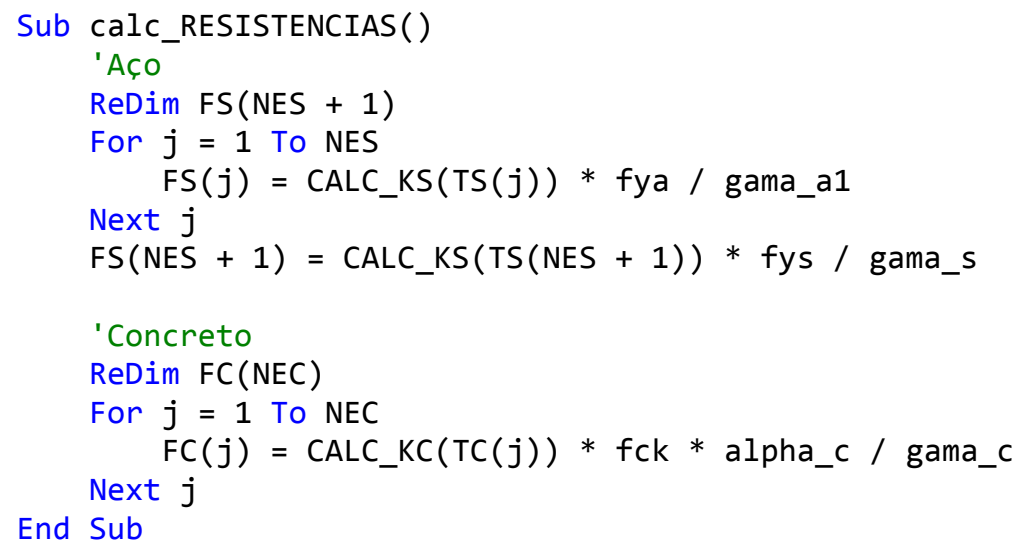




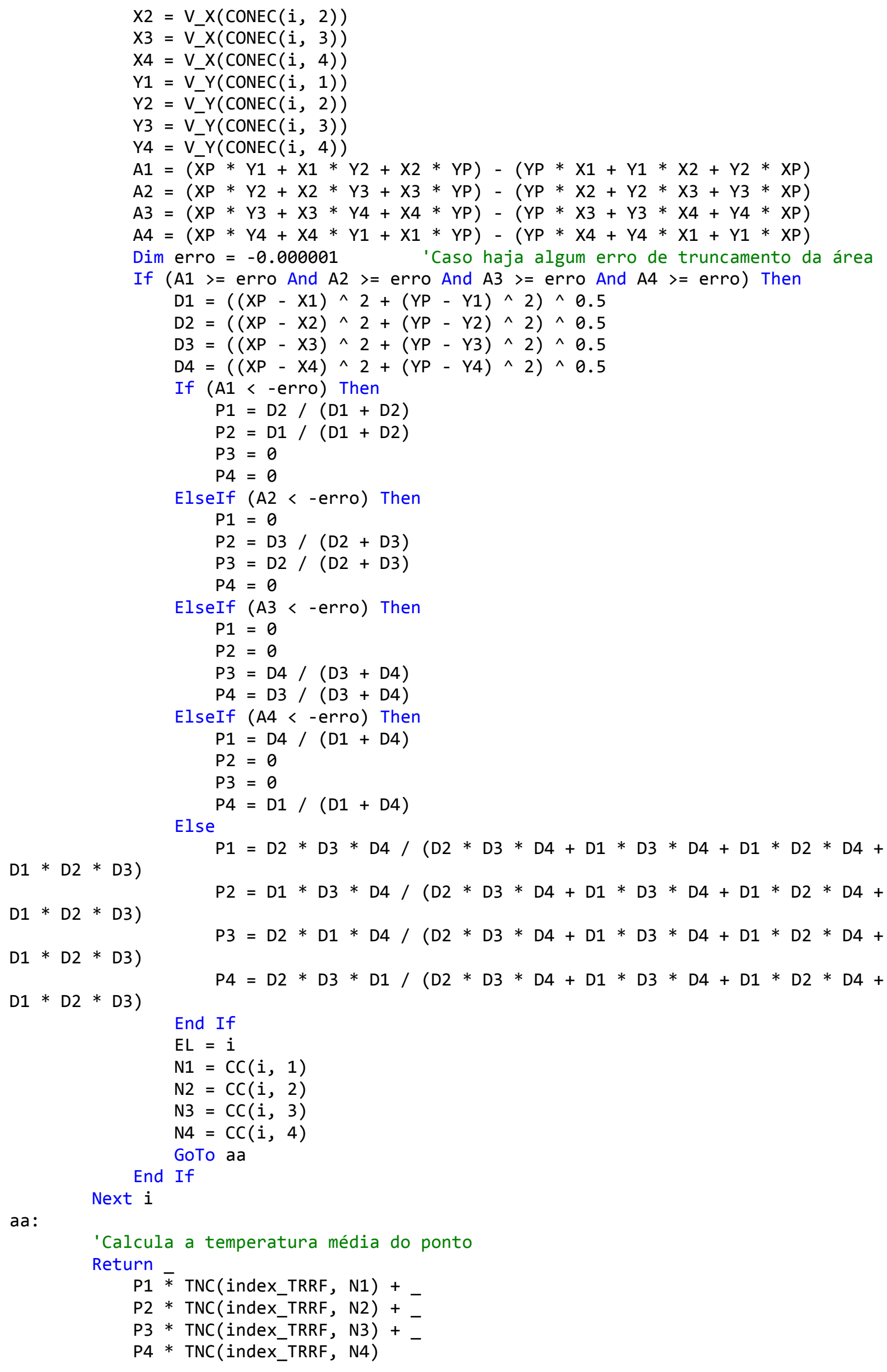


End Function

\section{E.13. Função para cálculo do coeficiente de redução da resistência do concreto}

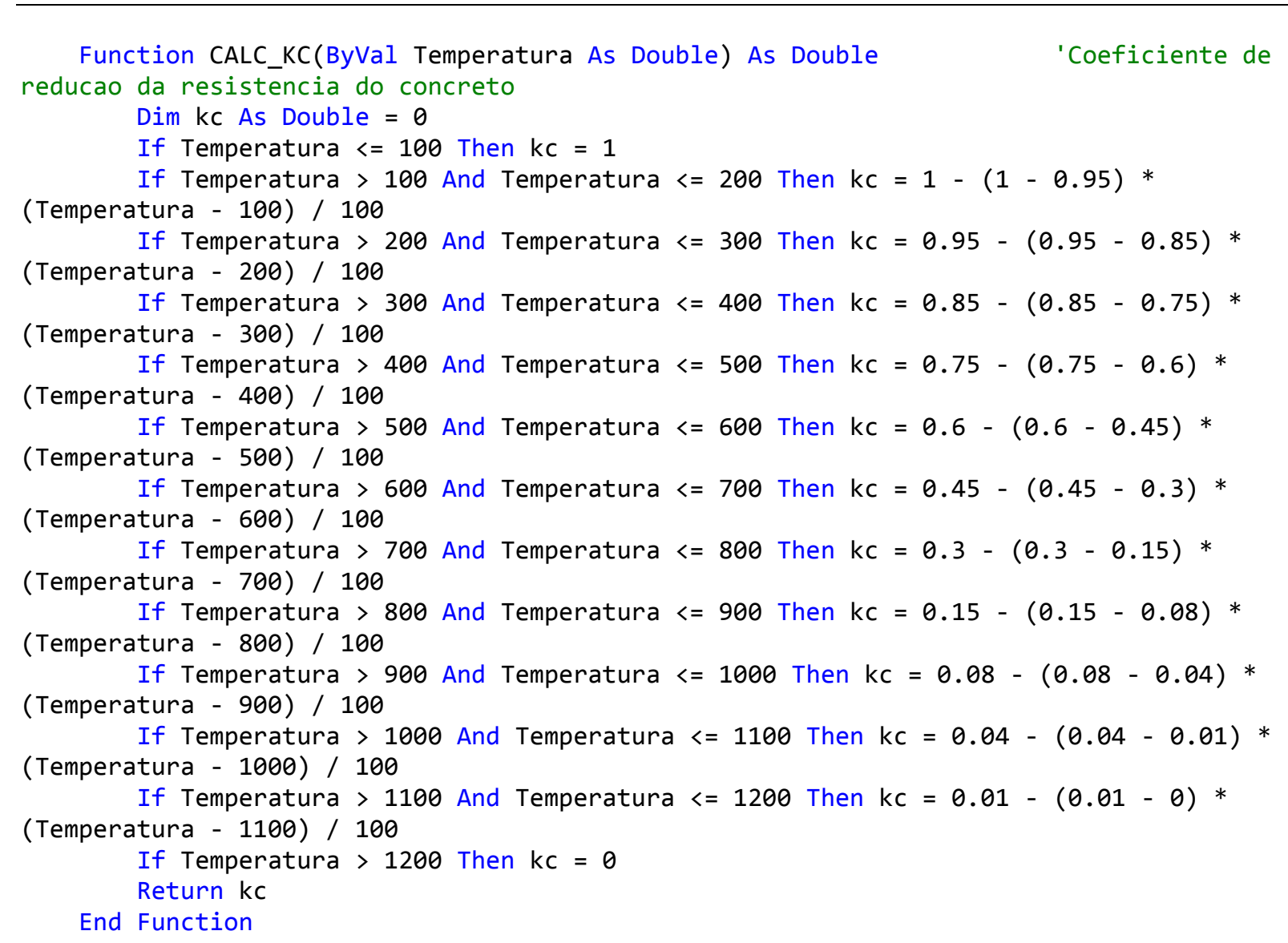

\section{E.14. Função para cálculo do coeficiente de redução da tensão de escoamento do aço}

Function CALC_KS(ByVal Temperatura As Double) As Double

'Coeficiente de reducao da tensao de escoamento

Dim ky As Double $=0$

If Temperatura $<=400$ Then $\mathrm{ky}=1$

If Temperatura $>400$ And Temperatura $<=500$ Then ky $=1-(1-0.78) *$

(Temperatura - 400) / 100

If Temperatura $>500$ And Temperatura $<=600$ Then ky $=0.78-(0.78-0.47)^{*}$ (Temperatura - 500) / 100

If Temperatura $>600$ And Temperatura $<=700$ Then ky $=0.47-(0.47-0.23) *$ (Temperatura - 600) / 100

If Temperatura $>700$ And Temperatura $<=800$ Then $\mathrm{ky}=0.23-(0.23-0.11) *$

(Temperatura - 700) / 100

If Temperatura $>800$ And Temperatura $<=900$ Then ky $=0.11-(0.11-0.06) *$

(Temperatura - 800) / 100

If Temperatura $>900$ Then ky $=0.06-0.02 *$ (Temperatura -900$) / 100$

Return ky

End Function 


\section{Apêndice F - Arquivo Batch para análise termoestrutural}

O script a seguir refere-se a um exemplo do arquivo de texto utilizado para a geração do modelo termoestrutural.

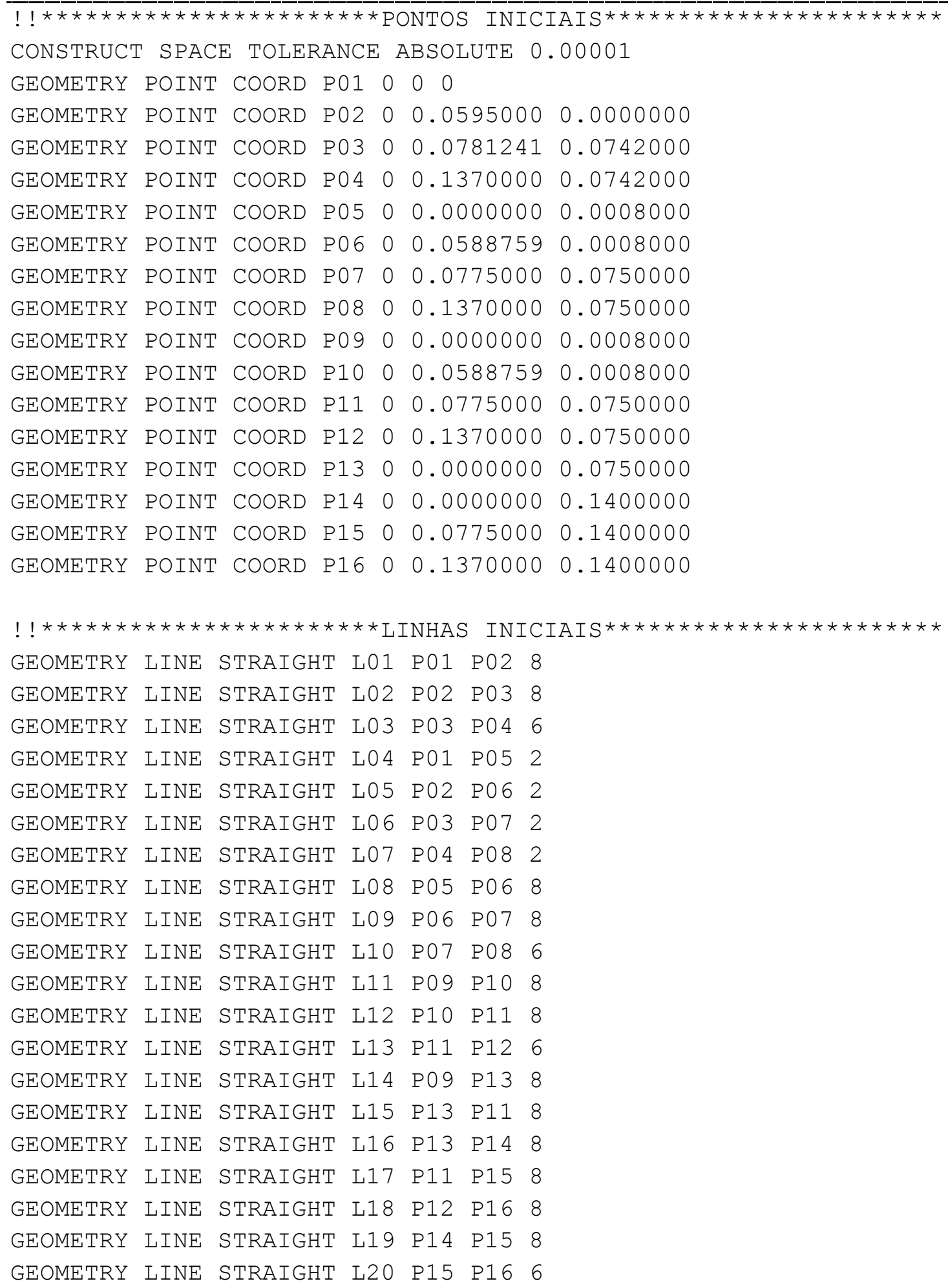




\begin{tabular}{llllllll}
\hline GEOMETRY & SURFACE & 4SIDES & SA1 & L01 & L05 & L08 & L04 \\
GEOMETRY & SURFACE & 4SIDES & SA2 & L02 & L06 & L09 & L05 \\
GEOMETRY & SURFACE & 4SIDES & SA3 & L03 & L07 & L10 & L06 \\
GEOMETRY & SURFACE & 4SIDES & SC1 & L11 & L12 & L15 & L14 \\
GEOMETRY & SURFACE & 4SIDES & SC2 & L15 & L17 & L19 & L16 \\
GEOMETRY & SURFACE & 4SIDES & SC3 & L13 & L18 & L20 & L17
\end{tabular}

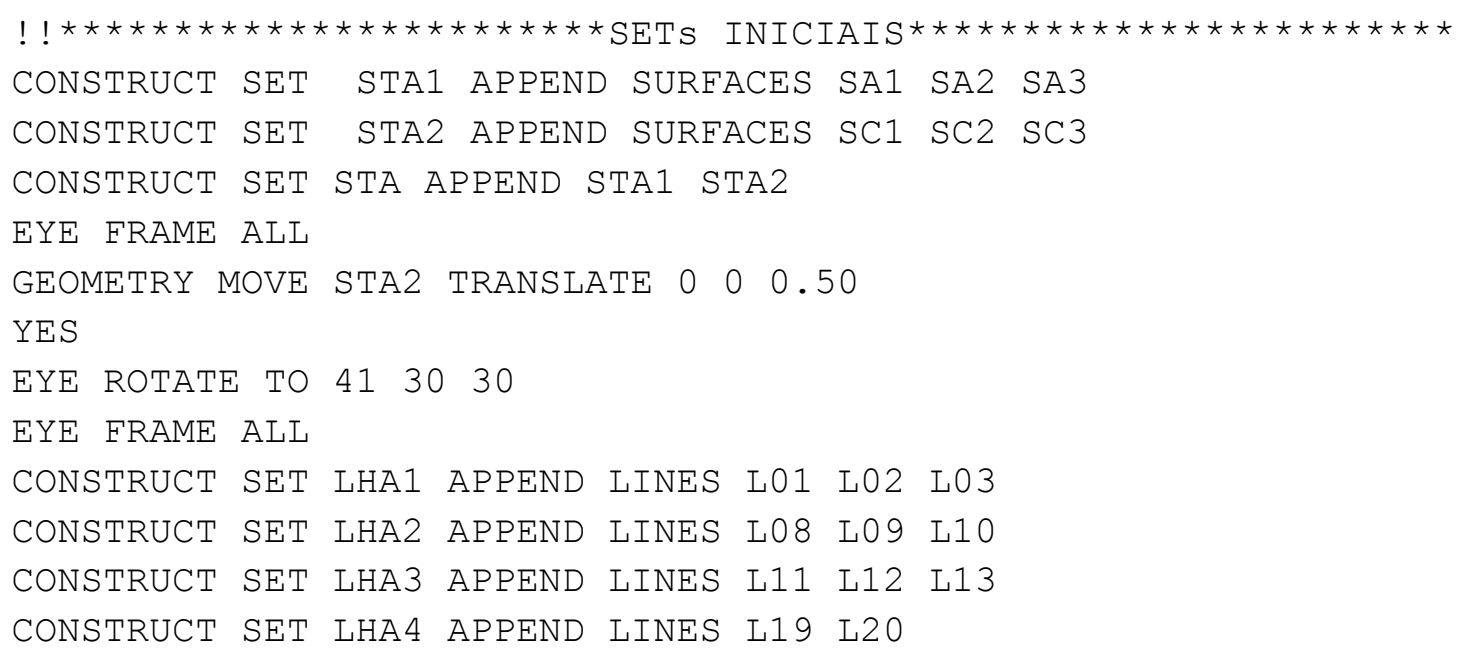




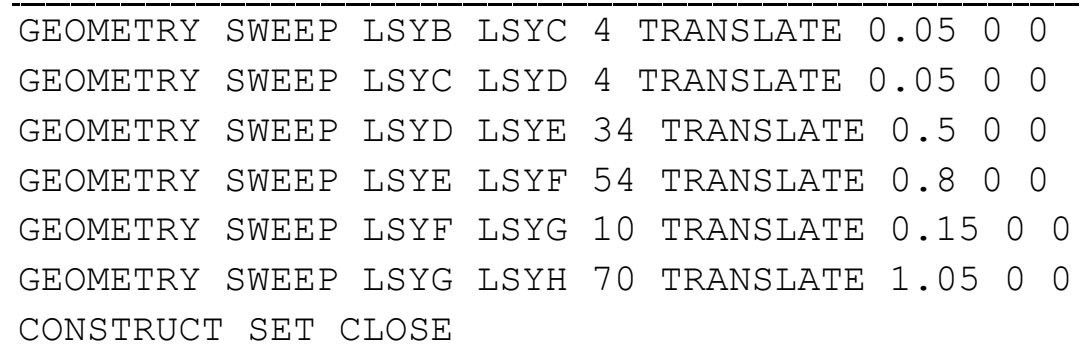




\begin{tabular}{lllllllll}
\hline GEOMETRY & SWEEP & LHA3 & LHB3 & 4 & TRANSLATE & 0.05 & 0 & 0 \\
GEOMETRY & SWEEP & LHB3 & LHC3 & 4 & TRANSLATE & 0.05 & 0 & 0 \\
GEOMETRY & SWEEP & LHC3 & LHD3 & 4 & TRANSLATE & 0.05 & 0 & 0 \\
GEOMETRY & SWEEP & LHD3 & LHE3 & 34 & TRANSLATE & 0.5 & 0 & 0 \\
GEOMETRY & SWEEP & LHE3 & LHF3 & 54 & TRANSLATE & 0.8 & 0 & 0 \\
GEOMETRY & SWEEP & LHE3 & LHG3 & 10 & TRANSLATE & 0.15 & 0 & 0 \\
GEOMETRY SWEEP LHG3 & LHH3 & 70 & TRANSLATE & 1.05 & 0 & 0 \\
CONSTRUCT & SET CLOSE & & & & & & &
\end{tabular}

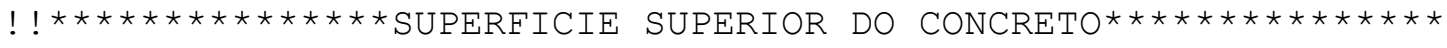
CONSTRUCT SET OPEN SCONS1 


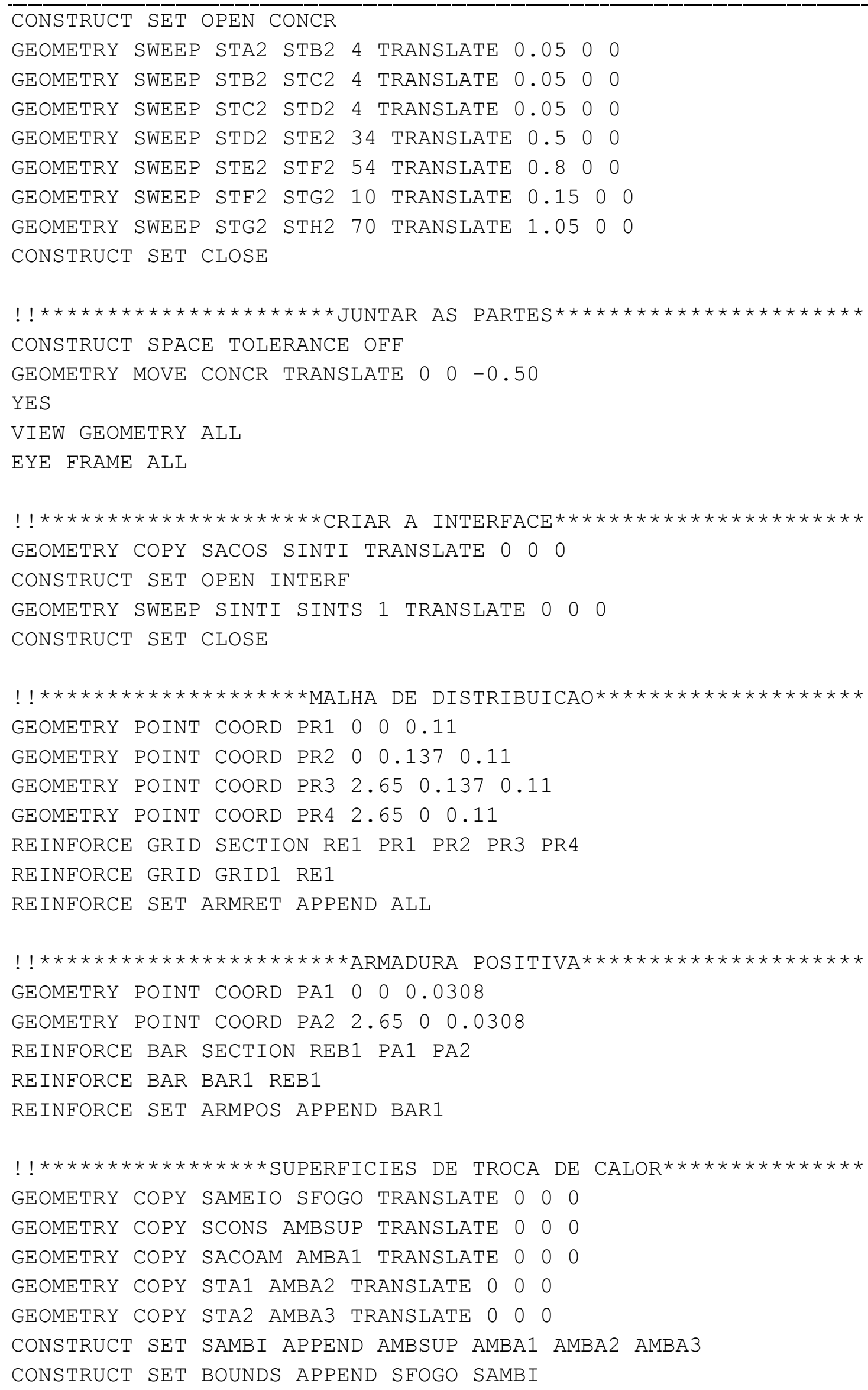




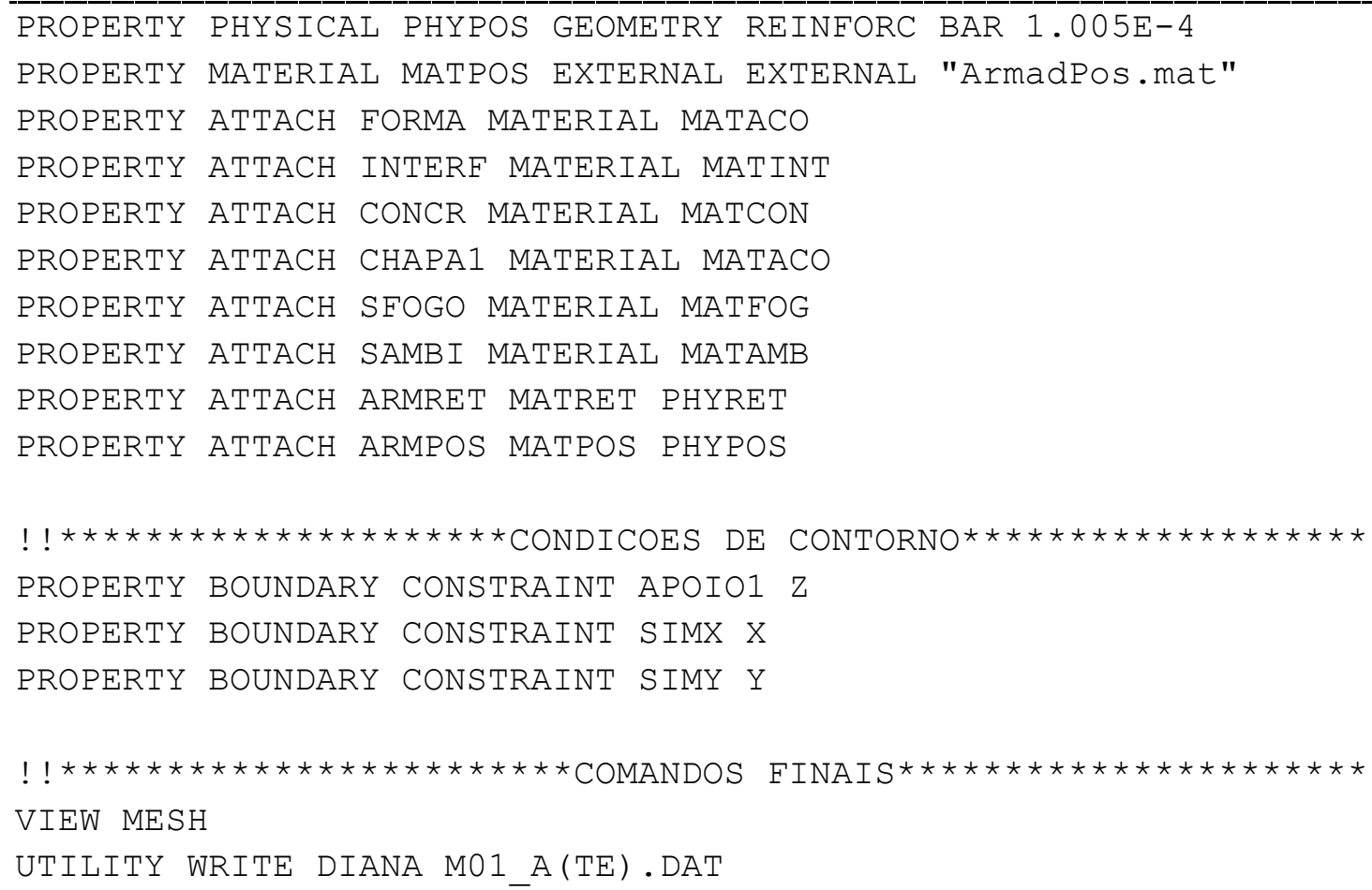




\title{
Apêndice G - Arquivo de propriedade termoestrutural do aço
}

\author{
CONDUC $0.5333 \mathrm{E}+02$ \\ CAPACI $0.3452 \mathrm{E}+07$ \\ TEMPER $0.0000 \mathrm{E}+00 \quad 0.2000 \mathrm{E}+02 \quad 0.1000 \mathrm{E}+03 \quad 0.1500 \mathrm{E}+03 \quad 0.2000 \mathrm{E}+03$ \\ $\begin{array}{llllll}0.2500 \mathrm{E}+03 & 0.3000 \mathrm{E}+03 & 0.3500 \mathrm{E}+03 & 0.4000 \mathrm{E}+03 & 0.4500 \mathrm{E}+03\end{array}$ \\ $\begin{array}{llllll}0.5000 \mathrm{E}+03 & 0.5500 \mathrm{E}+03 & 0.6000 \mathrm{E}+03 & 0.6500 \mathrm{E}+03 & 0.7000 \mathrm{E}+03\end{array}$ \\ $\begin{array}{llllll}0.7300 \mathrm{E}+03 & 0.7350 \mathrm{E}+03 & 0.7360 \mathrm{E}+03 & 0.7400 \mathrm{E}+03 & 0.7500 \mathrm{E}+03\end{array}$ \\ $\begin{array}{llllll}0.8000 \mathrm{E}+03 & 0.8500 \mathrm{E}+03 & 0.9000 \mathrm{E}+03 & 0.9500 \mathrm{E}+03 & 0.1000 \mathrm{E}+04\end{array}$ \\ $\begin{array}{llllll}0.1050 E+04 & 0.1100 E+04 & 0.1150 E+04 & 0.1200 E+04 & 0.1300 E+04\end{array}$ \\ CONDIS $0.5333 \mathrm{E}+02 \quad 0.5333 \mathrm{E}+02 \quad 0.5067 \mathrm{E}+02 \quad 0.4900 \mathrm{E}+02 \quad 0.4733 \mathrm{E}+02$

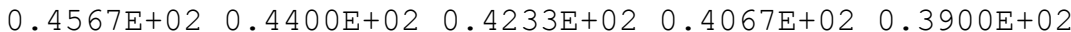 \\ $\begin{array}{lllll}0.3733 E+02 & 0.3567 E+02 & 0.3400 E+02 & 0.3233 E+02 & 0.3067 E+02\end{array}$ \\ $\begin{array}{llllll}0.2967 \mathrm{E}+02 & 0.2950 \mathrm{E}+02 & 0.2947 \mathrm{E}+02 & 0.2933 \mathrm{E}+02 & 0.2900 \mathrm{E}+02\end{array}$ \\ $\begin{array}{lllll}0.2733 \mathrm{E}+02 & 0.2730 \mathrm{E}+02 & 0.2730 \mathrm{E}+02 & 0.2730 \mathrm{E}+02 & 0.2730 \mathrm{E}+02\end{array}$ \\ $\begin{array}{llllll}0.2730 \mathrm{E}+02 & 0.2730 \mathrm{E}+02 & 0.2730 \mathrm{E}+02 & 0.2730 \mathrm{E}+02 & 0.2730 \mathrm{E}+02\end{array}$ \\ $\begin{array}{llllllll}\text { CAPATT } & 0.3452 \mathrm{E}+07 & 0.3452 \mathrm{E}+07 & 0.3828 \mathrm{E}+07 & 0.4007 \mathrm{E}+07 & 0.4159 \mathrm{E}+07\end{array}$ \\ $\begin{array}{llllll}0.4296 \mathrm{E}+07 & 0.4433 \mathrm{E}+07 & 0.4582 \mathrm{E}+07 & 0.4756 \mathrm{E}+07 & 0.4968 \mathrm{E}+07\end{array}$ \\ $\begin{array}{lllllll}0.5232 \mathrm{E}+07 & 0.5560 \mathrm{E}+07 & 0.5965 \mathrm{E}+07 & 0.6388 \mathrm{E}+07 & 0.7914 \mathrm{E}+07\end{array}$ \\ $\begin{array}{llllll}0.1799 E+08 & 0.3925 E+08 & 0.2798 E+08 & 0.1554 E+08 & 0.7362 E+07\end{array}$ \\ $\begin{array}{llllll}0.2027 \mathrm{E}+07 & 0.1176 \mathrm{E}+07 & 0.8277 \mathrm{E}+06 & 0.5102 \mathrm{E}+07 & 0.5102 \mathrm{E}+07\end{array}$ \\ $\begin{array}{llllll}0.5102 \mathrm{E}+07 & 0.5102 \mathrm{E}+07 & 0.5102 \mathrm{E}+07 & 0.5102 \mathrm{E}+07 & 0.5102 \mathrm{E}+07\end{array}$ \\ YOUNG $\quad 0.2000 \mathrm{E}+12$
}

POISON $0.3000 \mathrm{E}+00$

DENSIT 7850

$\begin{array}{lll}\text { TEMYOU } \quad 0.00 \quad 0.2000 \mathrm{E}+12 & 0.2000 \mathrm{E}+12\end{array}$

$100.00 \quad 0.2000 \mathrm{E}+12$

$200.00 \quad 0.1800 \mathrm{E}+12$

$300.00 \quad 0.1600 \mathrm{E}+12$

$400.00 \quad 0.1400 \mathrm{E}+12$

$500.00 \quad 0.1200 \mathrm{E}+12$

$600.00 \quad 0.6200 \mathrm{E}+11$

$700.00 \quad 0.2600 \mathrm{E}+11$

$800.00 \quad 0.1800 \mathrm{E}+11$

$900.00 \quad 0.1350 \mathrm{E}+11$

$1000.00 \quad 0.9000 \mathrm{E}+10$

$1100.00 \quad 0.4500 \mathrm{E}+10$

$1200.00 \quad 0.8941 \mathrm{E}+04$

$1300.00 \quad 0.2000 \mathrm{E}+07$

$\begin{array}{lll}\text { TEMALP } \quad 0.00 & 0.1216 \mathrm{E}-04\end{array}$

$20.00 \quad 0.1216 \mathrm{E}-04$

$750.00 \quad 0.1800 \mathrm{E}-04$

$750.01 \quad 0.0000 \mathrm{E}+00$

$860.00 \quad 0.0000 \mathrm{E}+00$

$860.010 .2000 \mathrm{E}-04$

YIELD VMISES

$1300.00 \quad 0.2000 \mathrm{E}-04$

YLDVAL $0.3500 \mathrm{E}+09$

$\begin{array}{rrrrrrr}\text { KAPPA } & 0.0000 & 0.0002 & 0.0004 & 0.0006 & 0.0008 & 0.0010 \\ 0.0020 & 0.0030 & 0.0040 & 0.0050 & 0.0060 & 0.0070 \\ \text { TEMYLD } & 0.0080 & 0.0090 & 0.0100 & 0.0110 & 0.0120 & 0.0130 \\ 0.0140 & 0.0150 & 0.0160 & 0.0170 & 0.0180 & 0.0190 \\ 0.0200 & 0.1000 & 0.1500 & 0.1750 & 0.2000 & 10.0000 \\ & 0.350 E+09 & 0.350 E+09 & 0.350 E+09 & 0.350 E+09 & 0.350 E+09 & 0.350 E+09 \\ & 0.350 E+09 & 0.350 E+09 & 0.350 E+09 & 0.350 E+09 & 0.350 E+09 & 0.350 E+09 \\ & 0.350 E+09 & 0.350 E+09 & 0.350 E+09 & 0.350 E+09 & 0.350 E+09 & 0.350 E+09 \\ & 0.350 E+09 & 0.350 E+09 & 0.350 E+09 & 0.350 E+09 & 0.350 E+09 & 0.350 E+09 \\ & 0.350 E+09 & 0.350 E+09 & 0.338 E+09 & 0.163 E+09 & 0.350 E+04 & 0.350 E+04 \\ & 0.350 E+09 & 0.350 E+09 & 0.350 E+09 & 0.350 E+09 & 0.350 E+09 & 0.350 E+09 \\ & 0.350 E+09 & 0.350 E+09 & 0.350 E+09 & 0.350 E+09 & 0.350 E+09 & 0.350 E+09 \\ & 0.350 E+09 & 0.350 E+09 & 0.350 E+09 & 0.350 E+09 & 0.350 E+09 & 0.350 E+09 \\ & 0.350 E+09 & 0.350 E+09 & 0.350 E+09 & 0.350 E+09 & 0.350 E+09 & 0.350 E+09\end{array}$


$\begin{array}{llllllll}0.350 E+09 & 0.350 E+09 & 0.338 E+09 & 0.163 E+09 & 0.350 E+04 & 0.350 E+04\end{array}$

200. $0.282 \mathrm{E}+09 \quad 0.291 \mathrm{E}+09 \quad 0.295 \mathrm{E}+09 \quad 0.299 \mathrm{E}+09 \quad 0.301 \mathrm{E}+09 \quad 0.303 \mathrm{E}+09$ $\begin{array}{llllllll}0.312 \mathrm{E}+09 & 0.319 \mathrm{E}+09 & 0.324 \mathrm{E}+09 & 0.328 \mathrm{E}+09 & 0.332 \mathrm{E}+09 & 0.335 \mathrm{E}+09\end{array}$ $\begin{array}{lllllll}0.338 E+09 & 0.340 E+09 & 0.342 E+09 & 0.344 E+09 & 0.346 E+09 & 0.347 E+09\end{array}$ $\begin{array}{llllll}0.348 \mathrm{E}+09 & 0.349 \mathrm{E}+09 & 0.349 \mathrm{E}+09 & 0.350 \mathrm{E}+09 & 0.350 \mathrm{E}+09 & 0.350 \mathrm{E}+09\end{array}$ $\begin{array}{lllllll}0.350 \mathrm{E}+09 & 0.350 \mathrm{E}+09 & 0.339 \mathrm{E}+09 & 0.164 \mathrm{E}+09 & 0.350 \mathrm{E}+04 & 0.350 \mathrm{E}+04\end{array}$

$300.0 .215 \mathrm{E}+09 \quad 0.230 \mathrm{E}+09 \quad 0.238 \mathrm{E}+09 \quad 0.244 \mathrm{E}+09 \quad 0.249 \mathrm{E}+09 \quad 0.254 \mathrm{E}+09$ $\begin{array}{lllllll}0.272 \mathrm{E}+09 & 0.285 \mathrm{E}+09 & 0.296 \mathrm{E}+09 & 0.305 \mathrm{E}+09 & 0.312 \mathrm{E}+09 & 0.319 \mathrm{E}+09\end{array}$ $\begin{array}{llllll}0.325 E+09 & 0.330 E+09 & 0.334 E+09 & 0.337 E+09 & 0.341 E+09 & 0.343 E+09\end{array}$ $\begin{array}{llllll}0.346 \mathrm{E}+09 & 0.347 \mathrm{E}+09 & 0.349 \mathrm{E}+09 & 0.349 \mathrm{E}+09 & 0.350 \mathrm{E}+09 & 0.350 \mathrm{E}+09\end{array}$ $\begin{array}{lllllll}0.350 E+09 & 0.350 E+09 & 0.341 E+09 & 0.166 E+09 & 0.350 E+04 & 0.350 E+04\end{array}$

$400.0 .147 \mathrm{E}+09 \quad 0.166 \mathrm{E}+09 \quad 0.177 \mathrm{E}+09 \quad 0.187 \mathrm{E}+09 \quad 0.195 \mathrm{E}+09 \quad 0.202 \mathrm{E}+09$ $\begin{array}{lllllll}0.229 \mathrm{E}+09 & 0.249 \mathrm{E}+09 & 0.265 \mathrm{E}+09 & 0.279 \mathrm{E}+09 & 0.291 \mathrm{E}+09 & 0.301 \mathrm{E}+09\end{array}$ $\begin{array}{llllll}0.310 E+09 & 0.317 E+09 & 0.324 E+09 & 0.330 E+09 & 0.335 E+09 & 0.339 E+09\end{array}$ $\begin{array}{lllllll}0.342 E+09 & 0.345 E+09 & 0.347 E+09 & 0.349 E+09 & 0.350 E+09 & 0.350 E+09\end{array}$ $\begin{array}{lllllll}0.350 \mathrm{E}+09 & 0.350 \mathrm{E}+09 & 0.343 \mathrm{E}+09 & 0.168 \mathrm{E}+09 & 0.350 \mathrm{E}+04 & 0.350 \mathrm{E}+04\end{array}$

$500.0 .126 \mathrm{E}+09 \quad 0.140 \mathrm{E}+09 \quad 0.149 \mathrm{E}+09 \quad 0.156 \mathrm{E}+09 \quad 0.162 \mathrm{E}+09 \quad 0.167 \mathrm{E}+09$ $\begin{array}{lllllll}0.186 \mathrm{E}+09 & 0.201 \mathrm{E}+09 & 0.213 \mathrm{E}+09 & 0.222 \mathrm{E}+09 & 0.231 \mathrm{E}+09 & 0.238 \mathrm{E}+09\end{array}$ $\begin{array}{lllllll}0.244 \mathrm{E}+09 & 0.250 \mathrm{E}+09 & 0.254 \mathrm{E}+09 & 0.259 \mathrm{E}+09 & 0.262 \mathrm{E}+09 & 0.265 \mathrm{E}+09\end{array}$ $\begin{array}{llllll}0.268 E+09 & 0.270 E+09 & 0.271 E+09 & 0.272 E+09 & 0.273 E+09 & 0.273 E+09\end{array}$ $\begin{array}{lllllll}0.273 E+09 & 0.273 E+09 & 0.267 E+09 & 0.131 E+09 & 0.350 E+04 & 0.350 E+04\end{array}$

$600.0 .630 \mathrm{E}+08 \quad 0.717 \mathrm{E}+08 \quad 0.775 \mathrm{E}+08 \quad 0.822 \mathrm{E}+08 \quad 0.862 \mathrm{E}+08 \quad 0.897 \mathrm{E}+08$ $\begin{array}{lllllll}0.103 E+09 & 0.114 E+09 & 0.122 E+09 & 0.129 E+09 & 0.135 E+09 & 0.140 E+09\end{array}$ $\begin{array}{llllll}0.144 \mathrm{E}+09 & 0.148 \mathrm{E}+09 & 0.151 \mathrm{E}+09 & 0.154 \mathrm{E}+09 & 0.157 \mathrm{E}+09 & 0.159 \mathrm{E}+09\end{array}$ $\begin{array}{lllllll}0.161 \mathrm{E}+09 & 0.162 \mathrm{E}+09 & 0.163 \mathrm{E}+09 & 0.164 \mathrm{E}+09 & 0.164 \mathrm{E}+09 & 0.164 \mathrm{E}+09\end{array}$ $\begin{array}{lllllll}0.164 \mathrm{E}+09 & 0.164 \mathrm{E}+09 & 0.161 \mathrm{E}+09 & 0.789 \mathrm{E}+08 & 0.350 \mathrm{E}+04 & 0.350 \mathrm{E}+04\end{array}$

$\begin{array}{lllllll}700 . & 0.263 \mathrm{E}+08 & 0.303 \mathrm{E}+08 & 0.333 \mathrm{E}+08 & 0.357 \mathrm{E}+08 & 0.378 \mathrm{E}+08 & 0.397 \mathrm{E}+08\end{array}$ $\begin{array}{lllllll}0.471 \mathrm{E}+08 & 0.526 \mathrm{E}+08 & 0.571 \mathrm{E}+08 & 0.608 \mathrm{E}+08 & 0.641 \mathrm{E}+08 & 0.668 \mathrm{E}+08\end{array}$ $\begin{array}{lllllll}0.693 \mathrm{E}+08 & 0.714 \mathrm{E}+08 & 0.732 \mathrm{E}+08 & 0.748 \mathrm{E}+08 & 0.762 \mathrm{E}+08 & 0.774 \mathrm{E}+08\end{array}$ $\begin{array}{lllllll}0.784 \mathrm{E}+08 & 0.791 \mathrm{E}+08 & 0.797 \mathrm{E}+08 & 0.802 \mathrm{E}+08 & 0.804 \mathrm{E}+08 & 0.805 \mathrm{E}+08\end{array}$ $\begin{array}{lllllll}0.805 \mathrm{E}+08 & 0.805 \mathrm{E}+08 & 0.789 \mathrm{E}+08 & 0.386 \mathrm{E}+08 & 0.350 \mathrm{E}+04 & 0.350 \mathrm{E}+04\end{array}$

$800.0 .175 \mathrm{E}+08 \quad 0.196 \mathrm{E}+08 \quad 0.208 \mathrm{E}+08 \quad 0.218 \mathrm{E}+08 \quad 0.226 \mathrm{E}+08 \quad 0.234 \mathrm{E}+08$ $\begin{array}{lllllll}0.261 E+08 & 0.282 E+08 & 0.299 E+08 & 0.313 E+08 & 0.324 E+08 & 0.335 E+08\end{array}$ $\begin{array}{lllllll}0.344 \mathrm{E}+08 & 0.351 \mathrm{E}+08 & 0.358 \mathrm{E}+08 & 0.364 \mathrm{E}+08 & 0.369 \mathrm{E}+08 & 0.373 \mathrm{E}+08\end{array}$ $\begin{array}{llllll}0.377 \mathrm{E}+08 & 0.380 \mathrm{E}+08 & 0.382 \mathrm{E}+08 & 0.384 \mathrm{E}+08 & 0.385 \mathrm{E}+08 & 0.385 \mathrm{E}+08\end{array}$ $\begin{array}{lllllll}0.385 \mathrm{E}+08 & 0.385 \mathrm{E}+08 & 0.378 \mathrm{E}+08 & 0.185 \mathrm{E}+08 & 0.350 \mathrm{E}+04 & 0.350 \mathrm{E}+04\end{array}$

$900.0 .131 \mathrm{E}+08 \quad 0.141 \mathrm{E}+08 \quad 0.145 \mathrm{E}+08 \quad 0.149 \mathrm{E}+08 \quad 0.152 \mathrm{E}+08 \quad 0.155 \mathrm{E}+08$ $\begin{array}{lllllll}0.165 \mathrm{E}+08 & 0.173 \mathrm{E}+08 & 0.179 \mathrm{E}+08 & 0.184 \mathrm{E}+08 & 0.188 \mathrm{E}+08 & 0.192 \mathrm{E}+08\end{array}$ $\begin{array}{lllllll}0.195 \mathrm{E}+08 & 0.198 \mathrm{E}+08 & 0.200 \mathrm{E}+08 & 0.202 \mathrm{E}+08 & 0.204 \mathrm{E}+08 & 0.206 \mathrm{E}+08\end{array}$ $\begin{array}{lllllll}0.207 \mathrm{E}+08 & 0.208 \mathrm{E}+08 & 0.209 \mathrm{E}+08 & 0.210 \mathrm{E}+08 & 0.210 \mathrm{E}+08 & 0.210 \mathrm{E}+08\end{array}$ $\begin{array}{lllllll}0.210 \mathrm{E}+08 & 0.210 \mathrm{E}+08 & 0.206 \mathrm{E}+08 & 0.101 \mathrm{E}+08 & 0.350 \mathrm{E}+04 & 0.350 \mathrm{E}+04\end{array}$

$1000.0 .875 \mathrm{E}+07 \quad 0.938 \mathrm{E}+07 \quad 0.970 \mathrm{E}+07 \quad 0.994 \mathrm{E}+07 \quad 0.101 \mathrm{E}+08 \quad 0.103 \mathrm{E}+08$ $\begin{array}{lllllll}0.110 \mathrm{E}+08 & 0.115 \mathrm{E}+08 & 0.119 \mathrm{E}+08 & 0.122 \mathrm{E}+08 & 0.125 \mathrm{E}+08 & 0.128 \mathrm{E}+08\end{array}$ $\begin{array}{lllllll}0.130 \mathrm{E}+08 & 0.132 \mathrm{E}+08 & 0.134 \mathrm{E}+08 & 0.135 \mathrm{E}+08 & 0.136 \mathrm{E}+08 & 0.137 \mathrm{E}+08\end{array}$ $\begin{array}{lllllll}0.138 \mathrm{E}+08 & 0.139 \mathrm{E}+08 & 0.139 \mathrm{E}+08 & 0.140 \mathrm{E}+08 & 0.140 \mathrm{E}+08 & 0.140 \mathrm{E}+08\end{array}$ $\begin{array}{lllllll}0.140 \mathrm{E}+08 & 0.140 \mathrm{E}+08 & 0.137 \mathrm{E}+08 & 0.673 \mathrm{E}+07 & 0.350 \mathrm{E}+04 & 0.350 \mathrm{E}+04\end{array}$

$1100.0 .438 \mathrm{E}+07 \quad 0.469 \mathrm{E}+07 \quad 0.485 \mathrm{E}+07 \quad 0.497 \mathrm{E}+07 \quad 0.507 \mathrm{E}+07 \quad 0.516 \mathrm{E}+07$ $\begin{array}{lllllll}0.550 \mathrm{E}+07 & 0.575 \mathrm{E}+07 & 0.595 \mathrm{E}+07 & 0.612 \mathrm{E}+07 & 0.627 \mathrm{E}+07 & 0.639 \mathrm{E}+07\end{array}$ $\begin{array}{lllllll}0.650 \mathrm{E}+07 & 0.659 \mathrm{E}+07 & 0.668 \mathrm{E}+07 & 0.675 \mathrm{E}+07 & 0.681 \mathrm{E}+07 & 0.686 \mathrm{E}+07\end{array}$ $\begin{array}{llllllll}0.690 \mathrm{E}+07 & 0.694 \mathrm{E}+07 & 0.697 \mathrm{E}+07 & 0.698 \mathrm{E}+07 & 0.700 \mathrm{E}+07 & 0.700 \mathrm{E}+07\end{array}$ $\begin{array}{lllllll}0.700 \mathrm{E}+07 & 0.700 \mathrm{E}+07 & 0.686 \mathrm{E}+07 & 0.336 \mathrm{E}+07 & 0.350 \mathrm{E}+04 & 0.350 \mathrm{E}+04\end{array}$

1200. $0.143 \mathrm{E}+02 \quad 0.160 \mathrm{E}+02 \quad 0.173 \mathrm{E}+02 \quad 0.185 \mathrm{E}+02 \quad 0.196 \mathrm{E}+02 \quad 0.205 \mathrm{E}+02$ $\begin{array}{lllllll}0.245 \mathrm{E}+02 & 0.276 \mathrm{E}+02 & 0.301 \mathrm{E}+02 & 0.322 \mathrm{E}+02 & 0.340 \mathrm{E}+02 & 0.356 \mathrm{E}+02\end{array}$ $\begin{array}{llllll}0.370 \mathrm{E}+02 & 0.382 \mathrm{E}+02 & 0.392 \mathrm{E}+02 & 0.401 \mathrm{E}+02 & 0.409 \mathrm{E}+02 & 0.415 \mathrm{E}+02\end{array}$ $\begin{array}{lllllll}0.420 \mathrm{E}+02 & 0.424 \mathrm{E}+02 & 0.427 \mathrm{E}+02 & 0.429 \mathrm{E}+02 & 0.430 \mathrm{E}+02 & 0.430 \mathrm{E}+02\end{array}$ $\begin{array}{llllll}0.430 \mathrm{E}+02 & 0.430 \mathrm{E}+02 & 0.416 \mathrm{E}+02 & 0.201 \mathrm{E}+02 & 0.350 \mathrm{E}+02 & 0.350 \mathrm{E}+02\end{array}$ 


\section{Apêndice H - Arquivo de propriedade termoestrutural do concreto}

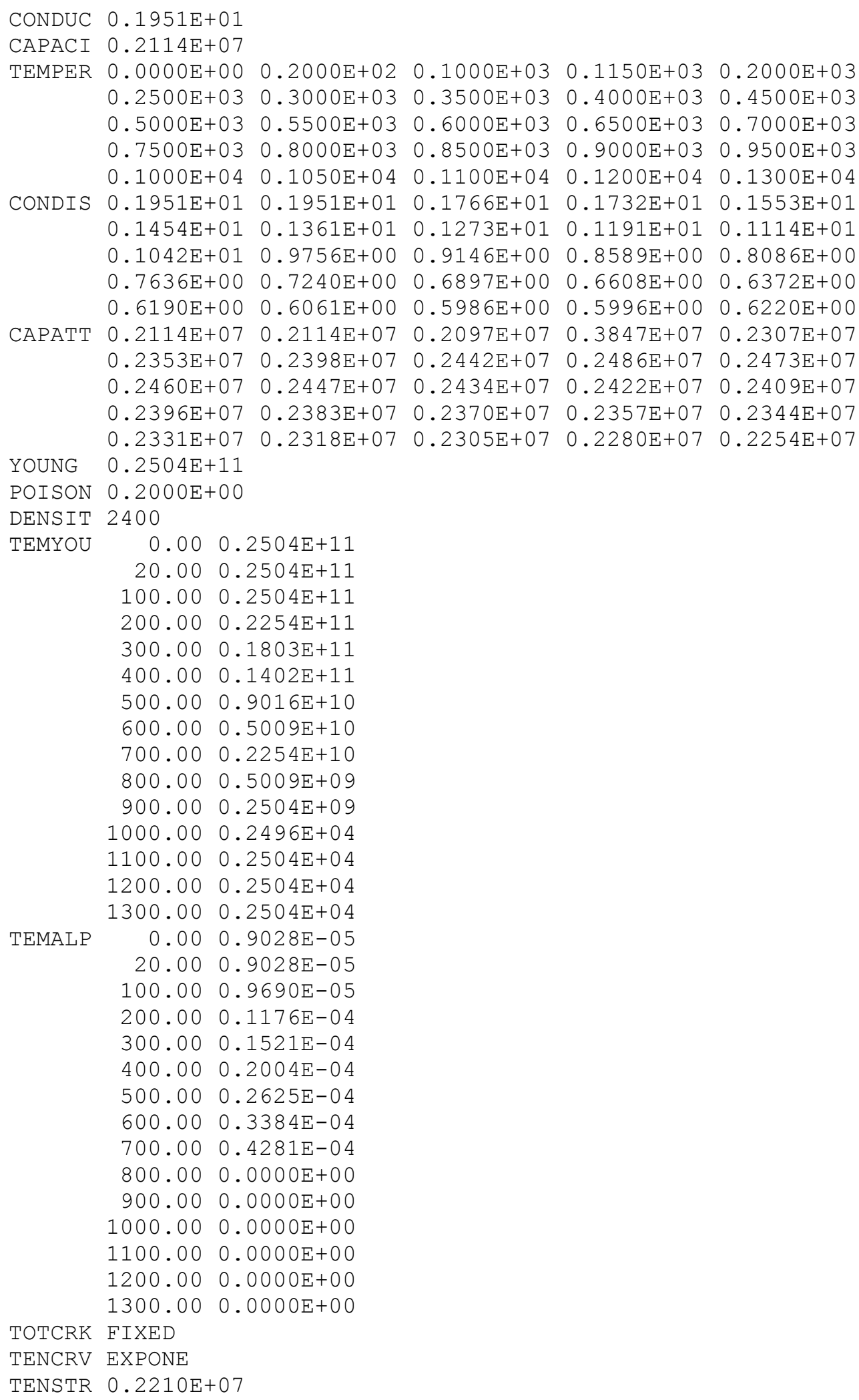




\begin{tabular}{|c|c|c|}
\hline GF1 & $0.6168 \mathrm{E}$ & +02 \\
\hline TEMTST & 0.00 & $0.2210 \mathrm{E}+07$ \\
\hline & 20.00 & $0.2210 \mathrm{E}+07$ \\
\hline & 100.00 & $0.2210 \mathrm{E}+07$ \\
\hline & 200.00 & $0.1769 \mathrm{E}+07$ \\
\hline & 300.00 & $0.1327 \mathrm{E}+07$ \\
\hline & 400.00 & $0.8855 E+06$ \\
\hline & 500.00 & $0.4439 E+06$ \\
\hline & 600.00 & $0.2210 \mathrm{E}+04$ \\
\hline & 700.00 & $0.2210 \mathrm{E}+04$ \\
\hline & 800.00 & $0.2210 \mathrm{E}+04$ \\
\hline & 900.00 & $0.2210 \mathrm{E}+04$ \\
\hline & 1000.00 & $0.2210 E+04$ \\
\hline & 1100.00 & $0.2210 \mathrm{E}+04$ \\
\hline & 1200.00 & $0.2210 \mathrm{E}+04$ \\
\hline & 1300.00 & $0.2210 \mathrm{E}+04$ \\
\hline GF1 & 0.00 & $0.6168 E+02$ \\
\hline & 20.00 & $0.6168 E+02$ \\
\hline & 100.00 & $0.6168 \mathrm{E}+02$ \\
\hline & 200.00 & $0.6013 E+02$ \\
\hline & 300.00 & $0.5697 \mathrm{E}+02$ \\
\hline & 400.00 & $0.5374 \mathrm{E}+02$ \\
\hline & 500.00 & $0.4874 \mathrm{E}+02$ \\
\hline & 600.00 & $0.4349 E+02$ \\
\hline & 700.00 & $0.3797 E+02$ \\
\hline & 800.00 & $0.3207 \mathrm{E}+02$ \\
\hline & 900.00 & $0.2915 E+02$ \\
\hline & 1000.00 & $0.2743 E+02$ \\
\hline & 1100.00 & $0.2611 \mathrm{E}+02$ \\
\hline & 1200.00 & $0.2566 \mathrm{E}+02$ \\
\hline & 1300.00 & $0.2566 \mathrm{E}+02$ \\
\hline COMCRV & PARABO & \\
\hline COMSTR & $0.2000 \mathrm{E}-$ & -08 \\
\hline GC & $0.3084 \mathrm{E}-$ & -04 \\
\hline TEMCST & 0.00 & $0.2000 \mathrm{E}+08$ \\
\hline & 20.00 & $0.2000 \mathrm{E}+08$ \\
\hline & 100.00 & $0.2000 \mathrm{E}+08$ \\
\hline & 200.00 & $0.1900 \mathrm{E}+08$ \\
\hline & 300.00 & $0.1700 \mathrm{E}+08$ \\
\hline & 400.00 & $0.1500 \mathrm{E}+08$ \\
\hline & 500.00 & $0.1200 \mathrm{E}+08$ \\
\hline & 600.00 & $0.9000 \mathrm{E}+07$ \\
\hline & 700.00 & $0.6000 \mathrm{E}+07$ \\
\hline & 800.00 & $0.3000 \mathrm{E}+07$ \\
\hline & 900.00 & $0.1600 \mathrm{E}+07$ \\
\hline & 1000.00 & $0.8000 \mathrm{E}+06$ \\
\hline & 1100.00 & $0.2000 \mathrm{E}+06$ \\
\hline & 1200.00 & $0.2000 \mathrm{E}+02$ \\
\hline & 1300.00 & $0.2000 \mathrm{E}+02$ \\
\hline & CONSTA & \\
\hline & 0.99 & \\
\hline
\end{tabular}




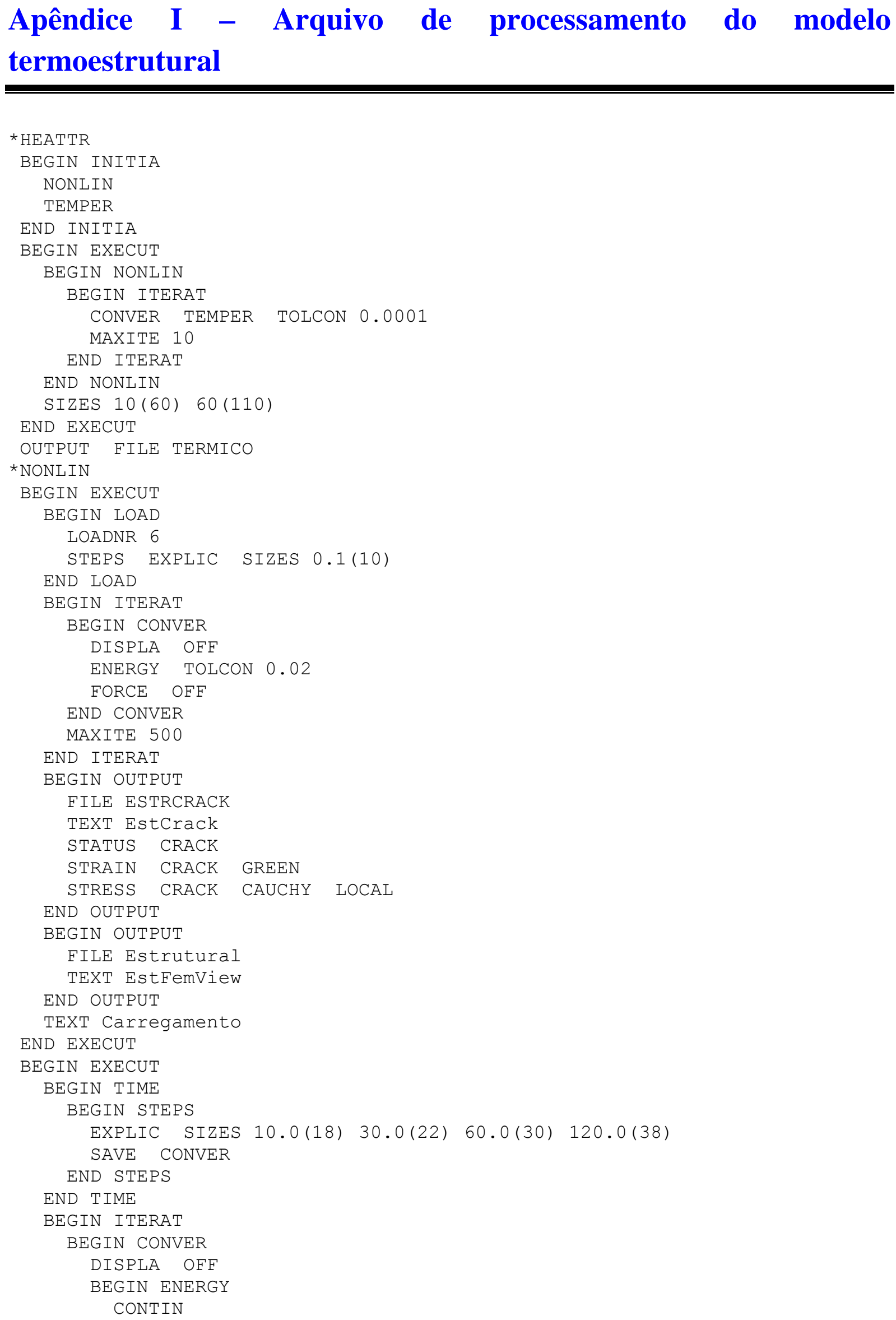




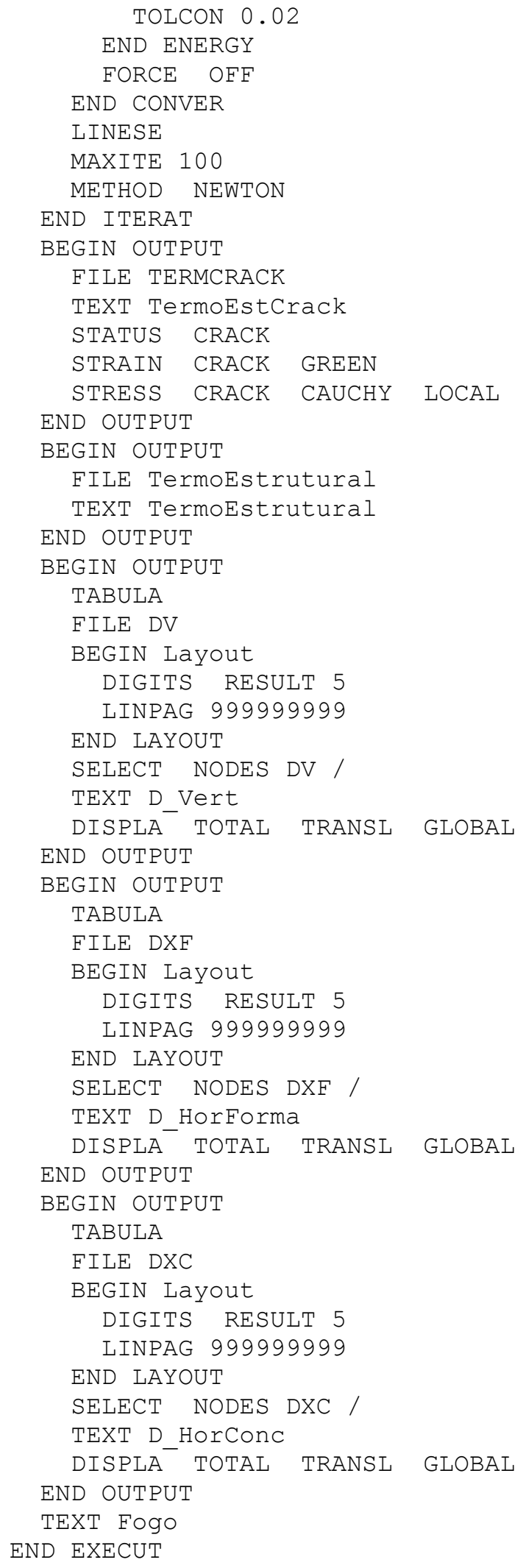




\section{Apêndice $\mathbf{J}$ - Resultados adicionais de validação do modelo térmico}

Neste apêndice são apresentados os resultados adicionais da validação do modelo térmico referentes aos pontos de medidas da temperatura T16, T20 e T21 do modelo experimental de GUO (2011) e numérico, apresentados no item 5.3.4 deste trabalho.

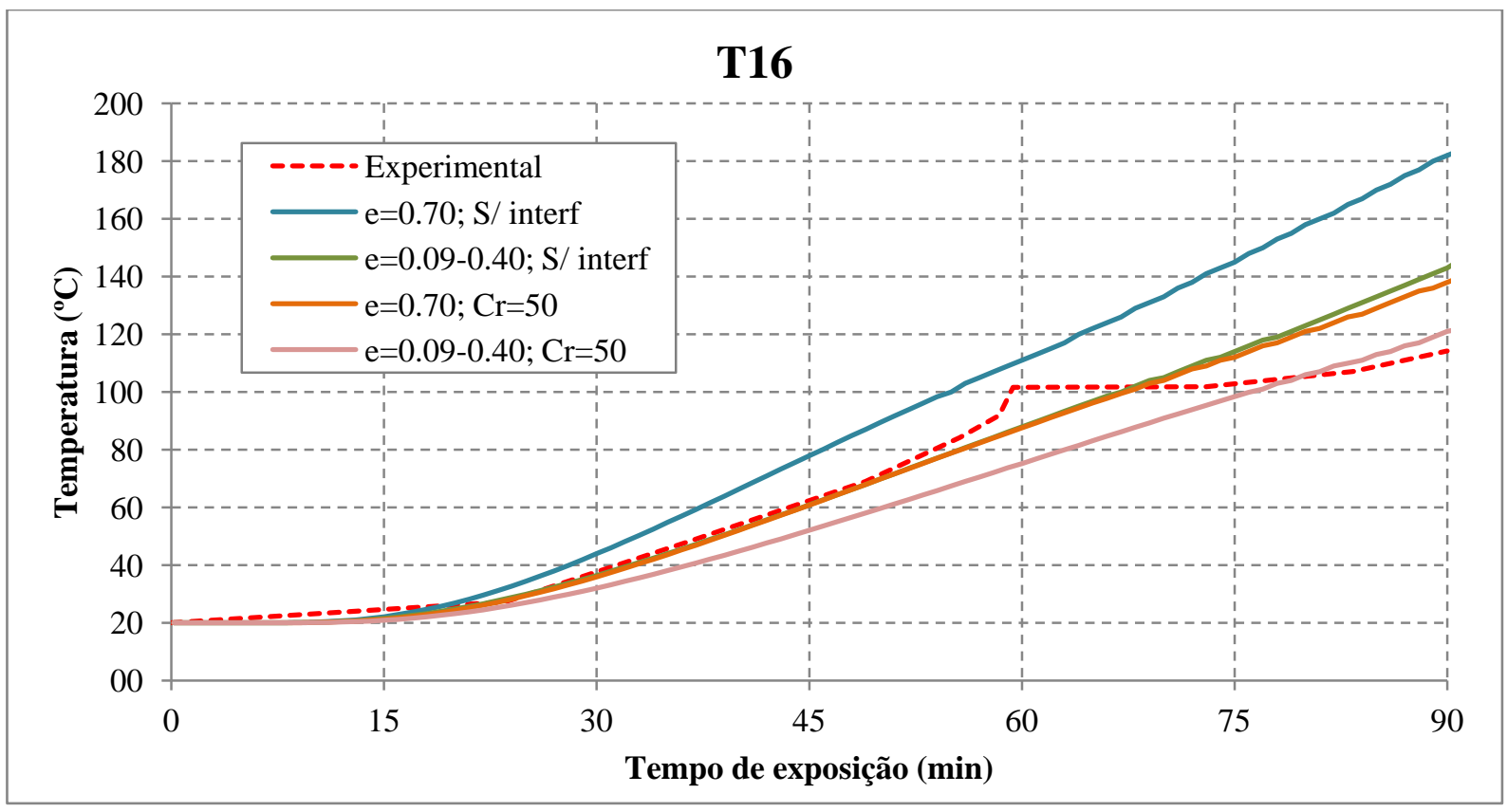

Figura J. 1 - Temperatura do concreto (ponto de medida T16) vs. Tempo de exposição.

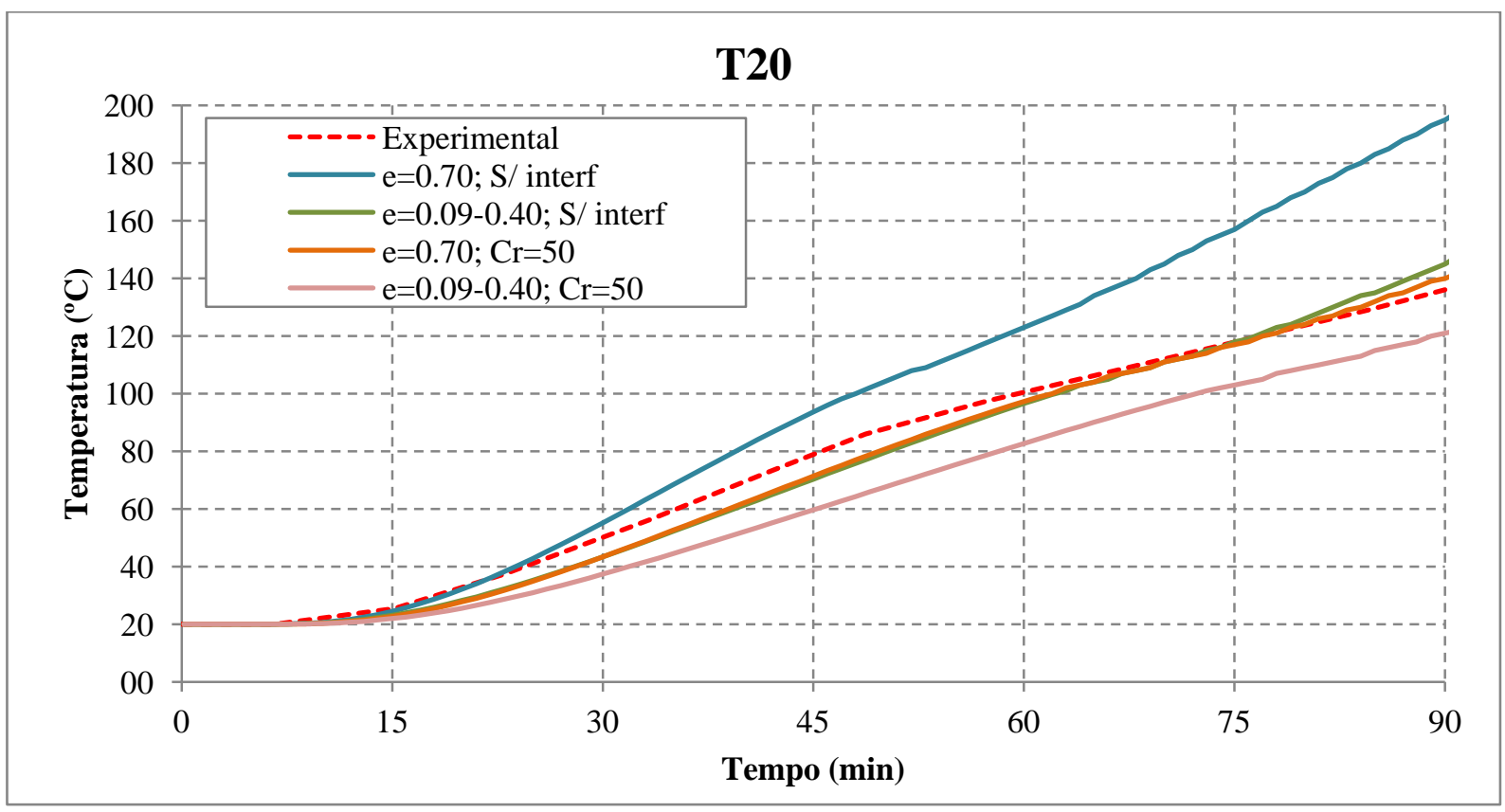

Figura J. 2 - Temperatura do concreto (ponto de medida T20) vs. Tempo de exposição. 


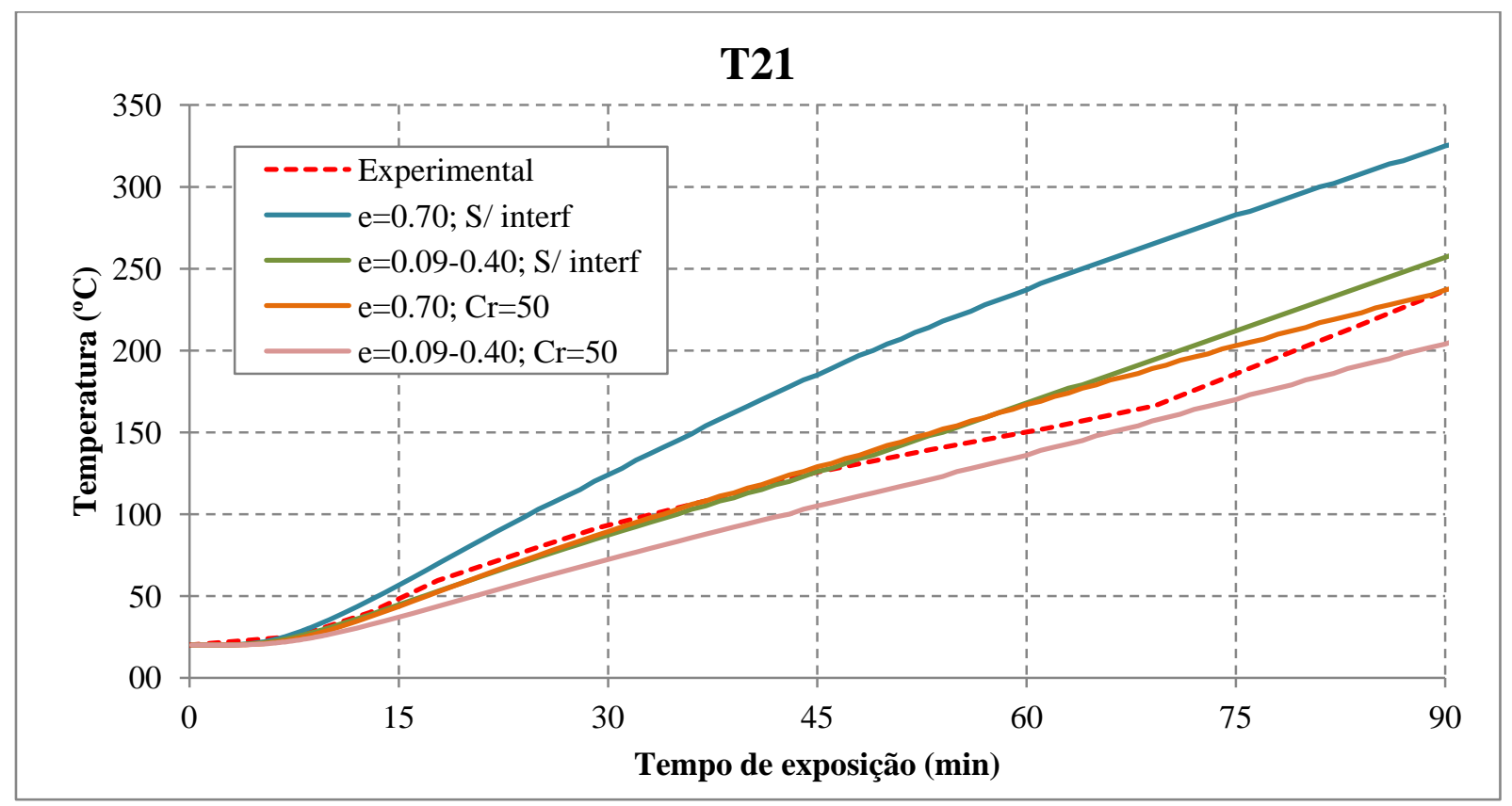

Figura J. 3 - Temperatura do concreto (ponto de medida T21) vs. Tempo de exposição.

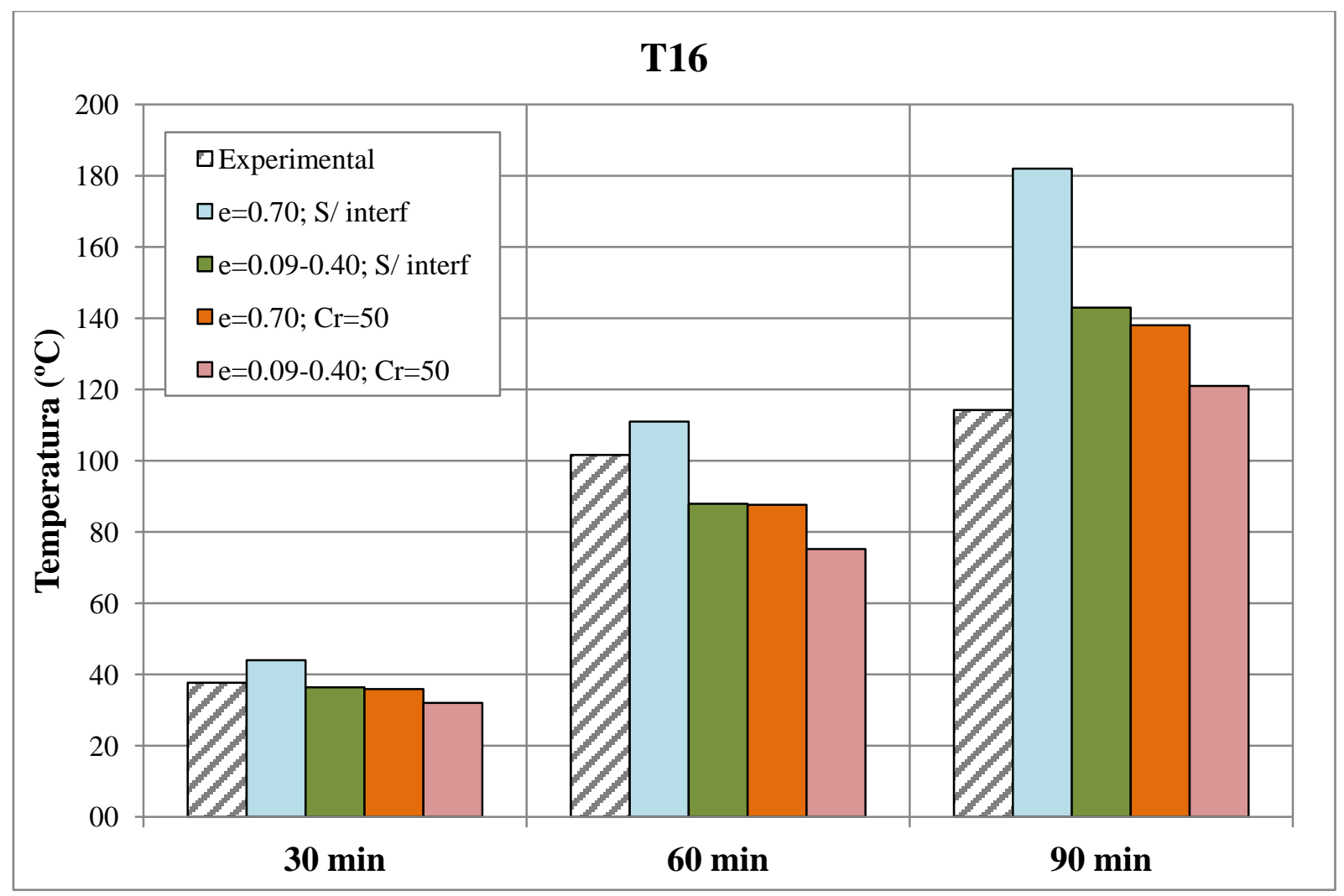

Figura J. 4 - Comparação entre a temperatura do concreto (ponto de medida T16) para 30, 60 e 90 min. 


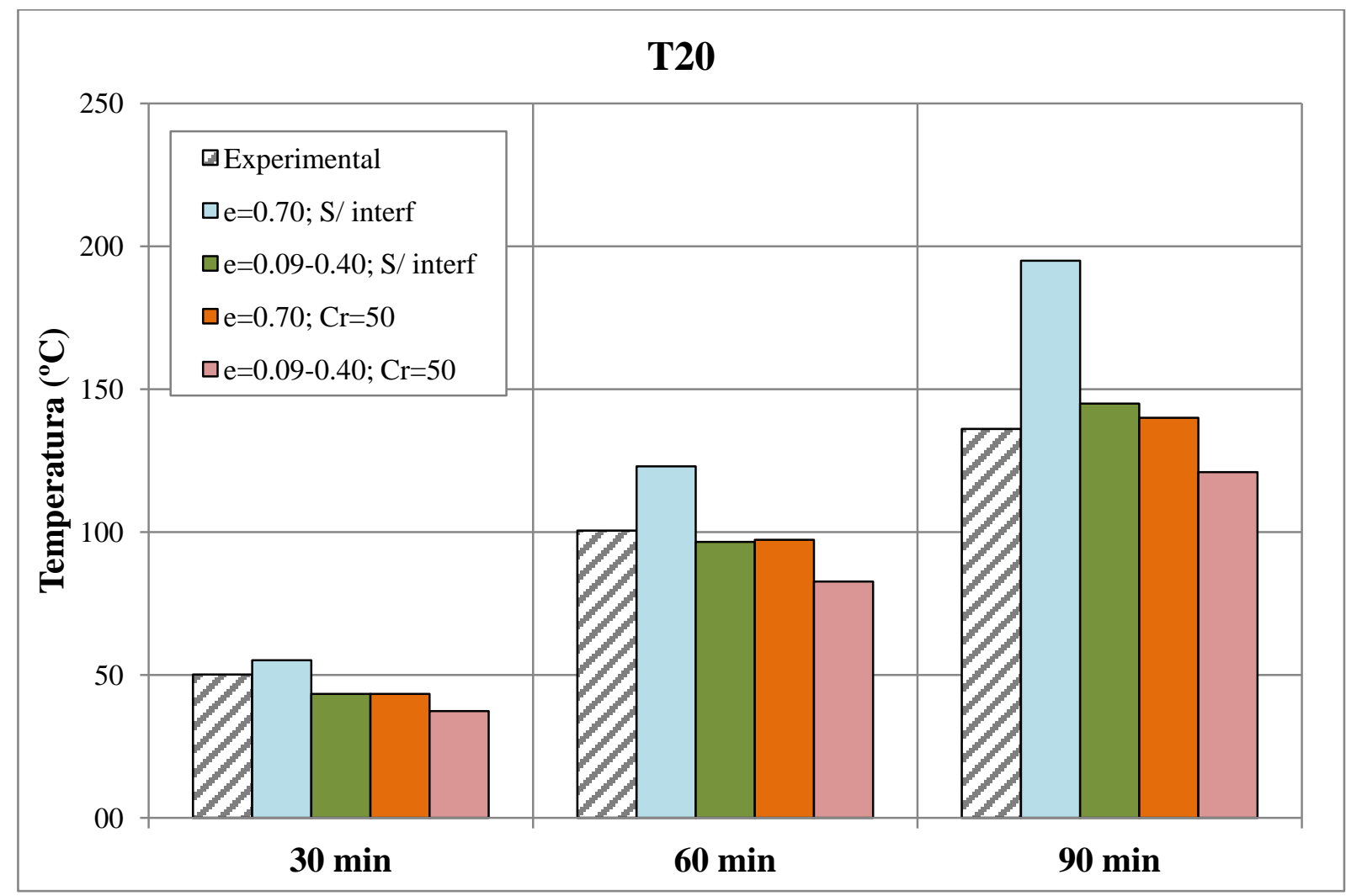

Figura J. 5 - Comparação entre a temperatura do concreto (ponto de medida T20) para 30, 60 e 90 min.

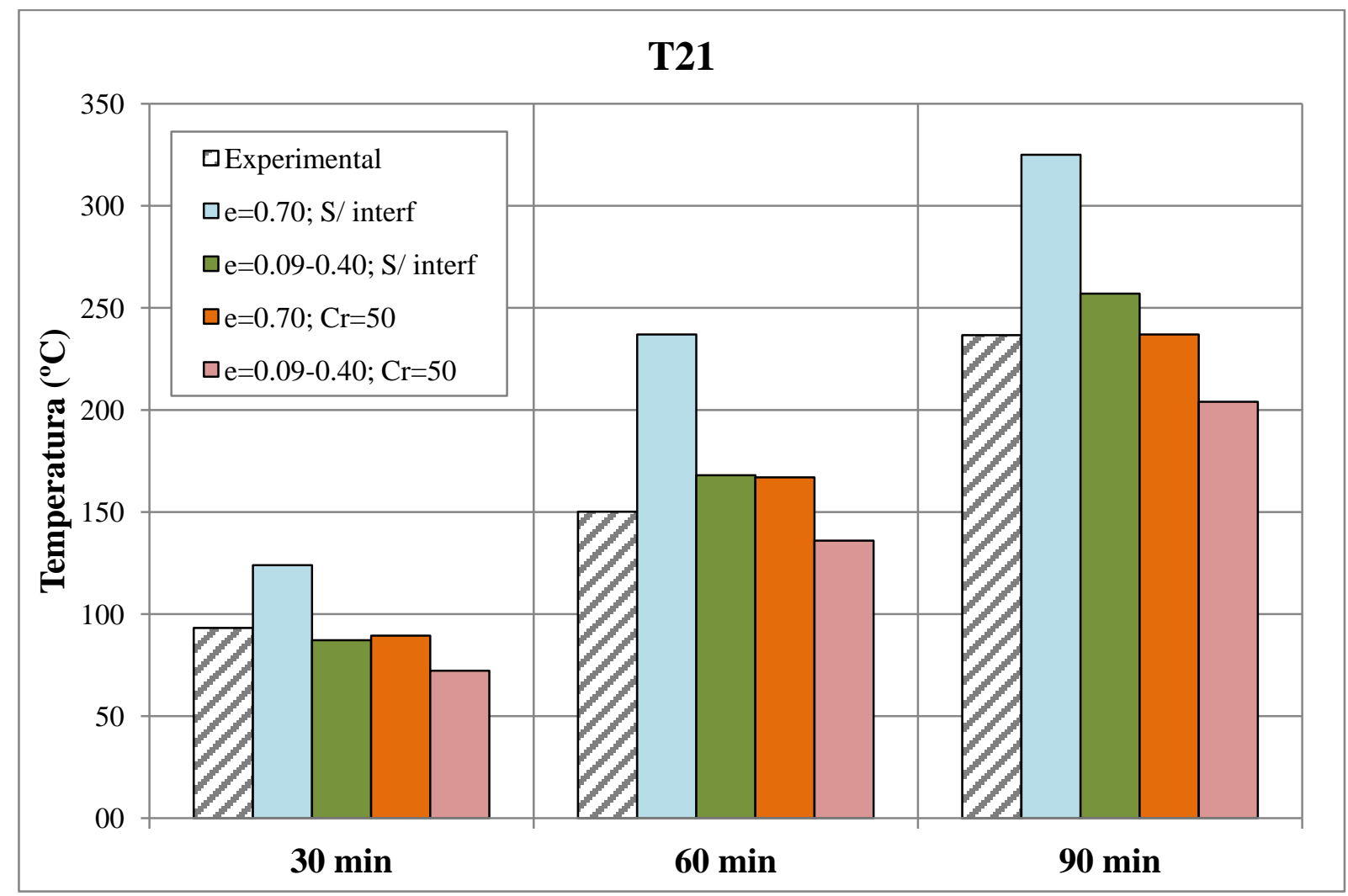

Figura J. 6 - Comparação entre a temperatura do concreto (ponto de medida T21) para 30, 60 e 90 min. 


\section{Apêndice K - Resultados adicionais do modelo térmico}

Neste apêndice são apresentados os resultados numéricos e segundo a ABNT NBR 14323:2013 referentes às temperaturas dos componentes da fôrma de aço dos modelos M01, M02 e M03, não apresentados no item 4.4 deste trabalho.
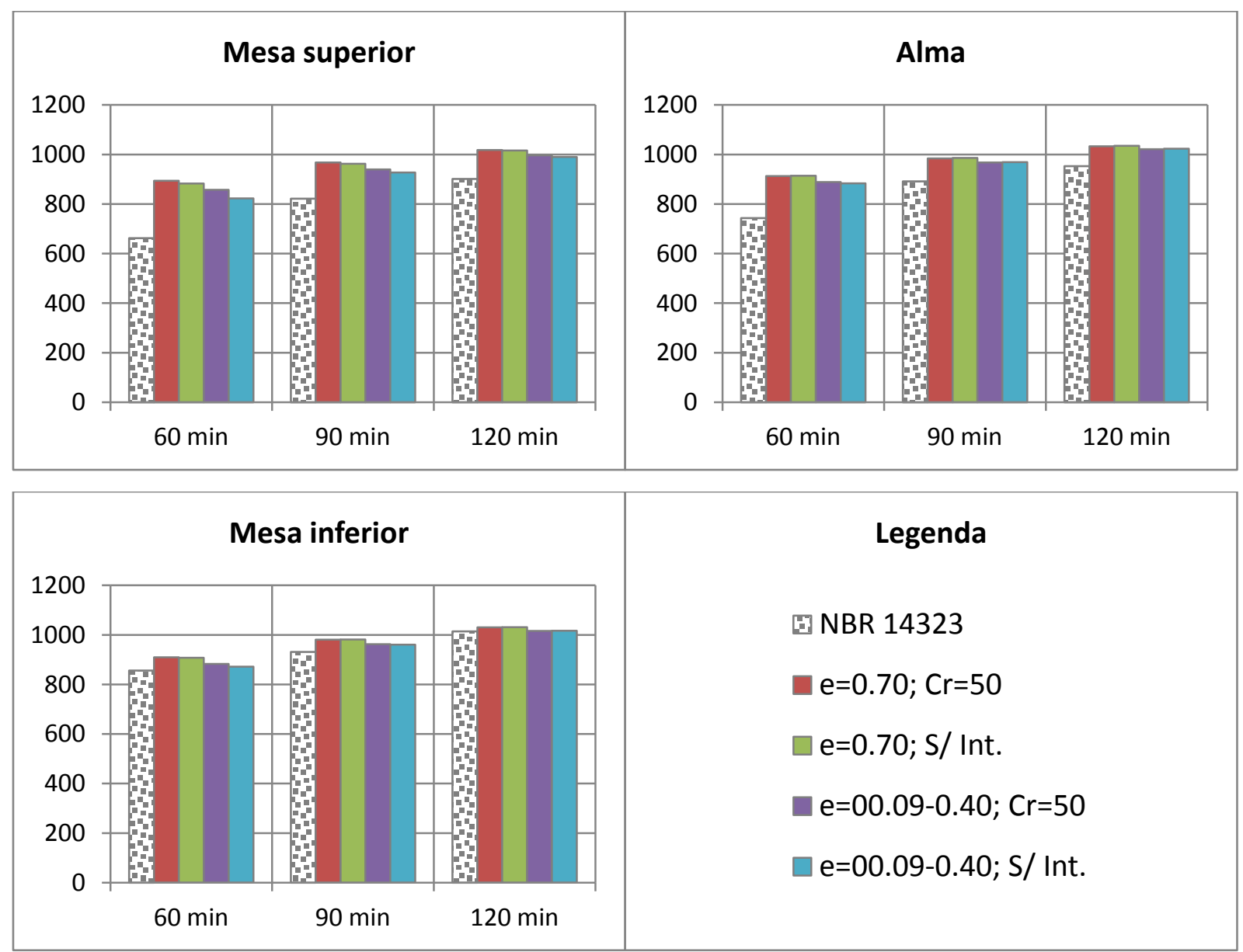

Figura K.1 - Temperatura para cada componente da fôrma de aço para tempos de exposição de 60, 90 e 120 minutos (Modelo M01) 


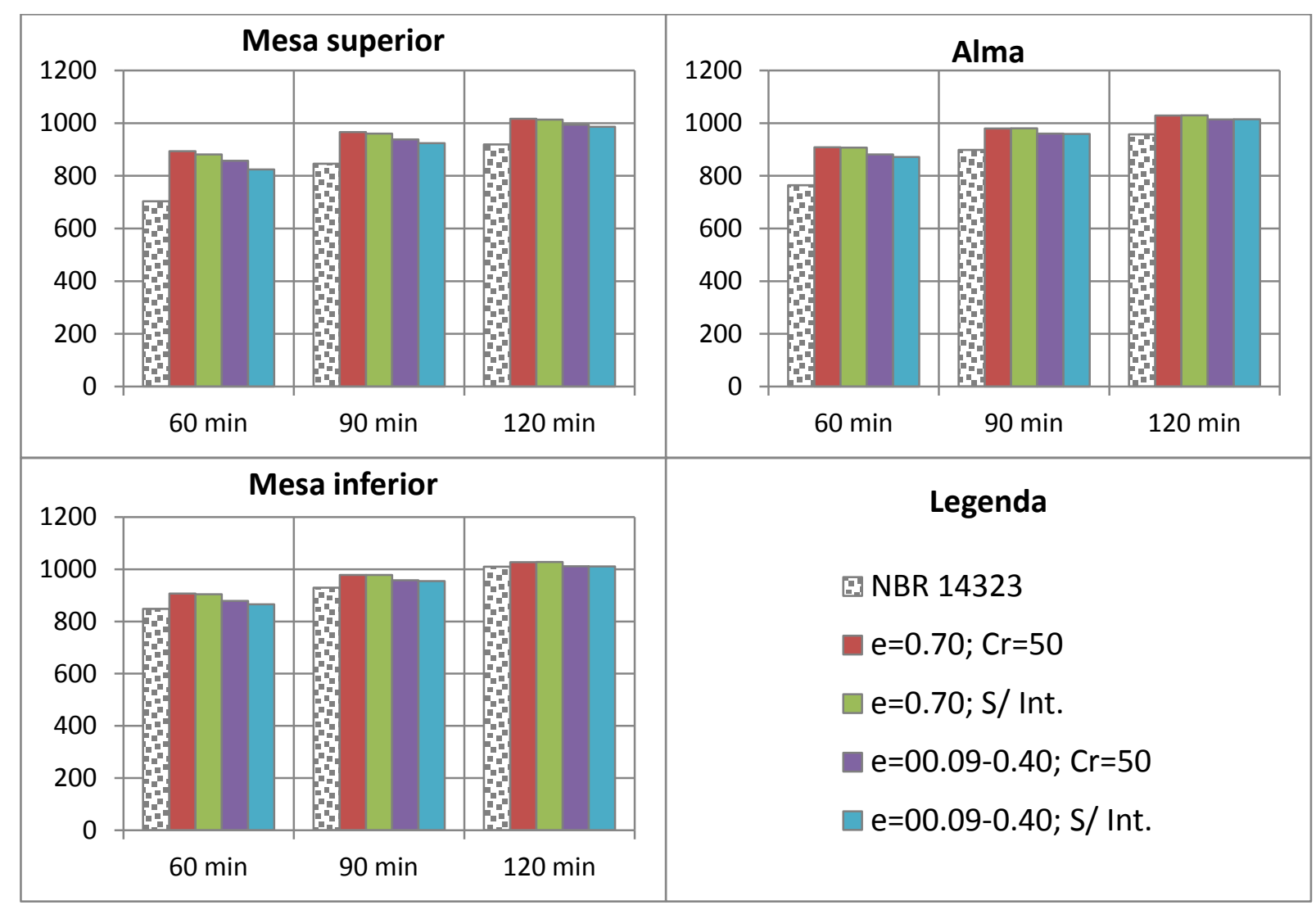

Figura K2 - Temperatura para cada componente da fôrma de aço para tempos de exposição de 60,90 e 120 minutos (Modelo M02)

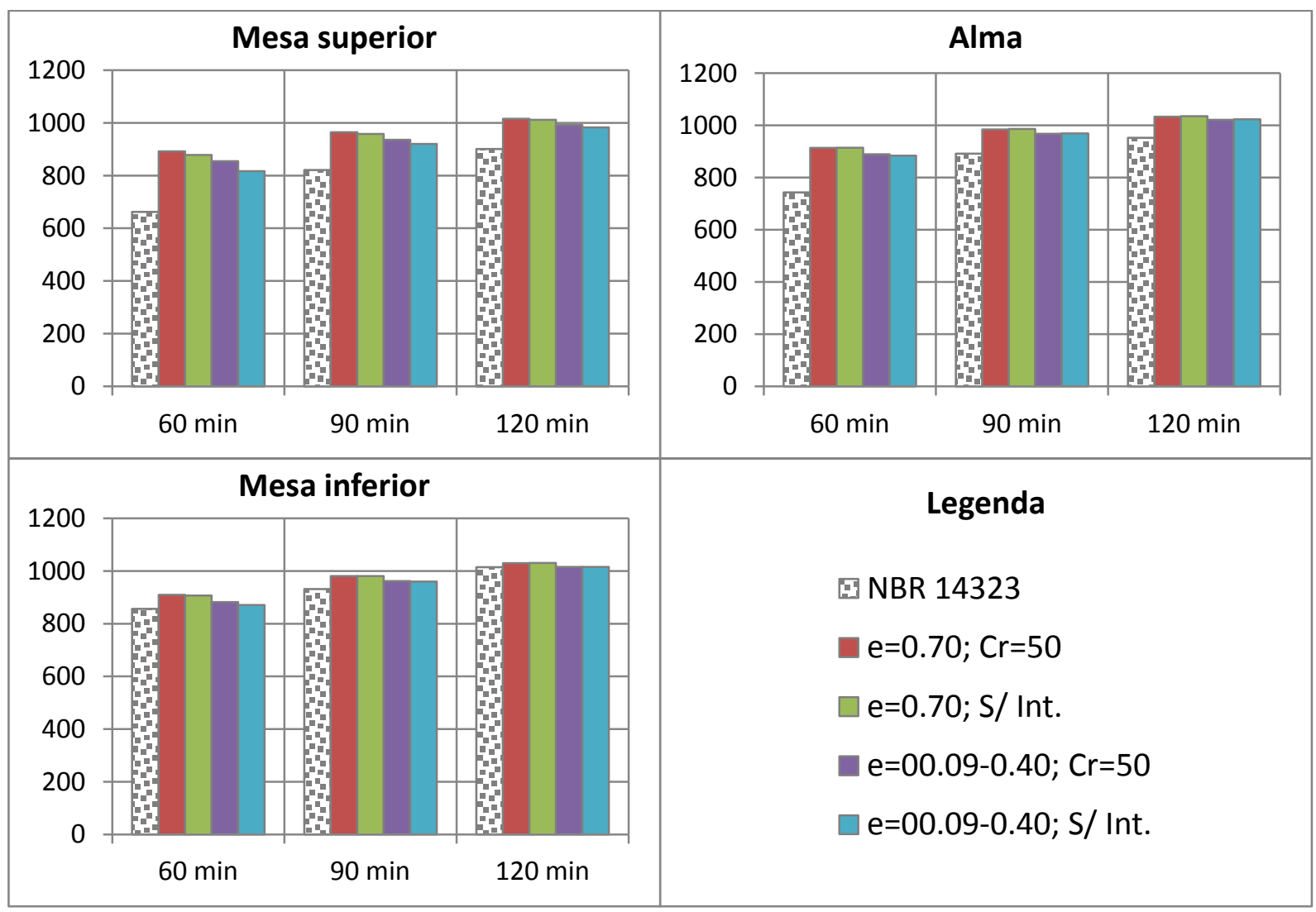

Figura K.3 - Temperatura para cada componente da fôrma de aço para tempos de exposição de 60,90 e 120 minutos (Modelo M03) 


\section{Apêndice L - Gráficos para análise do posicionamento da armadura na laje.}

Este apêndice apresenta os gráficos para cálculo do posicionamento da armadura que maximize a resistência à flexão $\left(u_{f 3, \text { ótimo }}\right)$ em função da altura total da laje $\left(h_{t}\right)$. São apresentados casos considerando a área da armadura positiva $\left(A_{s}\right)$ iguais a 201, 314, 490 e 707 $\mathrm{mm}^{2}$, emissividade resultante igual a 0,70 e variável entre 0,09 e 0,40 para as temperaturas de $250^{\circ} \mathrm{C}$ e $800{ }^{\circ} \mathrm{C}$ e três casos de fôrma de aço, com alturas (HF) de 50,59 e $75 \mathrm{~mm}$. As dimensões dessas fôrmas são apresentadas nas Figuras 2.12, 2.13 e 2.14 (Capítulo 2).

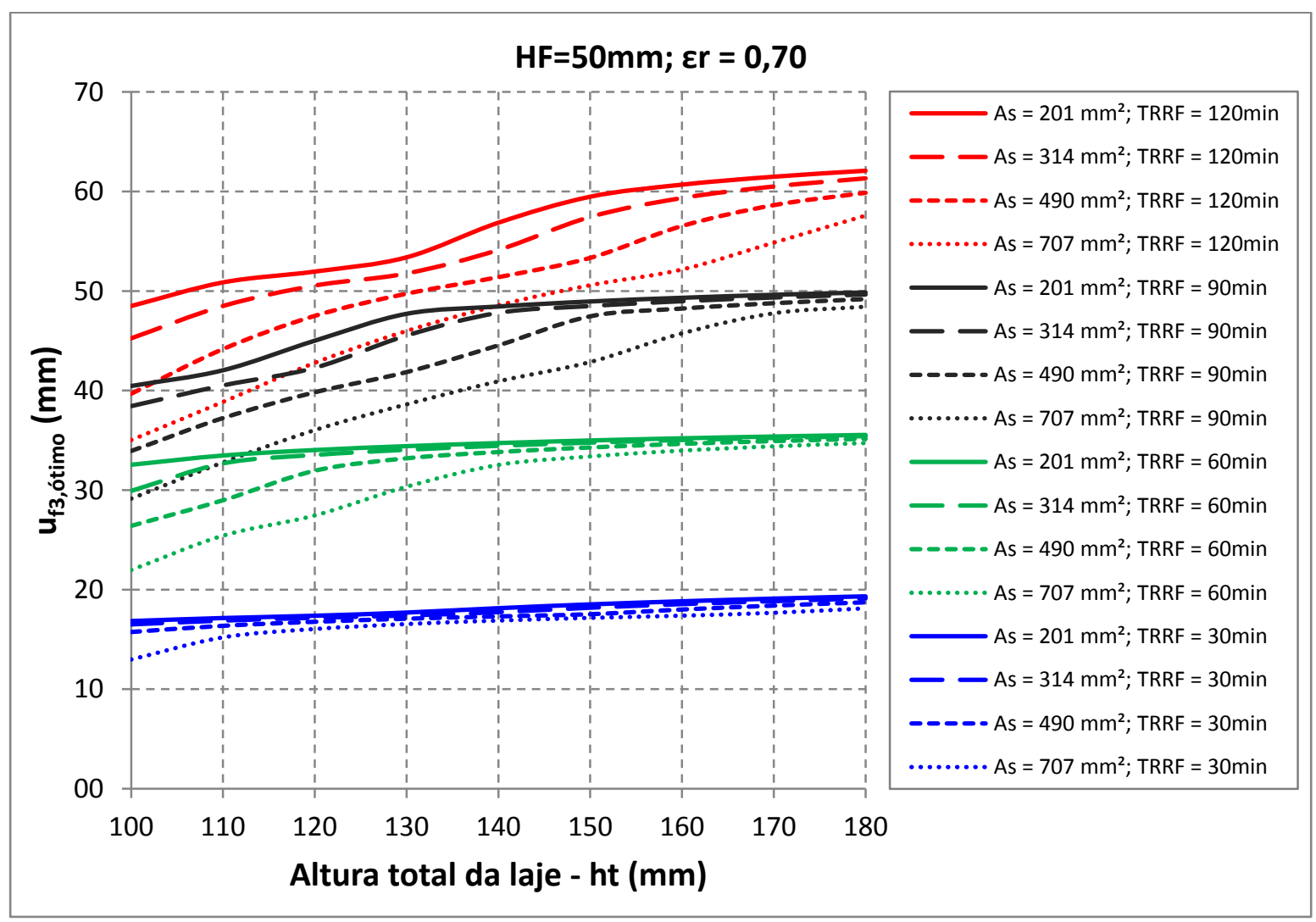

Figura L.1 $-u_{f 3, \text { ótimo }} v s$. Altura total da laje para $\mathrm{HF}=50 \mathrm{~mm}$ e $\varepsilon_{r}=0,70$ 


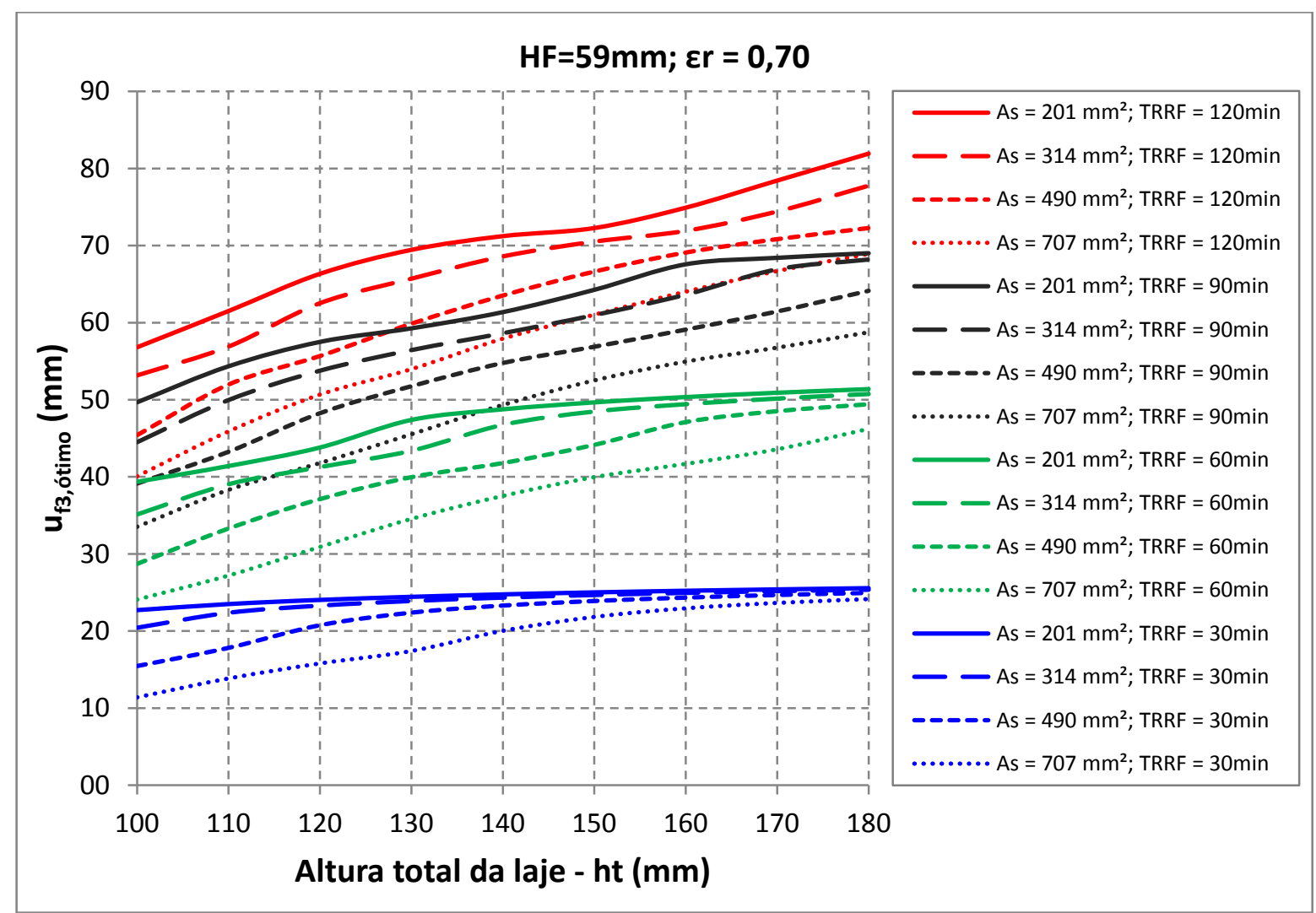

Figura L.2 $-u_{f 3, \text { ótimo }} v s$. Altura total da laje para $\mathrm{HF}=59 \mathrm{~mm}$ e $\varepsilon_{r}=0,70$

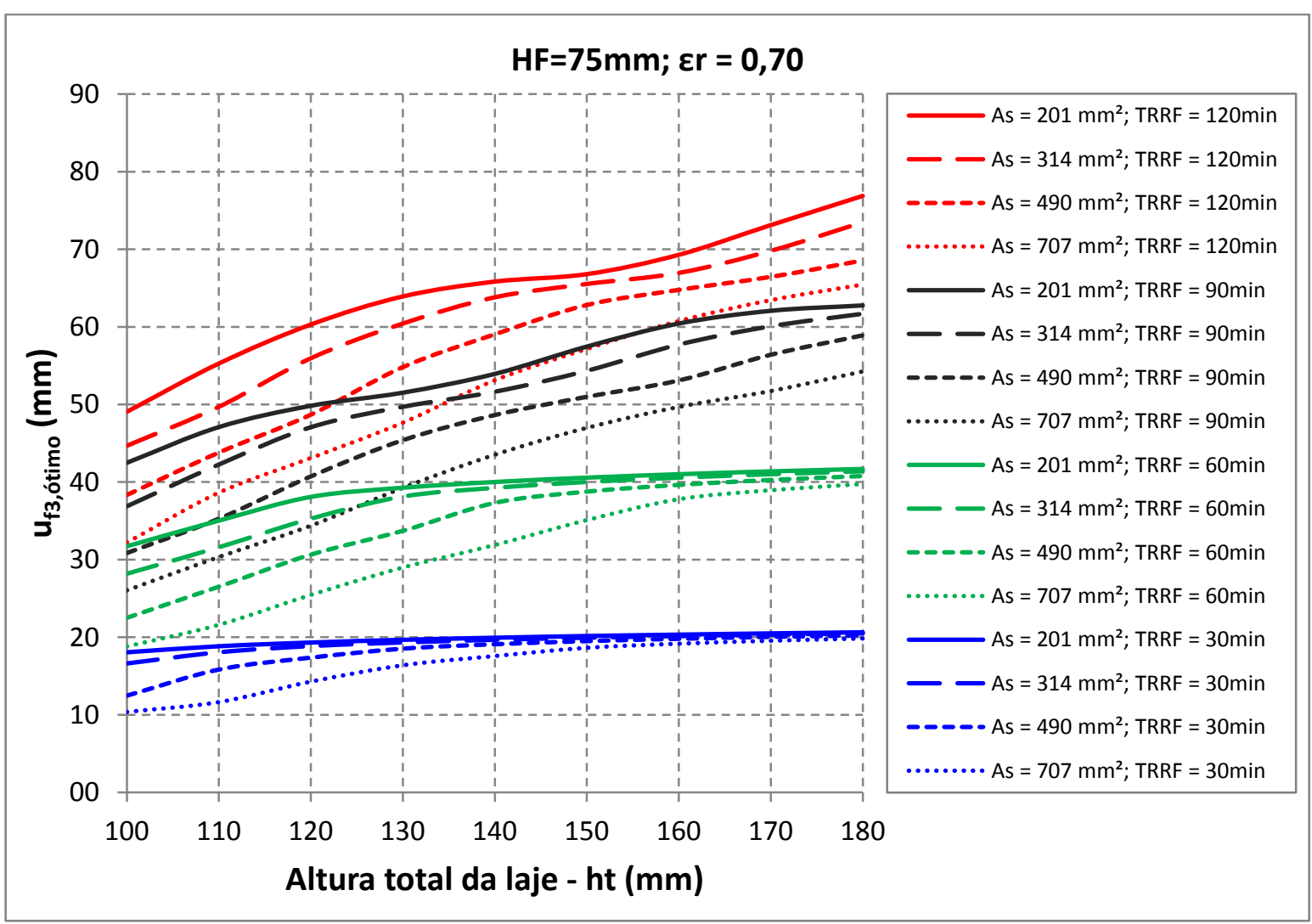

Figura L.3 $-u_{f 3, \text { ótimo }} v s$. Altura total da laje para $\mathrm{HF}=75 \mathrm{~mm}$ e $\varepsilon_{r}=0,70$ 


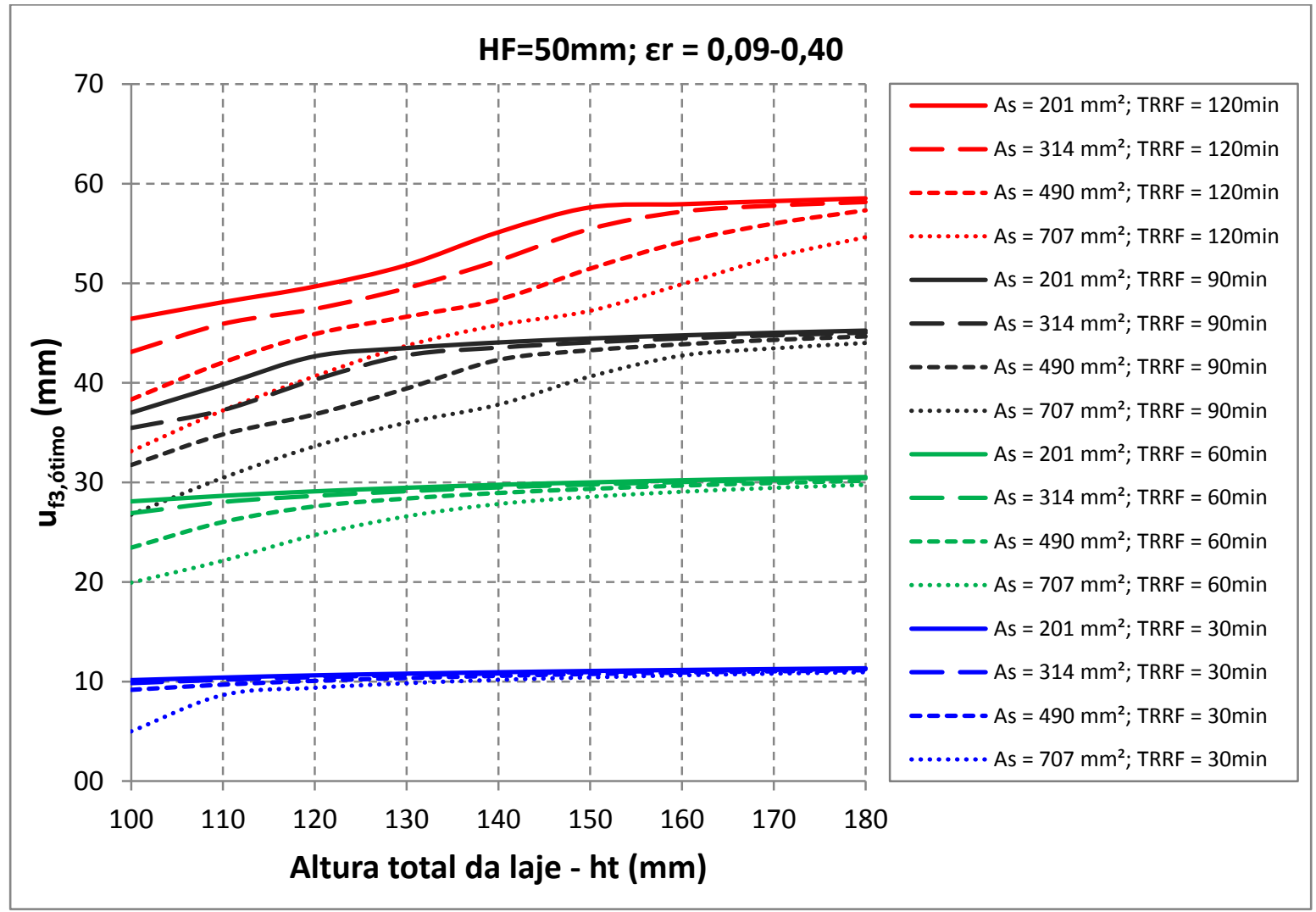

Figura L.4 $-u_{f 3, \text { ótimo }}$ vs. Altura total da laje para $\mathrm{HF}=50 \mathrm{~mm}$ e $\varepsilon_{r}=0,09-0,40$

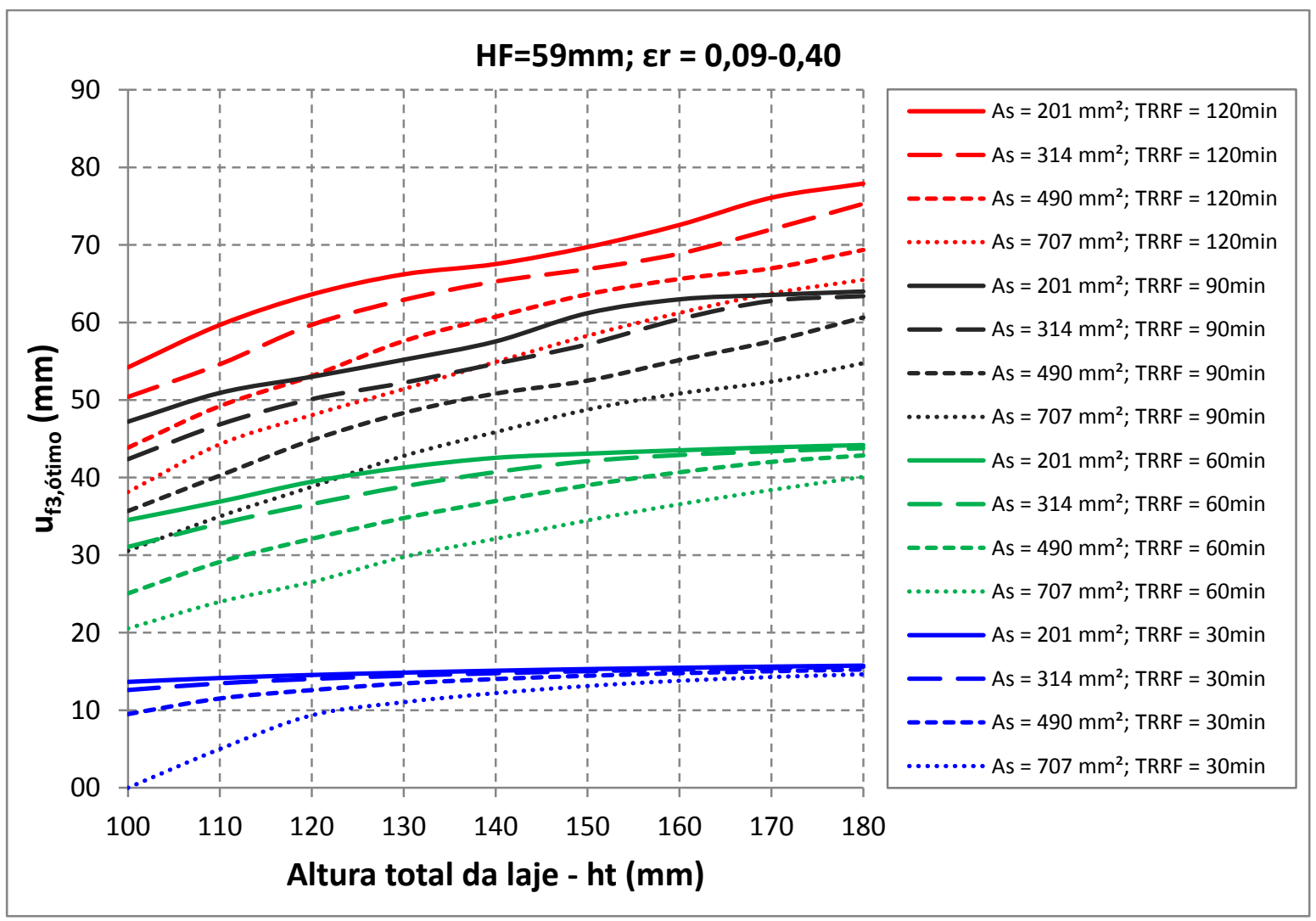

Figura L.5 $-u_{f 3, \text { ótimo }}$ vs. Altura total da laje para $\mathrm{HF}=59 \mathrm{~mm}$ e $\varepsilon_{r}=0,09-0,40$ 


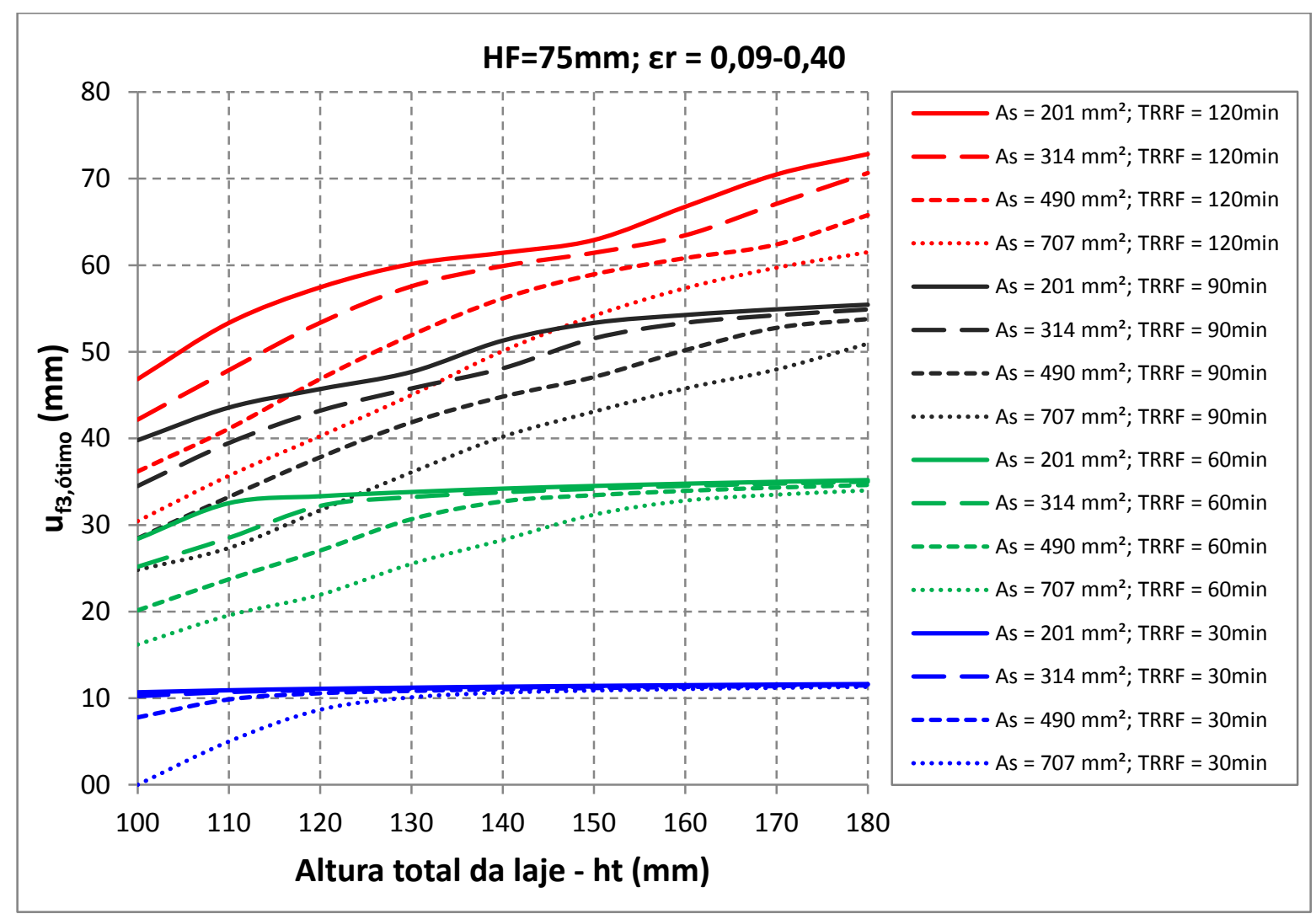

Figura L.6 $-u_{f 3, \text { ótimo }} v s$. Altura total da laje para HF=75mm e $\varepsilon_{r}=0,09-0,40$ 